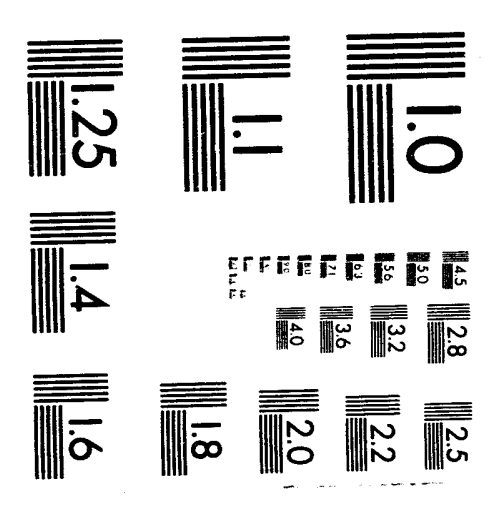



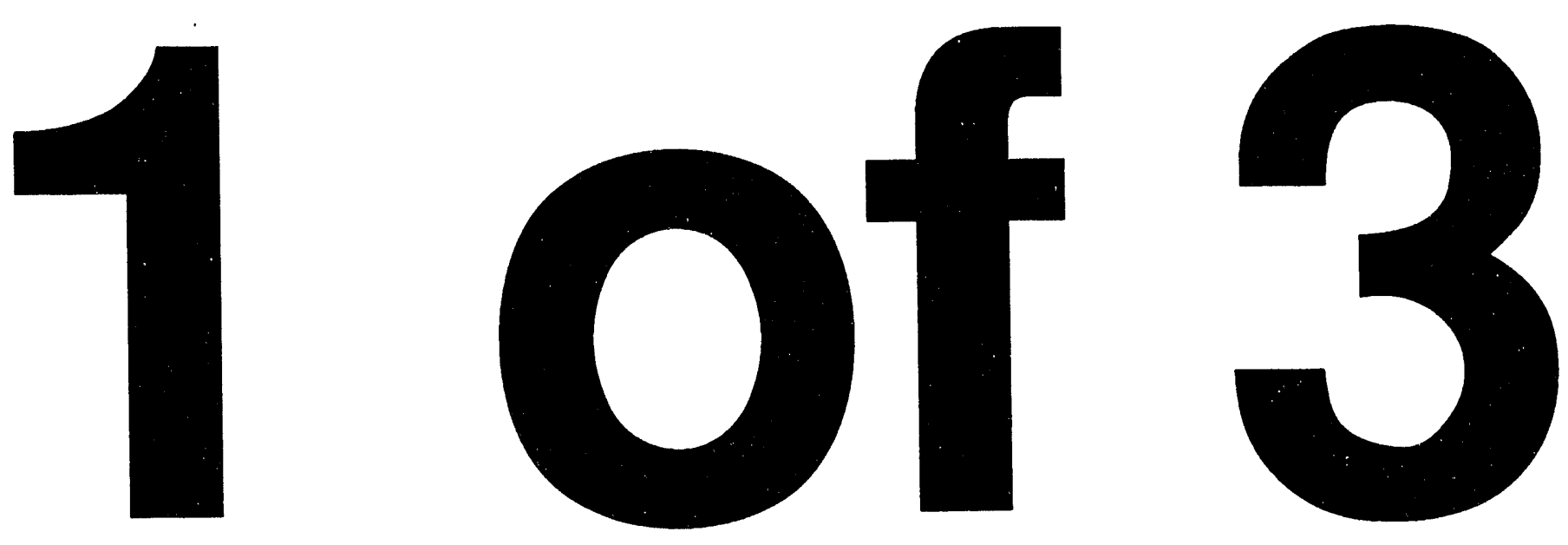
LBL-33342

UC-000

\title{
Monitoring Peak Power and Cooling Energy Savings of Shade Trees and White Surfaces in the Sacramento Municipal Utility District (SMUD) Service Area: \\ Project Design and Preliminary Results
}

\author{
H. Akbari, S. Bretz, J. Hanford, A. Rosenfeld, D. Sailor, H. Taha \\ Energy Analysis Program \\ Energy and Environment Division \\ Lawrence Berkeley Laboratory \\ University of California \\ Berkeley, California 94720 \\ and \\ Willem Bos \\ Sacramento Municipal Utility District (SMUD) \\ prepared for \\ California Institute for Energy Efficiency \\ and \\ Sacramento Municipal Utility District
}

December 1992

This work was jointly supported by the California Institute for Energy Efficiency (CIEE) and the Sacramento Municipal Utility District (SMUD) through the U.S. Department of Energy, under contract DE-AC0376SF00098. 
Table of Contents $\ldots \ldots \ldots \ldots \ldots \ldots \ldots \ldots \ldots \ldots \ldots \ldots \ldots \ldots \ldots$

List of figures $\ldots \ldots \ldots \ldots \ldots \ldots \ldots \ldots \ldots \ldots \ldots \ldots \ldots \ldots \ldots$

List of Tables $\ldots \ldots \ldots \ldots \ldots \ldots \ldots \ldots \ldots \ldots \ldots \ldots \ldots \ldots \ldots \ldots$

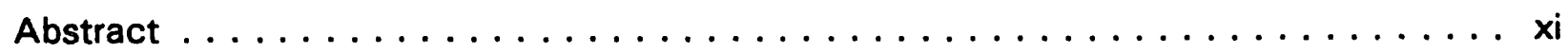

Acknowledgement $\ldots \ldots \ldots \ldots \ldots \ldots \ldots \ldots \ldots \ldots \ldots \ldots \ldots \ldots \ldots \ldots$

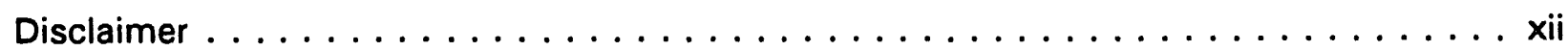

Executive Summary $\ldots \ldots \ldots \ldots \ldots \ldots \ldots \ldots \ldots \ldots \ldots \ldots \ldots \ldots \ldots$

I. Introduction .........................

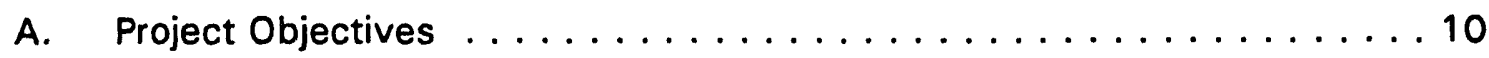

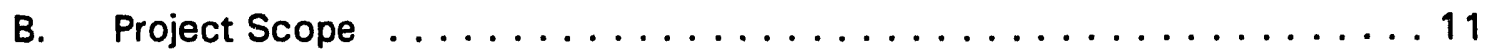

Sample Selection . . . . . . . . . . . . . . . . . 11

Impacts on Heating Energy Use . . . . . . . . . . . . . 11

The Impact of Reflected Radiation on the

Cooling Energy Use of Adjacent Buildings . . . . . . . . . . . 12

Experimental Protocols ..................... 12

Trees and Air Quality . . . . . . . . . . . . . . . . . . . 12

Practical Implementation Issues . . . . . . . . . . . . 13

C. Project Tasks ...................... 13

Task 0: Detailed Workplan . . . . . . . . . . . . . . . . 13

Task 1: Performance Data for White Surfaces . . . . . . . . . . . . . 14

Task 2: Demonstration, Validation, and Documentation ........ . 14

Task 3: Simulations of Energy and Peak Savings . . . . . . . . . . 14

D. Organization of Report ..................... 15

References ....................... 16

II. Site Selection, Descriptions and Modifications, and Monitoring Protocols . . . 18 


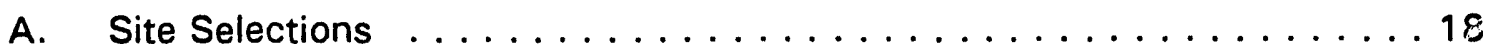

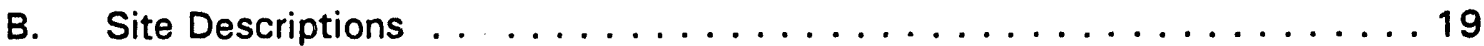

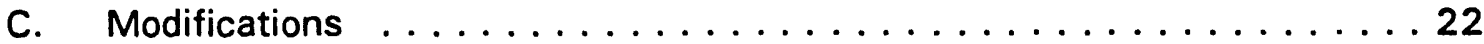

Albedo Modifications . . . . . . . . . . . . . . . . 22

Tree Modifications . . . . . . . . . . . . . . . . . 22

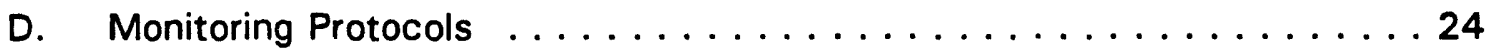

Measurement Goals ....................... 24

Data Product and Output . . . . . . . . . . . . . . . 24

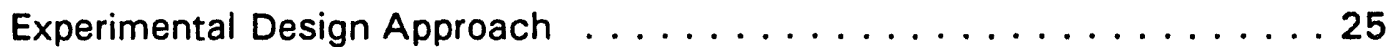

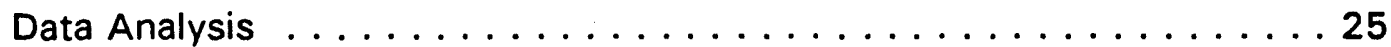

Data Accuracy, Quality ControlNerification, and Format . . . . . . 25

III. Equipment, Instrurnentation, and Calibration $\ldots \ldots \ldots \ldots$

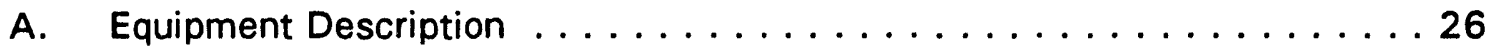

B. Site Instrumentation ..................... 28

C. Calibration .......................... 30

Bench Calibration and Conversion Constants . . . . . . . . . . . 30

Pre- and Post-Retrofit Dynamic Calibration . . . . . . . . . . . . 30

IV. Experience with Monitoring Equipment and Building Modifications . . . . . . 34

A. Monitoring Equipment . . . . . . . . . . . . . . . . 34

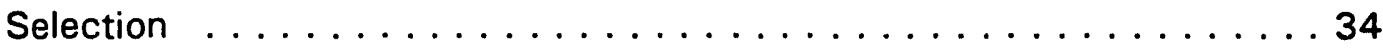

Purchasing Equipment $\ldots \ldots \ldots \ldots \ldots \ldots \ldots \ldots$

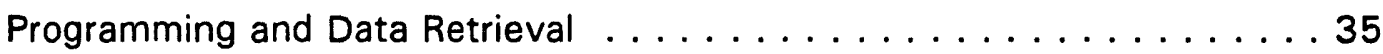

Problems Encountered . . . . . . . . . . . . . . . . . . . . . . 35

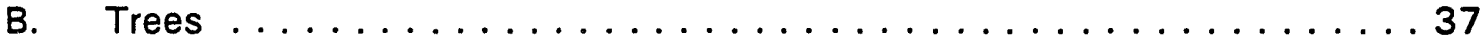

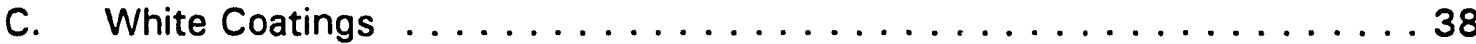

V. Analysis of Measured Data and Comparison with Simulations . . . . . . . . . 39

A. Introduction and Approach . . . . . . . . . . . . . 39

B. Data Analysis Methodology . . . . . . . . . . . . . . 40

C. Simulation Methodology . . . . . . . . . . . . . . . 41

Building Geometry and Adjoining Surfaces . . . . . . . . . . . . . 41

Thermal Integrity . . . . . . . . . . . . . . . . . . . . . 45 
HVAC System Characteristics . ................ 46

Distribution System Location and Efficiency $\ldots \ldots \ldots \ldots \ldots \ldots \ldots 47$

Climate Data ........................... 52

Site Model Calibration Overview $\ldots \ldots \ldots \ldots \ldots \ldots \ldots \ldots \ldots \ldots$

D. Measured Energy Savings Results and Comparison with Simulations . . . 55

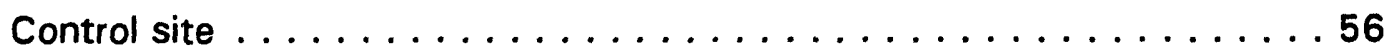

Albedo Modification Sites . . . . . . . . . . . . . . . . . . 64

Vegetation Modification Sites ..................... 90

Discussion ............................ 123

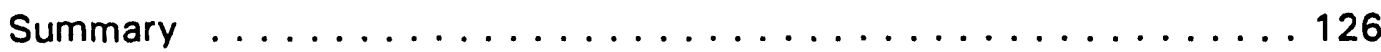

E. Microclimate Variations . . . . . . . . . . . . . . . . 131

References ............................ 141

VI. Savings Estimates for Four California Regions . . . . . . . . . . . . 143

A. Introduction and Approach ................... 143

B. Methodology .......................... 144

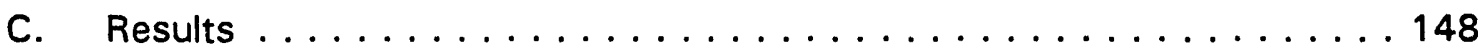

VII. Summary and Conclusion ........................ 160

\section{ATTACHMENTS}

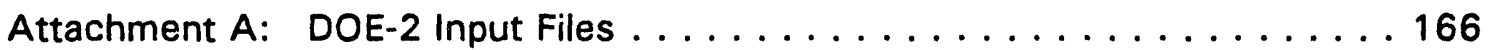

Attachment B: Experiment Design/Protocol .............. 213 


\section{List of Figures}

Figure $\mathrm{II}-1$ Monitoring sites in Sacramento . . . . . . . . . . . . . 20

Figure III-1

Figure $V-1 A$

Figure $V-1 B$

Figure $V-2 A$

Figure V-2B

Figure V-2C

Figure V-2D

Figure V-2E

Figure $V-2 F$

Figure V-3A

Figure $V-3 B$

Figure V-3C

Figure V-3D

Figure V-3E

Figure V-3F

Figure V-3G

Figure $\mathrm{V}-3 \mathrm{H}$

Figure V-3I

Moisture and temperature probe . . . . . . . . . . . . . . 29

House 6, tree case, viewed from Southwest . . . . . . . . . . . . . 43

House 8, tree case, viewed from Southwest . . . . . . . . . . . . . . . 44

Site 1: Daily cooling electricity use (kWh/day) vs daily maximum outdoor air temperature $\left({ }^{\circ} \mathrm{C}\right) \ldots \ldots \ldots \ldots$

Site 1: Hourly cooling electricity use $(\mathrm{Wh} / \mathrm{h})$ vs mean hourly outdoor air temperature $\left({ }^{\circ} \mathrm{C}\right) \ldots \ldots \ldots \ldots \ldots$

Site 1: Hourly cooling electricity use $(\mathrm{Wh} / \mathrm{h})$ vs hourly difference between outdoor and indoor air temperatures $\left({ }^{\circ} \mathrm{C}\right) \ldots \ldots \ldots 6$

Compressor watt-hours and building interior temperature for $9 / 13$ to

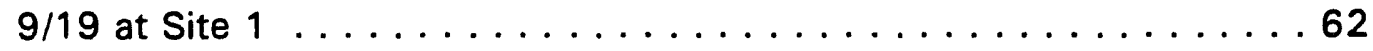

Compressor watt-hours and building interior temperature for $10 / 7$ to

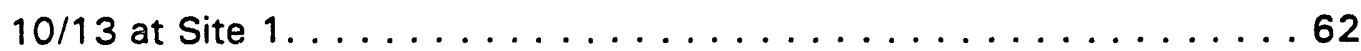

Site 1 : Simulation results daily data for period of monitoring . . . . . . 63

Site 2: Daily cooling electricity use (kWh/day) vs daily maximum outdoor air temperature $\left({ }^{\circ} \mathrm{C}\right)$ for pre-and post-retrofit periods . . . . . 66

Site 2: Variation in total daily horizontal solar radiation ( $\mathrm{kWh} / \mathrm{day}$ ) over 45 days of monitoring at Site $2 \ldots \ldots \ldots 7$

Site 2: Hourly cooling electricity use (Wh/h) vs mean outdoor air temperature $\left({ }^{\circ} \mathrm{C}\right)$ for pre- and post-retrofit conditions $\ldots \ldots \ldots 70$

Site 2: Hourly cooling electricity use (Wh/h) vs hourly difference between outdoor and indoor air temperatures $\left({ }^{\circ} \mathrm{C}\right) \ldots \ldots \ldots 71$

Site 2: Roof surface temperature $\left({ }^{\circ} \mathrm{C}\right)$ vs solar radiation $\left(\mathrm{W} / \mathrm{m}^{2}\right)$ at 20-minute intervals for the low-albedo case . . . . . . . . . . . 72 Site 2: Roof surface temperature $\left({ }^{\circ} \mathrm{C}\right)$ vs solar radiation $\left(\mathrm{W} / \mathrm{m}^{2}\right)$ 20-minute intervals for the high-albedo case Line is a regression fit . . . 73 Compressor watt-hours and building interior temperature for $9 / 1$ to $9 / 7$ at Site $2 \ldots \ldots \ldots \ldots \ldots \ldots \ldots$. . . . . . . . . . . . . .

Compressor watt-hours and building interior temperature for $9 / 17$ to $9 / 23$ at Site $2 \ldots \ldots \ldots \ldots \ldots$. . . . . . . . . . . . . . . . . Simulated compressor watt-hours for $9 / 1$ to $9 / 7$ at Site 2 
using different weather inputs . . . . . . . . . . . . 76

Figure V-3J Simulated compressor watt-hours for $9 / 17$ to $9 / 23$ at Site 2 using different weather inputs . . . . . . . . . . 76

Figure $V-3 K \quad$ Site 2: Simulation results daily data for period of monitoring $\ldots \ldots \ldots 77$

Figure V-4A Site B: Daily cooling electricity use ( $\mathrm{kWh} /$ day) at the test unit vs daily cooling electricity use $(\mathrm{kWh} /$ day) at the control unit . . . . . . 79

Figure V-4B Site B: Hourly cooling electricity use (Wh/h) vs mean hourly outdoor air temperature $\left({ }^{\circ} \mathrm{C}\right)$ for pre-and post-retrofit conditions at the test

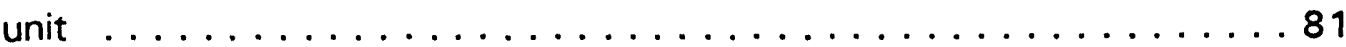

Figure V-4C Site B: Hourly cooling electricity use $(\mathrm{Wh} / \mathrm{h})$ vs hourly air temperature difference, outdoor minus indoor $\left({ }^{\circ} \mathrm{C}\right)$ at the test unit $\ldots \ldots \ldots 82$

Figure V-4D Site B: Roof surface temperature $\left({ }^{\circ} \mathrm{C}\right)$ vs horizontal solar radiation

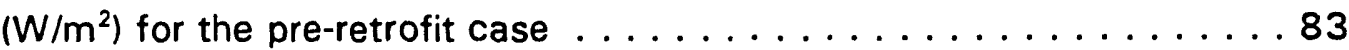

Figure V-4E Site B: Roof surface temperature $\left({ }^{\circ} \mathrm{C}\right)$ vs horizontal solar radiation $\left(W / m^{2}\right)$ for the post-retrofit case . . . . . . . . . . . . . 84

Figure V-4F Package $A C$ unit watt-hours and building interior temperature for $10 / 5$ to $10 / 11$ at Site $B \ldots \ldots \ldots \ldots \ldots$. . . . . . . . . . . . . .

Figure V-4G Package AC unit watt-hours and building interior temperature for $10 / 5$ to $10 / 11$ at Site $B \ldots \ldots \ldots \ldots$. . . . . . . . . . . . . . .

Figure $\mathrm{V}-4 \mathrm{H} \quad$ Simulated fan and compressor watt-hours for $10 / 5$ to $10 / 11$ at Site $B \ldots \ldots \ldots \ldots \ldots \ldots \ldots \ldots$. . . . . . . . . . . . . . . . . . .

Figure V-4I Simulated fan and compressor watt-hours for $10 / 5$ to $10 / 11$ at Site $B \ldots \ldots \ldots \ldots \ldots \ldots \ldots \ldots$. . . . . . . . . . . . . . . . . . . .

Figure $V-4 J \quad$ Site B: Simulation results daily data for occupied monitoring period . . . 89

Figure V-5A Site 5: Daily cooling electricity use ( $\mathrm{kWh} /$ day) vs daily maximum outdoor air temperature $\left({ }^{\circ} \mathrm{C}\right)$ for pre- and post retrofit conditions . . . . 91

Figure V-5B Site 5: Hourly cooling electricity use $(\mathrm{Wh} / \mathrm{h})$ vs mean hourly outdoor air temperature $\left({ }^{\circ} \mathrm{C}\right)$ for pre- and post-retrofit conditions . . . . . 92

Figure V-5C Compressor watt-hours and building interior temperature for 9/11 to $9 / 15$ at Site $5 \ldots \ldots \ldots \ldots \ldots \ldots \ldots \ldots \ldots$

Figure V-5D Compressor watt-hours and building interior temperature for $9 / 30$

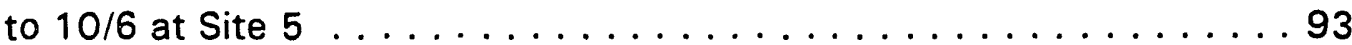

Figure V-5E Site 5: Simulation results daily data for period of monitoring $\ldots \ldots \ldots 95$ 
Figure V-6A Site 6: Daily cooling electricity use (kWh/day) vs daily maximum outdoor air temperature $\left({ }^{\circ} \mathrm{C}\right)$ for pre- and post-retrofit conditions . . . 97

Figure V-6B Site 6: Variation in total daily horizontal solar radiation ( $\mathrm{kWh} /$ day) over 39 days of monitoring at Site $6 \ldots \ldots \ldots$. . . . . . . 98

Figure V-6C Site 6: Hourly cooling electricity use (Wh/day) vs mean hourly outdoor air temperature $\left({ }^{\circ} \mathrm{C}\right)$ for pre- and post-retrofit conditions . . . . . . 99

Figure V-6D Site 6: Hourly cooling electricity use (Wh/h) vs hourly air temperature difference, outdoor minus indoor $\left({ }^{\circ} \mathrm{C}\right) \ldots \ldots \ldots$

Figure V-6E Site 6: West wall surface temperature $\left({ }^{\circ} \mathrm{C}\right)$ vs outdoor air temperature $\left({ }^{\circ} \mathrm{C}\right)$ for pre-retrofit conditions . . . . . . . . . . 102

Figure V-6F Site 6: West wall surface temperature $\left({ }^{\circ} \mathrm{C}\right)$ vs outdoor air temperature $\left({ }^{\circ} \mathrm{C}\right)$ for post-retrofit conditions . . . . . . . . . . 103

Figure V-6G Compressor watt-hours and building interior temperature for $9 / 17$ to $9 / 23$ at Site $6 \ldots \ldots \ldots \ldots$. . . . . . . . . . . . . . . . . . . . . . . . . .

Figure V-6H Compressor watt-hours and building interior temperature for $9 / 30$ to $10 / 6$ at Site $6 \ldots \ldots \ldots \ldots$. . . . . . . . . . . . . . . . . . . . . . . .

Figure $V-61 \quad$ Site 6 : Simulation results daily data for period of monitoring . . . . . 105

Figure V-7A Site 7: Daily cooling electricity use ( $\mathrm{kWh} /$ day) vs daily maximum outdoor air temperature $\left({ }^{\circ} \mathrm{C}\right)$ for pre- and post-retrofit conditions $\ldots 107$

Figure V-7B Site 7: Hourly cooling electricity use (Wh/h) vs mean hourly outdoor air temperature $\left({ }^{\circ} \mathrm{C}\right)$ for pre- and post-retrofit conditions . . . 108

Figure V-7C Site 7: Hourly cooling electricity use (Wh/h) vs hourly difference between outdoor and indoor air temperatures $\left({ }^{\circ} \mathrm{C}\right) \ldots \ldots \ldots$

Figure V-7D Site 7: Southwest wall surface temperature $\left({ }^{\circ} \mathrm{C}\right)$ vs outdoor air temperature $\left({ }^{\circ} \mathrm{C}\right)$ for pre-retrofit conditions . . . . . . . . . . 110

Figure V-7E Site 7: Southwest wall surface temperature $\left({ }^{\circ} \mathrm{C}\right)$ vs outdoor air temperature $\left({ }^{\circ} \mathrm{C}\right)$ for post-retrofit conditions, i.e., with two additional trees on southwest . . . . . . . . . . . . . . . 111

Figure V-7F Compressor watt-hours and building interior temperature for $9 / 4$ to $9 / 10$

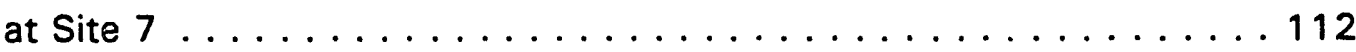

Figure V-7G Compressor watt-hours and building interior temperature for $9 / 25$ to $10 / 1$

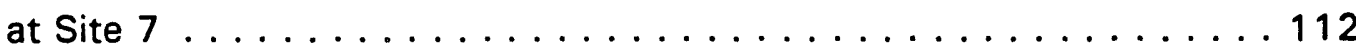

Figure $\mathrm{V}-7 \mathrm{H} \quad$ Site 7 : Simulation results daily data for period of monitoring $\ldots \ldots \ldots 114$ 
Figure V-8A Site 8: Daily cooling electricity use ( $k W h / d a y)$ vs daily maximum outdoor air temperature $\left({ }^{\circ} \mathrm{C}\right)$ for pre- and post-retrofit conditions. . . 116

Figure V-8B Site 8: Hourly cooling electricity use $(\mathrm{Wh} / \mathrm{h})$ vs mean hourly outdoor air temperature $\left({ }^{\circ} \mathrm{C}\right)$ for pre- and post-retrofit conditions. . . . . 117

Figure V-8C Site 8: Hourly cooling electricity use $(\mathrm{Wh} / \mathrm{h})$ vs hourly difference between outdoor and indoor air temperatures $\left({ }^{\circ} \mathrm{C}\right) . \ldots \ldots 118$

Figure V-8D Site 8: South wall surface temperature $\left({ }^{\circ} \mathrm{C}\right)$ vs horizontal solar radiation $\left(\mathrm{W} / \mathrm{m}^{2}\right)$ for pre-retrofit conditions. . . . . . . . . . . 119

Figure V-8E Site 8: South wall surface temperature $\left({ }^{\circ} \mathrm{C}\right)$ vs horizontal solar radiation $\left(\mathrm{W} / \mathrm{m}^{2}\right)$ for post-retrofit conditions. . . . . . . . . . . . 120

Figure V-8F Site 8: West wall surface temperature $\left({ }^{\circ} \mathrm{C}\right)$ vs horizontal solar radiation $\left(W / \mathrm{m}^{2}\right)$ for pre-retrofit conditions. . . . . . . . . . . . 121

Figure V-8G Site 8: West wall surface temperature $\left({ }^{\circ} \mathrm{C}\right)$ vs horizontal solar radiation $\left(W / \mathrm{m}^{2}\right)$ for post-retrofit conditions. . . . . . . . . . . 122

Figure $\mathrm{V}-8 \mathrm{H}$ Compressor watt-hours and building interior temperature for $8 / 30$ to $9 / 5$ at Site $8 . \ldots \ldots \ldots \ldots$. . . . . . . . . . . . . . . . . . . . 124

Figure V-81 Compressor watt-hours and building interior temperature for $10 / 2$

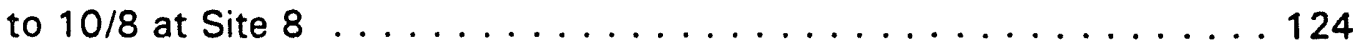

Figure $V-8 \mathrm{~J} \quad$ Site 8: Simulation results daily data for period of monitoring $\ldots \ldots 125$

Figure V-9A A comparison of maximum daily air temperatures (C) at Site 1 and at the Sacramento Executive Airport. . . . . . . . . . . . . . . . . 134

Figure V-9B Difference in hourly air temperatures $(C)$ between Sites 1 and the Sacramento Executive Airport, during the monitoring period of 1991.

Figure V-9C A comparison of maximum daily air temperatures (C) at Site 2 and at the Sacramento Executive Airport. . . . . . . . . . . . . . . . . 136

Figure V-9D Difference in hourly air temperatures $(C)$ between Sites 2 and the Sacramento Executive Airport, during the monitoring period of 1991.

Figure V-9E A comparison of maximum daily air temperatures (C) at Site 6 and at the Sacramento Executive Airport. . . . . . . . . . . . . . . . . 138

Figure V-9F. A comparison of maximum daily air temperatures (C) at Site 7 and at the Sacramento Executive Airport. . . . . . . . . . . . . . . . . . 140 
Figure VI-1 Annual cooling energy consumption (including fan energy) for Site 1 in four locations . . . . . . . . . . . . . . . . . 151

Figure VI-2 Annual cooling energy consumption (including fan energy) for Site 2 in four locations. . . . . . . . . . . . . . . . . . . . . . 152

Figure VI-3 Annual cooling energy consumption (including fan energy) for Site 5 in four locations . . . . . . . . . . . . . . . . . . . 153

Figure VI-4 Annual cooling energy consumption (including fan energy) for Site 6 in four locations . . . . . . . . . . . . . . . . . . . . . . . . . . . 154

Figure VI-5 Annual cooling energy consumption (including fan energy) for Site 7 in four locations. . . . . . . . . . . . . . . . . . . . 155

Figure VI-6 Annual cooling energy consumption (including fan energy) for Site 8 in four locations . . . . . . . . . . . . . . . . 156

Figure VI-7 Annual cooling energy consumption (including fan energy) for Site B in four locations . . . . . . . . . . . . . . . . . . . . . 157 


\section{List of Tables}

Table EX-1. Measured and Simulated Daily Energy Use and Peak Demand . . . . . . . 7

Table EX-2. Annual Cooling Energy Use and Peak Energy Demand (including Fan) (Sacramento $\mathrm{TMY}$ ) . . . . . . . . . . . . . 8

Table EX-3. Average Annual Cooling Energy and Peak Power Saving Potentials of Shade Trees and White Surfaces . . . . . . . . . . . . . 8

Table II-1. Site and Building Characteristics . . . . . . . . . . . 21

Table III-1. Photometers calibration constants $\left(\mathrm{W} / \mathrm{m}^{-2} / \mu \mathrm{A}\right)$ based on bench calibration at manufacturer site $\ldots \ldots \ldots \ldots \ldots \ldots$

Table III-2. Air Temperature Sensors Calibration $\ldots \ldots \ldots \ldots \ldots \ldots$

Table III-3. Solar Radiation Sensors Calibration . . . . . . . . . . . . . 32

Table III-4. Wind Speed Sensors Calibration . . . . . . . . . . . . 33

Table V-1. Building Geometry and Internal Loads Used in the DOE-2 Simulations . . 45

Table V-2. Building Conservation Levels and Base Case Surface Characteristics Assumed in the DOE-2 Simulations . . . . . . . . . . . 46

Table V-3. System Characteristics Assumed in the DOE-2 Simulations . . . . . 48

Table V-4. Ceiling and Foundation Construction and Duct Locations for House Sites in the SMUD Project . . . . . . . . . . . . . . . 49

Table V-5. Comparison of 1991 Airport Weather Data with Sacramento TMY . . . 53

Table V-6. 1991 Julian Days/Dates Within the Field Measurements' Time Frame . . . . . . . . . . . . . . . . . . . 55

Table V-7. Monitoring Periods, Albedo, and Emissivity of Control and Tests Units Coatings . . . . . . . . . . . . . . . . . . . 78

Table V-8 Comparison of Measured and Simulated Data On Daily Basis . . . . . 129

Table V-9 Model Estimates of Experimental Savings over Base Case Period . . . 130

Table V-10 Simulated Annual Cooling Energy Use and Peak energy Demand (including Fan) (Sacramento TMY weather) . . . . . . . . . . 131

Table VI-1 Listing of Parametric Run Descriptions . . . . . . . . . . . . . . 145

Table VI-2 California Climate Zone Data for Parametric Simulations . . . . . . 146

Table VI-3 Base Case Annual Cooling Energy and Percent Changes for Strategy Combinations (includes supply fan energy) . . . . . . . . . . . . . 149

Table VI-4 Base Case Peak Cooling and Percentage Changes for Strategy Combinations (includes supply fan energy) . . . . . . . . . . . 150 
Table VI-5 Average Annual Cooling Energy and Peak Power Saving Potentials of Shade Trees and White Surfaces . . . . . . . . . . . . . . 159 


\title{
Peak Power and Cooling Energy Savings
}

of Shade Trees and White Surfaces

\begin{abstract}
Urban areas in warm climates create summer heat islands of daily average intensity of $3-5^{\circ} \mathrm{C}$, adding to discomfort and increasing air-conditioning loads. Two important factors contributing to urban heat islands are reductions in albedo (lower overall city reflectance) and loss of vegetation (less evapotranspiration). Reducing summer heat islands by planting vegetation (shade trees) and increasing surface albedos, saves cooling energy, allows down-sizing of air conditioners, lowers air-conditioning peak demand, and reduces the emission of $\mathrm{CO}_{2}$ and other pollutants from electric power plants. The focus of this multi-year project, jointly sponsored by SMUD and the California Institute for Energy Efficiency (CIEE), was to measure the direct cooling effects of trees and white surfaces (mainly roofs) in a few buildings in Sacramento. The first-year project was to design the experiment and obtain base case data. We also obtained limited post retrofit data for some sites. This report provides an overview of the project activities during the first, 'ear at six sites. The measurement period for some of the sites was limited to September and October, which are transitional cooling months in Sacramento and hence the interpretation of results only apply to this period. In one house, recoating the dark roof with a high-albedo coating rendered air conditioning unnecessary for the month of September (possible savings of up to $10 \mathrm{kWh}$ per day and $2 \mathrm{~kW}$ of non-coincidental peak power). Savings of $50 \%$ relative to an identical base case bungalow were achieved when a school bungalow's roof and southeast wall were coated with a high-albedo coating during the same period. DOE-2 simulations of these two buildings indicated savings of significantly lower magnitude than those measured. Given these results, the large measured savings may in part be attributed to generally lower insolation during the post-monitoring period. Our measured data for the vegetation sites do not indicate conclusive results because shade trees were small and the cooling period was almost over. We need to collect more data over a longer cooling season in order to demonstrate savings conclusively. The DOE-2 simulations of these buildings appear to indicate very small or no savings from trees. The issue of comparing DOE-2 simulations with measured data will be addressed in further detail during the second year of the project.
\end{abstract}




\section{Acknowledgement}

This work was jointly supported by the California Institute for Energy Efficiency (CIEE) and the Sacramento Municipal Utility District (SMUD) through the U.S. Department of Energy, under contract DE-AC0376SF00098. We wish to acknowledge Bruce Vincent of SMUD and Tony Fung of SCE for their helpful suggestions and comments in preparing this final report. The initial DOE-2 inputs for the monitored buildings were prepared by Joe Huang. Di Ann Fager's support was crucial to timely completion of the report.

\section{Disclaimer}

The research reported here was funded in part by the California Institute for Energy Efficiency (CIEE), a research unit of the University of California. Publication of research results does not imply CIEE endorsement of or agreement with these findings, nor that of any CIEE sponsor. 


\section{Peak Power and Cooling Energy Savings \\ of Shade Trees and White Surfaces}

\section{Executive Summary}

Urban areas in warm climates create summer heat islands of daily average intensity of 3$5^{\circ} \mathrm{C}$, adding to discomfort and increasing air-conditioning loads. Two important factors contributing to urban heat islands are reductions in albedo (lower overall city reflectance) and loss of vegetation (less evapotranspiration). The lower concentration of vegetation in urban areas results in channeling a higher portion of the net solar gains into sensible heat rather than into latent heat, thus enhancing the heat island effect. Vegetation has a large impact on microclimate. In desert cities, for example, evapotranspiration (from trees in urban areas) is greater than of surrounding rural areas (treeless desert lands), actually lowering temperatures in the city; in climatological terms, this is referred to as the "oasis effect."

In response to the adverse effects of the urban "summer heat island" (SHI) of Sacramento, the Sacramento Municipal Utility District (SMUD) has embarked on a program to plant $1 / 2$ million shade trees over the next 10 years to reduce the SHI by shading homes, schools, and places of business. Reducing summer heat islands saves cooling energy, allows down-sizing of airconditioners, lowers air conditioning peak demand, and reduces the emission of $\mathrm{CO}_{2}$ and other pollutants from electric power plants.

Preliminary analysis indicates that an extensive implementation program of tree planting and white surfaces in Sacramento (reaching 250,000 unshaded houses) would yield residential cooling savings of about 600 peak MW. These energy savings can be delivered with little cost. White surfaces incur no incremental costs; whereas young trees cost about $\$ 10$ each. Including purchase, planting, and watering costs, the present-valued cost per saved peak $\mathrm{kW}$ from vegetation would be under $\$ 150$ per $\mathrm{kW}$ in Sacramento (ignoring the many other benefits of more trees, in terms of urban amenity, aesthetics, and outdoor comfort). 
The simulations of heat island mitigation measures provide a common basis for comparison of the measures and their potential energy and power savings. However, some important elements, related to actual building operation and both macro- and microclimate variations, are not easy to evaluate using simulations alone. In order to understand the realistic savings potential for SHI mitigation measures, before starting large-scale implementation, it is necessary to carry out field experiments to identify unforeseen problems, and to measure and document actual savings.

The focus of this project, jointly sponsored by SMUD and the California Institute for Energy Efficiency (CIEE), was to measure the direct cooling effects of trees and white surfaces (mainly roofs) in a few buildings in Sacramento.

The specific goals of the first year project were:

- to assess and document the albedo performance characteristics of various building and paving materials,

- to document the air-conditioning energy savings of shade trees and high-albedo surfaces by instrumenting and monitoring microclimate attributes and air-conditioning energy use in a few homes and a school in Sacramento,

- to compare simulation results with monitored data, and

- to provide an analysis of impacts of trees and white surfaces to assist SMUD in their program.

The project was designed as a collaborative effort between LBL and SMUD. The LBL participation involved project design, equipment installation, and data analysis. SMUD supplied the monitoring equipment and instrumentation. Other in kind contribution by SMUD included an engineer to instrument the selected buildings, collect data, and transfer them to LBL for analysis.

Major tasks in this project included:

Task 1: Performance Data for White Surfaces. This task included making contact with the industry and performing a review of the manufacturers products and literature, collecting data for white surfaces, documenting and comparing the data, performing cost-benefit analysis, and assessing of various strategies for encouraging a wide implementation of this 
measure. The purpose of this task was to provide information for creating an implementation scheme for SMUD and other utilities (see Bretz and Rosenfeld, 1992)

Task 2: Demonstration, Validation, and Documentation. The elements of this task included identification of monitoring sites, audits of the buildings, development of an experimental plan, specification and procurement of monitoring equipment, calibration of sensors, installation and testing of equipment, collection and review of test results, base case and retrofit monitoring (data collection), and data analysis to assess savings from experimental measures.

Task 3: Simulations of Energy and Peak Saving. This task included DOE-2 simulations of the buildings and a comparison of the simulated results with measured data. These results were then used to calibrate the model. The calibrated model was used to extrapolate results for different combinations of tree shading and albedo strategies in four differents climates.

This final report is prepared in seven chapters and two attachments. ${ }^{*}$ Chapter I provides an overview of the project. Chapter II discusses the process of site selection, provides information on site characteristics, and discusses the albedo and tree modification experiment performed on each site. For each site, we developed a monitoring protocol for data measurement and provided guidelines for building operation. Monitoring protocols for all sites are presented in Attachment $\mathrm{B}$, and the overall monitoring protocol is discussed in Chapter III. Chapter III also presents a general description of the installed equipment, instrumentation of the sites, and calibration of the equipment. Chapter IV is a summary of our field experience in performing this monitoring project. Chapter V, the data analysis chapter, is the heart of this report. In Chapter V, we present a review of the data analysis and simulation methodologies, discuss the measured and simulated energy impacts of white surfaces and shade trees for each site, compare simulation results with measured data, and discuss the differences. Chapter VI extrapolates our calibrated DOE-2 simulations to four climate regions in California, i.e., Sacramento, Riverside, Fresno, and Pasadena.

\footnotetext{
* Three other attachments which were included in the draft report have been omitted here. The first one is LBL-31721, High Albedo Materials for Reducing Building Cooling Energy Use, $\mathrm{H}$. Taha, D. Salior, and H. Akbari. The second omitted attachment is LBL-32467, Implementation of Solar Reflective Surfaces: Materials and Utility Programs, S. Bretz, H. Akbari, A. Rosenfeld, and H. Taha. Also for the sake of brevity, the detailed workplan attachment has been omitted.
} 
Chapter VII provides a summary of the project and suggests tasks to be completed in the second year project.

This project was implemented over two years. The first year project was to design the experiment and obtain base case data. We also obtained limited post retrofit data for some sites. Hence the first year report is preliminary in nature, and all conclusions are subject to further verification during the next year.

The measurement period for some of the sites were limited to September and October. These are transitional cooling months in Sacramento, and the measured results presented here are limited to these measurement periods. During the second year project we will measure the impacts of shade trees and white roofs during the peak of the cooling season. However, for the 1991 report, with the help of simulations, we estimate the impact of high-albedo roofs and shade trees on cooling energy use for the hot summer months of June, July, and August.

For each site, pre- and post-retrofit cooling electricity use data are examined as a function of outdoor temperature (means and maxima), indoor temperatures, indoor/outdoor temperature differences, and solar radiation, as appropriate to each particular case. A discussion of solar radiation and its change over time (during the monitoring period) is provided in order to demonstrate the decrease in solar radiation during the monitoring period and it's effect on cooling energy use. Finally, hourly time-series of cooling electricity usage are shown and compared with simulated results.

A major objective of this project was to quantify the potential of high-albedo materials and vegetation for reducing cooling energy use in buildings. The first year measured data indicated that albedo modifications had significant impacts on cooling energy use. We did not gather sufficient data to conclusively demonstrate the impact of vegetation modifications.

In one house, recoating the dark roof with a high-albedo coating rendered air conditioning unnecessary for the month of September. Savings of $50 \%$ compared with the identical base case bungalow were achieved when a school bungalow's roof and south-east wall were coated with a high-albedo coating during the same period. DOE-2 simulations of these two buildings indicated savings of significantly lower magnitude than those measured. Given these results the 
large measured savings may in part be attributed to generally lower insolation during the postmonitoring period.

For the vegetation sites, savings were generally lower than those for the albedo cases. In one house, the addition of two trees on the west and one tree on the south sides resulted in a reduction of $-40 \%$ in cooling energy use, whereas the addition of two southwest trees to another home reduced its cooling energy by $-30 \%$. The other two other cases showed smaller savings. The addition of two trees on the east side of a well-shaded house reduced its cooling energy use by $-10 \%$, and the addition of six trees on the south side of a completely unshaded home reduced its energy use by only $\sim 10 \%$. However, these savings will be smaller once corrected for solar intensity and so, should be regarded as possible overestimates.

The DOE-2 simulations of these buildings appear to indicate very small or no savings from trees. The issue of comparing DOE-2 simulations with measured data will be addressed in further detail during the second year of this project. Ways of improving the simulations to reflect actual conditions are suggested in this report.

In addition to differences in internal loads, schedules, and envelope characteristics, one reason that some sites had larger percent savings than others might be the fact that the local microclimate was different from one location to another. For example, Site 2 was in a cooler environment, heavily shaded, and therefore, this might have helped save $100 \%$ of cooling energy use in September when the roof was recoated with a high-albedo coating. Site 8, on the other hand, was in a warmer part of Sacramento, and that might explain why only $10 \%$ or less of cooling energy was saved by planting six trees on its south side. Microclimate variations are briefly discussed in this report.

In general, the $\mathrm{DOE}_{-}-2$ simulations confirmed our measured data. Simulations indicated that the albedo modifications made to Sites 2 and $B$ could produce significant changes in cooling energy use. On the other hand, the simulated direct shading effect of trees used in the study led to almost imperceptible changes in cooling use, most likely because of their small size.

Note that the simulations only calculate the direct effect of trees on building surfaces and windows. Any indirect cooling effects of these trees cannot be evaluated in the DOE-2 model. 
Other effects, such as increased cooling system performance from direct shading of the airconditioning condenser unit or indirect/microclimate effects of evapotranspiration were not modeled. The DOE-2 simulation results suggest that the direct shading effects on cooling demand are not significant in these cases because the trees were small.

The impact of the modifications on cooling energy use are summarized in Table EX-1 for both measured and simulated data. We present average daily cooling energy consumption during the pre- and post-periods from the measured data and from the model. We also present simulated daily cooling energy use during the pre-period, but using the modified case building input. The models were used to evaluate cooling usage over the specific periods of monitoring for comparison.

In Table EX-2, we present monthly and annual estimates of cooling energy use from the simulation models. Note that in this case we use the Sacramento TMY (Typical Meteorological Year) weather tape, and thus do not account for microclimates specific to each site.

We used the calibrated simulation models for the six houses and the school bungalow to estimate cooling energy savings for other combinations of tree and albedo strategies and in four climates regions in California. In this parametric study, we modeled the direct shading impact of varying amounts of tree cover as well as the effects of changes in roof and wall albedos.

The average annual energy and peak power savings potentials are summarized in Table EX-3. The savings are averaged using the basecase consumption for each building as a weighting factor. The average energy saving potentials is about $33 \%$ in Fresno and about $42 \%$ in other climate regions. The average peak power saving potentials is about $17 \%$ to $20 \%$. Note that, since the air-conditioning systems are designed for Sacramento climate, the peak power savings for other climates, particularly Fresno, may be underestimated. 
Table EX-1. Measured and Simulated Daily Energy Use and Peak Demand

\begin{tabular}{|c|c|c|c|c|c|c|c|}
\hline \multirow[b]{2}{*}{ Site } & \multirow[b]{2}{*}{$\begin{array}{l}\text { Building } \\
\text { Modification }\end{array}$} & \multicolumn{2}{|c|}{ Period } & \multicolumn{2}{|c|}{$\begin{array}{c}\text { Measured } \\
\text { Average Daily }\end{array}$} & \multicolumn{2}{|c|}{$\begin{array}{c}\text { Simulated } \\
\text { Average Daily }\end{array}$} \\
\hline & & $\begin{array}{l}\text { start } \\
\text { day }\end{array}$ & $\begin{array}{l}\text { stop } \\
\text { day }\end{array}$ & $\begin{array}{l}\text { Energy } \\
(\mathrm{kWh})\end{array}$ & $\begin{array}{l}\text { Peak } \\
(\mathrm{kW})\end{array}$ & $\begin{array}{c}\text { Energy Peak } \\
(\mathrm{kWh})\end{array}$ & $(\mathrm{kW})$ \\
\hline Site 1 & Control & 236 & 293 & 5.17 & 1.40 & 7.00 & 1.41 \\
\hline Site 2 & $\begin{array}{l}\text { Base } \\
\text { Albedo } \\
\text { Albedo }\end{array}$ & $\begin{array}{l}235 \\
260 \\
235\end{array}$ & $\begin{array}{l}253 \\
293 \\
253\end{array}$ & $\begin{array}{l}2.95 \\
0.39\end{array}$ & $\begin{array}{l}0.90 \\
0.18\end{array}$ & $\begin{array}{l}3.26 \\
0.34 \\
0.93\end{array}$ & $\begin{array}{l}0.67 \\
0.11 \\
0.24\end{array}$ \\
\hline Site 5 & $\begin{array}{l}\text { Base } \\
\text { Trees } \\
\text { Trees }\end{array}$ & $\begin{array}{l}254 \\
268 \\
254 \\
\end{array}$ & $\begin{array}{l}258 \\
293 \\
258\end{array}$ & $\begin{array}{r}10.33 \\
9.75\end{array}$ & $\begin{array}{l}1.91 \\
2.03\end{array}$ & $\begin{array}{l}7.55 \\
8.90 \\
7.22 \\
\end{array}$ & $\begin{array}{l}1.49 \\
1.68 \\
1.47\end{array}$ \\
\hline Site 6 & $\begin{array}{l}\text { Base } \\
\text { Trees } \\
\text { Trees }\end{array}$ & $\begin{array}{l}234 \\
268 \\
234 \\
\end{array}$ & $\begin{array}{l}266 \\
294 \\
266 \\
\end{array}$ & $\begin{array}{l}5.51 \\
3.60\end{array}$ & $\begin{array}{l}1.72 \\
1.27\end{array}$ & $\begin{array}{l}7.49 \\
5.03 \\
7.46 \\
\end{array}$ & $\begin{array}{l}1.51 \\
1.20 \\
1.50 \\
\end{array}$ \\
\hline Site 7 & $\begin{array}{l}\text { Base } \\
\text { Trees } \\
\text { Trees }\end{array}$ & $\begin{array}{l}247 \\
268 \\
247\end{array}$ & $\begin{array}{l}266 \\
291 \\
266\end{array}$ & $\begin{array}{l}7.95 \\
6.81\end{array}$ & $\begin{array}{l}1.51 \\
1.65\end{array}$ & $\begin{array}{l}13.15 \\
11.49 \\
13.09\end{array}$ & $\begin{array}{l}2.12 \\
2.00 \\
2.10\end{array}$ \\
\hline Site 8 & $\begin{array}{l}\text { Base } \\
\text { Trees } \\
\text { Trees }\end{array}$ & $\begin{array}{l}235 \\
268 \\
235\end{array}$ & $\begin{array}{l}248 \\
294 \\
248\end{array}$ & $\begin{array}{l}20.68 \\
14.79\end{array}$ & $\begin{array}{l}2.69 \\
2.23\end{array}$ & $\begin{array}{l}20.10 \\
17.09 \\
19.93\end{array}$ & $\begin{array}{l}2.45 \\
2.43 \\
2.43\end{array}$ \\
\hline Site B* & $\begin{array}{l}\text { White ( } 78^{\circ} \mathrm{F} \text { Tsct) } \\
\text { Metal ( } 70^{\circ} \mathrm{F} \text { Tsct) } \\
\text { Metal ( } 78^{\circ} \mathrm{F} \text { Tsct) }\end{array}$ & & & $\begin{array}{r}6.93 \\
17.35\end{array}$ & $\begin{array}{l}1.30 \\
2.70\end{array}$ & $\begin{array}{r}7.92 \\
15.78 \\
9.36 \\
\end{array}$ & $\begin{array}{l}1.22 \\
1.70 \\
1.39\end{array}$ \\
\hline
\end{tabular}

* Thermostat settings at Site B were changed during the monitoring period. Monitoring took place for thermostat setting of $70^{\circ} \mathrm{F}$ and $78^{\circ} \mathrm{F}$ as indicated above. 
Table EX-2. Annual Cooling Energy Use and Peak Energy Demand (including Fan) (Sacramento TMY Weather)

\begin{tabular}{|ll|rr|}
\hline & & $\mathbf{k W h}$ & $\mathbf{k W}$ \\
\hline Site 1 & Control & 1166 & 3.99 \\
\hline Site 2 & Base & 793 & 2.93 \\
Site 2 & Albedo & 466 & 2.47 \\
\hline Site 5 & Base & 1865 & 4.46 \\
Site 5 & Trees & 1822 & 4.44 \\
\hline Site 6 & Base & 1250 & 4.24 \\
Site 6 & Trees & 1244 & 4.24 \\
\hline Site 7 & Base & 2285 & 4.23 \\
Site 7 & Trees & 2276 & 4.23 \\
\hline Site 8 & Base & 2804 & 3.73 \\
Site 8 & Trees & 2746 & 3.73 \\
\hline Site B & Base & 1099 & 3.48 \\
Site B & Albedo & 863 & 2.80 \\
\hline
\end{tabular}

* School occupancy schedule is $1 / 1-5 / 31$ and $9 / 3-12 / 31$ with appropriate holidays.

Table EX-3. Average Annual Cooling Energy and Peak Power Saving Potentials of Shade Trees and White Surfaces. The savings are averaged using the basecase consumption for each building as a weighting factor.

\begin{tabular}{|l|cc|cc|}
\hline \multirow{2}{*}{ Climate } & \multicolumn{2}{|c|}{ Base Case } & \multicolumn{2}{c|}{ Savings } \\
& Energy & Peak & Energy & Peak \\
& $(\mathrm{kWh})$ & $(\mathrm{kW})$ & $(\%)$ & $(\%)$ \\
\hline Fresno & 3306 & 4.28 & 33 & 17 \\
Riverside & 2056 & 3.69 & 42 & 19 \\
Sacramento & 1399 & 3.78 & 43 & 19 \\
Pasadena & 1427 & 3.30 & 42 & 20 \\
\hline
\end{tabular}




\section{INTRODUCTION}

Urban areas in warm climates create summer heat islands that increase daily average temperatures by $3-5^{\circ} \mathrm{C}$, add to discomfort, and increase air-conditioning loads. Two important factors contributing to urban heat islands are reductions in albedo (lower overall city reflectance) and loss of vegetation (less evapotranspiration). A typical urban surface has an albedo of $\sim 15 \%$ and is lower than the albedo of rural areas $(-25 \%)$, which results in an increase $(-10 \%)$ in urban solar absorption. The lower concentration of vegetation in urban areas results in channeling a higher portion of the net solar gains into sensible heat rather than into latent heat, thus enhancing the heat island effect. Vegetation has a large impact on microclimate. For example, evapotranspiration (from trees in urban areas) in desert cities, is greater than that of surrounding rural areas (treeless desert lands), actually lowering temperatures in the city, in climatological terms, this is referred to as the "oasis effect."

We have been studying how to mitigate the heat island effect in U.S. cities by increasing urban vegetation and albedo. Preliminary estimates of potential summer peak and energy savings from summer heat island (SHI) mitigation have been made for single-family residences in Sacramento, California, using the DOE-2 building simulation model. The results indicate that shading homes (windows, walls, and roofs) with trees can save as much as $34 \%$ of their peak cooling demand on a hot summer day (Akbari et al. 1990, Huang et al. 1990). Even more promising results were obtained by simulating a change in the overall albedo of the city, from an existing $-15-20 \%$ to a "whitewashed" $40 \%$ (Akbari et al. 1990, Taha et al. 1988). Under such conditions, the simulated peak cooling demand dropped by $-40-50 \%$ in Sacramento. The overall combined effects of trees and white surfaces may yield savings of as much as $50 \%$ in residential cooling peak demand in Sacramento.

An extensive implementation program in Sacramento (reaching 250,000 unshaded houses) could yield residential cooling savings of about 600 peak MW. These energy savings can be delivered with little cost. White surfaces incur no incremental costs; whereas young trees initially cost about $\$ 10$ each. Including purchase, planting, and watering costs, the present-valued cost per saved peak $\mathrm{kW}$, in Sacramento, would be less than $\$ 150$ (ignoring the many other benefits of more trees, in terms of urban amenity, aesthetics, and outdoor comfort) (SMUD 1990). 
The simulations of heat island mitigation measures provide a common basis for comparison of the measures and their potential energy and power savings. However, some important elements, related to actual building operations and both macro- and microclimatic variations, are not easy to evaluate using simulations alone. In order to understand the realistic savings potential for each SHI mitigation measure, before starting large-scale implementation, it is appropriate to carry out field experiments to identify unforeseen problems and measure and document actual savings.

Measured energy savings from urban trees and white surfaces are scarce. The only previous experimental case study, related to the impact of vegetation, is that of Parker (1981) in Florida. In that experiment, Parker measured the cooling energy consumption of a mobile building before and after adding trees and shrubs, and found savings of up to 50\%. On the other hand, no significant data are available on the effects of white surfaces. It is the objective of this project to monitor both of these effects in several buildings in Sacramento.

Trees and white surfaces affect the cooling energy consumption of a building in two ways:

1. Direct Effect: Trees shade buildings, blocking solar gain. White roofs and walls reflect most incident solar energy. Both of these factors decrease buildings cooling loads,

2. Indirect Effect: Microclimatic variations resulting from changes in the surface heat balance caused by evapotranspiration and lower solar heating of the light-colored buildings and surfaces.

\section{A. Project Objectives}

This project is a collaborative effort with The Sacramento Utility District (SMUD) to assess, monitor, and document the direct effects of shade trees and white surfaces. The project was implemented in two phases. The focus of the first phase was to measure the direct cooling effects of trees and white surfaces (mainly roofs) with particular emphasis on trees.

The specific goals of the first year project were:

- to document the air-conditioning energy savings of shade trees and albedo changes by instrumenting and monitoring microclimate attributes and air-conditioning energy use in a few selected homes and a school in Sacramento, 
- to compare simulation results with monitored data,

- to provide analysis of the impacts of trees and white surfaces to assist SMUD in its program, and

- to assess and document the albedo performance characteristics of various building and paving materials and specify/recommend how they should be used in an incentive program.

\section{B. Project Scope}

As we discussed above, the objective of this project was limited to measuring the direct impact of shade trees and white surfaces on cooling energy use of several buildings in Sacramento. There are several other impacts that trees and white surfaces may have on building energy use and the local environment that may need to be addressed in follow-up studies. Some of these other energy and environmental factors are discussed below.

\section{Sample Selection}

Only seven buildings participated in this study. The sample included only those buildings, out of approximately 100, whose occupants/owners responded positively and agreed to participate in this project. Hence, the sample of monitored buildings, by no means, is representative of the population. Furthermore, we do not account for the effects of the possible changes in occupants' behaviors as a result of participation in the monitoring study. Care must be taken in extrapolating the results to other climates and building types. With the help of calibrated simulations, we present some extrapolated savings for other climate regions, for the buildings types studied.

\section{Impacts on Heating Energy Use}

Trees and white surfaces affect the heating energy use of a building. In several earlier studies, with the help of simulations, we addressed the heating energy use of buildings (Akbari and Taha 1991, Taha and Akbari 1988, Huang and Akbari 1990). Trees have a negative effect on heating energy consumption by shading a building and a positive effect by shielding the building from cold winter wind. Although these effects are not fully understood for all different climate regions and all building types, earlier studies indicate that trees may also save energy in winter, particularly in cold climates. The impact of white surfaces is even less understood. Our simulations for two California cities indicated that about $10-20 \%$ of the summertime cooling energy savings are taken back through increased wintertime heating. Future studies should address, in 
detail, the heating impacts of trees and white surfaces.

\section{The Impact of Reflected Radiation on the Cooling Energy Use of Adjacent Buildings}

The impact of the reflected radiation from a building on the adjacent buildings is another issue for further consideration. Simple calculations, however, show that the total (sum of long-and short-wave radiation) incident on a neighboring building is independent of the albedo of the test building; simply, under equilibrium conditions, the solar radiation incident on a surface is either reflected back as short-wave radiation or absorbed by the surface and re-emitted as long-wave radiation. The proportion of the long-wave and short-wave radiation, however, is important on the cooling energy load of a zone. If the reflected radiation is incident on a opaque wall, the higher the fraction of the short-wave radiation, the lower the cooling energy load of the zone. If the reflected radiation is incident on windows, it is obviously better to have a lower fraction of short-wave radiation. A study should be designed to address this issue in further detail.

\section{Experimental Protocols}

A practical issue of serious concern in a field experiment is normalization of data for crosscomparison with other building types and across different climates. Issues such as operation of the air conditioners, windows, and curtains are typical of such complexities. For instance, some people may have a higher tolerance for elevated indoor temperatures than others. Some may open the windows as soon as the outdoor conditions are favorable and some may not. In this project, we have not addressed these variations in the actual operations of the experimental buildings. We have developed a set of guidelines for building operations that would make the data analysis less cumbersome. These guidelines are discussed in this report. A separate study is needed to compare these guidelines with a statistically representative assessment of prevailing practices in the operation of buildings.

\section{Trees and Air Quality}

Although trees are known for their shading and neighborhood-cooling effects, some trees are also known for their impacts on other environmental issues such as air quality. Some trees emit reactive organic gases (ROG) that contribute to air pollution; some trees improve the air quality by collecting the dust and larger particles from the air. The California Institute for Energy Efficiency (CIEE) has sponsored a project to study the impact of trees and white surfaces on the air quality of the Los Angeles Basin (Ritschard et al. 1992). 


\section{Practical Implementation Issues}

There may be some legal issues related to trees. In a letter to the Principal Investigator, Tony Fung of Southern California Edison Company states that, "Trees create more disputes among neighbors than any other subject matter. Practical issues such as driveway breakups, foundation cracking, sewageipipe blockage and breakage, view reduction, as well as potential hazards (fire, storm, etc.), should be addressed" and studied in detail. Before embarking on a major implementation program, the utilities should address and study all implementation issues that need to be considered in a program. Pilot studies are usually good vehicles to gather field experience for program implementation.

Of equal importance is the long-term change of the surface albedo and shading of trees. The short-term focus of this monitoring project did not provide an opportunity to address the long-term changes in albedo and tree shading. These issues need to be studied over longer periods.

\section{Project Tasks}

The project focused on collecting performance data for white surfaces, demonstrating and validating energy savings of shade trees and white surfaces in several buildings in Sacramento. The project also includes a performance assessment of different products and treatments for white surfaces to specify/recommend how to use white surfaces in buildings to achieve capacity and energy savings. As stated earlier, the project was designed as a collaborative effort between Lawrence Berkeley Laboratories (LBL) and SMUD. The LBL participation involved project design, equipment installation, and data analysis. SMUD supplied the monitoring equipment and instrumentation. Other in-kind contributions by SMUD included an engineer to instrument the selected buildings, collect data, and transfer them to LBL for analysis.

Major tasks in this project included:

Task 0: Detailed Workplan. In collaboration with SMUD, we developed a workplan outlining the details of the project's scope and tasks. The workplan focused on the details of the monitoring experiment, where a significant coordination between SMUD and LBL was needed. This task was completed and delivered to SMUD and CIEE in March 1991. 
Task 1: Performance Data for White Surfaces. We assessed the albedo performance characteristics of various building and paving materials and specified/recommended how they should be used to achieve peak power and energy savings. This task included reviewing the manufacturers' products and literature, collecting data for white surfaces, contacting the paint industry for data, documenting and comparing data, performing a cost-benefit analysis, and assessing various strategies to encourage a wide implementation of this measure. Our findings regarding this task are summarized in two earlier reports prepared for CIEE and SMUD (Taha et al. 1992 and Bretz et al. 1992).

Task 2: Demonstration, Validation, and Documentation. In this task we studied and documented the air-conditioning energy savings of shade trees and albedo changes by instrumenting and monitoring microclimate attributes and air-conditioning energy use at seven sites in Sacramento. The elements of this task included identification of monitoring sites, audits of the buildings, development of a plan for the experiment, specification and procurement of monitoring equipment, installation and testing of equipment, collection and review of test results, base case and retrofit monitoring (data collection), data analysis, and preparation of reports. All the major elements of this task were performed jointly by LBL and SMUD.

Task 3: Simulations of Energy and Peak Savings. We performed DOE-2 simulations of the buildings, compared the simulated results with monitored data, and refined and validated prediction algorithms. Based on the results of Task 2, we performed an analysis for white surfaces and shade trees for four representative climates in California.

Our preliminary findings regarding Tasks 2 and 3 were reported in an interim report to CIEE and SMUD (Akbari et al. 1992). In the interim report, we discussed the project design, specification and procurement of the monitoring equipment, calibration, installation, and validation of the data-logging systems, and the preliminary analysis of the collected data for three sites. This final report updates the work presented in the interim report and completes the analysis of the measured data collected during the first year of the project. 


\section{Organization of Report}

This report was prepared to document the first year efforts of the monitoring task and to provide preliminary savings results. In addition to this introductory chapter (Chapter I), the report is organized into six other chapters.

Chapter II discusses the process of site selection and provides an overview of the characteristics of each site. The chapter also describes the albedo and tree modification experiments performed on each site.

For each site, we developed a distinct monitoring protocol for data measurement and provided guidelines for the operation of the site. Each protocol discusses the overall characteristics of the site, the data points, data monitoring intervals, and a guideline for the operation of the building. Monitoring protocols for all sites are presented in Attachment B, and the overall monitoring protocol is also discussed in Chapter II.

Chapter III presents a general description of the installed equipment, instrumentation of the sites, and calibration of the equipment. In this chapter we first discuss the characteristics of sensors and data loggers used in the project. Then we discuss the installation of the instruments on each site. Finally, we briefly review both the bench calibration and the pre- and post-dynamic calibration of the monitoring systems.

Chapter IV is a summary of our field experience in performing this monitoring project. We first discuss our experience and problems encountered in selecting, purchasing, installing, and programming the monitoring equipment. Bringing shade trees to the sites and changing the albedo of the roofs and walls, at times, provided serious challenges to this project. This chapter also discusses our practical experience regarding tree-planting and white-surfacing of the sites.

Chapter $\mathrm{V}$ is the data analysis chapter. We first present an overall review of the data analysis and simulation methodologies. Then we present the measured and simulated energy impacts of white surfaces and shade trees for each site, compare simulation results with measured data, and discuss the differences. This chapter concludes by providing a summary of the simulated and measured savings for all sites and by providing a brief review of microclimate variations on each site.

In Chapter VI we use the calibrated simulation models for the six houses and the school bungalows to estimate cooling energy savings for other combinations of tree and albedo strategies and in four climates regions in California. In this parametric study, we model the direct shading impact of varying amounts of tree cover as well as the effects of changes in roof and 
wall albedos.

Chapter VII is the summary and conclusion chapter. This chapter provides an overview of the results and recomendations for the 1992 monitoring project.

\section{References}

Akbari, H., Huang, J., Sailor, D., Taha, H; and Bos, W. 1991. "Monitoring Peak Power and Cooling Energy Savings of Shade Trees and White Surfaces in the Sacramento Municipal Utility District (SMUD) Service Area," An Interim Report prepared for California Institute for Energy Efficiency and SMUD, Lawrence Berkeley Laboratory, Berkeley, CA.

Akbari, H. and Taha, H. 1991. "The Impact of Trees and White Surfaces on Residential Heating and Cooling Energy Use in Four Canadian Cities," Energy, the International Journal, 17(2), pp. 141-149, 1992, also Lawrence Berkeley Laboratory Report No. LBL-30131, 1991, also published as "The Impact of Trees and White Surfaces on Residential Heating and Cooling Energy Use in Four Canadian Cities," Friends of the Earth, Ottawa, Canada, 1991.

Akbari, H., Rosenfeld, A., and Taha, H. 1990. "Summer Heat Islands, Urban Trees, and White Surfaces," Proceedings of American Society of Heating, Refrigeration, and Air conditioning Engineers, Atlanta, Georgia, (February), also Lawrence Berkeley Laboratory Report No. LBL-28308.

Akbari, H., Huang, J., Martien, P., Rainer, L., Rosenfeld, A., and Taha, H. 1988. "The Impact of Summer Heat Islands on Cooling Energy Consumption and Global $\mathrm{CO}_{2}$ Concentration," Proceeding of ACEEE 1988 Summer Study on Energy Efficiency in Buildings, Vol 5, pp. 11-23, Asilomar, CA (August).

Akbari, H., Taha, H., Huang, J., and Rosenfeld, A. 1986. "Undoing Summer Heat Islands can save Giga Watts of Power," Proceeding of ACEEE 1986 Summer Study on Energy Efficiency in Buildings, Vol. 2, pp. 7-22, Santa Cruz, August 17-23, 1986, also Lawrence Berkeley Laboratory Report No. LBL-21893 (July). 
Huang, Y. J., Akbari, H.; Taha, H. 1990. "The Wind-Shielding and Shading Effects of Trees on Residential Heating and Cooling Requirements," Proceedings of American Society of Heating, Refrigeration, and Air conditioning Engineers, Atlanta, Georgia (February), also Lawrence Berkeley Laboratory Report No. LBL-24131.

Huang, J., Akbari, H., Taha, H., and Rosenfeld, A. 1987. "The Potential of Vegetation in Reducing Summer Cooling Load in Residential Buildings," J. of Climate and Applied Meteorology, Vol. 26, No. 9, pp. 1103-1116. also Lawrence Berkeley Laboratory Report No. LBL-21291, July 1986.

SMUD 1990. "A Program to Plant 500,000 Trees in Sacramento over the Next 10 Years," Sacramento Municipal Utility District, August.

Ritschard, R., et al. 1993. "Analysis of Energy Efficiency and Air Quality," Lawrence Berkeley Laboratory Report No. LBL-33051.

Taha, H., Sailor, D., and Akbari, H. 1992. "High-albedo Materials for Reducing Building Cooling Energy Use," Lawrence Berkeley Laboratory Report No. 31721.

Taha, H., Akbari, H., Rosenfeld, A., and Huang, J. 1988. "Residential Cooling Loads and the Urban Heat Island: The Effect of Albedo," Energy and Environment, Vol. 23, No. 4, pp. 271-283. Lawrence Berkeley Laboratory Report No. LBL-24008. 


\section{SITE SELECTION, DESCRIPTIONS, MODIFICATIONS, AND MONITORING PROTOCOLS}

\section{A. Sites Selection}

During the early stages of this project, we sent questionnaires and inquiry forms to homeowners in the Sacramento area. The forms were sent to recipients from a list of people who had previously participated in other monitoring projects conducted by this and other groups. In addition, some of the forms were sent to SMUD employees. Each questionnaire/form requested information on building characteristics, occupancy schedules, and system characteristics/opcrations, as well as general information on the site and the surrounding albedo and vegetation density. The questionnaires also contained a request for consent to instrument the buildings. Appendix A shows an example of the questionnaire.

The initial number of respondents was not large $(-15)$, and additional factors further reduced this number. Many of those who initially expressed interest in participating did not respond in the final screening stages. We were left with 6 buildings, $\dagger$ which we decided to monitor. In addition to these buildings, two bungalows at a nearby school were made available for the monitoring project.

Therefore, we did not actually select these buildings, rather, they were opportunity sites. We had no control over the selection, and the only choice we had was to decide which would be vegetation cases and which would be assigned to albedo modifications. In the following sections, we describe each site and exr.'،in how it was monitored.*

† Initially we had recruited cight sitcs for monitoring: Site 1 through Site 8. However, Sites 3 and 4 withdrew at a latter stage and did not participate in the project. To keep our records straight, we kept the initial numbers of the sites throughout the project.

- Due to the very process of site sclection, and the limited responses that we received, the sites are by no means representative of the entire area. Also, duc to these limitations, the results of this project will not have statistical significance. 


\section{B. Site Description}

Six of the seven sites formed an arc about $32 \mathrm{~km}$ long, stretching from northeast Sacramento to its southeastern newer areas. The seventh site was a school, where we monitored two classroom bungalows. Figure II-1 shows the relative locations of these sites. Table II-1 summarizes the characteristics of the participant buildings.

Site 1 was the northernmost site of the arc. It was located in a relatively new residential area and was typical of new construction. Since it was shaded and located next to a similar but unshaded building (site 8), we decided to use site 1 as a control station. Site 2, located in the older area of Carmichael, was selected as an albedo case because all the exterior walls (and portions of the roof) were heavily shaded by dense vegetation, and also because the owner gave us permission to permanently re-coat his roof with a white elastomeric coating.

Site 5 was well shaded on the south side but could accommodate two small trees on the unshaded cast side. Site 6 , the southernmost of all, was located in a new residential area that had a low tree cover. The house itself had little vegetation, particularly on the west side. We decided to position two trees to shade the west windows and partially shade the condenser unit. Also, the roof was highly insulated, thus establishing another reason for monitoring this site as a vegetation, not albedo, case. Thus sites 5 and 6 were monitored for vegetation effects.

Site 8 was a mirror image of site 1 and adjacent to it. It had no vegetation cover and accordingly, we decided to use it as a vegetation case. Finally, at the school site, we monitored two classrooms for the impacts of albedo modification. The units were adjacent to each other $(-0.5$ $\mathrm{m}$ gap between them) and had similar exposure, dimensions, occupancy, cooling systems, and other characteristics. 


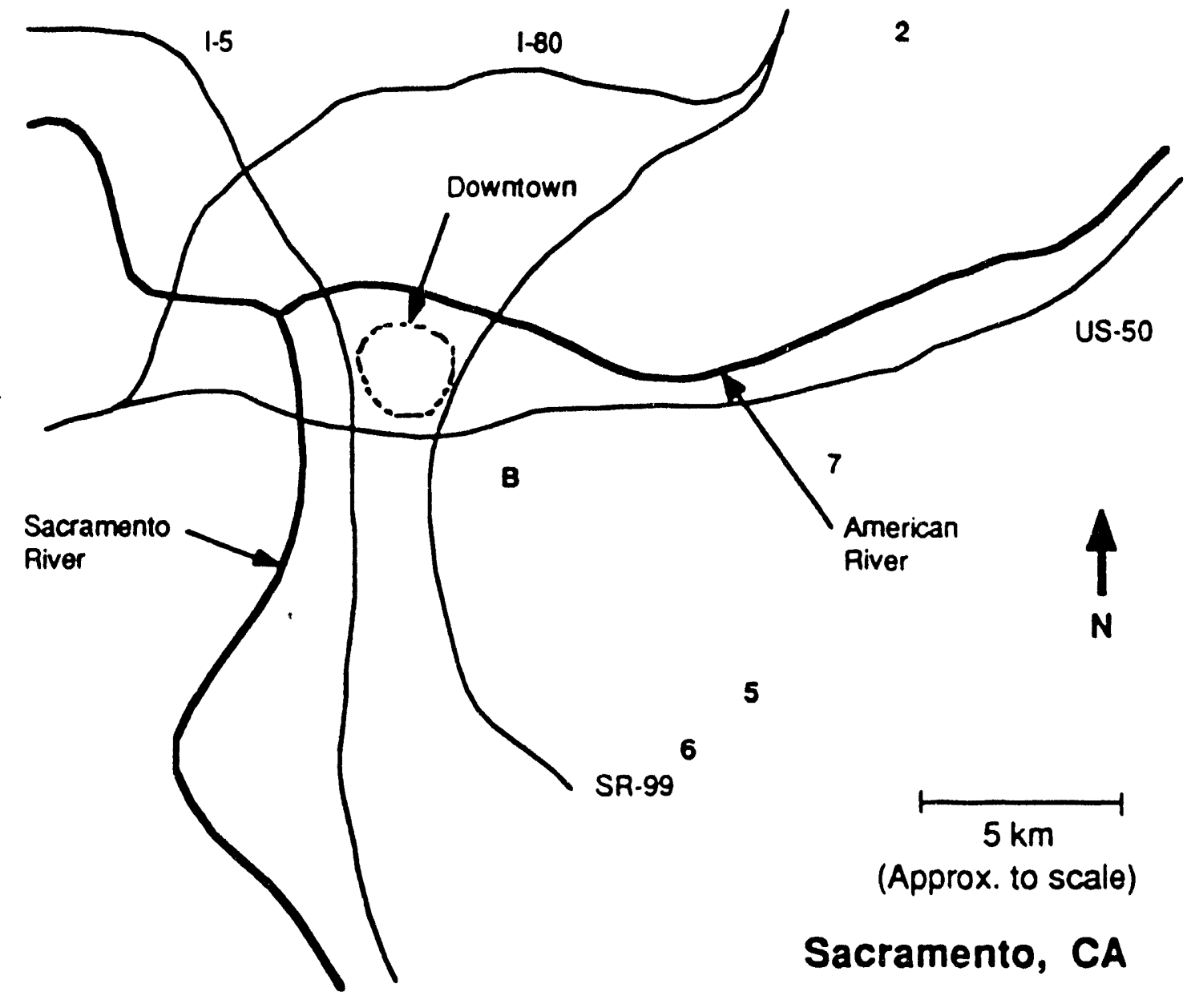

FIGURE II-1. Monitoring sites in Sacramento 
Table II-1 Site and Building characteristics.

Building description, schedules, thermostat settings,

and other vital information is listed below for all sites.

Unknown characteristics and those determined by qualitative inspection are marked with symbols (see footnotes).

\begin{tabular}{|c|c|c|c|c|c|c|c|}
\hline $\begin{array}{l}\text { Site } \rightarrow \\
\text { Case } \rightarrow\end{array}$ & $\begin{array}{c}\text { Site } 1 \\
\text { (control) }\end{array}$ & $\begin{array}{c}\text { Site } 2 \\
\text { (albedo) }\end{array}$ & $\begin{array}{c}\text { Site } 5 \\
\text { (vegetation) } \\
\end{array}$ & $\begin{array}{c}\text { Site } 6 \\
\text { (vegetation) } \\
\end{array}$ & $\begin{array}{c}\text { Site } 7 \\
\text { (vegetation) }\end{array}$ & $\begin{array}{c}\text { Site } 8 \\
\text { (vegetation) } \\
\end{array}$ & $\begin{array}{c}\text { Site B } \\
\text { (albedo) }\end{array}$ \\
\hline Building Type $\rightarrow$ & house & house & house & house & house & house & school \\
\hline $\begin{array}{l}\text { Site vegetation" } \\
\text { Neighborhood vegetation } \neq \\
\text { Albedo* } \\
\text { Neighborhood albedo } \neq\end{array}$ & $\begin{array}{l}\text { moderate } \\
\text { moderate-low } \\
\text { low } \\
\text { moderate }\end{array}$ & $\begin{array}{l}\text { heavy } \\
\text { moderate-heavy } \\
\text { low } \\
\text { moderate-high }\end{array}$ & $\begin{array}{l}\text { moderate } \\
\text { moderate-low } \\
\text { low } \\
\text { moderate-high } \\
\end{array}$ & $\begin{array}{l}\text { low } \\
\text { low } \\
\text { moderate-low } \\
\text { moderate } \\
\end{array}$ & $\begin{array}{l}\text { moderate-low } \\
\text { moderate } \\
\text { low } \\
\text { moderate-low } \\
\end{array}$ & $\begin{array}{l}\text { low } \\
\text { moderate-low } \\
\text { low } \\
\text { moderate } \\
\end{array}$ & $\begin{array}{l}\text { low } \\
\text { low } \\
\text { moderate-low } \\
\text { moderale }\end{array}$ \\
\hline \multicolumn{8}{|l|}{ Bullding description } \\
\hline $\begin{array}{l}\mathrm{ft}^{2}+ \\
\text { Building age } \\
\text { No. of stories } \\
\text { Roof material } \\
\text { Wall material } \\
\text { Roof insulation } \\
\text { Wall insulation } \\
\text { Windows } \\
\text { Foundation } \\
\text { Air conditioner } \\
\text { Heater } \\
\text { Duct }\end{array}$ & $\begin{array}{l}1000 \\
8 \\
1 \\
\text { comp. shingles } \\
\text { stucco/brick } \\
\text { R-19 } \\
\text { R-11 } \\
2-\text { pane } \\
\text { slab } \\
\text { central } \\
\text { central } \\
\text { ceiling } \\
\end{array}$ & $\begin{array}{l}1825 \\
29 \\
1 \\
\text { rolled comp. } \\
\text { plywood } \\
\text { R-11 } \\
\text { R-8 } \\
1-\text { pane } \\
\text { crawl } \\
\text { central } 3.5 T \\
\text { gas } 90000 \text { Btu } \\
\text { crawl } \\
\end{array}$ & $\begin{array}{l}1500 \\
5 \\
1 \\
\text { comp. shingles } \\
\text { wood siding } \\
\text { R-19 } \\
\text { R-11 } \\
2 \text {-pane } \\
\text { slab } \\
\text { central 3T } \\
\text { HP } \\
\text { ceiling } \\
\end{array}$ & $\begin{array}{l}1200 \\
4 \\
1 \\
\text { asph. shingles } \\
\text { stucco/siding } \\
\text { R-30 } \\
\text { R-11 } \\
2 \text {-pane } \\
\text { slab } \\
\text { central 3T } \\
\text { Furnace } \\
\text { ceiling }\end{array}$ & $\begin{array}{l}1450 \\
10 \\
1 \\
\text { comp. shake } \\
\text { stucco } \\
R-19 \\
R-11 \\
2-\text { pane } \\
\text { slab } \\
\text { central } \\
\text { gas } 42000 \text { Btu } \\
\text { ceiling }\end{array}$ & $\begin{array}{l}900 \\
8 \\
1 \\
\text { comp. shingle } \\
\text { stucco } \\
\text { R-19 } \\
\text { R-11 } \\
2 \text {-pane } \\
\text { slab } \\
\text { central } \\
\text { central } \\
\text { ceiling } \\
\end{array}$ & $\begin{array}{l}960 \\
2 \\
1 \\
\text { corrug. metal } \\
\text { plywood siding } \\
\text { R-19 } \\
\text { R-11 } \\
2 \text {-pane } \\
\text { crawl } \\
\text { HP } 34600 \\
\text { HP } \\
\text { ceiling }\end{array}$ \\
\hline \multicolumn{8}{|l|}{ Schedules } \\
\hline $\begin{array}{l}\text { No. of occupants } \\
\text { Weekday schedule } \\
\text { Weekend schedule }\end{array}$ & $\begin{array}{l}1 \\
0(700-1830) \\
0(1 / 2 \text { wknd }) \\
\end{array}$ & $\begin{array}{l}2 \\
0(700-1830) \\
2 \text { (ail) }\end{array}$ & $\begin{array}{l}2 \\
0(530-2000) \\
1 \text { (all) } \\
\end{array}$ & $\begin{array}{l}4 \\
0(800-1700) \\
\text { vary }\end{array}$ & $\begin{array}{l}6 \\
8 \\
8 \\
\end{array}$ & $\begin{array}{l}1 \\
0(800-1700) \\
\text { vary }\end{array}$ & $\begin{array}{l}0 \text { summer, }-20 \text { school } \\
-20(800-1700) \\
0 \text { (all) }\end{array}$ \\
\hline \multicolumn{8}{|l|}{$\overline{\text { Thermostat setting }}$} \\
\hline $\begin{array}{l}\text { Heating }\left({ }^{\circ} \mathrm{F}\right) \\
\text { Cooling }\left({ }^{\circ} \mathrm{F}\right)\end{array}$ & $\begin{array}{l}68 \\
72\end{array}$ & $\begin{array}{l}68 \\
80\end{array}$ & $\begin{array}{l}70 \\
80\end{array}$ & $\begin{array}{l}68 \\
80\end{array}$ & $\begin{array}{l}68 \\
\text { not used }\end{array}$ & $\begin{array}{l}70 \\
82 \\
\end{array}$ & $\begin{array}{l}8 \\
78 \\
\end{array}$ \\
\hline
\end{tabular}

- Pre-monitoring conditions

$\uparrow$ Excluding garage

$¥$ Determined by visual inspection

8 Information not available at this time

Abbreviations: comp. $=$ composition, asph. $=$ asphalt, comug. $=$ corrugated, wknd. $=$ week end 


\section{Modifications}

\section{Albedo Modifications}

Site B

One of the two school bungalows was painted twice (with different colors) to test the effects of albedo modification on surface temperature and air conditioner energy use. On 8-9-91, we started logging data for the "basecase" configuration, that is, the school as it was. Based on our measurements, the metallic roof had an albedo of 0.34 (and an estimated emissivity of about 0.3). On 8-21-91, we started logging data again, after the roof and the southeast wall were painted dark brown (the actual painting took place on 8-19). Our measurements indicated an albedo of 0.08 (and an estimated emissivity of $(0.95$ ) for the brown paint. Finally, on 8-30-91, we began logging data after the roof and the southeast wall were painted white (actual painting took place on 8-28), with a version of the Enerchron (1) white elastomeric coating. Our albedo readings indicated a value of 0.68 (we assumed a similar emissivity as that of the brown paint, i.e., 0.95).

Site 2

We started to download data from this site on 8-22-91. The basecase albedo for the blackpainted rolled composition roof was $(0.18$ over the living area and 0.30 over the garage (not conditioned). After painting with a reflective version of Enerchron $\circledast$, our measurements indicated albedos of 0.77 over the living area and 0.81 over the garage. A yellowish hue over the living areas (resulting from fallen leaves) was the reason behind the lower albedo values. Data logging with the white roof started on 9-13-91.

\section{Tree Modifications}

Tree modifications were performed mainly with trees in movable containers placed adjacent to walls and windows. At the time of positioning (9-24-91), these trees had a leaf cover of about $50 \%$ based on our estimates. The following information is available to characterize the small trees that were placed on the vegetation sites:

- Leaf-Area Index (LAl): the cumulative leaf area integrated over a specified height range (usually from stem height to crown height) divided by the site area (ground surface) the tree is occupying: We estimate the LAI to be around 2 . 
- Stem height: the height above ground of the lowest stem branchings: $-1.5 \mathrm{~m}$.

- Crown height: the height above ground of the highest stem of the tree: $-2.4 \mathrm{~m}$.

- Canopy diameter: the diameter of the canopy as seen from above the tree: $-1-1.5 \mathrm{~m}$.

- Silhouette area: the projected area of the tree's canopy (such as that seen by the sun or the wind): $-2 \mathrm{~m}^{2}$.

- Porosity: the amount of unobstructed area seen through the canopy by an observer at a specified dircction (such as from a wall or underneath the tree): $\sim 50 \%$.

Although these trees can grow to $9 \mathrm{~m}$ tall by about $9 \mathrm{~m}$ abreast, their sizes at the time of monitoring were small. Their impacts on energy use will be much larger once they grow to full size.

Site 5

This house was well shaded on the south and north sides. On the west side there was only one small window, but on the east side there were two bedroom windows that we shaded with two of the trees described above. These trees were removed at the end of the data collection period, as they blocked the narrow walkway on the east side of the building.

Site 6

This site had no trees on the west-facing side. We shaded two west-facing windows and partially shaded the condenser unit (also located on the west side of the house). An additional tree was placed to shade one bedroom window on the south.

Site 7

This site had a relatively low amount of trees. The windows facing south west, north west, and north east were all unshaded. There was a tall tree on the south side of the building, but it was too far removed to cast any shadows on these windows. We positioned two small trees so that the south west windows were shaded. 
Site 8

This site had a very low tree cover (the lowest among all others considered in this study). It had a translucent patio cover on the south west corner that did not block solar radiation. A large tree $(6 \mathrm{~m}$ across, $8 \mathrm{~m}$ tall) was planted on the south west corner of the building on 9-17-91. Because the truck could not get close enough, the tree was planted relatively far $(-5 \mathrm{~m})$ from the southwest corner. This tree would thus cast a shadow on the wall starting at about 4 P.M.. In addition to this permanent tree, 7 other small trees (as described above) were placed along the south wall to shade the windows and portions of the wall as well as the condenser unit.

\section{Monitoring Protocols}

Prior to the start of monitoring, we developed detailed experiment design protocols for each site. These protocols, which act as stand-alone documents, are contained in Attachment B. While the specifics of each site dictated variations in the experiment protocols, the essential features are the same, and are described bclow.

\section{Measurement Goals}

Each site was identified as either the control site (site 1), a vegetation site (sites 5,6, 7, and 8), or an albedo site (sites 2 and B). Regardless of whether a test site was to be used as an albedo case or a vegetation case, certain indoor and outdoor variables needed to be measured. The equipment used for these measurements and the instrumentation methods are described Chapter III (Equipment, Instrumentation, and Calibration).

\section{Data Product and Output}

There are two types of products to be expected from each site. First, environmental characteristic data such as building albedo, vegetation type/tree cover, and view factors were evaluated. Second, microclimate and energy use data for the air-conditioning unit were recorded. Data analysis included initial examination of the data for outliers, missing data, and signal-saturated output. The next phase of data analysis consists of two categories: intercomparison among all sites within the pre-modification period, and intercomparison with concurrent data from other sites and prior data from the same site after modification. 


\section{Experimental Design Approach}

A schedule was proposed for modifying each site. The goal was to monitor each building in each phase of modification for at least two weeks. Unfortunately, this was not possible in all cases. Initially, it was planned that certain sites would be returned to the base configuration near the end of the monitoring period. This was not done. It was also necessary to specify standard operating procedures for the buildings, so that the data analysis could proceed with as few variables as possible. It was therefore requested that: windows remain closed at all times; thermostat settings be identical and constant; and lights be turned on and off in a consistent, similar, and predictable fashion. During the course of the monitoring period, some anomalous data were recorded and later explained to he a result of a deviation from the standard operating procedures.

\section{Data Analysis}

Data analysis proceeded under the assumption that changes in air-conditioning energy use were resulting from albedo and vegetation modifications. As has been pointed out elsewhere in this report, this assumption may not be valid in some cases. Each protocol document contains a table that gives the sampling/averaging and logging intervals for each sensor.

\section{Data Accuracy, Quality Control/Verification, and Format}

During the monitoring period, data were downloaded by SMUD and sent to LBL on $31 / 2$ " IBM-formatted disks. Initial data analysis had proceeded without benefit of pre- and postcalibration analysis but was iater adjusted accordingly. The data-reduction procedure was also refined to account for sensor error/drift. A post-calibration of the equipment was performed to aid in defining data accuracy and correcting for sensor error.

At the end of each protocol document is a site drawing depicting the orientation and layout of the building. This drawing also specifies the locations of each sensor, including the weather station. The locations of the condenser and air handler, potential locations for trees (at vegetation sites), and the locations and sizes of windows are shown. 


\section{EQUIPMENT, INSTRUMENTATION, AND CALIBRATION}

The study required the measurement of numerous variables at each site. To facilitate an orderly procedure for these measurements and to ensure data quality, we developed methods for using and interfacing sensors. The following three sections are devoted to the tasks of: (a) describing the sensors used, how they work, and how accurate they are; (b) discussing in general how we used these sensors to perform the measurements we required; and (c) explaining how we calibrated and/or verified the performance of the sensors. In addition, we also discuss our technique for measuring roof albedo.

\section{A. Equipment Description}

Depending upon the requirements at a given site, we employed a variety of sensors to measure the necessary variables: air temperature, surface temperature, relative humidity, wind speed, wind direction, solar radiation, air conditioner energy use, and sub-surface soil temperature and moisture. Sensors were used to monitor these variables for either a 10 minute time step (for those variables that change quickly), or 20 minute time step (for those that do not change rapidly). A brief description of these sensors follows.

Temperature: Indoor, outdoor, surface, soil, and supply and return air temperatures were measured using 24-gauge type-T thermocouples from Omega. These thermocouples have a quick response and are generally accurate to within a degree Celsius. In all uses of these thermocouples, it was necessary to extend the length of the wire by using 24-gauge type-T thermocouple wire, also from Omega.

Relative Humidity and Air Temperature: The Hygrometrix Inc. Model P-20-HT combined humidity and air temperature probe (and associated electronics conditioning box) was used to measure ambient indoor and outdoor relative humidity and air temperature. The humidity sensor is a composite of organic and inorganic crystals that sense moisture by the hygromechanical stress of crystallite structures acting on a metal beam. The resulting strain of the beam is measured by silicon strain gauges bonded to the beam. This sensor is mounted in a $1 / 2$-inch diameter probe (roughly 4 inches in length). This probe is connected to a signal-processing electronics box through standard six-wire phone cable. The signal-processing box generates two voltage signals that represent relative humidity and air temperature. Hygrometrix claims a full-range linear response to relative humidity from 0 to $100 \%$. 
Wind Speed and Direction: The Model 038 Sentinel wind speed and direction probe from Met One was used to chararterize the local wind. The wind speed sensor is a cup anemometer that has a range of 0 to $100 \mathrm{mph}$ with a starting threshold of $1 \mathrm{mph}$, and a stated accuracy of \pm $0.25 \mathrm{mph}$. The anemometer utilizes a sealed magnetic switch that produces two pulses per revolution at a rate proportional to wind speed. The wind direction sensor position is transmitted by a $10 \mathrm{~K} \Omega$ potentiometer. The range of wind direction measurement is 0 to $360^{\circ}$ with a starting threshold of $1 \mathrm{mph}$ and an accuracy of $\pm 3^{\circ}$.

Solar Radiation: A Licor Pyranometer Sensor, model LI-200SA, was used to measure incoming solar radiation. This instrument uses a silicon photovoltaic detector mounted in a fully cosine-corrected head. The pyranometer spectral in response $(0.1-1.2 \mu \mathrm{m})$ does not cover the full range of the solar spectrum. Licor claims, however, that under natural daylight conditions, the LI-200SA is accurate to within $5 \%$. The sensors we acquired had sensitivity ranging from 90 to $98 \mu \mathrm{A} / 1000 \mathrm{Wm}^{-2}$.

Soil Moisture: Delmhorst Inc. gypsum block soil moisture sensors were used to measure soil moisture tension. These blocks are made of gypsum cast around two concentric electrodes. When a block is connected to a voltage source and allowed to come into equilibrium with moist soil, current flows between the clectrodes. By measuring the electrical resistance of these blocks, available soil moisture can be inferred using an empirical look-up table provided by Delmhorst.

Air-conditioning Encrgy Use: The PM-1000 power monitor from Rochester Instrument Systems (RIS) was used to measure air-conditioning energy usage. The PM-1000 works by measuring line voltage and current, electronically computing the energy being used, and reporting a pulse output which is proportional to Watt-hours.

Data Logger: In order to record and store data continuously over the course of the investigation, Zi-Tech Instrument Corporation Dataloggers, model DT100F, were used. These data loggers allow 23 differential analog channels of input and 9 channels for digital input. They come equipped with thermocouple linearization and cold junction compensation circuitry.

Albedo: To measure albedo, we used an Eppley PSP (Precision Spectral Pyranometer), a high-precision radiometer that is sensitive to radiant energy in the $0.28-2.8 \mu \mathrm{m}$ band. That PSP yielded an output of $9.98 \mu \mathrm{V}$ per W/m ${ }^{2}$, had a linearity of $\pm 0.5 \%$ between 0 and $1400 \mathrm{~W} / \mathrm{m}^{2}$, and a response time of 1 second. These characteristics were obtained based on calibration at the EPPLEY Laboratory, in Newport, R.I. 
The double-dome design of the PSP minimizes the effects of convection (on read-out) resulting from tilting the pyranometer at different angles. For this reason, the PSP was especially suitable for the type of albedo measurements we performed in this project, since the measurements required the apparatus to alternatively face up and down.

The PSP was mounted at the end of a stand we designed for this purpose in another project. For each roof, we took several measurements to detect any spatial variation in albedo (which we did in some cases, e.g:, Site 2). The albedo values we obtained in this field project compared well with the values obtained from roof albedo measurement tests on other sites that we performed in another project.

\section{B. Site Instrumentation}

Air Tempcratures: Air-conditioning supply and return air temperatures were typically measured by feeding the end of a thermocouple through the ducting so that the tip of the thermocouple was roughly one inch from the outlct vent of the ducting. This provided representative supply and return temperatures. Indoor and outdoor ambient air temperatures were measured using the temperature output from the Hygrometrix sensor mounted as discussed below.

Relative Humidity and Air Temperature: The indoor relative humidity/air temperature sensor was typically placed at least 2 feet below cciling level with the tip of the probe roughly 6 inches away from the wall. In order to measure typical indoor ambient conditions, these sensors were located so that they were not influenced by the impingement of cool air from air conditioner supply vents. The outdoor humidity/temperature sensor was usually placed underneath a deck overhang or eave so that it was not subject to direct insolation. Furthermore, to ensure that representative ambient outdoor conditions were being measured, this sensor was located so that it was well ventilated.

Wind Speed and Dircction: The Met One wind sensors were mounted on a section ( 3 to 5 feet long) of PVC pipe. This piping was, in turn, secured to either the rooftop or a corner of the building so that the sensors themselves were roughly 3 - 5 feet above roof level and about 20-25 feet above ground.

Soil Temperature and Moisture: Sub-surface soil temperatures were measured using type$T$ thermocouples mounted in a sealed probe, as depicted in Figure III-1. This probe was installed in the soil by digging a 6 inch diameter, 24 inch deep hole with a standard post-hole digger. The soil temperature probe was then positioned in the hole so that the first brass tube 
was 4-1/2 inches from the surface. The three brass probes were then pushed into the side of the hole in order to cause minimal disturbance to the soil. The hole was then backfilled with dirt, installing the moisture sensors at two depths. The resulting soil measurement system is depicted in Figure III-1.

Data Loggers: In order to simplify the connection of the many sensors at each site to the data logger, we prepared each data logger in advance by internally wire-wrapping certain circuitry connections. This resulted in the ability to connect sensors quickly and easily at a test site and program the data logger to average, record, and save data. Data were typically saved at 10 minute intervals and down-loaded by phone modems every 3 days. Data loggers were placed in the garage (at residential sites) and inside classrooms (at the school site).

Figure III-1. Moisture and temperature probe

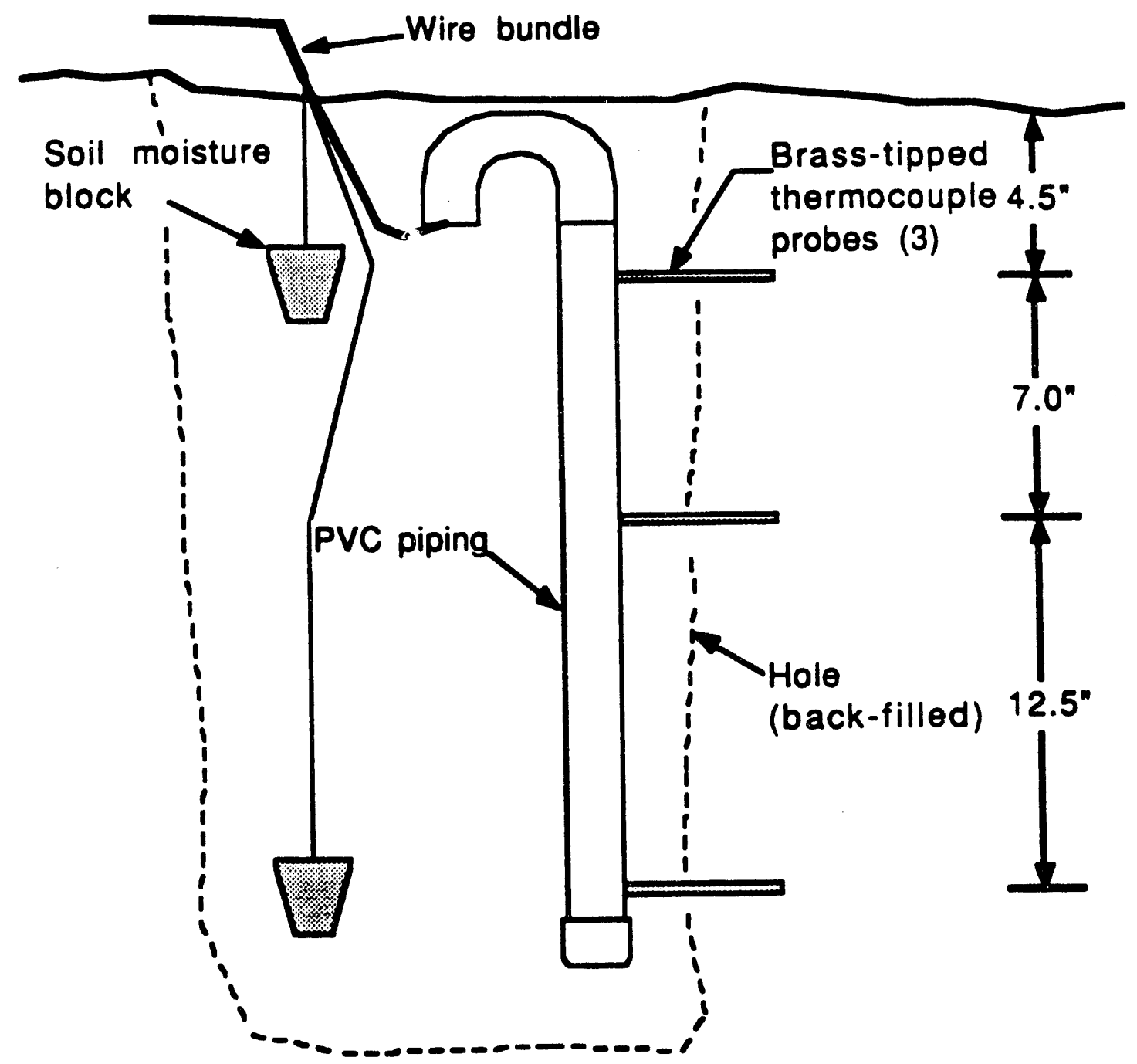




\section{Calibration}

\section{Bench Calibration and Conversion Constants}

Prior to the dynamic (field) calibration that we performed, bench calibration was carried out. When interpreting the output, conversion from analog to digital and to meaningful physical units was necessary. For wind speed, wind direction, and solar radiation, the following conversions were used:

1. The cup anemometers were calibrated to give two pulses per revolution. An rpm (revolution per minute) count is obtained by dividing the pulses in a minute by a factor of 2 . Then, equation 1 is used to convert to $\mathrm{ms}^{-1}$ :

$$
\bar{V}_{(m / s)}=\frac{\omega}{37.5(067}+0.44704
$$

where $\omega$ is rpm. The wind speed data we present in this report are 10-minute averages.

2. The wind vanes circuitry was supplied with 5 volts DC, and wind direction was found as a linear function of voltage output (V) by:

$$
\theta=72 \mathrm{~V}
$$

where $V$ is the output voltage and $\theta$ is degrees clockwise from north. The wind direction data we present in this report are instantaneous values at the end of each 10 minute interval.

3. Each photometer (pyranometer) was supplied with a calibration constant taken from bench tests. At the monitoring sites, each photometer was connected to a millivolt adapter with a resistance of $147 \Omega$. Conversion to $\mathrm{W} \mathrm{m}^{-2}$ units was obtained from Table III-1.

\section{Pre- and Post-Retrofit Dynamic Calibration}

Before installation at the residential and school sites, the sensors and data-loggers were dynamically calibrated side by side in a large open yard at SMUD. After the end of the project, the sensors were recalibrated to make sure no drift had occurred. Data from post-calibration are discussed in this section since some sensors were not available when we performed pre-calibration. We should note that for available sensors, both pre- and post-calibration indicate the same performance. Each combination of sensors, wires, connections, and a data-logger formed a "set" of components that we kept together at the 
TABLE III-1. Photometers calibration constants $\left(\mathrm{W} \mathrm{m}^{-2} / \mu \mathrm{A}\right)$ based on bench calibration at manufacturer site. Individual photometers were connected to a millivolt adapter with a resistance of $147 \Omega$.

\begin{tabular}{ll} 
PHOTOMETER & $\begin{array}{l}\text { Multiplier } \\
\mathrm{W} \mathrm{m}^{-2} / \mu \mathrm{A}\end{array}$ \\
\hline Site 8 (photometer A) & 11.05 \\
Site 8 (photometer B) & 10.75 \\
Site 2 & 10.55 \\
Site 6 (photometer A) & 10.17 \\
Site 6 (photometer B) & 10.99 \\
Site B & 91.1 \\
\hline
\end{tabular}

calibration site and after we moved the equipment to the monitoring sites. The components of each set were identificd by their serial numbers. Each of the pre- and post-calibration periods lasted for one week. Pre-calibration was performed in August 1991, whereas postcalibration was performed in December 1991.

In the dynamic calibration configuration, sets of sensors and data-loggers were positioned side by side in an open yard. Similar sensors, e.g., wind vanes, cup anemometers, photometers, etc., were grouped together and placed very close to each other. The purpose of dynamic calibration was to detect potential deviations in readings of similar sensors, as well as to test the correlation in readings of the same variable as measured by different sensors, e.g., air temperature measured by thermocouples vs air temperature measured by RTDs (Resistance Temperature Detectors). A week of post calibration yielded the formulas and correiations given in Tables III-2 through III-4.

These tables provide correlations among variables between a specific site (set) and the control site (set). In addition to these correlations, other relationships within each set (each site) were developed involving indoor air temperature sensors and thermocouples. These 
TABLE III-2. Air temperature sensors calibration. " $c$ " means corrected temperature, and the numbers refer to corresponding sites. Control air temperature is at Site $B$, and $\alpha$ is significance of F-Test.

\begin{tabular}{|lll|}
\hline Correction & Adj. $\mathrm{R}^{2}$ & $\alpha$ \\
\hline $\mathrm{T} 5 \mathrm{c}=0.9545 \mathrm{~T} 5+0.5189$ & 0.9934 & 0.0001 \\
$\mathrm{~T} 2 \mathrm{c}=0.9641 \mathrm{~T} 2+0.5420$ & 0.9941 & 0.0001 \\
$\mathrm{~T} 1 \mathrm{c}=0.9533 \mathrm{~T} 1+0.5392$ & 0.9967 & 0.0001 \\
$\mathrm{~T} 7 \mathrm{c}=0.9456 \mathrm{~T} 7+0.3092$ & 0.9889 & 0.0001 \\
$\mathrm{~T} 6 \mathrm{c}=0.9555 \mathrm{~T} 6+0.4318$ & 0.9975 & 0.0001 \\
\hline
\end{tabular}

TABLE 11I-3. Solar radiation sensors calibration. " $c$ " means corrected solar radiation, and the numbers refer to corresponding sites. Control solar radiation is at Site $B$, and $\alpha$ is significance of F-Test.

\begin{tabular}{|lll|}
\hline Correction & Adj. $\mathrm{R}^{2}$ & $\alpha$ \\
\hline $\mathrm{K}(\mathrm{c}=0.95(13) \mathrm{K}(\mathrm{C}+3.4239$ & 0.9463 & 0.0001 \\
$\mathrm{~K} 2 \mathrm{c}=0.9753 \mathrm{~K} 2+2.0229$ & 0.9390 & 0.0001 \\
$\mathrm{~K} 8 \mathrm{c}=1.0397 \mathrm{~K} \delta+10.821$ & 0.8812 & 0.0001 \\
\hline
\end{tabular}

correlations are given in Table III-5. In each case, except for Site 8, the control temperature was the outdoor air temperature at that particular site. In Site 8 , the control temperature was that of the indoor air, since Site 8 was not equipped with an outdoor air temperature sensor. In this table, Tai is indoor air temperature, TT means thermocouple temperature, "c" indicates corrected temperature, and $\alpha$ is significance of F-test.

After subjecting the raw data-files to the criteria and conversions set forth in these sections, data from each site were manipulated to handle format problems, missing/wrong date 
TABLE III-4. Wind speed sensors calibration. "c" means corrected wind speed, and the numbers refer to corresponding sites. Control wind speed temperature is at Site 1 , and $\alpha$ is significance of F-Test.

\begin{tabular}{|lll|}
\hline Correlation & Adj. $R^{2}$ & $\alpha$ \\
\hline$U 5 c=0.9603$ U5 +0.0036 & 0.9918 & 0.0001 \\
$U 2 c=0.9200 \cup 2+0.1747$ & 0.8412 & 0.0001 \\
$U 6 c=1.0717 U 6-0.0754$ & 0.9760 & 0.0001 \\
$U 7 c=0.9731 U 7+0.0186$ & 0.9442 & 0.0001 \\
$U B c=0.9859 U B+0.0084$ & 0.9766 & 0.0001 \\
\hline
\end{tabular}

and time stamps, and missmig/erroneous data. 


\section{EXPERIENCE WITH MONITORING EQUIPMENT AND BUILDING MODIFICATIONS}

\section{A. Monitoring Equipment}

\section{Selection}

Criteria for equipment selection were simple and straightforward. We obtained the highest quality and most accurate equipment available within budget constraints.

- The $\mathrm{Zi}$ Tech datalogger was selected from a list of five manufactures for many reasons. $\mathrm{Zi}$ Tech's equipment has a sufficient amount of input channels: 23 differential or 46 single-ended analog inputs, 8 digital inputs, and 8 digital outputs. It had the lowest cost for the required features and no hidden costs for additional required accessories. Programming, including communication with the equipment both on a local and remote level, was relatively simple. Previous experience with other monitoring projects using this equipment also factored in the decision.

- Sensors selected were typical of equipment commonly used in the field. Besides keeping cost in mind, we decided to obtain high quality and accurate sensors. Also, delivery time was utmost in importance due to time constraints of this project.

\section{Purchasing Equipment}

Purchase orders were sent to vendors in the first week of June after all monitoring equipment was finalized and approved. Equipinent was ordered at this late date due to increased time involved with site selection. All equipment was scheduled to and did arrive within a 30 day period except for the dataloggers and temperature/humidity sensors. The large cost associated with the dataloggers and temperature/humidity sensors required that they be sent out for bids. This process delayed equipment arrival by an additional 30 days on top the thirty days required for delivery from Australia. Though a 60 daly period for delivery of monitoring equipment is not unusual, installation was delayed until the first week of August. To ensure arrival of equipment in time for future installations, a minimum of 90 days must be allowed for delivery. 


\section{Programming and Data Retrieval}

Programming the $\mathrm{Zi}$ Tech dataloggers was fairly simple and straightforward. This is due to pre-wire-wrapping of each datalogger (substituting hardware configuration in lieu of software programming) allowing the user to assign specific terminals to specific input channels, output channels, and signal conditioners.

Some problems were encountered with programming the datalogger's clock to record in the desired HH:MM:SS (hour:minute:seconds) format. Time format was continuously returned in the seconds only format. This problem persisted even after confirming the proper programming of the clock from the manufacturer. We found by chance that the problem occurred when we were downloading data using the software program supplied with the datalogger. When we downloaded data using our modem's communications program (Bitcom), time was returned in the desired HH:MM:SS format. This condition only occurred using a direct (local) connection and was never encountered with a remote (modem) connection.

Another obstacle we confronted at the beginning of the data-collection period was a loss of recorded data. This occurred several times before a solution was found. The condition causing data not be to recorded was a program flag (/L) to enable data recording being reset to the disable $(\Omega)$ position. After trial and error and many consultations with the manufacturer's representatives, we found the culprit to be the datalogger's communications program. Once this was known, a simple solution simple was to not connect the serial cable to the datalogger until the communication program had fully initialized.

Our data were recorded in 10 and 20 minute intervals. The 10 minute interval was recording 7 to 9 channels whereas the twenty minute interval was recording 8 to 13 channels. So when the data was downloaded, records of the two separate time intervals were uneven, making it difficult to align similar channels in the same columns, thus incurring time-intensive data manipulation. To eliminate this condition, all channels should be recorded at the same time interval wherever possible to simplify data analysis.

\section{Problems Encountered}

As expected with a monitoring project of this size, we encountered problems, primarily related to equipment installed in the field. We were able to identify some of these problems and remedy them on-line. Other conditions, concerning site control, were not so easily remedied. All site control conditions, including thermostat settings and window shades schedules, 
depended on the occupants' cooperation.

Initial problems with the remote communication with dataloggers in the field occurred between the phone modem and datalogger. Through numerous discussions with both the representatives of the modem and datalogger manufacturers, plus our own trial and error we were able to solve this problem, which was identified as the serial cable between the phone modem and datalogger. After many combinations of pin configurations were tried, we found the correct configuration for SMUD's particular modem pool arrangement.

Sensor problems were minimal (3.5\%); only 4 sensors out of 115 sensors had problems. There were two surface thermocouples and also a pyranometer that had fallen down. All three sensors were mounted on a stucco wall with duct tape. Heat from the wall and its dryness would not allow the tape to remain adhered for a long time. This condition was easily solved by applying a small amount of silicon sealant on the thermocouple and wall and then applying duct tape over. The pyranometer's problem was solved by screw-mounting it to the wall. The last sensor to have a problem was an air-conditioning supply temperature thermocouple that had a bad connection, which we repaired. There were three occasions when the temperature and humidity sensors and watt-hour recordings were incorrect. These were not hardware problems but software problems caused by power outages and resetting the program incorrectly. These power outages also caused some of the modems to malfunction, which required site visits to induce a power reset and then complete reprogramming of both the datalogger and phone modem.

The site control problems concerned the thermostat settings and window operation/shading. At the school site, all of the thermostats were controlled by a separate timer that we set to identical schedules. Unbeknown to us, after a series of power outages, these timers were offset by approximately seven hours until data were retrieved and reviewed. The timers were reset and their off flags removed to prevent future problems. Once school was in session we experienced another set of thermostat control problems. The temperature setting was frequently lowered from $78^{\circ} \mathrm{F}$ to $72^{\circ} \mathrm{F}$ in the unmodified (control) classroom. At each data retrieval the thermostat would usually have to be reset even though it was in a locked cover. There were no similar problems experienced at the residential sites. What was experienced, however, was a reluctance to leave all window coverings open as requested. Site 6 would always completely shut window coverings on the weekend and Site 8 would halfway close the mini-blinds throughout the entire test period. 
These site control problems affected measured cooling energy use in several ways. At the school site, the irregularity in the thermostat setpoint affected our cooling energy savings estimates. The air-conditioning system uses more energy when set at a lower indoor temperature. Removing window coverings increases the heat gain to the house and thus raises cooling energy use and lowers savings estimates. Problems with power outages, equipment problems, and faulty sensors limited the amount of data available and lessened the statistical reliability of our conclusions.

When the majority of data had been collected and some data analysis had begun, the kilowatt-hour usage of the air-conditioners seemed to be noticeably lower than expected. Even though we did not monitor the air-handler's power usage, adding this additional load to the monitored load still did not seem to correct the problem. To verify if the datalogging equipment was correctly measuring watt-hours, an independent source of measurement was needed. This was done using a Esterline Angus "Power Master IIIB ac multimeter" and directly comparing its instantaneous readings with the dataloggers' in 5 minute intervals. We found that the dataloggers' readings were exactly one half of the Esterline's measurement. The reason was the installation of the power monitor's current transformer, i.e., two passes through the current transformer instead of the single pass that was implemented. In either case, doubling the datalogger's recorded power measurements provided the correct energy usage for the condensing units at all sites.

\section{B. Trees}

Four of the six residential sites were chosen to be modified with shade trees. Our objective was to directly shade all south- and west-facing walls and windows and also the air conditioner's condenser unit. Although large mature trees were preferred for shade modification, yard access conditions, existing landscaping, and site owner's objections reduced our expectations down to planting one large red oak tree at only one site. Even this large tree could not be planted as close to the house as desired because of the size of the tree planting equipment and the yard and patio constraints. Smaller, more portable (hand carried) trees were needed, but the largest portable tree that could be located in Sacramento were 24 inch box trees.

Limited by the amount of trees available to us for shading, we decided to concentrate on three sites, Sites 8,6 , and 7 , in respective order of importance. At site 8 , which had the large oak tree brought in, we also located seven small trees to shade the south wall. At Site 6, we brought 
in three small trees to shade one west-facing bedroom window and the condenser unit and one tree to shade one south-facing bedroom window. At Site 7, two trees were brought in to shade two southwest-facing bedroom windows. After initial placement of these trees, one of the project staff returned the next day to relocate them to maximize shading at approximately two to three o'clock in the afternoon.

Attempting to heavily shade residential sites that previously lacked shade proved to be a difficult task. First, the number of sites should be kept to a minimum in order to concentrate available vegetation resources and to reduce the time involved in implementing these modifications. Second, effort is needed to locate trees of sufficient size and shading. Third, the logistics of delivering, locating and planting all vegetation (including heavy equipment such as trucks and forklifts) must be considered. Not to be overlooked are a site owner's objections and concerns to be address thoroughly and completely before including them on a final list of sites.

\section{White Coatings}

SMUD contacted three manufacturers of reflective white coatings to ask if they would like to have their product tested in this monitoring project. The manufacturers were

\section{National Coatings}

\section{Thermo Materials}

\section{Helios}

Only two of the three manufacturer's contractors in the Sacramento area returned our call and expressed interest in participating. Of these two only one contractor considered doing all of the work involved in modifying the two chosen albedo sites and within our time schedule. Through this process of elimination we decided by default to use Helios's Enerchron coating product at both albedo test sites. 


\section{ANALYSIS OF MEASURED DATA AND COMPARISON WITH SIMULATIONS}

\section{A. Introduction and Approach}

This chapter presents and discusses the results of our analysis of the measured and simulated data for the seven buildings that participated in this monitoring project. The chapter includes a detailed analysis of the measured data, a comparison with the DOE-2 simulated results, and use of the measured data for calibration of the DOE-2 model. Finally, the chapter presents the results of our DOE-2 simulations and describes the use of the DOE-2 model to estimate cooling energy impacts over the entire cooling season.

The measurement period for some of the sites was limited to Septe iber and October 1991. These months typically are transitional cooling months in Sacramento, and the measured results presented here are limited to these measurement periods. With the help of simulations, we estimate the impact of high-albedo roofs and shade trees on cooling energy use for the hot summer months of June, July, and August.

Although it was clear that we would need to continue the experiment for a second cooling period, the collection and analysis of the data for the first year provided invaluable insight at a minimum marginal cost of data collection and analysis. Hence, the data presented in this report mainly characterizes the base case conditions for the experiment.

Our approach for data analysis includes a presentation and discussion of the measured data followed by DOE-2 simulation model development to estimate the energy use of the buildings. We calibrate our simulation results with the measured data and use the calibrated models to gain insight into interdependencies among variables.

An important component of this project was to model the monitored buildings using the DOE-2.1D building energy program and perform computer simulations to better understand and assess the measured data. The approach for the modeling component of the project included (1) initial model development using data from site surveys, (2) comparison of the models with measured data at an hourly time scale, (3) modifications of some of the inputs based on perceived problems with the original simulations, and (4) comparison of the results from the measured data with model predictions. 
Once the computer models are calibrated against the monitored data, i.e., adjusted to correspond as closely as possible to the measured data during the monitoring period, they are then used to analyze the potential savings for the same strategies under different climate and building conditions, such as during peak summer conditions, and to extrapolate from the limited monitoring period to longer time spans, such as over an entire year. In addition, the computer models can be used to study variations and combinations of tree-planting and albedo strategies beyond those that were directly measured. The danger of relying solely on simulations is that the cumulative effects of input errors, simplifying assumptions about building operations, and deficiencies in the modeling techniques can often produce computer results that may differ from real measured energy use by as much as $50-100 \%$. This project allowed us to combine the veracity of the measured data with the flexibility of computer simulations to extrapolate the results.

In the sections to follow, we first discuss the data analysis approach and simulation methodology. Next we present data and discuss results for the buildings that participated in highalbedo and shade-tree experiments, respectively. The chapter concludes with a summary of the measured and simulated data followed by a discussion of microclimate variations around the monitored buildings and a comparison with airport weather.

\section{B. Data Analysis Methodology}

Our data analysis approach has two major components: graphical presentation of the measured data and regression analysis. The collected data have been gathered in different time intervals. We first integrate the 10-minute interval data and produce hourly files. For each building, we show plots of cooling energy use against drybulb temperature. The plots include hourly $\mathrm{kWh}$ vs hourly outdoor air temperature, daily $\mathrm{kWh}$ vs average daytime outdoor air temperature, and daily $\mathrm{kWh}$ vs daily maximum outdoor air temperature. We also present cooling electricity use plotted against the difference between outdoor and indoor air temperatures. This tends to suppress the data variations and normalize for the changes in inside temperature. Our plots also include time series of total daily solar radiation on the building roofs and walls as appropriate.

We have only analyzed the most reliable data from the first year of data collection. Since some of our measurements, particularly outside surface temperature measurements, are questionable, we only briefly present and discuss them in this first year report. 


\section{Simulation Methodology}

The intent of the computer modeling is to mirror as accurately as possible the actual situations encountered in the field during the monitoring period. Therefore, care has been taken to model the buildings as realistically as possible, including the materials, construction, insulation levels, geometry, and surface properties of the buildings, the location of windows, and the shading effects of overhangs, trees, and adjoining buildings. Similarly, we attempted to duplicate the internal conditions of the buildings, including the indoor temperature and internal heat gain from occupants, lights, and equipment. We have also tried to estimate the cooling system characteristics from available data and to accurately model the system performance. In order to reproduce the actual weather of the monitoring period, we used hourly weather data for August 1 through October 31 acquired from the National Climatic Data Center (NCDC) for the Sacramento Executive airport, supplemented with on-site weather data gathered during the monitoring effort.

We first developed models based on data collected for each site by the LBL and SMUD pro; it teams. These models were the basis for initial comparisons with the measured data. The data we used in the comparisons consisted of cooling energy consumption and interior temperature.

We refined thr models to the point where we felt that the disagreements between the measured and simulated data were not significant, or where disagreements, which we could not explain based on survey characteristics, still existed. We then used the models to assess the daily energy savings identified in the analysis of the measured data. Finally, we used the models to estimate savings for an entire year instead of the 2-3 months during which the measurements took place. In the next chapter, we discuss how the models were used to estimate potential energy savings from shade trees and high-albedo building surfaces in other climates.

In this section, we describe the model inputs and how they were derived, as well as some of the primary findings from the calibration task.

\section{Building Geometry and Adjoining Surfaces}

Computer models were generated for each of the seven buildings that were monitored in this project. For simplicity, these buildings will be referred to throughout this section as either Site 1 through 8 (residential sites), or as Site B (school site). The geometry of the buildings was 
based on measurements made by SMUD, complemented by measurements and photographs taken by the LBL project team. Although care has been taken to model the buildings as realistically as possible, there are inherent limitations in the DOE-2 program, modeling approaches, or data used to develop DOE-2 input that limit the accuracy of the simulations.

A graphics program was created to read the DOE-2 input files and produce threedimensional drawings of all surfaces being modeled, including walls and roofs, shading devices such as eaves and overhead patio shades, neighboring buildings that may shade the modeled buildings, and vegetation. These computer drawings were used to debug the DOE-2 input files. Figures V-1A and VI-1B are sample drawings of the DOE-2 input files for Sites 6 and 8, viewing the buildings from the southwest. Note that the DOE-2 program models only flat rectangular surfaces, so that three-dimensional objects such as trees are approximated by a set of flat surfaces and end up looking like boxes. In the figures shown here, trees added as part of the experiment are marked in the plan by $X$ 's. The tree surfaces are given a transmissivity value that approximates the amount of solar radiation passing through the leaves and the canopy. These figures also show neighboring buildings, represented by the freestanding surfaces to the north and west. Shading elements that are above ground level are reflected in the plan by dotted lines. Garages are modeled as unconditioned spaces attached to the houses. Table V-1 gives the general dimensions and internal loads of the houses obtained by reconciling the survey results with the building geometries derived from the modeling effort.

The internal loads shown on Table V-1 are based on (1) site survey results, (2) electricity billing data for each site, and (3) standard engineering assumptions. For the residential sites, the magnitude of the internal loads from appliances and lighting are estimated from the minimum monthly electricity consumption over the previous 16 months. Previous LBL work has shown that approximately $75 \%$ of typical residential electricity usage is input to the conditioned space as sensible heat gains and $10 \%$ is input as latent gains (Huang et al., 1987), with the remaining $15 \%$ occurring outside of the conditioned space. Occupant internal gains are based on the number of occupants per house as reported in the site surveys as well as previous work (Ritschard et al., 1992, ASHRAE, 1989). Two different internal gains schedules were developed: one for occupants and one for appliances. For each of these, we developed schedules for occupied and unoccupied days to account for typical occupancy patterns identified by each building owner in the original site surveys. The appliance heat gain schedule was taken from the ASHRAE 90.2 Standard model input (ASHRAE, 1990), and a modified version was used to 


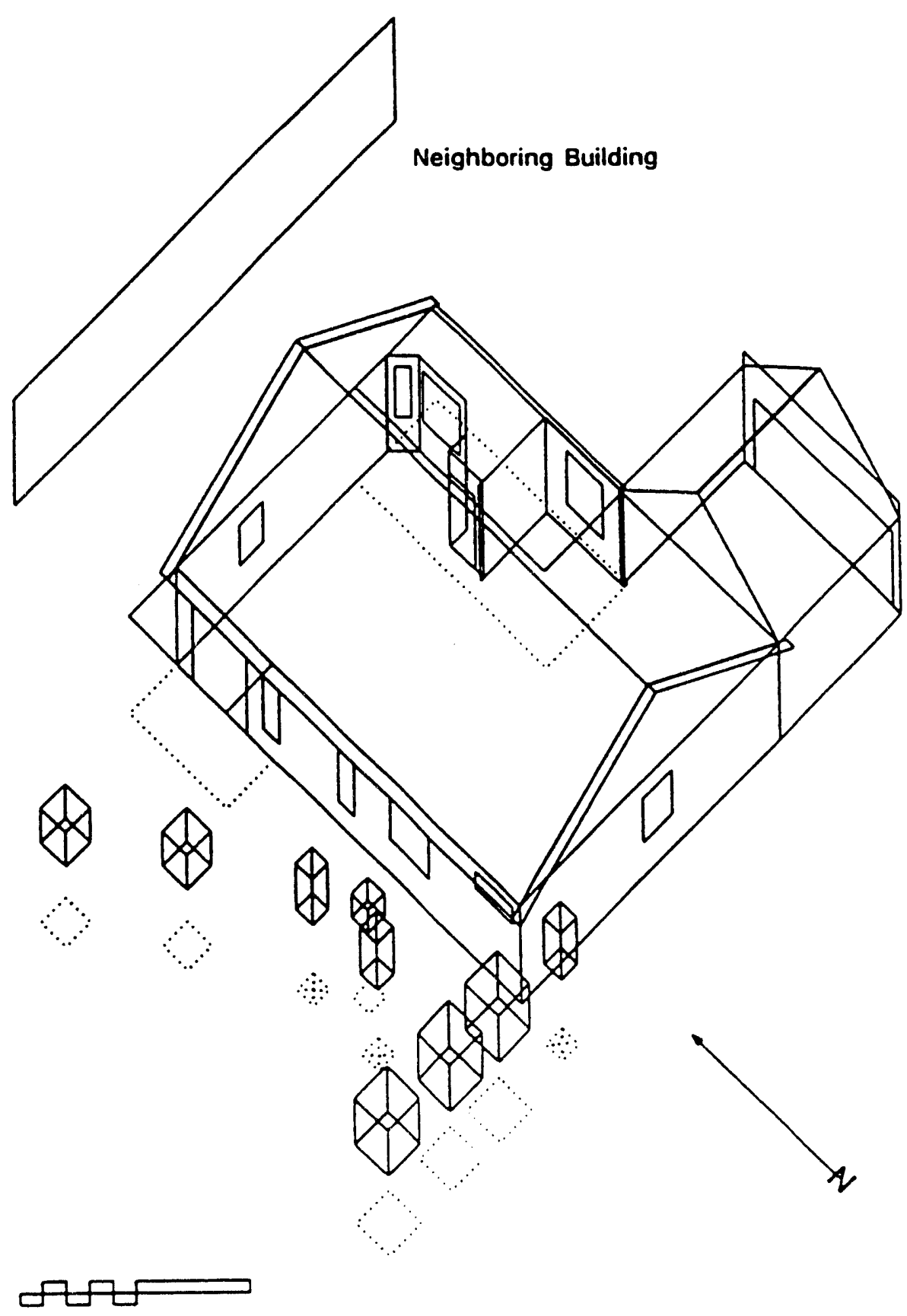

20 feet

Figure V-1A House 6, tree case, viewed from the southwest: Boxes represent trees, boxes with $x$ 's represent trees added for the monitoring project. Neighboring buildings and trees are modeled as building shades in DOE-2. Dotted lines show the ground projection of building shades. 


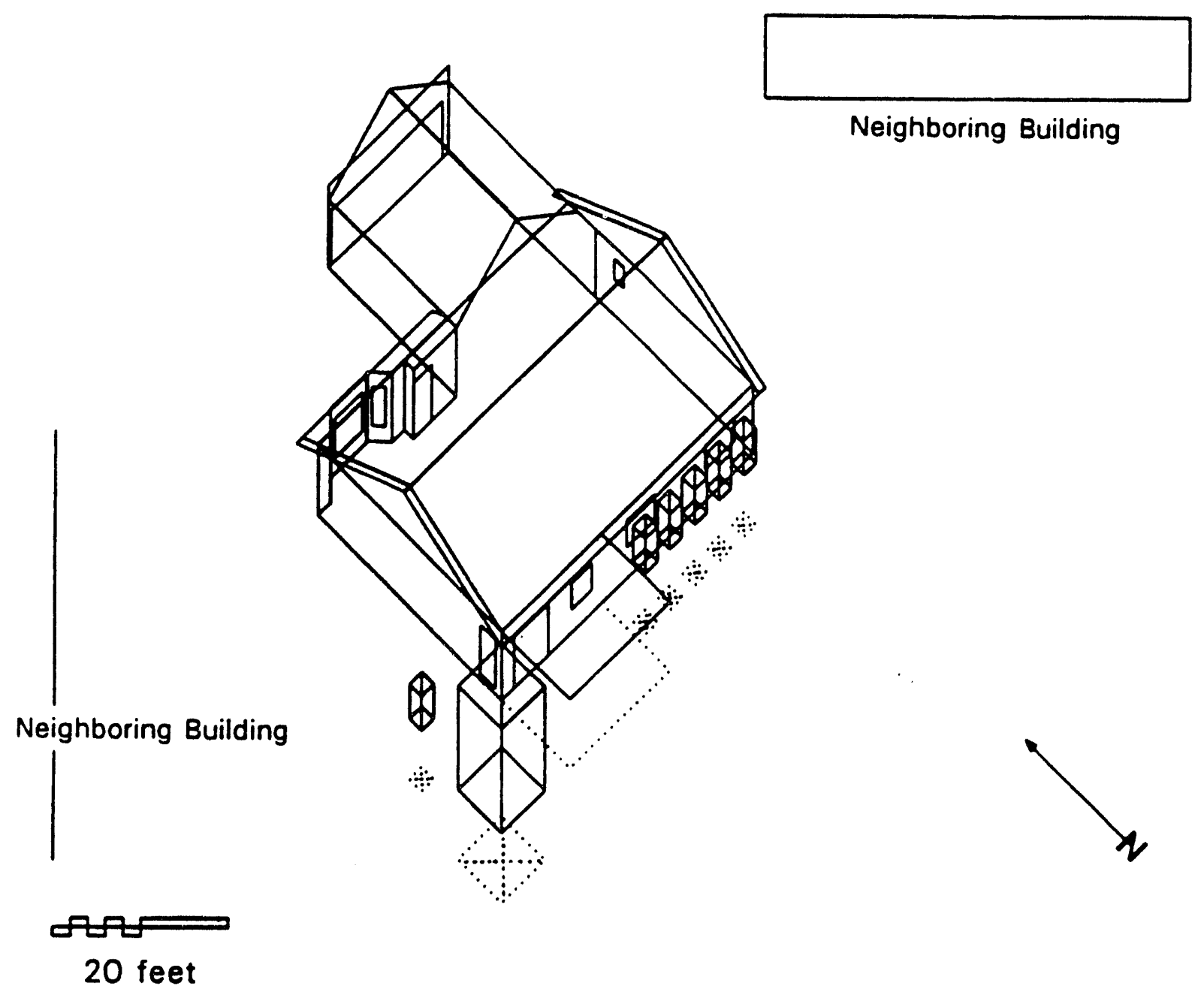

Figure V-1B House 8, tree case, viewed from the southwest: Boxes represent trees, boxes with $x$ 's represent trees added for the monitoring project. Neighboring buildings and trees are modeled as building shades in DOE-2. Dotted lines show the ground projection of building shades. 
describe the unoccupied condition. The occupancy schedule was taken from previous California Energy Commission work (Muira, J. and Horn, M., 1980), and was also modified to describe the unoccupied condition. For the School, a simple 9 A.M. to 4 P.M. weekday schedule was used with a 1.5 watts $/ \mathrm{ft}^{2}$ lighting load and occupancy of 25 children.

Table V-1. Building Geometry and Internal Loads Used in the DOE-2 Simulations

\begin{tabular}{|c|c|c|c|c|c|c|c|}
\hline & \multirow{2}{*}{$\begin{array}{l}\text { Cond. } \\
\text { floor } \\
\text { area } \\
\left(\mathrm{ft}^{2}\right)\end{array}$} & \multirow{2}{*}{$\begin{array}{l}\text { Cond. } \\
\text { volume } \\
\left(\mathrm{ft}^{3}\right)\end{array}$} & \multirow{2}{*}{$\begin{array}{l}\text { Perimeter } \\
\text { length } \\
(\mathrm{ft})\end{array}$} & \multirow{2}{*}{$\begin{array}{l}\text { Exterior } \\
\text { wall } \\
\text { height } \\
\text { (ft) }\end{array}$} & \multirow{2}{*}{$\begin{array}{c}\text { Internal } \\
\text { wall } \\
\text { area } \\
\left(\mathrm{ft}^{2}\right)\end{array}$} & \multicolumn{2}{|c|}{ Internal loads } \\
\hline & & & & & & $\begin{array}{l}\text { Sensible } \\
\text { (Btu/day) }\end{array}$ & $\begin{array}{l}\text { Latent } \\
\text { ratio* }\end{array}$ \\
\hline Site 1 & 1122 & 10098 & 143 & 8 & 800 & 30000 & 0.22 \\
\hline Site 2 & 1701 & 15309 & 201 & 8 & 1436 & 31000 & 0.22 \\
\hline Site 5 & 1544 & 13896 & 192 & 8 & 1480 & 42000 & 0.20 \\
\hline Site 6 & 1291 & 11619 & 156 & 8.5 & 990 & 47000 & 0.20 \\
\hline Site 7 & 1165 & 10485 & 189 & 8.5 & 1000 & 66000 & 0.18 \\
\hline Site 8 & 1122 & 10098 & 143 & 8 & 800 & 47000 & 0.19 \\
\hline School ${ }^{\dagger}$ & 960 & 9600 & 128 & 10 & 0 & 68000 & 0.40 \\
\hline
\end{tabular}

- Latent load (Btu/day) $=$ Sensible Load $\times$ Latent Ratio

† Lighting 1.5 watts $/ \mathrm{ft}^{2}$ plus 25 per students $\times 350$ Btu/hr (ASHRAE 1989) from 9 am to $4 \mathrm{pm}$.

\section{Thermal Integrity}

The insulation characteristics of each house are based on information reported in the surveys, or, for the school bungalows, on the building's engineering drawings and specifications. The existing roof and wall albedos were estimated based on the material and color shown in the photographs taken by the LBL project team. In Sites 2 and B, the roof albedo was obtained from on-site measurements by the LBL staff. The window characteristics are also taken from the 
survey results, while an average effective-leakage-fraction of 0.0005 (leakage area/floor area), corresponding to an infiltration rate of around 0.5 air change/hour, was assumed for all buildings. Table V-2 summarizes the conservation levels used in the DOE-2 simulations.

Table V-2. Building Conservation Levels and Base Case Surface Characteristics Assumed in the DOE-2 Simulations

\begin{tabular}{|c|c|c|c|c|c|c|c|c|}
\hline \multirow[b]{2}{*}{ Site } & \multicolumn{3}{|c|}{ Roof/Ceiling } & \multicolumn{3}{|c|}{ Wall } & \multirow{2}{*}{$\begin{array}{c}\text { Infilt- } \\
\text { ration } \\
\text { (approx. ACH) }\end{array}$} & \multirow{2}{*}{$\begin{array}{l}\text { Num. of } \\
\text { window } \\
\text { panes }\end{array}$} \\
\hline & $\begin{array}{c}\text { R- } \\
\text { value }\end{array}$ & Albedo & $\begin{array}{l}\text { Color/ } \\
\text { material }\end{array}$ & $\begin{array}{c}\text { R- } \\
\text { value }\end{array}$ & Albedo & $\begin{array}{c}\text { Color/ } \\
\text { material }\end{array}$ & & \\
\hline Site 1 & 19 & 0.40 & $\begin{array}{c}\tan \\
\text { shingles }\end{array}$ & 11 & 0.30 & $\begin{array}{c}\tan \\
\text { stucco }\end{array}$ & 0.5 & 2 \\
\hline Site 2 & 11 & 0.18 & $\begin{array}{c}\text { silver } \\
\text { composition }\end{array}$ & $7^{\circ}$ & 0.30 & $\begin{array}{l}\text { khaki } \\
\text { wood }\end{array}$ & 0.5 & 1 \\
\hline Site 5 & 30 & 0.16 & $\begin{array}{l}\text { med brown } \\
\text { shingle }\end{array}$ & 11 & 0.50 & $\begin{array}{l}\text { It tan } \\
\text { wood }\end{array}$ & 0.5 & 2 \\
\hline Site 6 & 30 & 0.35 & $\begin{array}{l}\text { It brown } \\
\text { shingle }\end{array}$ & 11 & 0.40 & $\begin{array}{l}\text { It blue } \\
\text { stucco }\end{array}$ & 0.5 & 2 \\
\hline Site 7 & 19 & 0.16 & $\begin{array}{l}\text { med brown } \\
\text { shingle }\end{array}$ & 11 & 0.45 & $\begin{array}{l}\text { off-white } \\
\text { stucco }\end{array}$ & 0.5 & 2 \\
\hline Site 8 & 19 & 0.16 & $\begin{array}{c}\text { med brown } \\
\text { shingle }\end{array}$ & 11 & 0.30 & $\begin{array}{c}\tan \\
\text { stucco }\end{array}$ & 0.5 & 2 \\
\hline School & 19 & 0.34 & $\begin{array}{c}\text { dull white } \\
\text { metal }\end{array}$ & 11 & 0.30 & $\begin{array}{l}\tan \\
\text { wood }\end{array}$ & 0.5 & 1 \\
\hline
\end{tabular}

-Wall between house and garage is uninsulated.

\section{HVAC System Characteristics}

System types, capacities, and air flowrates are based on site reports, supplemented by cooling equipment product literature for some sites, and are listed in Table V-3. For air-conditioner efficiencies, Site 2 had the most complete and reliable data because it was a newer, highefficiency unit. Sites 5 (with a heat pump), 6 , and 7 had enough information to make reasonable estimates. No information was available for the heat pumps at Sites 1 and 8. The same cooling efficiency was used at these sites as at Site 5, the other heat pump site. The cooling efficiency at the school site is an estimate. 
With the product data for sites 2 and 7, a comparison of cooling performance at part-load and at non-rated outdoor drybulb and indoor wetbulb conditions was made to assess the reliability of the DOE-2 cooling system default curves. The differences for these sites were considered not significant enough to develop specific equipment efficiency and capacity curves for each site. Heat pump heating efficiencies are taken from the product literature.

The thermostat settings were originally based on the experimental design control, calling for constant $78^{\circ} \mathrm{F}\left(25.5^{\circ} \mathrm{C}\right)$ setpoints in all houses and the school. However, schedules and setpoints were developed for each building to closely match the measured data. Those presented in Table V-3 are the final input values used. For Site 1, we developed a thermostat setpoint schedule to best mimic the measured interior temperature data. The thermostat in the school control building, once occupied, was frequently readjusted downward. For the final DOE-2 simulations, the thermostat was set at $70^{\circ} \mathrm{F}\left(21.1^{\circ} \mathrm{C}\right)$ to best match the metered data. Other observations relating to the thermostat operation are discussed later in this chapter. In addition, we modeled the buildings with windows closed. The occupants were asked to keep the windows closed at all times so that cooling provided by window venting would not be a factor in the results.

Supply fan wattages, while not directly measured and not included in the measured data except for at Site B, were estimated to have an air flow of $0.333 \mathrm{~W} / \mathrm{CFM}$ for the house sites and 0.417 W/CFM (733 Watts) at Site B.

\section{Distribution System Location and Efficiency}

Initial comparisons between simulated and measured cooling energy consumption data showed that the simulation models were underpredicting peak cooling use by $100 \%$ or more. This suggested that there may be substantial inefficiencies in the cooling systems at most sites. This may be due to (1) air conditioner inefficiencies, or (2) duct system inefficiencies. Without adequate testing of all the HVAC equipment, we cannot definitively determine the source of this inefficiency, but previous work has shown there are significant losses in residential duct systems in California due to air leakage and conduction. Moreover, there is a large variation in the amount of duct leakage across different buildings (Modera et al., 1991, Proctor and Pernick, 1992). 
Table V-3. System Characteristics Assumed in the DOE-2 Simulations

\begin{tabular}{|c|c|c|c|c|c|c|c|c|c|}
\hline Site & $\begin{array}{l}\text { Heat } \\
\text { Temp. } \\
\text { (F) }\end{array}$ & $\begin{array}{l}\text { Cool } \\
\text { Temp. } \\
\text { (F) }\end{array}$ & Type & $\begin{array}{c}\text { Heating E } \\
\text { Cap. } \\
\text { (Btu/hr) }\end{array}$ & $\begin{array}{l}\text { Eff. } \\
(\% / C O P)\end{array}$ & Type & $\begin{array}{l}\text { ooling Eq } \\
\text { Cap. } \\
\text { (Btu/hr) }\end{array}$ & $\begin{array}{l}\text { Eff. } \\
\text { (COP) }\end{array}$ & $\begin{array}{c}\text { Air flow } \\
\text { Rate } \\
\text { (CFM) }\end{array}$ \\
\hline House 1 & 68 & $78 t$ & HP & 21000 & 2.1 & HP & 24000 & 2.1 & 800 \\
\hline House 2 & 68 & 80 & Furn & 90000 & 70 & $\mathrm{~A} / \mathrm{C}$ & 40000 & 3.57 & 1060 \\
\hline House 5 & 70 & 78 & HP & 29000 & 2.1 & HP & 29000 & 2.1 & 1060 \\
\hline House 6 & 68 & 82 & Furn & 60000 & 70 & $A / C$ & 38000 & 2.35 & 1200 \\
\hline House 7 & 68 & 78 & Furn & 47000 & 70 & $\mathrm{~A} / \mathrm{C}$ & 36000 & 2.77 & 1200 \\
\hline House 8 & 70 & 76 & HP & 21000 & 2.1 & HP & 24000 & 2.1 & 800 \\
\hline School & 68 & $78^{\circ}$ & HP & 50000 & 2.7 & HP & 34600 & 2.7 & 1760 \\
\hline
\end{tabular}

Note: Heating sctbacks were used at Site 2 and the School.

† Schedule used, with cooling enabled at 3 p.m.

- School control building modeled with $70^{\circ} \mathrm{F}$ thermostat setpoint.

In cooling mode, supply ducts leak conditioned air and conduct heat from the zones they pass through, while return ducts pick up unconditioned air from these zones. Thus, the location of the duct system is also important in determining the efficiency of the system. At all houses except for Site 2, the supply and return duct systems are located in the attic. At Site 2, the supply ducts are in the crawlspace while the return is located fully within the conditioned space, since the air handler and coils are in an interior closet. In fact, in this building there are virtually no return ducts. Thus, it is not surprising that early simulations of the buildings showed a substantial under-prediction of measured cooling energy use at all sites except for Site 2 . The duct locations are summarized in Table V-4.

Based on measured data and simulations performed by Modera et al. (1991), a simple duct efficiency model was incorporated into the DOE-2 simulations. Results from a series of detailed building and duct system simulations performed on typical houses with attic supply and return 


\begin{tabular}{|c|c|c|c|c|c|c|c|}
\hline \multicolumn{8}{|c|}{$\begin{array}{l}\text { Table V-4. Ceiling and Foundation Construction and Duct Locations for } \\
\text { House Sites in the SMUD Project }\end{array}$} \\
\hline Site & $\begin{array}{l}\text { Year } \\
\text { Built }\end{array}$ & $\begin{array}{c}\text { Ceiling } \\
\text { Construction }\end{array}$ & $\begin{array}{l}\text { Foundation } \\
\text { Construction }\end{array}$ & $\begin{array}{c}\text { Supply } \\
\text { Duct }\end{array}$ & $\begin{array}{l}\text { Return } \\
\text { Duct }\end{array}$ & $\begin{array}{l}\text { Duct } \\
\text { Insulation* }\end{array}$ & $\begin{array}{c}\text { Duct } \\
\text { Condition* }\end{array}$ \\
\hline Site 1 & 1984 & $\begin{array}{l}\text { Attic and } \\
\text { Vaulted }\end{array}$ & Slab & Attic & $\begin{array}{l}\text { Attic and } \\
\text { Garage }\end{array}$ & & \\
\hline Site 2 & 1963 & $\begin{array}{l}\text { Low-Pitch } \\
\text { Vaulted }\end{array}$ & Crawl & Crawl & $\begin{array}{l}\text { Indoor } \\
\text { Closet }\end{array}$ & Yes & Good \\
\hline Site 5 & 1987 & Attic & Slab & Attic & $\begin{array}{l}\text { Attic and } \\
\text { Garage }\end{array}$ & Yes & OK-flexduct \\
\hline Site 6 & 1988 & $\begin{array}{l}\text { Attic and } \\
\text { Vaulted }\end{array}$ & Slab & Attic & $\begin{array}{l}\text { Attic and } \\
\text { Garage }\end{array}$ & & \\
\hline Site 7 & 1982 & Attic & Slab & Attic & $\begin{array}{l}\text { Attic and } \\
\text { Garage }\end{array}$ & & \\
\hline Site 8 & 1984 & $\begin{array}{l}\text { Attic and } \\
\text { Vaulted }\end{array}$ & Slab & Attic & $\begin{array}{c}\text { Attic and } \\
\text { Garage }\end{array}$ & & \\
\hline Site B & 1989 & $\begin{array}{l}\text { Dropped } \\
\text { Ceiling }\end{array}$ & Crawl & $\begin{array}{l}\text { Dropped } \\
\text { Ceiling }\end{array}$ & None & & \\
\hline
\end{tabular}

- From previous house audits by Modera et al. 1991.

ducts were used to correlate duct efficiencies with (1) outdoor drybulb temperatures, (2) attic temperatures, and (3) solar gain. The fit of the efficiency data to attic temperature was good. Two different duct conditions were modeled; one for typical California duct systems and one for improved ducts with one-half the leakage of typical ducts. The ducts in both cases are insulated with $\mathbf{R}-4$ duct insulation. 
We have complete data on the duct systems for Sites 2 and 5 from an earlier study (Modera et al., 1991). Both of these sites have ducts that are closer to the typical levels of leakage than the improved level. We have no data on the duct conditions in the other homes. Thus, we modeled all sites with the typical duct efficiency model except for Site 2 and Site B. At Site 2 , the supply ducts are in a crawl space and there are essentially no return ducts, and we have not yet characterized the performance of this type of duct system. In addition, cooling performance of these ducts will not be as degraded, since there is no return duct and the supply ducts are in the crawlspace, which will not be as warm as the attic. At Site B, all of the ducts are in the conditioned space of the buildings. The duct efficiency regression lines are as follows:

New: duct.eff $=1.346-0.00656 \times$ attic.temp $\left(R^{2}=.84\right)$

Old: duct.eff $=1.379-0.00766 \times$ attic.temp $\left(R^{2}=.85\right)$

In the DOE-2 model, the efficiency of the air conditioner is recalculated each hour based on the previous hour's attic temperature. In addition, the cooling capacity of the air-conditioning system is scaled downwards by the same duct efficiency value. While this is a great simplification of the complex interactions between the attic space conditions, the duct system, and the air-conditioner itself, it appears to capture most important effects of duct performance on air-conditioner electricity use reliably. However, we have found that under peak conditions, i.e. when the AC unit runs at peak capacity for the entire hour, this model becomes unstable, and cannot accurately predict peak cooling energy use.

Since the duct efficiency is calculated based on attic temperature, correctly modeling the attic becomes important for estimating both the heat flow into the conditioned space and the attic temperatures that the duct system sees. In initial simulations of the monitored buildings, we did not model the attic space. Instead, the attic was modeled as a simple R-value in the roof construction. There are several reasons for not modeling the attic as a zone in DOE-2.

1. Attics are typically gabled, while DOE-2 computes space temperatures based on an assumed rectangular space.

2. DOE-2 does not model the radiation exchange component of heat transfer, which may be a large effect in cooling mode where surfaces are typically quite warm. 
3. Attic ventilation rates, which are important for determining attic temperature, are typically unknown and vary a great deal from house to house (Huang et al., 1987).

However, to accurately simulate the duct efficiency, we needed to know the attic temperature where the ducts are located. Thus, attics are modeled as unconditioned zones so that attic temperatures can be calculated. From the simulated duct efficiencies, it was also possible to correlate duct efficiency with outdoor temperature (as a proxy for attic temperature), but the regression $\mathbf{R}$-squared is only about $\mathbf{0 . 5 0}$.

Since attic temperatures are extremely sensitive to the inputs used, primarily ventilation rates, we performed sensitivity analysis. Initial simulations with attic ventilation at $1 \mathrm{ft}^{2} / 150 \mathrm{ft}^{2}$ produced lower than expected attic temperatures. Thus, attics are modeled with $1 \mathrm{ft}^{2} / 450 \mathrm{ft}^{2}$ of ventilation area. Peak attic temperatures in August thus range from $109^{\circ} \mathrm{F}$ at Site 1 to $131^{\circ} \mathrm{F}$ at Site 7.

Given the importance of the duct system in the cooling energy use of a building, the impact of a high-albedo roof on cooling energy will be more than just for the change in conductive loads. With ducts in the attic space, the higher albedo roof will both reduce the cooling load on the conditioned space and increase the cooling system efficiency. However, in this study no attic duct buildings were included as albedo test cases. Site 2, the only albedo test site among the houses, does not have ducts in the attic. In fact, it has no attic. However, with the calibrated models for the other sites, we can estimate the effect of a high albedo roof on duct efficiencies and overall cooling energy use. These are discussed in the following chapter. 


\section{Climate Data}

Data for August 1 through October 31, 1991, covering the period of monitoring, was obtained from the National Climatic Data Center (NCDC) in Asheville, NC. These data served as the primary climatic input for the DOE-2 simulations. These data were measured at the Sacramento Executive Airport and include hourly dry bulb and wet bulb temperatures, wind speed and direction, cloud cover, and cloud type. The last two items are used with a modified DOE-2 algorithm, based on Fresno solar and cloud cover data, to calculate the amount of solar gain. $\dagger$

Ideally, the simulations would use data collected from each site as inputs. However, there were significant data gaps, making it difficult to construct complete microclimatic databases. In addition, the solar data collected was not readily transferable into the required DOE-2 input format. Thus, the Airport data was used for all sites except for Site 2, which will be discussed later in more detail. At Site 2, actual data for drybulb temperature, relative humidity (used together to calculate wet bulb temperatures) and windspeed were used as model inputs.

Normally, building simulations use climatic inputs from weather data describing "typical" conditions, such as TMY (Typical Meteorological Year) weather tapes. This project greatly benefited from using climate data taken from the actual period of monitoring at the Airport, a nearby location. A comparison of the NCDC Airport weather data for August through October with the TMY data illustrates the degree to which these three months were "typical." This comparison is shown in Table V-5. Compared to the TMY data, the monitored period was cooler (fewer cooling degree days and degree hours) in August, but warmer in September and October. In addition, the monitored period had less solar radiation than the TMY data in August, but in September and October, had more direct normal solar radiation but less total horizontal solar.

† The algorithm was supplied by Fred Buhl, Building Technologies Program, Lawrence Berkeley Laboratory. 
Table V-5. Comparison of 1991 Airport Weather Data with Sacramento TMY

\begin{tabular}{|c|c|c|c|c|c|c|}
\hline & \multicolumn{3}{|c|}{ Sacramento TMY } & \multicolumn{3}{|c|}{1991 NCDC Airport Data } \\
\hline & Aug & Sep & Oct & Aug & Sep & Oct \\
\hline \multicolumn{7}{|c|}{ Daily Averages $\left({ }^{\circ} \mathrm{F}\right)$} \\
\hline Dry Bulb & 73 & 70 & 63 & 71 & 72 & 67 \\
\hline Wet Bulb & 61 & 59 & 55 & 61 & 60 & 55 \\
\hline Maximum & 101 & 100 & 94 & 89 & 92 & 85 \\
\hline Minimum & 53 & 49 & 41 & 58 & 57 & 53 \\
\hline Wind(mph) & 9.0 & 7.7 & 6.6 & 9.3 & 6.6 & 6.7 \\
\hline \multicolumn{7}{|c|}{ Degree Days (base $65^{\circ} \mathrm{F}$ ) } \\
\hline Heating & 5 & 5 & 86 & 1 & 1 & 83 \\
\hline Cooling & 324 & 207 & 72 & 249 & 289 & 204 \\
\hline \multicolumn{7}{|c|}{ Cooling Degree Hours $/ 24$ (base $75^{\circ} \mathrm{F}$ ) } \\
\hline & 144 & 78 & 26 & 105 & 134 & 91 \\
\hline \multicolumn{7}{|c|}{ Average Daily Solar $\left(\mathrm{Btu} / \mathrm{ft}^{2}\right)$} \\
\hline Dir. Normal & 2694 & 2311 & 1745 & 2358 & 2423 & 1917 \\
\hline Tot. Horiz. & 2391 & 1928 & 1297 & 2091 & 1791 & 1239 \\
\hline
\end{tabular}

\section{Site model calibration overview}

To calibrate the models for each building, we compared model outputs for cooling compressor energy consumption and interior temperatures to corresponding measured data at the hourly level. At most monitoring sites, the measured data had significant gaps, which precluded the possibility of comparing the models with the measured data over long-term periods. On the other hand, the DOE-2 model works on an hourly time-step. Thus, comparisons with the measured data at its original 10-minute time step were difficult. Based on the limitations of the data and the model, we chose one week of continuous hourly data from the pre- and postmodification data sets to compare with corresponding simulation results. At Site 5, there was no 
complete week of measured data in the pre-period, so we compare the results for a five-day period. At the school site (B), we compare simulated and measured data for the test building and for the control building, but over the same time period, when the school was occupied.

Initially, the comparisons were made for cooling compressor energy consumption and outdoor temperature. These comparisons also identified sites with significantly different ambient temperature regimes than the NCDC airport site and suggested that the simulations for Site 2 would be greatly improved by using the actual weather data collected for that site. A summary of the differences in outdoor temperatures between all sites is presented at the end of this chapter.

Indoor temperature data gave clues to occupant behavior and thermostat management that helped explain some of the differences between simulated and measured cooling data. The calibration results presented here show simulated and measured data for interior temperature and cooling compressor energy use. It should be noted that the DOE-2 model treats the building (not including the garage) as one zone; that is, the entire indoor space is conditioned to the same temperature. Indoor temperature was measured at a single point in each building, typically a bedroom or living room. While this single point may not be representative of the whole house or the thermal conditions at the thermostat, it gives us some indication as to how the house is cooled.

The project participants were asked to keep their thermostats consistently set at $78^{\circ} \mathrm{F}(25.5$ ${ }^{\circ} \mathrm{C}$ ), a setting that was also used in the simulations. The graphics that follow, however, suggest that on some days the thermostats were reset, while at some sites the thermostat may be functioning incorrectly. The simulated indoor temperature is consistent and smooth, whereas the data suggest this was not necessarily true in all rooms of the houses studied. It must also be noted that the primary method of determining the impact of the modifications on these buildings is the change in cooling energy use. 


\section{Measured Energy Savings Results and Comparison with Simulations}

In this section, we discuss the analysis of measured and simulated data from all seven sites monitored in Sacramento, CA, between August and October 1991. The results are presented on a site-by-site basis and some analysis for all sites collectively is also given.

The measured data are discussed in terms of environmental, microclimate, indoor, and outdoor monitored conditions, as appropriate. In addition, cooling electricity use is discussed to quantify the impacts of albedo and vegetation modifications.

In each site, the cooling electricity use is examined as a function of outdoor temperature (means and maxima), indoor temperatures, indoor/outdoor temperature differences, and solar radiation, as appropriate to each particular case. The analysis is carried out for pre-retrofit (basecase) and post-retrofit (albedo or vegetation modifications) conditions. The results are presented ai both daily and hourly time scales. A discussion of solar radiation and its change over time (during the monitoring period) is also given. This is to account for the lower solar heating of the building envelopes during the latter parts of the monitoring period. Finally, hourly time-series of cooling electricity usage are also shown when comparisons with simulated results are performed.

In this study, we used Julian dates to keep track of measured data. In Table V-6, Julian days are tabulated with their corresponding 1991 calendar dates for quick reference.

Table V-6. 1991 Julian Days / Dates Within the Field Measurements'

Time Frame

\begin{tabular}{|llllll|}
\hline Calendar day & JD & Calendar day & JD & Calendar day & JD \\
\hline $08-01-91$ & 213 & $09-01-91$ & 244 & $10-01-91$ & 274 \\
$08-05-91$ & 217 & $09-05-91$ & 248 & $10-05-91$ & 278 \\
$08-10-91$ & 222 & $09-10-91$ & 253 & $10-10-91$ & 283 \\
$08-15-91$ & 227 & $09-15-91$ & 258 & $10-15-91$ & 288 \\
$08-20-91$ & 232 & $09-20-91$ & 263 & $10-20-91$ & 293 \\
$08-25-91$ & 237 & $09-25-91$ & 268 & & \\
$08-30-91$ & 242 & $09-30-91$ & 273 & & \\
\hline
\end{tabular}


We discuss energy or electricity use in terms of condenser electricity consumption, i.e., air-handler fan energy use in split systems is not accounted for. About 0.2 to $0.3 \mathrm{~kW}$ should be added to the results to account for that component. This applies to all residential sites we monitored. In the school bungalows, cooling was achieved with heat pumps and the reported electricity use is that of the entire packaged unit.

Following the presentation of the measured data for each site, we present the comparisons of simulated and measured hourly cooling energy use and indoor temperature using the final model inputs. These show the degree to which the models correctly predict the actual conditions on an hourly basis at each site. On each figure, we also show the measured and predicted average daily energy use for the days during the period where cooling energy use is consistent.

Finally, the use of simulation models to estimate energy savings from the vegetation and albedo modifications is presented. Simulated daily cooling energy estimates are plotted against daily maximum outdoor temperatures. On each graph are three sets of data. One set reproduces the measured data from the base case period; that is, the base case building over the time period of measurement in the base condition. In some cases more data points may appear in the simulation results because of missing measured data between the start and stop days. Likewise, a second data set reproduces the measured data from the modified condition over the period of measurement in the modified condition. The third data set is the model estimates for the modified case (high albedo or trees) simulated during the base case period condition. This adjusts for differences in climate not accounted for by the $\mathrm{kWh}$ versus temperature relationship, primarily solar insolation. Each set of data is described by a simple linear regression line drawn through the points. The difference between the lines drawn through the modified case/base period set and the base case/base period set represent the actual savings from the modifications as predicted by the simulation models.

\section{Control site (Site 1)}

Site 1 was instrumented and monitored as a control site where no albedo or vegetation modifications were performed. Data from this site were available for 60 days [Julian day (JD) 235 through JD 294], but there were 18 days of missing data (JD 240 - 247, 263 - 266, and 269 274). The data from this site were used to get reference weather and energy use sets when needed. 
Site 1 was located far northeast of Sacramento and was in a relatively newer area. Neighborhood vegetation was medium to low and the site vegetation was low except that the walls were lined with shrubs. Figure V-2A shows daily data from this site, where cooling electricity use in $\mathrm{kWh} /$ day is plotted against the maximum daily temperature $\left({ }^{\circ} \mathrm{C}\right)$ at Site 1 . One can see that mechanical cooling started after the outdoor maximum temperature went over $30^{\circ} \mathrm{C}$. $\mathrm{A}$ linear regression line was fitted to the data to show the general trend in cooling energy use as a function of daily maximum temperature. The slope of this line is about $1.2 \mathrm{kWh} /$ day per ${ }^{\circ} \mathrm{C}$ of maximum daily temperature. This means that the cooling electricity use at Site 1 could be decreased by $-6 \mathrm{kWh} /$ day if the maximum outside air temperature were decreased by $\sim 5^{\circ} \mathrm{C}$. Based on computer simulations of microclimates, a reduction of this magnitude in maximum daytime heat island appears to be feasible [Taha et al., 1991, Taha et al., 1992].

In terms of hourly data, Figure V-2B describes the conditions at Site 1 . In this figure, the cooling energy use in $\mathrm{Wh} \mathrm{h}^{-1}$ is plotted versus mean hourly outdoor air temperature $\left({ }^{\circ} \mathrm{C}\right)$. Recall that outdoor air temperature was read every 10 minutes and in this figure, we present the mean of 6 readings per hour. ${ }^{1}$ The data in Figure V-2B indicate that there was cooling energy use within the outdoor temperature range of $17-40^{\circ} \mathrm{C}$. We should be cautious when interpreting the data at the lower end of the range (temperatures $17-23^{\circ} \mathrm{C}$ ) as some of that energy may be heating energy use (since Site 1 had a heat pump unit).

In Figure V-2C, the same energy use data are plotted against the hourly outdoor-indoor temperature difference (To- $\mathrm{Ti}$ ). The sloping of the scatter is obvious and indicates that there was need for cooling when the outdoor temperature was in the range of -7 to $12^{\circ} \mathrm{K}$ higher than the indoor temperature.

The comparison of hourly measured and simulated data for Site 1 are presented in Figures V-2D and VI-2E. The measured interior temperature data shows a distinct morning peak followed by a more thermostatically controlled period, as if a threshold temperature must be reached before the cooling system is activated. This produces a delayed spike in cooling energy use. We mimic this observed behavior by adding a thermostat setpoint schedule that allows cooling starting at 3 P.M. However, the simulated indoor temperature is consistently lower in the morning and the peak cooling load is not well matched in the pre-period. The measured

\footnotetext{
1 A similar procedure was applied to indoor air temperature, temperature differences, and relative humidity.
} 
interior temperature data also suggests that the building cools down at night slower than the simulated building.

In general, however, the daily cooling electricity totals match well over the period for which there exists consistent data. The lack of cooling energy use on days 280 and 281 suggests that cooling may have been turned off on those days.

Daily $\mathrm{kWh}$ from the simulation model is plotted against the peak outdoor temperature in Figure V-2F. The regression line through the points meets the $0 \mathrm{kWh}$ axis at $29^{\circ} \mathrm{C}$ in the measured data and $27^{\circ} \mathrm{C}$ in the simulated data. At $40{ }^{\circ} \mathrm{C}$ daily maximum temperature, the measured data regression line gives $13 \mathrm{kWh} /$ day while the line for the simulated data gives $14 \mathrm{kWh} /$ day. 


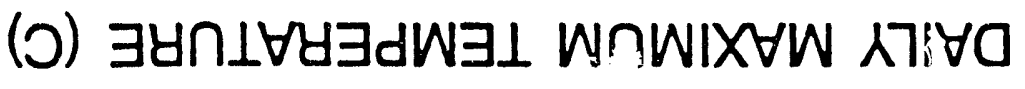

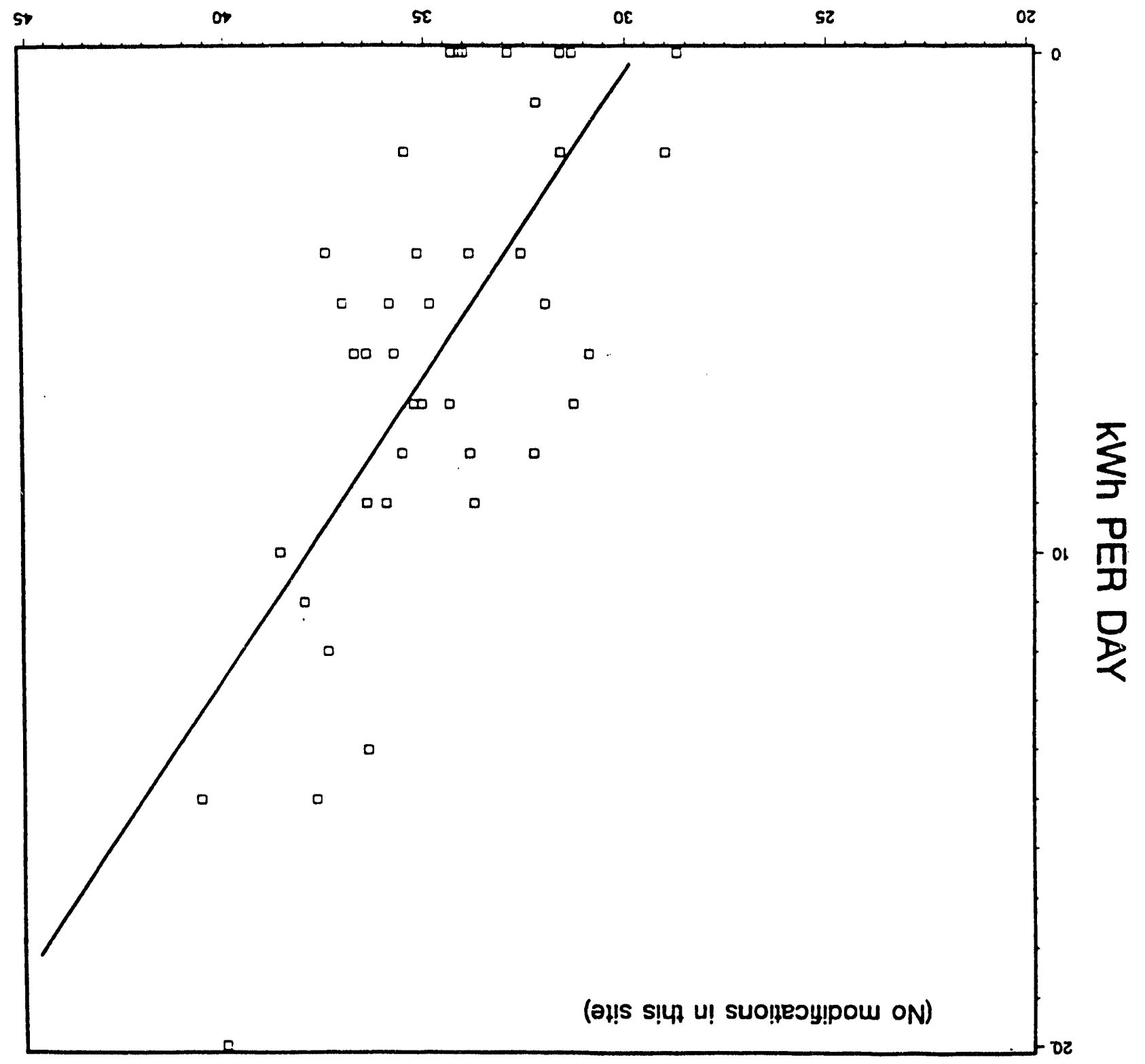

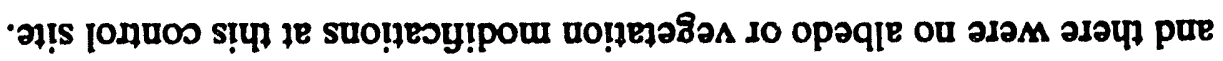

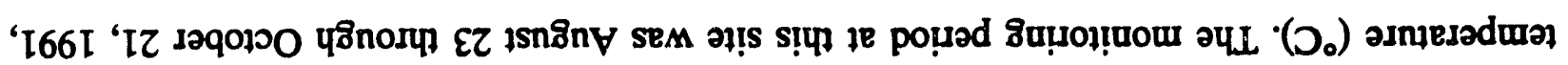

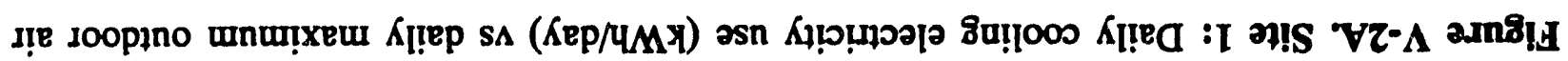


Figure V-2B. Site 1: Hourly cooling electricity use $(\mathrm{Wh} / \mathrm{h})$ vs mean hourly outdoor air temperature $\left({ }^{\circ} \mathrm{C}\right)$. The monitoring period at this site was August 23 through October 21, 1991, and there were no albedo or vegetation modifications at this control site.

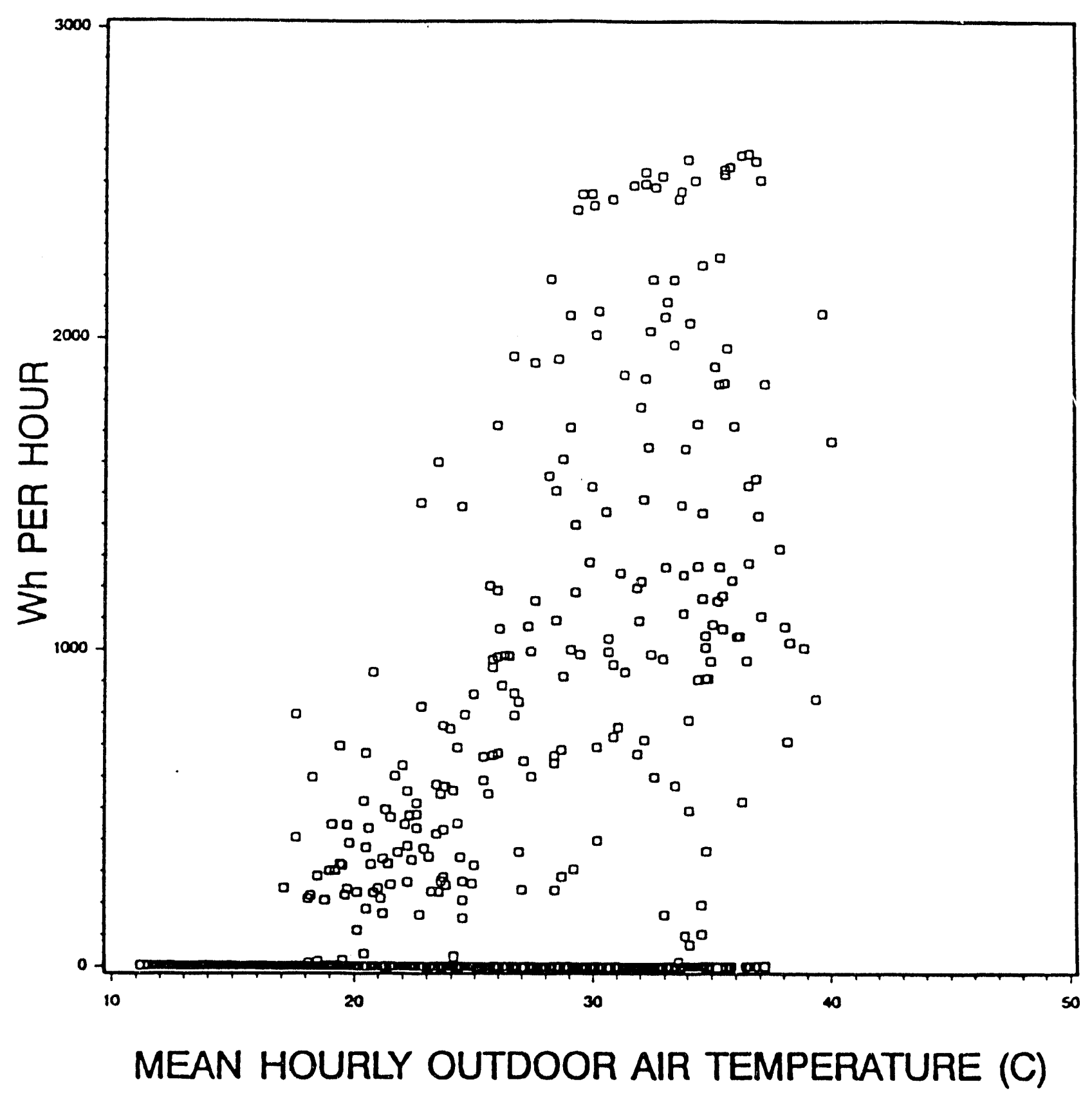


Figure V-2C. Site 1: Hourly cooling electricity use $(\mathrm{Wh} / \mathrm{h})$ vs hourly difference between outdoor and indoor air temperatures $\left({ }^{\circ} \mathrm{C}\right)$. The monitoring period at this site was August 23 through October 21,1991 , and there were no albedo or vegetation modifications at this control site.

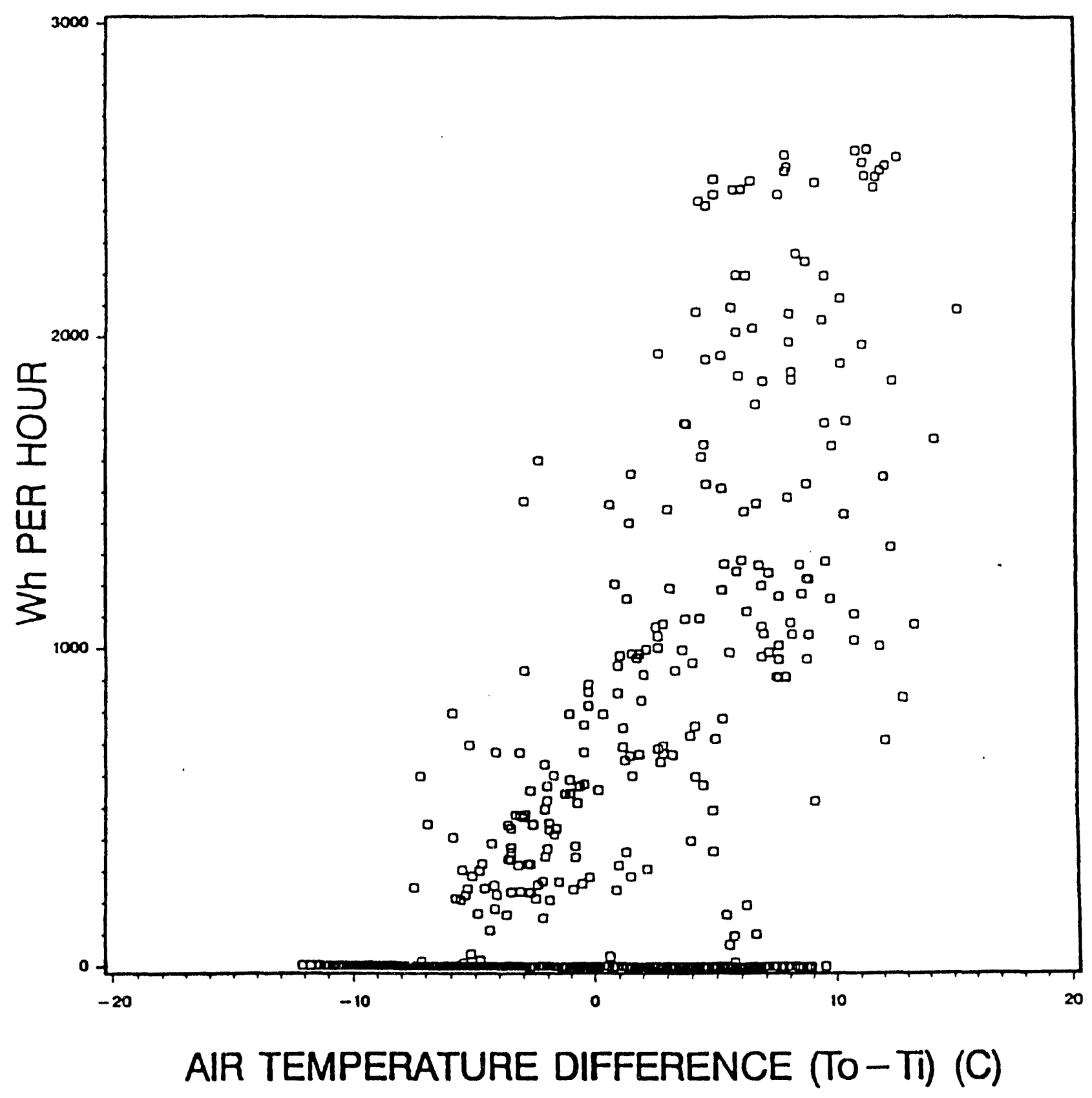


Figure V-2D. Compressor watt hours and building interior temperature for 9/13 to 9/19 at Site 1 . Comparison of measured and simulated data during late summer.

Days 258 to 260 Measured: $10.0 \mathrm{kWh} /$ day DOE-2: $10.7 \mathrm{kWh} /$ day.

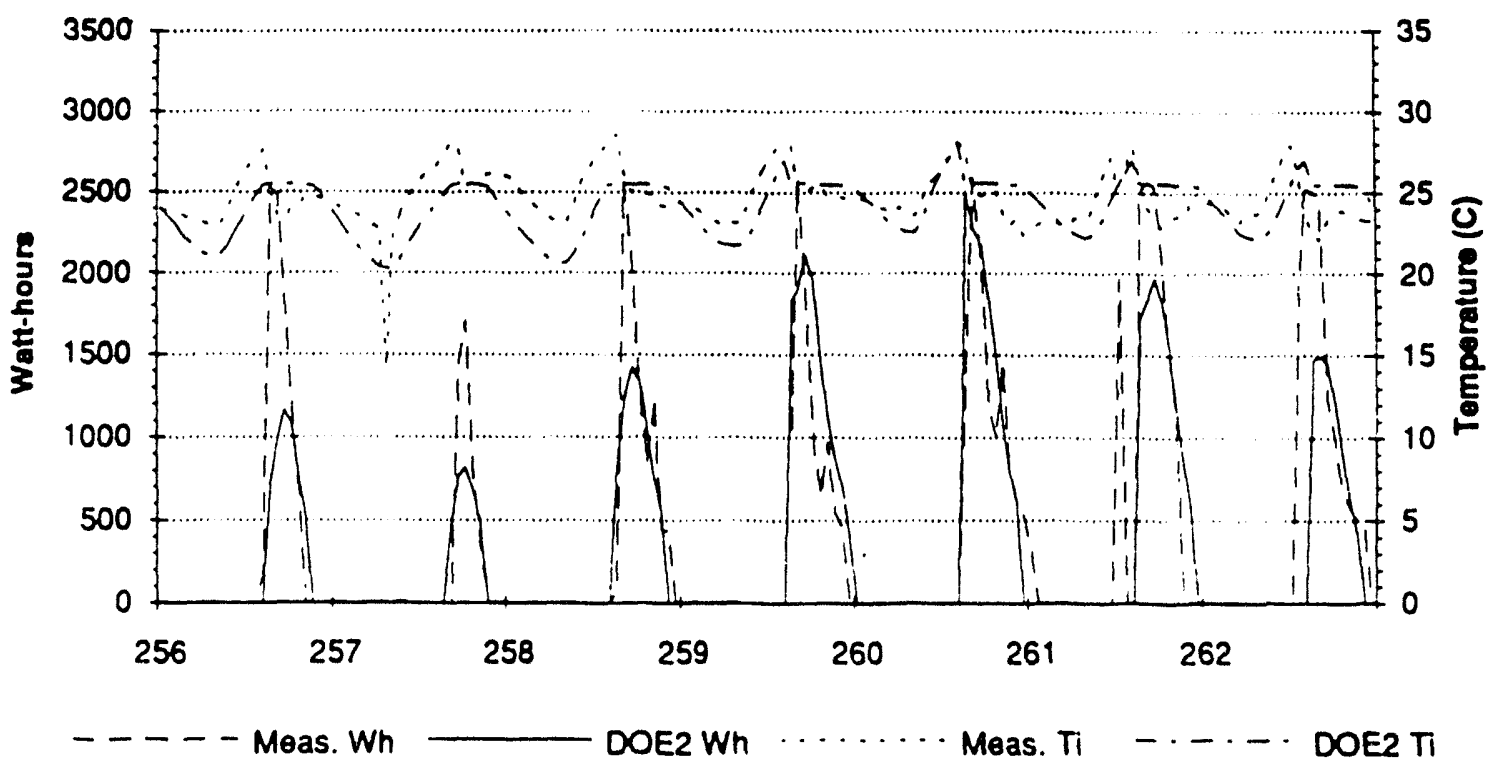

Figure V-2E. Compressor watt hours and building interior temperature for $10 / 7$ to $10 / 13$ at Site 1. Comparison of measured and simulated data during late summer.

Days 284 to 286 Measured: $7.4 \mathrm{kWh} /$ day DOE-2: $7.7 \mathrm{kWh} /$ day.

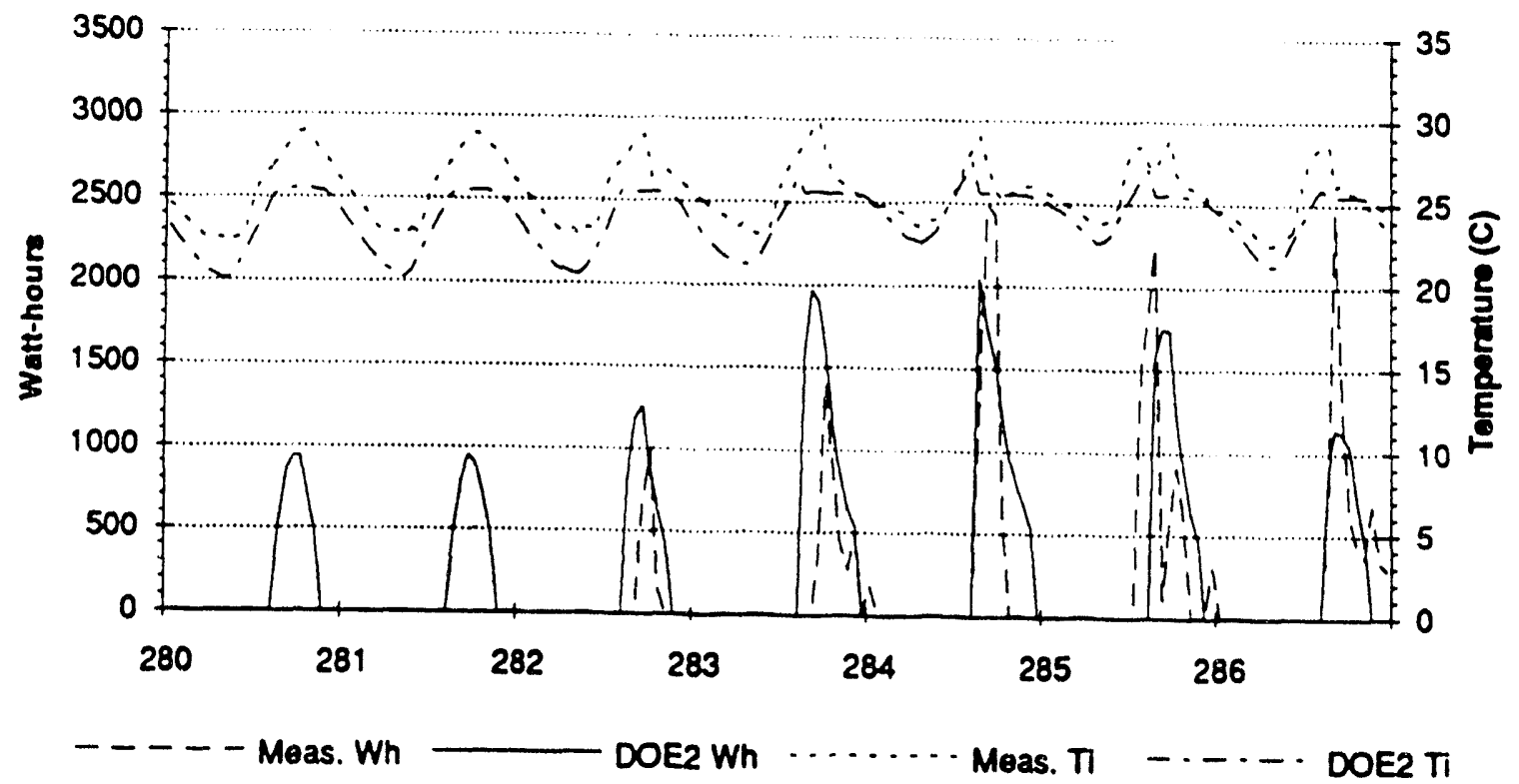


Figure V-2F. Site 1: Simulation Results Daily data for period of monitoring. No modifications in this site; days 235-294.

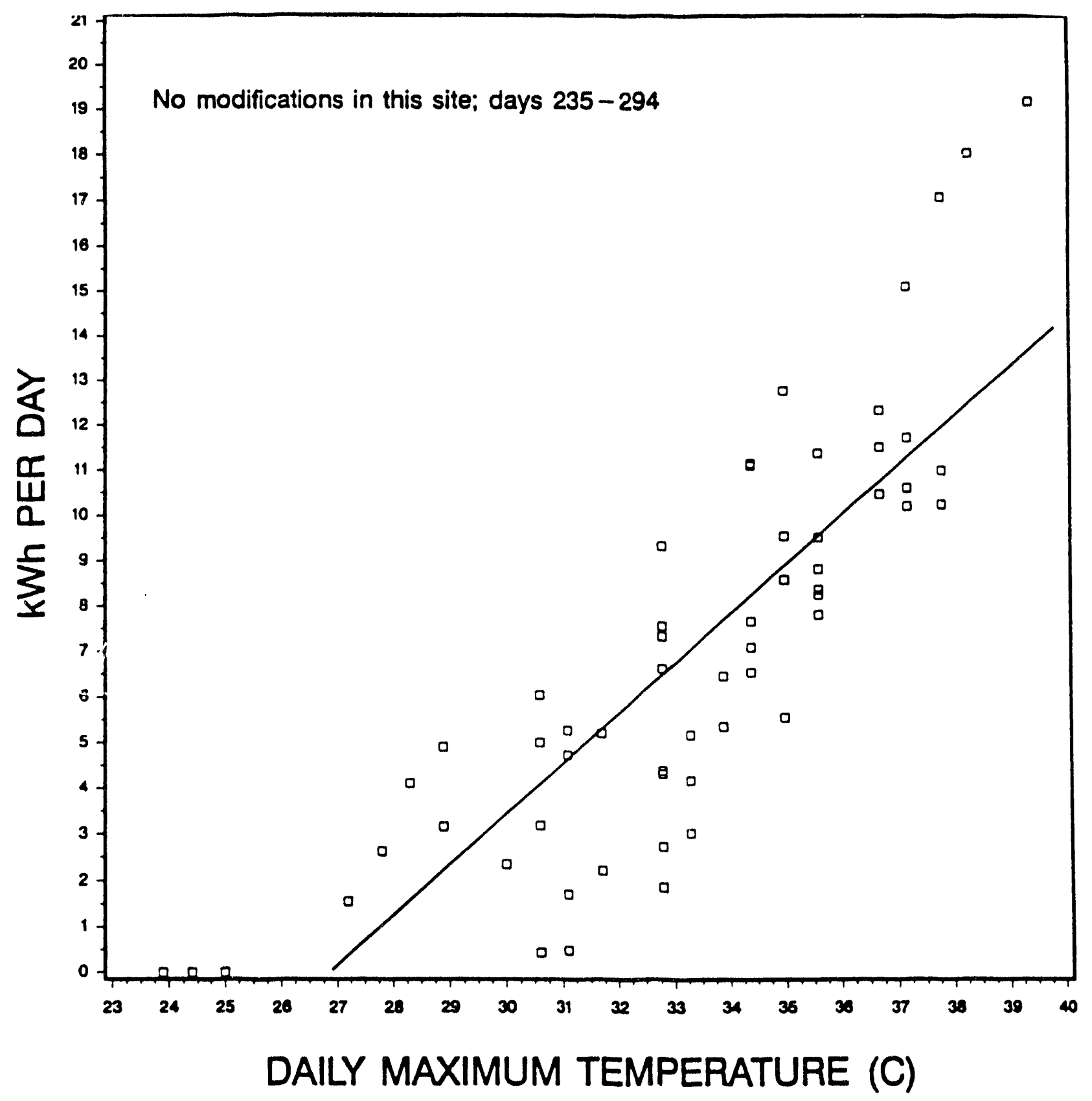




\section{Albedo Modification Sites}

Site 2

Site 2 was monitored to examine the effects of a roof's albedo modifications on cooling energy use. Twenty days of data for pre-modification conditions (JD 234 - 253) and 35 days of data for post-modification conditions (JD 259 - 293) were available for this site. There were missing data for 4 days in the "pre" period and one day in the "post" period.

Site 2 was located in a heavily vegetated area of Carmichael (northeast of Sacramento) and both neighborhood and site vegetation were high. Since the major path for heat gain into this house was the roof, coating it with a high-albedo coating was perhaps the most significant modification that could affect its energy performance.

Figure V-3A shows daily data from this site. Cooling electricity use in $\mathrm{kWh} /$ day is plotted against the maximum daily temperature $\left({ }^{\circ} \mathrm{C}\right)$ at Site 2 . The squares represent daily cooling energy use for the case with a dark roof (albedo $=0.18$ ), whereas the triangles represent the energy use for the case with a whitened roof (albedo $=0.77$ ). In effect, increasing the albedo of the roof canceled all the cooling energy use in that building. The reason why there appears to be cooling energy use even after whitening the roof (shown with arrows) is that the thermostat setting was lowered from $25.5^{\circ} \mathrm{C}$ down to $-23.5^{\circ} \mathrm{C}$ in a few post-retrofit days. The downwardpointing arrows suggest that these points should actually be lying on the $x$-axis. But practically speaking, the cooling load disappeared after the application of a high-albedo coating on the roof (to a maximum outdoor air temperature of $34^{\circ} \mathrm{C}$ ). However, these results may overestimate the savings since they were obtained in late summer when ambient temperature and solar gains are lower, i.e., higher maximum daily temperatures for pre-retrofit period were not observed during the post-retrofit period.

In Figure V-3A, a linear regression fit is also shown. The solid line corresponds to the dark roof situation, and has a slope of $0.86 \mathrm{kWh} /$ day per ${ }^{\circ} \mathrm{C}$ of maximum air temperature. The owner of this house reported that heat gain through the garage wall was significantly reduced after the roof was coated white, and that had a large impact on cooling needs in the building. 
It is also worth noting that solar intensity was generally lower during the "post" period, as shown in Figure V-3B. In this figure, we can see that across a period of 45 days, the daily total solar radiation received at Site 2 decreased from $7.2 \mathrm{kWh} /$ day to $4 \mathrm{kWh} /$ day (squares correspond to the "pre" interval, whereas diamonds correspond to the "post" interval). How much of an effect this decrease had on the reduction in cooling energy use cannot be determined 
Figure V.3A. Site 2: Daily cooling electricity use ( $\mathrm{kWh} /$ day) vs daily maximum outdoor air temperature $\left({ }^{\circ} \mathrm{C}\right)$ for pre- and post-retrofit periods. Pre-retrofit monitoring period at this site was August 22 through September 11 and the post-retrofit period was September 16 through October 21, 1991. Pre-retrofit albedo $=0.18$, post retrofit albedo $=0.77$. The arrows indicate points that would have otherwise been on the zero energy use line were it not for the thermostat resetting from $78^{\circ} \mathrm{F}$ down to $74^{\circ} \mathrm{F}$. Line is a regression fit through the pre-retrofit data points.

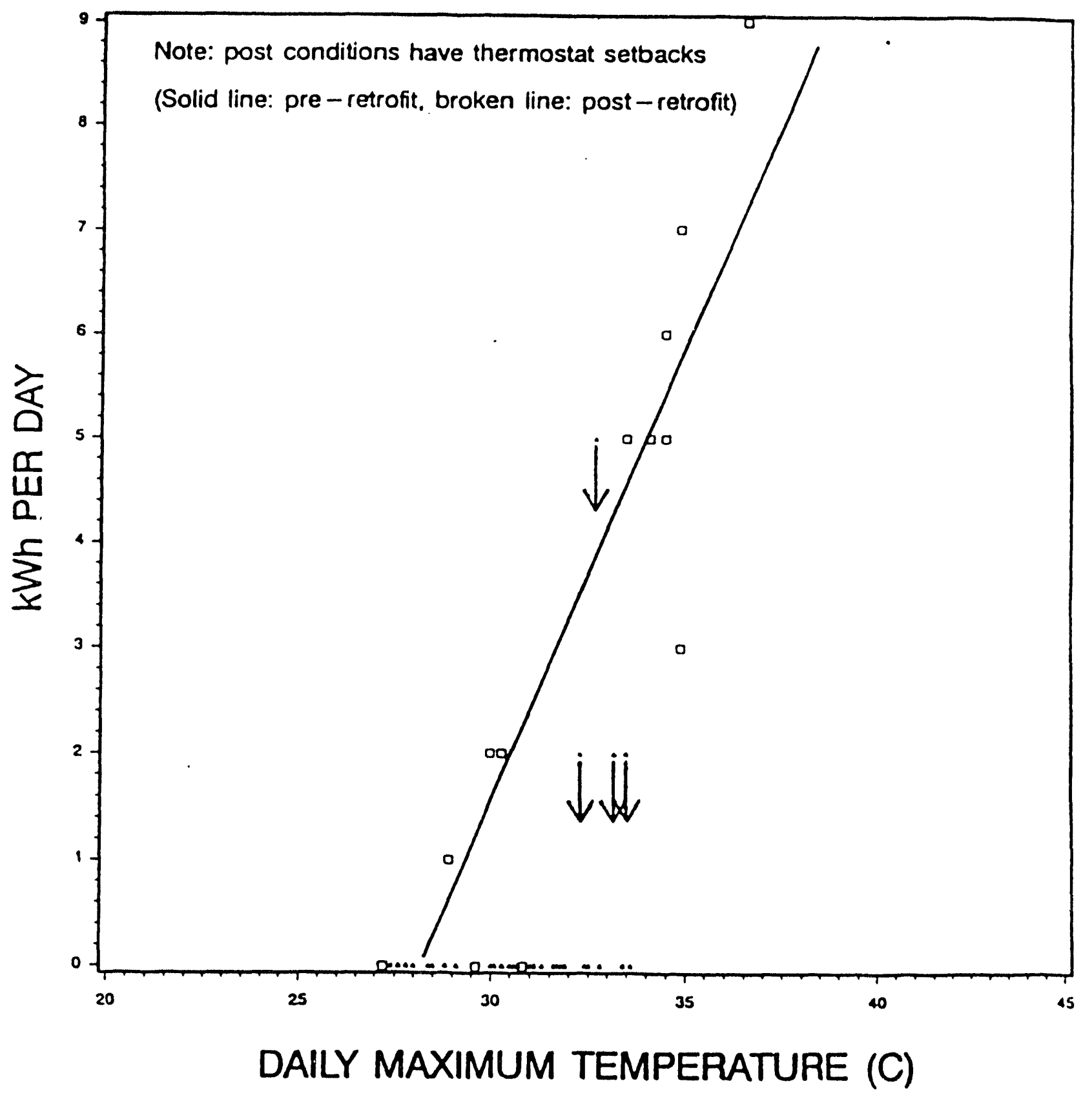


Figure V-3B. Site 2: Variation in total daily horizontal solar radiation (kWh/day) over 45 days of monitoring. The left portion of the graph represents solar radiation during the pre-retrofit period whereas the right portion represents radiation during the post-retrofit period. Pre-retrofit monitoring period at this site was August 22 through September 11 and the post-retrofit period was September 16 through October 21, 1991.

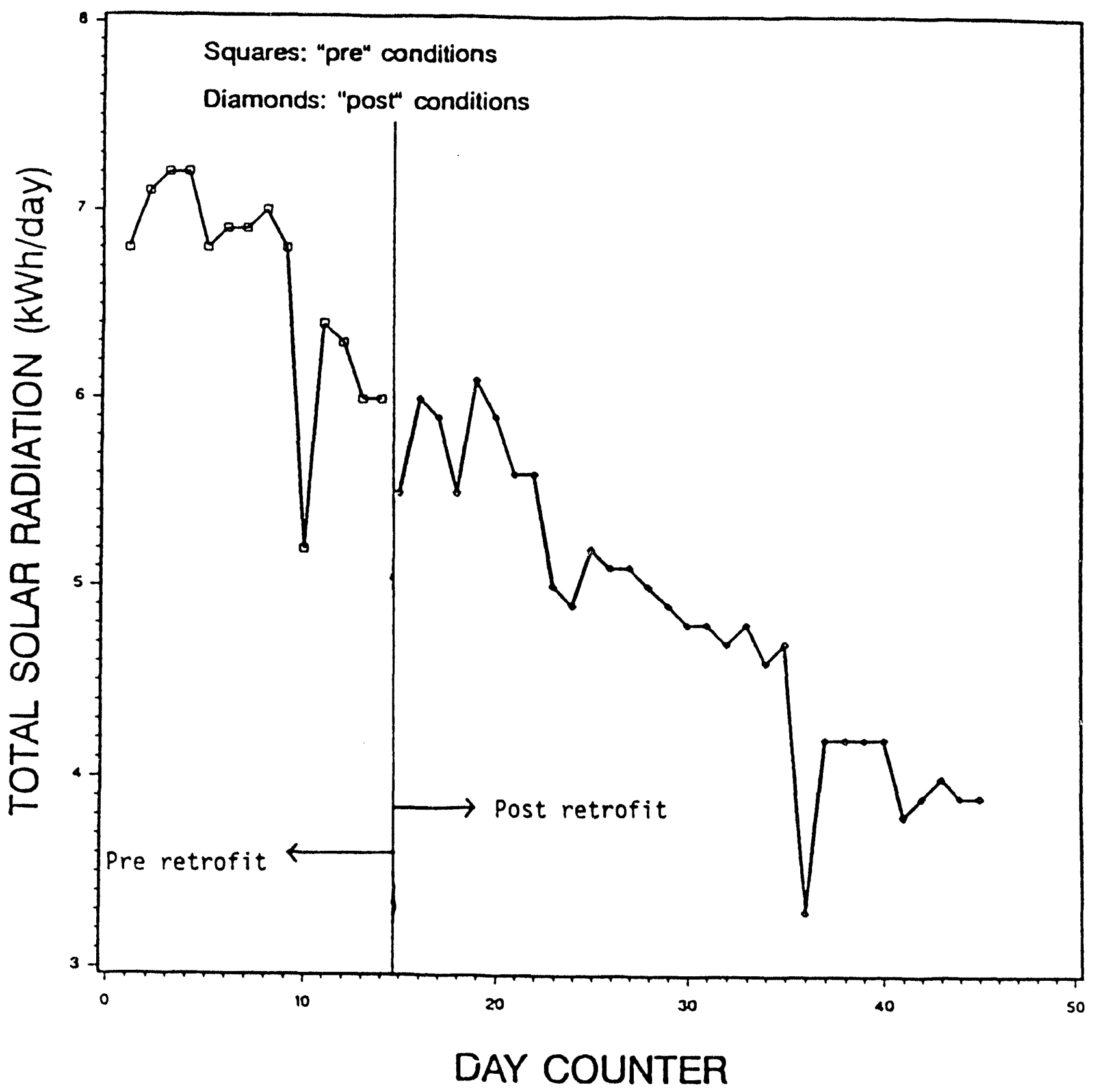


from measured data alone because most of the points corresponding to the "post" period lie on the $x$-axis (see the triangle symbols in Figure V-3A). DOE-2.1D simulations of this site were performed for corresponding periods and appear to indicate that about $20 \%$ of the measured savings may be caused by the effect of lower insolation during the post-monitoring period.

In Figure V-3C, hourly data are shown, where cooling energy use in $\mathrm{Wh} \mathrm{h}^{-1}$ is plotted versus the mean hourly outdoor air temperature $\left({ }^{\circ} \mathrm{C}\right)$ at Site 2 . The solid line is a fit to "pre" conditions and the broken line is a fit to "post" conditions. The large amount of energy savings is clear. In Figure V-3D, the same energy use data are plotted against the hourly outdoor-indoor temperature difference (To-Ti). The sloping of the scatter is now more obvious, and indicates that there was need for cooling when the outdoor temperature was in the range of $0-9^{\circ} \mathrm{C}$ higher than the indoor temperature. Because of thermostat reset during the "post" period, we did not perform regressions to estimate savings (as we did with the daily data), as savings could reach $100 \%$ were it not for the setpoint lowering. As in the case with daily data, correction for solar intensity is necessary at the hourly level, too ( $-20 \%$ of measured savings are not caused by albedo modifications). 
Analysis of the 20-minute data reveals some other aspects of the impact of albedo modification. In Figures V-3E and V-3F, for instance, the roof surface temperature is plotted versus solar radiation for the cases before and after modification, respectively (note that the surface temperature data are questionable). Each is fitted with a regression line, and from these we can see that the surface temperature of the roof is lower in the high-albedo case. The regression lines indicate that the surface temperature at high albedo was about $5^{\circ} \mathrm{C}$ lower in the afternoon than the one with the low albedo. Recall, however, that this depression underestimates the the impact of the albedo on surface temperature, because of the improper contact of the thermocouple with the surface. That is, the decrease in surface temperature should be larger than reported here, but short of reliable surface temperature data, we cannot find the actual temperature of the roof. Note that this problem does not exist in the cases where roofs are made of shingles, because the thermocouple is fully embedded in the material. But with this roof, which is flat and solid, the thermocouple cannot be embedded. In the second year of monitoring, we will attempt to correct this problem. We will analyze surface temperature data once more reliable data are collected.

The hourly comparisons of simulated and measured $d^{\text {nt }}$ f 7 r Site 2 are presented in Figures V.3G and V-3H. The thermostat operates as expected at and the simulated interior 
Figure V-3C Site 2: Hourly cooling electricity use $(\mathrm{Wh} / \mathrm{h})$ vs mean outdoor temperature $\left({ }^{\circ} \mathrm{C}\right)$ for pre- and post retrofit conditions. Pre-retrofit albedo $=0.18$, post-retrofit albedo $=0.77$. The solid line represents the low albedo case (pre-retrofit). Pre-retrofit monitoring period at this site was August 22 through September 11 and the post-retrofit period was September 16 through October 21, 1991.

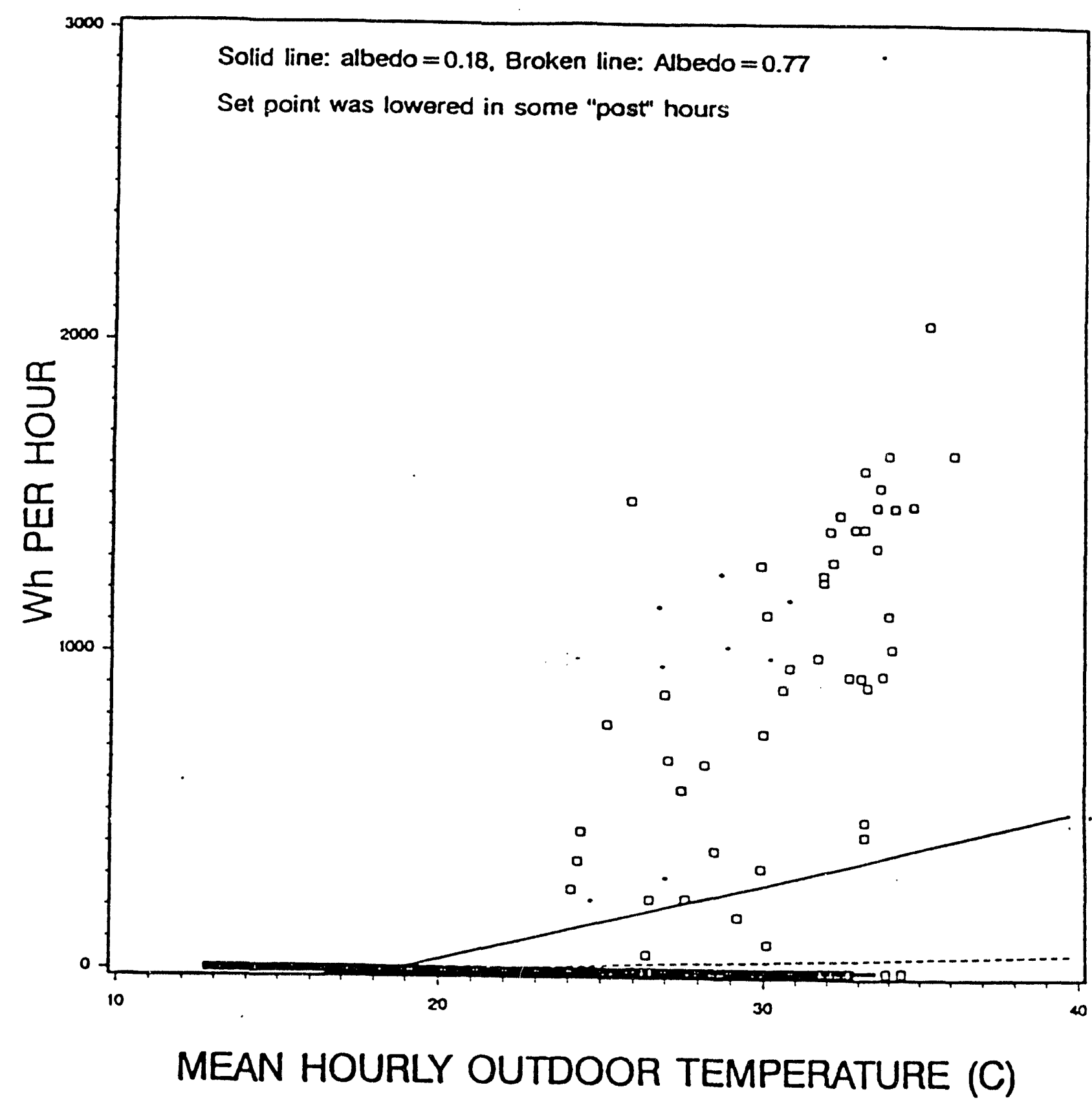


Figure V-3D. Site 2: Hourly cooling electricity use (Wh/h) vs difference between outdoor and indoor temperatures $\left({ }^{\circ} \mathrm{C}\right)$. Squares represent low-albedo case and diamonds represent the highalbedo case. Pre-retrofit monitoring period at this site was August 22 through September 11 and the post-retrofit period was September 16 through October 21, 1991.

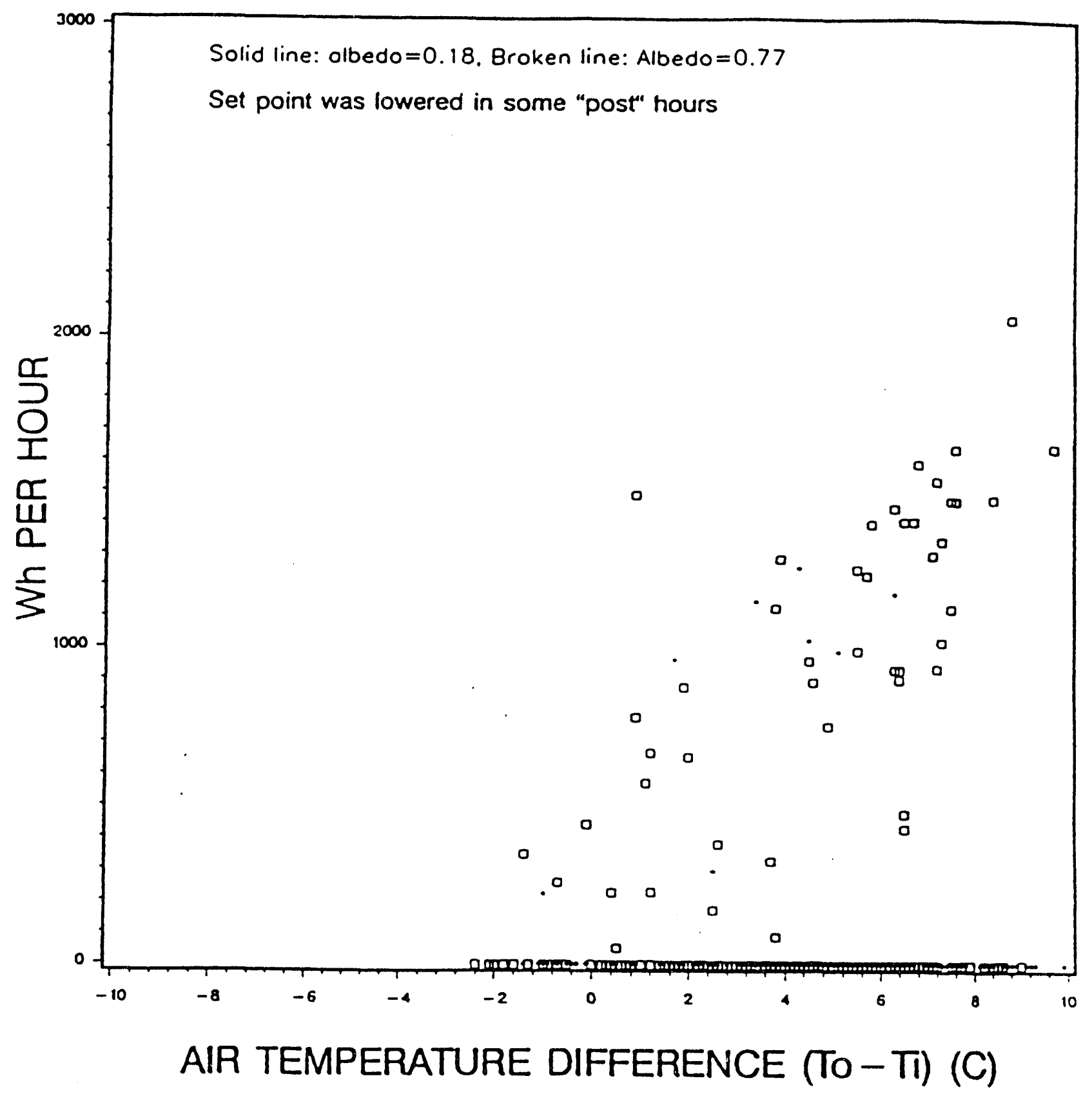




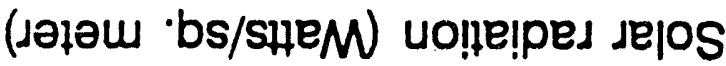

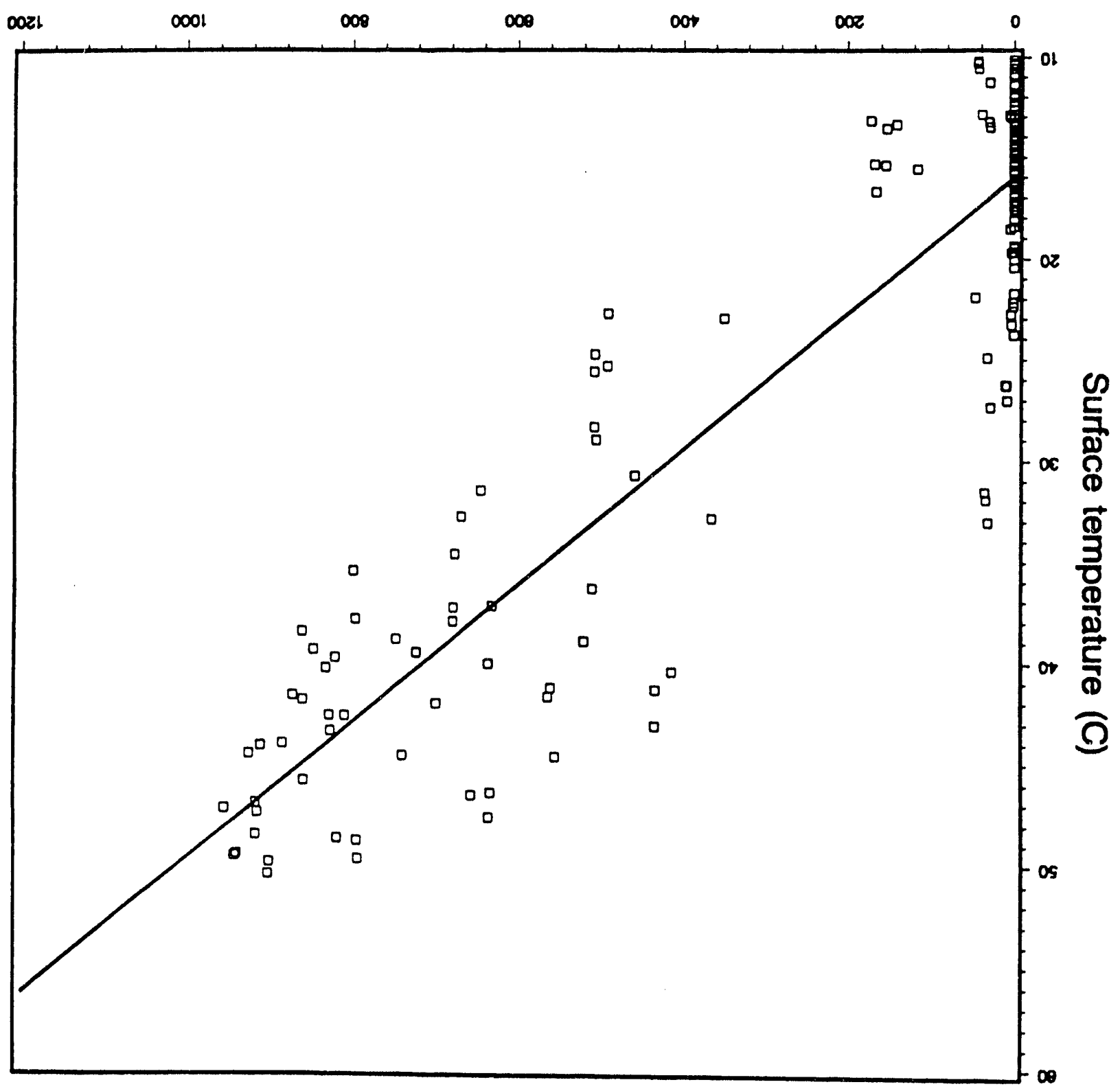

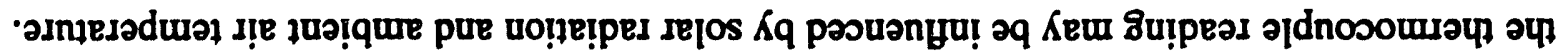

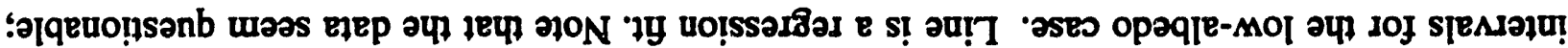

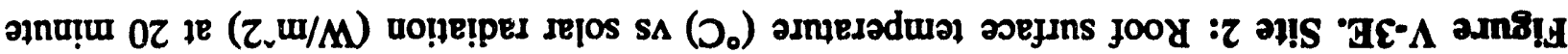


Figure V-3F. Site 2: Roof surface temperature $\left({ }^{\circ} \mathrm{C}\right)$ vs solar radiation $\left(\mathrm{W} / \mathrm{m}^{\wedge} 2\right)$ at 20 minute intervals for the high-albedo case. Line is a regression fit. Note that the data seem questionable; the thermocouple reading may be influenced by solar radiation and ambient air temperature.

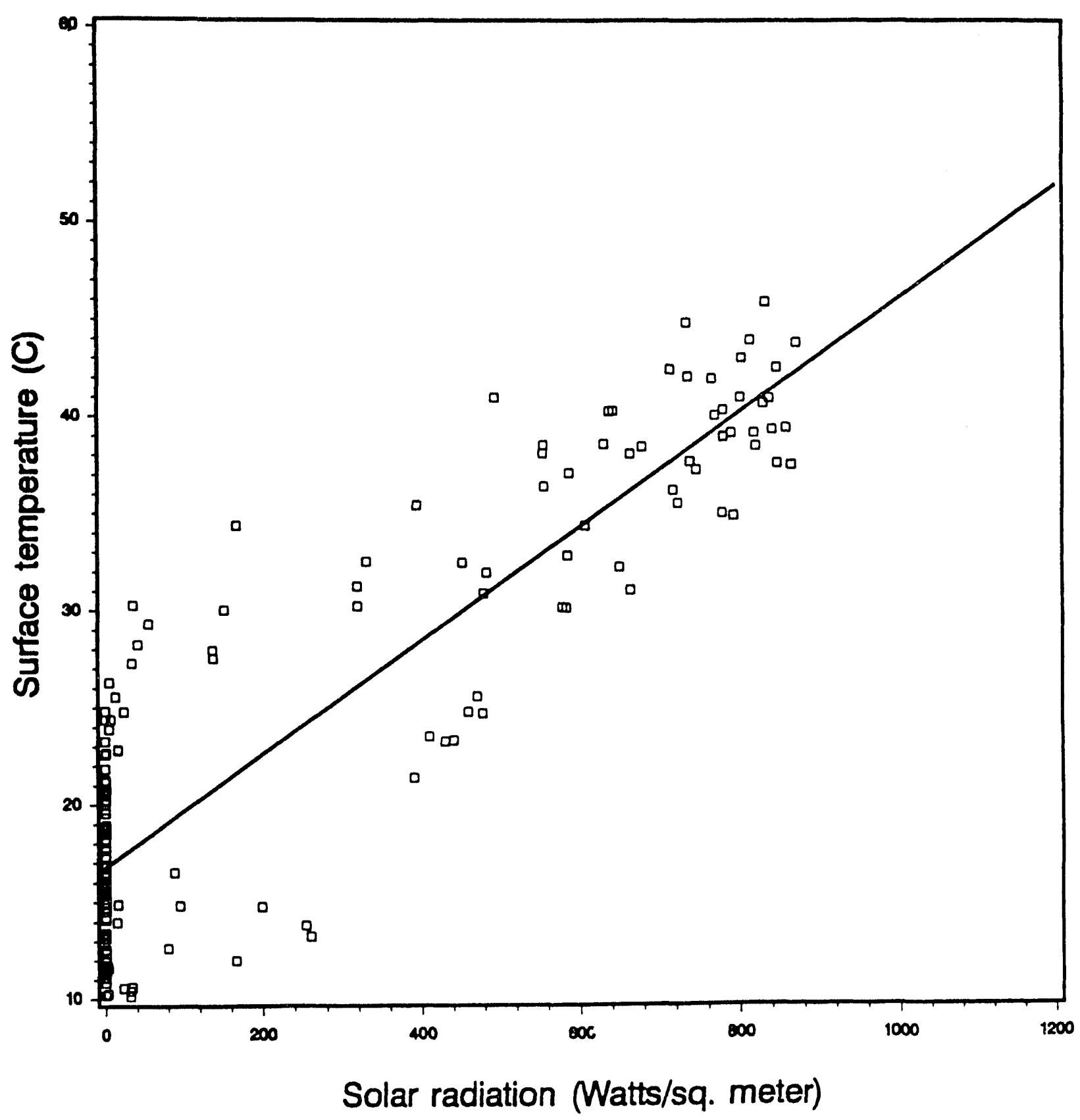


Figure V-3G. Compressor watt hours and building interior temperature for $9 / 1$ to $9 / 7$ at Site 2 . Comparison before albedo modification using ACTUAL SITE temperature and windspeed.

Days 245 to 248 Measured: $5.5 \mathrm{kWh} /$ day DOE-2: $7.0 \mathrm{kWh} /$ day.

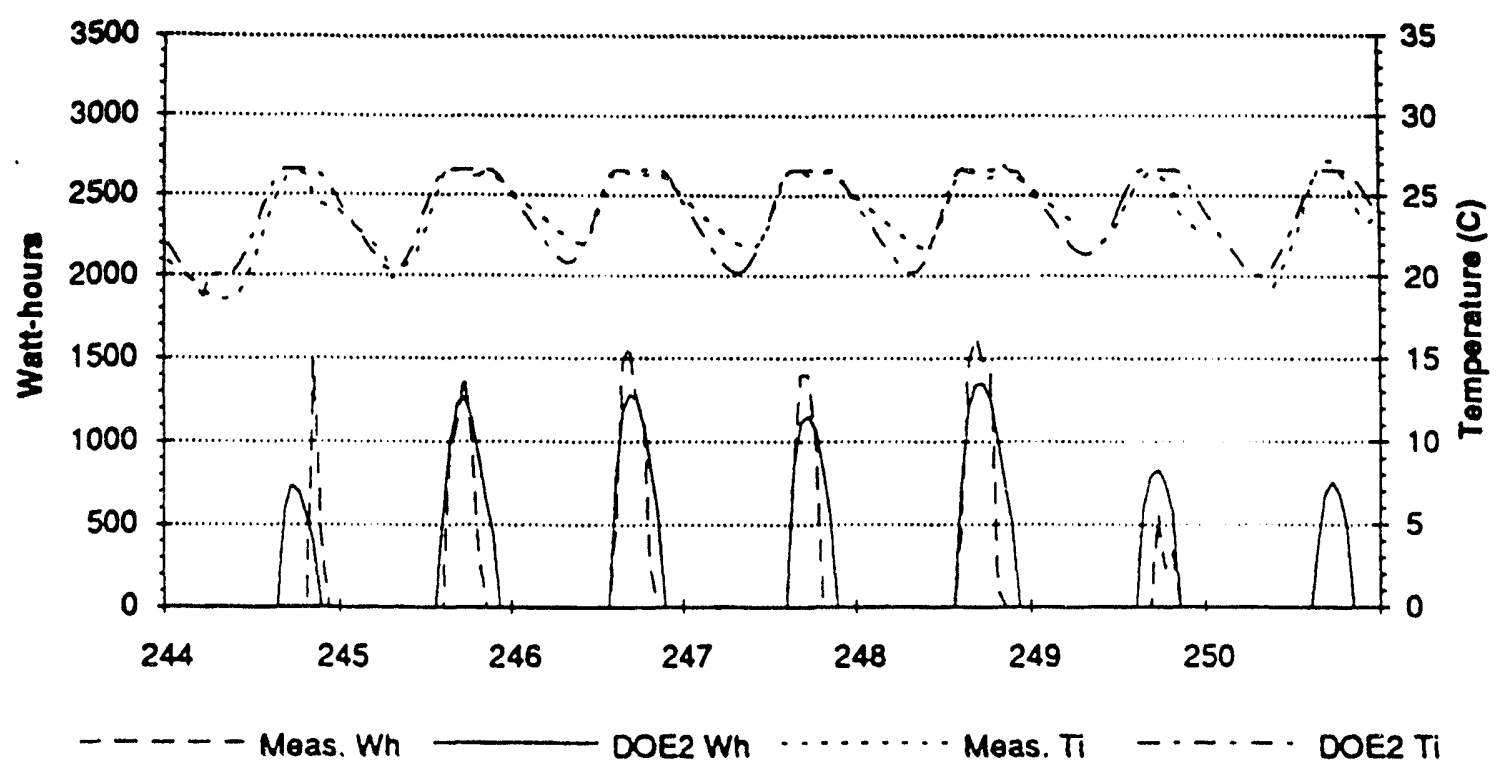

Figure V-3H. Compressor watt hours and building interior temperature for 9/17 to 9/23 at Site 2. Comparison after albedo modification using ACTUAL SITE temperature and windspeed. Days 260 to 266 Measured: $0.3 \mathrm{kWh} /$ day DOE-2: $0.9 \mathrm{kWh} /$ day.

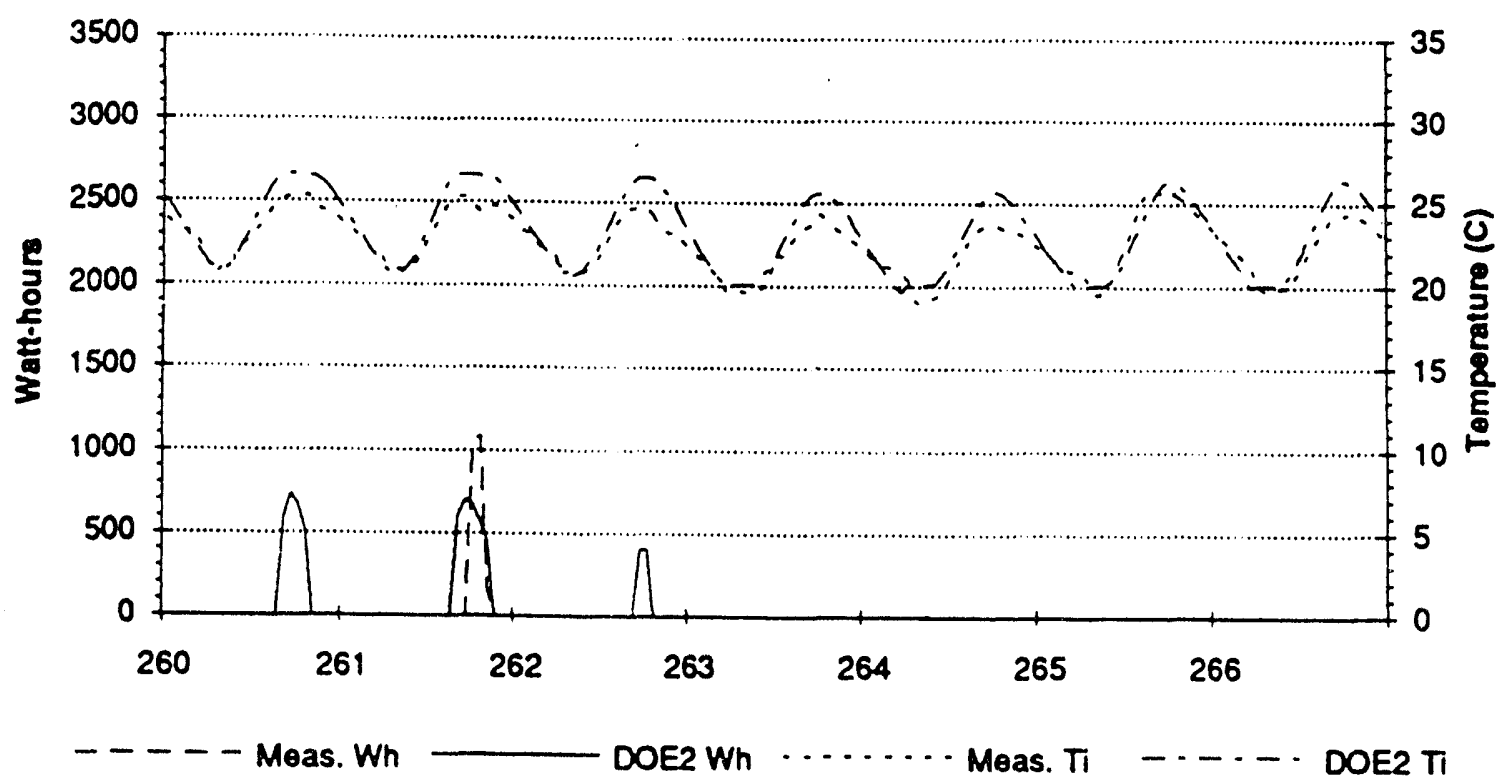


temperatures match the measured data extremely well except that the simulated building appears to cool faster at night than the measured data suggests. In addition, the cooling energy use is relatively well simulated. In the pre-period, the simulated peaks are slightly lower than the measured peaks, but the simulated total daily usage is $20 \%$ too high. The simulations capture the effect seen earlier, where after painting the roof of the building white, cooling use dropped virtually to zero. The measured data in Figure $\mathrm{V}-3 \mathrm{H}$ show that the interior temperature hovered just below the thermostat setpoint during that week. The simulation model reaches the setpoint and on a few days during this period, and a small amount of cooling is used.

As previously mentioned, a site-specific weather data set was produced for Site 2 from the site-measured temperature, humidity, and windspeed data. A study of the sensitivity of this model to climatic inputs is shown in Figures V-3I and V-3J. The impact of changing from airport temperature and windspeed data to site data was to decrease the simulated peak cooling load on very hot days by $40 \%$ or $1.0 \mathrm{~kW}$, and on more typical days by $0.5 \mathrm{~kW}$. The microclimate surrounding Site 2 has a large impact on its cooling energy use.

In Figure V-3K we present simulated daily cooling energy use versus daily maximum temperature from the Site 2 model. As shown in the calibration charts, the simulations overpredict daily cooling energy use. At an outdoor temperature of $35^{\circ} \mathrm{C}$, the model predicts about 7.5 $\mathrm{kWh} /$ day, while the measured data regression line predicts about $6.0 \mathrm{kWh} /$ day, a difference of $25 \%$. The simulation model also allows us to account for changing climatic conditions over the period of measurement. The model shows that when simulating the dark roof and white roof cases over the base case time period, the savings are approximately $60 \%$. 
Figure V-3I. Simulated compressor watt hours for $9 / 1$ to $9 / 7$ at Site 2 using different weather inputs. Comparison before albedo modification showing effects of temperature and windspeed. Days 244 to 250 AP data: $8.5 \mathrm{kWh} /$ day Site Data: $5.3 \mathrm{kWh} /$ day.

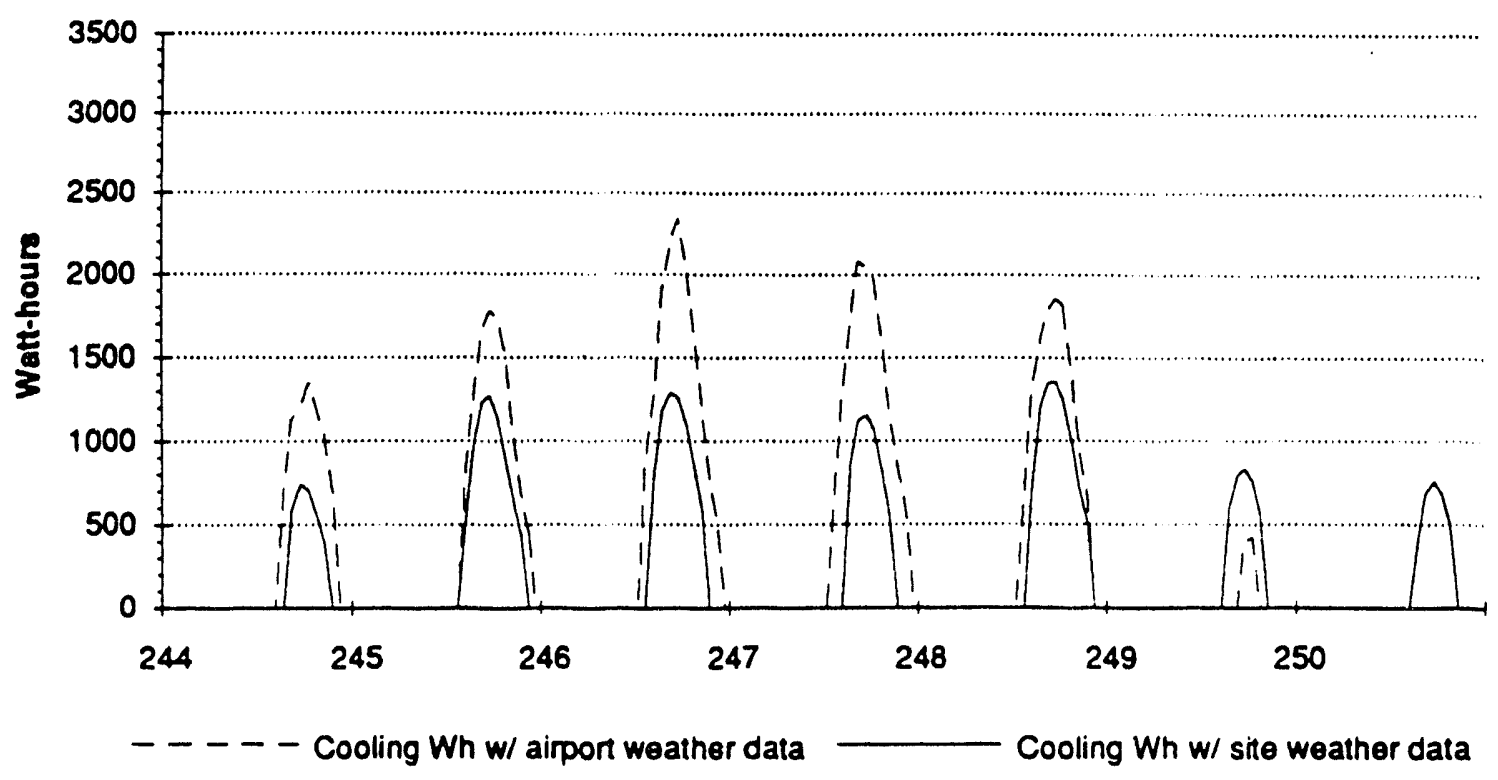

Figure V-3J. Compressor watt hours and building interior temperature for 9/17 to 9/23 at Site 2 using different weather inputs. Comparison after albedo modification showing effects of temperature and windspeed.

Davs 260 to 266 AP data: $2.6 \mathrm{kWh} /$ day Site Data: $0.9 \mathrm{kWh} /$ day.

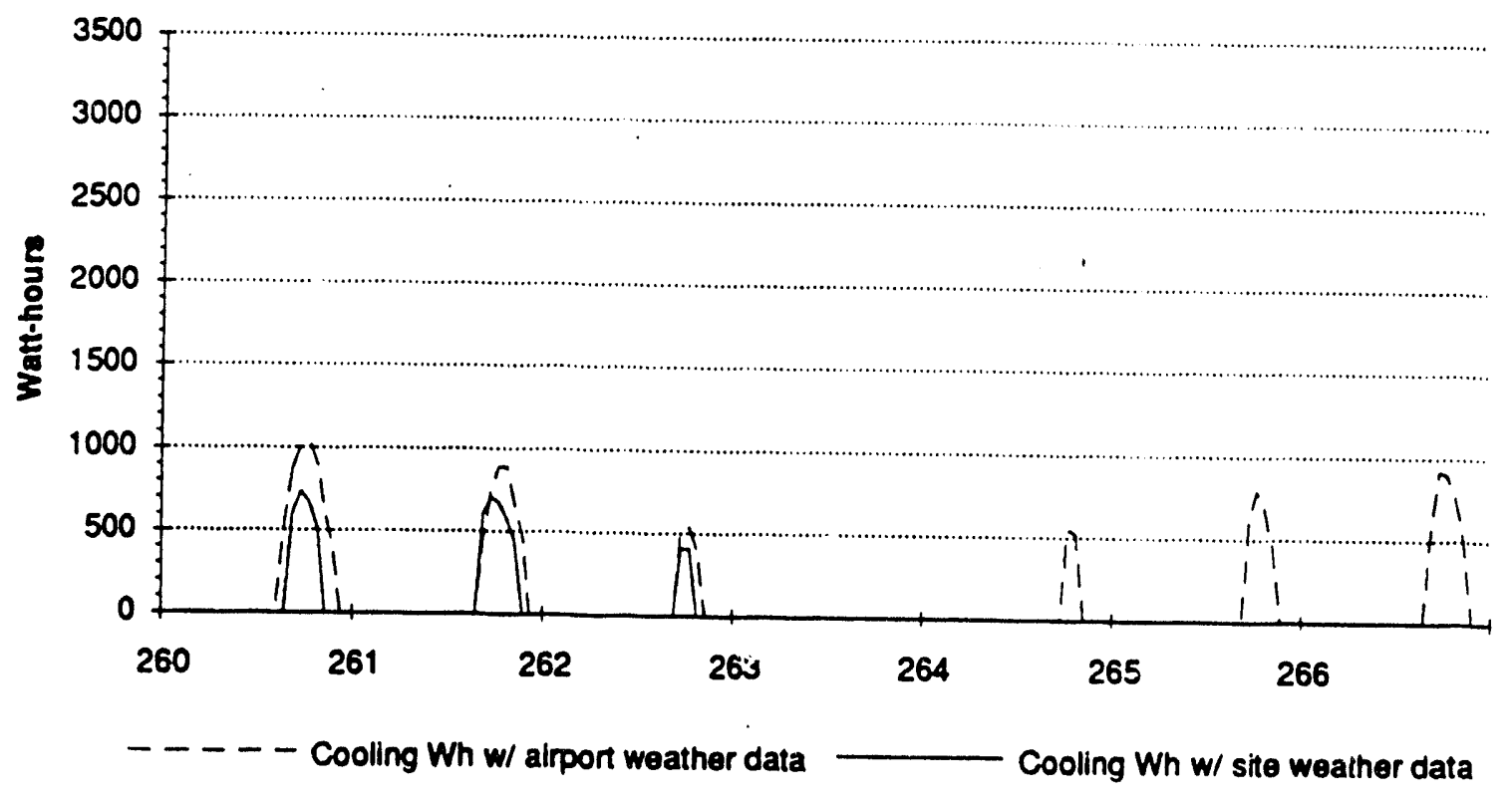


Figure V-3K Site 2 Simulation Results: Daily data Simulations were performed using Site temperature and windspeed data. The square and solid line represent the dark roof in late summer (day 235-253). Crosses and dashed line represents the white roof in late summer (days 235253). Triangles and dotted line represent a white roof during fall (days 260 - 293).

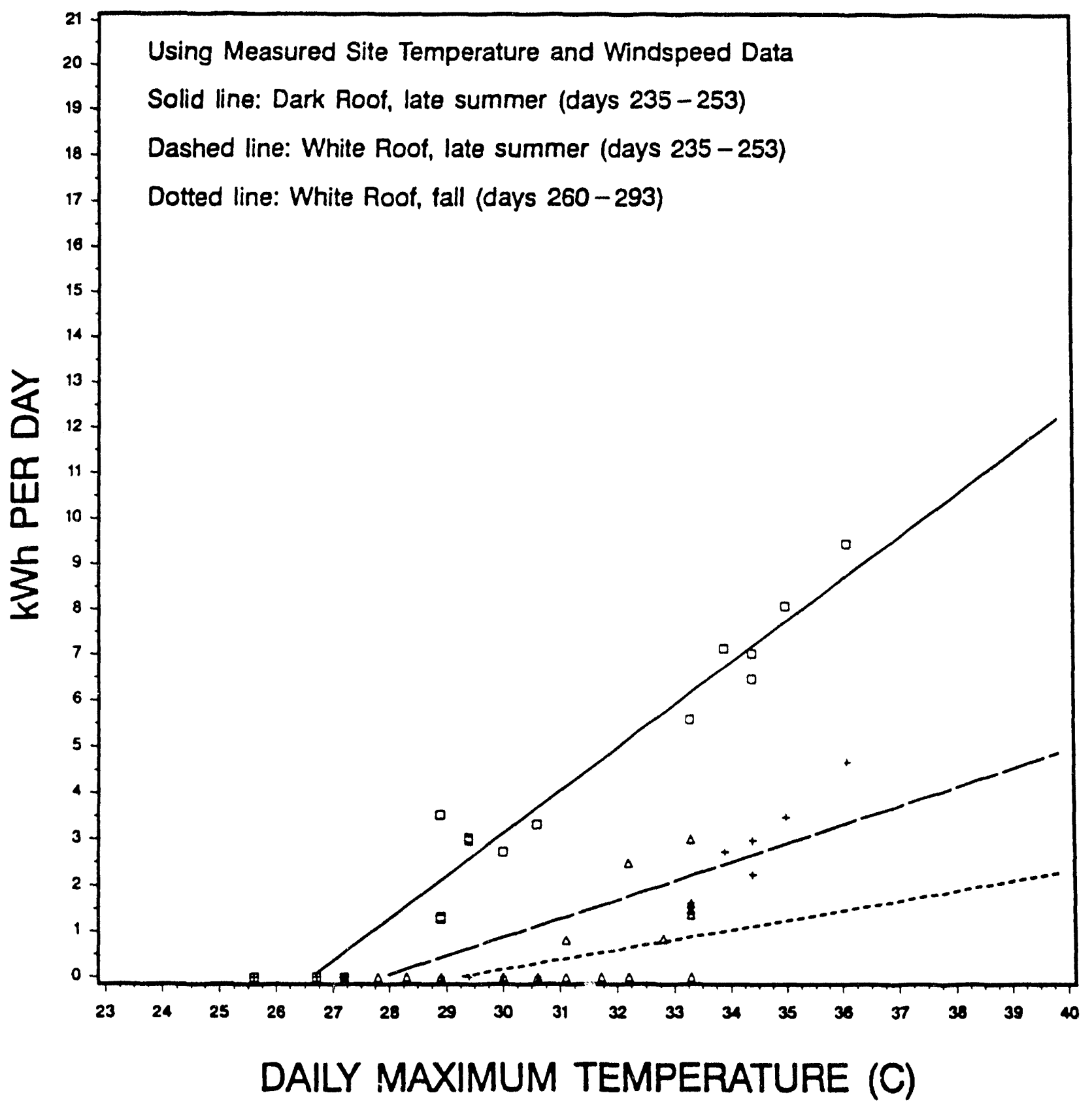


Site B

Site B is a school in which two classroom bungalows (one test and one control) were monitored. The test unit was fully instrumented, whereas the control unit was provided only with a $\mathrm{kWh}$-meter. The test unit underwent two modifications during the monitoring period. First its roof and southeast wall were coated with a brown paint and the unit was monitored in that state for about one week. Then, the roof and the southeast wall of the test unit were coated white and monitored for 35 days. Table V-7 gives values for albedo $(\alpha)$ and emissivity $(\varepsilon)$ of walls and roofs of both test and control units throughout the monitoring period.

TABLE V-7

Monitoring periods, albedo, and emissivity of control and test units coatings.

\begin{tabular}{|l|c|c|c|c|c|c|c|c|c|c|}
\hline & \multicolumn{4}{|c|}{ Control unit } & \multicolumn{4}{c|}{ Test unit } \\
Moof & \multicolumn{3}{|c|}{ All walls } & \multicolumn{3}{c|}{ Roof } & \multicolumn{2}{c|}{ SE wall } & \multicolumn{2}{c|}{ Other walls } \\
Monitoring & $\alpha$ & $\varepsilon$ & $\alpha$ & $\varepsilon$ & $\alpha$ & $\varepsilon$ & $\alpha$ & $\varepsilon$ & $\alpha$ & $\varepsilon$ \\
\hline Period A (Aug 11 to Aug 18) & 0.34 & 0.30 & 0.30 & 0.95 & 0.34 & 0.30 & 0.30 & 0.95 & 0.30 & 0.95 \\
Period B (Aug 20 to Aug 27) & 0.34 & 0.30 & 0.30 & 0.95 & 0.08 & 0.95 & 0.08 & 0.95 & 0.30 & 0.95 \\
Period C (Aug 28 to Sep 2) & 0.34 & 0.30 & 0.30 & 0.95 & 0.68 & 0.95 & 0.68 & 0.95 & 0.30 & 0.95 \\
Period D (Sep 3 to Oct 21) & 0.34 & 0.30 & 0.30 & 0.95 & 0.68 & 0.95 & 0.68 & 0.95 & 0.30 & 0.95 \\
\hline
\end{tabular}

Period A corresponds to the basecase configuration, Period B corresponds to the time interval during which the test unit had a brown roof and brown southeast wall. Period $\mathrm{C}$ corresponds to the time interval during which the roof and the wall of the test unit were coated white. During all three periods, both test and control units were unoccupied. Finally, Period D corresponds to the interval during which the test unit was coated white and both units were occupied after school started.

Figure V-4A shows daily cooling energy use data for both test and control units for Period $D$, i.e., when both test and control units were occupied. There are 35 days of data (points) in this figure, and the regression line indicates that the cooling energy use in the white-coated test unit was abou: $50 \%$ of the amount of cooling energy used in the control unit (with yellow walls and metallic roof) under :-entical climate conditions. One should keep in mind, however, that in addition to the effect of higher albedo coatings on the roof and southeast wall of the test unit, other factors that might have contributed to the higher energy usage in the control unit include: 
Figure V-4A. Site B: Daily cooling electricity use ( $\mathrm{kWh} /$ day) at the test unit vs daily cooling electricity use ( $\mathrm{kWh} /$ day) at the control unit. The control unit has a metallic roof and yellow walls, whereas the test unit has a white roof, white southeast wall, and yellow northwest wall. Both units are occupied. Monitoring period is from September 3 through October 21, 1991.

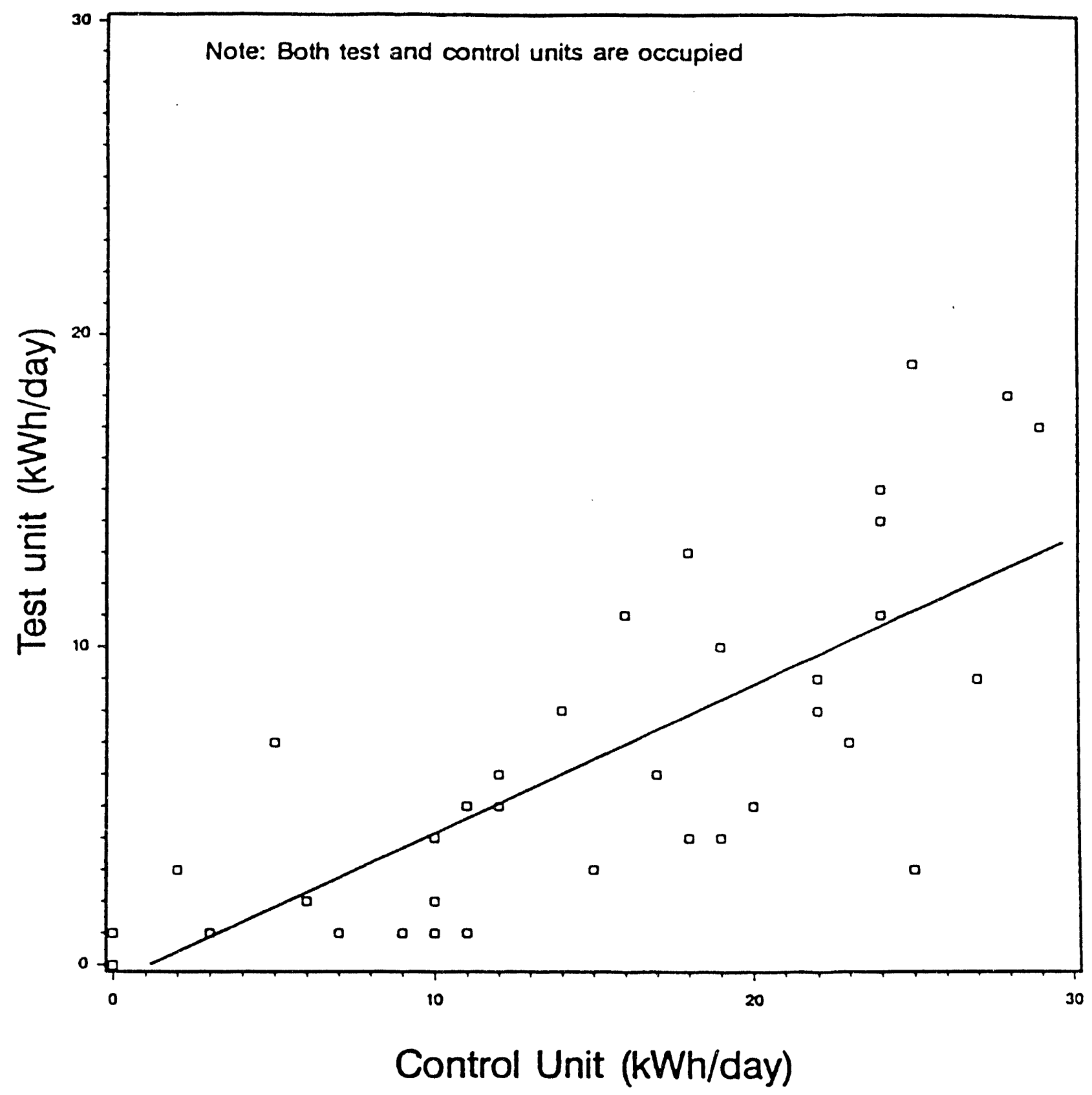


1. Thermostat reset in the control classroom. The thermostat in that unit was frequently reset to $-22.5^{\circ} \mathrm{C}$, during the monitoring period (compared to $25.5^{\circ} \mathrm{C}$ in the test unit).

2. Lower emissivity $(-0.30)$ of the metallic roof compared to the emissivity of the painted roof $(-0.95)$ in either brown or white configurations.

The DOE-2 simulations appear to indicate that only $15-20 \%$ of the measured savings are resulted from the high albedo coating. The rest is a result of thermostat setting and emissivity differences and will be covered in the following discussion.

At the hourly level, Figures V-4B and V-4C show data for the test unit during Periods B and $\mathrm{C}$ (brown and white, both unoccupied cases). Because the amount of data available is small, no regression was performed. But we can still see that moving from an albedo of 0.08 (brown) to 0.68 (white) had a significant impact on cooling energy use. Figure V-4B indicates that while cooling with the low albedo case started at an outdoor ai't temperature of $22^{\circ} \mathrm{C}$ and went all the way up to $2.4 \mathrm{kWh} / \mathrm{h}$, cooling energy use in the case with white coating started at an outdoor air temperature of $31^{\circ} \mathrm{C}$ and went up to about $1.7 \mathrm{kWh} / \mathrm{h}$.

Figure V-4C shows that while cooling needs in the low albedo case encompass a To-Ti range from $-3^{\circ} \mathrm{C}$ to $+11^{\circ} \mathrm{C}$, the cooling needs in the case with high albedo were confined to a To-Ti range of $+4^{\circ} \mathrm{C}$ to $+12^{\circ} \mathrm{C}$. Note that, in these correlations, there was no need to adjust for solar radiation as Periods $\mathrm{B}$ and $\mathrm{C}$ were short and Period $\mathrm{C}$ immediately followed Period $\mathrm{B}$, so that there was no significant decrease in solar radiation over these intervals (total daily irradiance during Period B was $-7 \mathrm{kWh} /$ day and during Period $\mathrm{C} \sim 6.9 \mathrm{kWh} /$ day. Also, there are no concerns regarding emissivity or thermostat settings since this is the same unoccupied (test) unit.

In Figures $V-4 D$ and $V-4 E$, the roof surface temperature for the cases before and after albedo modifications is shown. From the regression lines, one can see that, on the average, the afternoon surface temperature in the white roof was $10^{\circ} \mathrm{C}$ lower than with the brown roof. Note that this surface temperature depression is probably an underestimate since we had the same problem as discussed in Site 2, namely, that the thermocouple could not be embedded in the roofing material.

The comparison of hourly simulated and measured data for Site B (the school) are presented in Figures V-4F and V-4G. The top graphic, Figure V-4F, compares data from the test building; while the bottom graphic compares data from the control building ove- the same 
Figure V-4B. Site B: Hourly cooling electricity use (Wh/h) vs mean hourly outdoor air temperature $\left({ }^{\circ} \mathrm{C}\right)$ for pre- and post-retrofit conditions at the test unit. The squares represent the preconditions (albedo $=0.08$, brown), whereas the diamonds represent the post-conditions (albedo = 0.68, white). Monitoring period is from August 20 through September 2, 1991.

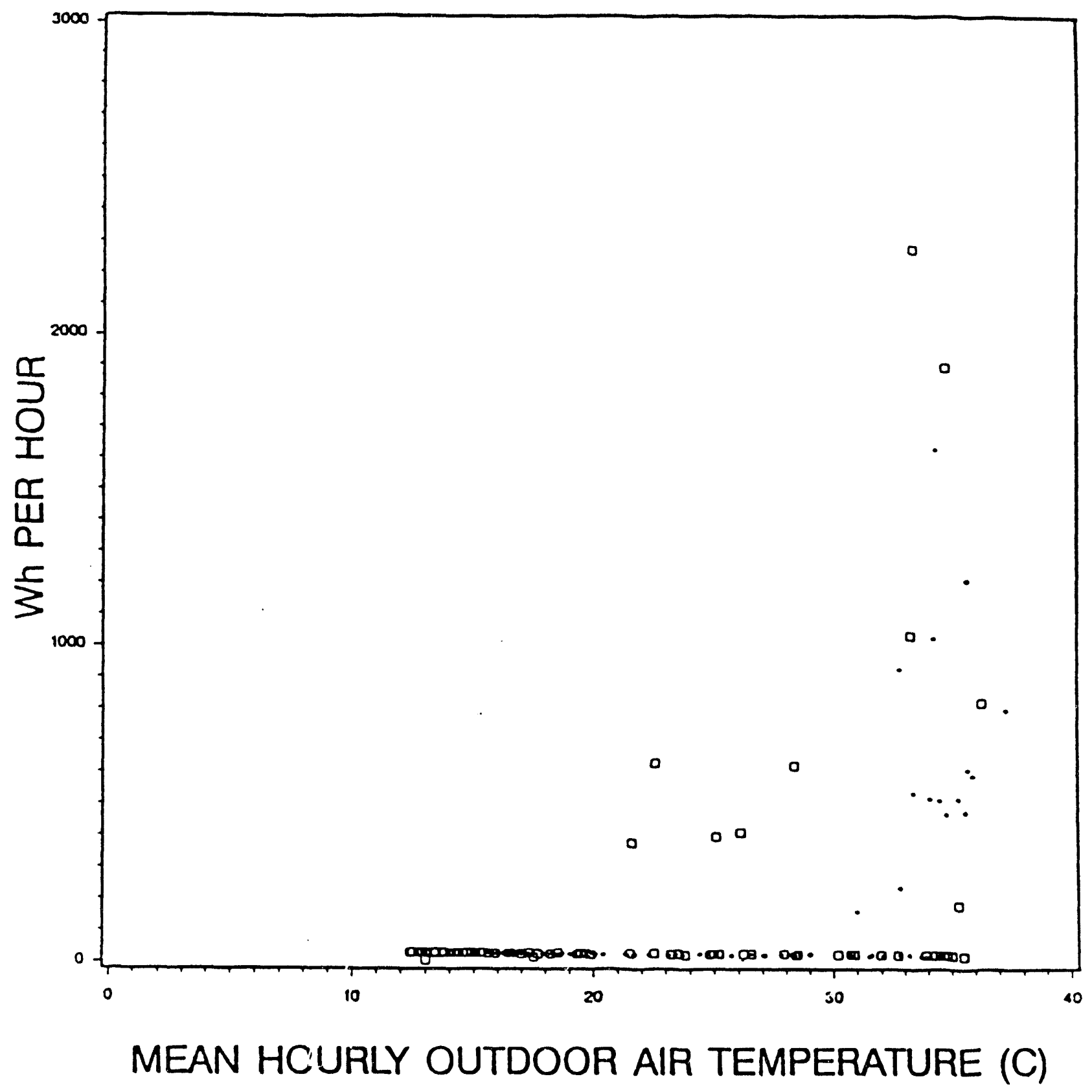


Figure V-4C. Site B: Hourly cooling electricity use $(\mathrm{Wh} / \mathrm{h})$ vs mean hourly air temperature difference, outdoor minus indoor $\left({ }^{\circ} \mathrm{C}\right)$ at the test unit. The squares represent the pre-conditions (albedo $=0.08$, brown), whereas the diamonds represent the post-conditions (albedo $=0.68$, white). Monitoring period is from August 20 through September 2, 1.991.

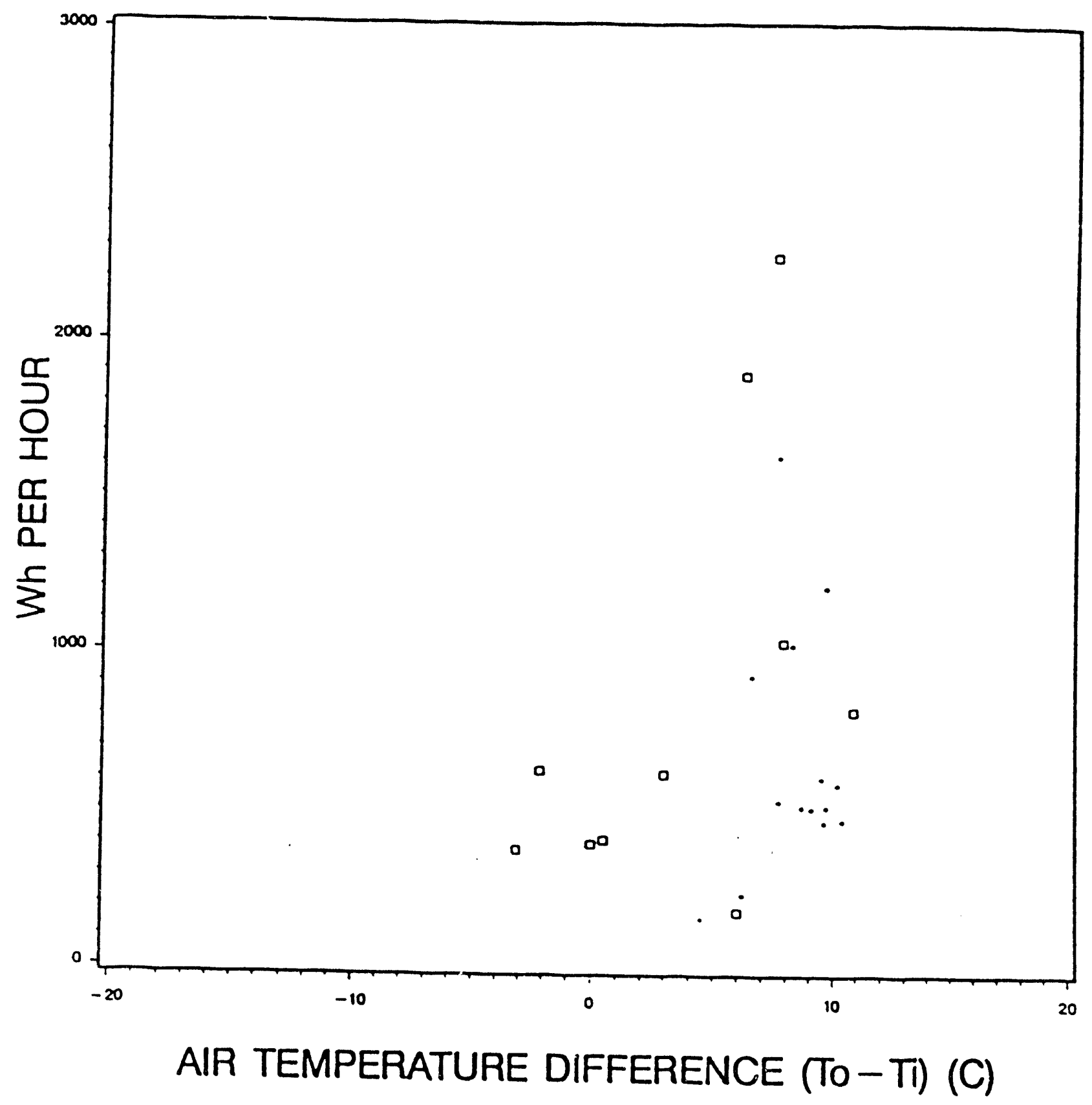




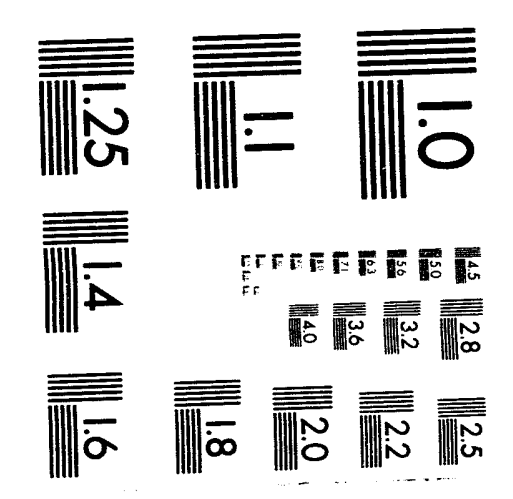



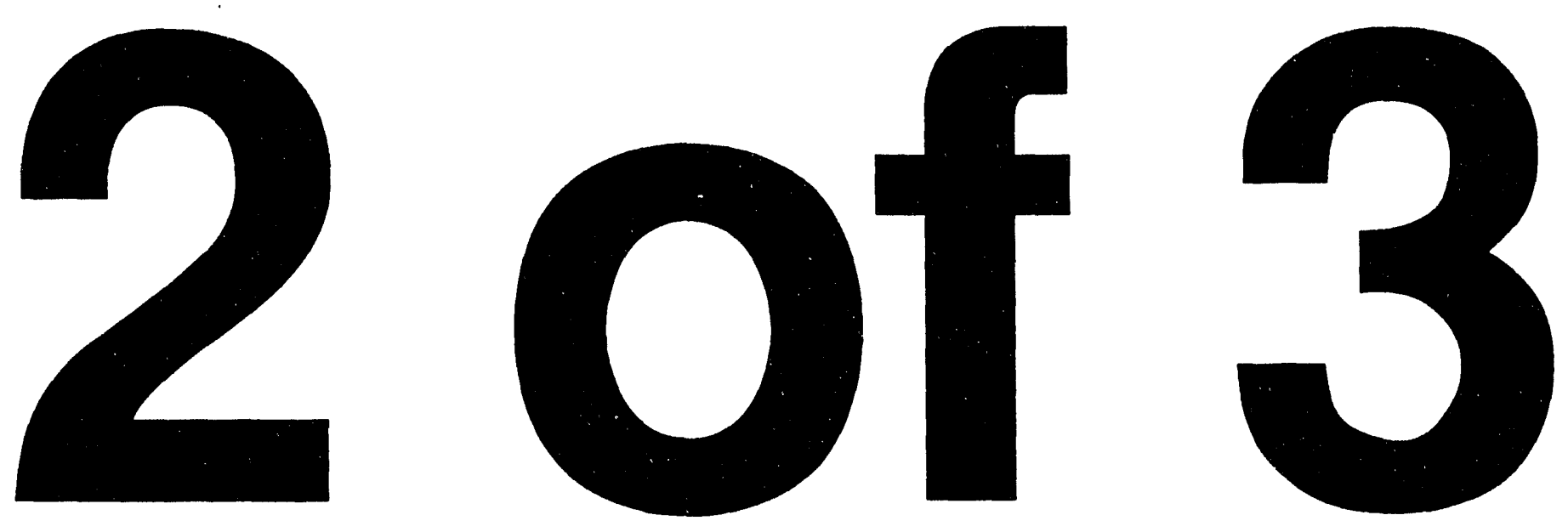
Figure V-4D. Site B: Roof surface temperature $\left({ }^{\circ} \mathrm{C}\right)$ vs horizontal solar radiation $\left(\mathrm{W} / \mathrm{m}^{2}\right)$ for the pre-retrofit case. Albedo is $\mathbf{0 . 0 8}$. Line is a regression fit. This is monitoring period August 20 through August 27, 1991.

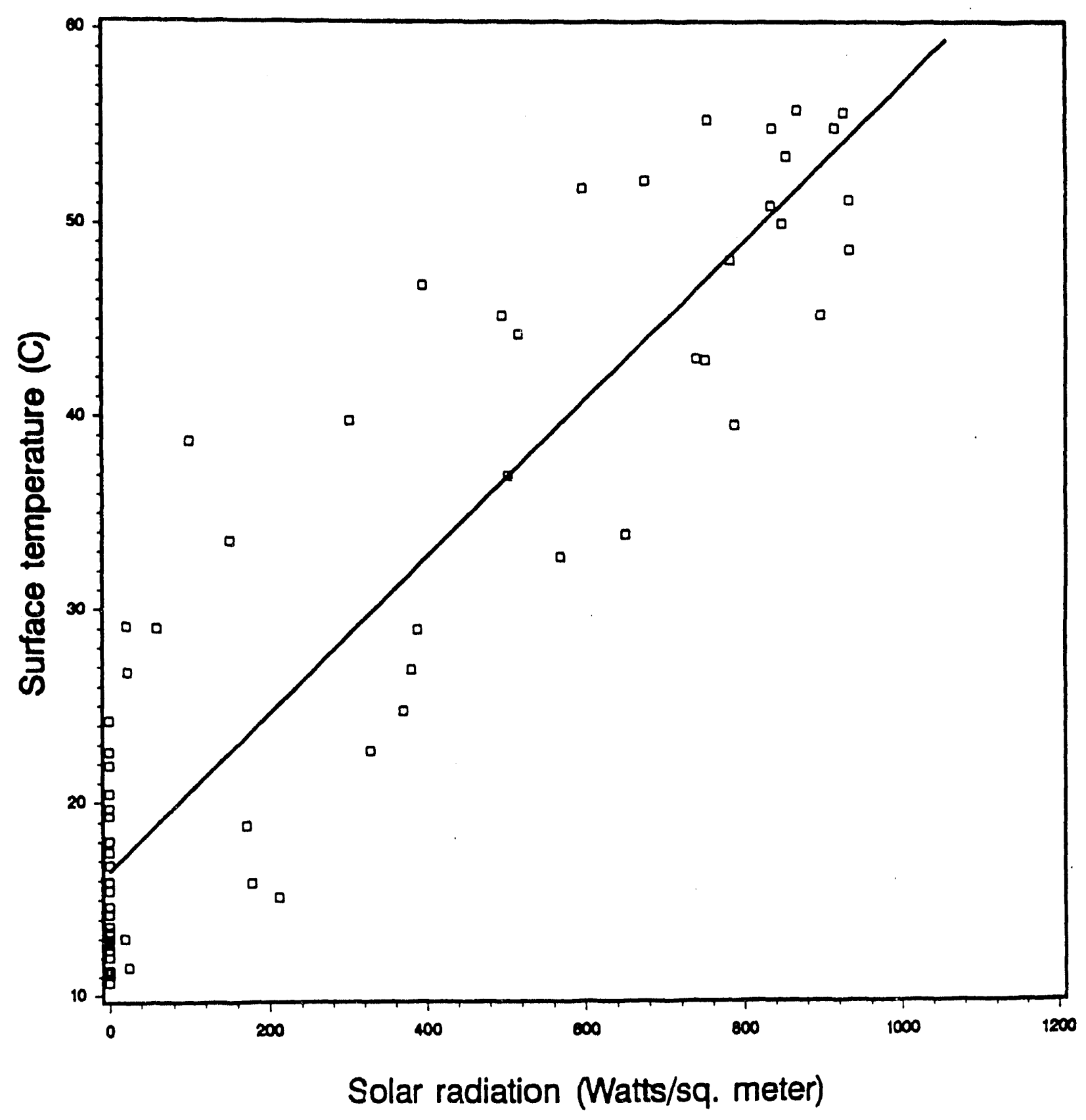


Figure V-4E. Site B: Roof surface temperature $\left({ }^{\circ} \mathrm{C}\right)$ vs horizontal solar radiation $\left(W / \mathrm{m}^{\wedge} 2\right)$ for the post-retrofit case. Albedo is $\mathbf{0 . 6 8}$. Line is a regression fit. This is monitoring period August 30 through September 2, 1991.

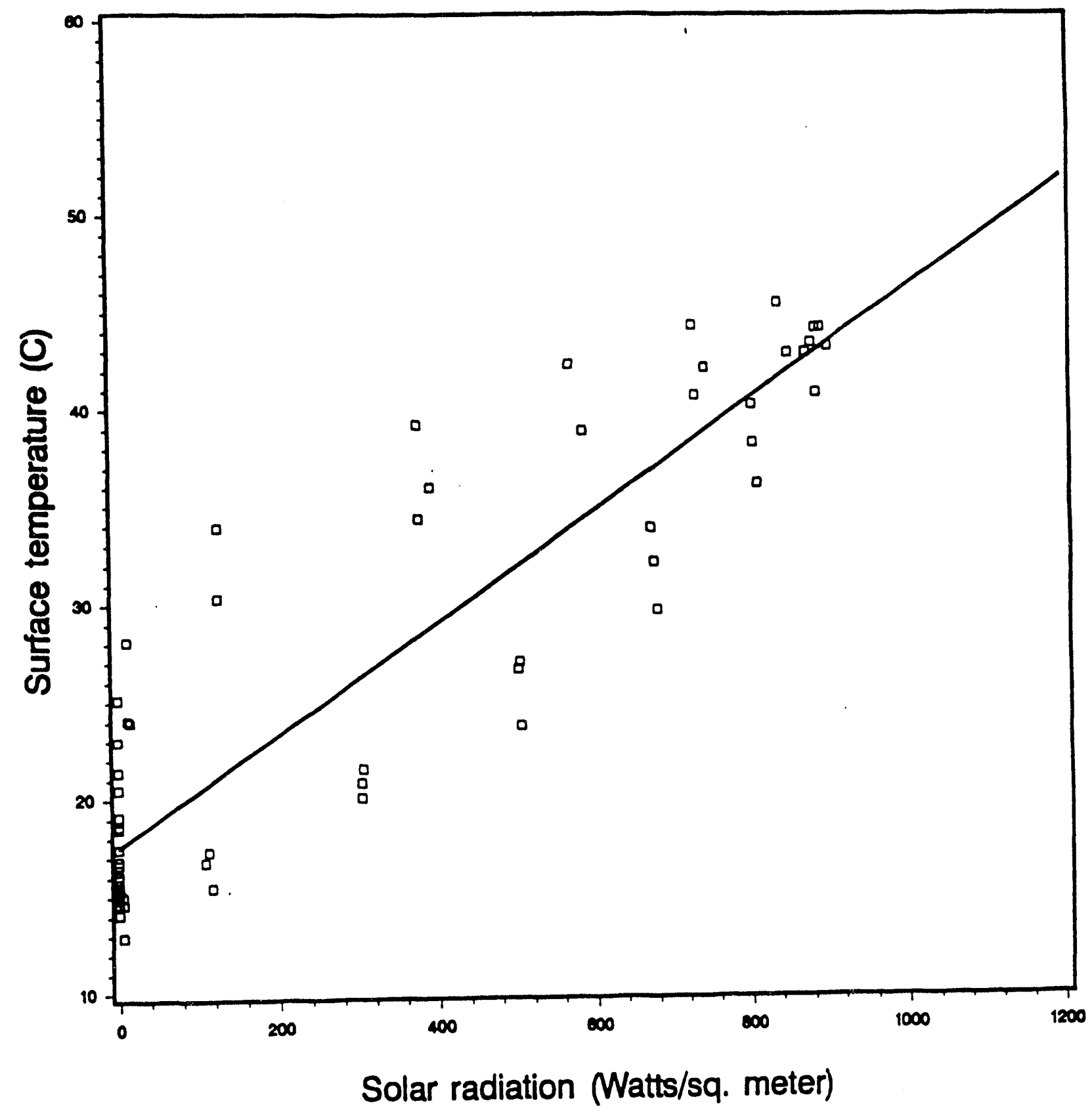


Figure V-4F. Package AC unit watt nours and building interior temperature for $10 / 5$ to $10 / 11$ at Site B. Comparison of measured and simulated data for TEST building (at $78^{\circ} \mathrm{F}$ setpoint). Days 280 to 282 Measured: $9.6 \mathrm{kWh} /$ day DOE-2: $10.8 \mathrm{kWh} /$ day.

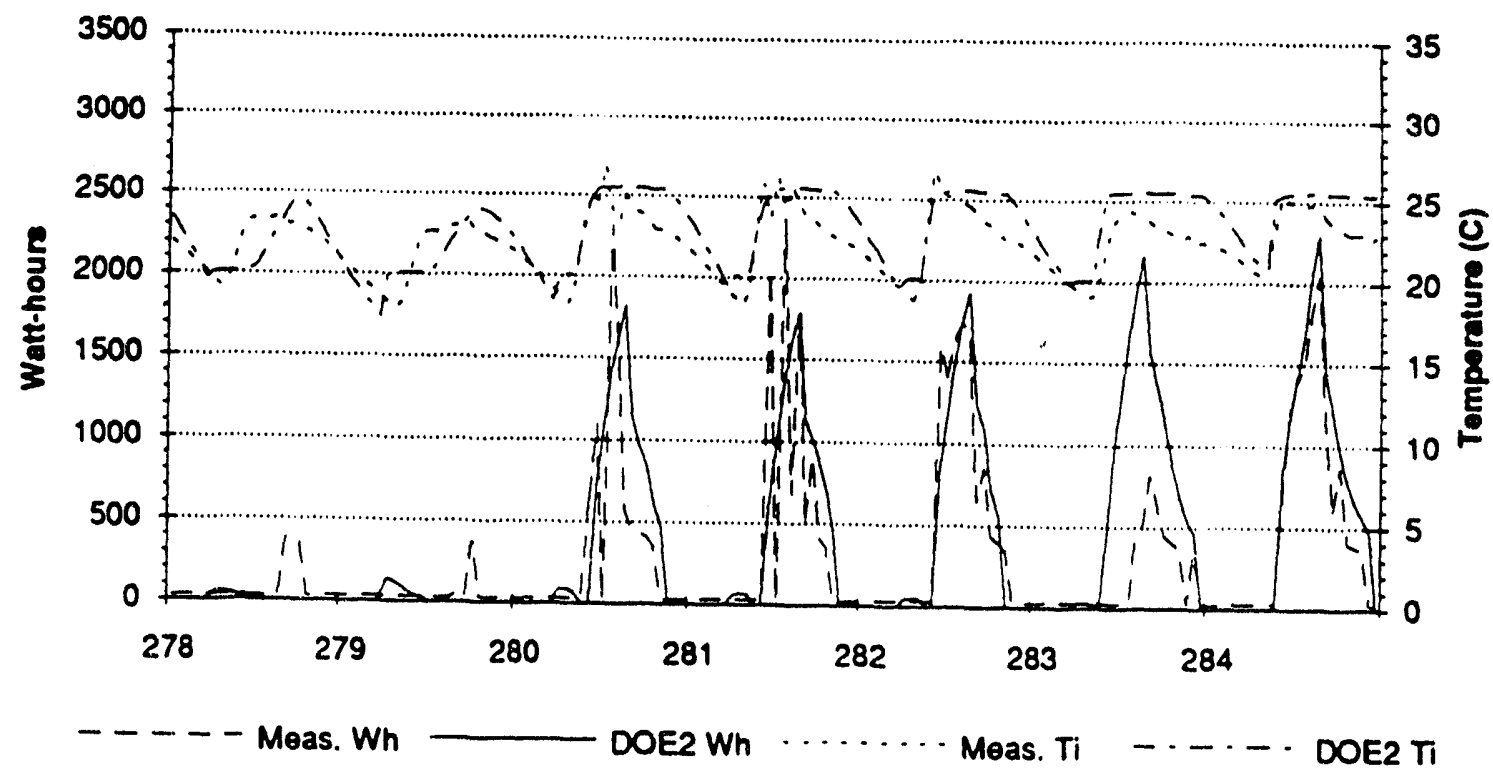

Figure V-4G. Package AC unit watt hours and building interior temperature for $10 / 5$ to $10 / 11$ at Site B. Comparison of measured and simulated data for CONTROL building (at $70^{\circ} \mathrm{F}$ setpoint). Days 280 to 282 Measured: $22.8 \mathrm{kWh} /$ day DOE-2: $22.3 \mathrm{kWh} /$ day.

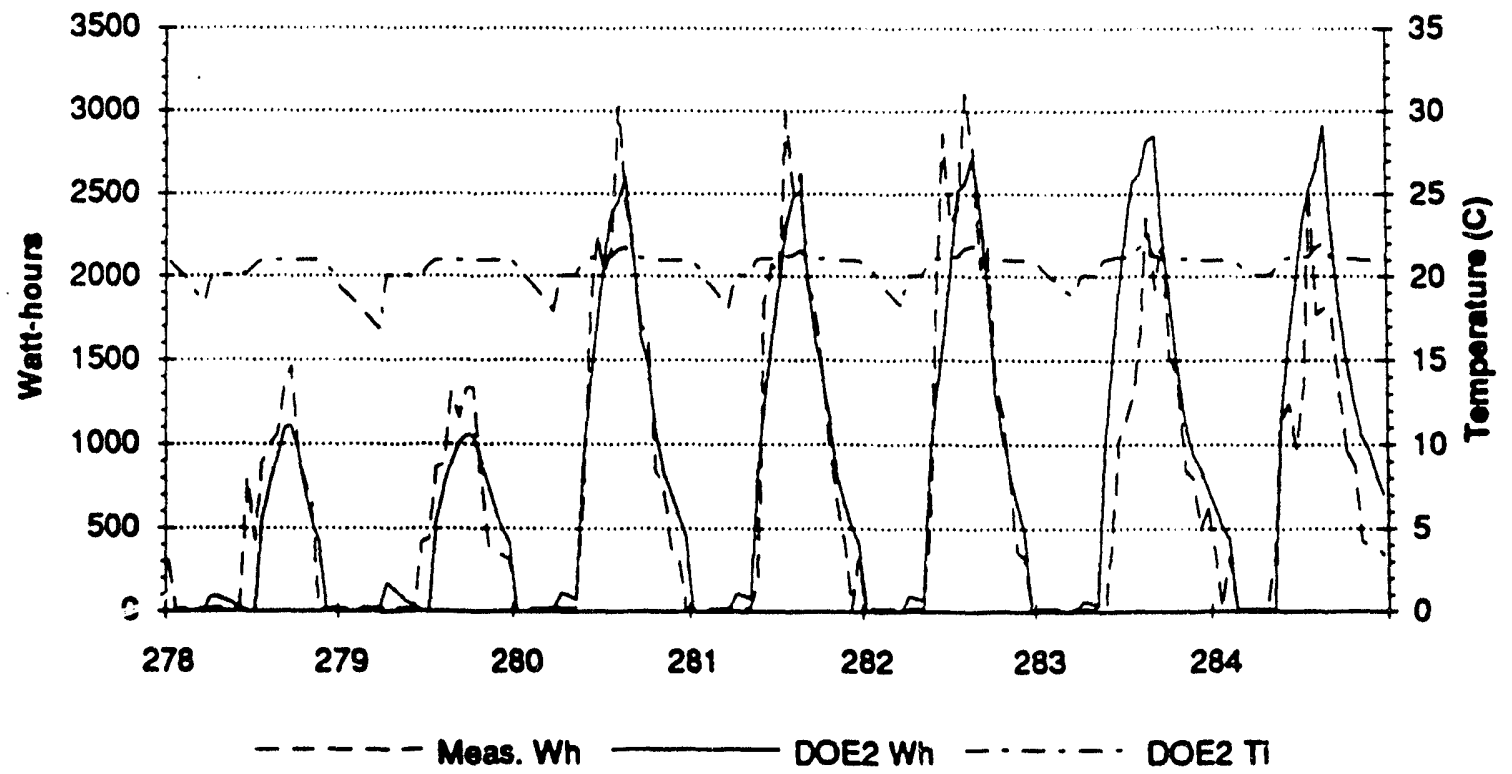


time period. Because the control building did not have an indoor temperature sensor installed, no comparison is made here. However, visits to the site during the monitoring period suggest that the thermostat in this building was frequently reset to a lower temperature than the prescribed $26^{\circ} \mathrm{C}$, with typical settings of 21,22 , or 23 . The best fit to the measured data occurs with simulations at a thermostat setting of $21^{\circ} \mathrm{C}$, so that value is used in the remainder of the analysis. The agreement in energy consumption for the test building is slightly high, but the peak cooling load matches well. Note that cooling energy consumption on days 280 and 281 is extremely variable from hour to hour. The agreement in energy consumption with the test building is quite good.

Note that the data shown here are for the period after school began for the fall term, which is the period with the greatest amount of data. Days 278 and 279 are a weekend with no occupancy, and the difference in the cooling loads between weekdays and weekends suggests that cooling in these buildings is driven by internal gains from occupants and lights. In fact, the DOE-2 simulations show that $65 \%$ (in September) to $85 \%$ (in October) of the cooling load is due to internal heat gains. Day 283 also appears to be slightly abnormal in the case of both buildings.

Parametric simulations were performed to study the impacts of painting the roof and wall white, thereby increasing the albedo of those surfaces and increasing the emissivity of the metallic roof. The cooling impact of these changes is compared with the potential error from assuming a thermostat setting of $21^{\circ} \mathrm{C}$ in the control building in Figures $\mathbf{V}-4 \mathrm{H}$ and $\mathrm{V}-4 \mathrm{I}$. The model estimates of the albedo and emissivity impacts are relatively small, particularly in comparison to the impacts of the thermostat setpoints. Without real knowledge of the thermostat setpoint or the interior temperature in the control building, therefore, no concrete conclusions can be made about the discrepancy between the simulated and measured data. 
The simulations for the school site suggest that there are significant reductions in the cooling load resulting from albedo modifications, although less than shown simply by the measured data. The summary of simulation results is shown in Figure V-4J. Daily cooling energy consumption for weekdays during the occupied period is plotted versus daily maximum temperature for three cases. The top set of data is for the metal roof condition at a $21^{\circ} \mathrm{C}$ interior temperature (the simulated control site). The bottom set of data is for the white roof condition at a $26^{\circ} \mathrm{C}$ indoor temperature. The middle set of data adjusts for the difference in thermostat setpoint, and suggests that actual savings from the white roof over this period are about 1 to $2 \mathrm{kWh} /$ day, depending on the temperature. The top and bottom regression lines show similar results as the measured data, where the difference in cooling energy consumption between the test and control units is about $50 \%$. 
Figure V-4H. SIMULATED fan and compressor watt hours 10/5 to 10/11 at Site B. Simulation of bungalow in BASE and ALBEDO cases at same thermostat setpoint.

Days 278 to 284 White Roof: $9.1 \mathrm{kWh} /$ day Metal: $10.6 \mathrm{kWh} /$ day.

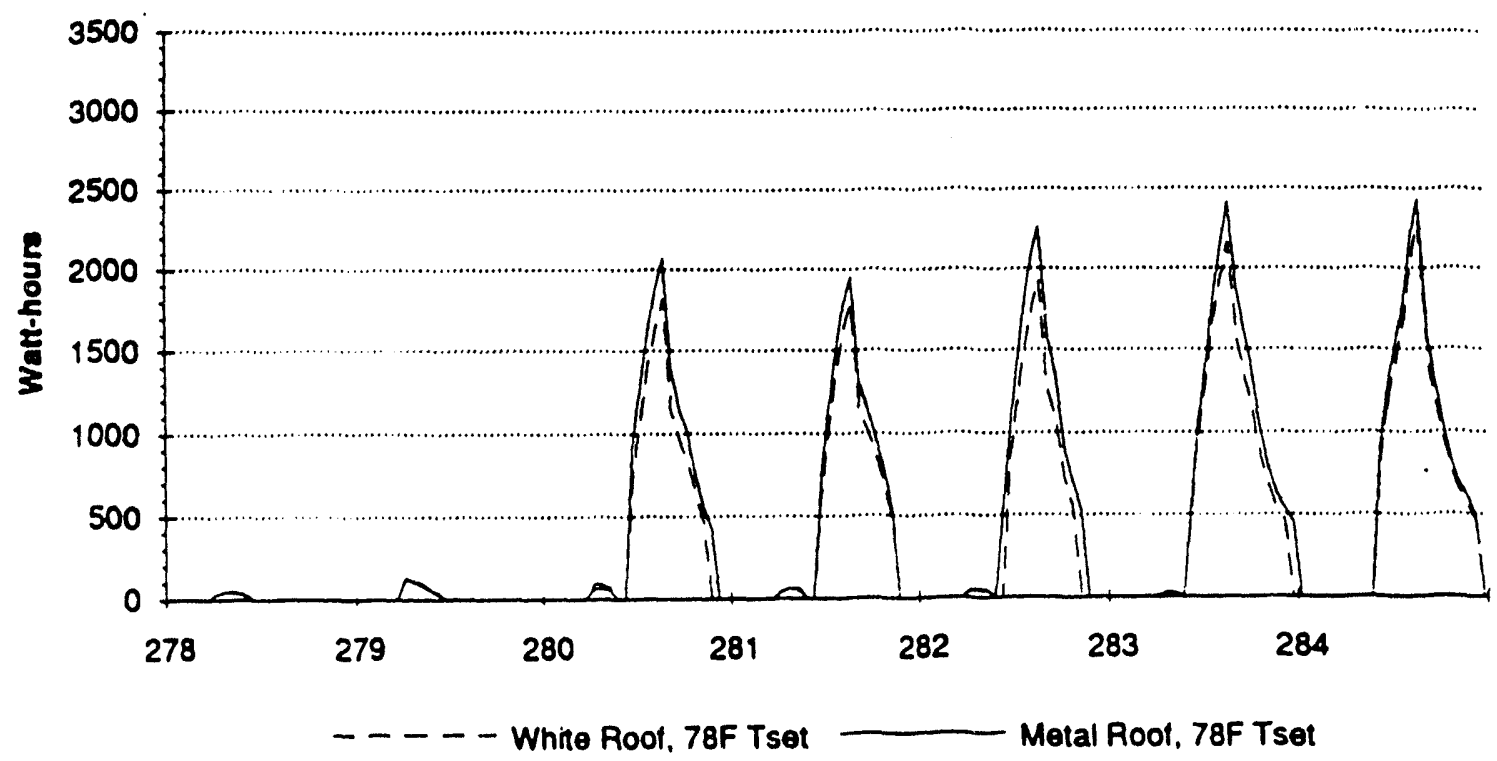

Figure V-4I. SIMULATED fan and compressor watt hours 10/5 to 10/11 at Site B. Simulation of bungalow in BASE case at two different thermostat setpoints.

Days 278 to $28470^{\circ} \mathrm{F}$ Tset: $19.6 \mathrm{kWh} /$ day $78^{\circ} \mathrm{F}$ Tset: $10.6 \mathrm{kWh} /$ day.

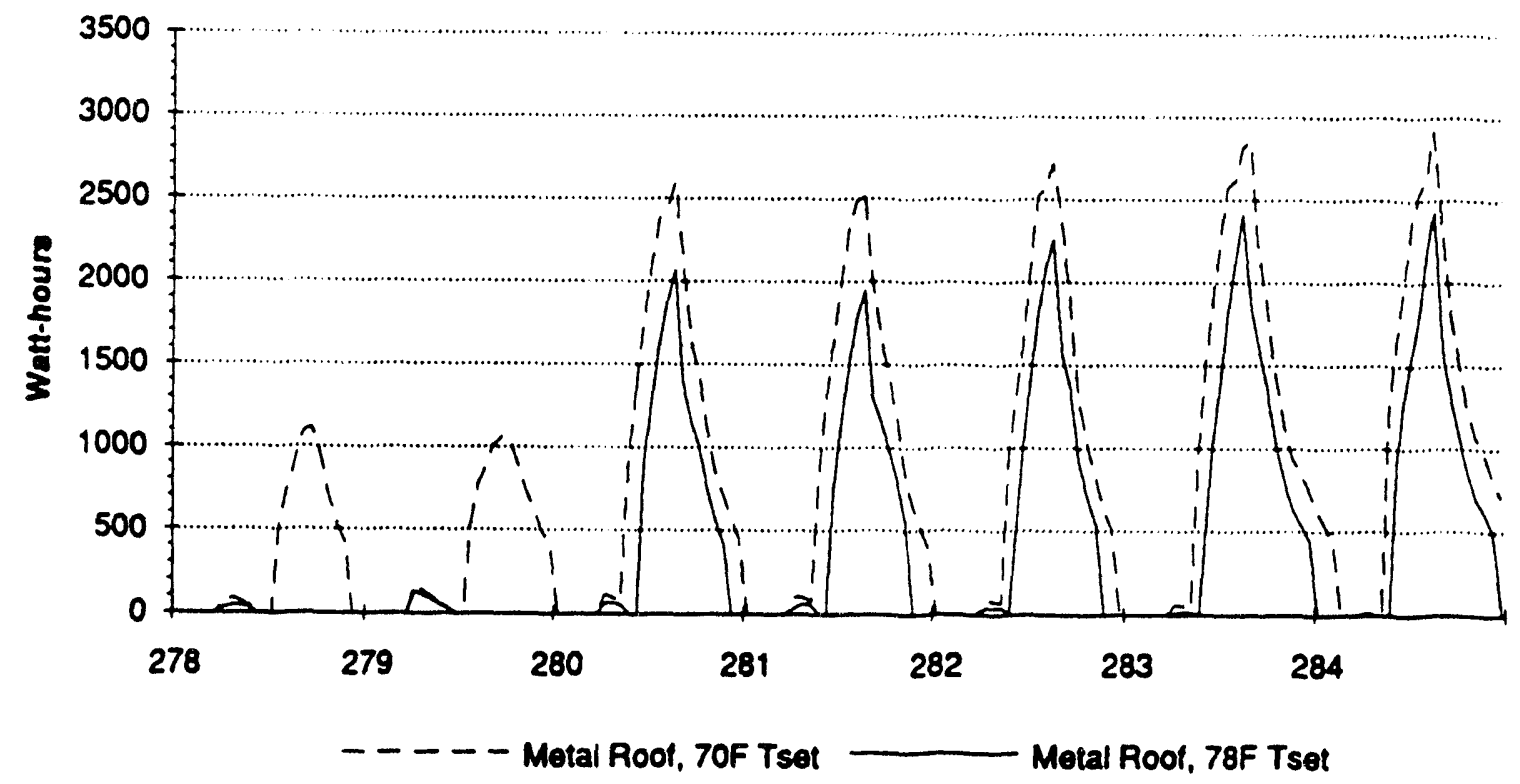


Figure V-4J. Site B: Daily data for occupied monitoring period: Square and solid line represent a metal roof at $21^{\circ} \mathrm{C}$ interior temperature. Crosses and Dashed lines represent a metal roof at $26^{\circ} \mathrm{C}$ interior temperature. Triangles and dotted line represents a white roof at $26^{\circ} \mathrm{C}$ interior temperature.

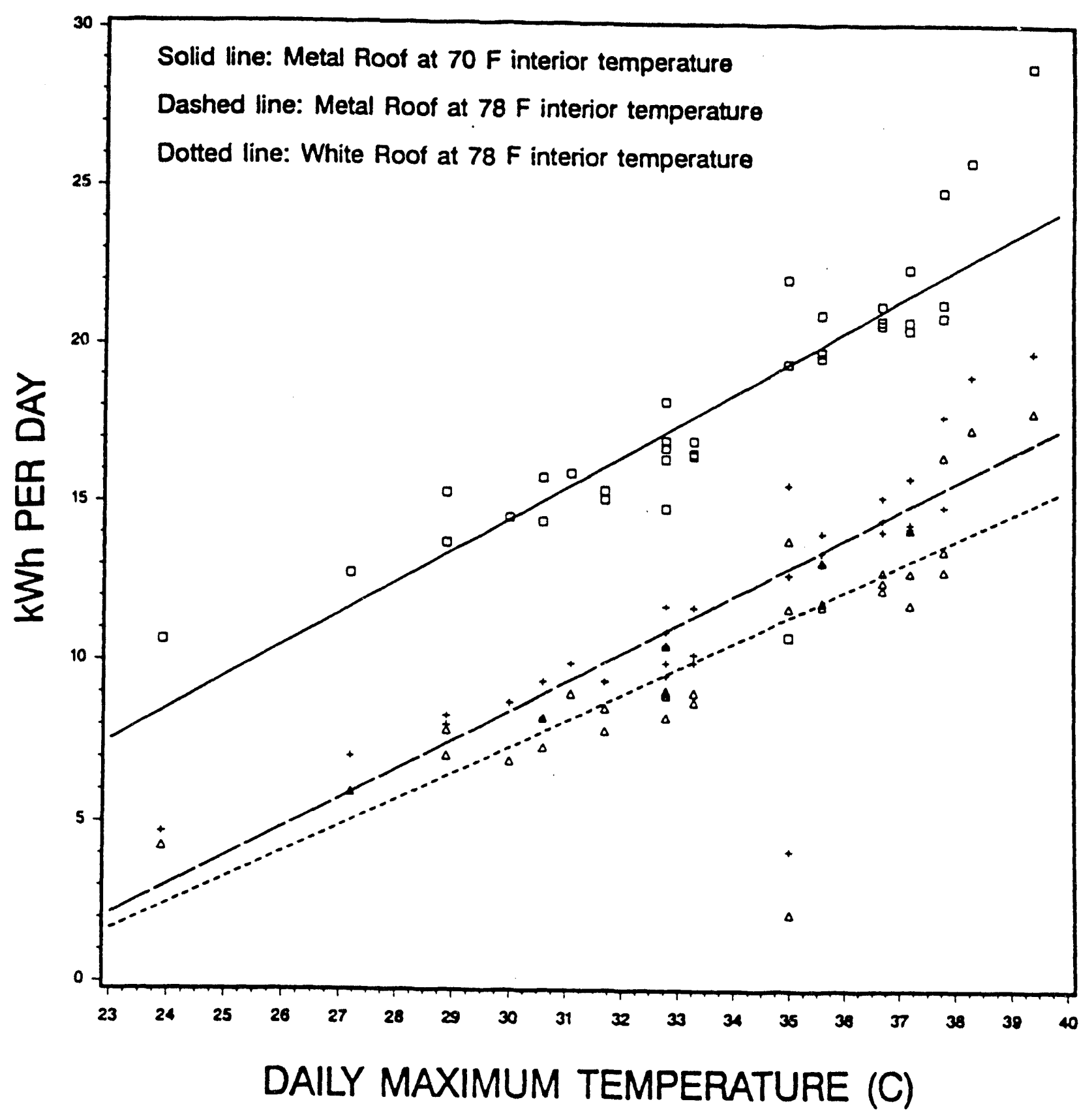




\section{Vegetation Modification Sites}

Site 5

This site is located far southeast of Sacramento. The neighborhood is relatively new and vegetation is generally low. This particular house, however, was well vegetated on the north and south sides, and was additionally well shaded by means of a large overhang running the entire length of the south side. It had minimal exposure (windows) on the west side. The only notential locations for placing trees were two small windows on the east side. The house was first monitored for 11 days (JD 249 - 259), and then two small trees were placed on the east side, and the building was monitored again for 26 days (JD 268 - 293).

Because of the existing heavy shading and since the trees were placed on the east side (which has a relatively small impact on heat gain), we expected little differences in energy use between the base and the modified cases. Figure V-5A shows that there was not much difference between the two cases on a daily basis. For example, at $38^{\circ} \mathrm{C}$, there are savings of $2 \mathrm{kWh} /$ day resulting from the two trees. These savings correspond to $-14 \%$ at that temperature. Figure V. SB shows hourly data from Site 5 in $\mathrm{Wh} / \mathrm{h}$ plotted versus mean hourly outdoor air temperature $\left({ }^{\circ} \mathrm{C}\right)$. At $38^{\circ} \mathrm{C}$, the savings indicated by the regression lines amount to only $\sim 7 \%$. If a correction for solar radiation is performed, there may be minimal or no savings in cooling energy use at this site.

DOE-2 simulations of this site indicate that the savings were not caused by the small trees, but by the effects of lower insolation. The comparison of measured and simulated data for Site 5 are presented in Figures V-5C and V-5D. Only five days of complete measured data were available for the comparison during the pre-period.

If we look at the best days in each time series, for example 255 through 257 in Figure V-5C and 275 through 277 in Figure V-5D, we see that the peak cooling load predicted by the model agrees well with the measured data. However, the DOE-2 model overpredicts daily cooling energy in the pre-period and underpredicts in the post-period. We were not able to determine the cause of this discrepancy. In the post-period, the simulated cooling consumption continues much longer into the evening than the measured data show. This may be due to slightly lower outdoor temperatures at the site in the evening as compared to the airport. In the post-period, this discrepancy results in the simulated daily cooling being $25 \%$ higher than measured. In addition, days 278 and 279 in the post-period have extremely high cooling energy use which 
Figure V-5A. Site 5: Daily cooling electricity use (kWh/day) vs maximum outdoor air temperature $\left({ }^{\circ} \mathrm{C}\right)$ for pre- and post-retrofit conditions. Post-conditions with two additional trees on east. Solid regression line is for pre-retrofit conditions, broken regression line is for post-retrofit. Preretrofit monitoring period at this site was September 6 through September 23, and the postretrofit period was September 25 through October 21, 1991.

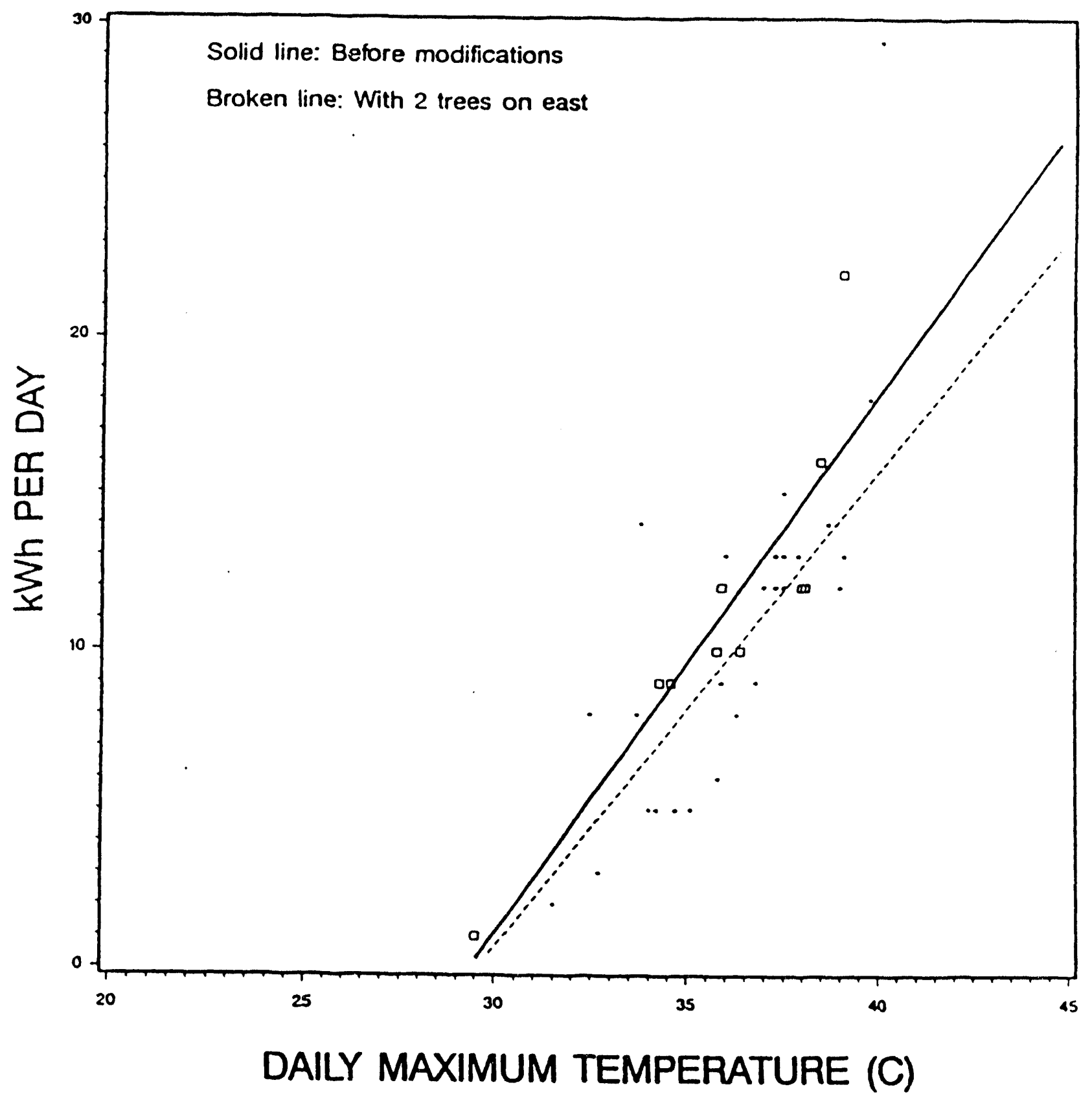


Figure V-5B. Site 5: Hourly cooling electricity use (Wh/h) vs mean hourly outdoor air temperature $\left({ }^{\circ} \mathrm{C}\right)$ for pre- and post-retrofit conditions. Post-conditions with two additional trees on east. Solid regression line is for pre-retrofit conditions, broken regression line is for post-retrofit. Preretrofit monitoring period at this site was September 6 through September 23, and the postretrofit period was September 25 through October 21, 1991.

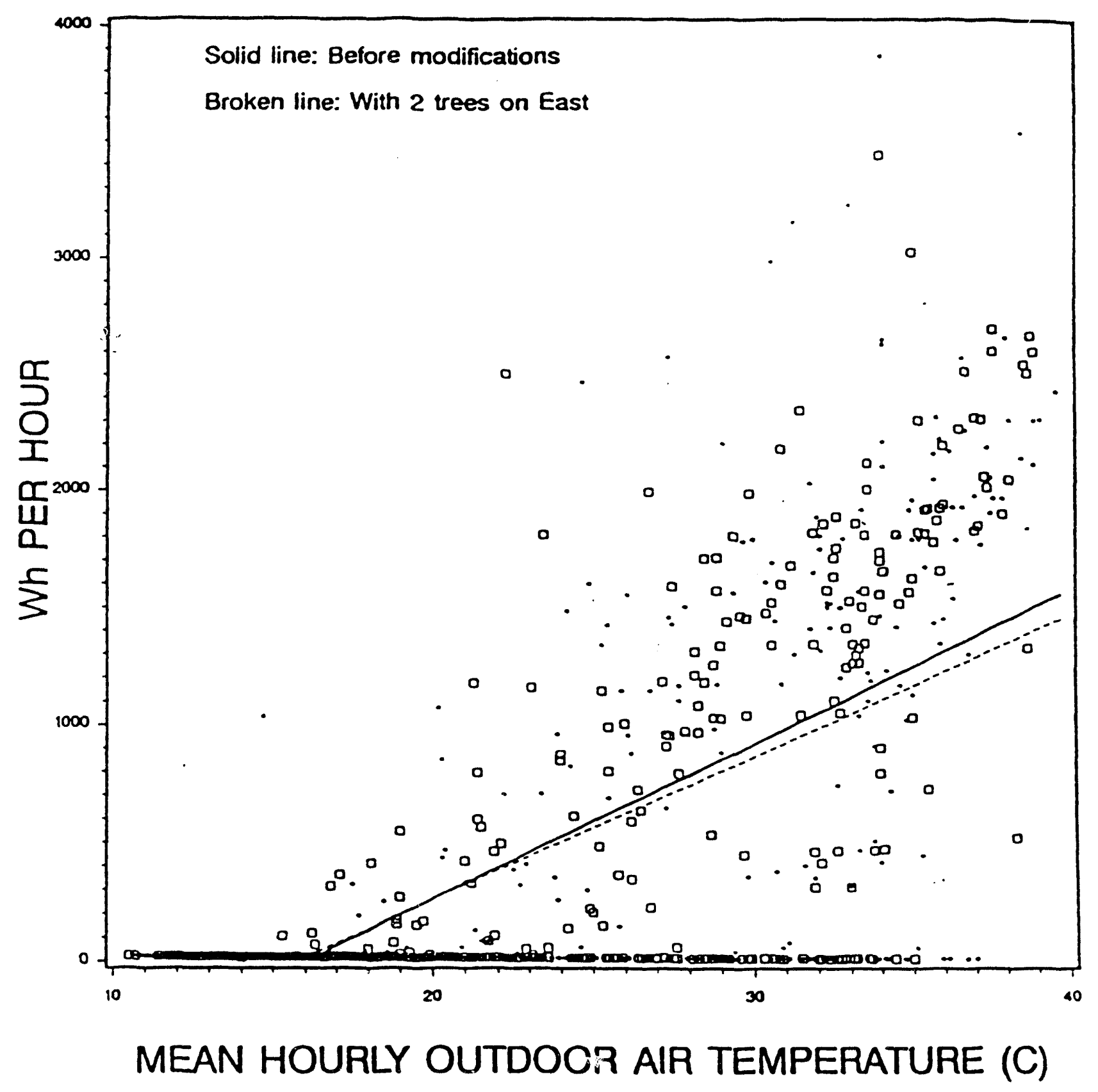


Figure V-5C. Compressor watt hours and building interior temperature for 9/11 to 9/15 at Site 5 . Comparison of measured and simulated data before vegetation modification.

Days 255 to 258 Measured: $10.3 \mathrm{kWh} /$ day DOE-2: $7.7 \mathrm{kWh} /$ day.

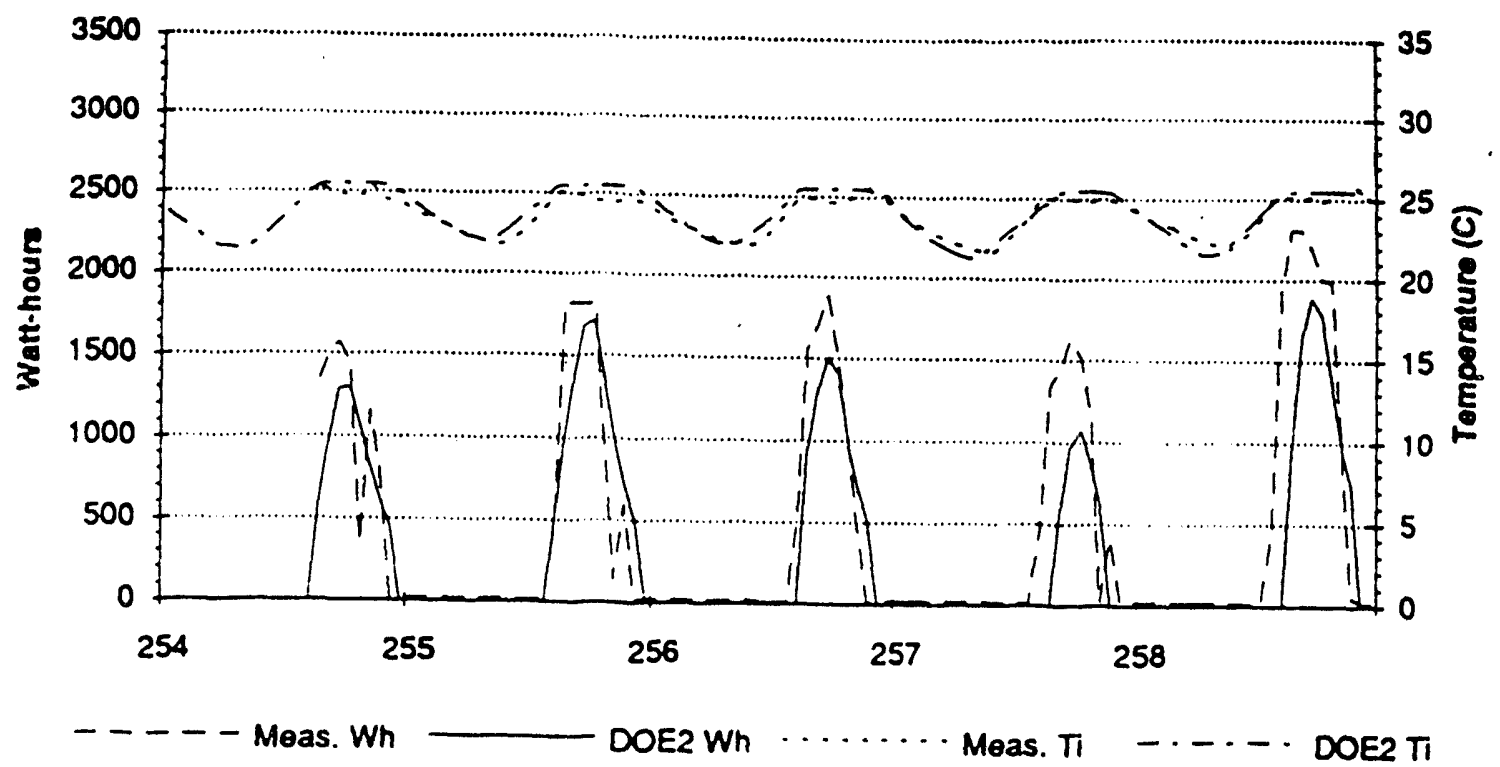

Figure V-5D. Compressor watt hours and building interior temperature for $9 / 30$ to $10 / 6$ at Site 5 . Comparison of measured and simulated data before vegetation modification.

Days 275 to 277 Measured: $13.3 \mathrm{kWh} /$ day DOE-2: $16.6 \mathrm{kWh} /$ day.

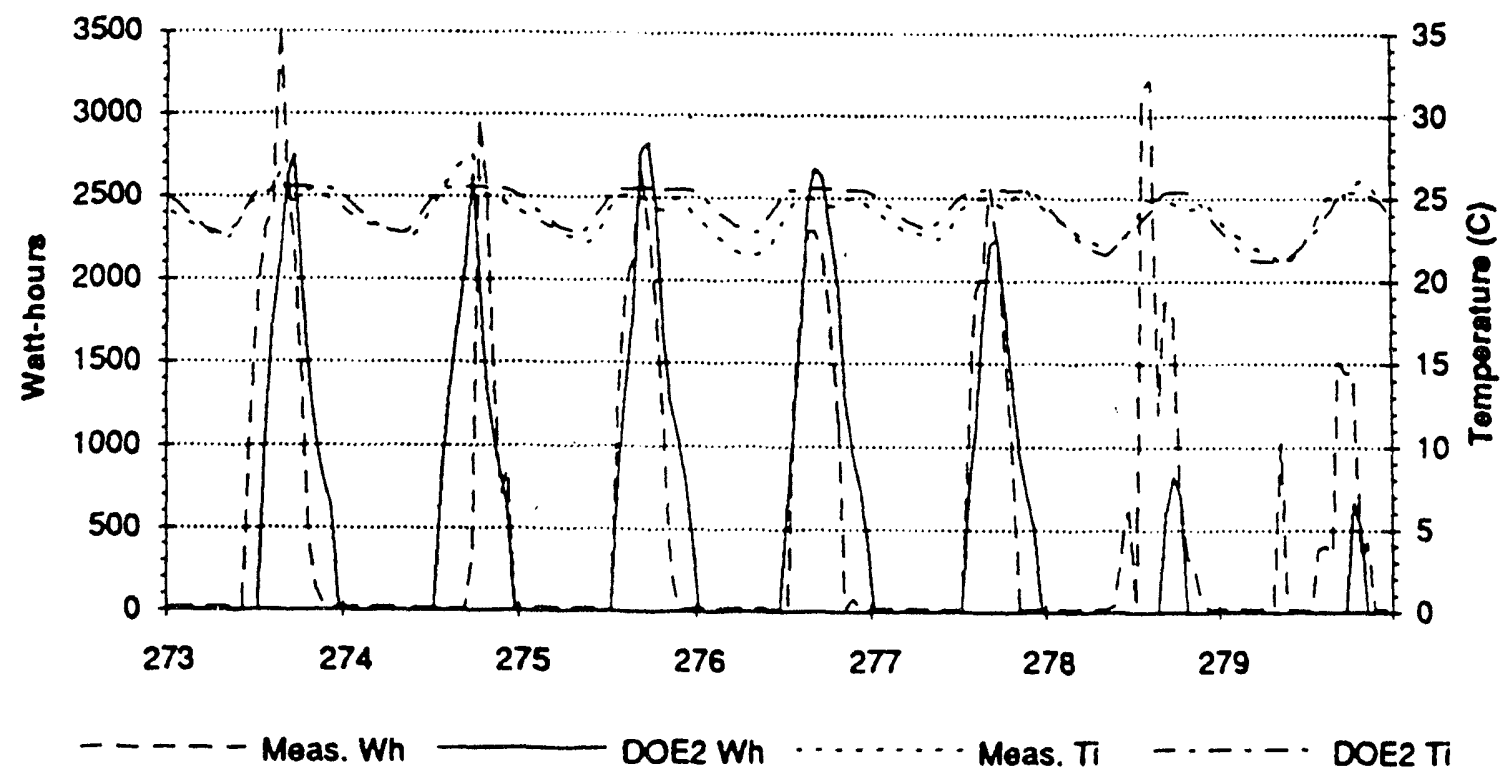


is not explained by the climatic conditions on those days.

Daily cooling usage plotted against outdoor temperature is shown in Figure V-5E. The correlation with the measured data shown in Figure V-5A is not good. This may be due to the scarcity of measured data in the pre-period. However, both the simulated and the measured data show a daily usage of about $18 \mathrm{kWh} /$ day at $40^{\circ} \mathrm{C}$. Figure V-5E also shows that after accounting for changes in the climatic conditions between the pre- and post-periods, there is little difference between the trees and base case. The difference in slopes for the regression lines through the points also suggests that the impact of the change in solar insolation over the project period is a more important factor in determining cooling energy consumption when the outside temperatures are relatively low. 
Figure V-5E: Site 5 Simulation Results: Daily data for monitoring period Squares and solid line represent base case in late summer (days 249 - 266). Crosses and dashed line represent the addition of 2 shade trees in late summer (days 249 - 266). Triangles and dotted line represent the case of 2 shade trees in fall (days 268 - 294).

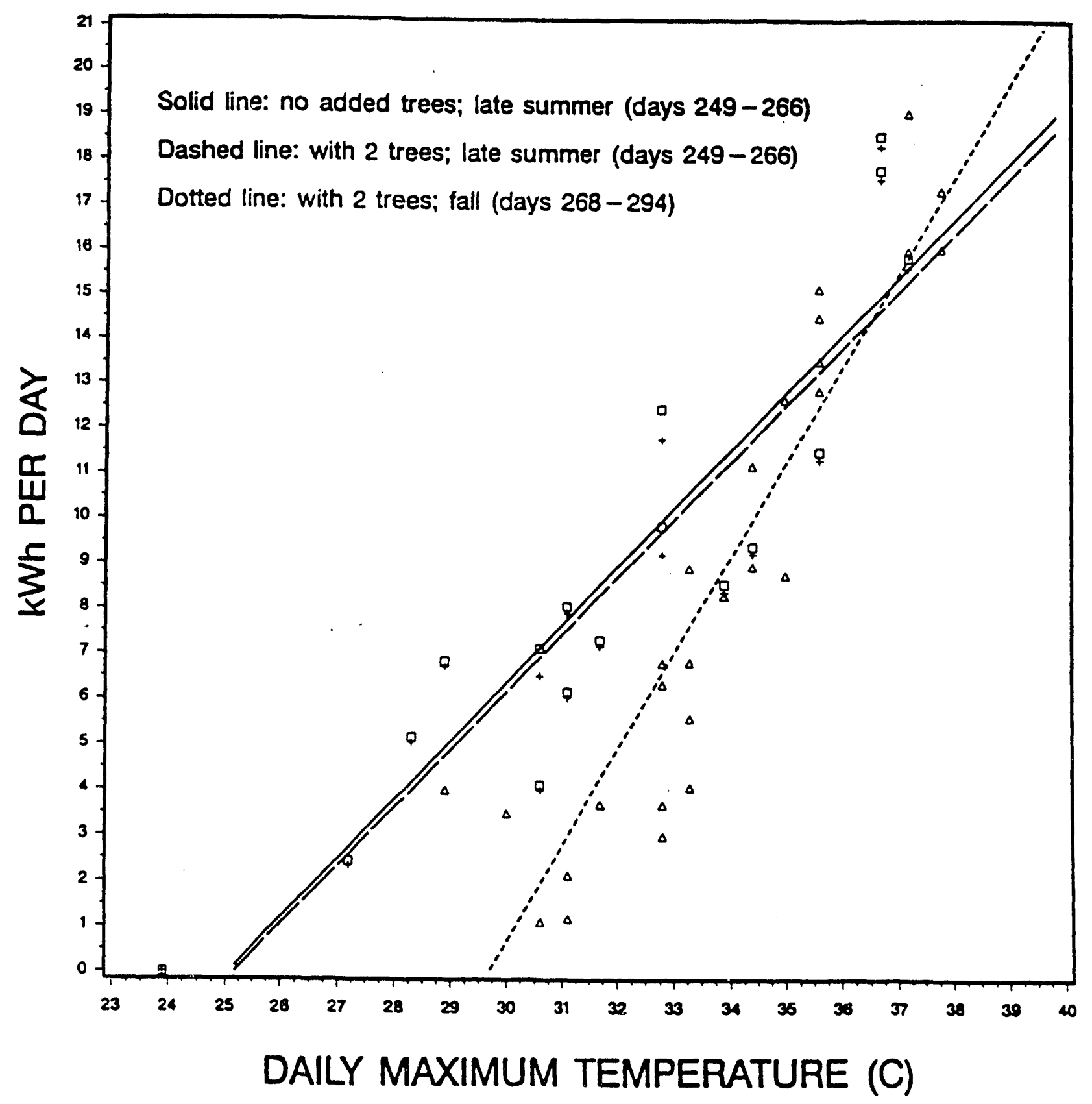


Site 6

This site is also located far southeast of Sacramento. It is in a relatively newer development, and both the house and surroundings vegetation density is low. Pre- and post-retrofit data for this site are available for 33 days (JD 233 - 265) and 26 days (JD 268 - 293), respectively. There were six missing days in the "pre" monitoring period and seven missing days in the "post" monitoring period. In the "post" monitoring period, two trees were placed on the west side and one tree on the south side. The condenser unit was also partially shaded by one of the west trees.

Figure V-6A shows daily energy use data plotted versus the maximum daily temperature at Site 6. For example, at $38^{\circ} \mathrm{C}$, there is a reduction of $4.5 \mathrm{kWh} /$ day $(-30 \%)$ in cooling electricity use. Figure V-6B shows the decrease in daily total solar radiation across the entire monitoring period at Site 6 . The solid line represents the conditions before vegetation modifications took place, whereas the broken line represents the conditions afterwards. The large dips represent periods with overcast skies. In general, we can see that, across $\mathbf{4 0}$ days of monitoring at this site, the daily total solar radiation dropped from $7 \mathrm{kWh} /$ day down to $-4 \mathrm{kWh} /$ day. The implications of lower insolation on "savings" are estimated with the help of DOE-2 simulations. These appear to indicate that almost all of the measured savings resulted from the effects of lower solar radiation intensity.

At the hourly scale, energy use was correlated to mean hourly outdoor air temperature and to the outdoor-indoor air temperature difference (To-Ti). Figure V-6C shows the first case. The squares represent the hours before vegetation modifications took place, whereas the small diamonds represent those hours after 2 trees on the west side and one tree on the south side were installed. Looking again at an outdoor air temperature of $38^{\circ} \mathrm{C}$, the regression lines indicate that there were reductions of $38 \%$ in energy use. Figure V-6D shows the same hourly data, but in this case, it was plotted versus hourly nutdoor minus indoor air temperature difference. The bulk of the cooling energy use occurred when outside air temperature was $0-10^{\circ} \mathrm{C}$ higher than indoor air temperature. When outdoor air temperature was $5^{\circ} \mathrm{C}$ higher than that indoors, the regression indicates savings in cooling energy of $44 \%$ because of the trees. However, the DOE- 2 simulations of this site appear to indicate that most of the savings in cooling energy use were not caused by vegetation, but by the lower insolation. 
Figure V-6A. Site 6: Daily cooling electricity use ( $\mathrm{kWh} /$ day) vs maximum outdoor air temperature $\left({ }^{\circ} \mathrm{C}\right)$ for pre- and post-retrofit conditions. Post-conditions include two additional trees on west and one tree on south. Solid regression line is for pre-retrofit conditions, broken regression line is for post-retrofit. Pre-retrofit monitoring period at this site was August 21 through September 22, and the post-retrofit period was September 25 through October 21, 1991.

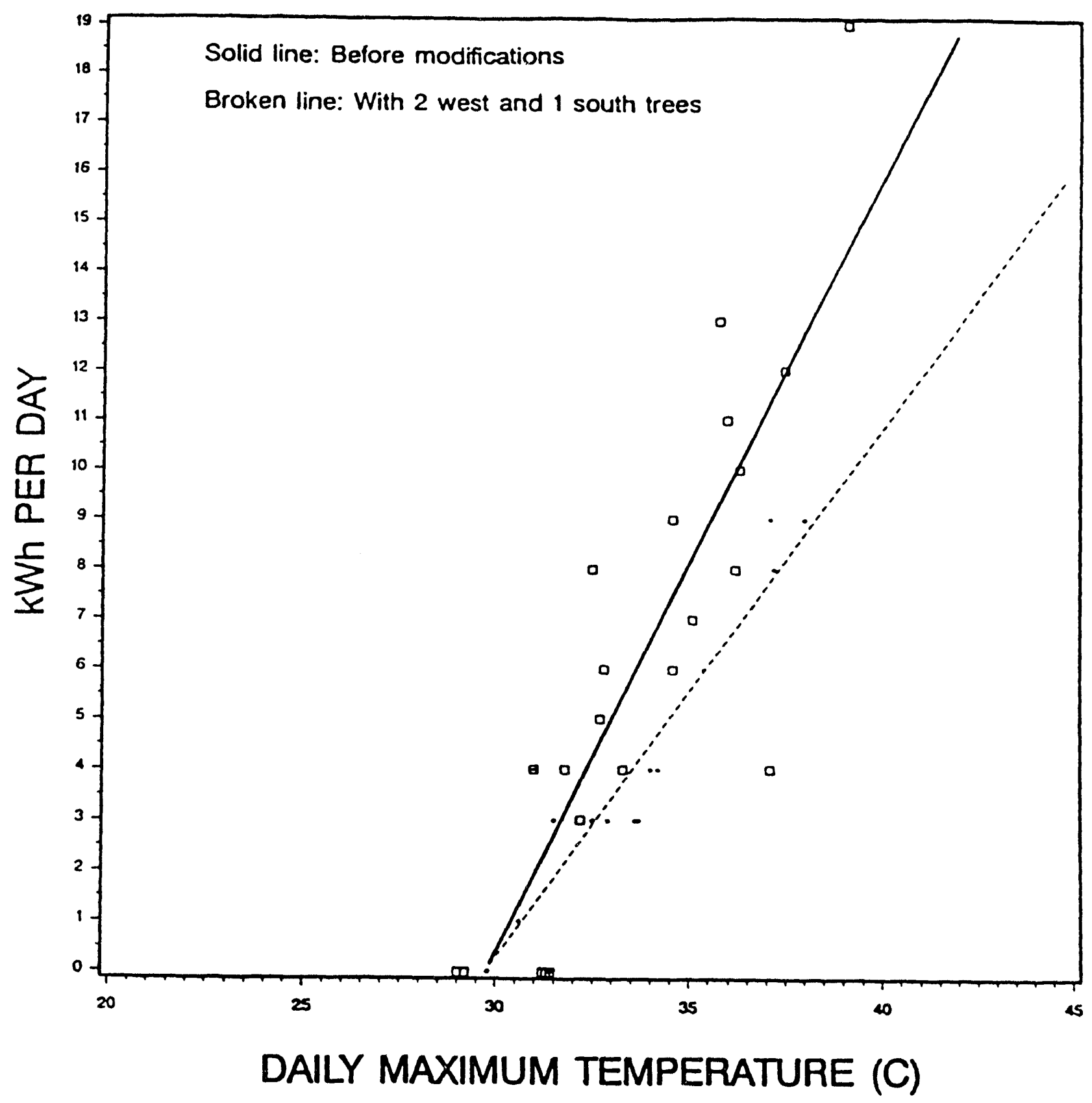


Figure V-6B. Site 6: Variation in total daily horizontal solar radiation ( $\mathrm{kWh} /$ day) over 39 day of monitoring at Site 6 . The left portion of the graph represents solar radiation during the preretrofit period whereas the right portion represents radiation during the post-retrofit period. Preretrofit monitoring period at this site was August 21 through September 22, and the post-retrofit period was September 25 through October 21, 1991.

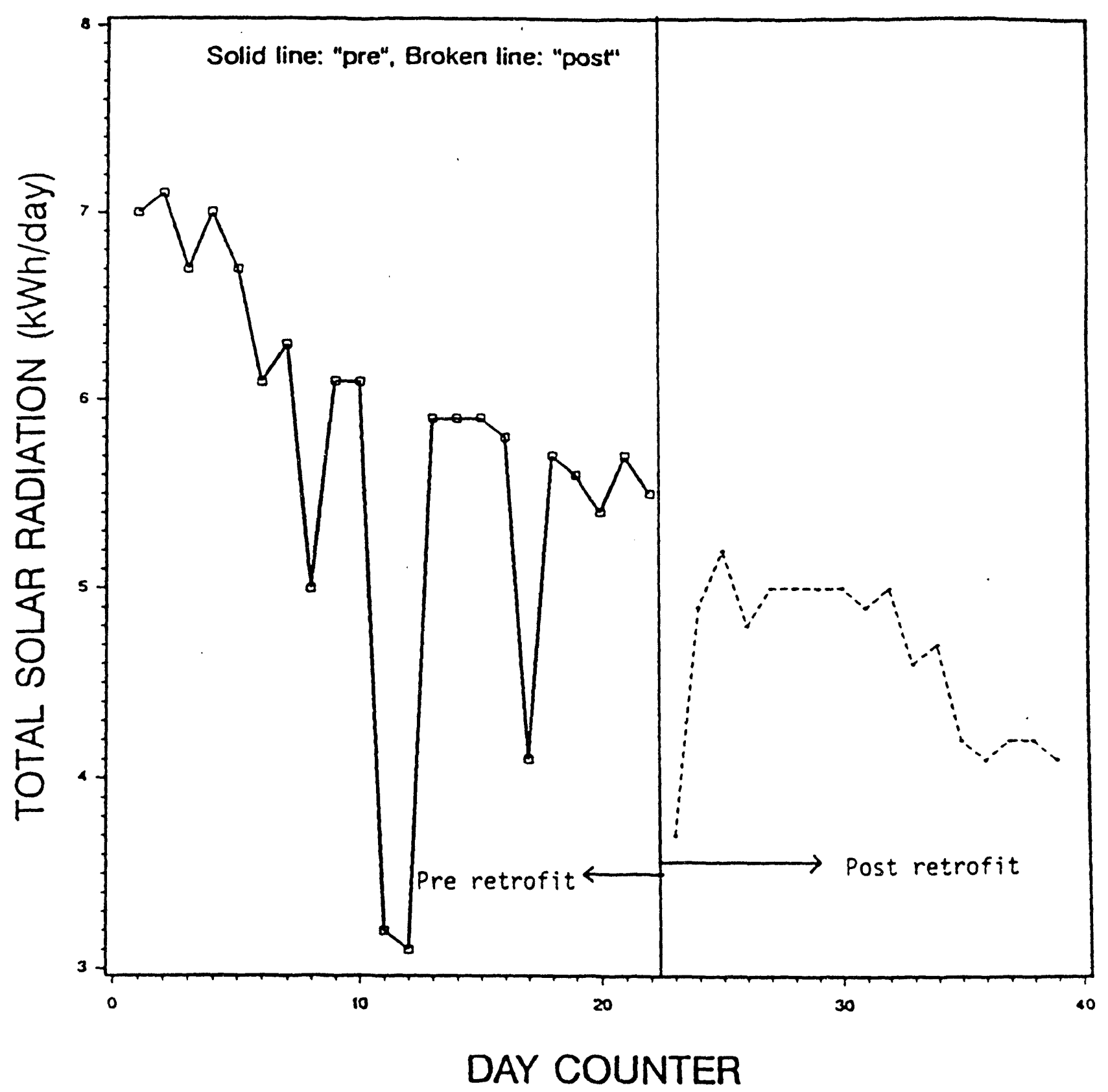


Figure V-6C. Site 6: Hourly cooling electricity use (Wh/h) vs mean hourly outdoor air temperature $\left({ }^{\circ} \mathrm{C}\right)$ for pre- and post-retrofit conditions. Post-conditions include two additional trees on west and one tree on south. Solid regression line is for pre-retrofit conditions, broken regression line is for post-retrofit. Pre-retrofit monitoring period at this site was August 21 through September 22, and the post-retrofit period was September 25 through October 21, 1991.

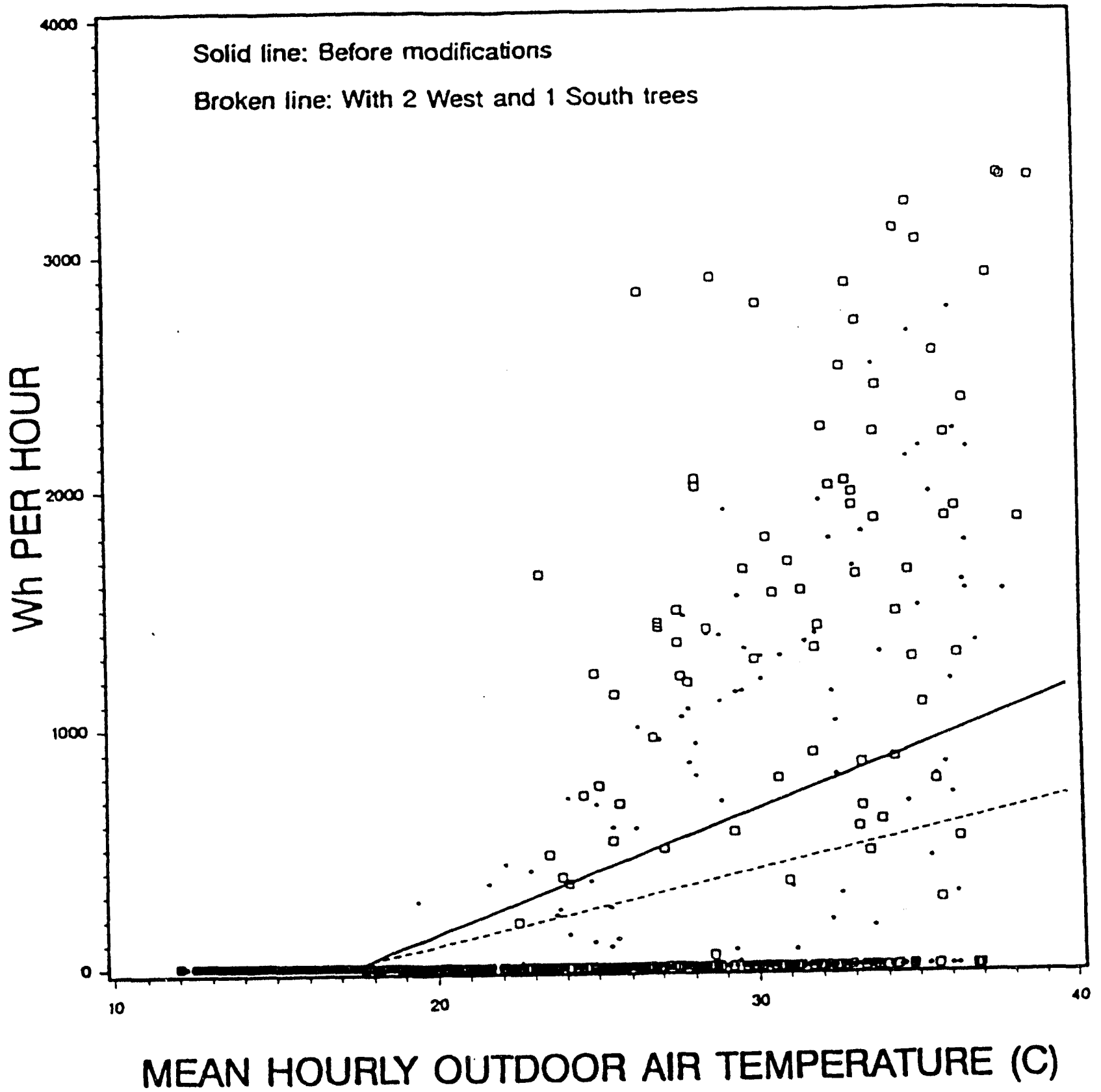


Figure V-6D. Site 6: Hourly cooling electricity use (W/h/h) vs hourly air temperature difference, outdoor minus indoor $\left({ }^{\circ} \mathrm{C}\right)$. Post-conditions include two additional trees on west and one tree on south. Solid regression line is for pre-retrofit conditions, broken regression line is for postretrofit. Pre-retrofit monitoring period at this site was August 21 through September 22, and the post-retrofit period was September 25 through October 21, 1991.

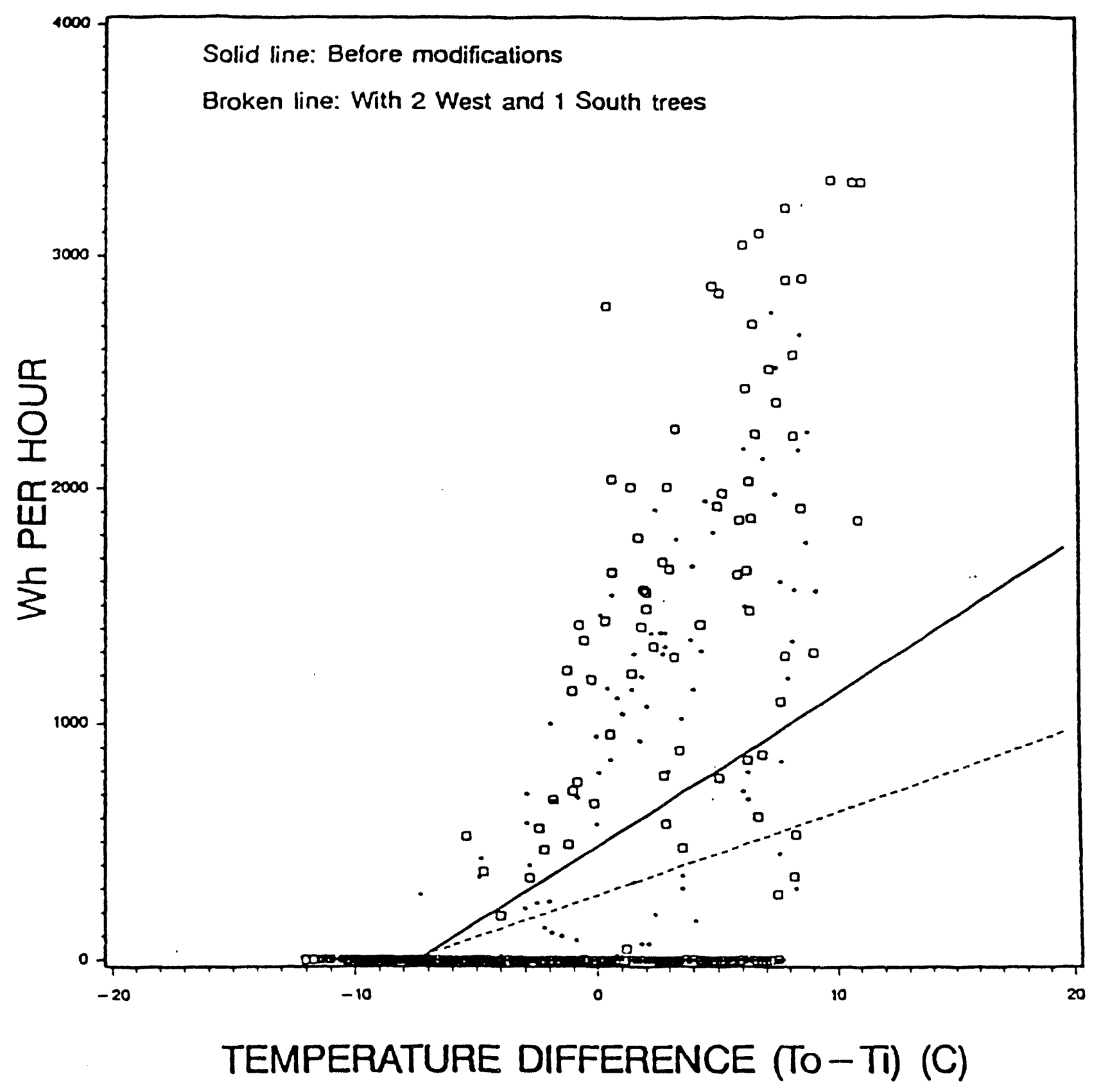


In Figure V-6E and V-6F, the surface temperature of the west wall is plotted versus the outdoor air temperature for both pre- and post-modification cases. In each case, a linear fit is shown, and according to these lines, we can see that in the afternoon, when outdoor air temperature is around $35^{\circ} \mathrm{C}$ (when the west wall is insolated), the surface temperature of the wall is on the average $4^{\circ} \mathrm{C}$ lower with the trees in place than the case without trees. Recall that the trees $w$ ire small and that effect is small accordingly. Also, some of the effect may have been caused by lower insolation.

The comparison of measured and simulated data for Site 6 are presented in Figures V-6G and V-6H. At this site, the simulated peak load coincides with the measured peak for the postperiod, but is typically $0.5 \mathrm{~kW}$ lower in the pre-period. The models also overpredict cooling energy use in the post-period more than in the pre-period. As at Site 5, the simulated building has cooling consumption later into the evening than the real building, which leads to the overprediction of total daily cooling use. We also see at Site 6 that the outdoor temperature drops faster in the evening than at the airport, which may explain some of the disagreements.

The simulated cooling use is plotted against outdoor temperature in Figure V-6I. The model and measured data shown in Figure V-6A agree well on cooling energy consumption at higher temperatures. The measured data shows $15 \mathrm{kWh} /$ day at $40^{\circ} \mathrm{C}$ in the pre-period and 10.5 $\mathrm{kWh} /$ day at $40^{\circ} \mathrm{C}$ in the post-period. The model predicts 16 and $13.5 \mathrm{kWh} /$ day, respectively. The model also shows that when the same climatic inputs are used for the base and tree cases, there is virtually no difference in cooling energy consumption. 
Figure V-6E. Site 6: West wall surface temperature $\left({ }^{\circ} \mathrm{C}\right)$ vs outdoor air temperature $\left({ }^{\circ} \mathrm{C}\right)$ for pre-retrofit conditions. Solid line is regression fit to the data. Pre-retrofit monitoring period at this site was August 21 through September 22, and the post-retrofit period was September 25 through October 21, 1991.

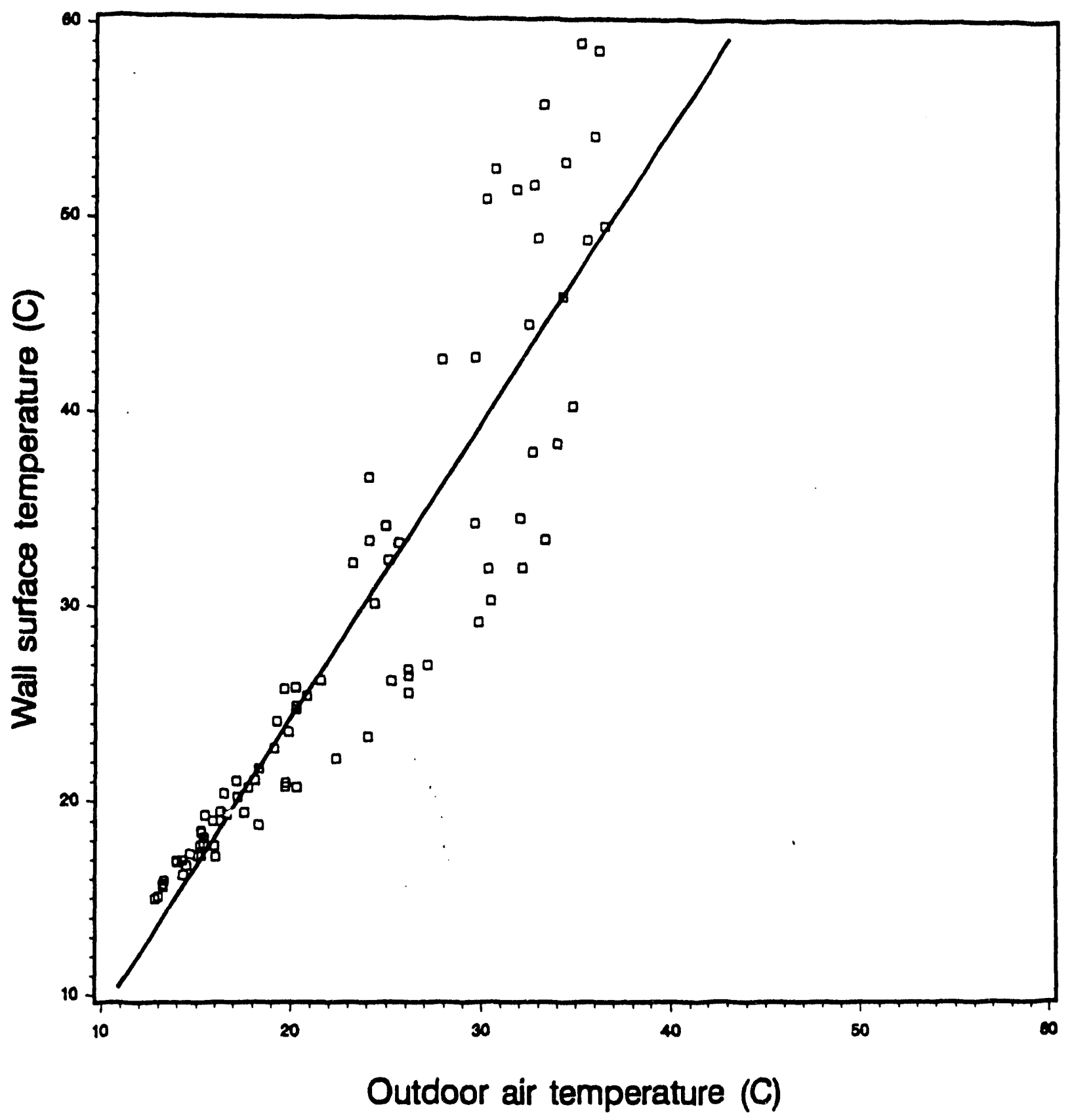


Figure V-6F. Site 6: West wall surface temperature $\left({ }^{\circ} \mathrm{C}\right)$ vs outdoor air temperature $\left({ }^{\circ} \mathrm{C}\right)$ for post-retrofit conditions. Solid line is regression fit to the data. Post-retrofit condition: two additional trees on west and one additional tree on south. Pre-retrofit monitoring period at this site was August 21 through September 22, and the post-retrofit period was September 25 through October 21, 1991.

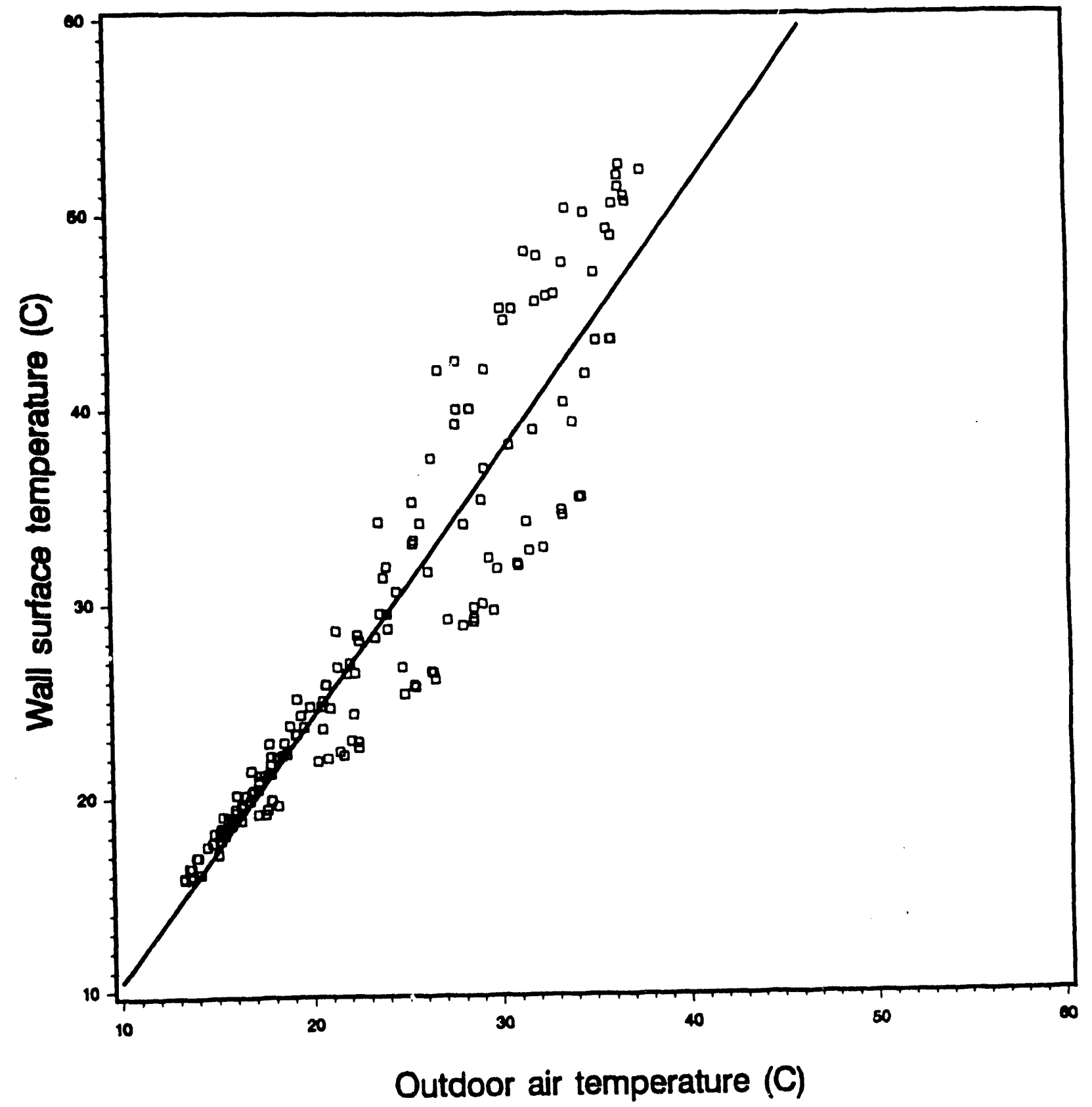


Figure V-6G. Compressor watt hours and building interior temperature for 9/17 to 9/23 at Site 6. Comparison of measured and simulated data before vegetation modification.

Days 260 to 266 Measured: $7.7 \mathrm{kWh} /$ day DOE-2: $8.5 \mathrm{kWh} /$ day.

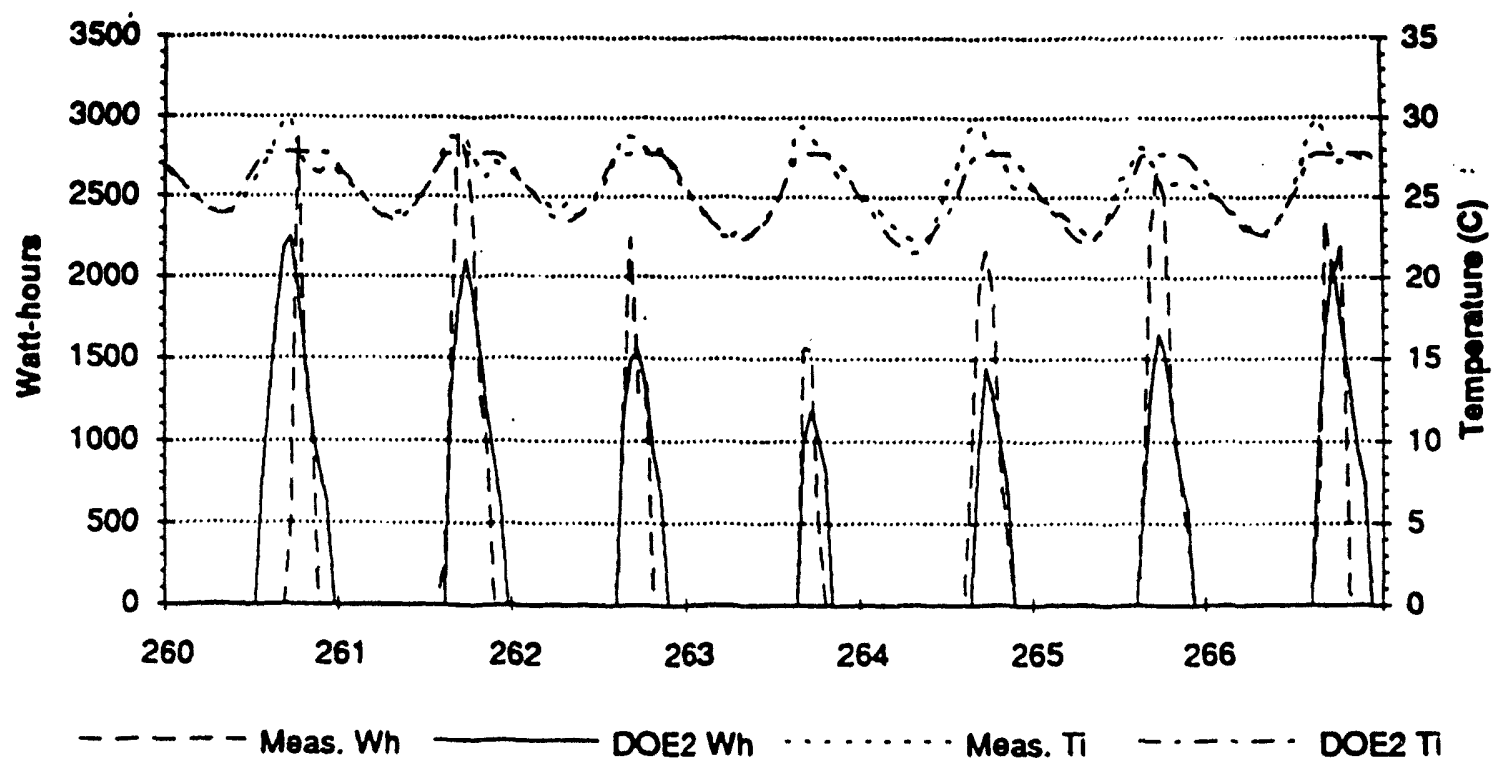

Figure V-6H. Compressor watt hours and building interior temperature for $9 / 30$ to 10/6 at Site 6. Comparison of measured and simulated data after vegetation modification.

Days 274 to 277 Measured: $8.3 \mathrm{kWh} /$ day DOE-2: $10.4 \mathrm{kWh} /$ day.

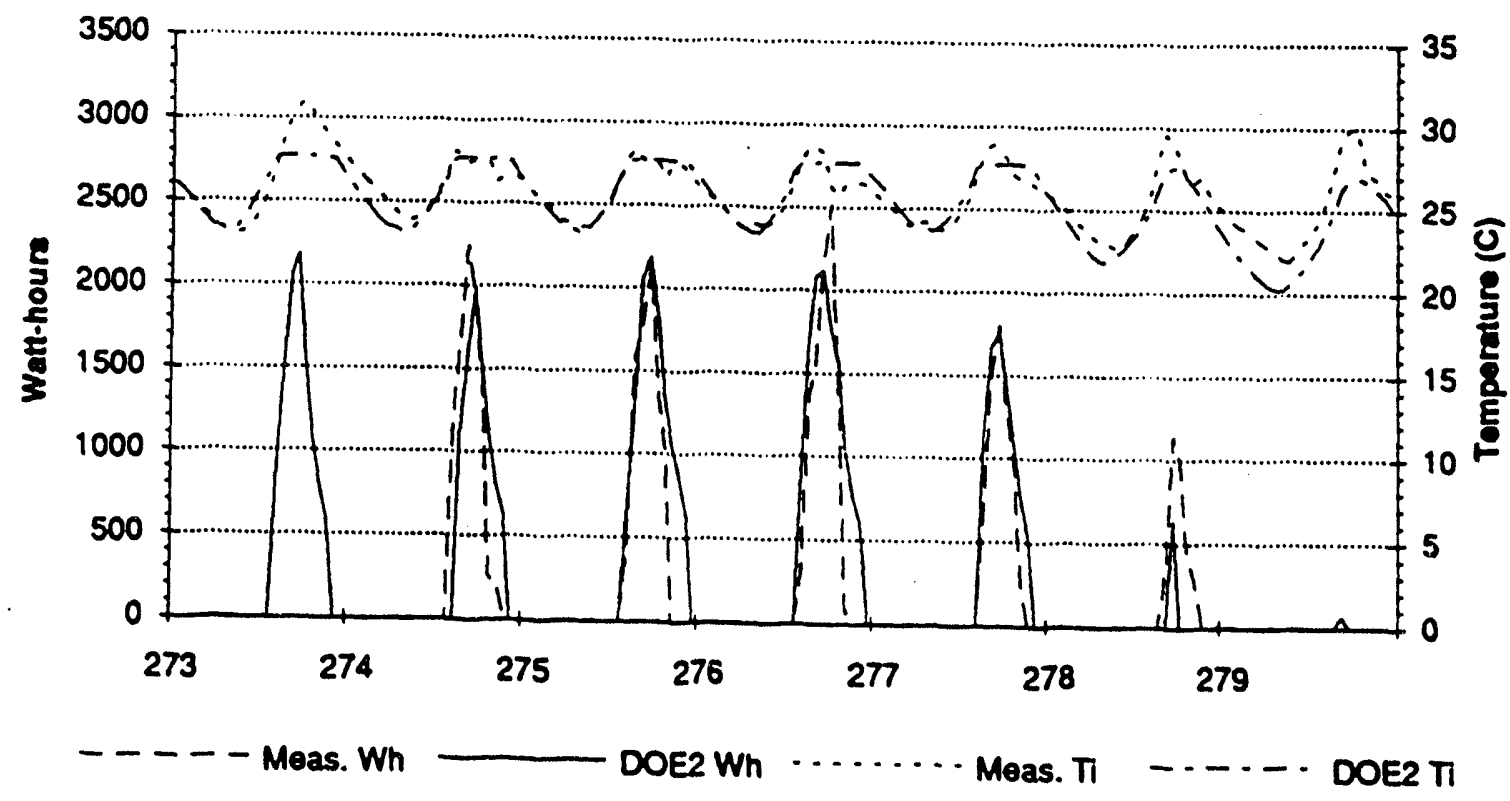


Figure V-61. Site 6: Simulation Results: Daily Data Squares and solid line represent base case in late summer (days 249 - 266). Crosses and dashed line represent the addition of 3 shade trees in late summer (days 249 - 266). Triangles and dotted line represent the case of 3 shade trees in fall (days 268 - 294).

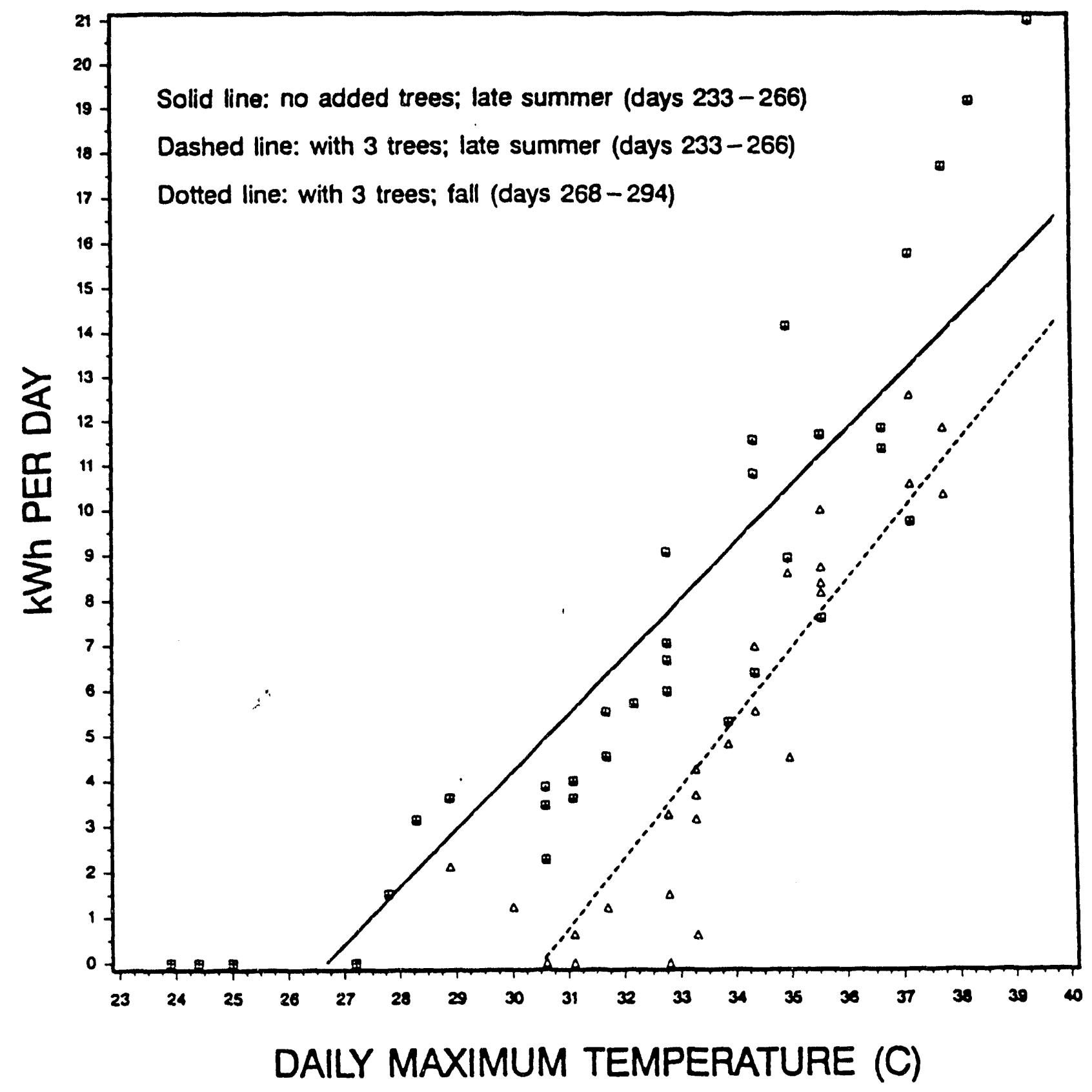


Site 7

Site 7 is located far southeast of Sacramento, just west of Mather AFB, in a relatively open area. Vegetation at both neighborhood and building scales was moderate. Site 7 had two unshaded southwest windows, which were subsequently shaded with two small trees. Pre- and post-retrofit data for this site were available for 20 days (JD 245 - 265) and 23 days (JD 268 290), respectively. There were a few hours of missing data in both "pre" and "post" monitoring periods.

Figure V-7A shows daily data for Site 7. As in the previous figures, the solid line represents pre-modification conditions whereas the broken line represents conditions after two trees were placed on the southwest side. For example, at $38^{\circ} \mathrm{C}$ outdoor air temperature, the positioning of 2 southwest trees resulted in a reduction of $-5 \mathrm{kWh} /$ day or about $34 \%$ of cooling electricity use.

The hourly data suggest smaller changes. Figures V-7B and V-7C represent hourly energy use data plotted versus mean hourly outdoor air temperature and the hourly difference in temperature between outdoor and indoor air, respectively. Figure V-7B indicates a reduction of only $6 \%$ at $38^{\circ} \mathrm{C}$, and Figure $\mathrm{V}-7 \mathrm{C}$ indicates that at an outdoor minus indoor air temperature difference of $5^{\circ} \mathrm{C}$, the reductions amount to about $20 \%$. The DOE- 2 simulations indicate that almost all these reductions were caused by lower insolation.

Figures V-7D and V-7E depict the changes in the surface temperature of the southwest wall before and after trees were in place. In a fashion similar to that discussed earlier, the regression lines in those figures indicate that the change in surface temperature of the southwest wall was not significant. But that is probably because the temperature sensor was not in a shaded spot. The temperature difference in the afternoon, as indicated by the regression lines, amounts to only $0.5^{\circ} \mathrm{C}$ (on the average) and is close to sensor accuracy.

The comparisons of hourly simulated and measured data for Site 7 are presented in Figures V-7F and V-7G. This site shows highly erratic behavior in both cooling energy use and interior temperatures. There are days of no cooling (248), the thermostat "threshold" $(250,270$, and 272), and other unexplained noise (247 and 268). On the most controlled days, such as 251 to 253 and 269,270 , and 273 , the simulated peak load is similar to the measured peak while the daily simulated totals are slightly higher. 
Figure V-7A. Site 7: Daily cooling electricity use ( $\mathrm{kWh} / \mathrm{day})$ vs maximum outdoor air temperature $\left({ }^{\circ} \mathrm{C}\right)$ for pre- and post-retrofit conditions. Post-conditions with two additional trees on southwest. Solid regression line is for pre-retrofit conditions, broken regression line is for postretrofit. Pre-retrofit monitoring period at this site was September 3 through September 23, and the post-retrofit period was September 25 through October 18, 1991.

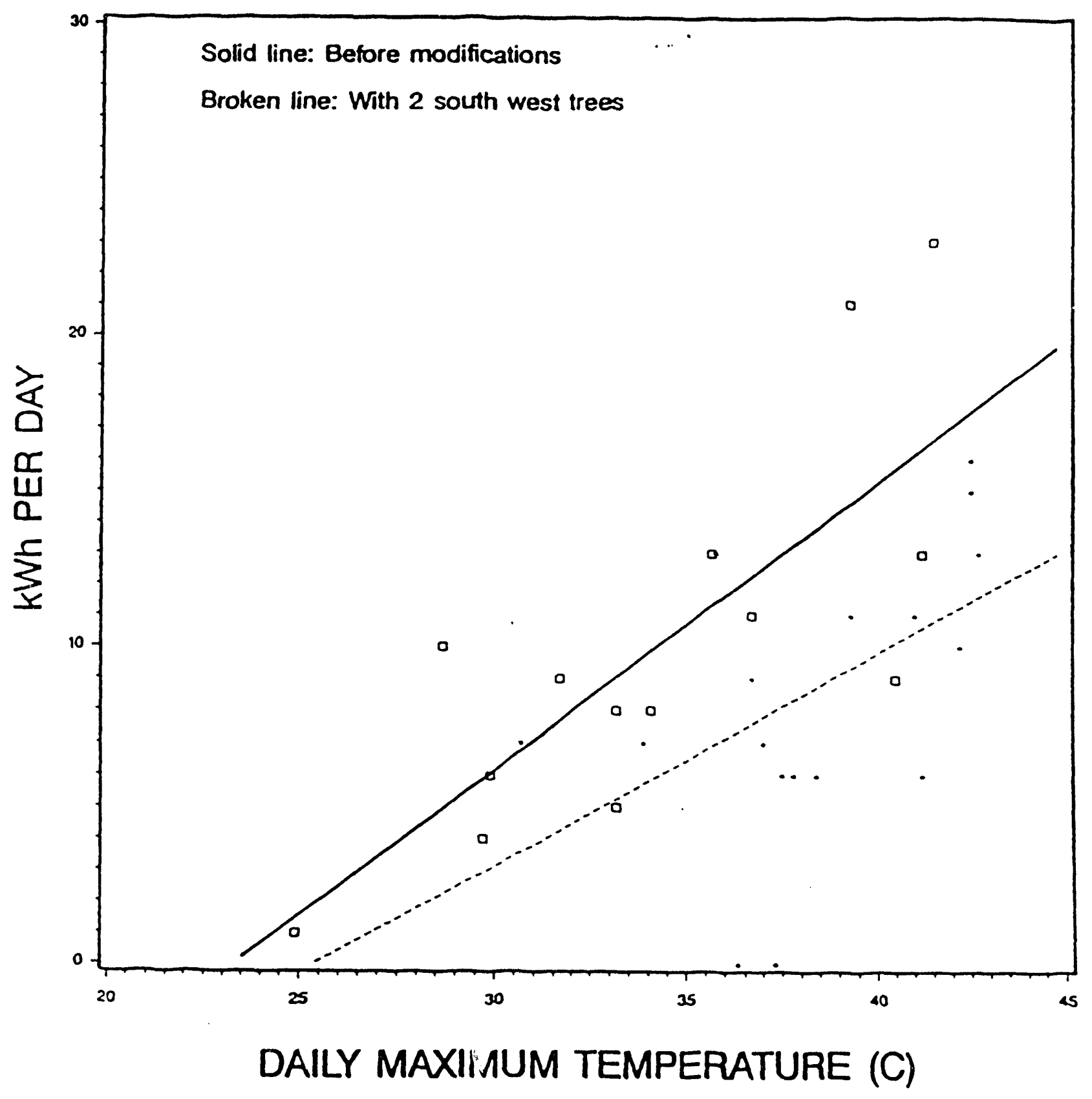


Figure V-7B. Site 7: Hourly cooling electricity use ( Wh/h) vs mean hourly outdoor temperature $\left({ }^{\circ} \mathrm{C}\right)$ for pre- and post- retrofit conditions. Post-conditions with two additional trees on southwest. Solid regression line is for pre-retrofit conditions, broken regression line is for postretrofit. Pre-retrofit monitoring period at this site was September 3 through September 23, and the post-retrofit period was September 25 through October 18, 1991.

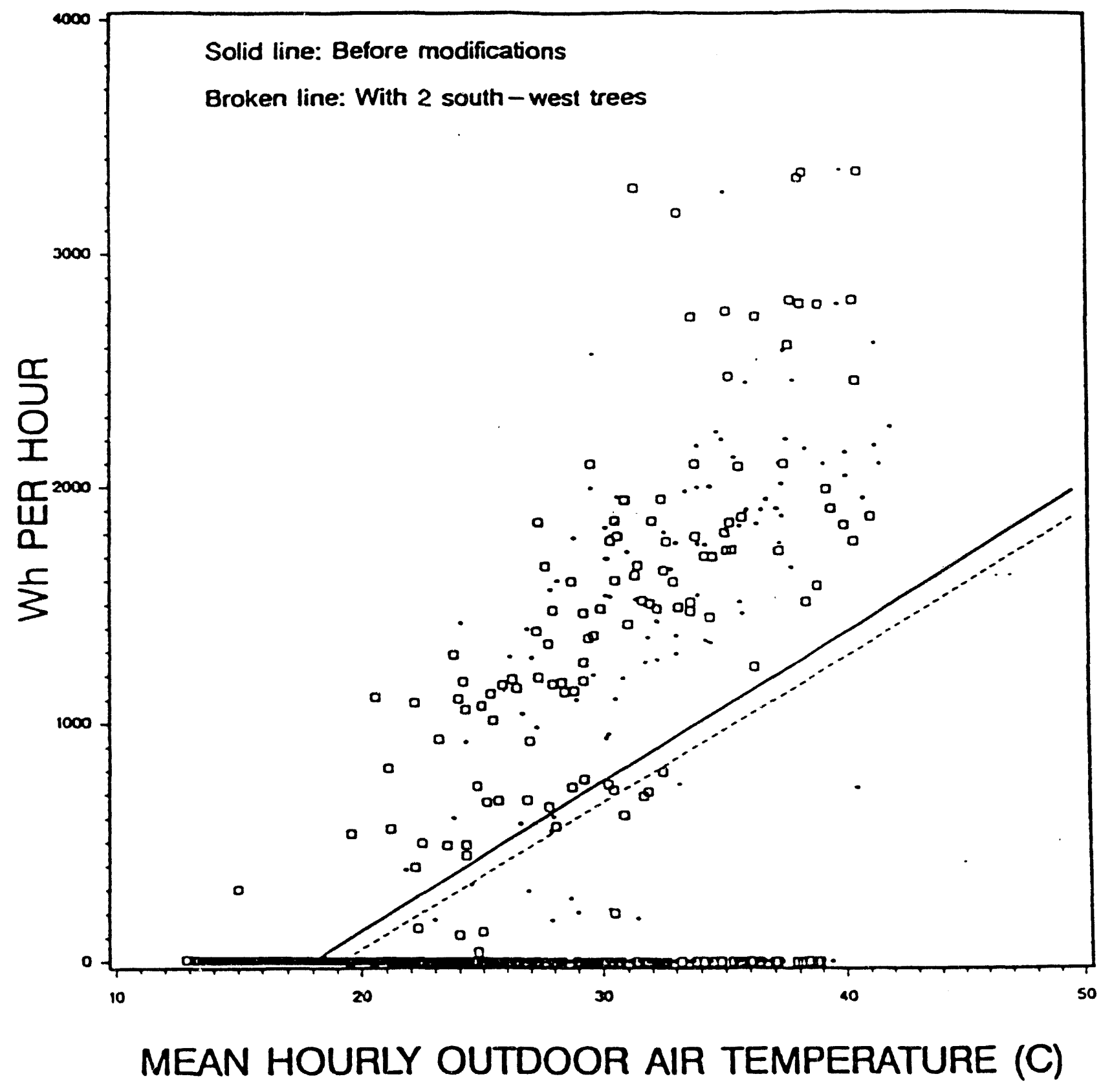


Figure V-7C. Site 7: Hourly cooling electricity use $(\mathrm{Wh} / \mathrm{h})$ vs hourly difference between outdoor and indoor air temperature $\left({ }^{\circ} \mathrm{C}\right)$. Solid regression line represents pre-retrofit conditions, whereas the broken regression line represents post-retrofit conditions, i.e., with two trees on the southwest. Pre-retrofit monitoring period at this site was September 3 through September 23, and the post-retrofit period was September 25 through October 18, 1991.

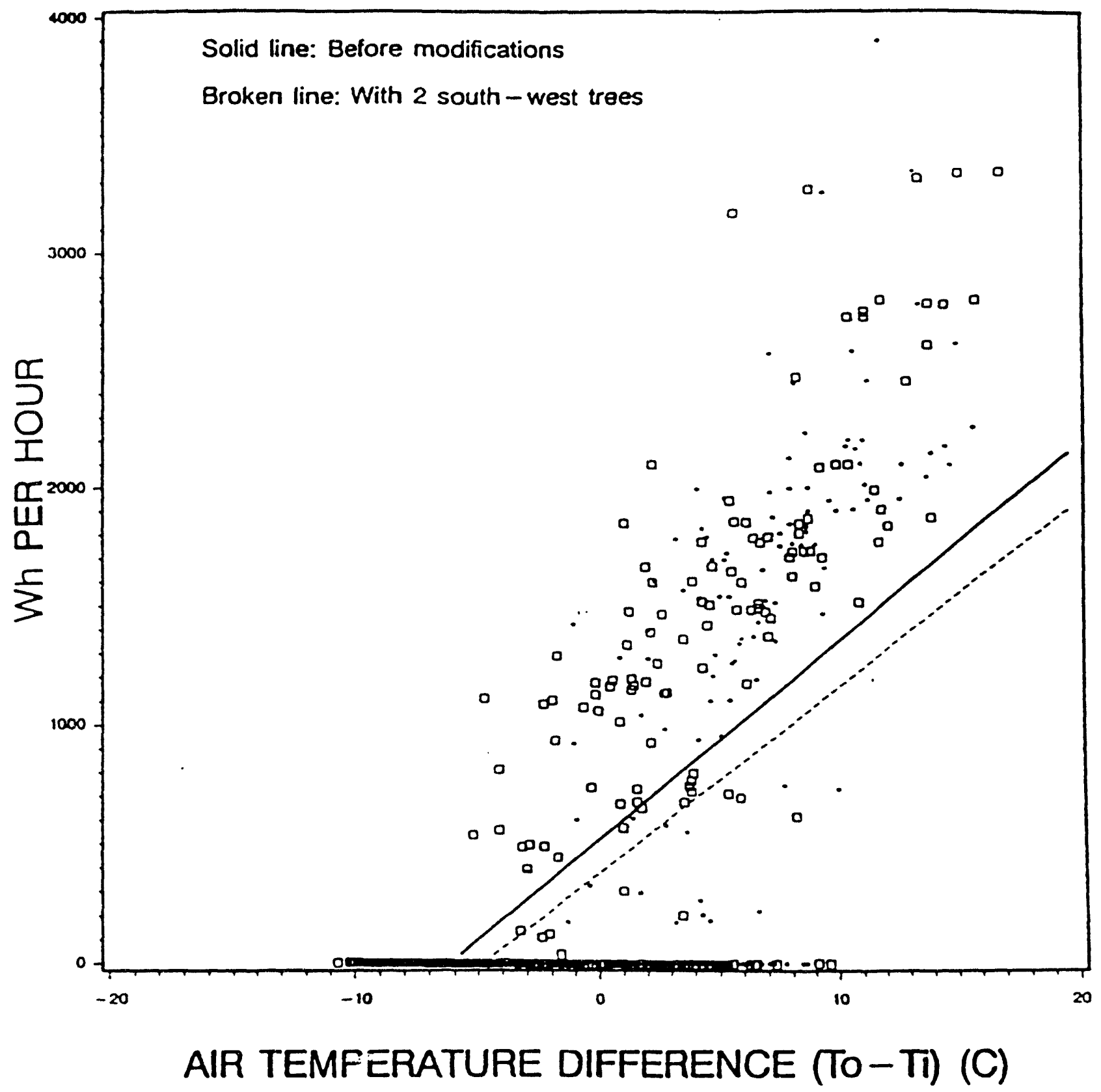


Figure V-7D. Site 7: Southwest wall surface temperature $\left({ }^{\circ} \mathrm{C}\right)$ vs outdoor air temperature $\left({ }^{\circ} \mathrm{C}\right)$ for pre-retrofit conditions. Solid line is a regression fit to the data. Pre-retrofit monitoring period at this site was September 3 through September 23, and the post-retrofit period was September 25 through October 18, 1991.

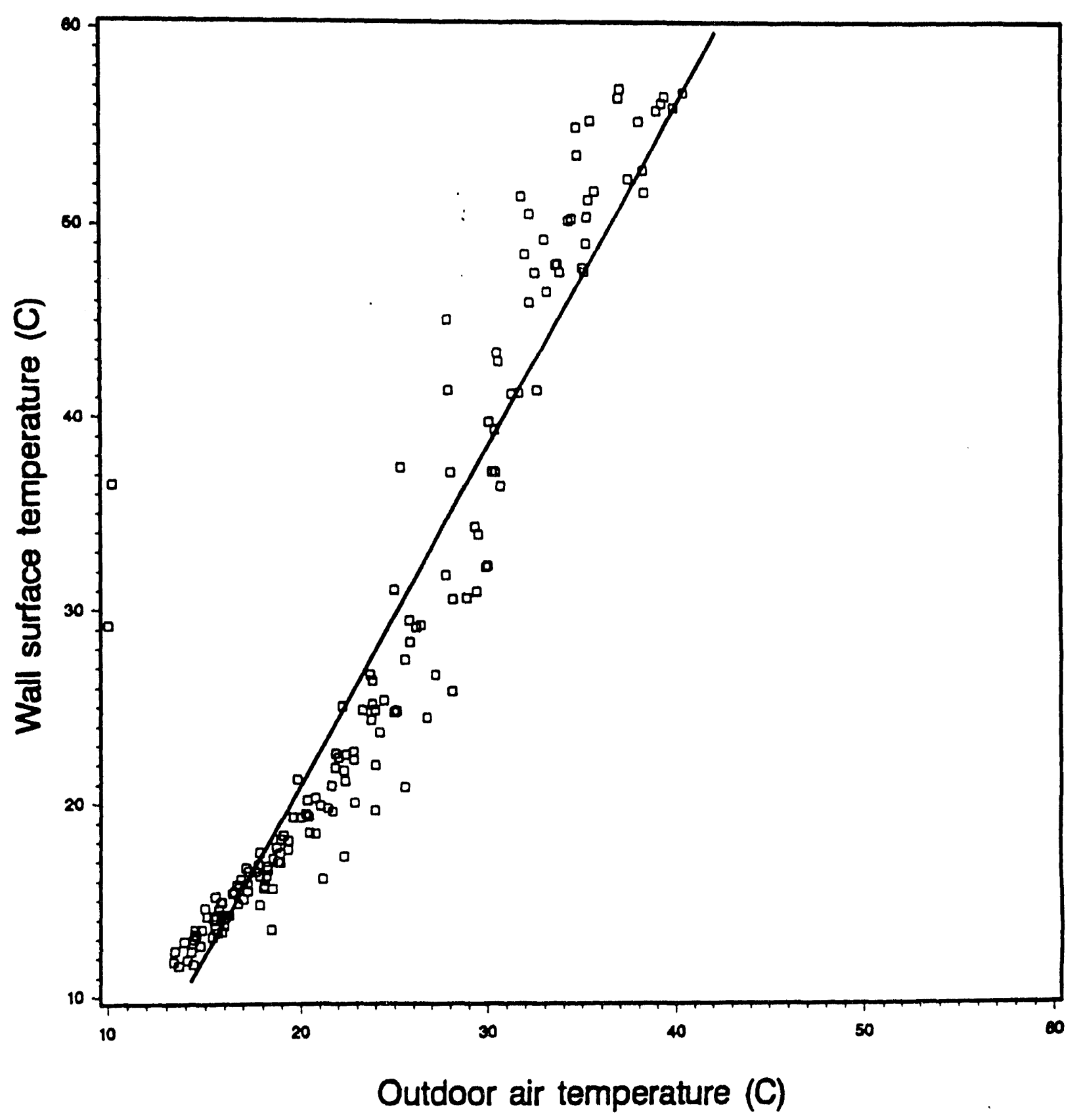


Figure V-7E. Site 7: Southwest wall surface temperature $\left({ }^{\circ} \mathrm{C}\right)$ vs outdoor air temperature $\left({ }^{\circ} \mathrm{C}\right)$ for post-retrofit conditions, i.e., with two additional tress on the southwest. Solid line is a regression fit to the data. Pre-retrofit monitoring period at this site was September 3 through September 23, and the post-retrofit period was September 25 through October 18, 1991.

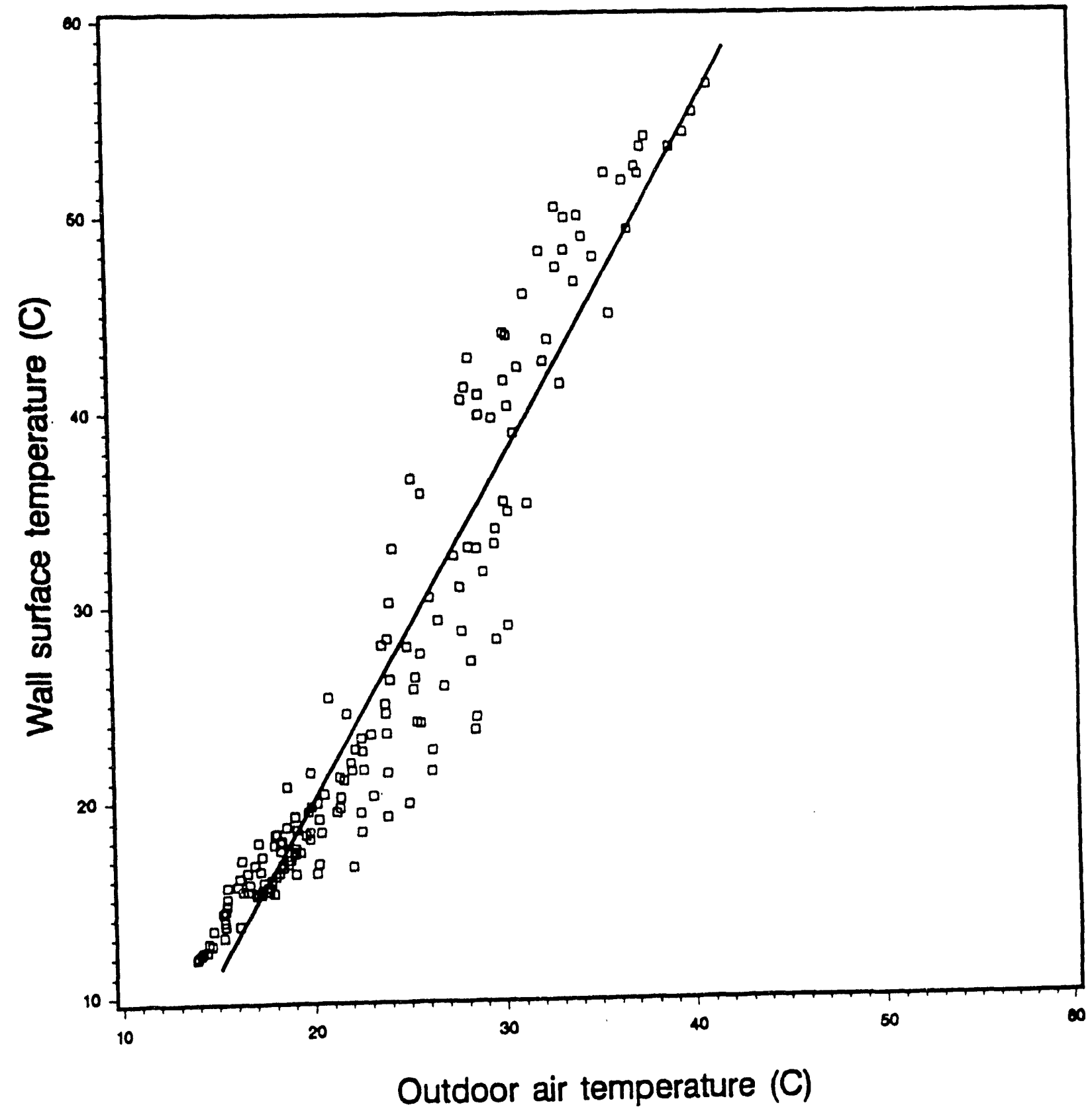


Figure V-7F. Compressor watt hours and building interior temperature for 9/4 to 9/10 at Site 7 . Comparison of measured and simulated data before vegetation modification.

Days 249 to 253 Measured: $6.2 \mathrm{kWh} /$ day DOE-2: $7.2 \mathrm{kWh} /$ day.

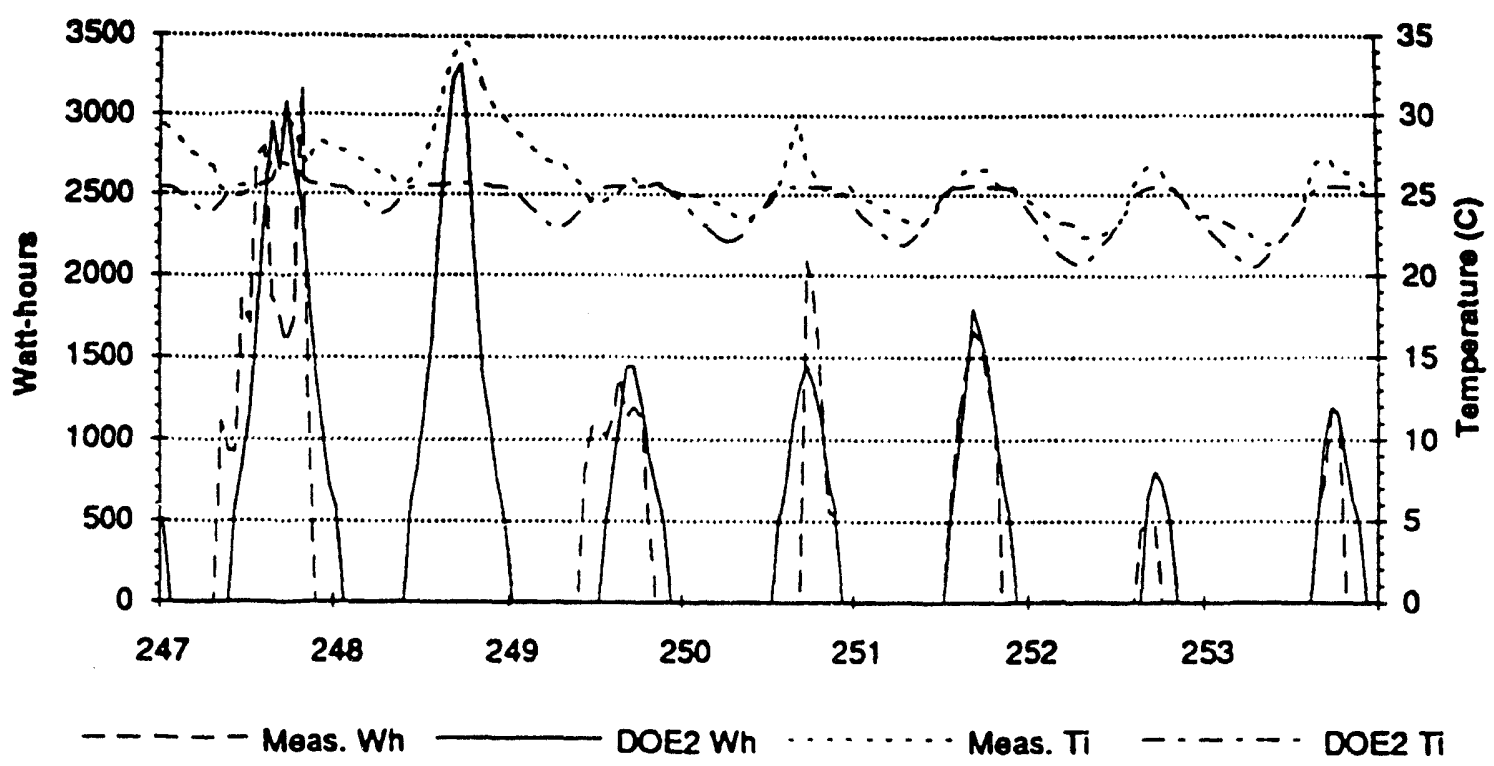

Figure V-7G. Compressor watt hours and building interior temperature for 9/25 to 10/1 at Site 7. Comparison of measured and simulated data after vegetation modification.

Days 269 to 271 Measured: $6.8 \mathrm{kWh} /$ day DOE-2: $7.9 \mathrm{kWh} / \mathrm{day}$.

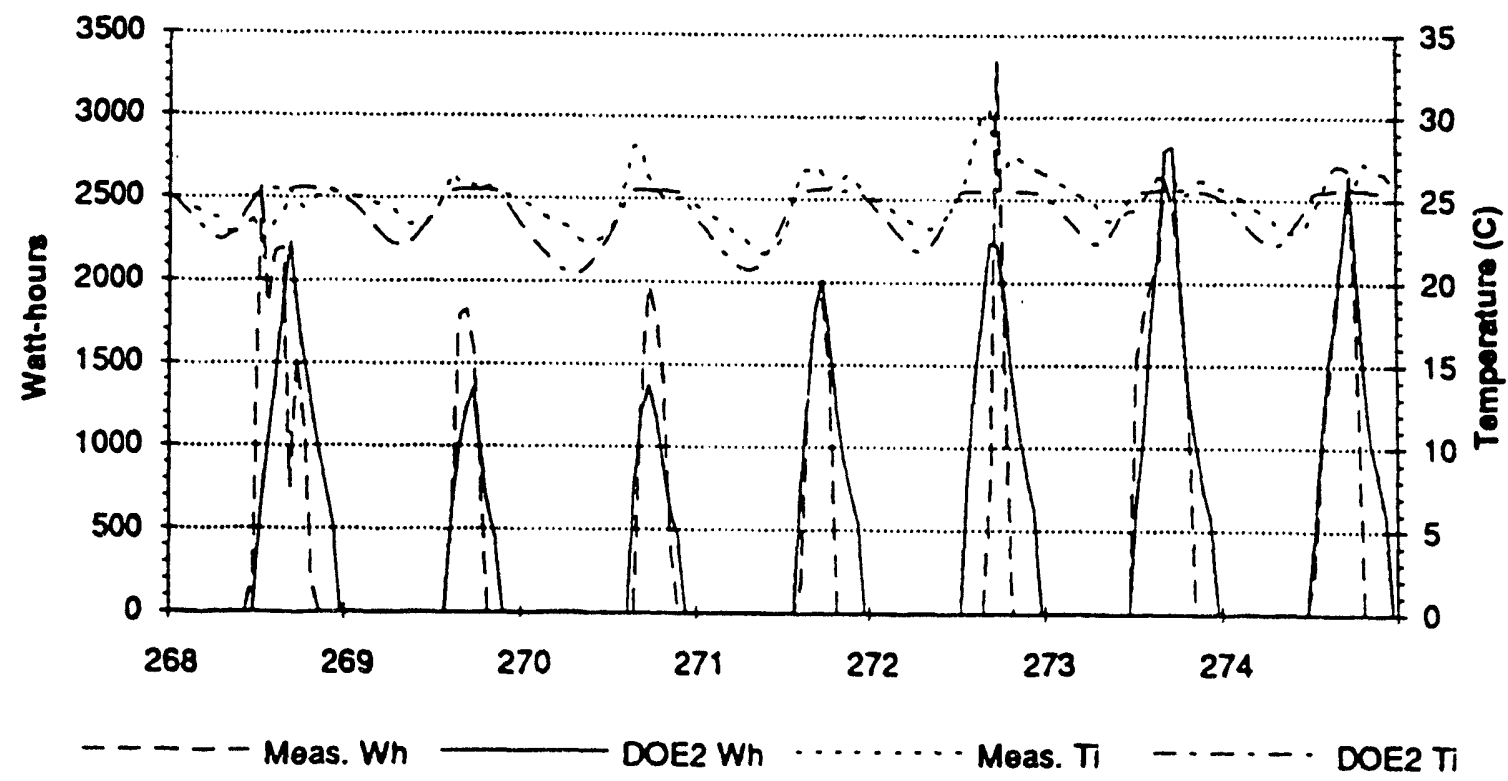


The simulated daily data is plotted in Figure V-7H. The simulated data does not agree well with the measured data shown in Figure V-7A. This is likely because of the erratic cooling energy use shown in Figures V-7F and V-7G. The model also predicts no real difference between the base and the tree case. 
Figure V-7H. Site 7: Simulation Results: Daily data. Squares and solid line represent base case in late summer (days 249 - 266). Crosses and dashed line represent the addition of 2 shade trees in late summer (days 249 - 266). Triangles and dotted line represent the case of 2 shade trees in fall (days 268 - 294).

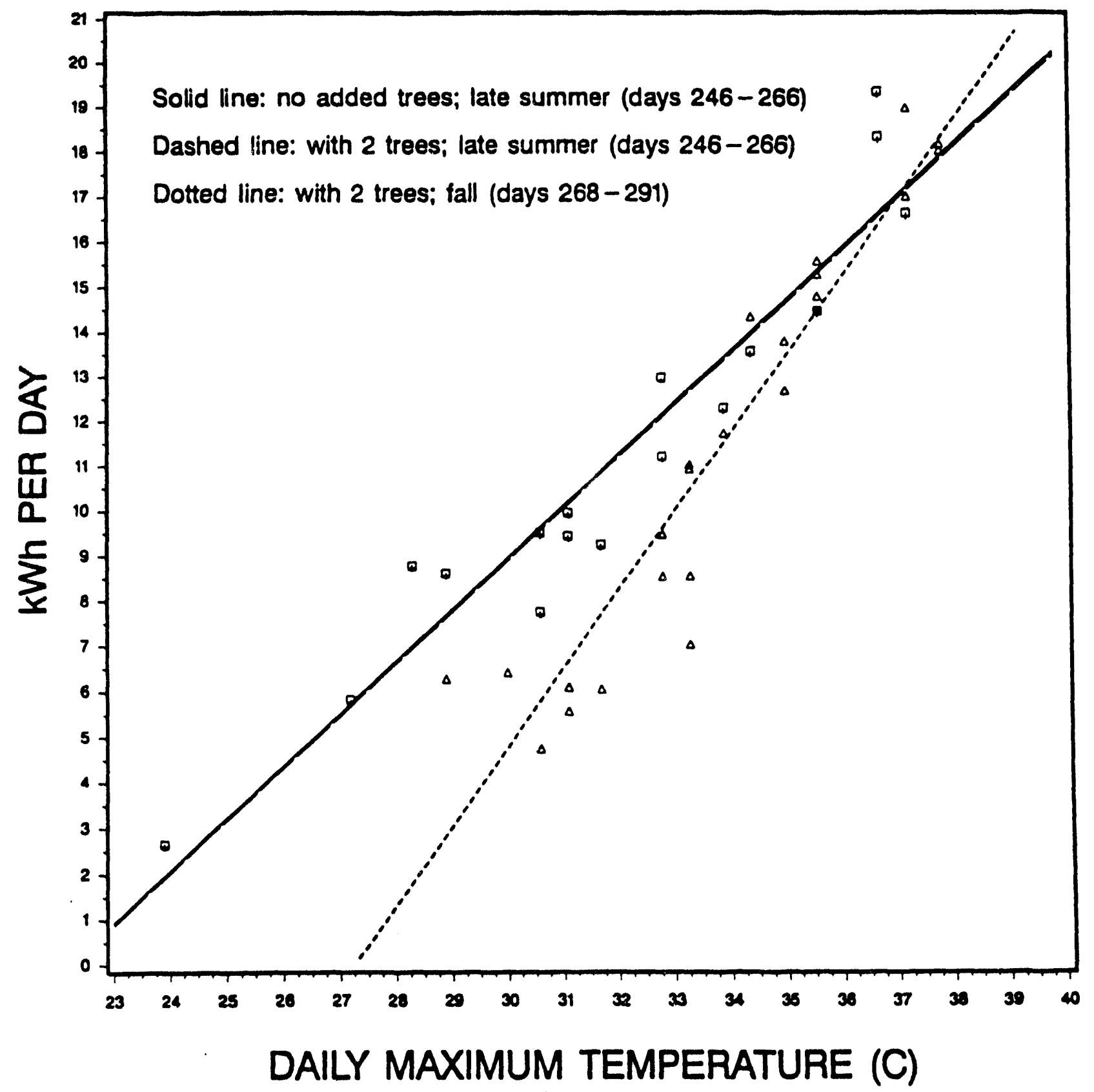


Site 8

Site 8 is located just next to Site 1 (in northeast Sacramento) and has similar surrounds. However, Site 8 has much less vegetation than Site 1 and, in fact, the building envelope was mostly unshaded. We decided to position several trees along the south wall, so as to shade the windows and portions of the wall. Figure V-8A represents some of the daily data from that site. We do not show all the days because we were uncertain about some of the data. It appears that the thermostat was reset on some days (reset to lower than $25.5^{\circ} \mathrm{C}$ ) and in the daily data we present here, these days were removed. At $38^{\circ} \mathrm{C}$, there is a savings of $-2.5 \mathrm{kWh} /$ day in cooling electricity use, which amounts to a reduction of $12 \%$.

Figures V.8B and V-8C summarize hourly data at Site 8. At an outdoor air temperature of $38^{\circ} \mathrm{C}$, for example, the regression lines in Figure V-8B indicate a reduction of $7 \%$, and at an outdoor minus indoor air temperature difference of $5^{\circ} \mathrm{C}$, the reduction also amount to $7 \%$, according to the regressions in Figure V-8C. The DOE-2 simulations indicate that there could be no savings if the effects of lower insolation were accounted for.

However, the trees seem to have had a significant impact on the surface temperatures of the walls. Figures $\mathrm{V}-\mathbf{8 D}$ and $\mathrm{V}-\mathbf{8 E}$ show the temperature at the south wall, whereas Figures $\mathrm{V}-8 \mathrm{~F}$ and V-8G depict the surface temperature of the west wall. For each wall, the temperature is plotted versus solar radiation. The time-sequence of the scatter is in a counter-clockwise direction.

In Figure V-8D, we can see that an increase in solar radiation in the morning (lower scatter) results in increasing surface temperature at the south wall, and, as insolation continues, the afternoon temperatures (upper scatter are higher). Figure V-8E shows that, after the trees were in place, the afternoon south-wall surface temperatures (upper scatter) are generally lower than those depicted in Figure V-8D. On the average, the afternoon surface temperature on the south wall was decreased by $7^{\circ} \mathrm{C}$, due to the shading effects of trees. Recall that site 8 had more trees than other sites. The regression lines in these figures have no special usefulness aside from demarcating the lower and upper scatters (morning and afternoon hours).

In Figure V-8F the surface temperature at the west wall for the pre-conditions is shown. Examining the upper scatters show that although the maximum temperatures on the south and west walls are comparable, the timing of the maximum temperature on the west wall (Fig V-8F) is about 3 hours later than at the south wall (Fig 8D). Figure V-8G shows the large depression 
Figure V-8A. Site 8: Daily cooling electricity use ( $k W h / d a y)$ vs maximum outdoor air temperature $\left({ }^{\circ} \mathrm{C}\right)$ for pre- and post-retrofit conditions. Post-conditions with seven additional trees on south. Solid regression line is for pre-retrofit conditions, broken regression line is for postretrofit. Pre-retrofit monitoring period at this site was August 23 through September 6, and the post-retrofit period was September 25 through October 21, 1991.

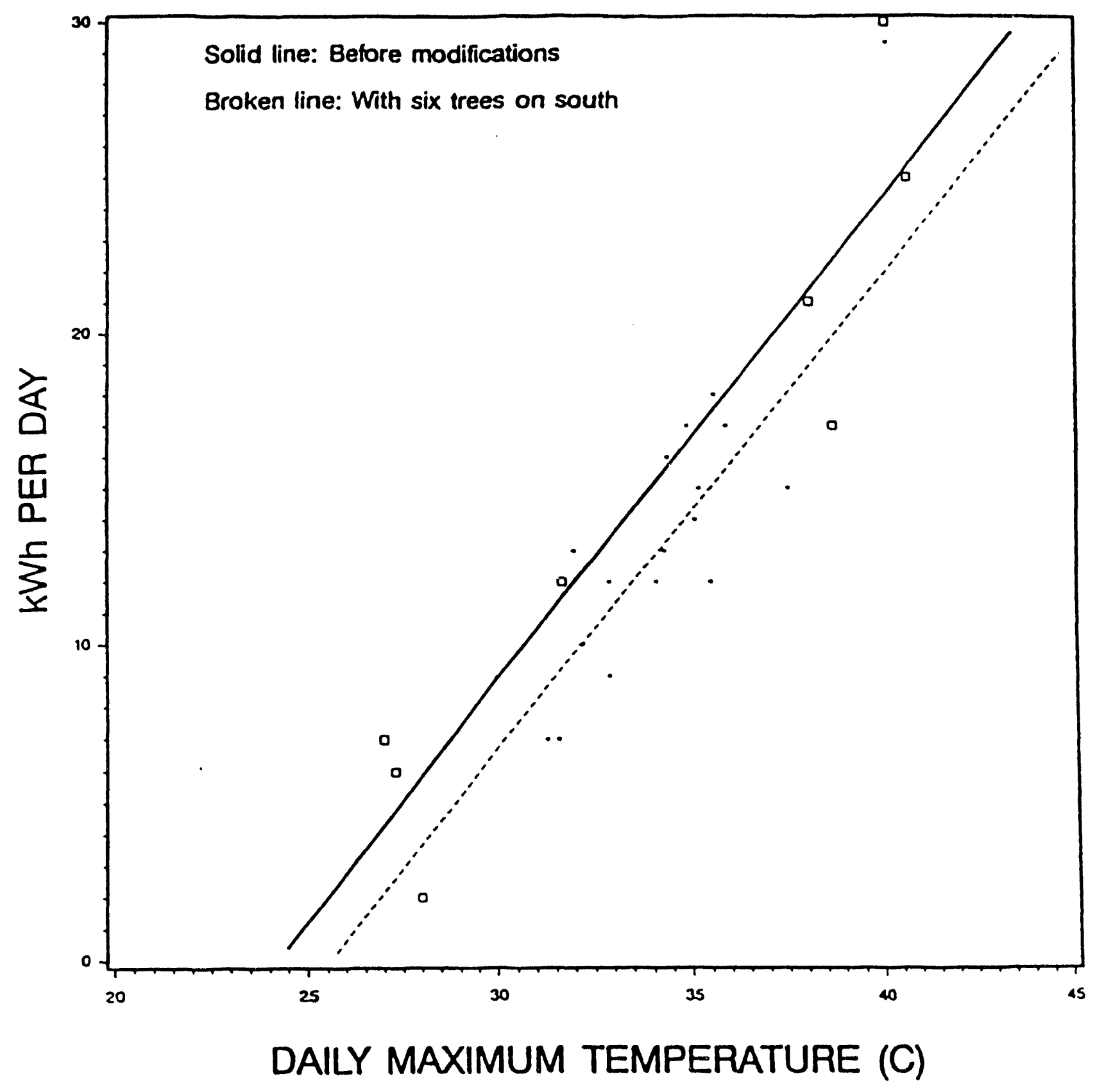


Figure V-8B. Site 8: Hourly cooling electricity use (Wh/h) vs mean hourly outdoor air temperature $\left({ }^{\circ} \mathrm{C}\right)$ for pre- and post-retrofit conditions. Post-conditions with seven additional trees on south. Solid regression line is for pre-retrofit conditions, broken regression line is for postretrofit. Pre-retrofit monitoring period at this site was August 23 through September 6, and the post-retrofit period was September 25 through October 21. 1991.

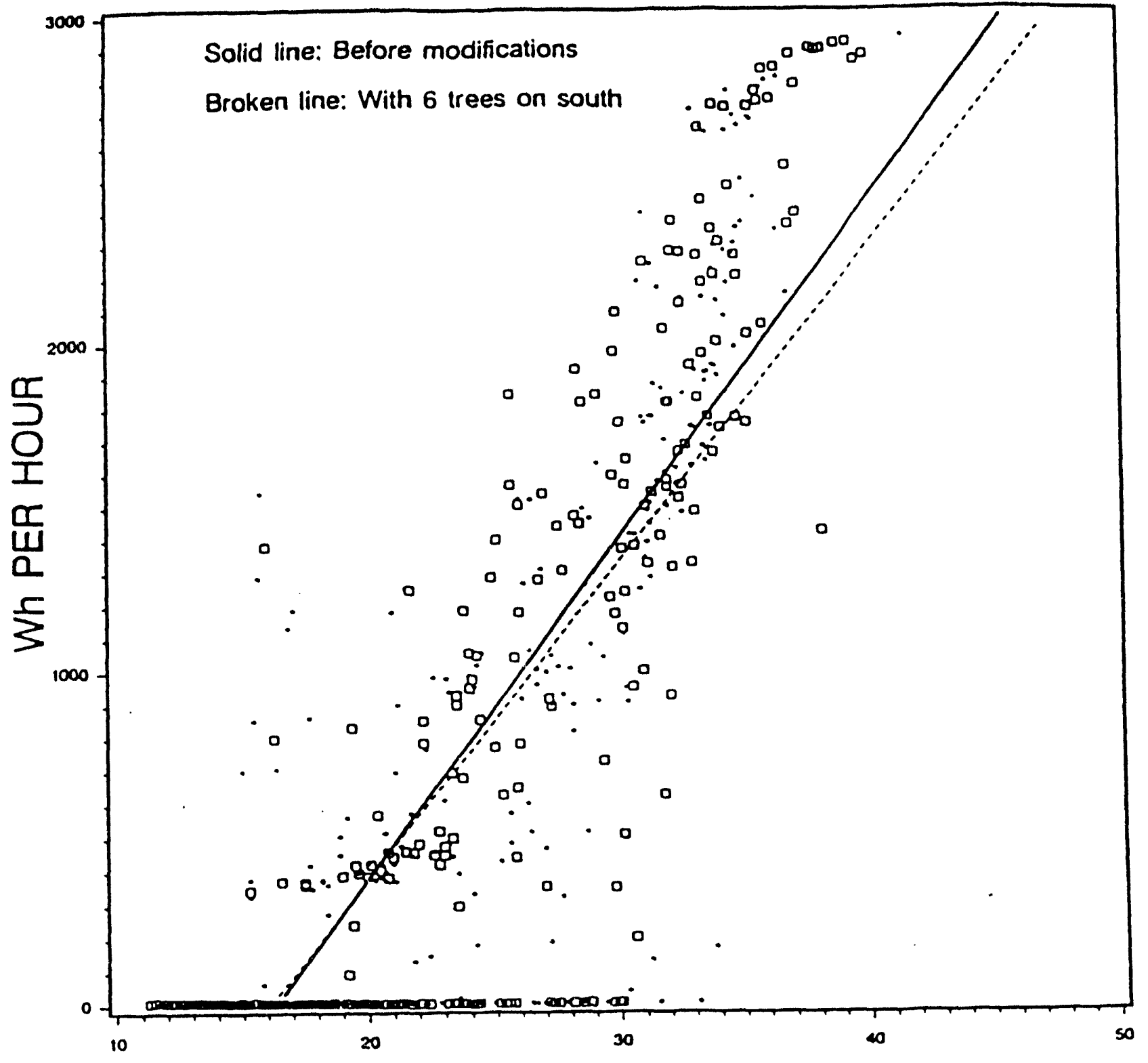

MEAN HOURLY OUTDOOR AIR TEMPERATURE (C) 
Figure V-8C. Site 8: Hourly cooling electricity use (Wh/h) vs hourly difference between outdoor and indoor air temperatures $\left({ }^{\circ} \mathrm{C}\right)$. Post-conditions include seven additional trees on south. Solid regression line is for pre-retrofit conditions, broken regression line is for post-retrofit. Preretrofit monitoring period at this site was August 23 through September 6, and the post-retrofit period was September 25 through October 21, 1991.

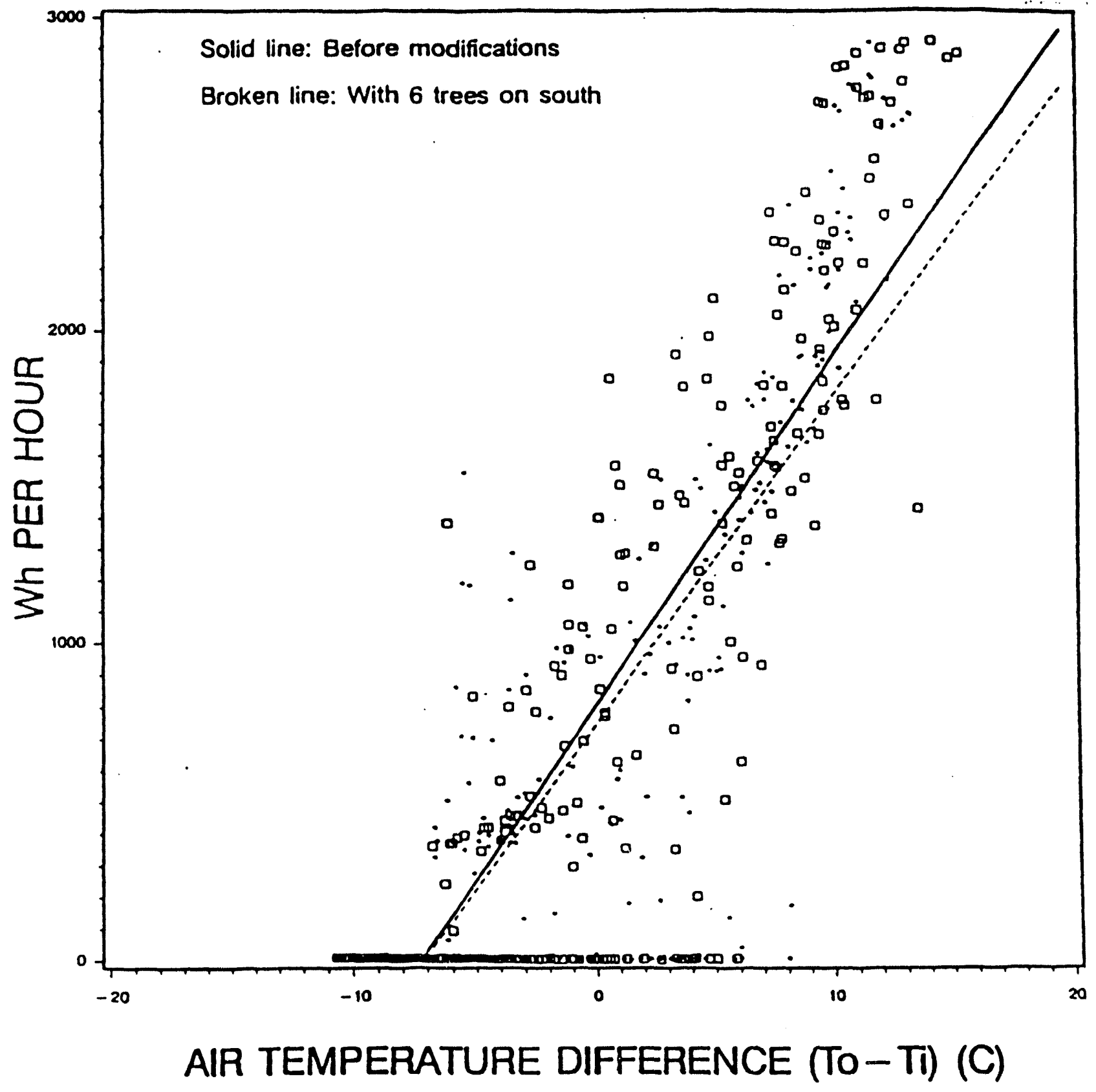



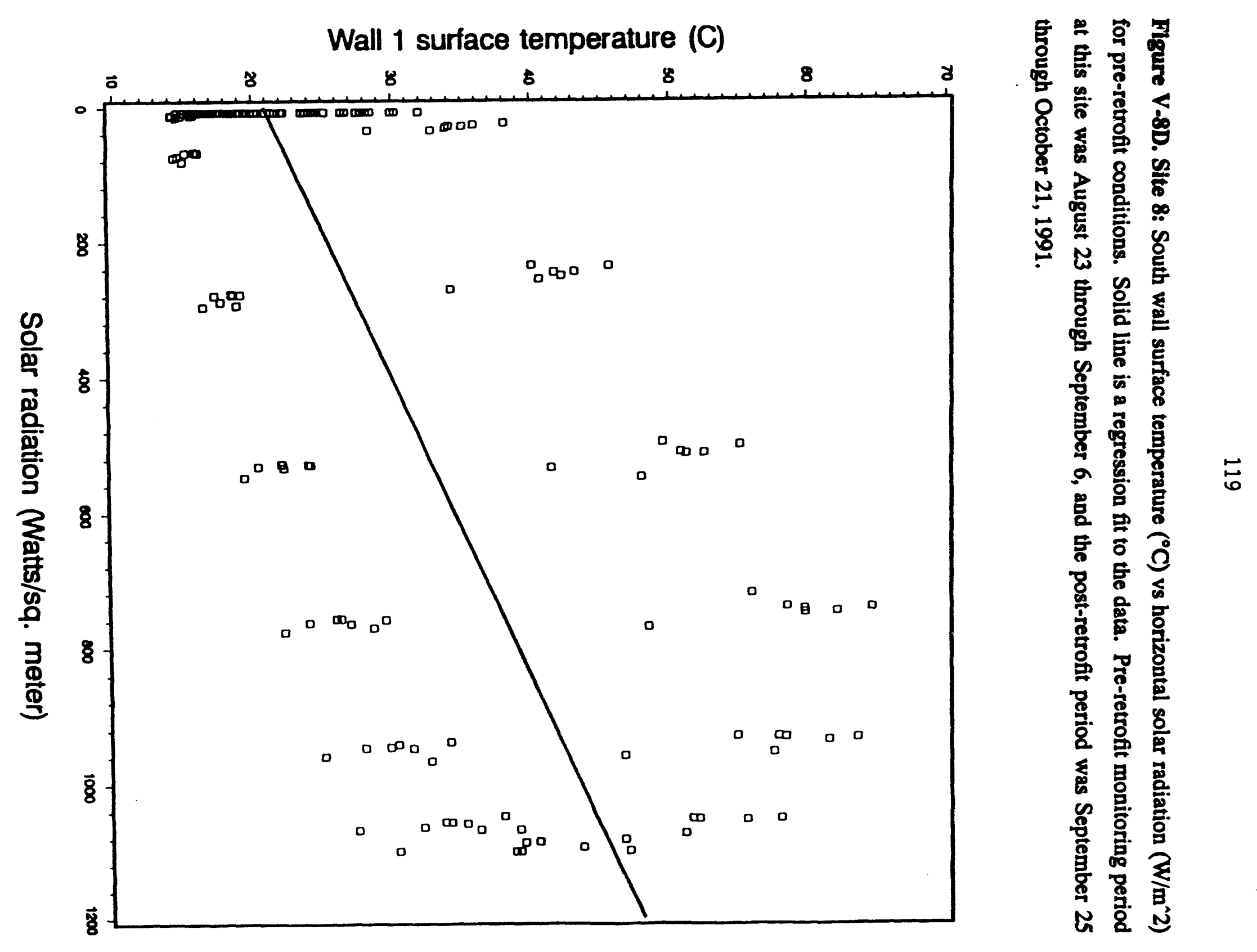
Figure V-8E. Site 8: South wall surface temperature $\left({ }^{\circ} \mathrm{C}\right)$ vs horizontal solar radiation $\left(\mathrm{W} / \mathrm{m}^{2}\right)$ for post-retrofit conditions. Solid line is a regression fit to the data. Pre-retrofit monitoring period at this site was August 23 through September 6, and the post-retrofit period was September 25 through October 21, 1991.

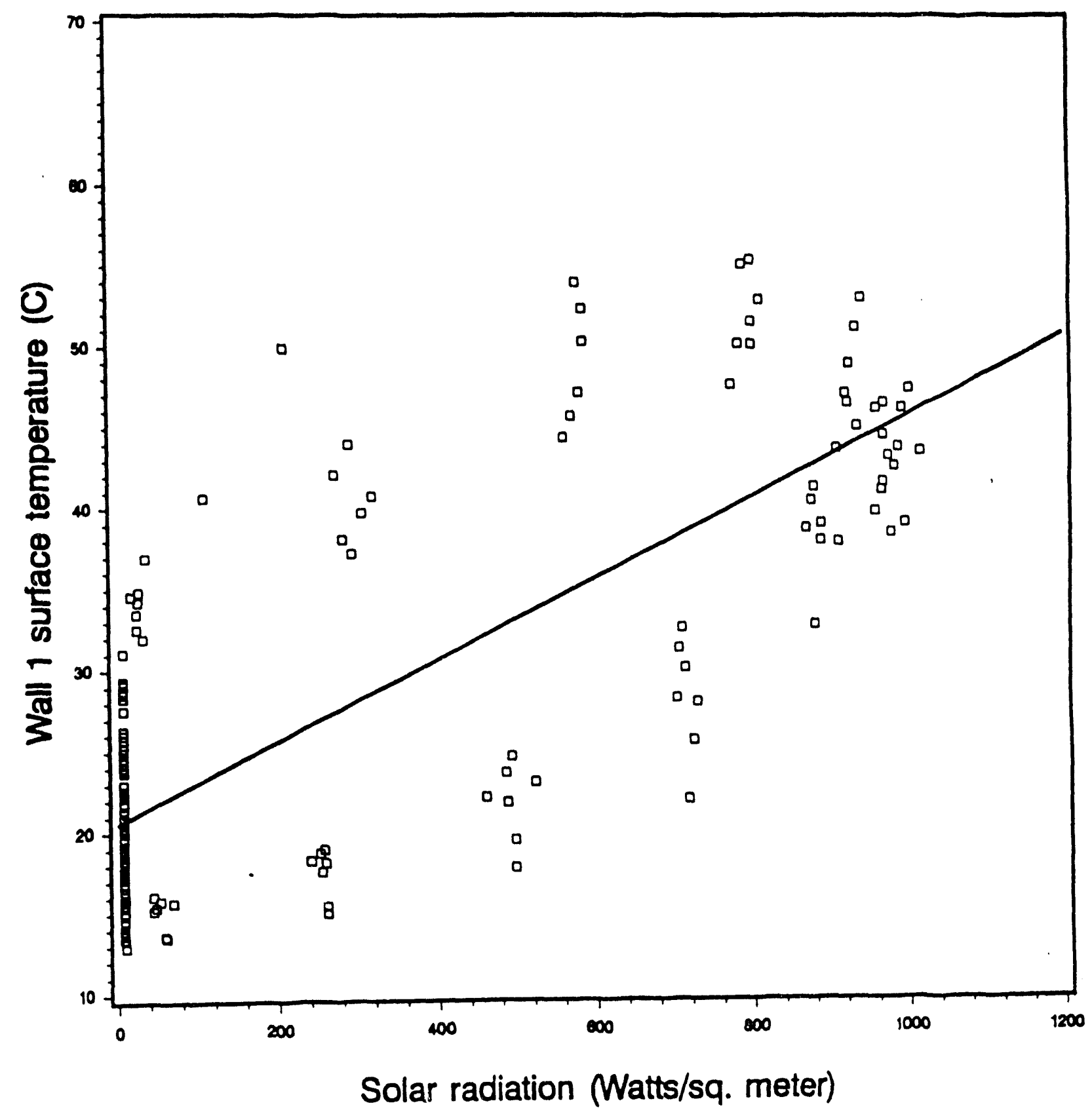


Figure V-8F. Site 8: West wall surface temperature $\left({ }^{\circ} \mathrm{C}\right)$ vs horizontal solar radiation $\left(\mathrm{W} / \mathrm{m}^{2}\right)$ for pre-retrofit conditions. Solid line is a regression fit to the data. Pre-retrofit monitoring period at this site was August 23 through September 6, and the post-retrofit period was September 25 through October 21, 1991.

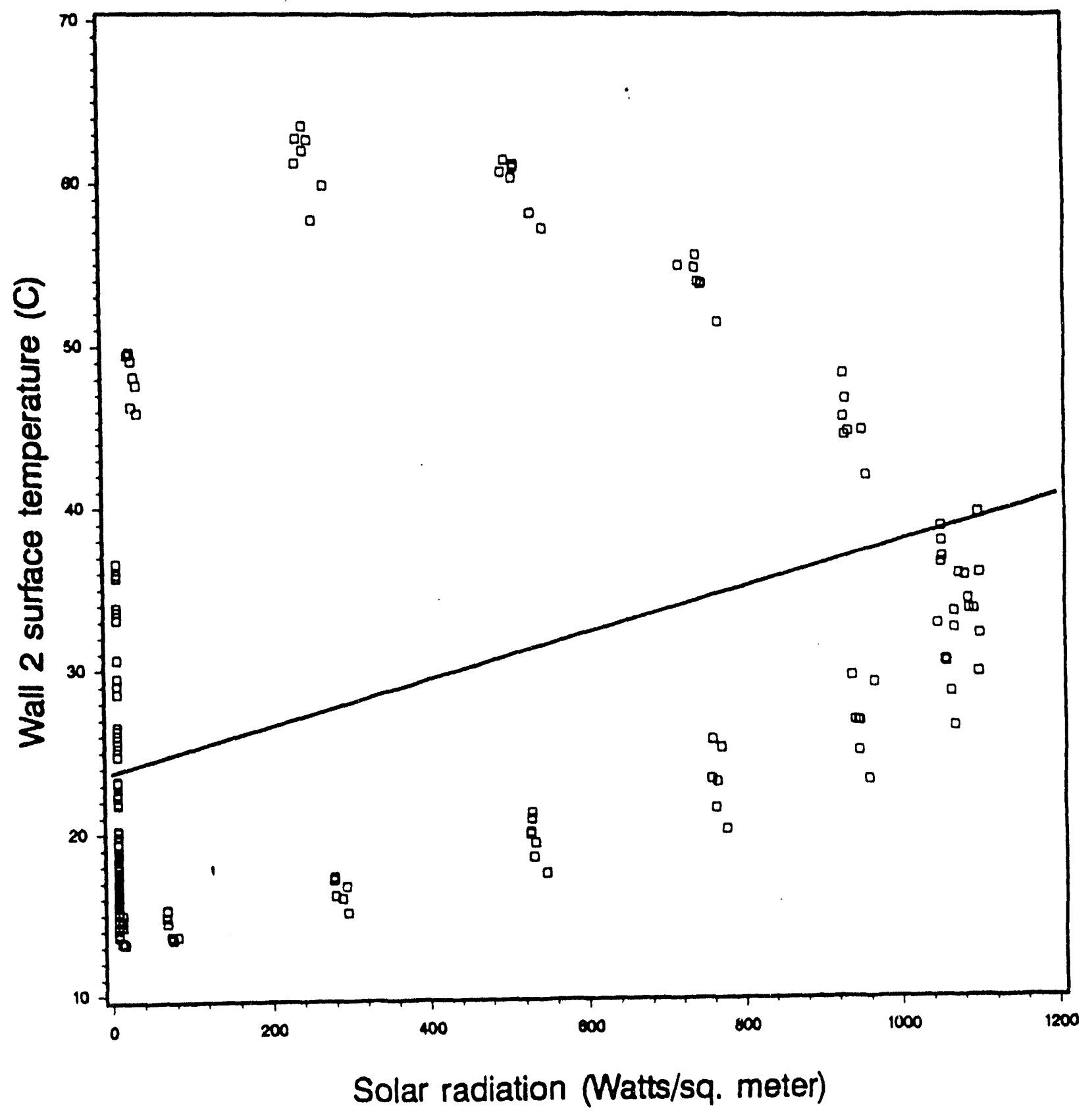


Figure V-8G. Site 8: West wall surface temperature $\left({ }^{\circ} \mathrm{C}\right)$ vs horizontal solar radiation $\left(\mathrm{W} / \mathrm{m}^{2}\right)$ for post-retrofit conditions. Solid line is a regression fit to the data. Pre-retrofit monitoring period at this site was August 23 through September 6, and the post-retrofit period was September 25 through October $21,1991$.

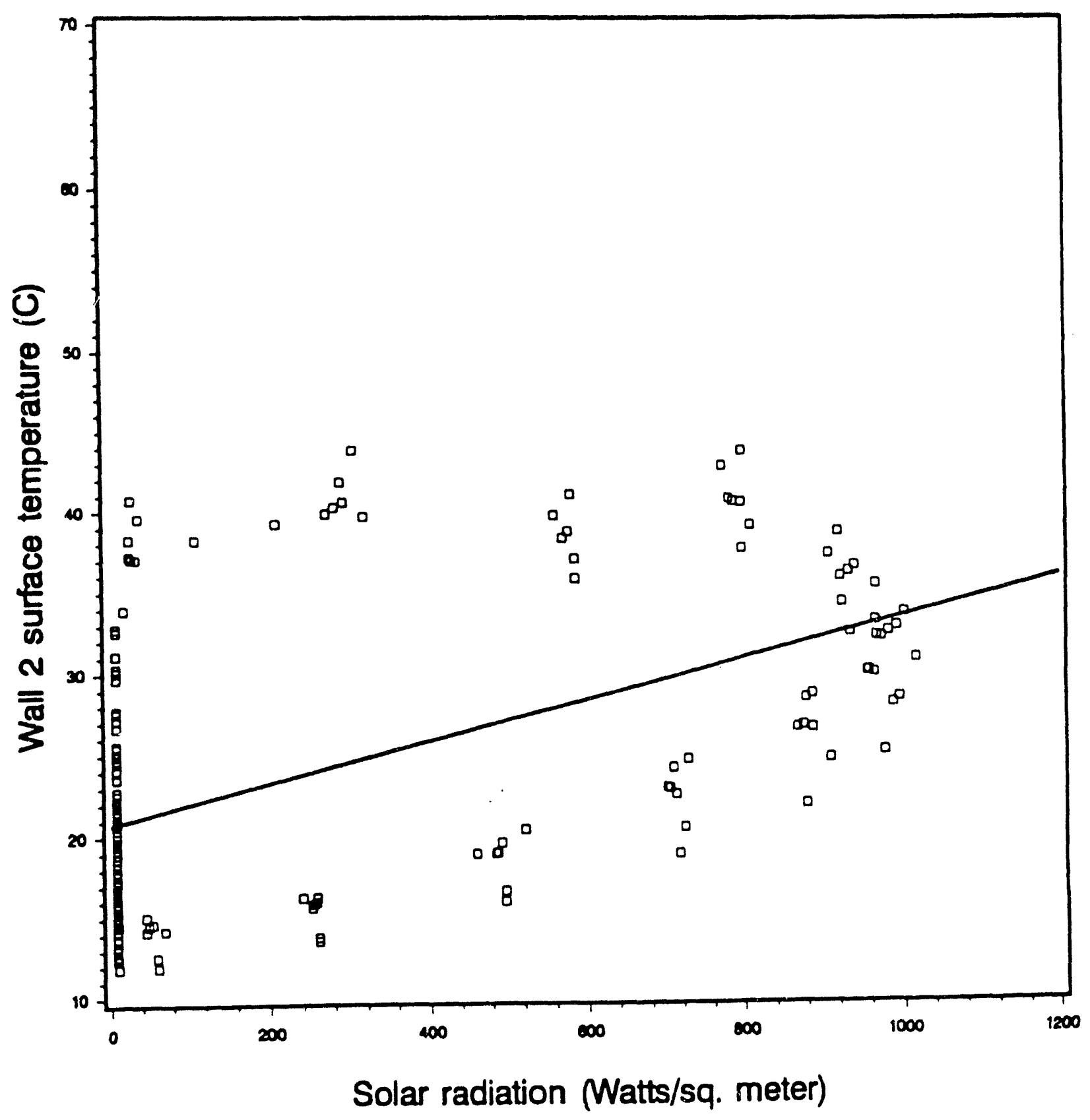


in the surface temperature of the west wall after the trees were in place. At the time of peak west-wall surface temperature (solar radiation $=300 \mathrm{Wm}^{-2}$ ), the surface temperature was on the average $20^{\circ} \mathrm{C}$ lower after the trees were in place (compare the upper scatter in Figures $\mathrm{V}-8 \mathrm{~F}$ and $V-8 G)$. Note that the solar radiation given in these figures is not the normal on the surface but the total horizontal solar radiation measured at roof level.

The comparisons of simulated and measured data for Site 8 are presented in Figures V-8H and V-8I. The indoor temperature at this site is well-controlled and the simulated load and measured load agree well except for a few days when the simulated peak is much higher than the measured peak. On these days, the cooling system in the house appears to be running continuously over several hours and the simulation model does not accurately predict the peak power draw of the equipment. The model overpredicts total daily cooling by about $12 \%$ to $14 \%$ in the pre- and post-periods. The measured data for Julian days 275 and 276 also suggests that nighttime cooling or heating is being supplied by the heat pump.

The simulated daily data are plotted in Figure V-8J. Compared to the measured data shown in Figure V-8A, the simulated data is consistently higher by about $4 \mathrm{kWh} /$ day over the pre-monitoring period, but the slope of the regression line is similar. As with the other tree sites, when accounting for the change in climatic conditions between the pre- and post-periods, the simulated cooling energy savings from the trees is minimal.

\section{Discussion}

Overall, the calibration and comparison exercises highlight the difficulty encountered in matching simulation results with measured data. The types and magnitudes of the errors are not consistent across the sites. The daily energy consumption is slightly overpredicted at Sites 2,5 (pre-period), 6, 7, and 8, but the peaks match well. Peak loads at Sites B and 5 match well, but daily energy consumption at Site 5 does not match well.

The analysis suggests the models could benefit from further refinements. However, given the current level of characterization for each site, the models perform reasonably well. The necessary refinements would focus on details of the cooling systems, which is the primary method of assessing albedo and vegetation impacts, occupancy patterns, thermostat operations, 
Figure V-8H. Compressor watt hours and building interior temperature for $8 / 30$ to $9 / 5$ at Site 8 . Comparison of measured and simulated data before vegetation modification.

Days 242 to 248 Measured: $22.5 \mathrm{kWh} /$ day DOE-2: $25.4 \mathrm{kWh} /$ day.

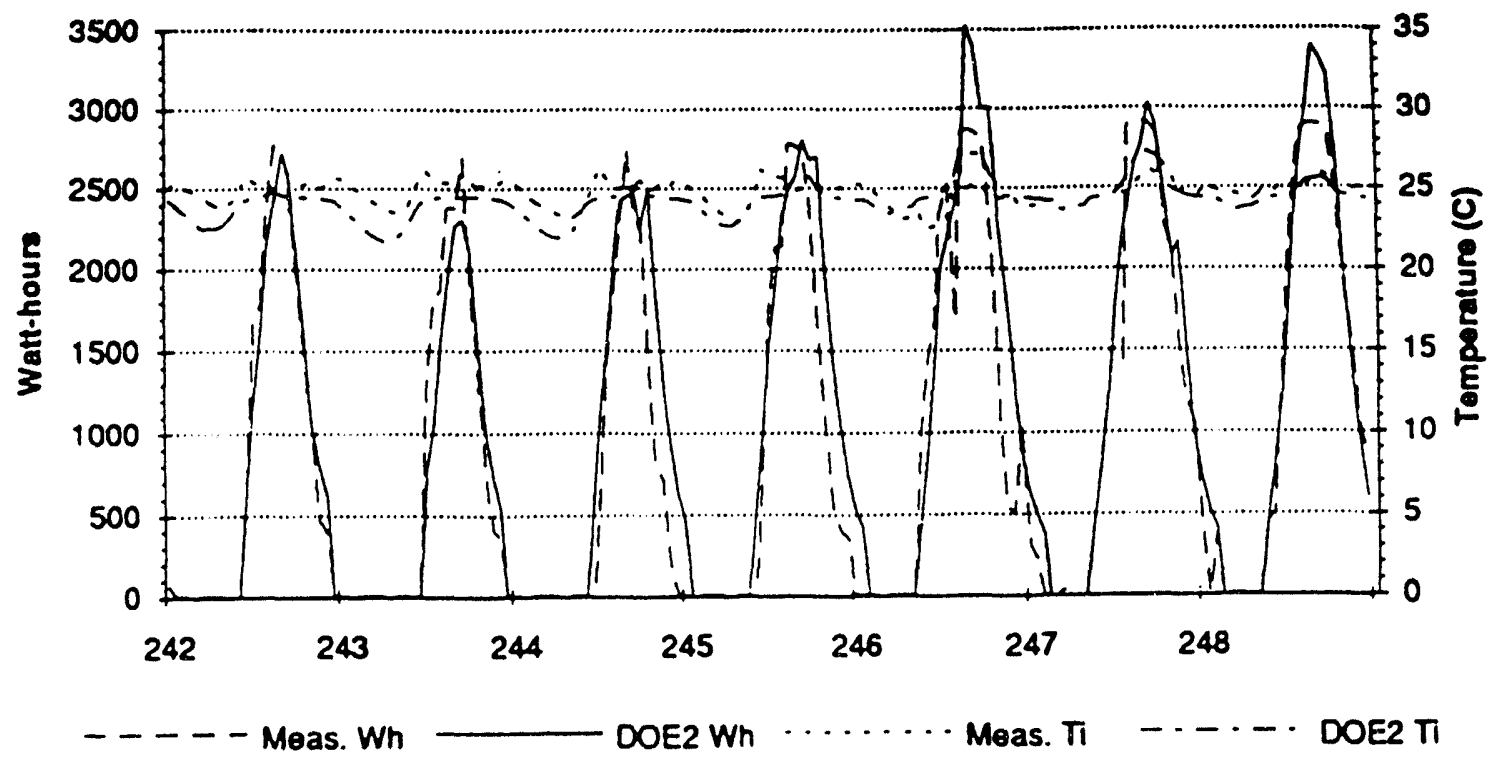

Figure V-8I. Compressor watt hour: and building interior temperature for $10 / 2$ to $10 / 8$ at Site 8 . Comparison of measured and simulated lata after vegetation modification.

Days 277 to 281 Measured: $12.7 \mathrm{kWh} /$ day DOE-2: $14.5 \mathrm{kWh} /$ day.

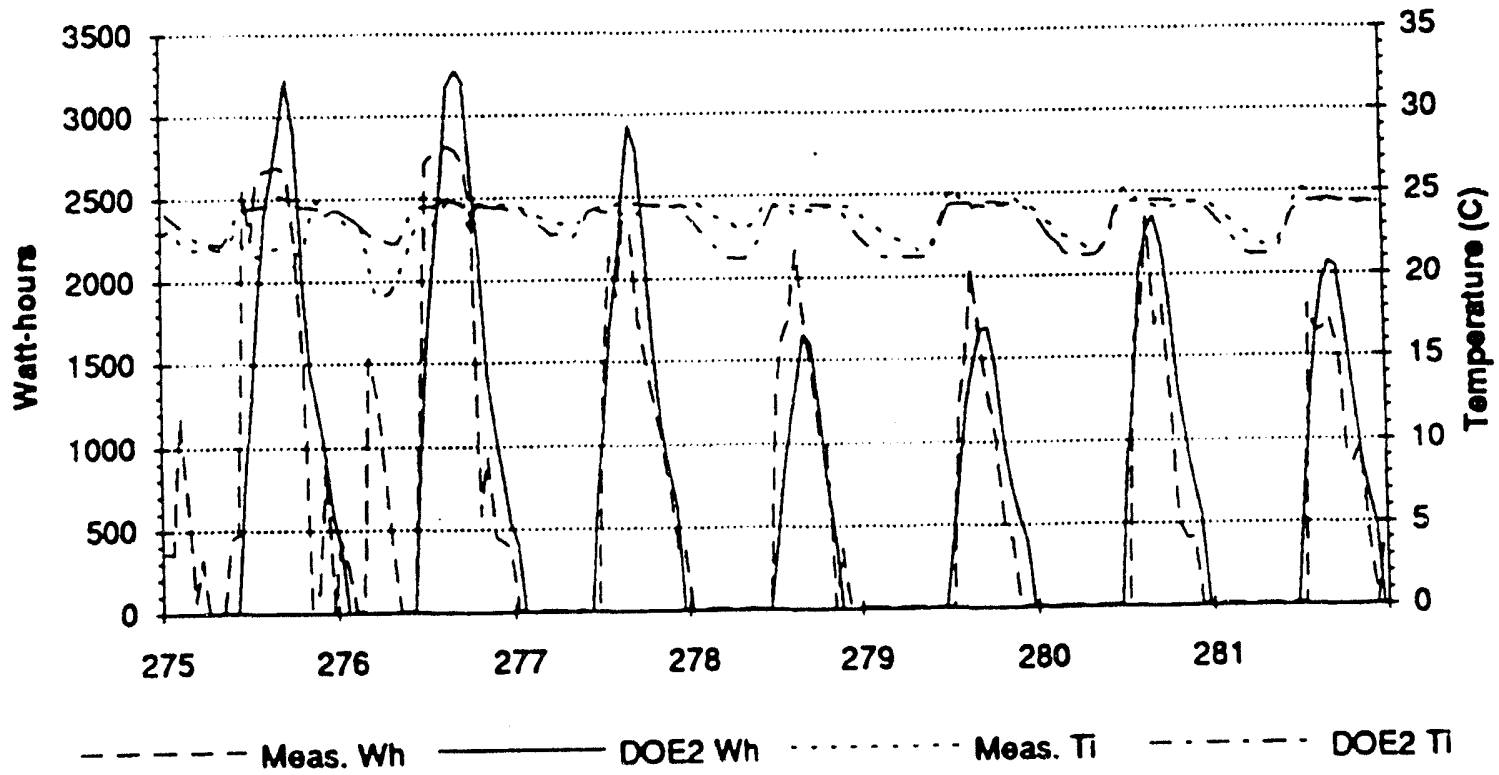


Figure V-8J. Site 8: Simulation Results: Daily data Squares and solid line represent base case in late summer (days 235 - 249). Crosses and dashed line represent the addition of 6 shade trees in late summer (days 235 - 249). Triangles and dotted line represent the case of 6 shade trees in fall (days 268 - 294).

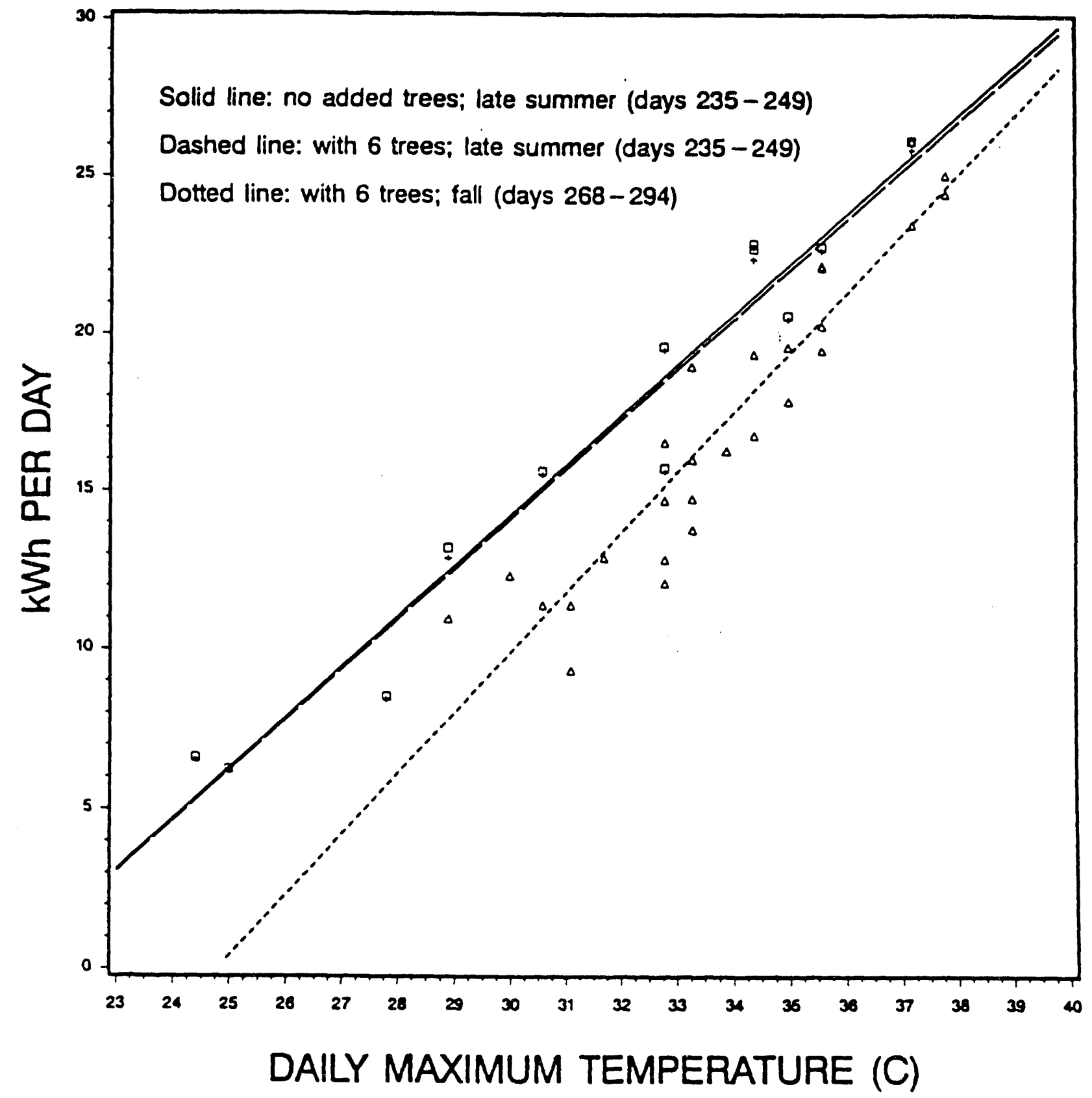


building thermal mass, and the local climate characteristics. The first-order refinements listed below include data that could be gathered to refine the model estimates in addition to existing data.

1. At a minimum, the ducting systems in each house should be tested for air leakage and conduction losses. These parameters could then be incorporated into the models to more accurately characterize duct performance at different climatic conditions.

2. The cooling equipment efficiency should also be tested. This testing could be one of several techniques ranging from simple spot testing to more complete monitoring of air flows and temperatures and electricity consumption.

3. More information about occupancy patterns and appliance usage schedules would improve the inputs for hourly internal gains inputs. The effect of improved characterization of internal gains is unclear, however.

4. Some of the interior temperature data shows the buildings have a slower thermal response to diurnal temperature swings than the model predicts. Better model inputs for thermal mass may improve the models in this area.

5. More complete climatic data for each site would allow us to develop model inputs that are more specific to a site's microclimate. The primary reason that site temperature data were not used with simulations was because of the amount of gaps in the measured data. In addition, the site solar data was not useful to the DOE-2 models because of the method of measurement. These problems will be solved in future work.

In future data-collection studies, the model calibration would also benefit from several indoor temperature sensors, which would help to understand the conditions throughout the building. In particular, a sensor located next to the thermostat would help explain and verify apparent thermostat abnormalities.

\section{Summary}

The purpose of this study was to quantify the potential of high-albedo materials and vegetation for reducing cooling energy use in buildings. The analysis of measured data indicates that albedo modifications had significant impacts on cooling energy use, whereas vegetation 
modifications had only small measurable impacts in two sites and negligible effects in others.

In one house, recoating the dark roof with a high-albedo coating indicated almost $100 \%$ savings in cooling energy use during September (uncorrected for insolation changes). Savings of 50\% were achieved when a school bungalow's roof and southeast wall were coated with a high-albedo coating. The original roof of the bungalow was metallic and its original southeast wall was painted yellow. DOE-2 simulations of the house also showed significant savings, but attributed some savings to generally lower insolation during the post-monitoring period. For the school bungalow, the simulations show only about $15 \%$ savings from the high albedo roof, and attribute some of the apparent savings to the different reported thermostat setpoints in the two buildings.

In the vegetation sites, savings were generally much lower than in the albedo cases. In one house, the addition of two trees on the west and one tree on the south sides resulted in saving $-40 \%$ in cooling energy use, whereas the addition of two southwest trees to another home reduced its cooling energy by $\sim 30 \%$. The other two other cases showed smaller savings. The addition of two trees on the east side of a well-shaded house reduced its cooling energy use by $-10 \%$, and the addition of six trees on the south side of a completely unshaded home reduced its energy use by only $\sim 10 \%$. However, these savings will be significantly smaller once corrected for solar intensity and so, should be regarded as possible overestimates.

The DOE-2 simulations of these buildings appear to indicate very small or no savings from trees. The issue of comparing DOE-2 simulations with measured data will be addressed in further detail during the second year of this project. Ways of improving the simulations to reflect actual conditions were suggested in this report.

In addition to internal loads, schedules, and envelope characteristics, the reason why some sites had larger savings than others might be the fact that the local microclimate was different from one location to another. For example, Site 2 was in a cooler environment, heavily shaded, and therefore, this might have helped save $100 \%$ of cooling energy use when the roof was recoated with a high-albedo coating. Site 8 , on the other hand, was in a warmer part of Sacramento, and that might explain why only $10 \%$ or less of cooling energy was saved by planting six trees on its south side. Microclimate variations are briefly discussed in Section $\mathrm{E}$.

The major conclusion of the simulation work is that the albedo modifications made to Sites 2 and $B$ produced significant changes in cooling energy use. On the other hand, the direct 
shading effect of the trees used in the study led to almost imperceptible changes in cooling use, most likely because of their small size. Any indirect cooling effects of these trees cannot be evaluated in the DOE-2 model.

An issue to keep in mind in the following year of this project is the start of monitoring. Preferably, this should start earlier in summer to avoid the concerns of seasonal cooling. An ideal time to start would be the month of June. Also, plenty of time should be allowed for equipment acquisition, testing, calibrating, and installing in the field. These tasks are the most crucial and demanding of all project phases. Finally, since some of the savings (in the vegetation sites) were larger than expected, we recommend repeating the entire experiment with more controlled vegetation tests. Also, in the second year of this project, larger and more mature trees should be used instead of the small ones.

The previous figures have shown that models seem to be reasonably calibrated against the measured given the level of detail gathered in the measured data and the difficulties of simulating real buildings under $r t a l$ conditions. A quantitative assessment of the model calibration is given in Table V-8. In this comparison we show the measured energy data and the simulated estimates on a daily basis for each site. We also show the results from a linear fit of the measured data to the simulated data. Note that we only include days with full data, and delete some of the days with abnormal cooling usage due to either extremely high peak usage or to days when the air-conditioning was essentially turned off.

For most sites, the correlation between the measured and the simulated data is above $70 \%$ (as given by the $\mathrm{R}^{2}$ ), although there are specific cases where this is not true. For example, at Site 2 the modified case period only has a few days with any cooling usage and the comparison is thus almost meaningless. The errors in the fit are typically between 1 and $3 \mathrm{kWh} /$ day. The peak cooling ( $\mathrm{kW}$ ) is more difficult to model than the daily total ( $\mathrm{kWh})$, most likely because of the many unknowns in cooling system performance and occupant behavior. However, for the school bungalow, the correlation between simulated and measured energy is better for the peak than for the daily total, and in general these two buildings are not modeled well.

The model estimates of the savings in cooling energy use are summarized in Table V.9. These are calculated by simulating the Base and Modified cases over the period of monitoring in the Base case. Note that the simulations only calculate the direct effect of building surface and window shading from the trees. Other effects, such as increased cooling system performance 
Table V-8. Comparison of Measured and Simulated Data on Daily Basis

\begin{tabular}{|c|c|c|c|c|c|c|c|c|c|c|c|}
\hline \multirow[b]{3}{*}{ Site } & \multirow[b]{3}{*}{ C } & \multirow{3}{*}{\multicolumn{2}{|c|}{$\begin{array}{l}\text { start stop } \mathrm{N}^{*} \\
\text { day day days }\end{array}$}} & \multicolumn{2}{|c|}{$\begin{array}{c}\text { Measured } \\
\text { Average Daily }\end{array}$} & \multicolumn{2}{|c|}{$\begin{array}{c}\text { Simulated } \dagger \\
\text { Average Daily }\end{array}$} & \multicolumn{4}{|c|}{$\begin{array}{c}\text { Regression Model Results } \\
\text { Measured }=a+b \times \text { Simulated }\end{array}$} \\
\hline & & & & Energy & Load & Energy & Load & Energ. & $(k W h)$ & Load ( & $(W)$ \\
\hline & & & & $(\mathrm{kWh})$ & $(\mathrm{kW})$ & $(\mathrm{kWh})$ & $(\mathrm{kW})$ & StdErr & $\mathrm{R}^{2}$ & StdErr & $\mathrm{R}^{2}$ \\
\hline Site 1 & Control & 236293 & 36 & 4.84 & 1.37 & 5.74 & 1.22 & 2.97 & 0.51 & 0.80 & 0.39 \\
\hline Site 2 & Base & 235253 & & 2.95 & 0.90 & 4.33 & 0.85 & 1.16 & 0.85 & 0.40 & 0.74 \\
\hline Site 2 & White $\neq$ & 260293 & 30 & 0.23 & 0.11 & 0.39 & 0.13 & 0.63 & 0.21 & 0.32 & 0.15 \\
\hline Site 2 & All & 235293 & 43 & 1.06 & 0.35 & 1.58 & 0.35 & 0.85 & 0.84 & 0.35 & 0.67 \\
\hline ite 5 & se§ & 255258 & & 10.33 & 1.91 & 66 & 1.54 & 2.76 & 0.3 & .19 & 0.72 \\
\hline Site 5 & Trees & 268293 & 23 & 9.20 & 1.91 & 8.64 & 1.63 & 2.63 & 0.56 & 0.36 & 0.47 \\
\hline Site 5 & All & 255293 & 27 & 9.37 & 1.91 & 8.50 & 1.62 & 2.61 & 0.5 & 0.34 & 0.48 \\
\hline Site 6 & Base & 234265 & 17 & & 1.68 & & 1.30 & 2.24 & 0.7 & .74 & 0.65 \\
\hline Site 6 & Trees & 268292 & 13 & 4.42 & 1.56 & 8 & 1.06 & 1.42 & 0.78 & .36 & 0.75 \\
\hline Site 6 & All & 234292 & 30 & 5.06 & 1.63 & .07 & 1.19 & 2.33 & 0.6 & 0.69 & 0.54 \\
\hline Site 7 & Base & 247265 & 14 & 1 & 1.93 & 26 & 1.97 & 3.50 & 0. & 51 & 0.57 \\
\hline Site 7 & Trees & 268290 & 20 & 33 & 1.89 & 34 & 2.01 & 2.81 & 0.71 & .85 & 0.39 \\
\hline Site 7 & All & 247290 & 34 & 8.81 & 1.91 & 11.72 & 1.99 & 3.06 & 0.7 & 0.71 & 0.43 \\
\hline Site 8 & Base & 236248 & & 1.68 & 2.69 & 35 & 2.72 & 2.30 & 0.87 & .15 & 0.80 \\
\hline Site 8 & Trees & 268293 & 25 & 14.79 & 2.23 & 17.15 & 2.42 & 3.31 & 0.64 & 0.28 & 0.56 \\
\hline Site 8 & All & 236293 & 33 & 16.22 & 2.34 & 18.41 & 2.49 & 3.16 & 0.73 & 0.29 & 0.58 \\
\hline Site & & 246293 & 25 & 93 & 1.30 & 6 & 1.38 & 3.8 & 0. & 0.51 & 0.65 \\
\hline Site B2 & Metal** & 246293 & 25 & 17.35 & 2.70 & 19.59 & 2.16 & 6.06 & 0.37 & 0.67 & 0.42 \\
\hline
\end{tabular}

* Days with $100 \%$ data capture only (sclected days removed at each site with erratic cooling usage).

+ Average of simulated data only for days with complete measured data

$¥ R^{2}$ for Site 2 post period is low because almost all values are 0 .

$\$$ Site 5 "pre" period data contains only four days for the comparison.

* Thermostat setpoint for Site B1 is $78^{\circ} \mathrm{F}$ and for $\mathrm{B} 2$ is $70^{\circ} \mathrm{F}$. 
from direct shading of the air-conditioning condenser unit or indirect/microclimate effects of evapotranspiration were not modeled directly. The DOE-2 simulation results suggest only that the direct shading effects on cooling demand are not significant in these cases because the trees were small.

Table V-9. Model Estimates of Experimental Savings over Base Case Period

\begin{tabular}{|c|c|c|c|c|c|c|c|}
\hline \multirow[b]{2}{*}{ Site } & \multirow[b]{2}{*}{ Case } & \multicolumn{2}{|c|}{$\begin{array}{c}\text { Base Case } \\
\text { Average Daily Usage }\end{array}$} & \multicolumn{4}{|c|}{$\begin{array}{c}\text { Modified Case } \\
\text { Average Daily Savings }\end{array}$} \\
\hline & & $(\mathrm{kWh})$ & $(\mathrm{kW})$ & $(k W h)$ & (\%) & $(\mathrm{kW})$ & $(\%)$ \\
\hline Site 2 & Albedo & 3.26 & 0.67 & 2.33 & 71 & 0.43 & 64 \\
\hline Site 5 & Trees & 7.55 & 1.49 & 0.33 & 4 & 0.02 & 1 \\
\hline Site 6 & Trees & 7.49 & 1.51 & 0.03 & 1 & 0.01 & 1 \\
\hline Site 7 & Trees & 13.15 & 2.12 & 0.06 & 1 & 0.02 & 1 \\
\hline Site 8 & Trees & 20.10 & 2.45 & 0.17 & 1 & 0.02 & 1 \\
\hline Site $B \dagger$ & Albedo & 9.36 & 1.39 & 1.44 & 15 & 0.17 & 12 \\
\hline
\end{tabular}

† Base case is occupied building with metal roof simulated with $78^{\circ} \mathrm{F}$ setpoint.

In Table V-10, we present monthly and annual estimates of cooling energy use from the simulation models. Note that in this case we use the Sacramento TMY weather tape, and thus do not account for microclimates specific to each site. 
Table V-10. Simulated Annual Cooling Energy Use and Peak Energy Demand (including Fan) (Sacramento TMY Weather)

\begin{tabular}{|c|c|c|c|c|c|c|c|c|c|}
\hline & \multicolumn{6}{|c|}{ Month } & \multirow{2}{*}{$\begin{array}{l}\text { Total } \\
\text { Year }\end{array}$} \\
\hline & & & May & Jun & Jul & Aug & Sep & Oct & \\
\hline $\begin{array}{l}\text { Site } 1 \\
\end{array}$ & Control & $\begin{array}{l}\mathbf{k W h} \\
\mathbf{k W}\end{array}$ & $\begin{array}{r}74 \\
3.66\end{array}$ & $\begin{array}{r}170 \\
3.86\end{array}$ & $\begin{array}{r}377 \\
3.99\end{array}$ & $\begin{array}{l}355 \\
3.93\end{array}$ & $\begin{array}{r}161 \\
3.77\end{array}$ & $\begin{array}{r}29 \\
1.92\end{array}$ & $\begin{array}{l}1166 \\
3.99\end{array}$ \\
\hline$\overline{\text { Site } 2}$ & Base & $\begin{array}{l}\mathrm{kWh} \\
\mathrm{kW}\end{array}$ & $\begin{array}{r}79 \\
2.27\end{array}$ & $\begin{array}{r}121 \\
2.15\end{array}$ & $\begin{array}{r}278 \\
2.93\end{array}$ & $\begin{array}{r}223 \\
2.43\end{array}$ & $\begin{array}{r}79 \\
2.02\end{array}$ & $\begin{array}{r}13 \\
1.11\end{array}$ & $\begin{array}{r}793 \\
2.93\end{array}$ \\
\hline Site 2 & Albedo & $\begin{array}{l}\mathbf{k W h} \\
\mathbf{k W}\end{array}$ & $\begin{array}{r}32 \\
1.90\end{array}$ & $\begin{array}{r}60 \\
1.78\end{array}$ & $\begin{array}{r}188 \\
2.47\end{array}$ & $\begin{array}{r}140 \\
2.10\end{array}$ & $\begin{array}{r}41 \\
1.53\end{array}$ & $\begin{array}{c}5 \\
0.83\end{array}$ & $\begin{array}{r}466 \\
2.47\end{array}$ \\
\hline Site 5 & Base & $\begin{array}{l}\mathrm{kWh} \\
\mathrm{kW}\end{array}$ & $\begin{array}{r}122 \\
3.68\end{array}$ & $\begin{array}{r}271 \\
3.64\end{array}$ & $\begin{array}{r}607 \\
4.46\end{array}$ & $\begin{array}{r}564 \\
4.34\end{array}$ & $\begin{array}{r}255 \\
3.97\end{array}$ & $\begin{array}{r}46 \\
2.18\end{array}$ & $\begin{array}{l}1865 \\
4.46\end{array}$ \\
\hline Site 5 & Trees & $\begin{array}{l}\mathrm{kWh} \\
\mathrm{kW}\end{array}$ & $\begin{array}{r}115 \\
3.66\end{array}$ & $\begin{array}{r}264 \\
3.62\end{array}$ & $\begin{array}{r}597 \\
4.44\end{array}$ & $\begin{array}{r}554 \\
4.33\end{array}$ & $\begin{array}{r}246 \\
3.95\end{array}$ & $\begin{array}{r}46 \\
2.16\end{array}$ & $\begin{array}{l}1822 \\
4.44\end{array}$ \\
\hline Site 6 & Base & $\begin{array}{l}\mathrm{kWh} \\
\mathrm{kW}\end{array}$ & $\begin{array}{r}164 \\
4.14\end{array}$ & $\begin{array}{r}159 \\
2.93\end{array}$ & $\begin{array}{r}396 \\
4.24\end{array}$ & $\begin{array}{c}363 \\
3.54\end{array}$ & $\begin{array}{r}143 \\
3.01\end{array}$ & $\begin{array}{r}25 \\
1.68\end{array}$ & $\begin{array}{l}1250 \\
4.24\end{array}$ \\
\hline Site 6 & Trees & $\begin{array}{l}\mathrm{kWh} \\
\mathrm{kW}\end{array}$ & $\begin{array}{r}162 \\
4.11\end{array}$ & $\begin{array}{r}158 \\
2.92\end{array}$ & $\begin{array}{r}395 \\
4.24\end{array}$ & $\begin{array}{r}362 \\
3.54\end{array}$ & $\begin{array}{r}142 \\
3.01\end{array}$ & $\begin{array}{r}25 \\
1.66\end{array}$ & $\begin{array}{l}1244 \\
4.24\end{array}$ \\
\hline Site 7 & $\overline{\mathrm{Bz}}$ & $\begin{array}{l}\mathrm{kWh} \\
\mathrm{kW}\end{array}$ & $\begin{array}{r}223 \\
3.65\end{array}$ & $\begin{array}{r}364 \\
3.84\end{array}$ & $\begin{array}{l}657 \\
4.19\end{array}$ & $\begin{array}{r}608 \\
4.23\end{array}$ & $\begin{array}{r}342 \\
3.61\end{array}$ & $\begin{array}{r}91 \\
2.50\end{array}$ & $\begin{array}{l}2285 \\
4.23\end{array}$ \\
\hline Site 7 & Trees & $\begin{array}{l}k W h \\
k W\end{array}$ & $\begin{array}{r}222 \\
3.65\end{array}$ & $\begin{array}{r}363 \\
3.84 \\
\end{array}$ & $\begin{array}{r}657 \\
4.19\end{array}$ & $\begin{array}{r}606 \\
4.23\end{array}$ & $\begin{array}{r}340 \\
3.61\end{array}$ & $\begin{array}{r}88 \\
2.42\end{array}$ & $\begin{array}{l}2276 \\
4.23\end{array}$ \\
\hline Site 8 & Base & $\begin{array}{l}\mathrm{kWh} \\
\mathrm{kW}\end{array}$ & $\begin{array}{r}283 \\
3.28\end{array}$ & $\begin{array}{r}404 \\
3.52\end{array}$ & $\begin{array}{r}692 \\
3.73\end{array}$ & $\begin{array}{r}685 \\
3.66\end{array}$ & $\begin{array}{r}499 \\
3.58\end{array}$ & $\begin{array}{r}241 \\
3.05\end{array}$ & $\begin{array}{l}2804 \\
3.73\end{array}$ \\
\hline Site 8 & Trees & $\begin{array}{l}\mathbf{k W h} \\
\mathrm{kW}\end{array}$ & $\begin{array}{r}277 \\
3.26\end{array}$ & $\begin{array}{r}401 \\
3.52\end{array}$ & $\begin{array}{r}689 \\
3.73\end{array}$ & $\begin{array}{r}682 \\
3.66\end{array}$ & $\begin{array}{r}487 \\
3.58\end{array}$ & $\begin{array}{r}210 \\
2.97\end{array}$ & $\begin{array}{l}2746 \\
3.73\end{array}$ \\
\hline Site $B^{*}$ & Base & $\begin{array}{l}\mathrm{kWh} \\
\mathrm{kW}\end{array}$ & $\begin{array}{r}194 \\
2.70\end{array}$ & $\begin{array}{r}101 \\
1.51\end{array}$ & $\begin{array}{r}217 \\
1.91\end{array}$ & $\begin{array}{r}171 \\
3.48\end{array}$ & $\begin{array}{r}265 \\
2.73\end{array}$ & $\begin{array}{r}151 \\
2.27\end{array}$ & $\begin{array}{l}1099 \\
3.48\end{array}$ \\
\hline Site $B^{*}$ & Albedo & $\begin{array}{l}\mathrm{kWh} \\
\mathrm{kW}\end{array}$ & $\begin{array}{r}153 \\
2.53\end{array}$ & $\begin{array}{r}67 \\
1.37\end{array}$ & $\begin{array}{r}167 \\
1.67\end{array}$ & $\begin{array}{r}123 \\
2.80\end{array}$ & $\begin{array}{r}225 \\
2.47\end{array}$ & $\begin{array}{r}128 \\
2.07\end{array}$ & $\begin{array}{r}863 \\
2.80\end{array}$ \\
\hline
\end{tabular}

* School occupancy schedule is $1 / 1-5 / 31$ and $9 / 3-12 / 31$ with appropriate holidays.

\section{E. Microclimate Variations}

The sites we monitored are scattered over the greater Sacramento area, with typical distances of 4-10 miles from one to another. The distance between the northernmost and southernmost sites is about 20 miles. Due to this, and to local factors, the microclimates at these sites were different. Although microclimate variations from one site to another may have an impact on the absolute amount of energy used at one particular site, they have no impact on the differences in energy use between the pre- and post-retrofit conditions at a particular site. In this 
section, we discuss some aspects of these variations.

In addition to weather stations' data from each of the seven sites we monitored, data from the Sacramento Executive Airport weather station were also obtained for the 1991 monitoring period. Sites 5 and 6 were the closest to the airport, and Sites 5, 6, 1, and 8 had microclimate/landscape conditions similar to that of the airport. We discuss Site 1 as a representative of the new areas in north Sacramento, Site 2 as a representative of the Carmichael, older and well-vegetated areas, Site 7 to represent the eastern Sacramento parts, and finally, Site 6 to represent the newer, southem Sacramento areas. The temperatures at Sacramento Executive Airport are used as a basis for intercomparison among these sites.

In Figure V.9A, the maximum daily temperatures at Site 1 are plotted along with the maximum daily temperatures at the airport site for Julian days 213 through 305. The diamonds represent Site 1 whereas the squares represent the airport. The bold vertical lines, linking the diamonds and the squares, represent days when data from both sites are available. Examining these lines, we can see that Site 1 is consistently warmer than the airport except when there is no significant temperature difference.

In Figure V-9B, some hourly data from these two sites are examined. The figure shows the range, standard deviation, and mean of the data at each hour during the period under consideration. The solid line joins all the means. The vertical axis represents the difference in air temperature between Site 1 and the airport. We can see that, the mean of this difference fluctuates around $1^{\circ} \mathrm{C}$ (meaning that Site 1 is generally warmer than the airport by $-1^{\circ} \mathrm{C}$ ). However, between hours 13 and 20 , Site 1 is clearly warmer than the airport. And, at the time of maximum difference (18:00), Site 1 is generally $2^{\circ} \mathrm{C}$ warmer than the airport. On the other hand, Site 1 is cooler than the airport between 6 and 9 A.M.. These variations are caused by local factors, which give rise to different microclimates. But in general, the difference in temperature (except for the afternoon peak) is not very large, and that was expected since both Site 1 and the airport are in outlying areas with little vegetation and no particular topographic effects (water bodies, hills, etc.).

In Figure V-9C, daily maxima at Site 2 and the airport are shown. We can see that the bold lines are longer than those shown in Figure V-9A, indicating that the temperature difference between Site 2 and the airport is greater than that between Site 1 and the airport. Also, in this case, Site 2 is cooler than the airport all the times during the maximum temperature of the day. 
This indicates that Site 2 is cooler than the airport during late morning and afternoon hours. Hourly data from these sites are shown in Figure V-9D. It is clear that Site 2 is cooler during daylight hours and warmer during night hours than the airport. This is a typical behavior of well-vegetated areas, such as Carmichael, where Site 2 is located. Figure V-9D indicates that, on the average, Site 2 is $2^{\circ} \mathrm{C}$ cooler than the airport during daylight hours, and about $1.5^{\circ} \mathrm{C}$ warmer at night.

In Figure V-9E, the daily maxima at Site 6 and the airport are shown. One can see that the 
Figure V-9A. A comparison of daily maximum air temperatures $\left({ }^{\circ} \mathrm{C}\right)$ at Site 1 and the Sacramento Executive Airport. Bold vertical lines join points when data from both locations are available.

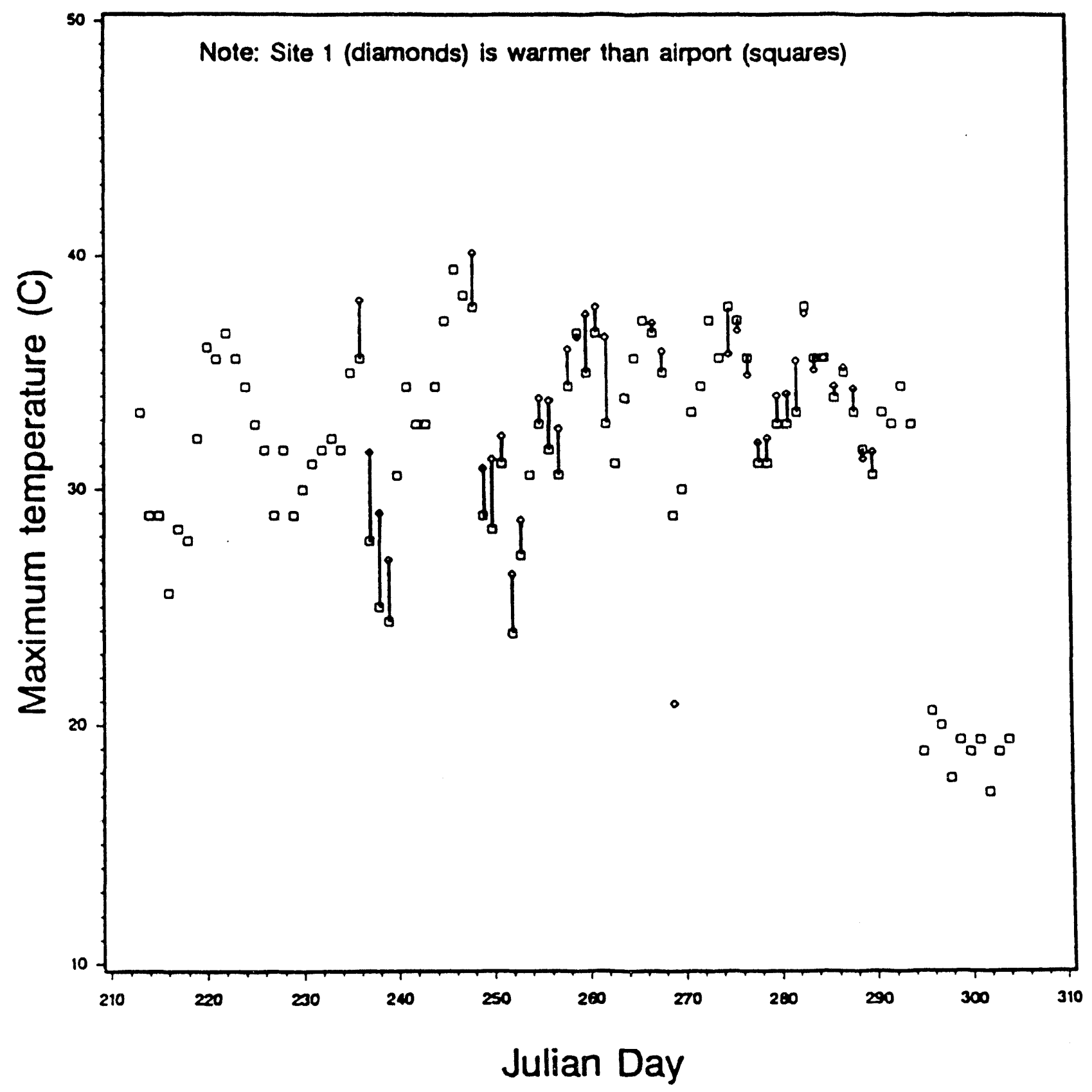


Figure V-9B. Difference in hourly air temperatures $\left({ }^{\circ} \mathrm{C}\right)$ between Site 1 and at the Sacramento Executive Airport, during the monitoring period of 1991. Shown are the maximum and minimum deviations, standard deviations, and mean (joined by the solid line).

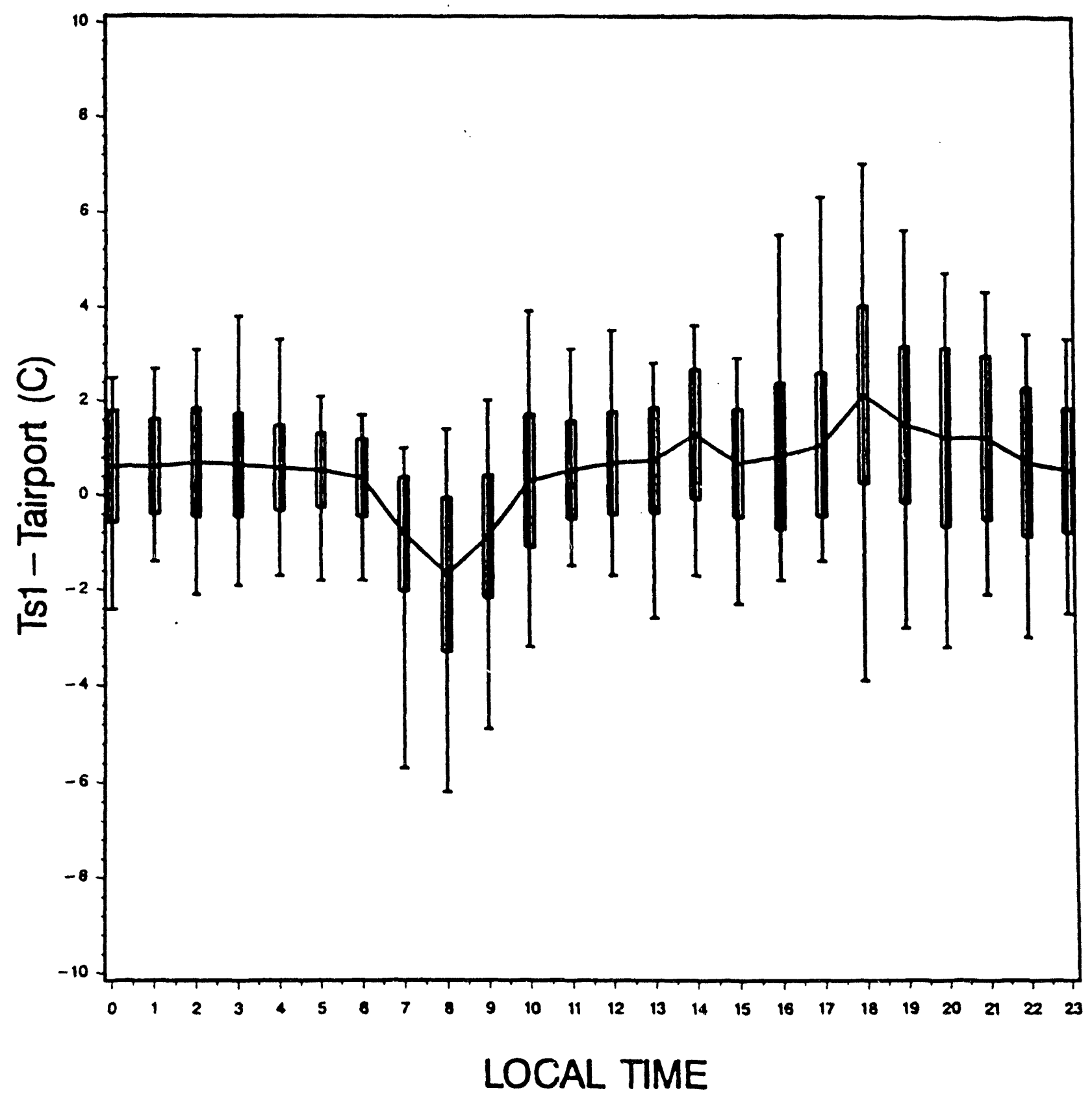


Figure V-9C. A comparison of maximum daily air temperatures $\left({ }^{\circ} \mathrm{C}\right.$ ) at Site 2 and at the Sacramento Executive Airport. Bold vertical lines join points when data from both locations are available.

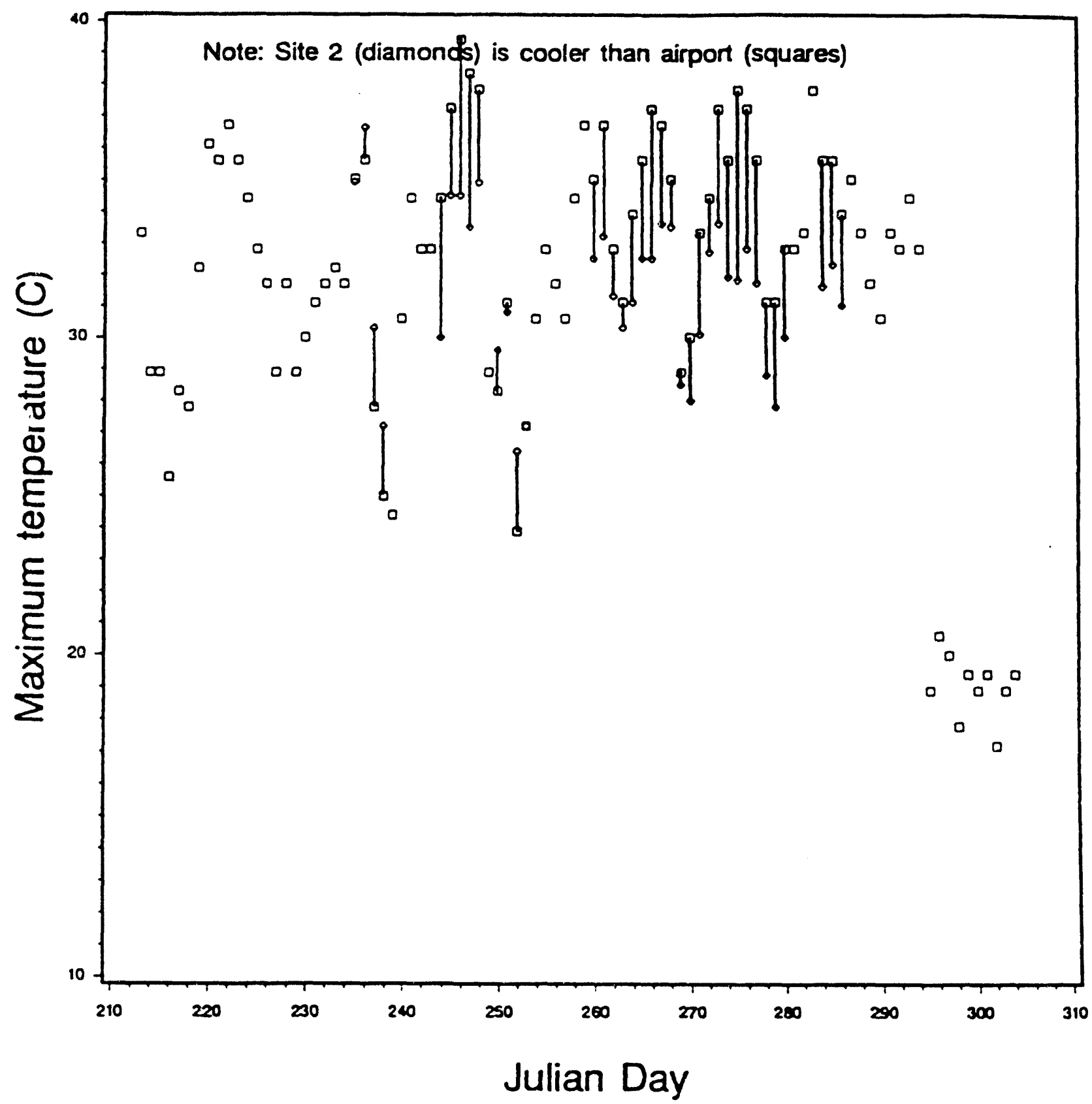


Figure V-9D. Difference in hourly air temperatures $\left({ }^{\circ} \mathrm{C}\right)$ between Site 2 and the Sacramento Executive Airport, during the monitoring period of 1991. Shown are the maximum and minimum deviations, standard deviations, and mean (joined by the solid line).

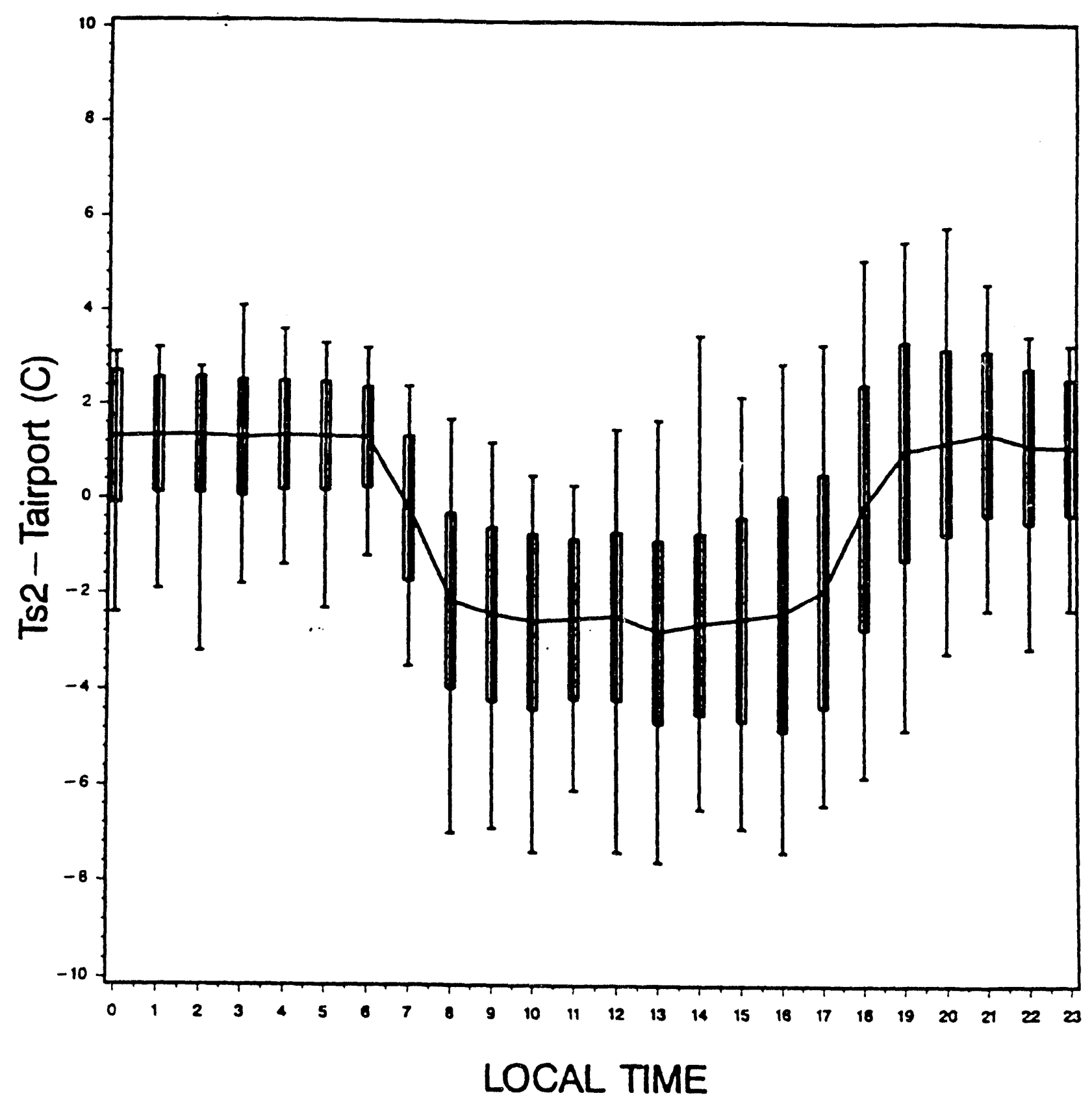


Figure V-9E. A comparison of maximum daily air temperatures $\left({ }^{\circ} \mathrm{C}\right)$ at Site 6 and at the Sacramento Executive Airport. Bold vertical lines join points when data from both locations are available.

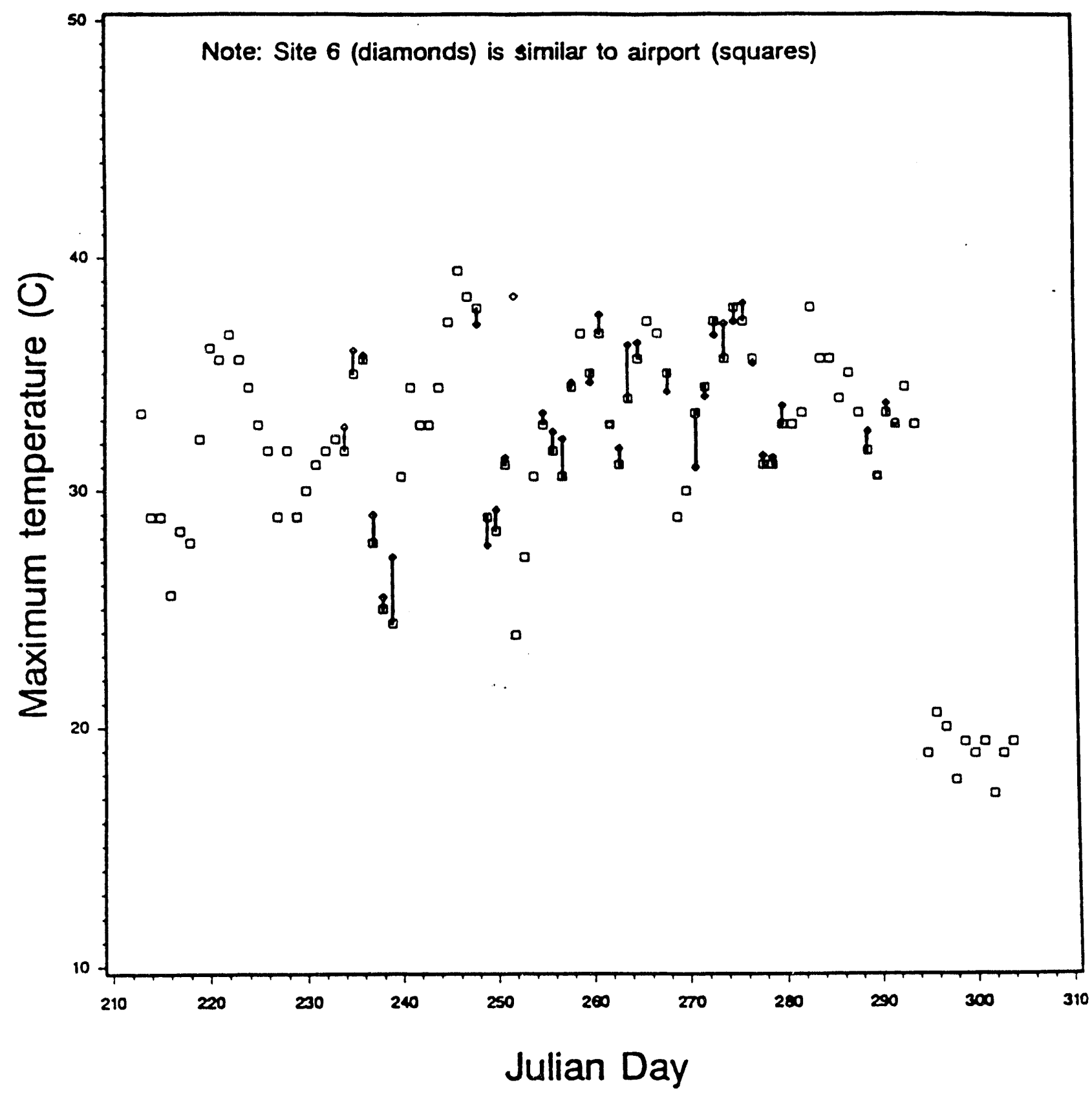


differences in temperatures are small, indicating that the afternoon microclimate at both locations is similar. This is expected, since Site 6 is the closest to the airport, in a newer area devoid of vegetation, and with a terrain type similar to that of the airport's surrounds.

Finally, Figure V-9F depcits data at the airport and Site 7. The maxima at Site 7 are consistently higher than the airport, and the difference is large in general. Site 7 is in a relatively open area, close to Mather AFB. Little vegetation is another factor in this site's microclimate.

In summary, the data we obtained from the 1991 monitoring of these sites indicated that, during the late summer months, afternoon temperatures are highest at Site 7 (East Sacramento), and lowest at Site 2 (Carmichael). In the other parts (North and South of Sacramento) conditions were in between and similar to the conditions at the Sacramento Executive Airport. 
Figure V-9F. A comparison of maximum daily air temperatures $\left({ }^{\circ} \mathrm{C}\right)$ at Site 7 and at the Sacramento Executive Airport. Bold vertical lines join points when data from both locations are available.

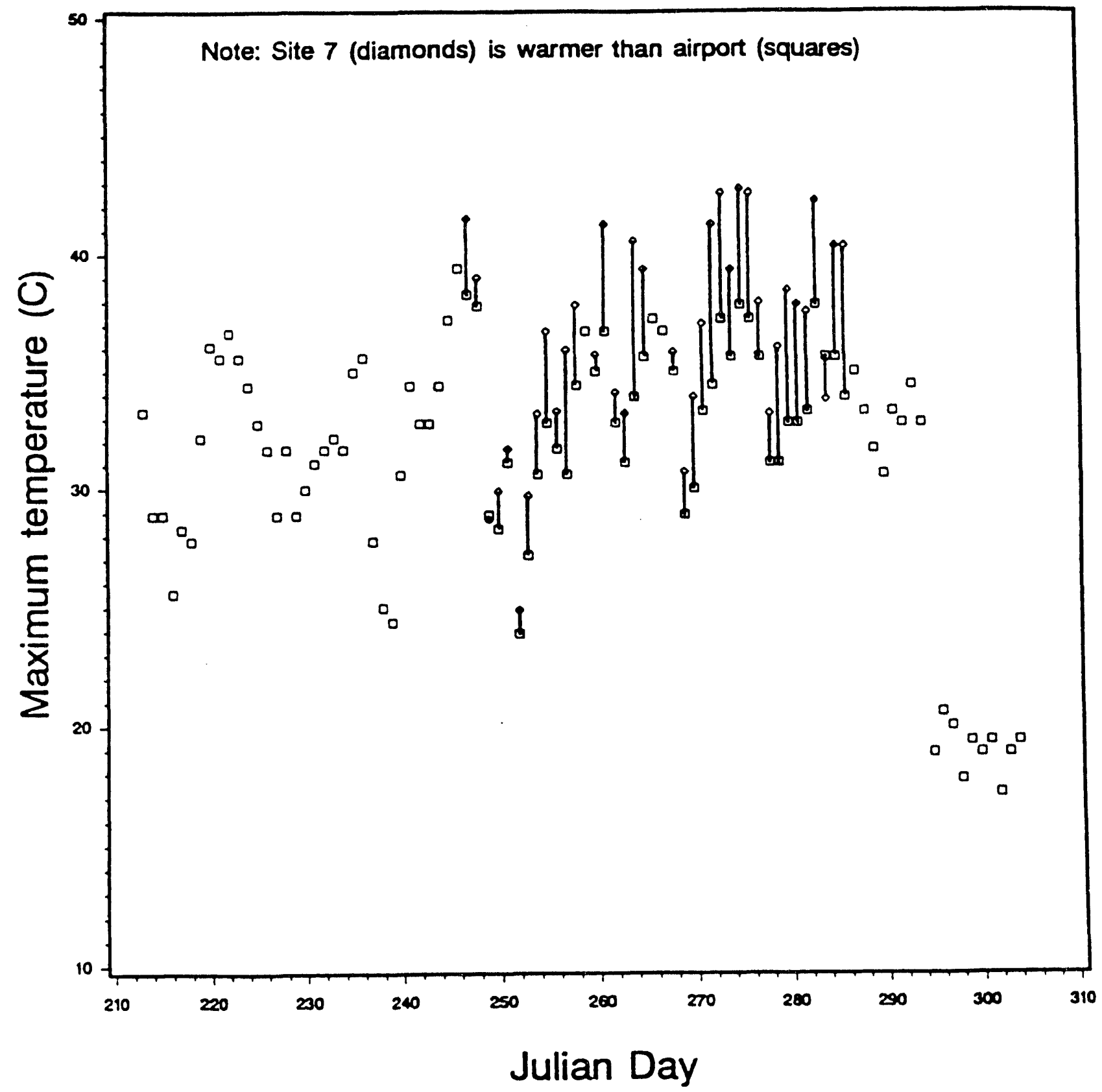




\section{REFERENCES}

American Society of Heating, Refrigeration and Air-conditioning Engineers (ASHRAE). 1989. ASHRAE Handbook of Fundamentals, Atlanta, GA.

American Society of Heating, Refrigeration and Air-conditioning Engineers (ASHRAE). 1990. "ASHREA Standard: Energy Efficient Design of New Low-rise Residential Buildings. (BSR/ASHRAE 90.2p), Public Review Draft". Altanta, GA.

Huang, Y.J., R. Ritschard, J. Bull, S. Byrme, I. Turiel, D. Wilson, C. Hsui and D. Foley. 1987. "Methodology and Assumptions for Evaluating Heating and Cooling Energy Requirements in New Single-Family Residential Buildings," Technical Support Document for the PEAR Microcomputer Program. Lawrence Berkeley Laboratory Report No. LBL-19128, Berkeley, CA.

Modera, M., D. Dickerhoff, R. Jansky, and B. Smith. 1991. "Improving the Energy Efficiency of Residential Air Distribution Systems in California: Final Report, Phase I," prepared for the California Institute of Energy Efficiency and U.S. Department of Energy, Lawrence Berkeley Laboratory Report No. LBL-30886, Berkeley, CA.

Muira, J. and M. Horn. 1980."Base Case Buildings," California Energy Commission and The Building and Appliance Standards Office. Sacramento, Ca., Item No. P400-80-021, Report No. 2, June 1980.

Proctor, J. and R. Pernick, 1992. "Getting It Right the Second Time: Measured Savings and Peak Reduction from Duct and Appliance Repairs," in Proceedings of the ACEEE 1992 Summer Study on Energy Efficiency in Buildings, American Council for an EnergyEfficient Economy, Washington, DC.

Ritschard, R. L., J. W. Hanford, and A. O. Sezgen. 1992. "Single-Family Heating and Cooling Requirements: Assumptions, Methods, and Summary Report," Gas Research Institute. Report No. GRI-91/0236, Chicago, IL. 
Taha, H., H. Akbari, and A. Rosenfeld. 1991. "Heat Island and Oasis Effects of Vegetative Canopies: Micro-Meteorological Field-Measurements," Theoretical and Applied Climatology, 44, pp. 123-138.

Taha, H., H. Akbari, D. Sailor, and R. Ritschard. 1992. "Urban Microclimates and Energy Use: Sensitivity to Surface Parameters and Anthropogenic Heat, "Lawrence Berkeley Laboratory Draft Report, to be submitted to Energy and Buildings. 


\section{SAVINGS ESTIMATES FOR FOUR CALIFORNIA REGIONS}

\section{A. Introduction and Approach}

In this chapter, we use the calibrated simulation models for the six houses and the school bungalow to estimate cooling energy savings for other combinations of tree and albedo strategies and in four climates regions in California. In this parametric study, we model the direct shading impact of varying amounts of tree cover as well as the effects of changes in roof and wall albedos. We consider these cases alone and in combination, and consider the same parametric cases for each of the seven buildings.

The study buildings, while not a statistically representative sample of buildings in California, do represent buildings with a range of construction types, cooling efficiencies, occupancy characteristics, shading conditions, and albedos. Thus, rather than using prototypical buildings for this extrapolation, we use the calibrated building models exactly as they are, except that we vary the vegetation, albedo, and climate characteristics. As a result, this analysis shows a range of impacts one could expect among buildings in California, but not necessarily average or typical results.

In order to make this analysis more useful, we model albedo and shading conditions that were not actually studied in the experimental measurement project and therefore not actually part of the calibration process. For example, because the experimental trees were small, DOE-2 predicted minimal impacts from trees, and we had expected the actual effect to be rather small. Thus, from the measured data we were not able to fully verify our strategies for modeling the shading impact of trees. Consequently, the savings estimates from shade trees presented in this chapter must be viewed as being derived from, but not themselves calibrated simulations. However, our ability to model the base case condition at Site 2 (which is heavily impacted by tree cover) with reasonable accuracy suggests that our tree modeling method is reliable.

In addition, our strategy for modeling changes in albedo using DOE-2 is extremely simple; we adjust the absorptivity of the roof or wall surface. For the two experimental sites where high albedo surfaces were employed, we achieved relatively good agreement with the measured data. Yet it is important to note that both buildings had almost flat roofs with no attics. Thus, we are fairly confident in our ability to model the effect of albedo changes on heat flows to the 


\section{•}

conditioned space for buildings without attics. However, in this extrapolation we are modeling light-colored roofs on houses with ducts in the attic space (in all buildings except for Site 2 and Site B). For these buildings, the effect is two-fold. The high albedo roof reduces heat gain to the conditioned space as well as improves duct efficiency by lowering the attic temperature. None of the experimental albedo cases were actually buildings with attics. Therefore, our modeling of the effect of the white roofs on cooling consumption in attic-duct houses should also be considered preliminary. More consideration to the attic interaction with the duct system performance will be given in future phases of the project.

\section{B. Methodology}

The parametric cases we considered are (1) changing the albedos of the roof and walls, (2) adding trees to the south, east, and west sides of the buildings, and (3) combinations of these strategies. For the albedo cases, we simulated albedos of $0.20,0.40$ and 0.70 for the roofs and $0.15,0.30$, and 0.50 for the walls. These are the ranges of albedo one can expect in actual field conditions.

For the trees, we simulated three conditions as well. The first case was with no shading from trees. In the second case, we added 1 tree to the west and east sides of the building and 2 trees on the south side. These were positioned at each building to give the maximum amount of shading over unshaded windows. Thus, the application of this measure will be specific to the configuration of each building. Each of the trees was 15 feet in diameter, with a canopy height of 10 feet. In the third case, we modeled full shading from several trees on the west, south, and east sides of the building so that they completely shade all the three walls and will shade portions of the roof depending on the time of year. The trees were of the same diameter and height as the individual trees mentioned previously but were spaced so that each touches the adjacent tree. This typically takes 2 trees on the short sides of the house and 4 trees along the long side of the house, or 8 trees total. The description of the parametric cases is given in Table VI-1.

We also simulated each of the buildings in four California climates. The climates we simulated were those of Fresno, Riverside, Sacramento, and Pasadena, which are listed here from the more severe to the less severe cooling climates. We used the CTZ weather tapes from the California Energy Commission (CEC) as the weather inputs. Some climate parameters from these weather tapes are given in Table VI-2. 
Finally, we modeled the base case building in each climate region. This is the building with the roof and wall albedos as modeled for the calibration exercise (see Chapter V) with the actual tree shading at each site. Note that for the parametric runs, surface albedos and existing trees are removed and replaced with the parametric parameters. Simulations for base case conditions show the magnitude of savings already being achieved at each site through higher albedo materials and tree shading. In addition, they show the magnitude of potential savings that can be achieved through further modifications.

Table VI-1. Listing of Parametric Run Descriptions

\begin{tabular}{|c|cc|ccc|}
\hline & \multicolumn{2}{|c|}{ Albedo } & \multicolumn{3}{c|}{$\begin{array}{c}\text { Number of Trees } \\
\text { South }\end{array}$} \\
\hline Case 1 & Roof & Wall & East & West \\
Case 2 & Med & Low & 0 & 0 & 0 \\
Case 3 & High & Hed & 0 & 0 & 0 \\
Case 4 & Low & Low & 0 & 0 & 0 \\
Case 5 & Med & Med & 1 & 2 & 1 \\
Case 6 & High & High & 1 & 2 & 1 \\
Case 7 & Low & Low & 2 & 2 & 1 \\
Case 8 & Med & Med & 2 & 4 & 2 \\
Case 9 & High & High & 2 & 4 & 2 \\
\hline
\end{tabular}

Albedos for Cases:

Low: Roof Albedo $=0.2$, Wall Albedo $=0.15$

Med: Roof Albedo $=0.4$, Wall Albedo $=0.3$

High: Roof Albedo=0.7, Wall Albedo $=0.5$

Tree Parameters:

All trees $15 \mathrm{ft}$ diameter, $10 \mathrm{ft}$ to base of canopy, shading windows. 
Table VI-2. California Climate Zone Data for Parametric Simulations

\begin{tabular}{|c|c|c|c|c|c|c|c|}
\hline & \multicolumn{7}{|c|}{ Month } \\
\hline & May & Jun & Jul & Aug & Sep & Oct & Year \\
\hline \multicolumn{8}{|c|}{$\begin{array}{l}\text { Fresno (CTZ13R) } \\
\left.\text { Daily Averages ( }{ }^{\circ} \mathrm{F}\right)\end{array}$} \\
\hline Dry Bulb & 70 & 78 & 82 & 80 & 74 & 65 & 64 \\
\hline Wet Bulb & 56 & 60 & 63 & 64 & 59 & 54 & 54 \\
\hline Maximum & 85 & 93 & 97 & 96 & 90 & 81 & 77 \\
\hline Minimum & 55 & 61 & 66 & 65 & 61 & 53 & 52 \\
\hline Wind (mph) & 8.6 & 7.6 & 6.2 & 5.8 & 6.6 & 5.2 & 6.3 \\
\hline \multicolumn{8}{|c|}{ Degree Days (base $65^{\circ} \mathrm{F}$ ) } \\
\hline Heating & 29 & 3 & 0 & 0 & 4 & 44 & 2228 \\
\hline Cooling & 184 & 367 & 519 & 492 & 310 & 92 & 1997 \\
\hline \multicolumn{8}{|c|}{ Cooling Degree Hours $/ 24$ (base $75^{\circ} \mathrm{F}$ ) } \\
\hline & 93 & 198 & 283 & 241 & 128 & 41 & 1012 \\
\hline \multicolumn{8}{|c|}{ Average Daily Solar (Btu/ft$\left.{ }^{2}\right)$} \\
\hline Dir. Normal & 2867 & 3108 & 3136 & 2761 & 2681 & 2055 & 2077 \\
\hline Tot. Horiz. & 2502 & 2719 & 2706 & 2398 & 2023 & 1455 & 1727 \\
\hline \multicolumn{8}{|c|}{$\begin{array}{l}\text { Riverside (CTZ10R) } \\
\text { Daily Averages }\left({ }^{\circ} \mathrm{F}\right)\end{array}$} \\
\hline Dry Bulb & 65 & 70 & 76 & 76 & 73 & 66 & 64 \\
\hline Wet Bulb & 55 & 60 & 64 & 62 & 59 & 52 & 53 \\
\hline Maximum & 79 & 86 & 94 & 93 & 39 & 81 & 79 \\
\hline Minimum & 53 & 56 & 61 & 62 & 59 & 53 & 50 \\
\hline Wind (mph) & 5.3 & 4.4 & 3.0 & 3.6 & 3.2 & 3.9 & 3.8 \\
\hline \multicolumn{8}{|c|}{ Degree Days (base $65^{\circ} \mathrm{F}$ ) } \\
\hline Heating & 31 & 0 & 0 & 0 & 4 & 58 & 1637 \\
\hline Cooling & 60 & 190 & 374 & 381 & 281 & 115 & 1437 \\
\hline \multicolumn{8}{|c|}{ Cooling Degree Hours $/ 24$ (base $75^{\circ} \mathrm{F}$ ) } \\
\hline & 30 & 89 & 181 & 172 & 131 & 70 & 725 \\
\hline \multicolumn{8}{|c|}{ Average Daily Solar $\left(\mathrm{Btu} / \mathrm{ft}^{2}\right)$} \\
\hline Dir. Normal & 1575 & 1696 & 2116 & 1815 & 1891 & 1420 & 1809 \\
\hline Tot. Horiz. & 1931 & 2039 & 2303 & 1969 & 1756 & 1321 & 1633 \\
\hline
\end{tabular}


Table VI-2. California Climate Zone Data for Parametric Simulations (cont.)

\begin{tabular}{|c|c|c|c|c|c|c|c|}
\hline & \multicolumn{7}{|c|}{ Month } \\
\hline & May & Jun & Jul & Aug & Sep & Oct & Year \\
\hline \multicolumn{8}{|c|}{ Sacramento (CTZ12R) } \\
\hline \multicolumn{8}{|c|}{ Daily Averages $\left({ }^{\circ} \mathrm{F}\right)$} \\
\hline Dry Bulb & 64 & 70 & 73 & 72 & 68 & 62 & 60 \\
\hline Wet Bulb & 55 & 58 & 60 & 60 & 57 & 53 & 52 \\
\hline Maximum & 80 & 87 & 92 & 91 & 87 & 78 & 74 \\
\hline Minimum & 50 & 55 & 57 & 57 & 55 & 49 & 48 \\
\hline Wind (mph) & 7.6 & 8.9 & 9.6 & 9.0 & 7.7 & 6.6 & 8.0 \\
\hline \multicolumn{8}{|c|}{ Degree Days (base $65^{\circ} \mathrm{F}$ ) } \\
\hline Heating & 58 & 13 & 3 & 8 & 7 & 86 & 2649 \\
\hline Cooling & 64 & 185 & 294 & 283 & 173 & 35 & 1038 \\
\hline \multicolumn{8}{|c|}{ Cooling Degree Hours/24 (base $75^{\circ} \mathrm{F}$ ) } \\
\hline & 44 & 95 & 147 & 134 & 76 & 24 & 527 \\
\hline \multicolumn{8}{|c|}{ Average Daily Solar $\left(B t u / f^{2}\right)$} \\
\hline Dir. Normal & 2715 & 3015 & 3090 & 2819 & 2522 & 1865 & 2016 \\
\hline Tot. Horiz. & 2395 & 2671 & 2691 & 2391 & 1928 & 1298 & 1652 \\
\hline \multicolumn{8}{|c|}{ Pasadena (CTZ09R) } \\
\hline \multicolumn{8}{|c|}{ Daily Averages $\left({ }^{\circ} \mathrm{F}\right)$} \\
\hline Dry Bulb & 64 & 68 & 73 & 73 & 72 & 67 & 64 \\
\hline Wet Bulb & 56 & 60 & 62 & 65 & 62 & 57 & 55 \\
\hline Maximum & 77 & 83 & 89 & 89 & 87 & 81 & 78 \\
\hline Minimum & 53 & 57 & 61 & 62 & 60 & 55 & 52 \\
\hline Wind (mph) & 4.4 & 5.0 & 7.8 & 7.6 & 4.0 & 6.0 & 5.6 \\
\hline \multicolumn{8}{|c|}{ Degree Days (base $65^{\circ} \mathrm{F}$ ) } \\
\hline Heating & 30 & 2 & 0 & 0 & 0 & 29 & 1260 \\
\hline Cooling & 38 & 151 & 306 & 320 & 248 & 118 & 1215 \\
\hline \multicolumn{8}{|c|}{ Cooling Degree Hours/24 (base $75^{\circ} \mathrm{F}$ ) } \\
\hline & 26 & 60 & 120 & 111 & 92 & 51 & 498 \\
\hline \multicolumn{8}{|c|}{ Average Daily Solar $\left(\mathrm{Btu} / \mathrm{ft}^{2}\right)$} \\
\hline Dir. Normal & 1577 & 1761 & 2308 & 1837 & 1836 & 1628 & 1762 \\
\hline Tot. Horiz. & 1820 & 2012 & 2387 & 1908 & 1737 & 1364 & 1589 \\
\hline
\end{tabular}




\section{Results}

We present the results for both annual cooling energy consumption and peak annual electricity demand in a series of tables and graphs. Table VI-3 gives the changes in annual cooling electricity consumption for the base case and the 9 different sensitivity cases in each climate region. Table VI-4 shows the impact on peak electricity consumption for cooling. Note that in this analysis, we include the supply fan energy as well as the condenser energy. In these tables, the basecase results are presented in the units of $\mathrm{kWh}$ per year and $\mathrm{kW}$. The results for all the parametric simulations are presented as percentage changes from the simulated base case value. Positive changes are energy and demand penalties, negative changes are savings.

The tabulated results for annual cooling energy consumption are also plotted in Figures VI-1 through VI-7. In each chart, there are three lines as well as the location of the base case. The top line is for the no-shade case (cases C1, C2, and C3), the middle line is for the 4-tree case (cases C4, C5, C6), and the bottom line is for the 8-tree case (cases C7, C8, and C9). The base case is marked by the black diamond. Note that the position of the base case is not exact. The plots have been simplified so that the $x$-axis is the roof albedo, whereas it actually represents both the roof albedo $(0.2,0.4$, and 0.7$)$ and wall albedos $(0.15,0.3,0.5)$. The base case building albedos are not always matched like the parameters used in the simulations.

For the high-albedo and high-tree shading cases, the results suggest the range of potential energy and peak savings in existing buildings from implementing these strategies. These range from about $25 \%$ in annual energy savings at Site 1 across all climates to $60 \%$ in annual savings for Site 6 in Pasadena. Higher percentage savings are found in the less extreme climates. Some of the savings from high albedo roofs arise also from increased duct system performance resulting from lower attic temperatures.

At Sites 1 and 2, cooling energy is already reduced by the current levels of shading when they are compared to no-tree simulation cases. The base case is plotted between the "4-Tree" and "8-Tree" cases for Sites 1 and 2. For the other four residential sites, as well as the school bungalow, the base case is close to the "No-Trees" case. With the calibrated simulations as the basecase, the simulations indicate that for most of the monitored buildings there is potential for energy savings between $18 \%$ to $60 \%$. The potentials for energy savings are even higher if we assume the low-albedo and no-shade tree parametric as a basecase. In that condition, the simulations indicate potentials for energy savings of about $25 \%$ to $70 \%$. 
Table VI-3. Base Case Annual Cooling Energy and Percent Changes for Strategy Combinations (includes supply fan energy)

\begin{tabular}{|c|c|c|c|c|c|c|c|c|c|c|}
\hline \multirow{3}{*}{$\begin{array}{l}\text { Site } \\
\text { and } \\
\text { Climate }\end{array}$} & \multirow{3}{*}{$\begin{array}{l}\text { Base } \\
\text { Case } \\
(\mathbf{k W h})\end{array}$} & \multicolumn{9}{|c|}{ Changes from Base Case (\%) } \\
\hline & & \multicolumn{3}{|c|}{$\begin{array}{l}\text { No Trees } \\
\text { Albedo }\end{array}$} & \multicolumn{3}{|c|}{$\begin{array}{c}\text { Four Trees } \\
\text { Albedo }\end{array}$} & \multicolumn{3}{|c|}{$\begin{array}{l}\text { Eight Trees } \\
\text { Albedo }\end{array}$} \\
\hline & & Low & Med & High & Low & Med & High & Low & Med & High \\
\hline \multicolumn{11}{|c|}{ Site I (base case has large trees to south and soumhwest; roof alb. $=0.40$, wall alb. $=0.30$ ) } \\
\hline Fresno & 2379 & 28 & 15 & -3 & 15 & 4 & -11 & 4 & -5 & -18 \\
\hline Riverside & 1182 & 41 & 20 & -7 & 23 & 5 & -17 & 9 & -5 & -24 \\
\hline Sacramento & 869 & 49 & 28 & 1 & 25 & 8 & -14 & 6 & -9 & -26 \\
\hline Pasadena & 732 & 48 & 25 & -2 & 25 & 7 & -16 & 8 & -6 & .25 \\
\hline \multicolumn{11}{|c|}{ Site 2 (base case has heavy vegetation on soum, west, and north; roof alb. $=0.18$, wall alb. $=0.30$ ) } \\
\hline Fresno & 1786 & 11 & -5 & -27 & 5 & -9 & -29 & -6 & -18 & -34 \\
\hline Riverside & 940 & 15 & -10 & -41 & 8 & -15 & -44 & -7 & -26 & -49 \\
\hline Sacramento & 653 & 17 & -7 & -38 & 9 & -12 & -40 & -9 & -27 & -48 \\
\hline Pasadena & 536 & 21 & -10 & -45 & 11 & -17 & -48 & -9 & -30 & -54 \\
\hline \multicolumn{11}{|c|}{ Site 5 (base case has no trees, south overhang; roof alb. $=0.16$, wall $a l b .=0.50$ ) } \\
\hline Fresno & 4055 & 4 & -9 & -27 & -8 & -19 & -35 & -16 & -26 & -38 \\
\hline Riverside & 2114 & 10 & -12 & -36 & -7 & -24 & -45 & -18 & -32 & 48 \\
\hline Sacramento & 1372 & 9 & -10 & -34 & -14 & -29 & -47 & -26 & -38 & -52 \\
\hline Pasadena & 1284 & 11 & -9 & .34 & -10 & -26 & -46 & .22 & -35 & -51 \\
\hline \multicolumn{11}{|c|}{ Site 6 (base case has small trees to soushwest and west; roof alb. $=0.35$, wall alb. $=0.40$ ) } \\
\hline Fresno & 2861 & 16 & -0 & -19 & -2 & -14 & -29 & -18 & -28 & -39 \\
\hline Riverside & 1124 & 27 & 2 & -26 & -1 & -19 & -40 & -22 & -35 & -52 \\
\hline Sacramento & 868 & 21 & 2 & -22 & -10 & -23 & -40 & -37 & 46 & -57 \\
\hline Pasadena & 672 & 27 & 3 & -25 & -7 & -26 & -45 & -36 & -47 & -60 \\
\hline \multicolumn{11}{|c|}{ Site 7 (base case has large east tree and small west tree; roof alb. $=0.16$, wall alb. $=0.45$ ) } \\
\hline Fresno & 4397 & 5 & -7 & -22 & -7 & -18 & -31 & -14 & -23 & -34 \\
\hline Riverside & 2796 & 9 & -9 & .31 & -7 & -22 & -40 & -15 & -27 & 43 \\
\hline Sacramento & 1977 & 9 & -6 & -24 & -13 & -25 & -39 & -22 & -31 & -43 \\
\hline Pasadena & 1961 & 10 & -6 & -26 & -10 & -23 & -39 & -17 & -28 & 42 \\
\hline \multicolumn{11}{|c|}{ Site 8 (base case has no trees; roof alb. $=0.16$, wall alb. $=0.30$ ) } \\
\hline Fresno & 5163 & 1 & -9 & -24 & -10 & -19 & -31 & -18 & -25 & -35 \\
\hline Riverside & 4198 & 2 & -13 & -33 & -10 & -23 & -40 & -18 & -29 & -43 \\
\hline Sacramento & 2711 & 1 & -11 & -28 & -16 & -26 & -40 & -27 & -35 & -46 \\
\hline Pasadena & 3188 & 1 & -11 & -28 & -12 & -23 & -38 & -20 & -30 & -43 \\
\hline \multicolumn{11}{|c|}{ Site $B$ (base case has full shading on east and west from buildings; roof alb. $=034$ (metal)*, wall alb. $=0.30)$} \\
\hline Fresno & 2498 & -1 & -8 & -19 & -10 & -15 & .24 & -13 & -18 & -25 \\
\hline Riverside & 2041 & -3 & -12 & -26 & -12 & -20 & -31 & -16 & -22 & -32 \\
\hline Sacramento & 1344 & 0 & -9 & .22 & -11 & -18 & -28 & -15 & -21 & -30 \\
\hline Pasadena & 1618 & -1 & -11 & -24 & -11 & -18 & .29 & -14 & -21 & -30 \\
\hline
\end{tabular}

* Metalic roof emissivity is $\mathbf{0 . 4}$. 
Table VI-4. Base Case Peak Cooling and Percentage Changes for Strategy Combinations (includes supply fan energy) $\neq$

\begin{tabular}{|c|c|c|c|c|c|c|c|c|c|c|}
\hline \multirow{3}{*}{$\begin{array}{l}\text { Site } \\
\text { and } \\
\text { Climate }\end{array}$} & \multirow{3}{*}{$\begin{array}{l}\text { Base } \\
\text { Case } \\
\text { (kW) }\end{array}$} & \multicolumn{9}{|c|}{ Changes from Base Case (\%) } \\
\hline & & \multicolumn{3}{|c|}{$\begin{array}{l}\text { No Trees } \\
\text { Albedo }\end{array}$} & \multicolumn{3}{|c|}{$\begin{array}{c}\text { Four Trees } \\
\text { Albedo }\end{array}$} & \multicolumn{3}{|c|}{$\begin{array}{c}\text { Eight Trees } \\
\text { Albedo }\end{array}$} \\
\hline & & Low & Med & High & Low & Med & High & Low & Med & High \\
\hline \multicolumn{11}{|c|}{ Site I (base case has large trees to south and southwest; roof alb. $=0.40$, wall alb. $=0.30) \dagger$} \\
\hline Fresno & 4.15 & -0 & 0 & -2 & -0 & 0 & -0 & 0 & 0 & 0 \\
\hline Riverside & 4.02 & -3 & -0 & 0 & -0 & -0 & 0 & -0 & 0 & 0 \\
\hline Sacramento & 4.01 & -0 & -0 & 0 & -0 & 0 & 0 & 0 & 0 & -3 \\
\hline Pasadena & 3.40 & 14 & 13 & -1 & 14 & 4 & -5 & 4 & -2 & -9 \\
\hline \multicolumn{11}{|c|}{ Site 2 (base case has heavy vegetation on soush, west, and norih; roof alb. $=0.18$, wall alb. $=0.30$ ) } \\
\hline Fresno & 3.28 & 3 & -5 & -16 & 1 & -6 & -17 & -3 & -9 & -19 \\
\hline Riverside & 2.64 & 4 & -6 & -19 & 2 & -8 & -20 & -2 & -11 & -21 \\
\hline Sacramento & 2.57 & 4 & -4 & -13 & 2 & -5 & -14 & -3 & -9 & -16 \\
\hline Pasadena & 2.37 & 4 & -3 & -11 & 2 & -4 & -12 & -3 & -8 & -14 \\
\hline \multicolumn{11}{|c|}{ Site 5 (base case has no trees, soush overhang; roof alb. $=0.16$, wall alb. $=0.50$ ) } \\
\hline Fresno & 4.99 & 0 & .7 & -10 & 0 & -7 & -11 & -6 & -8 & -11 \\
\hline Riverside & 4.62 & 0 & -3 & -24 & 0 & 4 & -28 & -3 & -10 & -30 \\
\hline Sacramento & 4.53 & 0 & -5 & -18 & -2 & -10 & -22 & -6 & -14 & -24 \\
\hline Pasadena & 4.04 & 1 & -10 & -22 & -7 & -17 & -25 & -13 & -21 & -27 \\
\hline \multicolumn{11}{|c|}{ Site 6 (base case has small trees to southwest and west; roof alb. $=0.35$, wall alb. $=0.40$ ) } \\
\hline Fresno & 5.75 & 2 & -1 & -25 & 2 & -6 & -29 & -4 & -19 & -37 \\
\hline Riverside & 3.41 & 21 & -1 & -16 & 8 & -9 & -22 & -1 & -17 & -30 \\
\hline Sacramento & 3.74 & 14 & -2 & -17 & 2 & -10 & -23 & -17 & -23 & -31 \\
\hline Pasadena & 2.96 & 11 & -0 & -13 & -2 & -11 & -20 & -12 & -20 & -28 \\
\hline \multicolumn{11}{|c|}{ Site 7 (base case has large east tree and small west tree; roof alb. $=0.16$, wall alb. $=0.45$ ) } \\
\hline Fresno & 4.81 & 0 & -10 & -12 & -2 & -10 & -12 & -10 & -11 & -12 \\
\hline Riverside & 4.36 & 0 & -4 & -20 & -1 & -11 & -26 & -2 & -15 & -27 \\
\hline Sacramento & 4.27 & 0 & -1 & -14 & -2 & -11 & -22 & -5 & -13 & -22 \\
\hline Pasadena & 3.73 & 1 & -8 & -18 & -2 & -16 & -23 & -7 & -18 & -24 \\
\hline \multicolumn{11}{|c|}{ Site 8 (base case has no trees; roof alb. $=0.16$, wall alb. $=0.30$ ) } \\
\hline Fresno & 4.09 & 0 & .7 & -9 & 0 & -7 & -10 & -6 & -8 & -10 \\
\hline Riverside & 3.79 & 0 & -1 & -4 & -0 & -3 & -8 & -1 & -3 & -10 \\
\hline Sacramento & 3.73 & 0 & -1 & -2 & -1 & -1 & -3 & -1 & -2 & -6 \\
\hline Pasadena & 3.59 & 0 & 0 & -17 & 0 & -10 & -19 & -8 & -18 & -24 \\
\hline \multicolumn{11}{|c|}{ Site B (base case has full shading on east and west from buildings; roof alb. $=0.34($ metal)*, wall alb. $=0.30)$} \\
\hline Fresno & 2.87 & 0 & -3 & -7 & -2 & -5 & -9 & -4 & -6 & -9 \\
\hline Riverside & 2.97 & 0 & -3 & -7 & -3 & -6 & -9 & -5 & -7 & .9 \\
\hline Sacramento & 3.64 & 0 & -9 & -20 & .9 & -16 & -26 & -14 & -20 & -27 \\
\hline Pasadena & 3.22 & 0 & -2 & -6 & -2 & -4 & -7 & -4 & -5 & -8 \\
\hline
\end{tabular}

¥ Cooling capacity is kept constant at all sites; systems may be undersized for Fresno climate.

$\dagger$ Cooling schedule at Site 1 causes system undersizing in all locations but Pasadena with no peak savings.

* Metalic roof emissivity is 0.4 . 
Figure VI-1. Annual cooling energy consumption (including fan energy) for Site 1 in four location. Wall albedo $=0.15,0.3$ and 0.5 for roof albedo $=0.2,0.4$ and 0.7. Base case (shown here as a black diamond) has large trees to south and southwest and high shrubbery along south wall. Major window area faces south and north. Savings for high albedo roofs are partly due to improvement in attic duct efficiency.
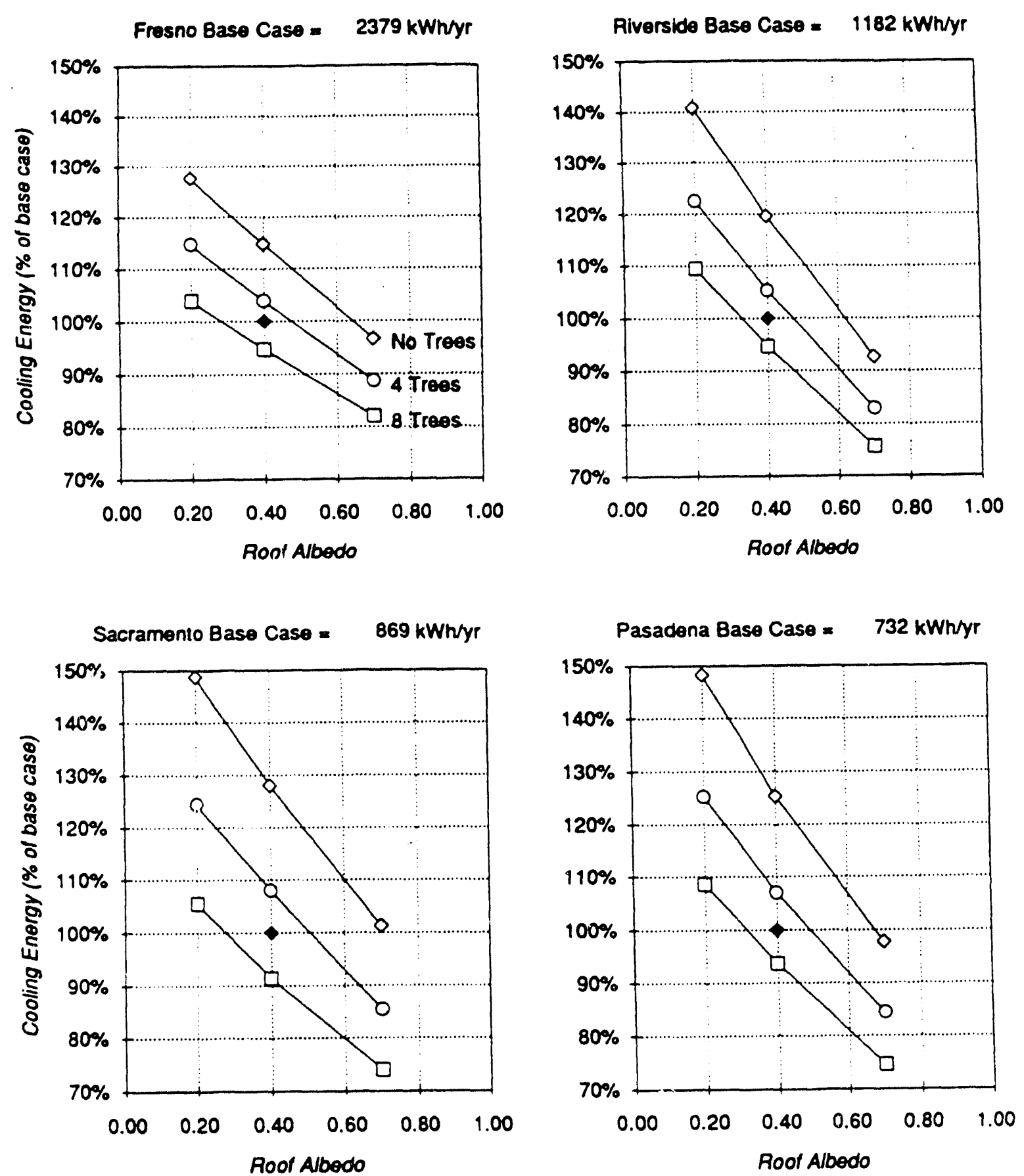
Figure VI-2. Annual cooling energy consumption (including fan energy) for Site 2 in four location. Wall albedo $=0.15,0.3$ and 0.5 for roof albedo $=0.2,0.4$ and 0.7 . Base case (shown here as a black diamond) has large trees along south, west, and north sides of house. Major exterior walls face south and north and window area faces north. Shading impact does not include microclimate effect of trees shown in measured data.
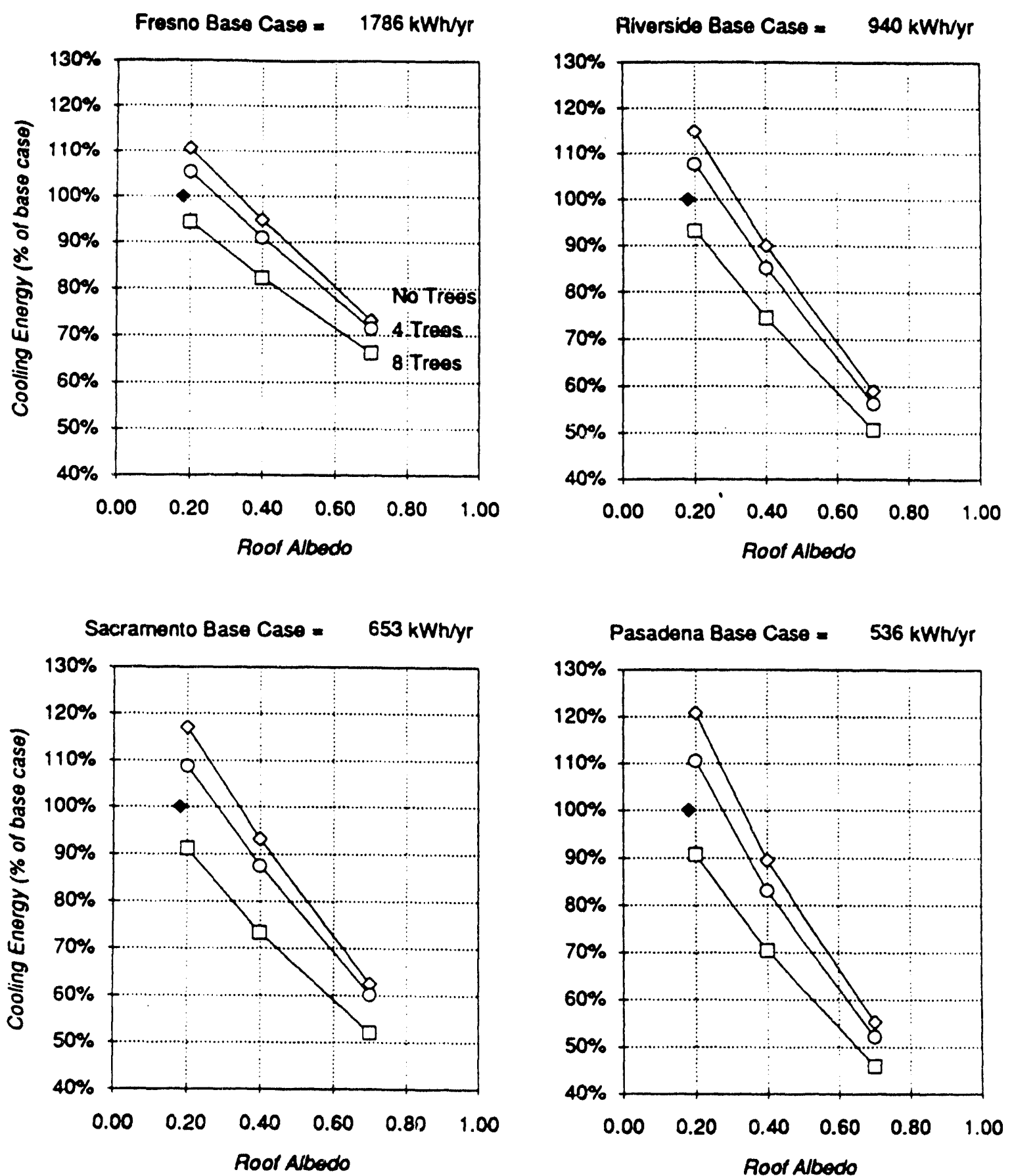
Figure VI-3. Annual cooling energy consumption (including fan energy) for Site 5 in four location. Wall albedo $=0.15,0.3$ and 0.5 for roof albedo $=0.2,0.4$ and 0.7 Base case (shown here as a black diamond) has no trees but some shading from south overhang and neighboring buildings. Major exterior wall are faces north and south and window area faces north, south, and east. Savings for high albedo roofs are partly due to improvement in duct efficiency.
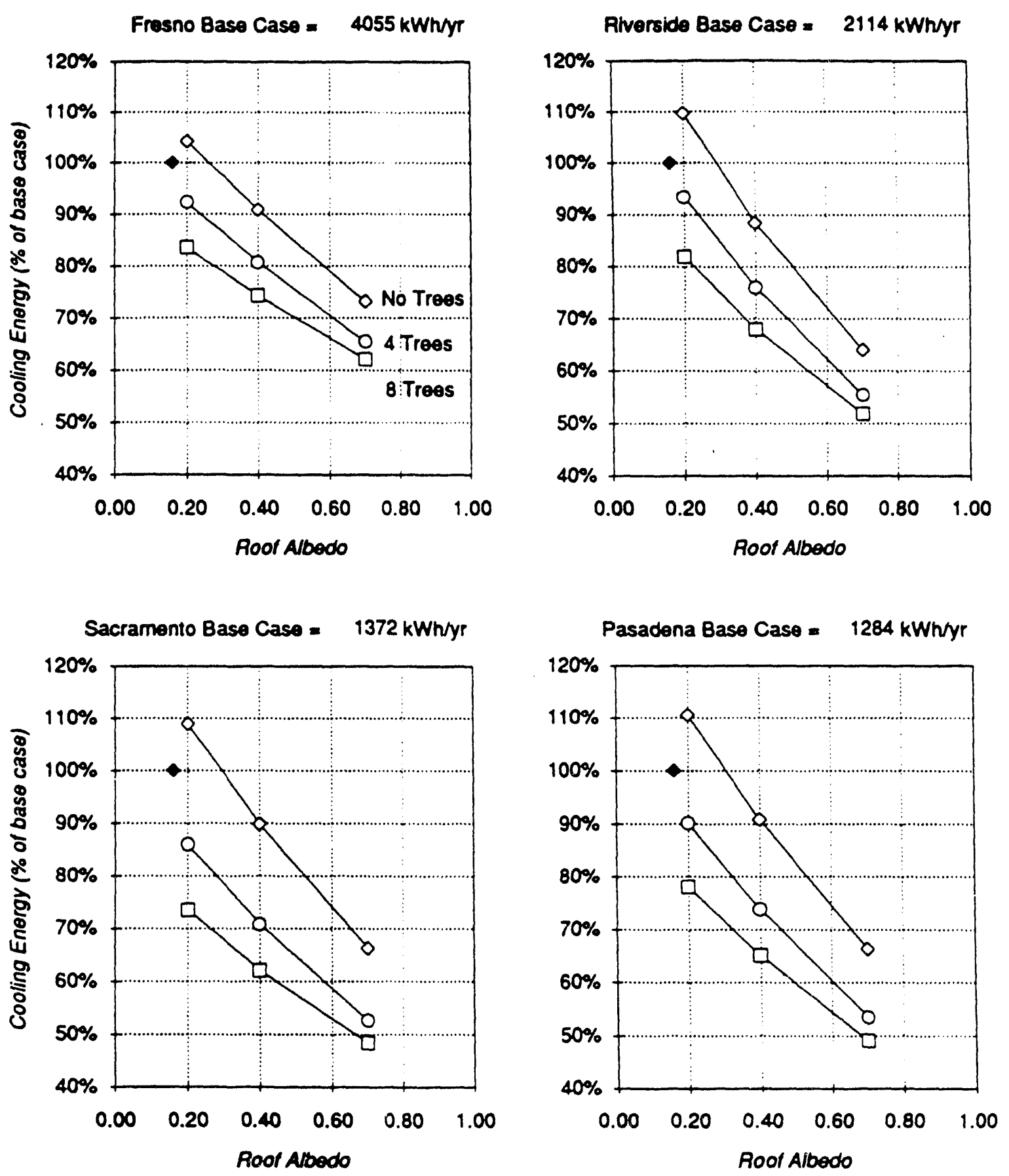
Figure VI-4. Annual cooling energy consumption (including fan energy) for Site 6 in four locations. Wall albedo $=0.15,0.3$ and 0.5 for roof albedo $=0.2,0.4$ and 0.7 Base case (shown here as a black diamond) has three small trees at southwest corner and two small trees on west. Major exterior wall and window area faces west. Savings for high albedo roofs are partly due to improvement in duct efficiency.
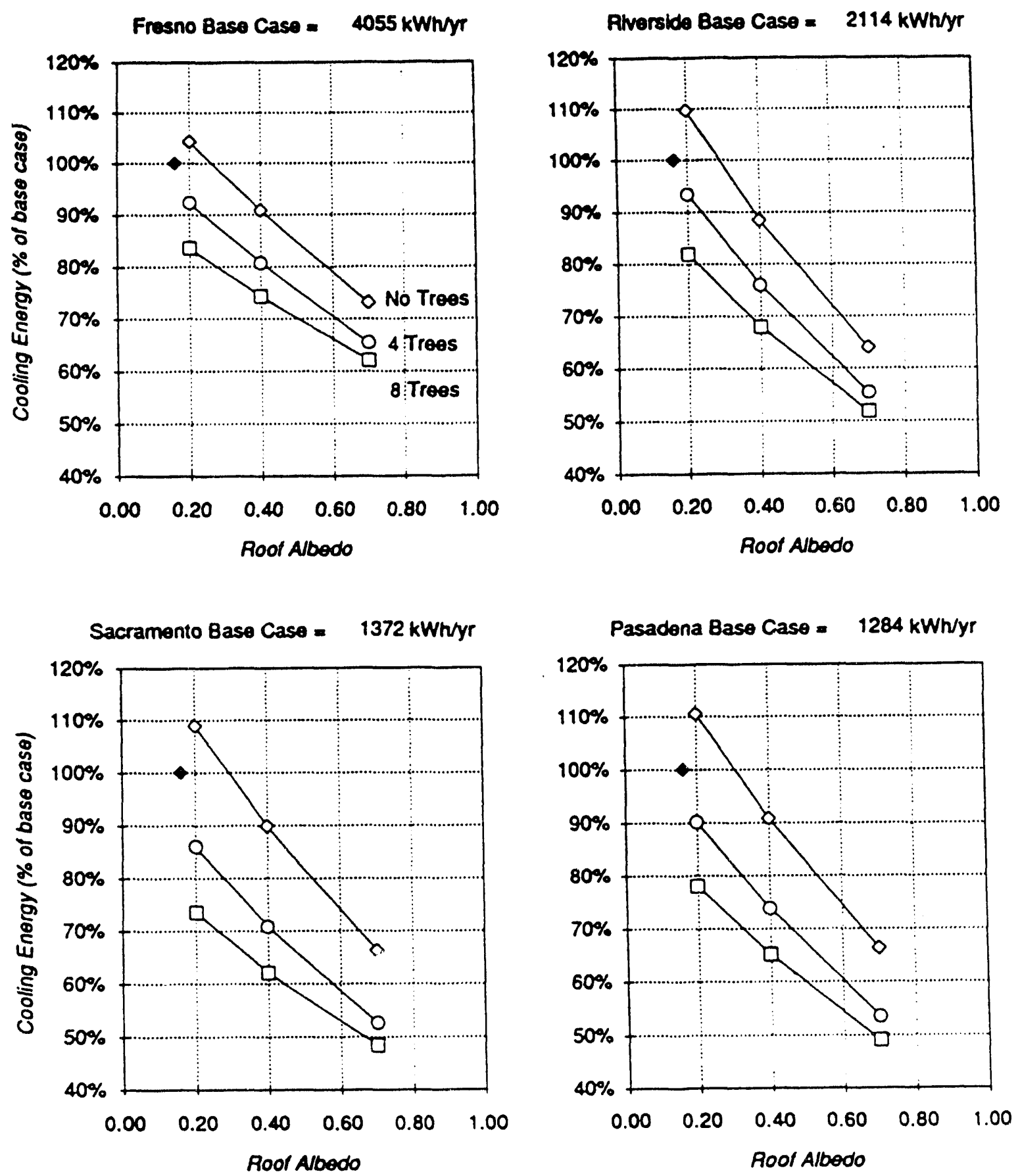
Figure VI-5. Annual cooling energy consumption (including fan energy) for Site 7 in four locations. Wall albedo $=0.15,0.3$ and 0.5 for roof albedo $=0.2,0.4$ and 0.7 Base case (shown here as a black diamond) has large tree to east and small tree to west. Major windows face east and west with 2 small south windows. Walls face all directions. Savings for high albedo roofs are partly due to improvement in duct efficiency.
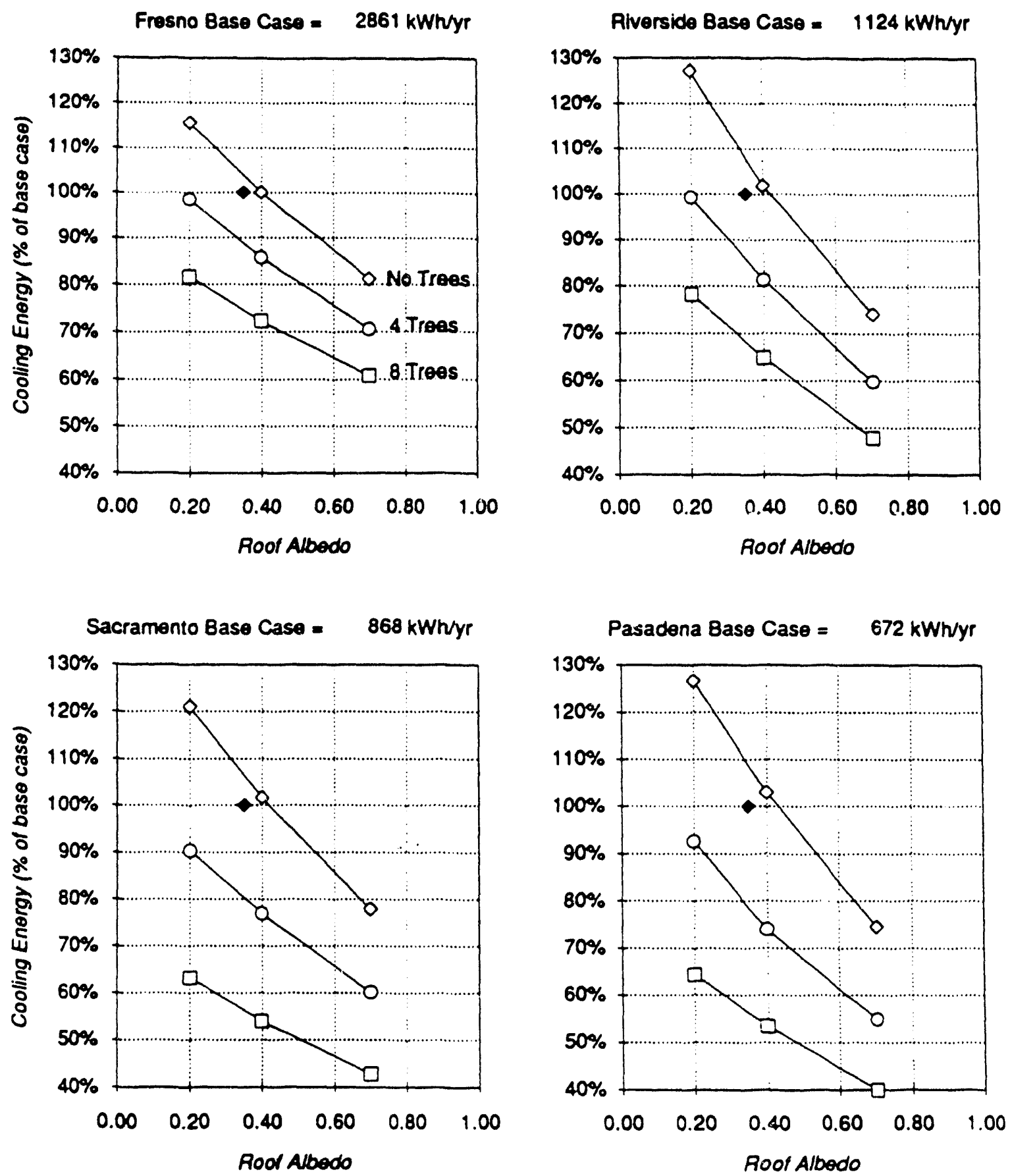
Figure VI-6. Annual cooling energy consumption (including fan energy) for Site 8 in four locations. Wall albedo $=0.15,0.3$ and 0.5 for roof albedo $=0.2,0.4$ and 0.7 Base case (shown here as a black diamond) has no tree cover and little shading from neighboring buildings. Major window and wall areas face south and north. Savings for high albedo roofs are partly due to improvement in duct efficiency Savings for high albedo roofs are partly due to improvement in duct efficiency.
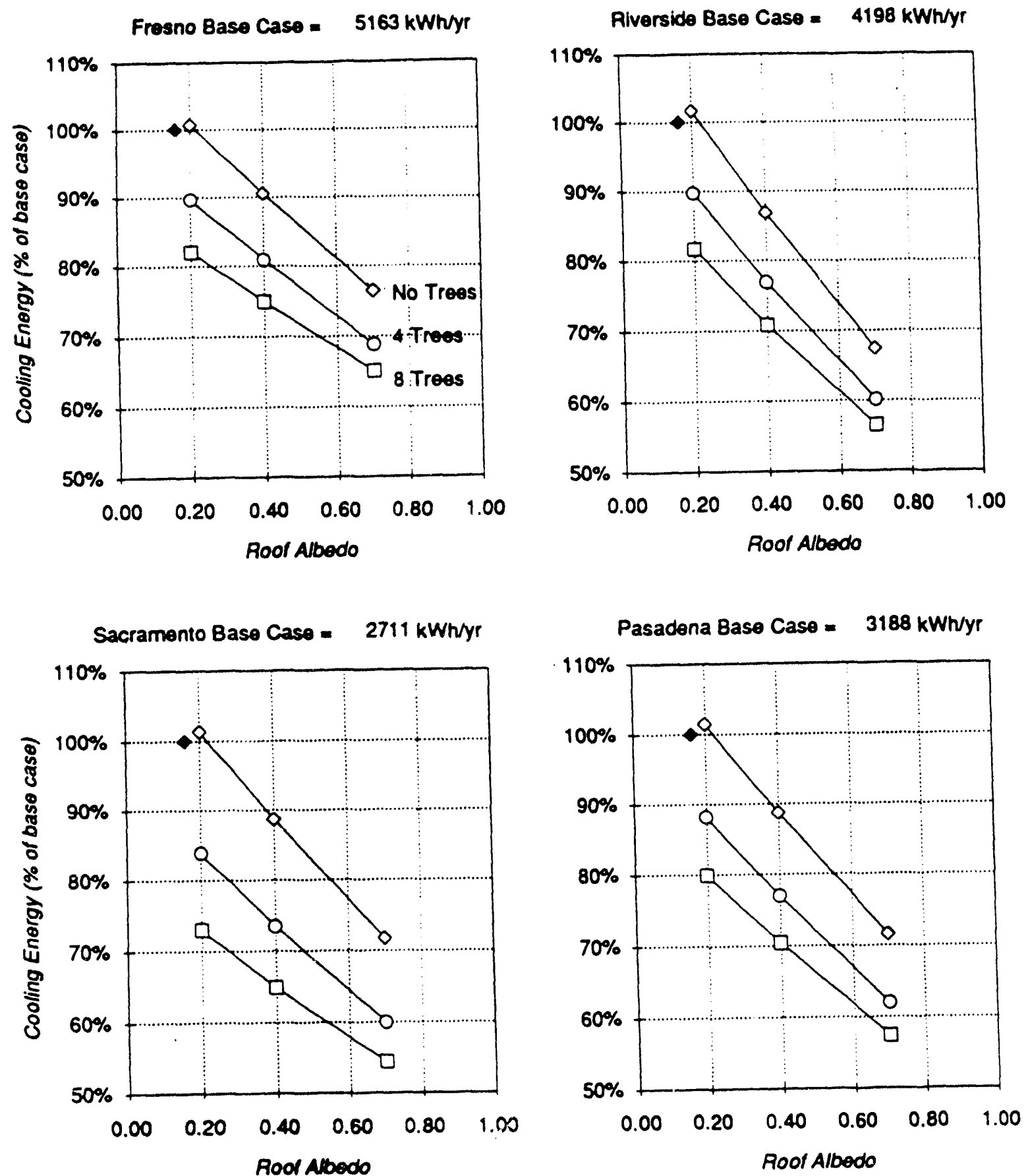
Figure VI-7. Annual cooling energy consumption (including fan energy) for Site 8 in four locations. Wall albedo $=0.15,0.3$ and 0.5 for roof albedo $=0.2,0.4$ and 0.7 Base case (shown here as a black diamond) has windows to south, south overhang, and east and west shading from buildings and trees. Buildings assumed to be unoccupied during June, July, August, and on weekends. Base case also includes the effect of the low emissivity of the unpainted metal roof.
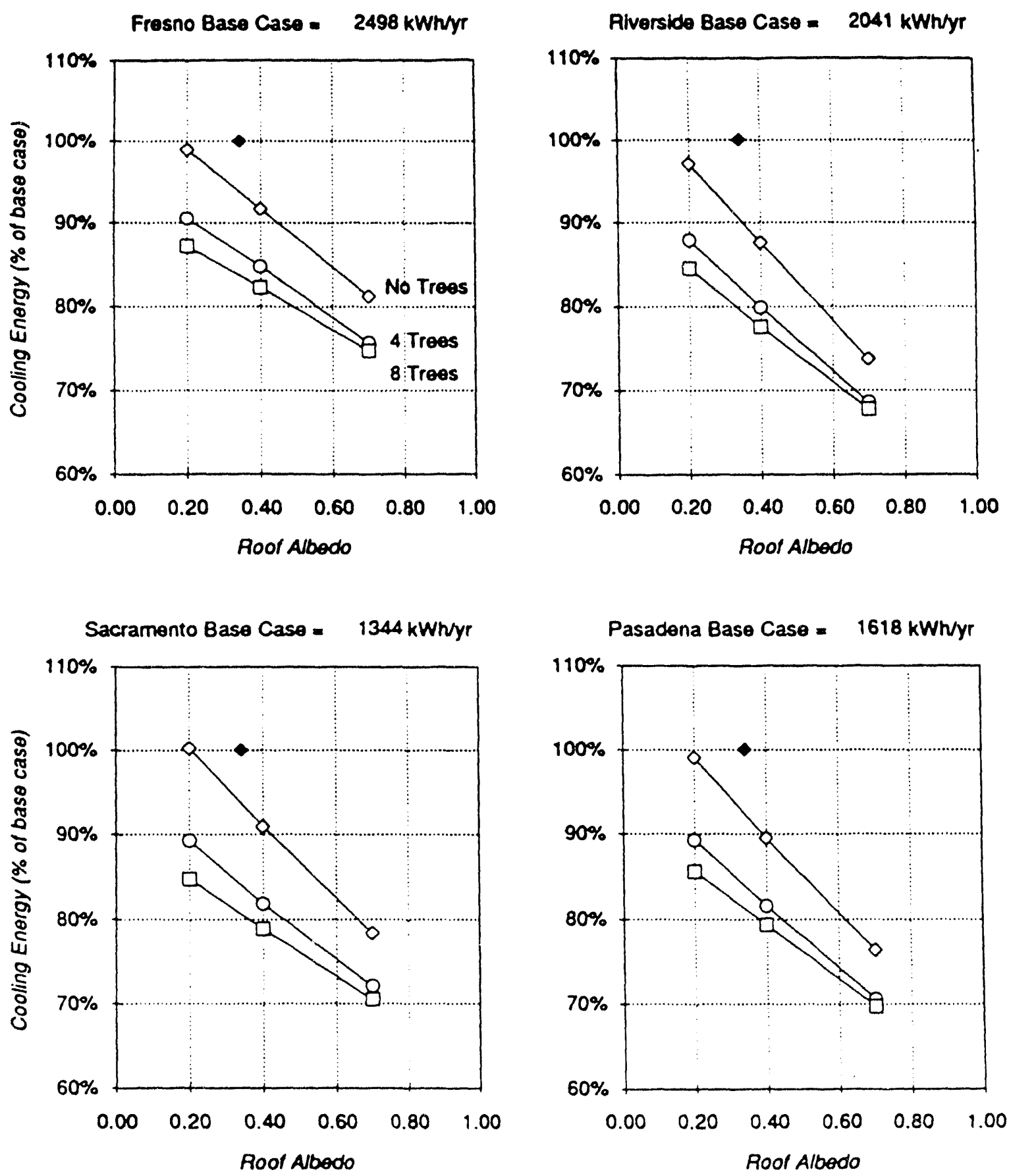
The comparison of calibrated basecase simulations with the parametric indicates that, in general, less than $10 \%$ of the potential energy savings of shade trees are achieved in present conditions. There are over $90 \%$ of the potential savings available as a target. The potentials for changing albedo of roofs and walls are also as great as shade trees. Most sites have roof albedos less than $30 \%$ and there is room to increase the roof albedo to $50 \%-70 \%$

It is also important to note that the air-conditioning systems in all climates are assumed to have the same capacity and characteristics as those of the basecase buildings in Sacramento. Hence, the simulated saving results for the hotter climates of Riverside and Fresno, where the capacity of the systems are undersized, are probably lower than the case where system were correctly designed for these climale conditions.

However, the impacts on peak electricity demand overall, as shown in Table VI-4, are not as significant as the impacts on annual energy use. This may be partly due to undersized cooling systems in these buildings for the more extreme cooling climates of Fresno and Riverside. In the Sacramento experimental period, the measured data showed maximum hourly cooling use only at Site 8. Peak demand is also affected by the duct efficiency in our model. The interactions between duct performance and roof albedo modifications, which affect attic temperature, will be addressed in more detail in future phases of the project. The simulated peak power savings are in the range of $3 \%$ to $30 \%$ in Sacramento with an average of about $20 \%$. We expect comparable demand savings in other climate regions.

We have averaged and summarized the annual energy and peak power savings in Table VI-5. The savings are averaged using the basecase consumption for each building as a weighting factor. The average energy saving potentials is about $33 \%$ in Fresno and about $42 \%$ in other climate regions. The average potential peak power savings are about $17 \%$ to $20 \%$. Note that, since the air-conditioning systems are designed for Sacramento ciimate, the peak power savings for other climates, particularly Fresno, may be underestimated. 
Table VI-5. Average Annual Cooling Energy and Peak Power Saving Potentials of Shade Trees and White Surfaces. The savings are averaged using the basecase consumption for each building as a weighting factor.

\begin{tabular}{|l|cc|cc|}
\hline & \multicolumn{2}{|c|}{ Base Case } & \multicolumn{2}{c|}{ Savings } \\
Energy & Peak & Energy & Peak \\
Climate & $(\mathrm{kWh})$ & $(\mathrm{kW})$ & $(\%)$ & $(\%)$ \\
\hline Fresno & 3306 & 4.28 & 33 & 17 \\
Riverside & 2056 & 3.69 & 42 & 19 \\
Sacramento & 1399 & 3.78 & 43 & 19 \\
Pasadena & 1427 & 3.30 & 42 & 20 \\
\hline
\end{tabular}




\section{SUMMARY AND CONCLUSIONS}

In this project we set to assess, monitor, and document the direct effects of shade trees and white surfaces on building cooling energy use. The specific goals of the first phase included assessing and documenting the albedo performance characteristics of various building and paving materials, specifying/recommending how they should be used in an incentive program, documenting the air-conditioning energy savings of shade trees and albedo changes by instrumenting a few selected sites in Sacramento, and comparing simulation results with monitored data.

This project was designed as a collaborative effort between LBL and SMUD. LBL's participation in this study involved project design, equipment installation, and data analysis whereas SMUD supplied the monitoring equipment and instrumentation and made an engineer's time available for instrumenting the selected buildings, collecting data, and transferring data to LBL for analysis.

Seven buildings (sites) were available for this study out of approximately 100 that were initially on a list of potential sites to participate in this project. Hence, the sample of monitored buildings is not representative of the current building stock in Sacramento and we caution against simplistic extrapolations of results from this report.

One of the sites was designated as a control, two sites (one house and one school) were used as albedo modification cases, and the rest of the sites was used for vegetation modifications. In the albedo cases, albedo was increased from a basecase value of about 0.15 to a new value of about 0.75 . Vegetation modifications, on the other hand, were performed mainly with trees in movable containers placed adjacent to walls and windows. At the time of positioning (9-24-91), these trees had a leaf cover of about $50 \%$ based on our estimates.

Prior to the start of monitoring, we developed detailed experiment design protocols for each site. While the specifics at each site dictated variations in the experiment protocols, the essential features were the same. Sites were identified as either control (site 1), vegetation site (sites 5, 6, 7, and 8), or albedo site (sites 2 and B). Regardless of whether a test site was to be used as an albedo case or a vegetation case, similar indoor and outdoor variables were measured in most locations.

Depending upon the requirements at a given site, we employed a variety of sensors to measure the necessary variables: air temperature, surface temperature, relative humidity, wind speed, wind direction, solar radiation, air conditioner energy use, and sub-surface soil 
temperature and moisture.

Prior to the dynamic (field) calibration of sensors, bench calibration was carried out. When interpreting the output, conversion from analog to digital and to meaningful physical units was necessary. Before installation at the residential and school sites, the sensors and data-loggers were dynamically calibrated side by side in a large open yard at SMUD. At the end of the project, the sensors were recalibrated to make sure no drift had occurred during the monitoring period. Each combination of sensors, wires, connections, and a data-logger formed a "set" of components that we kept together during calibration and throughout the monitoring period. Pre-calibration was performed in August 1991, whereas post-calibration was performed in December 1991.

The data loggers were programmed to record all variables at 20 minutes and some variables at 10 minutes. As expected with a monitoring project of this size we encountered some problems, primarily related to equipment in the field. We were able to identify some of these problems and remedy them on-line. Other conditions, concerning site control, were not so easily remedied. Some site control conditions, including thermostat settings and windows covering schedules, depended on the occupant's cooperation. Sensor problems were minimal (3.5\%); only four sensors out of one hundred and fifteen sensors had problems.

Two types of data were obtained from each site. The first included environmental characteristic data such as building albedo, vegetation type/tree cover, and view factors. The second include a microclimate and energy use data. Our initial analysis included checking for outliers, missing data, and signal-saturated output. Following that, we performed intercomparison among all sites within the pre-modification period as well as an intercomparison with concurrent data from other sites and prior data from the same site after modification.

The measurement period for some of the sites was limited to the months of September and October 1991. These months typically are transitional cooling months in Sacramento and, therefore, the results presented here are limited to these measurement periods. With the help of simulations, we were able to estimate the impacts of high-albedo roofs and shade trees on cooling energy use for the hot summer months of June, July, and August.

Another limitation that the project encountered was the small-sized trees made available for the shading experiment. Hence, the measured savings from shade trees need to be verified further in the next cooling season. 
Data analysis proceeded under the assumption that reductions in air conditioner energy use were a result of albedo and vegetation modifications. As has been pointed out elsewhere in this report, this assumption may not be valid in some cases.

An important component of this monitoring project was to model and simulate the monitored buildings using the DOE-2.1D building energy analysis program to better understand and evaluate the measured data. We developed models based on building characteristic data and measured temperature data collected for each site. These models were the basis for initial comparisons with the measured data. These models were also used to estimate savings for an entire year to supplement measured data from the two-month period of monitoring.

To calibrate the model for each building, we compared simulated hourly compressor energy use and interior temperatures to corresponding measured data. At most monitoring sites, the measured data had significant gaps, which precluded the possibility of comparing the models with the measured data over long-term periods. Based on the available measured data, we chose one week of continuous hourly data from the pre- and post-modification periods for comparisons.

In our analysis of data from the control site (Site 1), we found that mechanical cooling started when the outdoor daily maximum temperature exceeded $30^{\circ} \mathrm{C}$. Regression analysis indicated an increase in cooling load by about $1.2 \mathrm{kWh}^{-1} \mathrm{day}^{-1}$ per ${ }^{\circ} \mathrm{C}$ of maximum daily temperature. The comparison of hourly measured and simulated data for Site 1 showed that, in general, the total daily cooling electricity matched well over the period for which consistent data exists.

In the residential albedo site (Site 2), the analysis of measured data indicated that after increasing the albedo of the roof from 0.18 to 0.77 the air conditioner was not required to maintain the indoor setpoint temperature on the immediate two weeks of post retrofit which had comparable outdoor temperature. It is worth noting, however, that solar intensity was generally lower during the post-monitoring period, and that might explain why $100 \%$ reductions were possible. The DOE-2.1D simulations of this site, performed for corresponding periods, indicated that about $20 \%$ of the measured reductions may have been caused by the effect of lower insolation during the post-monitoring period.

In the other albedo site (school) the analysis of measured data showed that cooling energy use in the white-coated test unit was about $50 \%$ of the amount of cooling energy used in the control unit (with yellow walls and metallic roof). One should keep in mind, however, that in addition to the effect of higher albedo coatings on the roof and southeast wall of the test unit, other 
factors that might have contributed to the higher energy usage in the control unit included thermostat reset in the control classroom and lower emissivity $(-0.30)$ of the metallic roof compared to the emissivity of the painted roof $(-0.95)$ in the brown or white configurations. The DOE-2 simulations indicated that $15-20 \%$ of the measured savings were actually due to the high albedo coating. The rest was a result of thermostat setting and emissivity differences as was discussed in this report.

In the vegetation modification sites, varying results were obtained. In Site 5, for example, at $38^{\circ} \mathrm{C}$ outdoor air temperature, there were reductions of $2 \mathrm{kWh}^{-1}$ in cooling energy use after the placement of two trees on the east side. These reductions correspond to $-14 \%$ at that temperature. DOE-2 simulations of this site indicated that the reductions were mostly due to the effects of lower insolation during the post-monitoring period, rather than the placement of shade trees.

In Site 6 at $38^{\circ} \mathrm{C}$, there was a reduction of $4.5 \mathrm{kWh}$ day $^{-1}(-30 \%)$ in cooling energy use resulting from the placement of two trees on the west and one tree on the south sides. The comparison of measured and simulated data for Site 6 showed that the simulated peak load coincided with the measured peak for the post-period, but overpredicted the peak by about $0.5 \mathrm{~kW}$ on average in the pre-period. The model overpredicted cooling energy use in the post-period more than in the pre-period. When the same climatic inputs were used in the model for the base and tree cases, there was virtually no difference in cooling energy consumption, that is, no savings.

In Site 7, and at $38^{\circ} \mathrm{C}$ outdoor air temperature, the placement of 2 southwest trees resulted in a reduction of $-5 \mathrm{kWh}$ day $^{-1}$ or about $34 \%$ of cooling electricity use. However, the DOE-2 simulations indicated that almost all these reductions were caused by lower insolation during the post-monitoring period.

Finally, our analysis of data from Site 8 (which is located just next to Site 1) showed that at $38^{\circ} \mathrm{C}$, there were reduction of $-2.5 \mathrm{kWh}$ day $^{-1}$ in cooling electricity use, which amounts to a reduction of $12 \%$, resulting from the placement of seven small trees on the south side. Compared to the measurements, the simulated conditions for this site were consistently about 4 $\mathrm{kWh}$ /day higher over the pre-monitoring period. As v'ith the other tree sites, when the change in climatic conditions between the pre- and post-periods was accounted for, the simulated cooling energy savings from the trees was found to be minimal.

Overall, the calibration and comparison of measured and simulated conditions highlighted the difficulty of matching simulation results with measured data. The types and magnitudes of 
the errors were not consistent across the sites. The daily energy consumption was slightly overpredicted at Sites 2, 5 (pre-period), 6, 7, and 8, but the peaks matched well. Peak loads at Sites $B$ and 5 matched well, but daily energy consumption at Site 5 did not match well. Our analysis suggests the models could benefit from further refinements. However, given the current level of characterization for each site, the models perform reasonably well. The necessary refinements would focus on details of the cooling systems, which is the primary method of assessing albedo and vegetarion impacts, occupancy patterns, thermostat operations, building thermal mass, and the local climate characteristics.

Although in the first year project we have made significant progress in experiment design, debugging the system, obtaining base case condition, and a preliminary survey, we need to continue the experiment for another cooling season. During the second phase, the ducting system in each house should be tested for air leakage and conduction losses. These parameters could then be incorporated into the models to more accurately characterize duct performance at different climatic conditions. The cooling equipment efficiency may also be further characterized by simple spot testing or more complete monitoring of $a^{:} \quad$ is and temperatures and electricity consumption.

More information about occupancy patterns and appliance usage schedules would improve the inputs for hourly internal gains simulations. The effect of improved characterization of internal gains is unclear, however. Some of the interior temperature tata shows the buildings have a slower thermal response to diurnal temperature swings than the model predicts. Better model inputs for thermal mass may improve the models in this area.

More complete climatic data for each site would allow us to develop model inputs that are more specific to a site's microclimate. Significant gaps in site temperature data did not allow the data to be used in the simulations. In addition, the site solar data was not useful to the DOE-2 models because of the method of measurement. These problems should be addressed in future work.

Model calibration would also benefit from several indoor temperature sensors, which would help to understand the conditions throughout the building. In particular, a sensor located next to the thermostat would help explain and verify apparent thermostat abnormalities.

A nother issue to keep in mind in the second year of this project is the start of monitoring. Preferably, measurements should begin early in summer to avoid the concerns of seasonal cooling. An ideal time to start would be the month of June. Also, plenty of time should be allowed 
for equipment acquisition, testing, calibrating, and installing in the field. These tasks are the most crucial and demanding of all project tasks. Finally, in the second year of this project, larger and more mature trees should be used instead of the small ones. 
ATTACHMENT A

\section{DOE-2 INPUT FILES}




\section{DOE-2 INPUT FILE FOR SITE 1 BASE CASE}

POST-PROCESSOR PARTIAL ..

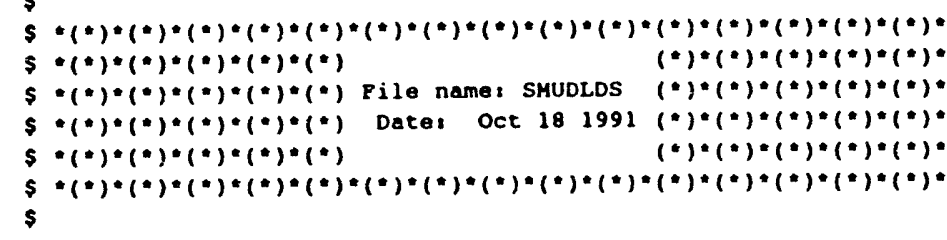

\$--

PARAMETER

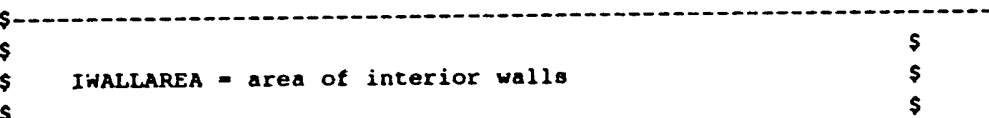

IWALLAREA is estimated from Haider's drawings (see notes) $S$ for HOUSVOL, assume average ceiling $\mathrm{Ht}$ of $9 \mathrm{ft}$.

INTLOAD - .75 $x$ minimum month daily electric usage SENS,

$\$+.10 \times$ minimum month daily electric usage LATN,

( $290 \mathrm{Btu} /$ day SENS + $580 \mathrm{Btu} /$ day LATN $) /$ person for DHW use

$+(2770$ Btu/day SENS + 2290 Btu/day LATN $) /$ person for occupancy (children counted as $.75 \times$ Adults)

$10 / 5$ internal loads changed to include only appliances and dhw s occupants calculated differently

SRes1 S ELRAREA-1122 HOUSVOL=10098 PERIM-143 IWALLAREA=799.99

SRES1 1 GARAREA-468 NEX-40.5 NEY=30.0

SRes1 \$ ROOFZ=7.999 ROOFHT=16.15 ROOFWD $=40.5$

\$ NWALEWD-2 SWALLWD-40.5 EWALLWD $=30.0$ WWRILWD $=25.5$

SREB 1 \$ WALLHT=7.999 SHADEHT=7.257

SRes1 INTLOAD=30006 LATLOAD $=.215$

SREB 1 \$ INTLOAD=27230 LATLOAD=.150 NUMOCC=1

SSacramento CS FSLABL=FSLABLDP BSLABL=BSLABLDP CGNDL=CGNDLDP
SSacramento CS R5BHALL-R5BWLLDP R1 OBWALL-R10BWLDP ROBWALL-ROBWLLDP \$R19 Coiling \$ VAULL - rl9vaul CEILL - r19coil

SR11 Stucco wall \$ WRLLL = rllswall

\$Basel $\$ \quad$ WALLABS $=0.70 \$$ tan stucco

SBasel S ROOFABS- 0.60 s tan shingles

SRegl S T1AX-12.4 T10X--1.6 T2AX-25.25 T2DX-11.25 T3AY-28.75 T3CY=14.75

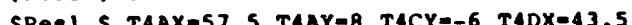

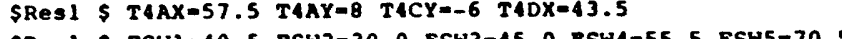

\$ReBl \$ PSW1 $=40.5$ FSH2-30.0 FSW3=45.0 PSW4-55.5 FSHS=70.5

SSacram One Slab FHo $\$$

SYEAT $\$$ RUN-PERIOD
DIAGNOSTIC

JAN 11991 THRU DEC 311991.

DIAGNOSTIC CAUTIONS, WIDE, ECHO, SINGLE-SPACED .

BUILDING-LOCATION LAT-38.52 LON-121.50 T-2=8 ALT=17

WS-HEIGHT-LIST=

$50,50,50,50,50,50,50,50,50,50,50,50)$

SRes1 S

$$
\text { A2 IMUTH }=-45
$$

\$Res1

A2 IMUTH=-45

\$NowndS TERRAIN-PAR1=.85 TERRAIN-PAR2=.20 
(10) $(0.52)$ (11) $(0.63)$ (12) $(0.21)$ (13) $(0.14)$

$(14,15)(0.00)(16.17)(0.29)(18)(0.64)$

(19) $(0.81) \quad(20)(1.00)(21)(0.96)$

(22) $(0.89) \quad(23)(0.77)(24)(0.41) \ldots$

Coc sold CEC/GRI oce schedule mod for unoce

$\begin{array}{llll}(1.6)(0.44) & \text { (7) }(0.53) \quad(8)(0.87)\end{array}$

$(9,18)(0.00)$

(19) $(0.81)$

(20) $(1.00)(21)(0.96)$

(22) $(0.89) \quad$ (23) $(0.77)(24)(0.44)$.

$\$$ internal loads includes all loads

SReEl S INTLDSCH SCHEDULE THRU DEC 31 (WD) UOCCAPPS (WEH) DAYINTSCH ..

\$Res 1 \$ INTLDSCH SCHEDULE THRU DEC 31 (WD) OCCNO (WEH) OCCYES ..
SRes1 S OCCSCH SCHEDULE THRU DEC 31 (W)

S-

S The following shading schedule is set for each house.

SHADCO SCHEDULE THRU MAY 31 (ALL) $(1,24)(0.80)$

$\begin{array}{lllll}\text { SHADCO SCHEDULE } & \text { THRU MAY } 31 & \text { (ALL) } & (1,24) & (0.80) \\ \text { SRES1 \$ } & \text { THRU OCT } 31 & \text { (ALL) } & (1,24) & (0.60)\end{array}$

$\begin{array}{lllll}\text { SRes1 } \$ & \text { THRU OCT } 31 \text { (ALL) } & (1,24) & (0.60) \\ & \text { THRU DEC } 31 \text { (ALL) } & (1,24) & (0.80)\end{array}$

The following cree shading schedules produce the follwing effective

trasmittances of 0.50 down to 0.10 during the summer and of 0.90

down to 0.50 during the winter. The Bquare root of the trangmittance

s is input under building-shades since light passing through a "tres"

s goes through two surfaces.

goes through two

STEU FEB 28 (ALL) $(1.24)(1.00)$ $(1,24)(0.745)$

THRU DEC 31 (ALL) $(1.24)(1.00)$.

TREETRANS2 SCHEDULE THRU FEB 28 (ANL) $(1,24)(1.00)$

$\begin{array}{llll}\text { THRU OCT } 31 \text { (ALL) } & (1,24)(0.707) \\ \text { THRU DEC } 31 \text { (ALL) } & (1,24)(1.00)\end{array}$

THRU DEC 31 (ALL) $(1,24)(1.00)$

TREETRANS3 SCHEDULE THRU PEB 28 (ALL) $(1,24)(1.00)$ THRU OCT 31 (ALL) $(1,24)(0.655)$ THRU DEC 31 (ALL) $(1,24)(1.00)$.

TREETRANS4 SCHEDULE THRU FEB 28 (ALL) $(1,24)(1.00)$ THRU OCT 31 (ALL) $(1,24)(0.577)$ THRU DEC 31 (ALL) $(1,24)(1.00)$.

TREETRANSS SCHEDULE THRU FEB 28 (ALL) $(1,24)(1.00)$ THRU OCT 31 (ALL) $(1,24)(0.447)$ THRU DEC 31 (ALL) $(1,24)(1.00) \ldots$

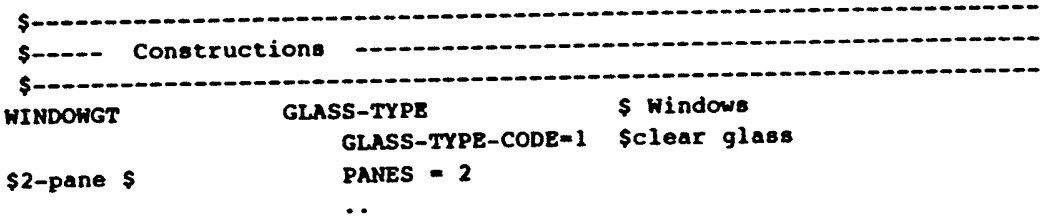

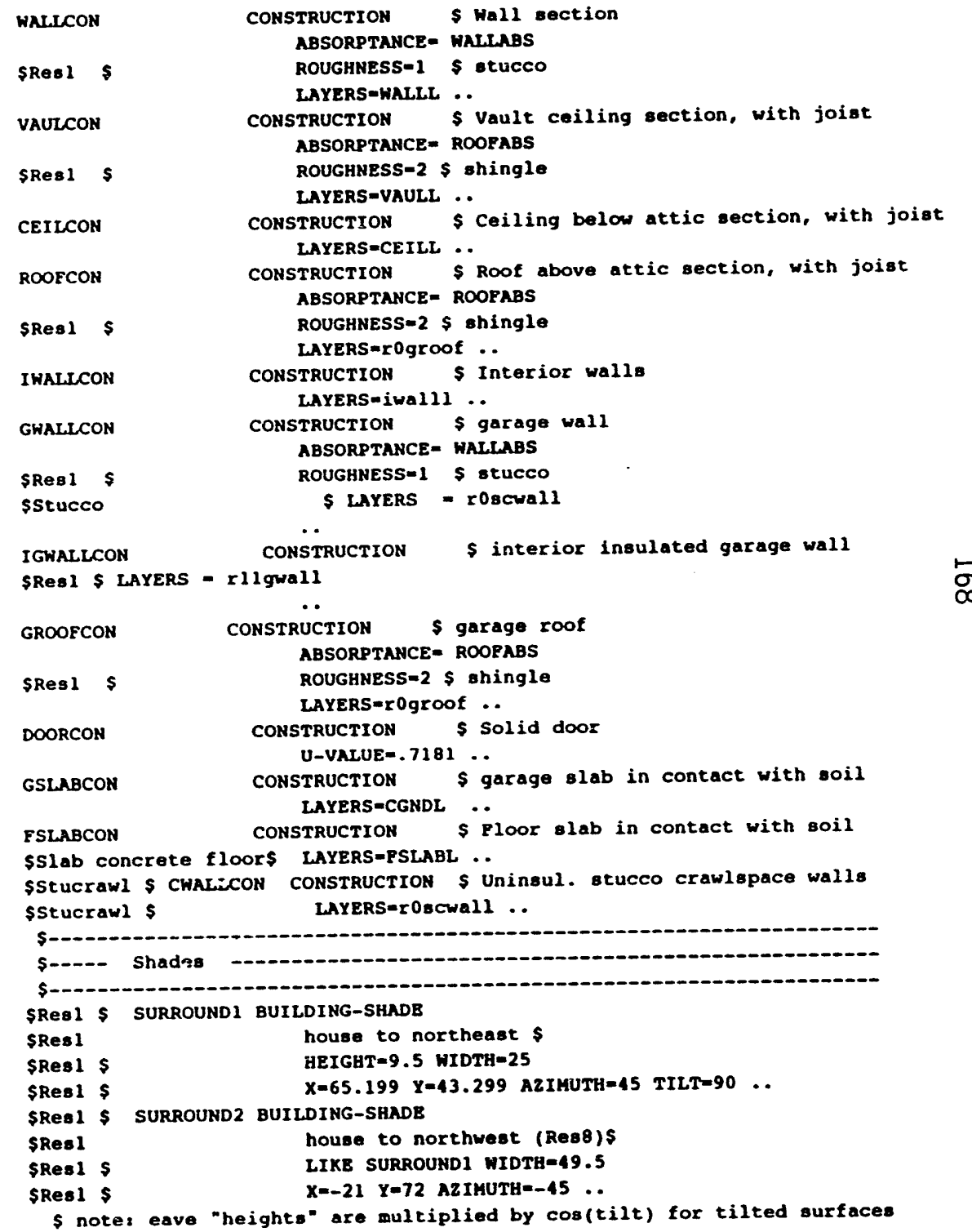


RAVEN BUILDING-SHADE $\$$ north eave

\$Res1 $\$$ HEIGHT-2.15 WIDTH=21 X-NEX Y-32 TILT-21.8 $z=S H A D E H T$..

EAVES BUILDING-SHADE LIKE EAVEN $\$$ south eave SResi \$ HIGHT-1.08

EAVEE BUILDING-SHADE LIKE RAVEN $\$$ east eave

\$Res1 \$

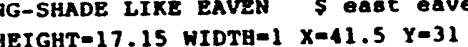

SRes1 \& EAVEE2 BUILDING-SHADE LIKE EAVEE $X=40.5$ Y=-1 AZ-180 ..

AMEN BUILOING-SHADE IIKE EAVEE \$ west eave

\$Res 1 \$ $x=0$

SRES1 \$ EAVEH2 BUILDING-SHADE LIKE EAVEE2 $X=-1 \ldots$

\$Resl \$ DECKOH BUILDING-SHADE \$ backyard deck overhang

SRes1 \$ HEIGHT=16 WIDTH=27

SReB1 \$ $\quad X=52.5 \quad y=4$ \&-WALLHT ..

\$ Treess First existing, then test trees

SEXTr1S TREES1A B-S HEIGHT=5 WIDTH=22 X=25 Y=-0.1 $2=0$ TILT=90

SEXTRIS

SEXTr1S TREES1B B-S LIKE TREES1A HIDTH=5 AZ-270 .

SEXTr1S TREES1B B-S LIKE TREESIA HIDTH=S

SEXTRIS TREESIC B-S LIKE TREES1A $Y=-5$.

$\begin{array}{llllll}\text { SEXTr1\$ TREES1D B-S LIKE TREES1B } & X-3 & \ldots & \\ \text { SEXTr1S TREES1E B-S LIKE TREES1A } & 2-5 & \text { TILT }-0 & \ldots\end{array}$

SEXTr1S TPEETIA B-S HEIGHT-17 WIDTH-17 X-59.5 Y--15.5 2-7 TILT-90

SETIS TRANSMITTANCE-0.707 SHADE-SCHEDULE-TREETRANSS ..

SEXTrIS TREET1B B-S LIKE TREET1A AZ-270 ..

SEXTY1S TREETIC B-S LIKE TREETIA $Y=-32.5 \ldots$

SEXTr1S TREETID B-S LIKE TREET1B X $=42.5 \ldots$

SEXTr1\$ TREETIE B-S LIKE TREETIA $2=24$ TILT=0 $x=59.5$ y=-15.5 AZ=0 ..

TREET2A B-S HEIGHT-26 WIDTH=26 $\quad x=23 \quad y=-16 \quad 2=7 \quad$ TILT $=90$

TRANSHITTANCE $=0.707$ SHADE-SCHEDULE=TREETRANSS ..

SEXTI1\$ TREET2B B-S LIKE TREET2A AZ=270 .

SEXTr1S TREET2C B-S LIKE TREET2A $Y=-42 \ldots$

SEXTK1S TREET2D B-S LIKE TREET2B X=-3 .

SEXTr1S TREET2E

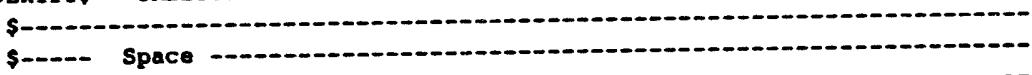

\$

$\$$

ROOMCOND SPACE-CONDITIONS

TEMPERATURE - $(74)$
SOURCE-TYPE-PROCESS

SOURCE-SCEEDULE-TNTLDSC

SOURCE-BTU/HR=INTLOND

SOURCE-SENSIBLE=1.

SOURCE-LATENT-LATLOAD

PEOPLE-SCHEDULE-OCCSCH

NUMBER-OF-PEOPLE-NUMOCC

PEOPLE-HG-LAT $=190$

PEOPLE-HG-SENS-230

INF-METHOD-S-G

SHedium Infiltration \$ FRAC-LEAK-AREA = .0005

$$
\begin{aligned}
& \$ \text { FRAC-LEA } \\
& \text { F-WEIGHT-0 }
\end{aligned}
$$

FURNI TURE-TYPE=LIGHT

FURH-FRACTION=0.29

FURN-WEIGHT $=3.30$

SET-DEFAULT FOR DOOR HEIGHT=6.5 WIDTH-3.0 CONSTRUCTION-DOORCON . SET-DEPAULT FOR EXTERIOR-WALI. SHADING-SURFACE-YES

SET-DEFAULT FOR WINDOW

GLASS-TYPE-WINDOWGT SHADING-SCHEDULE-SHADCO ..

THEROOM SPACE

SPACE-CONDITIONS-ROOMCOND

AREA-FLRAREA VOLUME=HOUSVOL ..

INTWALL INTERIOR-WAL

INT-WALL-TYPE-TNTERNAI

AREA-IWALLAREA CONSTRUCTION=IHALLCON ..

SREs 1 S MWALI1 EXTERIOR-WHIL CONSTRUCTION-WALLCON X-NEX Y-NEY

HEIGHT-WALLHT WIDTH-NWALLWD

SRES1 \$ NWALLL EXTERIOR-WALL LIKE NWALLL X-38.5 WIDTH-3.0 AZ=48.9 ..

SRES1 S NWIND2A WINDON $x=0.75 \quad x=1.8$ HEIGHT-4.5 HIDTH-1.5.

SRes1 S NHALL3 EXTERIOR-WALL LIKE NWALL1 $X=36.5$ Y=32 WIDTH=6.0 .

\$RESI \$ NWIND3A WINDOW LIKE NWIND2A HIDTH=4.5

SRes1 \$ NWALL4 EXTERIOR-HALL LIKE NWALLL $X=30.5$ Y $=32$ WIDTH=3.0 A2=-48.9.

SReS1 S NWIND4A WINDOW LIKE NWIND2A ..

SREs1 S MWALL5 EXTERIOR-HALL LIKE NWALL1 X=28.5 WIDTH=2.0 ..

SRes1 1 NWALL6 EXTERTOR-WALL LIKE NWALLI X-26.5 WIDTH-1.5 AZ=-90 ..

SReal S WALL7 EXTERIOR-WALL LIKE NWALLI X=26.5 Y=28.5 WIDTH=7.0 ..

SResi I NDOOR7A DOOR.

SREA 1 S NWALLB INTERIOR-WALI CONSTRUCTION=IGWALLCON

HEIGHT=HALLHT WIDTH=3 NEXT-TO=GARAGE .

SRES1 \$ NWALL9 INTERIOR-WALL LIKE NWALLB WIDTH-19.5 .

SWALL1 EXTERIOR-WALL

\$ReBI \$ LIKE NWRLLI $X=0.0$

HEIGHT=WALLHT WIDTH=SWALLHD $Y=0.0 \quad \mathrm{AZ}=180$

SRES1 \$ SWINDIA WINDOW $X=3$ Y=3.6 HEIGHT=2.7 WIDTH=4.8 $\ldots$ 
Res1 $\$$ SHIHD18 WIUDOH LIKE SHINDIA $x=16$ HEIGHT-3.0 WIDTH-4.5 ..

WINDO $x=26 \quad x=2.7$ HEIGHT=3.0 WIDTH=3.3 .

SWINDID WINDO $x=33$ Y $y=0.0$ HEIGHT-6.0 WIDTH-5.4

SRES1 S EWALL1 EXTERTOR-HALI LIXE NHALLI $Y=0$ A2=90

MIDTH-EWALLWD .

\$ReS1 \$ EHIND1A WINDON $X-1 \quad Y=0.6$ HEIGHT-5.7 HIDTH- $2.4 \ldots$

WWALL1 EXTERIOR-WALS

SREB 1 LIKE NWALLI $Y=25.5$

$x=0$ HIDTH-WWALLWD AZIMUTH- 270

.

SREBI $\$$ WWIND1A HINDOW $x=3$ $x=4.20$ HEIGHT- .40 WIDT

\$SIab \$ FOUNDATION UNDERGROUND-FLOOR \$ SLAb IIOOT

$\$ S I a b \$ \$$ HEIGHT-10 WIDTH-FLRAREA TIMES

\$SIab \$ TILT=180 CONSTRUCTION-FSLABCON

\$Slab \$ U-EFFECTIVE-FDNUEF

\$Slab \$ BUNCTION $-(*$ NONE*,*FNDQ*) .

SAtticS CEILING INTERIOR-WALL $\$$ Ceiling between House and Attic

SATtICS TILT=0 CONSTRUCTION-CEILCON

saceics AREA-PLPAREA NEXT-TO-ATTIC .

SAttic spaces

SAttics ATTIC

SAttics

\$Attic\$

SAttic

\$Attic

SReal \$

SAttics

SAttics

SAttics

SAtticS NROOF1

SAttic\$

\$Resi \$

SAttic\$

SAtticS SROOFI

SResi \$

SAttic\$

GARAGE

SPACE

POER INF-METHOD-S-G

ssume 1 ft2 of vents per $450 \mathrm{ft} 2$ of attic space area,

ELP - 75 , of vent area

PRAC-LEAK-AREA= .00167

FLOOR-WEIGHT 0

ZONE-TYPE-UNCONDITIONED $T=(80)$

Z-ROOF 2 HEIGHT=ROOFHT WIDTH=ROOFWD

CONSTRUCTION=ROOPCON

$X=N E X \quad Y=N E Y$ TILT $=21$.

MOOF LIKE NROOF 1

$X=0 \quad Y=0 \quad A Z I M U T H=180$

SPACE

AREA=GARAREA VOLUME-GARAREA TIMES 9.80 \$ avg height

INF-METHOD-S-G

PRAC-LEAK-AREA- $.0015 \$$ assume 3 times normal infilt

PLOOR-HEIGRT $=0$

ZONE-TYPE-UNCONDITIONED $T=(60)$

GARI EXTERIOR-WALL

\section{HFIGHT-WALLHT TILT $=90$}

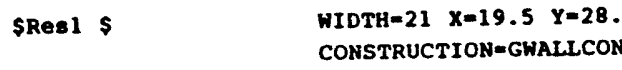

\$ garage Ewall
SReBI \$ GWINDI WINDOW

SRes1 \$

GAR2 EXTERIOR-WAL

HEIGHT=3 WIDTH-5 ... \$ window

LIKE GAR1

WIDTH-24 $x=0 \quad Y=49.5 \quad$ AZ=-90 \$ garage Mwall

\$Res 1 WIDTH

GAR3 EXTERIOR-WALL

LIXE GARI \& garage door wall

SRes $1 \$$ HEIGHT=9.8 WIDTH-19.5 X=19.5 Y=49.5 AZ-0 $\ldots$

SRes1 \$

GAR4 INTERIOR-WALI $\$$ insulated wall against house

SREs 1 AREA-180 CONSTRUCTION-IGWALLCON INT-WALL-TYPE-STANDARD NEXT-TO-THEROOH

GROOFI EXTERIOR-WALL

SRES1 S IXE GARI HEIGHT=11.4TITT=31.6

LIXE GARI HETGHT-11.4 TILTA31.6

SREB 1 SROOF 2 EXTERIOR-WALL

SReal $\$$ LIKE GAR2 HEIGHT=11.4 HIDTH-21 TILT=31.6

SResis Z-ROOFZ CONSTRUCTION-GROOFCON ..

GSLAB UNDERGROUND-PLOOR \$ Garage floor

HEIGHT-10 HIDTH=GARAREA TIMES .

TILT $=180$ CONSTRUCTION-GSLABCON

U-EFFECTIVE- .143 .. S Ref j.huang - ashrae paper

SHrRpt--.--

SHrRptLoads Reports

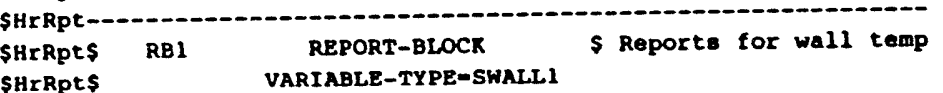

SHRRPtS VARIABLE-TYPE-SWALLI

SHIRPt\$ VARIABLE-LIST=(6) ..

SHrRpt 6-8urface T

SHrRPt\$ RB2 REPORT-BLOCK S Reports for roof temp VARIABLE-TYPE-SROOP

VARIABLE-LIST $=(6)$

SHrRptS

SHRRPS HRSCH SCHEDULE Hourly report schedule

stripts

SHrRpes

strente

SHrRpt\$ THRU DEC 31 (ALL) $(1,24$ ) (1) ..

HOURLY-REPORT

REPORT-SCHEDULE=HRSCH

SHrRpt\$ REPORT-BLOCK- (RB1, RB2) END ..

FUNCTION NAME - FNDO

LEVEL = UNDERGROUND-WALL .. 
ASSIGN DOY-IDOY UGPQ-QUGP UGWQ-QUGW ..

$(0,-3336.3)(1,-3389.2)(2,-3462.1)(3,-3450.6)(4,-3494.9)$ (5, -3548.8$)(6,-3512.7)(7,-3387.8)(8,-3400.9)(9,-3432.8)$ $(10,-3467.4)(11,-3408.3)(12,-3335.8)(13,-3164.1)(14,-3056.2)$ $(15,-3061.6)(16,-3176.4)(17,-3309.6)(18,-3360.7)(19,-3255.2)$ $(20,-3035.1)(21,-2849.8)(22,-2809.7)(23,-2858.6)(24,-2872.7)$ $(25,-2901.3)(26,-2954.2)(27,-2910.6)(28,-2832.9)(29,-2737.7)$ $(30,-2508.2)(31,-2379.1)(32,-2303.7)(33,-2479.3)(31,-2686.4)$ $(35,-2600.0)(36,-2500.5)(37,-2413.6)(38,-2189.9)(39,-2045.6)$ (35, -2608.0)( $36,-2500.5)(37,-2413.6)(30,-2189.9)(39,-2045.6)$ (40, -2134.6)( 41, -2002.3)( $12,-1946.5)(43,-1931.6)(41,-1942.3)$ $(45,-2040.4)(46,-1052.8)(47,-1659.4)(40,-1673.6)(49,-1538.1)$ $(50,-1285.3)(51,-1176.9)(52,-1189.2)(53,-1122.8)(54,-1020.4)$ $(55,-1070.9)(56,-1147.7)(57,-839.9)(58,-621.7)(59,-592.9)$ $(60,-577.7)(61,-569.9)(62,-507.0)(63,-493.0)(64,-494.7)$ $(65,-338.1)(66,-236.5)(67,-199.1)(68,-206.2)(69,-148.7)$ $(70,-30.5)(71,25.0)(72,81.5)(73,68.1)(74,-28.9)$ $(75,-49.4)(76,50.9)(77, \quad 73.1)(78,54.9)(79,-123.6)$ $(80,-331.5)(81,-320.9)(82,-271.8)(83,-264.4)(84,-250.2)$ $(85,-281.9)(86,-345,3)(87,-377.1)(88,-471.5)(89,-680.4)$ ( 85, -281.9)( 86, -345.3)( 87, -377.1)( 88, -471.5)( 89, -680.4) $(90,-661.4)(91,-665.3)(92,-717.0)(93,-771.9)(94,-825.7)$ $(95,-845.2)(96,-1001.8)(97,-1214.9)(98,-1290.1)(99,-1357.0)$ $(100,-1332.1)(101,-1377.6)(102,-1458.1)(103,-1635.8)(104,-1807.5)$ $(105,-1935.5)(106,-1957.5)(107,-2015.7)(108,-2097.4)(109,-2161.6)$ $(110,-2276.3)(111,-2428.2)(112,-2591.7)(113,-2814.0)(114,-2984.9)$ $(115,-2965.2)(116,-2985.4)(117,-2984.5)(118,-3194.8)(119,-3339.1)$ \$Duct $\$$ SUBR-FUNCTIONS

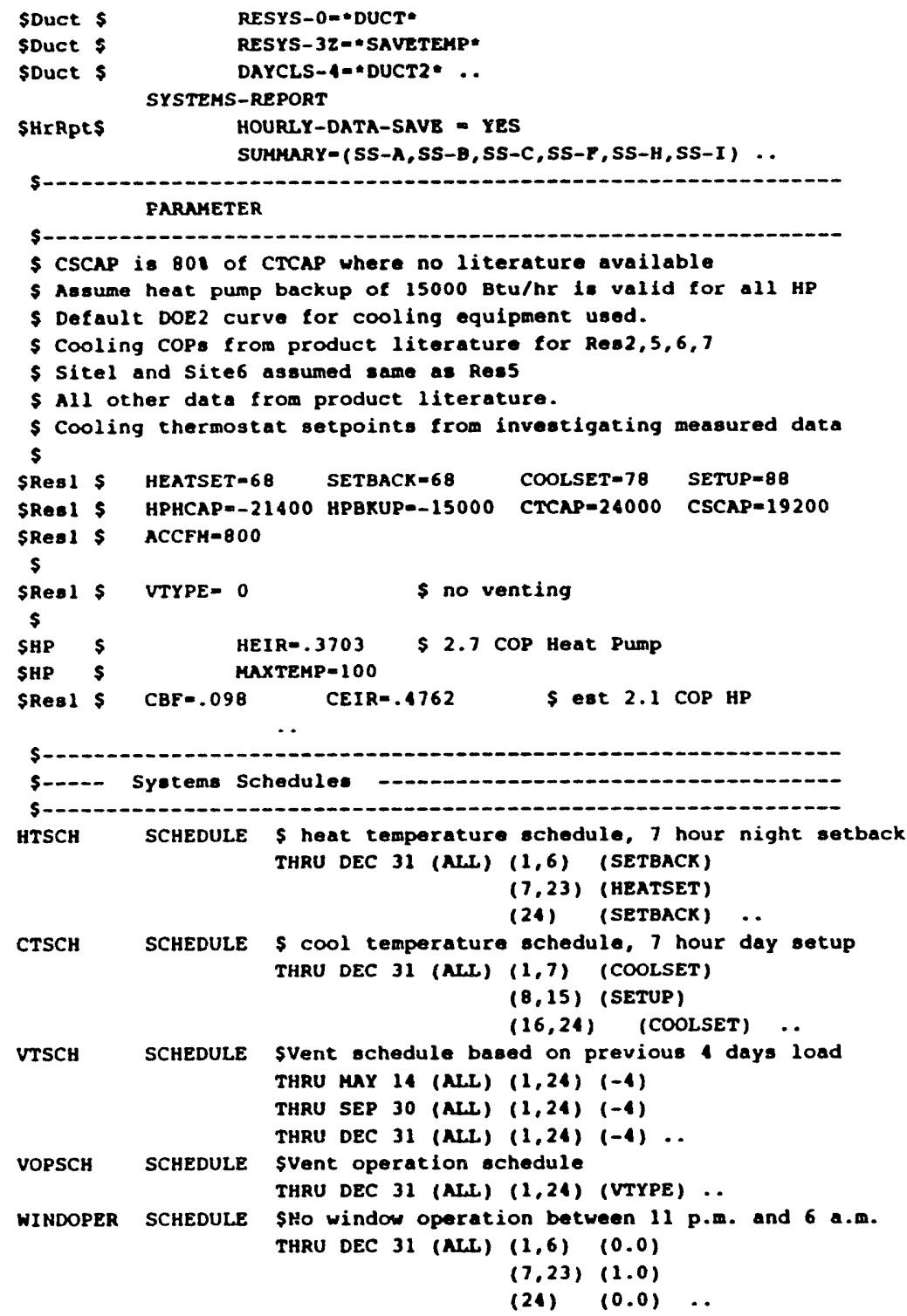




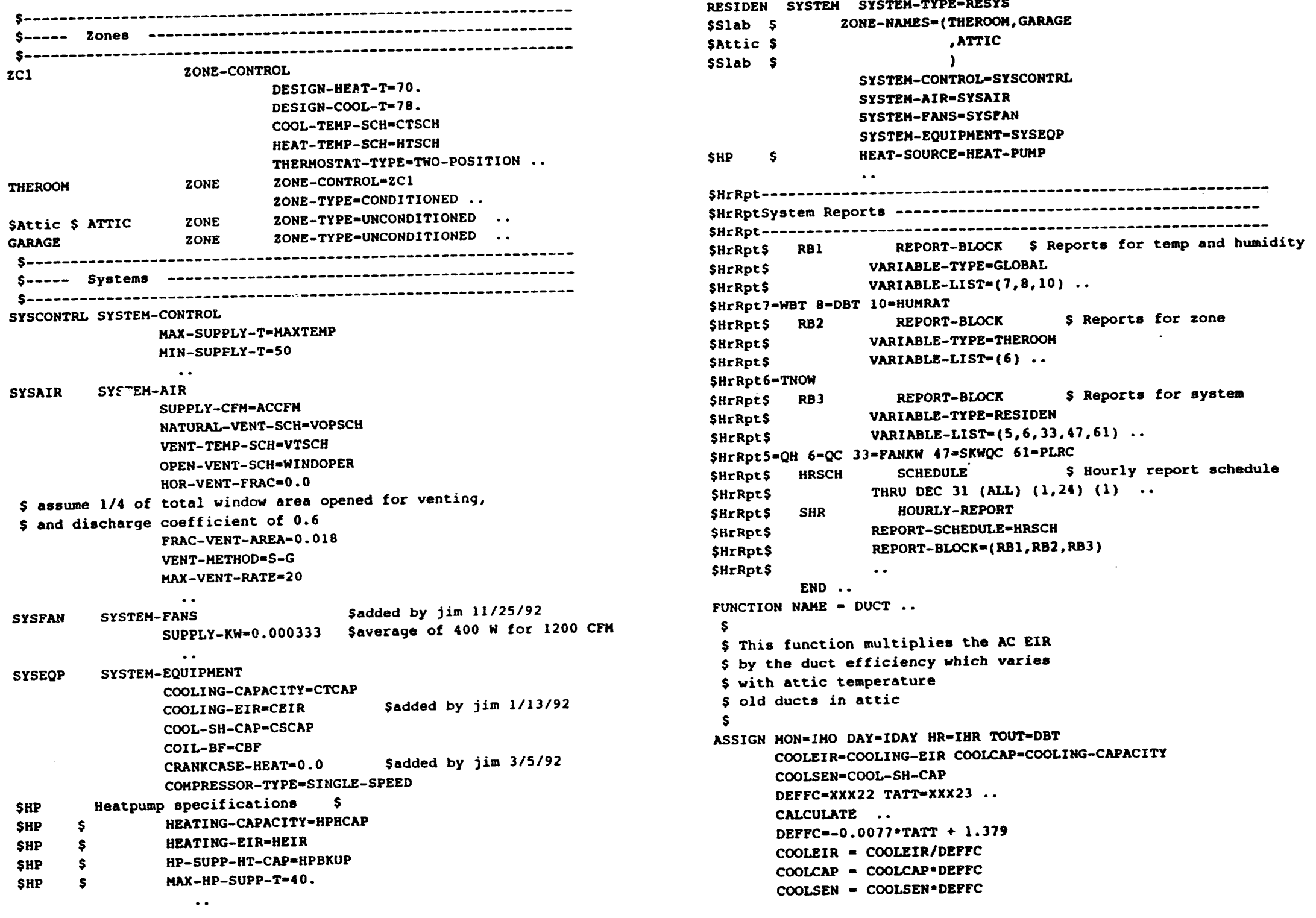


PRINT 20, MON, DAY, HR, TATT, DEFFC, COOLEIR

C 20 FORMAT('DUCT ',384.0,' TATT=',F4.0,' DEFFC=',

C +

F5.3, EIR=', F5.3)

END-FUNCTION .

FUNCTION NAME - DUCT2 ..

s

S This function resets $A C$ EIR to the input value

s old ducts in attic

ASS GN MON-IHO DAY-IDAY HR-IHR TOUT-DBT

COOLEIR-COOLING-EIR COOLCAP-COOLING-CAPACITY

COOLSEN-COOL-SH-CAP

DEFFC $=\times X \times 22$ TATT $=X \times \times 23 \ldots$

CALCULATE

COOLEIR - COOLEIR*DEPPC

COOLETR - COOLETREDEPFC

COOLCAP - COOLCAP/DEFPC

PRIMT 20 , MON, DAY, HR, TATY

DAY, HR, TATT, DEFFC, COOLEIR

20 formatl'DUCt ',3F4.0,' TATT=',F4.0,' DEFFC=',

C + E5.3, EIR=', P5.3)

END-FUNCTION .

FUNCTION NAME-SAVETEMP ...

gaves last hours zone temps for next hour's heat load

S calculation

$\$$

ASSIGN TATT $=x \times 23$.

ASSTGN TAO - THOH ZNAME = ZONE-NAME DBT=DBT NZ=NZ ..

ASSIGN HUMRAT=HUMRAT ..

CaLCULATE ..

IF (ZNAME.EQ. "THER") GO TO 100

IF (ZNAME.EQ. "GARA") GO TO 100

IF (ZNAME.EQ. "ATTI") GO TO 70

IF (N2.EQ.1) GO TO 100

IF (N2.EQ.2) GO TO 100

IF (N2.EQ.3) GO TO 70

IF (N2.EQ TO 100

c attic

70 TATT $=$ TNOH

Go To 100

100 CONTINUE

END-FUNCTION ..

COMPUTE SYSTEMS .

STOP .. 


\section{DOE-2 INPUT FILE FOR SITE 2 BASE CASE}

POST-PROCESSOR PARTIAL ..

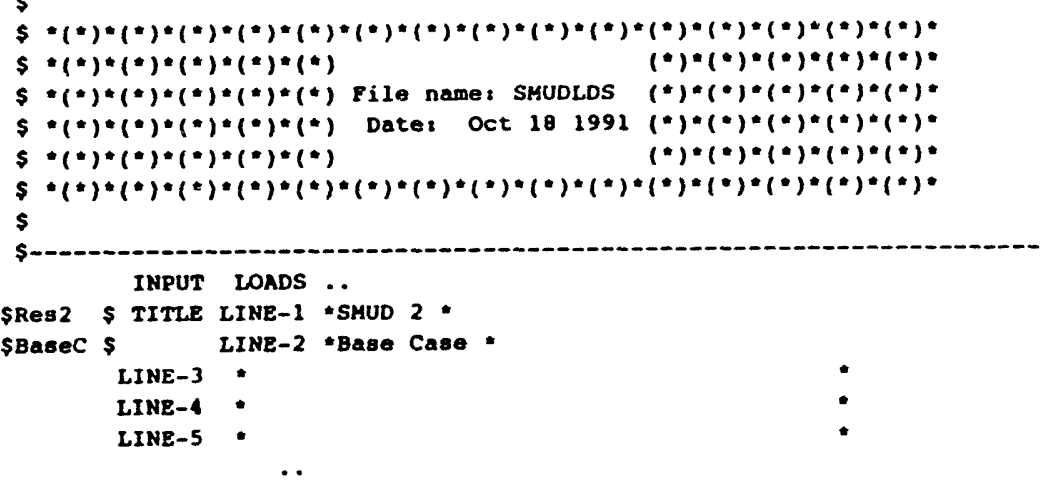

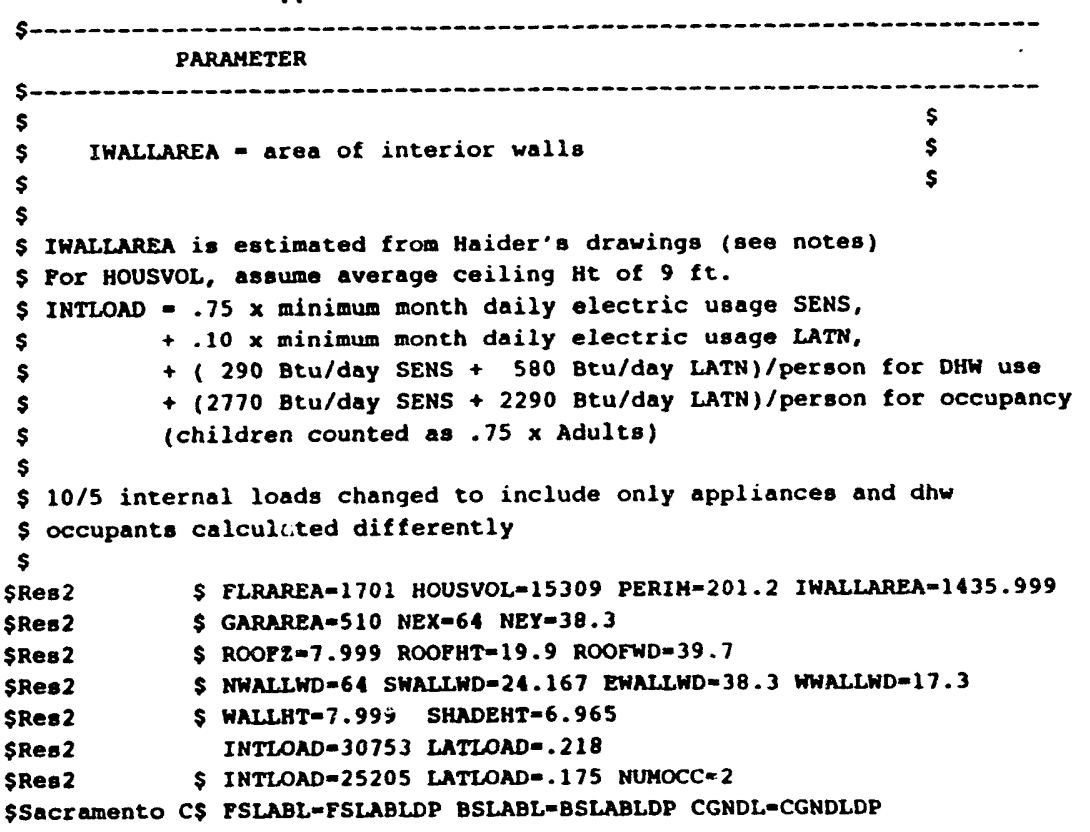

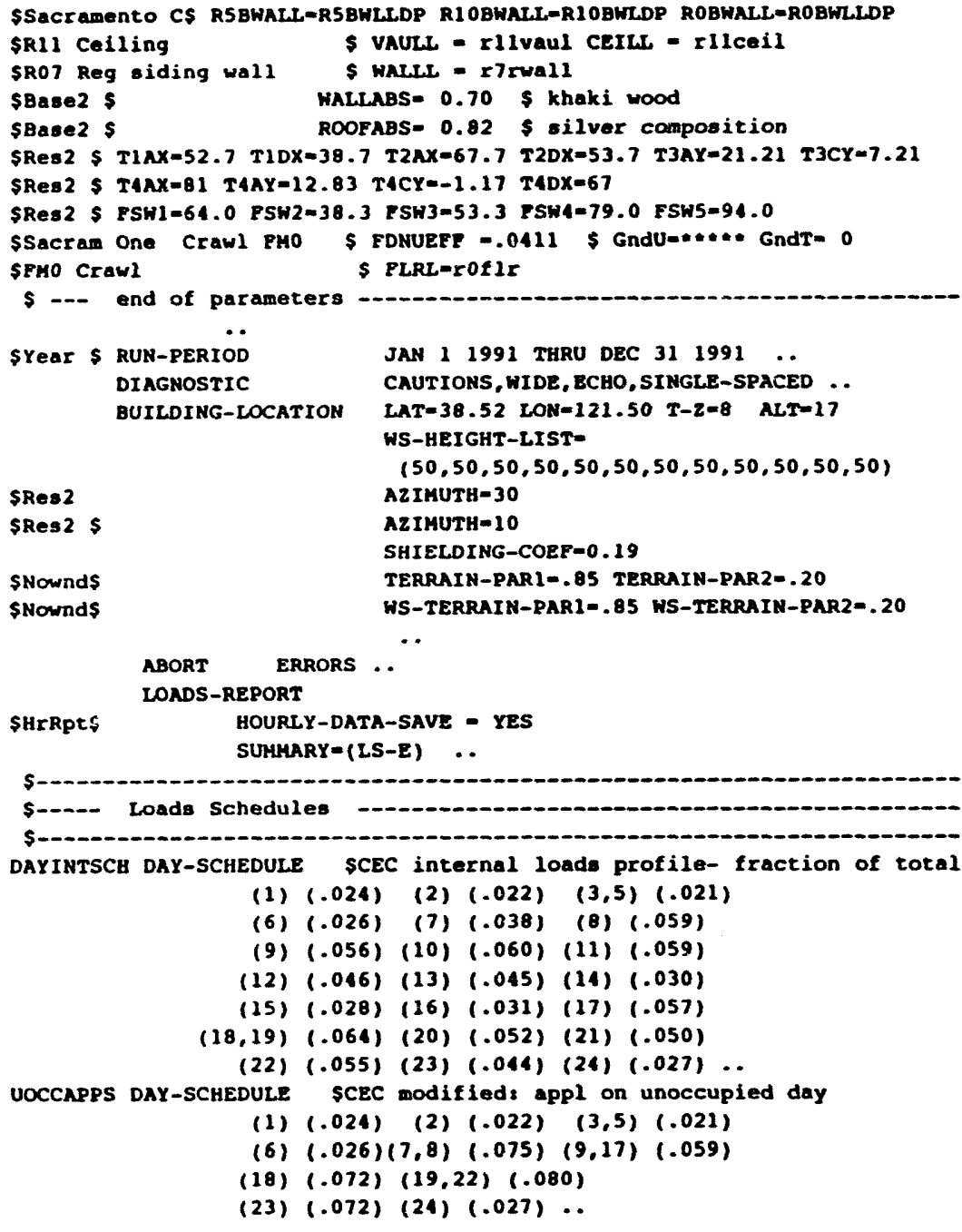


OCCYES DAY-SCHEDULE SOld CEC/GRI OCC schedule - fraction of peak

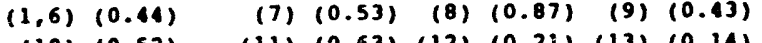

(10) $(0.52)$ (11) $(0.63)$ (12) $(0.21)(13)(0.14)$

$(14,15)(0.00)(16,17)(0.29)(18)(0.64)$

$\begin{array}{lll}\text { (19) }(0.81) & (20)(1.00)(21)(0.96)\end{array}$

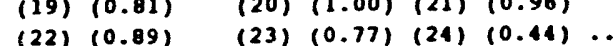

OCCMO DAY-SCHEDULE Sold CEC/GRI occ schedule mod for unoce

$(1,6)(0.44)$ (7) $(0.53)$ (8) $(0.87)$

$(9,18)(0.00)$

(19) $(0.81) \quad(20)(1.00)(21)(0.96)$

(22) $(0.89) \quad(23)(0.77)(24)(0.44) \ldots$

$s$ internal loads includes all loads-electric and dhw

s occupant loads are occupant only

SRES2 S INTLDSCH SCHEDULE THRU DEC 31 (WD) UOCCAPPS (WEH) DAYINTSCH . SREO2 S OCCSCH SCHEDURE THRU DEC 31 (WD) OCCNO (NEH) OCCYES

$\$-100$

S- The tollowing shading schedule is set for each houso.

SHADCO SCHEDULE THRU MAY 31 (ALL) $(1,24)(0.80)$

\$Res2 \$ THRU OCT 31 (ALL) $(1,24)(0.40)$

SRes 2 Ref. W.Bos, "closed shades $1 / 2$ way down from top daily,

especially on SW corner

THRU DEC 31 (ALL) $(1,24)(0.80) \ldots$

The following tree shading chedules produce the follwing effective \$ The following tree sumer and of 0.90 5 down to 0.50 during the winter. The square root of the transmittance $\$$ down to 0.50 during the winter. The square passing through a "tree"

$\$$ is input under building-shad
$\$$ goes through two surfaces.

TREETRANS1 SCHEDULE THRU FEB 28 (ALL) $(1,24)(1.00)$ THRU CCT 31 (ALL) $(1,24)(0.745)$ THRU DEC 31 (ALL) $(1,24)(1.00)$

TREETRANS2 SCHEDULE THRU FEB 28 (ALL) $(1,24)(1.00)$ THRU OCT 31 (ALL) $(1.24)(0.707)$ THRU DEC 31 (ALL) $(1,24)(1.00)$

TREETRANS3 SCHEDULE THRU PEB 28 (ALL) $(1,24)(1.00)$ THRU OCT 31 (ALL) $(1,24)(0.655)$ THRU DEC 31 (ALL) $(1,24)(1.00) \ldots$

TREETRANS4 SCHEDULE THRU FEB 28 (ALL) $(1,24)(1.00)$ THRU OCT 31 (ALL) $(1,24) \quad(0.577)$ THRU DEC 31 (ALC) $(1.24)(1.00) \ldots$

TREETRANSS SCHEDULE THRU FEB 28 (ALL) $(1.24)(1.00)$ THRU OCT 31 (ALL) $(1,24)(0.447)$

Sonstructions

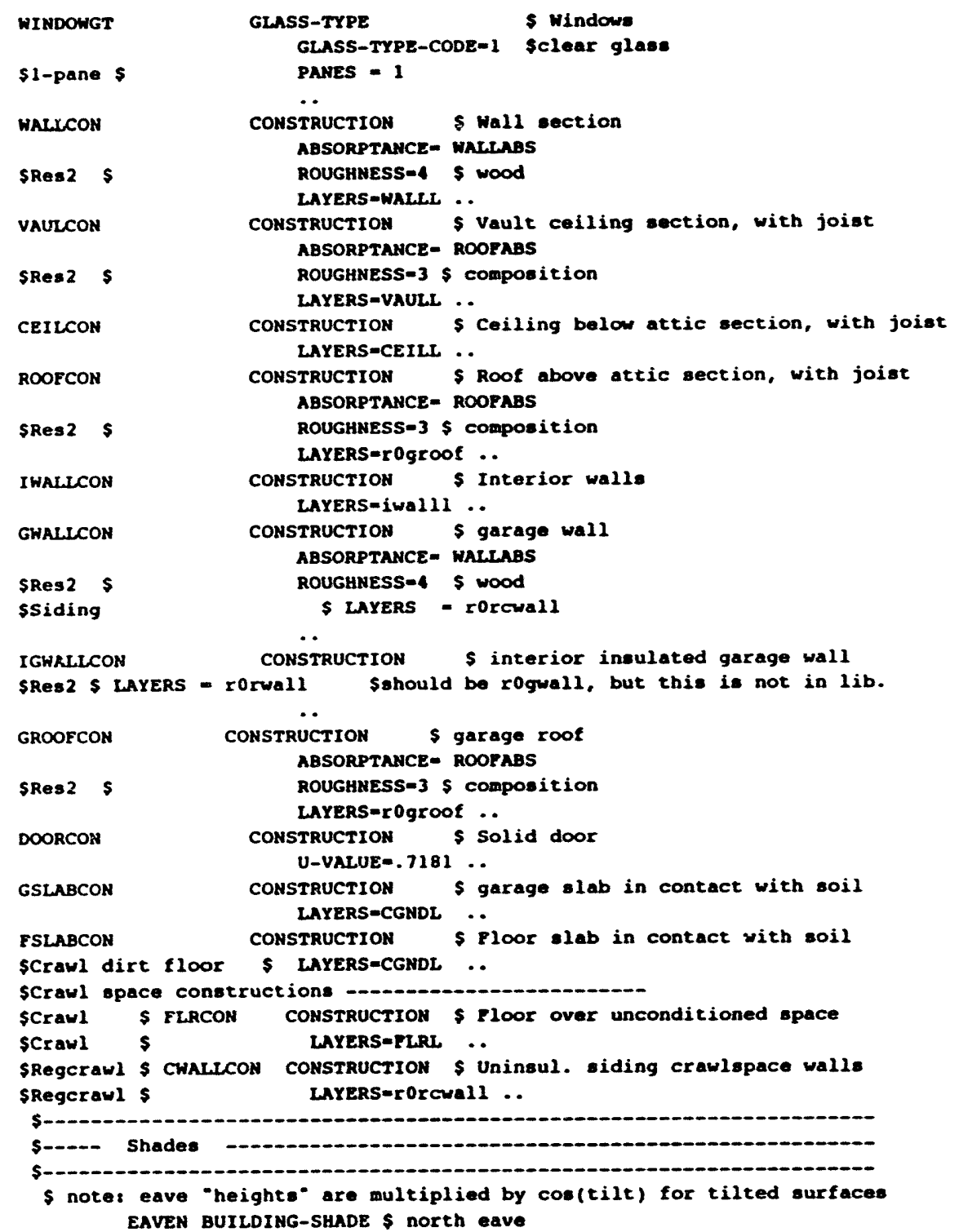



Z-SHADEHT ..

EAVES BUILDING-SHADE LIKE EAVEN \$ Bouth eave WIDTH=28.17 $\quad \mathrm{x}=35.83 \quad \mathrm{Y}=-4 \quad \mathrm{AZ}=180$

\$Res 2 \$

SRes 2 EAVES2 JUILDING-SHADE \$ overhang over garage

SRes 2 \$ LIKE EAVES WIDTH-28.3 X-0

EAVER BUILDING-SHADE LIKE EAVEN S east eave \$Res2 \$ HEIGHT-23.83 WIDTH $-4 \quad X=64 \quad Y=-4 \quad$ AZ-180

\$Reg2 \$ EAVEE 2 BUILDING-SHADE LIKE EAVEE $x-68$ y-42.3 A2=0 $\quad$.

RAVEH BUILDING-SHADE LIKE RAVEE $\$$ west eave

\$ReB2 \$ $x=-4$

SRes2 \$ EAVEW2 BUILDING-SHADE LIKE EAVEW $X=0 \quad Y=42.3 \quad A Z=0 \quad \ldots$

SRES $\$$ COURTYDN BUILDING-SHADE $\$$ courtyard north overhang

SRes2 $\$$ HEIGHT=4 WIDTH=15.5

SRes 2 S $X=39.83$ Y $=15.5$ 2-WALLHT .

SRes 2 S COURTYDE BUILDING-SHADE $\$$ courtyard east overhang

SRES 2 LIKE COURTYDN

SRes2 \$ Y $\quad Y=0$ AZ=90 2-HALLHT .

\$REs $\$$ COURTYDW BUILDING-SHADE $\$$ courtyard west overhang

SRES2 \$ COURTYW BUILDING COURTYDN

SRes2 $\$ \quad X=24.3$ AZ $=-90$.

S- Trees: Pirst existing, then test trees

SEXTr2S TREES1A B-S HEIGHT=5 HIDTH- $28 \quad x=66$ Y $\quad-3 \quad 2=0$ TILT=90

TRANSHITTANCE $=0.707$ SHADE-SCHEDULE-TREETRANSS ..

TREES1B B-S LIKE TREESIA HIDTH-4 A2-270 .

SEXTr2S TREESIC B-S LIKE TREESIA $Y=-7$.

SEXTY2S TREESIC B-S LIKE TRERS1B X-38

SEXTr2S TREESID B-S LIKE TREESIA HEIGHT-4 Z-5 TILT-0 ..

SEXTr2S TREESIE B-S LIKE TREESIA HEM $\quad x=71 \quad x=37 \quad 2=0$ TILT-90

SEXTr2S TREES2A B-S HEIGHT=S WOT SHADE-SCHEDULE-TREETRANSS ..

SEXTr2S TREES2B B-S LIKE TRERS2A HIDTH-34 AZ-270..

SEXTr2S TREES2C B-S LIKE TREES2A $Y=3 \ldots$

SEXTr2S TREES2D B-S LIKE TREES2B X=67 .

SExTr2S TREES2E B-S LTER TREES2A HEIGHT-34 2=5 TILT=0..

SEX

SExTr2S TREET1A B-S HEIGHC21 WI5 SHADE-SCHEDULP-TREETRANS4

TRANSHI TTANCE $=0.775$ SHADE-SCAE

SEXTr2\$ TREETIB B-S LIKE TREETIA A2-270...

$\begin{array}{ll}\text { \$EXTr2\$ TREET1C B-S LIKE TREET1A } & y=-25.5 \ldots \\ \text { SEXTr2S TREET1D B-S LIKE TREETIB } & x=19.5 \ldots\end{array}$
SEXTY2S TREETIE B-S LIKE TREET1A $2=28$ TILT- 0 ..

O-S HETGHT=21 WIOTA-21 $x-85.5$ Y-4.5 $2-7$ TILT=90

SEXTr2S TRANSHITTANCE-0.775 SHADE-SCBEDULE-TREETRANSA -

SEXTI2S TREET2B B-S LIKE TREET2A AZ-270 ..

SExTr2S TREET2C B-S LIRE TREET2A $x=-25.5$

SExTr2S TREeT2C O-S LIKE TREET2A $x-25.5 \%$

SEXTr2S TREET2D B-S LIKE TREET2A $2-28$ TILT=0.

SEXTr2 Several trees to south of house

$S E x T r 2$

SExTr2S

ExTr2

SExTr2S

SEXTr2S

$S E \times T \times 2 S$

$S E \times T r 2 S$

$\operatorname{SExTr} 2$

SExTr2s

SExtris

SExTris

SExTr2S

SExTr2S

TRANSHITTANCE $=0.775$ SHADE-SCHEDULE-TREETRANS4 .

REET3B B-S LIKE TREET3A WIDTH-14 AZ-270 -

TREET3C B-S LIXE TREET3A $y=43 \ldots$

TREET 3D B-S LIKE TREET $3 B \quad x=7$.

TREET3E B-S LIKE TREET3A 2-21 TILT=0 .

TPEET4A B-S HEIGHT=14 WIDTH-14 X--3 Y-37 Z-7 TILT=90

TRANSHITTANCE $=0.775$ SHADE-SCHEDULE-TREETRANS4 .

B-S LIKE TREETAA WIDTH-37 AZ-270

TREETAC B-S LIKE TREETAA $Y=0$.

TRers

TREETAE B-S LIKE TREET4A HEIGHT=37 2-21 TILT-0..

pace$$
\text { s }
$$

ROOMCOND SPACE-CONDITIONS

TEMPERATURE - (74)

SOURCE-TYPE-PROCESS

SOURCE-SCHEDULE=TNTLDSCH

SOURCE-BTU/HR-IUTLOAD

SOURE-BTU/HR-INTLOAT

SOURCE-LATENT-LATLOAD

PEOPLE-SCHEDULL-OCCSCH

MUHAER-OF-PEOPLE-NUMOCC

PEOPLE-HG-LAT 190

PEOPLE-HG-SENS $=230$

INF-METHOD-S-G

SMedium Infiltration

FLOOR-WEIGHT 0

FURNI TURE-TYPE-LIGHT

FURN-PRACTION=0.29

TUPN-HTIGHT- 3.30

SET-DEPAULT POR DOOR HEIGHT=6.5 WIDTH-3.0 CONSTRUCTION-DOORCON ..

SET-DEFAULT FOR EXTERIOR-WALL

SRES2 GND-FORM-FACTOR=O.

SRES2 SKY-PORM-FACTOR=0.1

SHADING-SURFACE-YES .

SET-DEFAUIT FOR MINDOW 
SRES2 GND-FORM-FACTOR=0.1

SRES2 SKY-FORM-FACTOR-O.1

GLASS-TYPE-WINDOWGT SHADING-SCHEDULE-SHADCO ..

\section{SPACE-CONDITIONS-ROOMCOND}

APPA-PLRAREA VOLUME-HOUSVOL...

INTWALC INTERIOR-WALL

INT-WALL-TYPE-INTERNA

AREA-IWALLAREA CONSTRUCTION-IWALLCON .

SRES2 \$ NWALL1 EXTERIOR-WALL CONSTRUCTION-WALLCON X-NEX Y-NEY HEIGHT-WALLHT WIDTH=NWALLWD

WINDOW $x=6.5 \quad y=0.0$ HEIGHT-6.67 WIDTH-5.5 .

\$Res2 \$ NWIND1A WINDOW $x-6.5$ T-0.0 HEICHI-6.67 WIDTH-5.S

SRes. 5 WHWD WINDOW LIKE NWIND1A $x=26$ WIDTH-11 ..

\$REs2 \$ NWINDIC KINDOW LIKE NWTNDIA $x=26$ WIDTH-11 ...

SRes2 \$ NWIDID WINDOW LIKE NWINDIA $x=48.5$.

SREe2 \$ NWINDIE WINDOW LIKE

$\begin{array}{ll}\text { SREB } \$ & \text { EXTERIOR-WALL } \\ \text { LIKE NWALLI } X=39.83\end{array}$

HEIGHT-WALLHT WIDTH=SWALLWD $Y=0.0 \quad A Z=180$

WINDOW $x=3$ Y=5.5 HEIGHT=1.83 WIDTH=5.67.

SRes2 S SWIR. 71A WINDOW X-3 Y SWINDIA $X=18 \ldots$

SReO2 SWALL2 EXTERIOR-WALL LIKE SWALLL $Y=15.5$ AZIMUTH $=-90$

SRes2 \$ WIDTH $=15.5$..

SRES2 \$ SWIND2A WINDOW LIKE SWIND1A $x=9 \ldots$

SRES2 S SWALL3 EXTERIOR-WALL LIKE SWALLL1 $x-24.33 \quad y=15.5$

\$Res2 \$ WIDTH $=15.5$..

SRES2 \$ SDOOR3A DOOR $x=6.33999$.

SRES2 S SHIND3A WINDOW $x=8.33 \quad x=7.33$ HEIGHT=1.00 HIDTH-3.33 ..

SRES2 S SHIND3B WINDOW LIKE SHIND3A $X=2 \ldots$

SRES2 \$ SWALLA INTERIOR-WALL CONSTRUCTION-IGWALLCON

SREs2 \$ HEIGHT-WALLHT WIDTH=5.5 NEXT-TO=GARAGE ..

SREQ2 S SWALLS INTERIOR-WALL LIKE SWALLA WIDTH=24.3 .

SREe 2 SHATS INXRER

\$RES 2 S ENALI 1 EXTERIOR-WALL LIKE

SRES2 $\$$ EWIND1A WINDOW $X=3 \quad y=5.67$ HEIGHT=1.83 WIDTH=5.67..

SRES2 S EWIND1B WINDOW LIKE EWIND1A $x=15$ WIDTH=6.67

$\$$ Res2 \$ EWINDIC WINDOW LIKE EHINDIA $x=32$..

WWALL1 EXTERIOR-WALI

\$ReB2 \$ LIKE NWALL1 Y-NEY

$X=0$ WIDTH-WWALLWD AZIHUTH $=270$$$
\text { (.) }
$$

SRES2 \$ WWINDIA WINDOW $x=0.57 \quad x=7.00$ HEIGHT= 1.67 GIDTH $=5.00 \ldots$

SRES 5 MUIND2A HINDOH LIKE WUIND1A $x=6.15$ HEIGHT=1.33 ...

SRES2 S WWIND3A HINDOW LIRE WHIND1A $x=11.71$ HEIGHT=1.00 ..

SCTaul S INTERFLR INTERIOR-WALL \$ Floor bet TheroOm and Crawlspace

\$Crawl \$ scrawl s SVault\$ HROOP

svaults

SRes 2 S

SRES2 S NROOP 2

SRes 2 S

SVaults SROOF

SRes2 S

\$Rea2 \$ SROOF2

\$Res 2 \$

GARAG

AREA-TLRAREA NEXT-TO-CRAMLSPACE ..

ROOF Z-ROOFZ BEIGHT-ROOFHT WIDTH-ROOEWD

CONSTRUCTION-VAULCO

$X$-NEX Y-MEY TILT=15.0

ROOF LIRE MROOR 1

$X-24.3$ Y-NEY HETGHT=17.9 WIDTH-24.3 ..

$x$ LIKE

$x=39.9$ Y $=0$ WTDTH-24.3 AZIMUTH-180 ..

$x=39.9$ y

$x=24 y=15.5 \quad z-12.15$ HEIGHT-3.695 WTDTH=15.5 ..

$x=24.3 \quad y=15.5 \quad 2-12.15$ HEIGHT-3.695 wID

SPACE

AREA-GARAREA VOLUME-GARAREA TIMES $9.80 \$$ avg height

INF-HETHODMS- $C$

PRAC-LEAR-AREA- .0015 $\$$ assume 3 times normal infile

PLCOR-WEIGHT $=0$

2ONE-TYPE-UNCONDITIONED T=(60)

GARI EXTERIOR-WALL

HETGHT-WALLHT TILT=90

SRes2 \$ WIOTB-21 $\quad x=0 \quad X=21 \quad A Z=-90 \quad$ \$ garage muall

LIRE GAR

SRes2 \$ WIDTH=15.5 X-24.3 Y=0 A2-90 \$ garage Evall

GAR3 EXTERIOR-WALL

LIRE GARI \$ garage door wall

SRES2 \$ HEIGHT=8.0 WTDTH=24.3 $X=0 \quad Y=0$ AZ-180 ..

SRes 2 s GDOOR DOOR $x=2$ WIDTH -20 .. \$ garage door

GARA INTERTOR-WRLt \$ insulated wall against house

SRES 2 S AREA-238.7 CONSTRUCTION-IGWALLCON INT-WALL-TYPE-STANDARD NEXT-TO=THEROOH

GROOF1 EXTERIOR-WALI

SRES2 \$ LIKE GAR3 HEIGHT=19.9 SILT-15.0

Z=ROORZ CONSTRUCTION-GROOFCON

SRES2 S GROOF 2 EXTERIOR-WALI

SRES 2 LIKE GROORI $X=24.3 \quad X-21 \quad 2=12.6$ AZ=0 HEIGHT=2.0 ..

GSLAB UNDERGROUND-FLOOR \$ GaTage flOOK HEIGHT= 10 WIDTH-GARAREA TIMES .1

TILT=180 CONSTRUCTION=GSLABCON

U-EFFECTIVE- .143 .. \$ Ref j.huang - ashrae paper

SCrawl S CRAHLSPACE SPACE

SCraul S CORATSPACE SPACE 3.00 


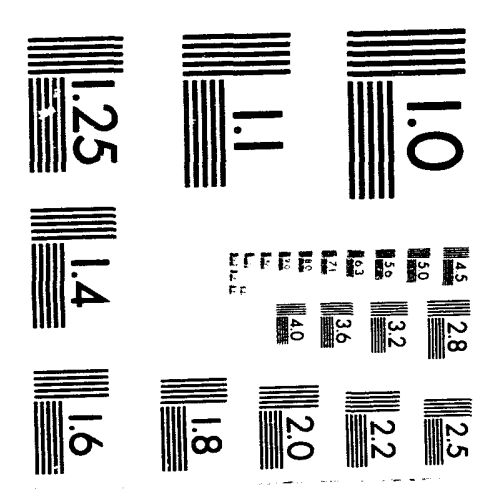



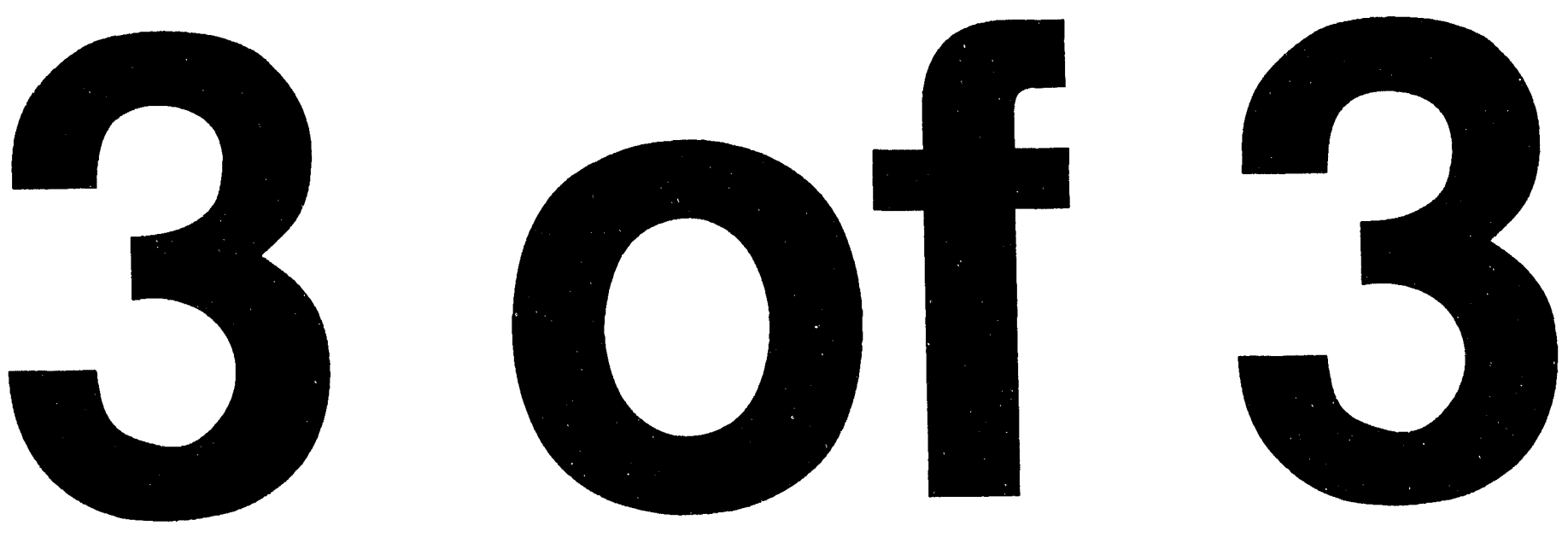


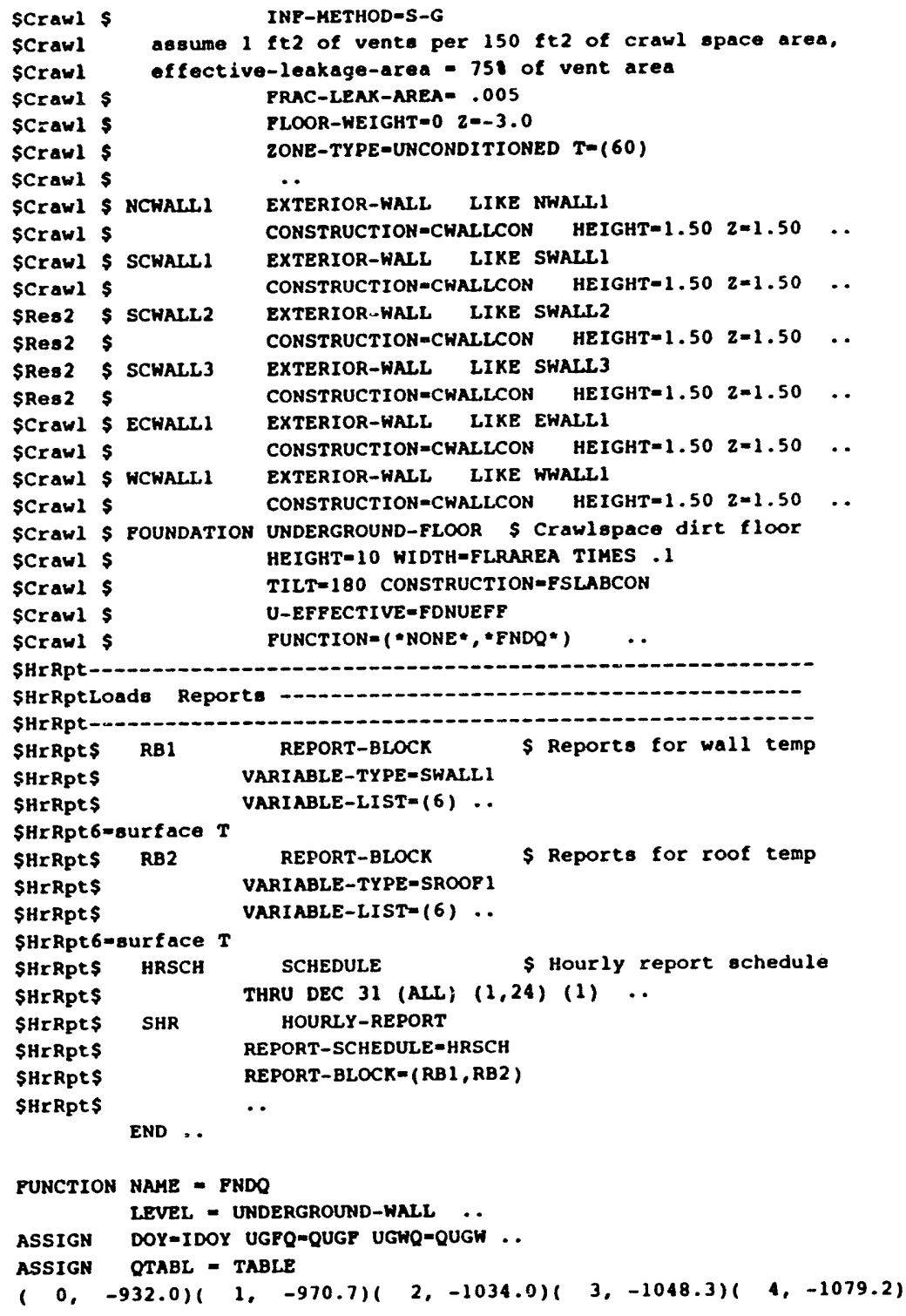

$(5,-1128.2)(6,-1121.9)(7,-1034.6)(8,-1024.4)(9,-1043.8)$ $(10,-1073.1)(11,-1044.6)(12,-983.8)(13,-858.8)(14,-749.8)$ $(15,-730.2)(16,-791.0)(17,-905.5)(18,-965.5)(19,-915.7)$ $(20,-754.4)(21,-587.8)(22,-520.4)(23,-533.8)(24,-547.7)$ $(25,-566.3)(26,-604.3)(27,-591.0)(28,-532.2)(29,-458.6)$ $(30,-282.3)(31,-146.2)(32,-64.8)(33,-144.9)(34,-320.5)$ $(35,-307.0)(36,-229.4)(37,-157.9)(38,-10.0)(39,-154.5)$ $(35,-307.0)(36,-229.4)(37,-157.9)(38, \quad 10.0)(39, \quad 154.5)$ $(10,132.1)(41,214.0)(42,278.9)(43,301.2)(44,307.5)$ $\begin{array}{llllll}(45, & 238.6)(46, & 347.9)(47, & 519.3)(48, & 543.7)(19, & 638.7) \\ (50, & 851.0)(51, & 970.8)(52, & 995.7)(53, & 1045.6)(54, & 1136.0)\end{array}$

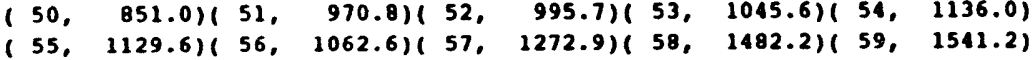
$(60,1570.1)(61,1587.3)(62,1635.8)(63,1662.3)(64,1667.0)$ $(65,1778.5)(66,1874.8)(67,1926.5)(68,1936.4)(69,1981.3)$ $(70,2075.1)(71,2137.9)(72,2194.4)(73,2204.5)(74,2145.8)$ $(75,2110.9)(76,2176.1)(77,2208.5)(78,2196.5)(79,2060.9)$ (80, 1889.1)(81, 1862.0)(82, 1892.5)(83, 1905.5)(84, 1919.5)

(85, 898.0$)(86,1854.9)(87,1818.2)(88,1758.9)(89,1582.3)$

$(85,1898.0)(86,1854.9)(87,1810.2)(88,178.9)(89,1582.3)$

$(90,1558.8)(91,1553.4)(92,1515.6)(93,1466.1)(94,1415.4)$

$(95,1393.7)(96,1290.6)(97,1105.7)(98,1014.4)(99,937.3)$

(100, 934.5)(101, 900.5)(102, 841.2)(103, 710.6)(104, 555.1)

(105, 427.5)(106, 371.4)(107, 320.3)(108, 245.0)(109, 183.5)

$\begin{array}{llllll}(110, & 84.3)(111, & -40.1)(112, & -181.7)(113, & -357.3)(114, & -536.0) \\ (115, & -566.9)(116, & -601.4)(117, & -604.4)(118, & -745.9)(119, & -895.5)\end{array}$

$(120,-893.2)(121,-918.5)(122,-933.9) \ldots$ CALCuLATE

WEEK $=$ DOY / 3.0

UGWO $=0.0$

UGPQ = PWL (QTABL, WEEK)

PRINT 10, DOY, WEEK, UGHQ, UGFO

10 FORMAT('FNDQ', 4FIO.2)

END-PUNCTION

COMPUTE LOADS .

POST-PROCESSOR PARTIAL ..

$2 *(*) *(*) *(*) *(*) *(*) *(*) *(*) *(*) *(*) *(*) *(*) *(*) *(*) *(*) *(*) *(*)$ $\{*(*) *(*) *(*) *(*) *(*) \quad(*) *(*) *(*) *(*) *(*) *$ $\$ \cdot(*) *(*) *(*) *(*) *(*)$ File namer $s \cdot(*) \cdot(*) *(*) *(*) *(*)$ Datez Oct $181991 \quad(*) *(*) *(*) *(*) *(*)$ $2:(*) *(*) *(*) *(*) *(*) \cdot(*) *(*) *(*) *(*) *(*) *(*) *(*) *(*) *(*) *(*) * *(*) *(*)$
$2 *(*) *(*) *(*) *(*) *(*)$ $\$$

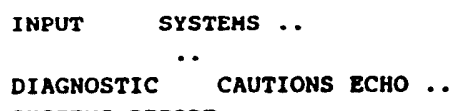




\section{PARAMETER}

\$ CSCAP is 80 of CTCAP where no literature available

S Assume heat pump backup of 15000 Btu/hr is valid for all HP

\$ Default DOE2 curve for cooling equipment used.

s Cooling COPs from product literature for Res $2,5,6,7$

S Sitel and Site6 assumed same as Res5

S All other data from product literature.

s cooling thermostat setpoints from investigating measured date

$\begin{array}{lllll}\text { SRes2 } \$ & \text { HEATSET }-68 & \text { SETBACK } 65 & \text { COOLSET-80 } & \text { SETUP-80 } \\ \text { \$RES2 \$ HCAPF }-90000 & \text { CTCAP-40000 } & \text { CSCAP-32000 } & \end{array}$

SRes2 \$ ACCFH=1200

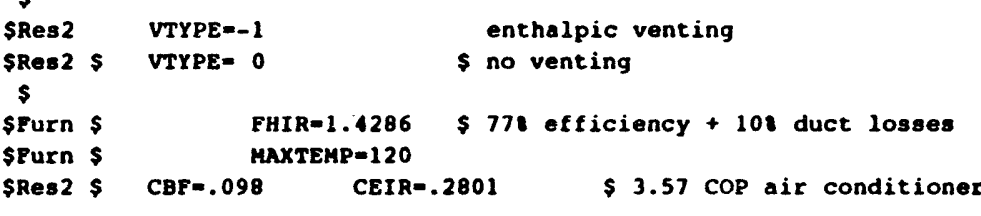

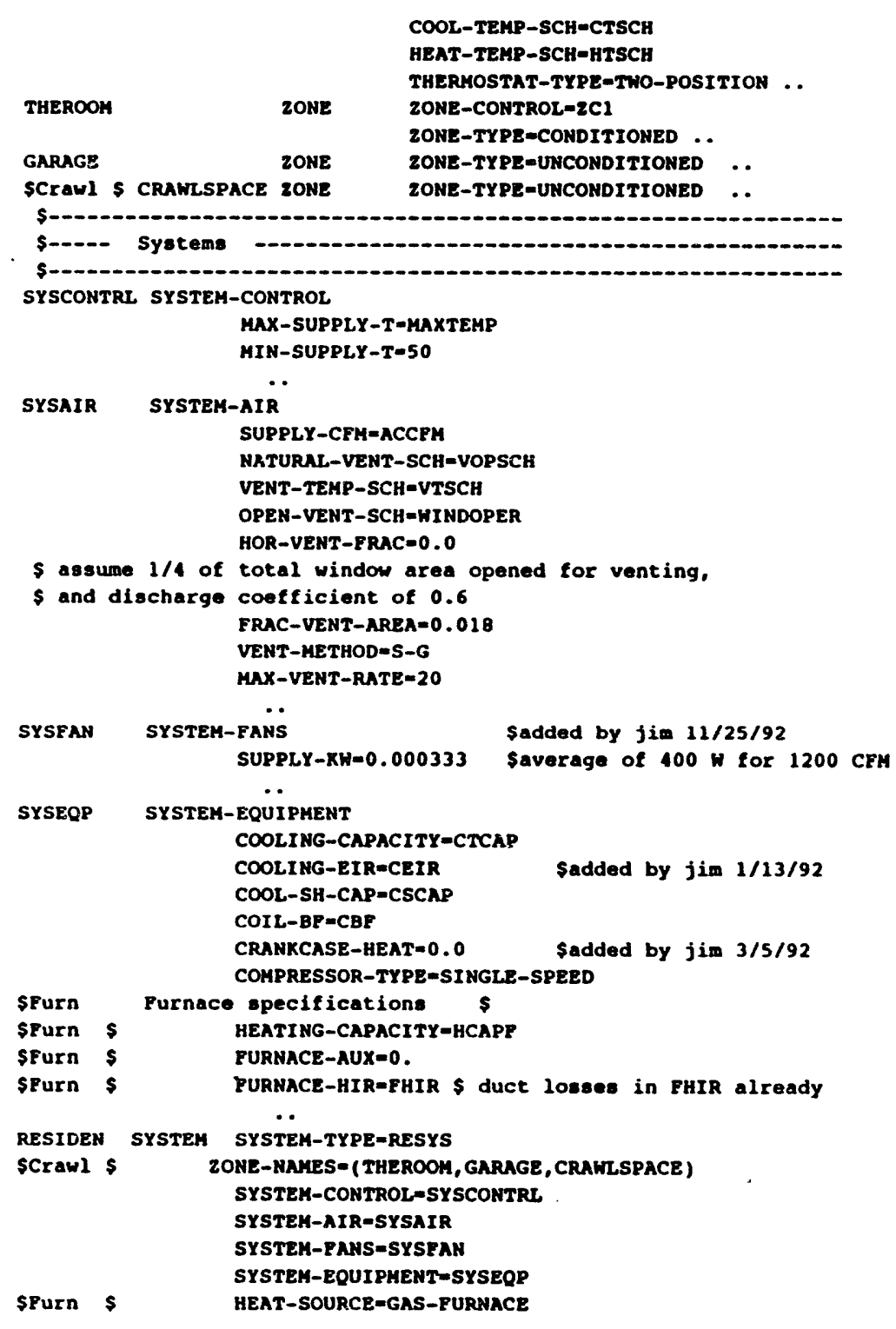




\author{
SHrRpt-- \\ SHrRptSystem Report: \\ SHrRpt-- \\ SHrRptS RBI REPORI \\ SHrRptS VARIABLE-TYPE-GLOBRL \\ SHrRptS VARIABLE-LIST $-(7,8,10)$. \\ P-DBT 10-HUARA \\ SHrRPtS RB2 REPORT-BLOCK \$ Reports for zONe \\ SHRRPTS VARIABLE-TYPE=THEROOA \\ SHIRPtS VARIABLE-LIST=(6) .. \\ SHrRpt6-TNOW \\ SHIRPES RB3
SHIRPES $\quad$ REPORT-BLOCK VARIABLE-TYPE-RESIDEN Reports for system \\ SHRRPtS VARIABLE-LIST= $(5,6,33,47,61)$ \\ SHrRpt5-QH 6-OC 33=FANKW 17-SKWQC 61=PLRC \\ SHrRptS HRSCH SCHEDULE \\ SHRRPES THRU DEC 31 (ALL) $(1,24)$ (1) .. \\ SHIRPTS SHR HOURLY-REPORT \\ SHrRPtS SHR REPORT-SCHEDULE-HRSCH \\ SHrRpt\$ REPORT-BLOCK= (RB1, RB2, RB3) \\ SHrRpts \\ $\cdot$ \\ COMPUTE SYSTEMS ..
}




\section{DOE-2 INPUT FILE FOR SITE 5 BASE CASE}

POST-PROCESSOR PARTIAL ..

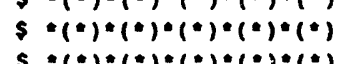

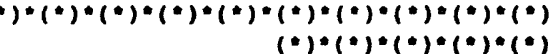

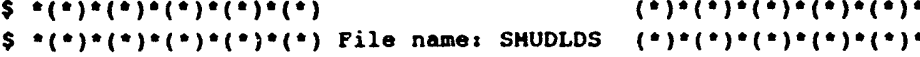

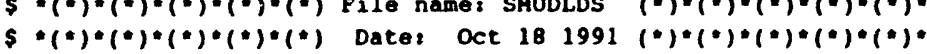

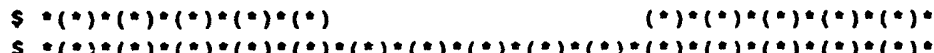
\$

\section{INPUT LOADS ..}

SBaseC \$ LINE-2 "Base Case -

LINE-3 :

LINE-4

LINE-5

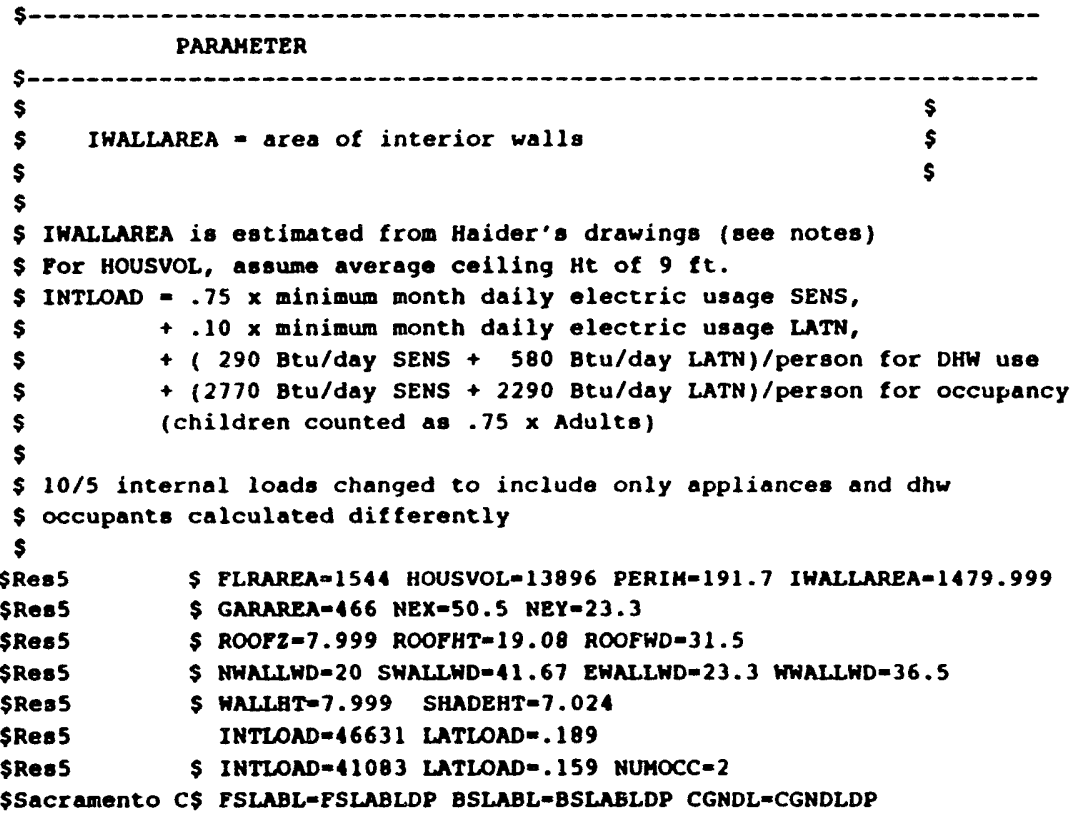

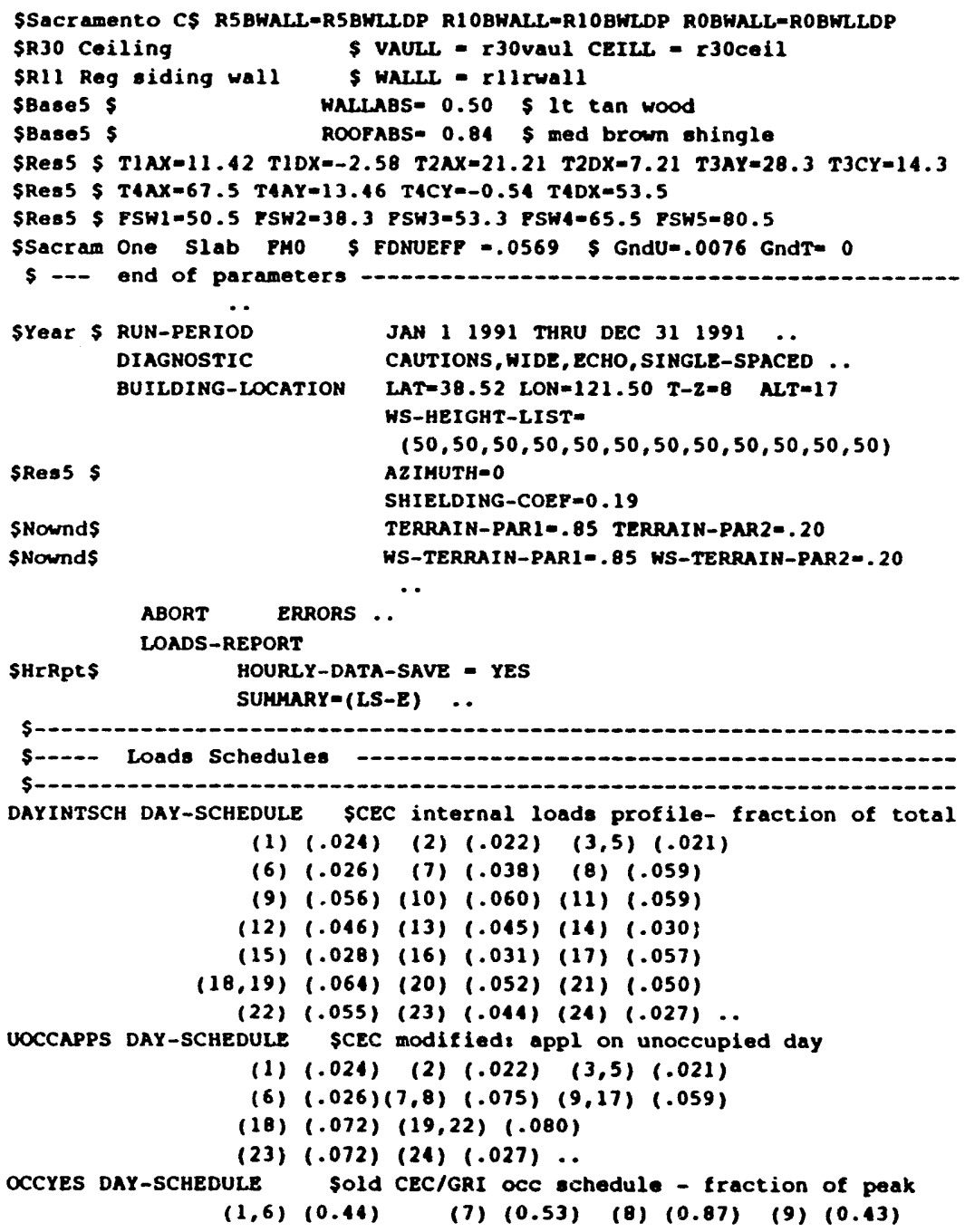




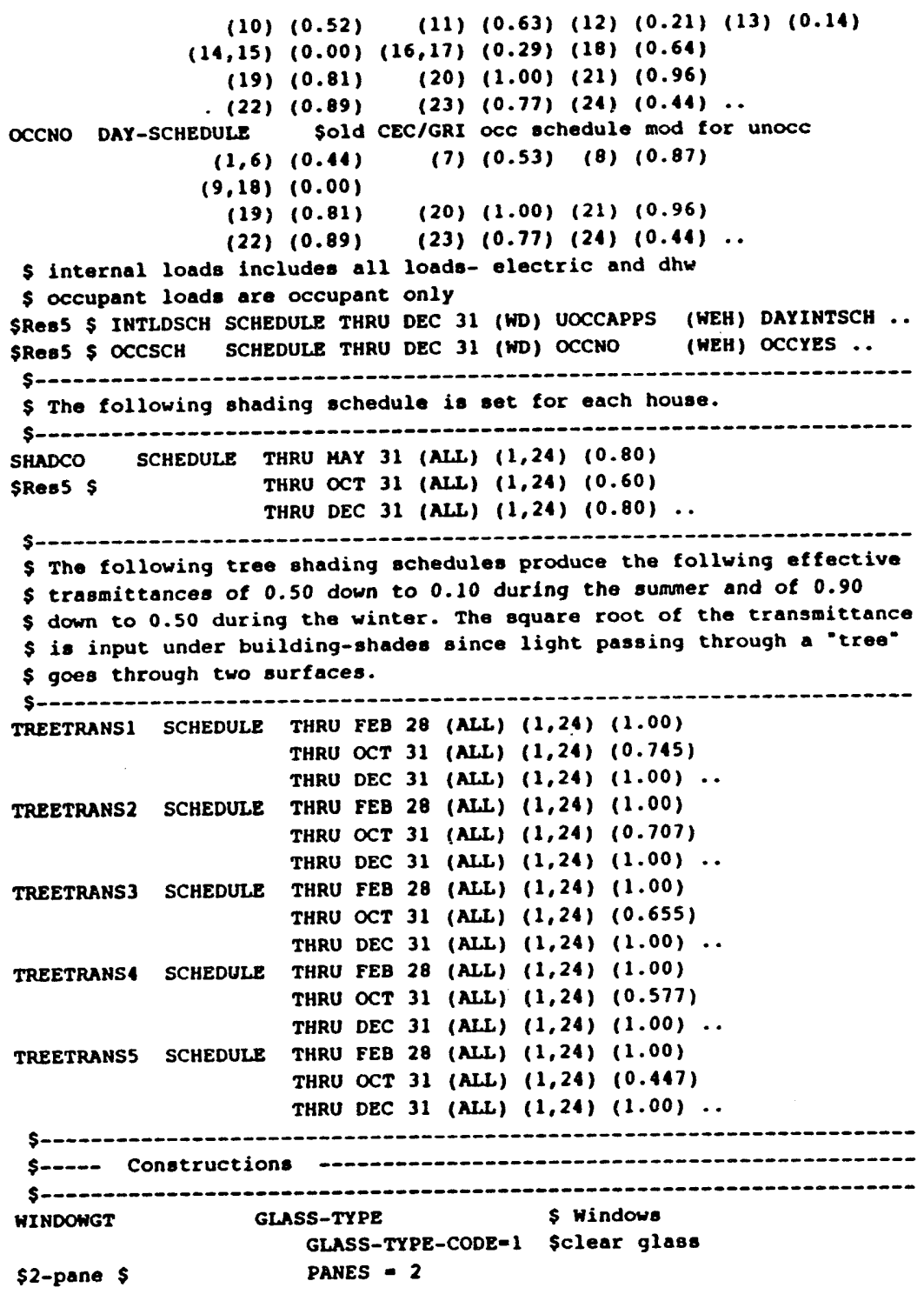

CONSTRUCTION \$ Wall section ABSORPTANCE - WALLABS ROUGHNESSE $\$$ WOOd

IGWALLCON SRES5 S LAYERS - rllgwall

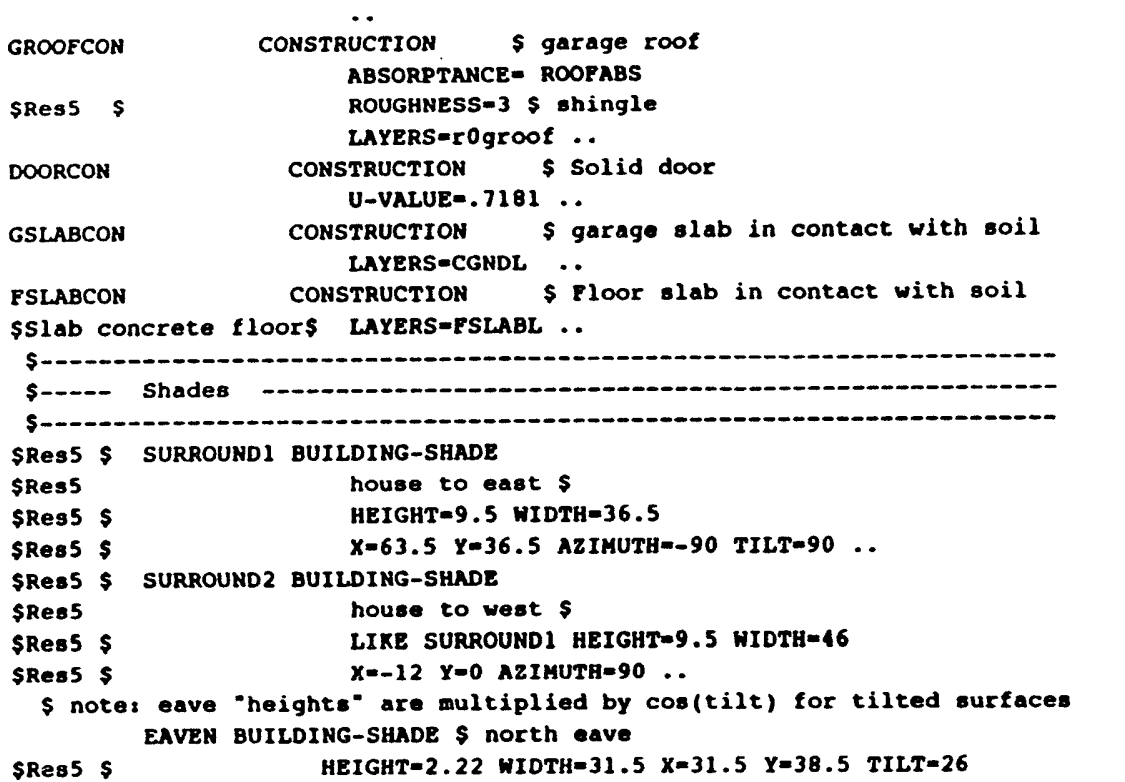


2-SHADEHT .

EAVES BUILDING-SHADE LIKE EAVEN \$ south eave

SRes5

SRees s HEIGHT-7.5 WIDTH-50.5 $x=0 \quad y=-7.6$ 2-WALLHT TRANSMITTANCE=0.10 AZ-180 TILT=0

SRes5 s

EAVEE BUILDING-SHADE LIKE EAVEN S east eave HEIGHT-0.001 $\$$ nO $\$$ ave

EAVEW BUILDING-SHADE LIKE EAVEE \$ west eave

SRees \$ HEIGHT $=0.001$ s no eave

SRes5 \$ ENTRY BUILDING-SHADE \$ entry overhang

$$
\begin{array}{ll}
\text { \$Res5 } \$ & \text { HEIGHT=7.5 WIDTH=8.0 } \\
\text { SRes5 } \$ & X=21 \quad X=36.5 \quad z=\text { WNLLHT .. }
\end{array}
$$$$
\text { Trees: Pirst existing, then test trees }
$$

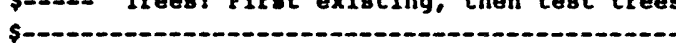$$
\text { s---on- }
$$

ROOHCOND SPACE-CONDITIONS

$$
\begin{aligned}
& \text { TEHPERATURE - (74) } \\
& \text { SOURCE-TYPE-PROCESS } \\
& \text { SOURCE-SCHEDULE-INTLDSC } \\
& \text { SOURCE-BTU/HR=INTLOAD } \\
& \text { SOURCE-SENSIBLE=1. } \\
& \text { SOURCE-LATENT=LATLOAD } \\
& \text { PEOPLE-SCHEDULE-OCCSCH } \\
& \text { NUMBER-OF-PEOPLE-NUMOCC } \\
& \text { PEOPLE-HG-LAT=190 } \\
& \text { PEOPLE-HG-SENS=230 } \\
& \text { INF-METHOD=S-G } \\
& \text { S } \text { \$ FRAC-LEAK-AREA - } \\
& \text { FLOOR-WEIGHT=0 } \\
& \text { FURNITURE-TYPE=LIGHT } \\
& \text { FURN-FRACTION=0.29 } \\
& \text { FURN-WEIGHT=3.30 }
\end{aligned}
$$

SHedium Infiltration \$ PRAC-LEAK-AREA = .0005

SET-DEFAULT FOR DOOR HEIGHT=6.5 HIDTH=3.0 CONSTRUCTIOH=DOORCON .. SET-DEFAULT FOR EXTERIOR-WALL

$$
\text { SHADING-SURPACE=YES. }
$$

SET-DEFAULT FOR WINDOW

GLASS-TYPE-WINDOWGT SHADING-SCHEDULE-SHADCO ..
THEROOM SPACE

\section{SPACE-CONDITIONS-ROOHCOND}

AREA-FLRAREA VOLUAE-HOUSVOL.

INTWALL INTERIOR-WALI

INT-WALL-TYPE-INTERNAL

AREA-IHALLAREA CONSTRUCTION-IHALLCON

SRES5 S MWALLI INTERIOR-WALL CONSTRUCTION-IGWALICON NEXT-TO-GARAGE HEIGHT-WALLHT WIDTH-NWALLWD

\$RES5 \$ NWALL2 INTERIOR-HALL LIKE NWALL1 WIDTH-13.25 .

SRESS \$ WWALL3 EXTERIOR-WALL CONSTRUCTION-HALLCON

SResS S HEIGHT-WALLHT HIDTH-10.5

SRes5 \& $\quad X=31.5 \quad y=36.5 \quad A Z=0$

SRESS \$ NWIND3A WINDOW $X=3.3 \quad y=3.67$ HEIGHT-3.67 HIDTH-6.00 $\ldots$

SRES5 \$ NWALLA EXTERIOR-WALL LIKE NWALL3

SREBS S WIDTH=7.5 X-21 A2=-90 ..

RES5 \$ MWALLS EXTERIOR-WALL LIXE MHALLI

SRes5 \$ WIDTH=8 $x=21 \quad Y=29$.

SRESS S NDOOR5A DOOR $X=2.5 \ldots$

\$RESS \$ WWALLG EXTERIOR-WALL LIKE NWALL4

SRess S $\quad X=13 \quad y=29$ AZ=90.

SRESS \$ NWALLT EXTERIOR-WALL LIKE NWALL3

SRes5 $\$$ WIDTH=13 $x=13 \ldots$

SRES5 \$ NHIND7B WINDOW LIKE NWIND3A $x=3.3 \ldots$

SWALE1 EXTERIOR-WALL

SRES5 \$ LIKE NWALL3 X-8.83

HEIGHT-WALLHT WIDTH-SGALLWD $Y=0.0 \quad$ AZ-180

HEIGHT-HALLHT WIDTH-SGALLWD $x=0.0$ AZ-180

SResS \$ SWIND1A WINDOW $x=3.2$ Y $=0.0$ HEIGHT=6.58 WIDTH-4.75 ..

SRESS SWIND1B WINDOW $X-13.2$ Y $=5.5$ HEIGHT $=2.0$ WIDTH $=4.00 \cdots$

SReES S SWALL2 EXTERIOR-WALL LIKE SWALLI

SRes5 $\$ \quad X=7.414 \quad Y=-1.414$ WIDTH=2 $A Z=135 \ldots$

SRES5 \$ SWALL3 EXTERIOR-WALL LIKE SWALL1

SRes5 S $\quad x=1.114 x=-1.414$ WIDTH-6

SREAS S SWIND3A WINDOW $x-1.125 \quad y=4.0$ HEIGHT=2.75 WIDTH=3.75

SRES5 S SWALLA EXTERIOR-WALL LIKE SWALL1

SRes5 $\$ X=0$ WIDTH=2 AZ-225.

SRes5 S EWALL1 EXTERIOR-WALL LIKE NWALL3 X=50.5 Y=0 A2-90 WIDTH-EHALLWD ..

SResS \$ EWIND1A WINDOW $X=3.5 \quad y=3.33$ HEIGHT=3.92 WIDTH=5.91 $\ldots$ SRES $\$$ EWIND1B WINDOW $x=15.5 \quad y=3.83$ HEIGHT=3.42 HIDTH-5.00 WWALL1 EXTERTOR-WALL

\$RES5 \$ LIKE NWALL3 Y-36.5

$X=0$ WIDTH-WWALLWD AZ IMUTH 270

SRES5 \$ WHIND1A WINDOW $X=15 \quad Y=4.08$ HEIGHT=3.00 HIDTH-4.00 .. \$Slab \$ POUNDATION UNDERGROUND-FLOOR \$ Slab tloOr

$$
\$ S I \text { Iab } \$ \text { HEIGHT=10 WIDTH-FLRAREA TIMES .1 }
$$




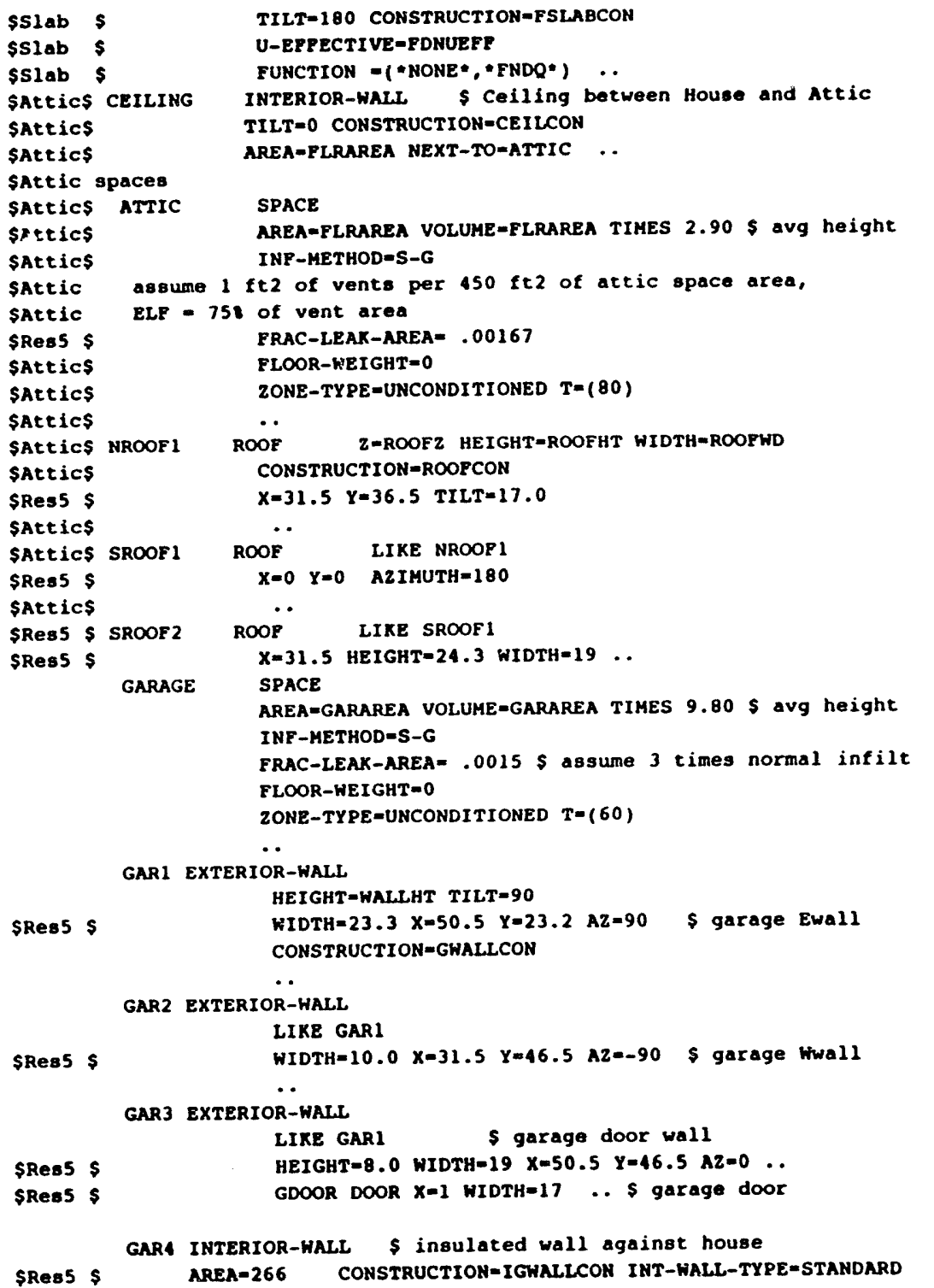

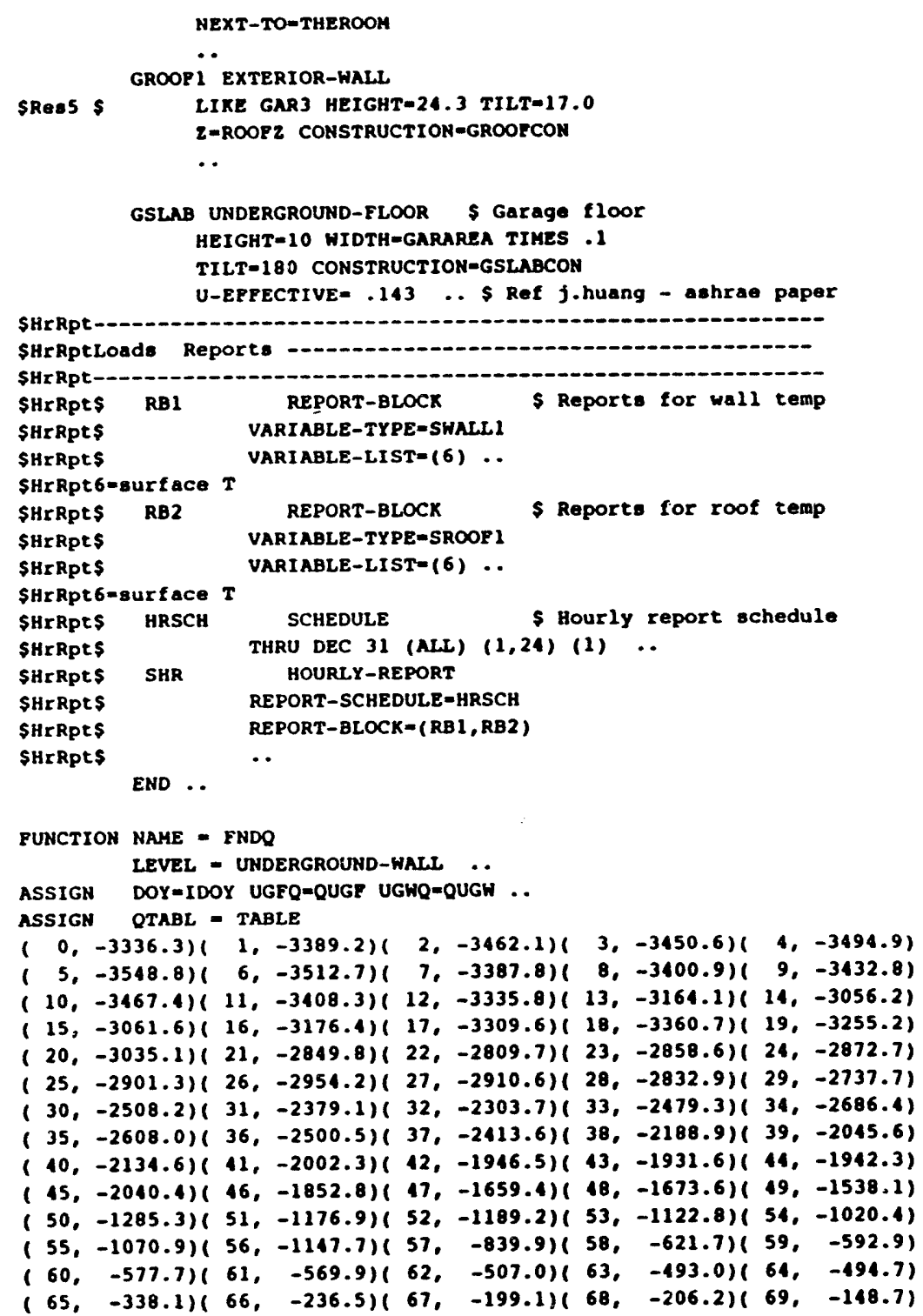


$(70,-30.5)(71, \quad 25.0)(72,81.5)(73,68.1)(74,-28.9)$ (75, -49.4$)(76,50.9)(77,73.1)(78, \quad 34.9)(79,-123.6)$ $(80,-331.5)(81,-320.9)(82,-271.8)(83,-264.4)(84,-250.2)$ $(85,-281.9)(86,-345.3)(87,-377.1)(88,-471.5)(89,-680.4)$ $(90,-661.4)(91,-665.3)(92,-717.0)(93,-771.9)(94,-825.7)$ $(95,-845.2)(96,-1001.8)(97,-1214.9)(98,-1290.1)(99,-1357.0)$ $(100,-1332.1)(101,-1377.6)(102,-1458,1)(103,-1635.8)(104,-1807.5)$ $(105,-1935.5)(106,-1957.5)(107,-2015.7)(108,-2097.4)(109,-2161.6)$ $(110,-2276.3)(111,-2428.2)(112,-2591.7)(113,-2814.8)(114,-2984.9)$ $(115,-2965.2)(116,-2985.4)(117,-2984.5)(118,-3194.8)(119,-3339.1)$ $(120,-3281.2)(121,-3316.4)(122,-3332.9)$.

Calcutate

WEEK $=$ DOY $/ 3$.

UGWO $=0.0$

UGPQ - PWL (QTABL, NEEK)

C PRINT 10, DOY, WEEK, UGHQ, UGFO

10 FORHAT('FNDQ', 4F10.2)

END-FUNCTION

COMPUTE LOADS.

POST-PROCESSOR PARTIAL.

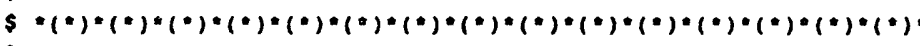

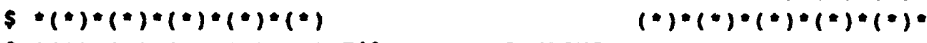

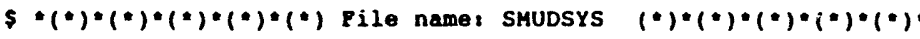
$S \cdot(\cdot) *(*) \cdot(\cdot) \cdot(*) \cdot(*)$ Datez Oct $181991(\cdot) \cdot(\cdot) \cdot(\cdot) \cdot(\cdot) \cdot(\cdot)$ $\$(\cdot) *(*) \cdot(\cdot) *(*) *(*) \quad(*) *(*) *(\cdot) *(*) *(*)$ $\{*(*) *(*) *(*) *(*) *(*) *(*) *(*) *(*) *(*) *(*) *(*) *(*) \cdot(*) \cdot(*) *(*))$

INPUT SYSTEMS ..

diagnostic " cautions echo ..

SOuct $S$ SUBR-FUNCTIONS

SDUCE $\$$ SUBR-FUNCTIONS
RESYS-0=\#DUCT.

SDuct $\$$ RESYS-32=-SAVETEMP

SDuct $\$$ DAYCLS-4--DUCT2*..

SYSTEMS-REPORT

SHrRptS HOURLY-DATA-SAVE - YES

SUMMARY = (SS-A, SS-B, SS-C, SS-F, SS-H, SS-I) .

PARAMETER

S CSCAP is 80 of CTCAP where no literature available

$\$$ Assume heat pump backup of 15000 Btu/hr is valid for all HP

$\$$ Default DOE2 curve for cooling equipment used.

\$ Cooling COPs from product literature for Res2,5,6,7

\$ Sitel and Siter assumed same as Res5

$\$$ All other data from product literature.

s Cooling thermostat setpoints from investigating measured data

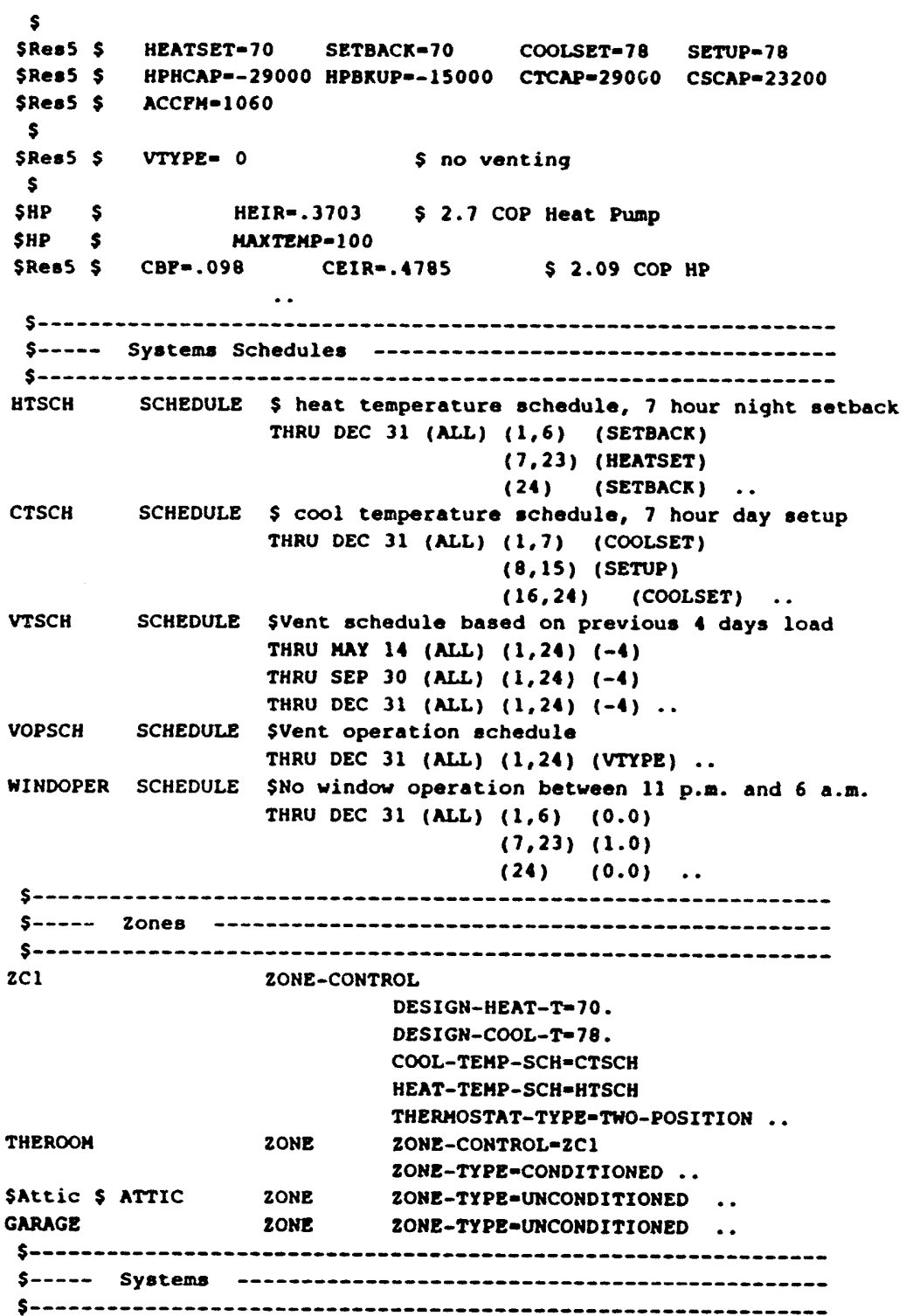


SYSCONTRL SYSTEM-CONTROL

MAX-SUPPLY-T-MAXTEMP

MIN-SUPPLY $-T=50$

\section{SYSAIR SYSTEM-AIR}

\section{SUPPLY-CFM-ACCFH}

NATURAL-VENT-SCH-VOPSCH

VENT-TEMP-SCH-VTSCH

OPEN-VENT-SCH-WINDOPE

HOR-VENT-FRAC-0.0

$\$$ assume $1 / 4$ of total window area opened for venting,

$\$$ and discharge coefficient of 0.6

FRAC-VENT-AREA 0.018

VENT-METHOD=S-G

MAX-VENT-RATE $=20$

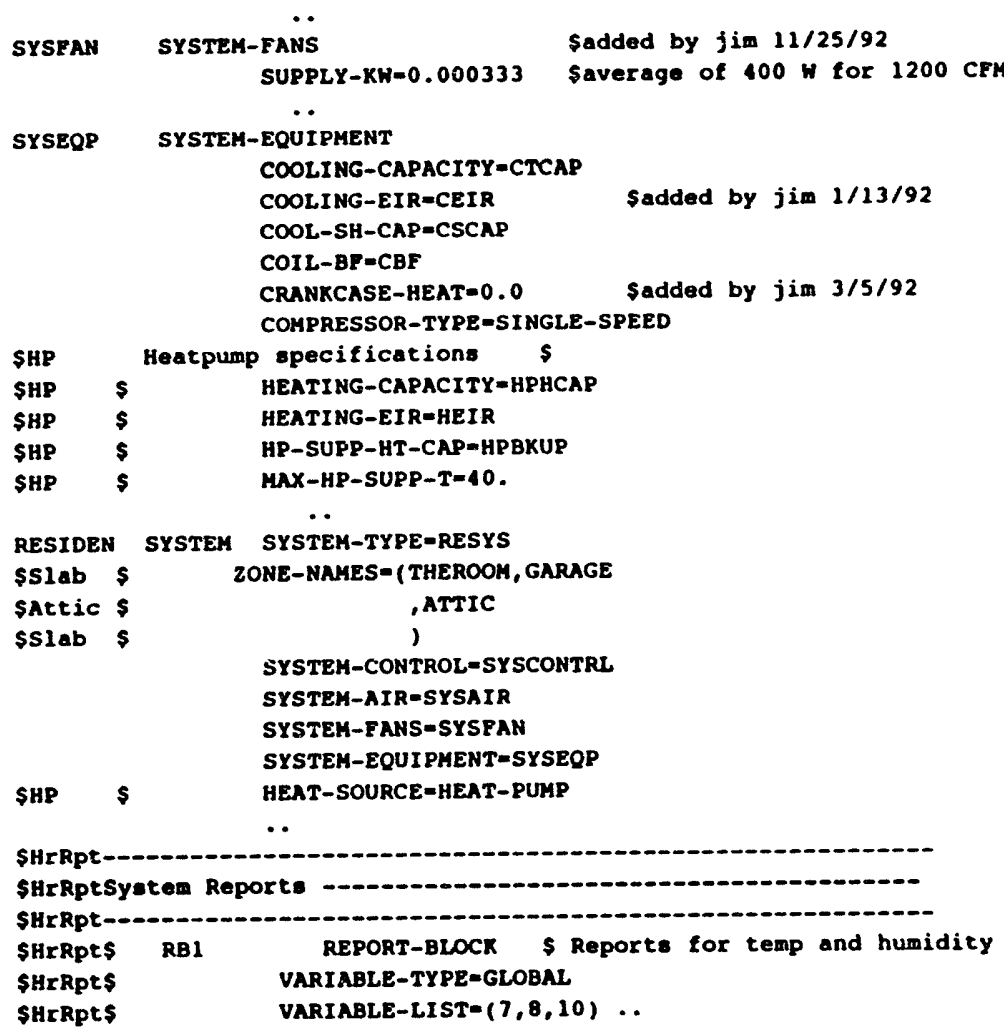

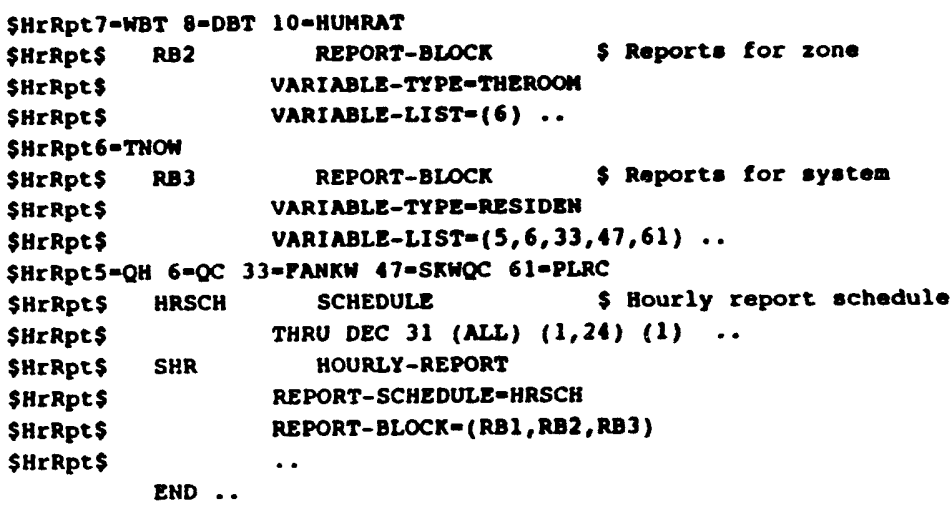

PUNCTION NAHE = DUCT ..

This function multiplies the AC EIR

$S$ by the duct efficiency which varies

$\$$ with attic remperature

s old ducts in attic

TOUT=DB

COOLEIR-COOLING-EIR COOLCAP-COOLING-CAPACIT

COOLSEN-COOL-SH-CAP

DEFFC $-X \times X 22$ TATT $=X \times \times 23 \ldots$

CALCULATE ..

DEFFC $=-0.0077 \cdot$ TATT +1.379

COOLEIR = COOLEIR/DEFFC

COOLCAP $=$ COOLCAP.DEFTC

COOLSEN - COOLSEN-DEFFC

C PRINT 20, MON, DAY, HR, TATT, DEETC, COOLEIR

20 PORMAT('DUCT, 3 , 3F.0, ' TATT=', T4.0, DEFFC='

C + F5.3.' EIR=', F5.3)

END-FUNCTION .

PUNCTION NAME - DUCT2 .

This function reset AC EIR to the input value

$s$ old ducte in attic

STIG MON-IMO DAY=IDAY HR-IHR TOUT=DBT

COOLPIR-COOLING-EIR COOLCAP-COOLING-CAPACITY

COOLSEN-COOL-SH-CAP

DEPFC $-x \times \times 22$ TATT $=X \times X 23 \ldots$

CaLCULATE ..

COOLEIR - COOLEIR DEFFC 
COOLCAP - COOLCAP/DEFTC

COOLSEN - COOLSEN/DEPTC

PRINT 20, MON, DAY, HR, TATT, DEFFC, COOLEIR

C 20 FORMAT('DUCT ',3F4.0,' TATT=', F4.0, ' DEFFC=',

C + F5.3, EIR=.,85.3)

END

END-FUNCTION ...

PUNCTION NAME-SAVETEMP .

S saves last hours zone temps for next hour's heat load $\$$ calculations

ASSIGN TATT $=X \times \times 23$.

ASSIGN TNOH = TNOW ZNAME = ZONE-NAME DBT-DBT NZ=NZ .

ASSIGN HUMRAT=HUMRAT ..

CALCULATE .

C IF (ZNAME.EQ."THER") GO TO 100

IF (ZNAME.EQ. "GARA-) GO TO 100

IF (ZNAME.EQ."ATTI") GO TO 70

IF (NZ.EQ.1) GO TO 100

IF (NZ.EO.2) 60 TO 100

IF (NZ.EQ.3) GO TO 70

GO TO 100

c attic

70 TATT $=$ TNON

GO TO 100

100 Continue

END

END-FUNCTION ..

COMPUTE SYSTEMS ..

STOP .. 


\section{DOE-2 INPUT FILE FOR SITE 6 BASE CASE}

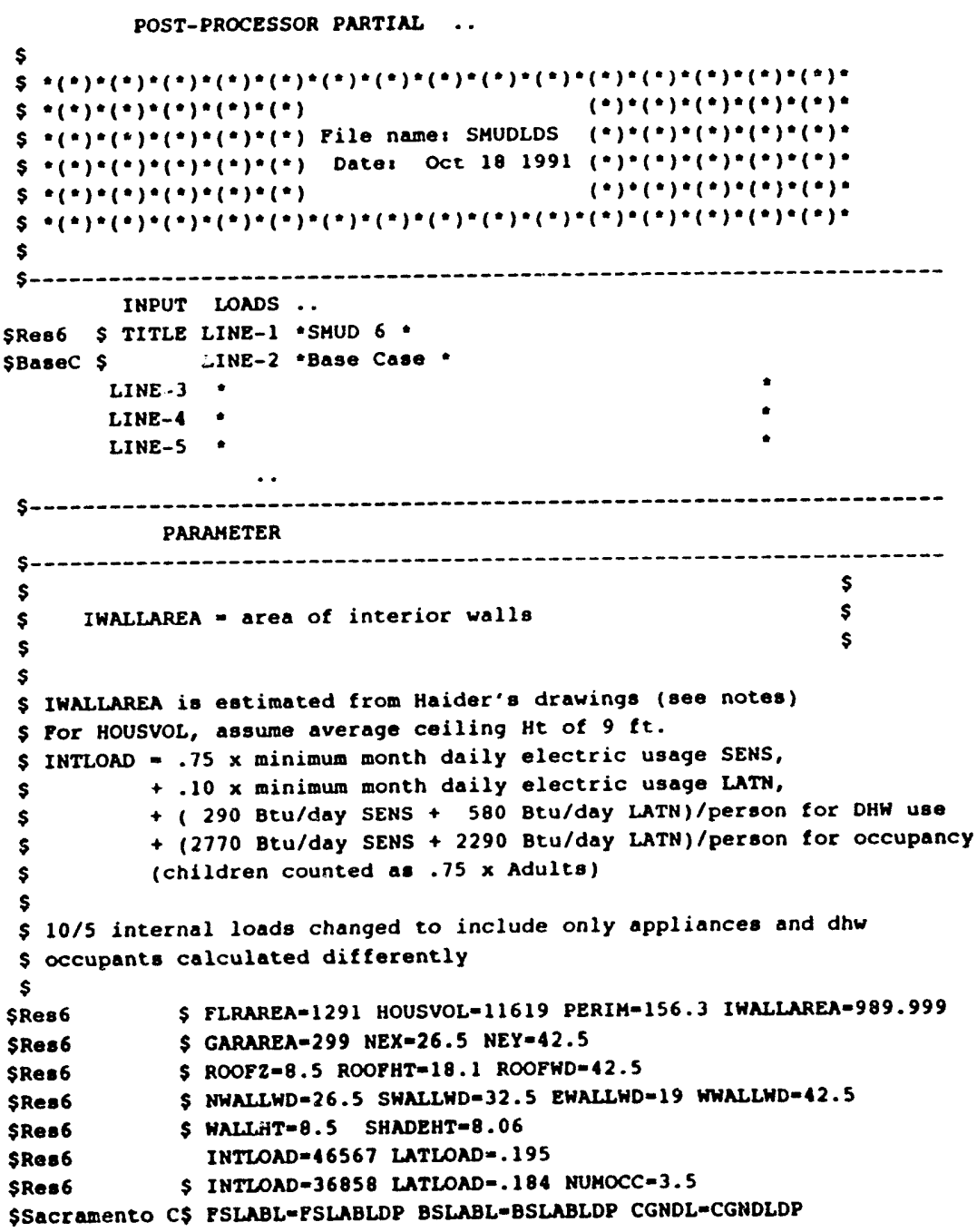

IWALLAREA is estimated from Haider's drawings (see notes)

5 Por HOUSVOL, assume average coiling Ht of $9 \mathrm{ft}$.

5 INTIOA = $.75 \times$ minimum month daily electric usage SENS,

$+10 \times$ minimum month daily electric usage

+ $10 \times$ minimum month daily electric usago Larn, for DHw use

$+(290 \mathrm{Btu} / \mathrm{day}$ SENS + 580 Btu/day LATN $) /$ person for DHW Use
+ ( $2770 \mathrm{Btu} / \mathrm{day}$ SENS $+2290 \mathrm{Btu} / \mathrm{day}$ LATN $) /$ person for occupancy

(children counted as $.75 \times$ Adults)

$10 / 5$ internal loads changed to include only appliances and dhw s occupants calculated differently

\$Res6 S FLRAREA-1291 HOUSVOL-11619 PERIM-156.3 IHALLAREA-989.999

SREs6 S GARAREA-299 NEX-26.5 NEY=42.5

\$Re86 6 \$ ROOF2-8.5 ROOFHT=18.1 ROOFWD-12.5

SRes6 S RWALLWD=26.5 SWALLHD=32.5 EWALLHD-19 WWALLHD-12.5

SRe86 \$ WALLAT-8.5 SHADEHT 8.06

SRes6 1 SRALC

SREB 6 SRACOMOCC-3.5

SSacramento C\$ PSLABL=PSLABLDP BSLABL-BSLABLDP CGNDL-CGNDLDP

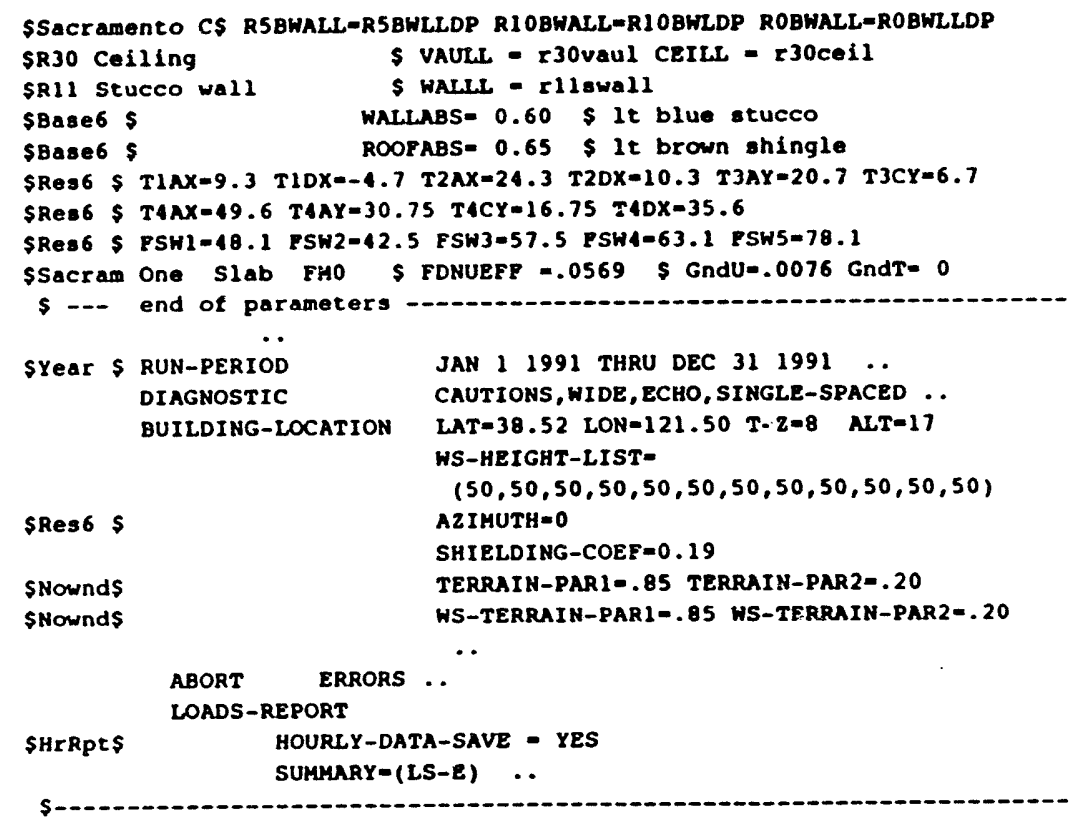

S--- Loads Schedules

DAYINTSCH DAY-SCHEDULE SCEC internal loads profile- fraction of total

(1) $(.024)$ (2) $(.022)(3,5)(.021)$

(6) $(.026)$ (7) $(.038)$ (8) $(.059)$

(9) $(.056)(10)(.060)$ (11) $(.059)$

(12) $(.046)(13)(.045)(14)(.030)$

(15) $(.028)(16)(.031)(17)(.057)$

$(18,19)(.064)(20)(.052)(21)(.050)$

(22) $(.055)(23)(.044)(24)(.027)$.

UOCCAPPS DAY-SCHEDULE SCEC modified: appl on unoccupied day

(1) $(.024)$ (2) $(.022)(3,5)(.021)$

(6) $(.026)(7.8)(.075)(9,17)(.059)$

(18) $(.072)(19,22)(.080)$

(23) $(.072)(24)(.027)$

occYes DAY-SCHEDULE Sold CEC/GRI occ schedule - fraction of peak

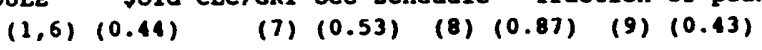


(10) $(0.52)$ (11) $(0.63)$ (12) $(0.21)(13)(0.14)$

$(14,15)(0.00)(16,17)(0.29)(18)(0.64)$

(19) $(0.81) \quad(20)(1.00)(21)(0.96)$

OCCAO DAY-SCHEDULE SOld CEC/GRI oce echedule mod tor unoce

$(1.6)(0.44) \quad(7)(0.53) \quad(0)(0.87)$

$(9.18)(0.00)$

(19) $(0.81) \quad(20)(1.00)(21)(0.96)$

(22) $(0.89)$ (23) $(0.77)(24)(0.46) \ldots$

s internal loade includes all loads- electric and dhw

S occupant loads are occupant only

\$REA6 \$ INTLDSCH SCHEDULE THRU DEC 31 (WD) UOCCAPPS (WEH) DAYINTSCH . \$RAA6 \$ OCCSCH SCHEDULE THRU DEC 31 (WD) OCCNO (WEH) OCCYES ..

The tollowing shading schedule is set for each houec.

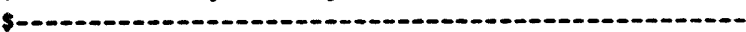

SHADCO SCHEDULE THRU MAY 31 (ALL) $(1,24)(0.80)$

SRES6 \$ THRU OCT 31 (ALL) $(1,24)(0.40$

\$Rea6 Ret. W.BOs, "aite6 has been keeping their shades closed

\$Ree6 opposite per our request

THRU DEC 31 (ALL) $(1,24)(0.80) \ldots$

The following tree shading schedules produce the follwing of fective trasmittance of 0.50 down to 0.10 during the summer and of 0.90

$\$$ down to 0.50 during the winter. The equare root of the transmittance

s is input under building-shades since light passing through a tree" $\$$ goes through two surfaces.

TREETRANS1 SCHEDULE THRU FEB 28 (ALC) $(1,26)(1.00)$

THRU OCT 31 (ALC) $(1,24)(0.745)$

THRU DEC 31 (ALC) $(1,24)(1.00) \ldots$

TREETRANS2 SCHEDULE THRU FEB 28 (ALL) $(1,24)(1.00)$

THRU OCT 31 (ALL) $(1,24)(0.707)$

THRU DEC 31 (ALL) $(1,24)(1.00) \ldots$

TREETRANS3 SCHEDULE THRU FEB 28 (ALL) $(1,24)(1.00)$

THRU OCT 31 (ALL) $(1,24)(0.655)$

THRU DEC 31 (ALL) $(1,24)(1.00) \ldots$

TREETRANSA SCHEDULE THRU FEB 28 (ALL) $(1,24)(1.00)$

THRU OCT 31 (ALL) $(1,24)(0.577)$

THRU DEC 31 (ALL) $(1,24)(1.00) \ldots$

TREETRANSS SCHEDULE THRU FEB 28 (ALL) $(1,26)(1.00)$

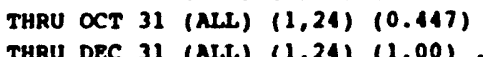

(-2onstruction

SINDOWGT

GLASS-TYPE

$\$$ windowe

GLSS-TYPE-CODE-1 Sclear glass

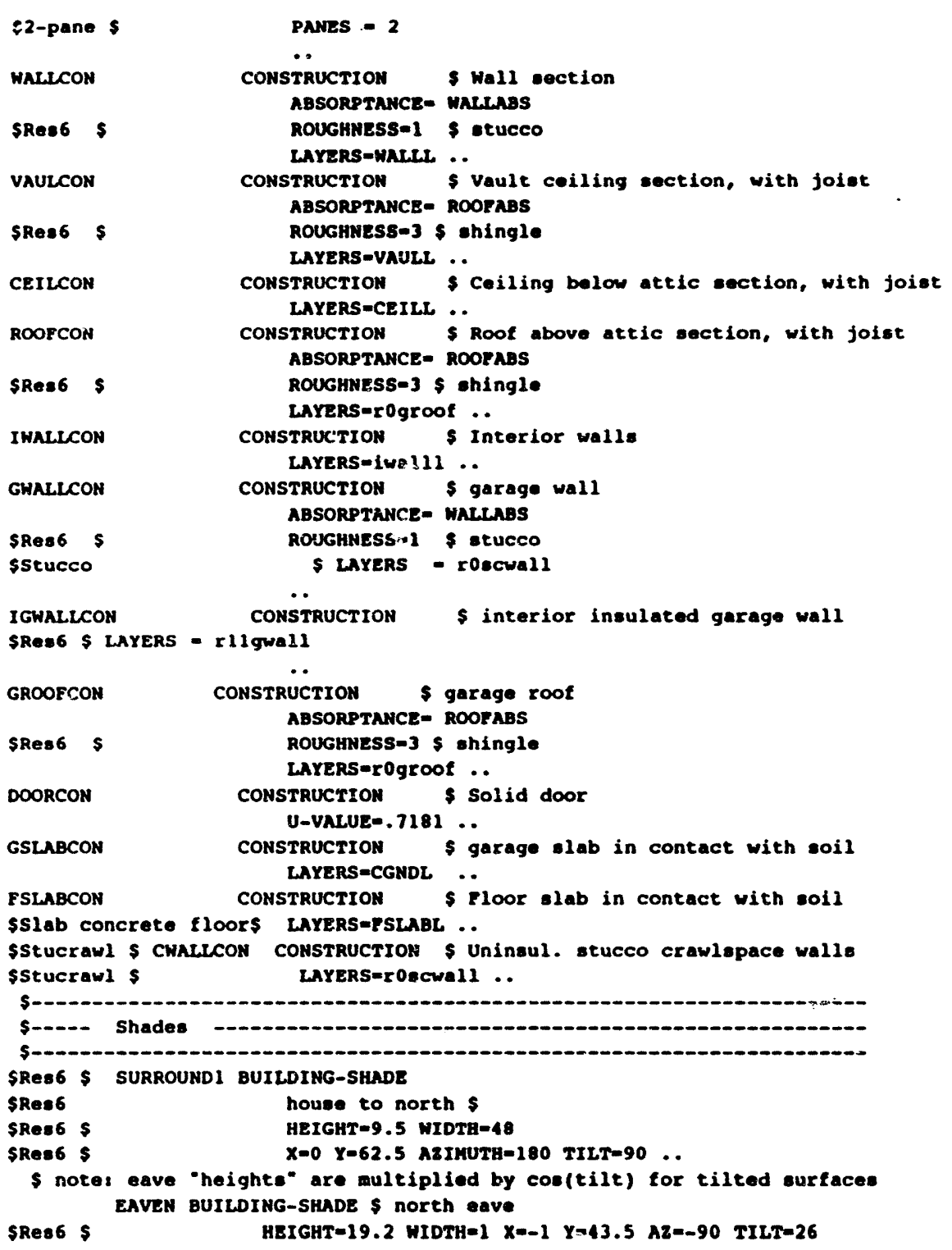


2-SHADEHT ..

SRES6 \$ EAVEN2 BUILDING-SHADE \$ north eave

SRes6 \$

LIKE EAVEN $X=33.5 \quad Y=42.5 \quad A Z-90 \ldots$

EAVES BUILDING-SHADE LIKE EAVEN S south eave

$$
X=0.0 \quad A z=-90
$$

\$Re日6 \$

\$Res6 \$ EAVES2 BUILDING-SHADE $\$$ north eave

SRES $\$$ LIKE EAVES $X=33.5$ Y=-1 A2=90 ..

EAVEE BUILDING-SHADE LIKE EAVEN \$ east eave

SRes6

SRes6 S HEIGHT-10.3 WIDTH=23.5 X-33 Y-19 2-WALLHT AZ $=90$ TILT $=0$

EAVEW BUILDING-SHADE LIKE EAVEE \$ west eave

SRES $\$$ HEIGHT-1.11 WIDTH=42.5 X=-1 $\quad \mathrm{Y=42.5}$ Z-SHADEHT

$\$$ Res6 \$ $A Z=-90$ TILT -26

SRes6 \$ PATIO BUILDING-SHADE \$ backyard patio overhang

SRes6 \$ HEIGHT=6 WIDTH=12 TRANSHITTANCE $=0.50$

SRese $s$ $X=0 \quad Y=30.5 \quad 2=$ WALLHT A2 $=90$

S-a Treess girst existing, then test trees

SEXTr6S TREETIA B-S HEIGHT-3 HIDTH-3 $X=-21.5$ Y=35 $2=7$ TILT=90

SEXTr6\$ TRANSHITTANCE=0.894 SHADE-SCHEDULE-TREETRANS2 ..

SExTr6\$

SExTr6\$

SExTr6\$

SExTr6\$

SExTr6\$

SExTr6\$

\$ExTr6\$

SExTr6S

SExTr6\$

SEXTr6\$

SExTr6\$

$\$ E \times T \times 6 \$$

SExTr6s

SExTr6s

SExTr6s

SExrras

sextros

sexirgs

SExTr6

SExTr6S

REET1B B-S LIKE TREET1A AZ-270 ..

TREETIC B-S LIKE TREETIA $y=32$.

TREETID B-S LIKE TREET1B $x--24.5$.

TREET1E B-S LIRE TREET1A $\quad z=10$ TILT=0 $x=-21.5 \quad Y=35$ AZ=0 $\ldots$

TREET2A B-S HEIGHT=3 WIDTH=3 $X=-15.5 \quad Y=26 \quad z=7$ TILT=90

TRANSHITTANCE $=0.894$ SHADE-SCHEDULE-TREETRANS 2 ..

TREET2B B-S LIKE TREET2A AZ=270 ..

TREET2C B-S LIKE TREET $2 A \quad X=23 \ldots$

TREET2D B-S LIKE TREET2B $x=-18.5$.

TREET2E B-S LIKE TREET2A $2=10$ TILT=0 $\quad x=-15.5 \quad$ y=26 AZ=0 $\quad$.

REET4A B-S HEIGHT-2 WIDTH=2 $x=-8 \quad y=11 \quad 2=7$ TILT=90

TRANSHITTANCE=0.894 SHADE-SCHEDULE-TREETRANS2 ..

TREET4B B-S LIKE TREETAA A2=270 .

TREETAC B-S LIKE TREETAA $Y=9$..

TREETAE B-S LIKE TREETAA $2=9$ TILT=0 $X=-8 \quad y=11$ AZ-0 $\ldots$

TPEET6A B-S GEIGHT=4 HIDTH=4 $\quad X=-20 \quad y=-3 \quad 2=7$ TILT=90

TPANSUITANCE-0.707 SHADE-SCHEDULE-TREETRANS5

TREET6B B-S LIKE TREET6A $A Z-270$.

TREET6C B-S LIKE TREET6A $Y=-7$..
SEXTY6S TREET6D B-S LIKE TREET6B X--24 .

SEXTr6\$ TREET6E B-S LIKE TREET6A 2-11 TILT=0 .

SEXTr6S TREET7A B-S HEIGHT=4 WIDTH-4 X=-12 Y=-3 2-7 TILT=90

SEXTr6S TRANSHITTANCE=0.707 SHADE-SCHEDULE-TREETRANSS -

SEXTr6\$ TREET7B B-S LIKE TREET7A AZ-270 ..

SEXTr6S TREET7C B-S LIRE TREBT7A Yo-7

SEXTr6S TREET7D B-S LIKE TREET7B $x=-16$.

SExTr6s TREETIE B-S LIKE TREET7A $2=11$ TILT=0

ThET

TEXTr6S TRANSHITTANCE-0.707 SHADE-SCHEDULE-TREETRANS5 -

SEXTr6S TREET8B B-S LIKE TREETBA AZ-270 ..

SEXTY6\$ TREET8C B-S LIKE TREETBA Y=-7 ..

SEXTr6\$ TREETOD B-S LIKE TREET8B $X=-10$.

SEXTr6\$ TREETBE B-S LIKE TREETBA 2=11 TILT=0 ..

S-o- Space

SOMCOND SPACE-CONDITIONS

TEMPERATURE - (74)

SOURCE-TYPE=PROCESS

SOURCE-SCHEDULE-INTLDSCH

SOURCE-BTU/HR-INTLOAD

SOURCE-SENSIBLE $=1$.

SOURCE-LATENT=LATLOAD

PEOPLE-SCHEDULE-OCCSCH

PEOPLE-HG-LAT -190

PEOPCE-

INF-METHOD-S-G

SMedium Infiltration S PRAC-LEAK-AREA $=.0005$

TLOOR-WEIGHT $=0$

PURNITURE-TYPE-LIGHT

FURN-FRACTION $=0.2$

FURN-WEIGHT $=3.30$

SET-DEFAULT FOR DOOR HEIGHT=6.5 WIDTH=3.0 CONSTRUCTION=DOORCON ..

SET-DEFAULT FOR EXTERIOR-WALI.

SHADING-SUREACE-YES

SET-DEFAULT FOR WINDOW

GLASS-TYPE-HINDOWGT SHADING-SCHEDULE-SHADCO ..

THEROOM SPACE

SPACE-CONDITIONS=ROOMCOND

AREA-PLRAREA VOLUME-HOUSVOL ..

INTWALI INTERIOR-WALI.

INT-WALL-TYPE-INTERNA

AREA-IWALLAREA CONSTRUCTION=IHALLCON ..

SRES6 S MHALIL EXTERIOR-WALI CONSTRUCTION\&WALLCON X=NEX Y-NEY 


\section{HEIGHT-WALLHT WIDTH-NWALLWD}

\$REA \$ NWINDIA WINDOW $X=15.5$ Y-3 HEIGHT=3.6 WIDTH=3.00 $\ldots$ SWALLI EXTERIOR-WALL

SRes6 S LIXE MWALLI $X=0$.

LIKE WWALCI $X=0.0$ (1)

SREB $\$$ SWINDIA WINDOH $X=15.5$ Y-2.999 HEIGHT=3.90 WIDTH=3.60 .. SRES6 S EHALL1 INTERIOR-WALL CONSTRUCTION-IGHALLCON

SRes6 \$ HEIGHT=HALLHT NEXT-TO-GARAGE WIDTH=EWALLWD ...

SRES6 S EWALL.2 EXTERIOR-WALL CONSTRUCTION-WALLCON

SReB6 \$ $X=32.6 \quad Y=19$ HEIGHT-WALLHT HIDTH=9.5 AZ-90 ‥

SRes6 S EWIND2A WTHDON $X-2.5 \quad Y=2.5$ HEIGHT=4.8 WIDTH $=4.5$.

SRe日 5 ENAL3

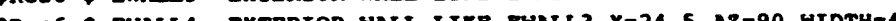

SRes6 \$ EDOORAA DOOR $X=1$.

SRES6 5 ENALLS EXIERIOR-WALL LIKE EWALLA $Y=32.5$ AZ=180 WIDTH=2 .

SRes6 \$ EWALL6 E-W LIKE EWALL2 X=26.5 Y=32.5 AZ=135 WIDTH=3 .

\$Res6 \$ EHIND6A WINDOW $X=.75 \quad y=2.999$ HEIGHT $=4.50$ WIDTH-1.50.

\$ReB6 \$ EWALL7 E-W LIKE EWALL2 $X=28.7$ Y=34.6 AZ=90 HIDTH-5.8 ..

SRes6 \$ ENIND7A HINDOW $X=.75 \quad Y=2.999$ HEIGHT=4.50 HIDTH=4.50.

SRES6 \$ EWALLS E-W LIKE EWR $X=28.7 \quad Y=40.4$ AZ=45 WIDTH=3 $\cdots$

SRes6 S EHINDQA WINDOH $X=.75 \quad Y=2.999$ HEIGHT-4.50 WIDTH=1.50 ..

SREg6 STHAL1 EXTERTOR-WALL

SRes6 \$ LTKE NWALLL $Y=42.5$

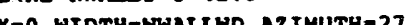

RRes6 \$ WHINDIN HINDOW $x=2 \quad y=0$ HEIGHT-6.7 WIDTH-6.7 ..

SRes6 S WHINDIB

SRES6 \$ WHINDIC HINDOW LIKE WWINDIB $X=20.0$.

SREA6 \$ WHINDID HINDOW $x=26.3 \quad y=3$ HEIGHT-3.70 WIDTH=5.

SRes6 \& WWIND1E HINDOW $x-37 \quad x=6.2$ HEIGHT=1.50 WIDTH-4.5 .

\$Slab \$ FOUNDATION UNDERGROUND-FLOOR \$ Slab tloor

SSIab \$ HEIGHT=10 WIDTH-PLRAREA TIMES . 1

TILT-180 CONSTRUCTION-FSLABCON

SSIab \$ U-EFFECTIVE-FDNUEFP

SSlab \$ O-EFFECTIVE-PDNUEF

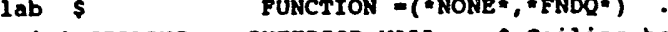

ceiling between House and Attic

SAtticS TIZT=O CONSTRUCTION=CEILCON

Sattics AREA-FLPAREA NEXT-TO-ATTIC.

SAttic spaces

SAttic\$ ATTIC SPACE

SAttic\$

SAttics

SAttic

SAttic

AREA-PLRAREA VOLURE-PLRAREA TIMES 2.90 \$ avg height

INF-METHOD-S-G

assume 1 ft2 of vents per $450 \mathrm{ft2}$ of attic space area, ELP - 75 of vent area

\$Res6 \$ FRAC-LEAR-AREA $=.00167$
Sattics

SAttics

SAttic\$

SAttic\$ NROOR

SAttics

SAttics

SRes6

SAttic\$

SAtics SROOZ

\$Res6 $\$$

SAttic

GARAG

ZONE-TYPE=UNCONDITIONED $T=(80)$

Z=ROOFZ HEIGHT=ROOFHT WIDTH-ROOFWD

CONSTRUCTION-ROOFCON

$X=32.5 \quad Y=0.0$ AZIMUTH-90 TILT=26

..

LIKE NROOF1

$X=0 \quad Y=42.5$ A2IMUTH=-90

SPACE

AREA-GARAREA VOLUME-GARAREA TIMES 9.80 \$ avg height INF-METHOD-S-G

FRAC-LEAK-AREA- .0015 S assume 3 times normal infilt

PLOOR-WEIGHT=O

ZONE-TYPE-UNCONDITIONED $T=(60)$

GAR1 EXTERIOR-WALL

HEIGHT-WALLHT TILT $=90$

\$Res6 $\$$

\section{HIDTH $-15.5 x=18 x=19.3$}

CONSTRUCTION=GHALLCON

\$ garage Nwall

GAR2 EXTERIOR-WALL

LIKE GAR

\$Res6 \$

$X=32.5 \quad Y=0 \quad A z=180$

garage Swall

GAR3 EXTERIOR-WALI

LIKE GARI \$ garage door wall

SRes6 \$ HEIGHT=9.8 WIDTH-19.3 Y=0 AZ=90..

SRes 6 S
SRes6 $\$$

GAR4 INTERIOR-WALL \$ insulated wall againat house AREA-164.5 CONSTRUCTION-IGWALLCON INT-HALL-TYPE-STANDARD NEXT-TO-THEROOM

GROOF I EXTERIOR-WALL

SRes6 \$ LIKE GARI HEIGHT=11.65 TILT=33.9

Z=ROOF2 CONSTRUCTIOH-GROOFCON

SREs6 S GROOF2 EXTERIOR-WALL

SRES6 \$ LIKE GRR2 HEIGHT=11.65 TILT=33.9

\$RES6 \$ Z=ROOPZ CONSTRUCTION=GROOFCON ..

GSLAB UNDERGROUND-FLOOR \$ GaIAgE tloo HEIGHT= 10 WIDTH-GARAREA TIMES - 1

TILT 180 CONSTRUCTION-GSLABCON

U-EFFECTIVE- .143 .. \$ Ref j.huang - ashrae paper 


\begin{tabular}{|c|c|c|c|}
\hline ArRpt- & & & \\
\hline $\begin{array}{l}\text { SHrRpt\$ } \\
\text { SHrRpt\$ }\end{array}$ & RBI & REPORT-BLOCK & Reports for wall temp \\
\hline $\begin{array}{l}\text { \$HrRpt\$ } \\
\text { \$HrRpt\$ }\end{array}$ & & VARIABLE-TYPE-SWALLL 1 & \\
\hline SHrRpt6= & urface $T$ & VARIABLE-LIST $=(6) \ldots$ & \\
\hline $\begin{array}{l}\text { \$HrRpt\$ } \\
\text { \$HrRpt\$ }\end{array}$ & RB2 & REPORT-BLOCK & Reports for roof temp \\
\hline $\begin{array}{l}\text { \$HrRpt\$ } \\
\text { \$HrRpt\$ }\end{array}$ & & VARIABLE-TYPE-SROOF I & \\
\hline $\begin{array}{l}\text { SHrRpt\$ } \\
\text { SHrRpt6= }\end{array}$ & & VARIABLE-LIST=(6) $\ldots$ & \\
\hline $\begin{array}{l}\text { SHrRpt6- } \\
\text { SHrRpt\$ }\end{array}$ & $\begin{array}{l}\text { urface T } \\
\text { HRSCH }\end{array}$ & SCHEDULE & Hourly report schedule \\
\hline SHrRptS & & $\begin{array}{l}\text { SCHEDULE } \\
\text { THRU DEC } 31 \text { (ALC) }(1,24\end{array}$ & ) (1) \\
\hline $\begin{array}{l}\text { SHrRpt\$ } \\
\text { \$HrRpt\$ }\end{array}$ & SHR & HOUREY-REPORT & \\
\hline $\begin{array}{l}\text { \$HrRpt\$ } \\
\text { \$HrRpt\$ }\end{array}$ & & REPORT-SCHEDULE-HRSCH & \\
\hline $\begin{array}{l}\text { SHrRpt\$ } \\
\text { SHrRpt\$ }\end{array}$ & & REPORT-BLOCK= (RB1, RB2) & \\
\hline & & . & \\
\hline
\end{tabular}

FUNCTION NAME - FNDQ

LEVEL - UNDERGROUND-WALL ..

ASSIGH DOY-IDOY UGPO-OUGR UGWQ=OUGW ..

ASSIGN QTABL = TABLE $20,-3462.1)(3,-3450.6)(4,-3494.9)$ $(0,-3336.3)(1,-3389.2)(2,-3462.1)(8,-3400.9)(9,-3432.8)$ $(5,-3548.8)(6,-3512.7)(12,-3335.8)(13,-3164.1)(14,-3056.2)$ $(10,-3467.4)(11,-3408.3)(12,-3335.6)(18,-3360.7)(19,-3255.2)$ $(15,-3061.6)(16,-3176.4)(17,-3309.6)(28,-3360.7)(19,-3285.2)$ $(20,-3035.1)(21,-2849.8)(22,-2009.7)(23,-2850.6)(24,-2872.7)$ $(25,-2901.3)(26,-2954.2)(27$, $(30,-2508.2)(31,-2379.1)(32,-2303.7)(33,-2479.3)(34,-2686.4)$ $(35,-2608.0)(36,-2500.5)(37,-2413.6)(38,-2188.9)(39,-2045.6)$ $(40,-2134.6)(41,-2002.3)(42,-1946.5)(43,-1931.6)(44,-1942.3)$ $(40,-2134.6)(41,-1852.8)(47,-1659.4)(48,-1673.6)(49,-1538.1)$ $(5,-2040.4)(46,-1852.8)(52,-1189.2)(53,-1122.8)(54,-1020.4)$ ( 50, -1285.3$)(51,-1176.9)(52,-1189)(58,-621.7)(59,-592.9)$ $(55,-1070.9)(56,-1147.7)(57,-507.0)(63,-493.0)(64,-494.7)$ $(60,-577.7)(61,-569.9)(62,-507.0)(63,-206.2)(69,-148.7)$ $(65,-338.1)(66,-236.5)(67,-199.1)(68,-206.2)(69,-28.9)$ $(70,-30.5)(71,25.0)(72,81.5)(73, \quad 68.1)(74,-28.9)$ $(75,-49.4)(76,50.9)(77, \quad 73.1)(78,-34.9)(79,-123.6)$ $(80,-331.5)(81,-320.9)(82,-271.8)(83,-264.4)(84,-250.2)$ $(85,-281.9)(86,-345.3)(87,-377.1)(88,-471.5)(89,-680.4)$ $(85,-2010)(96,-665.3)(92,-717.0)(93,-771.9)(94,-825.7)$ $(90,-6615)(96,-1001.8)(97,-1214.9)(98,-1290.1)(99,-1357.0)$ $(95,-845.2)(96,-1001.6)(102,-1458.1)(103,-1635.8)(104,-1807.5)$ $(100,-1332.1)(101,-1377.6)(102,-1458.7)(108,-2097.4)(109,-2161.6)$ (105, -1935.5)(106, $(110,-2276.3)(111,-2428.2)(112,-2591.7)(1130,-3194.8)(119,-3339.1)$

$(115,-2965.2)(116,-2985.4)(117,-2984.5)(118$,
$(120,-3281.2)(121,-3316.4)(122,-3332.9) \cdots$ Calculate .

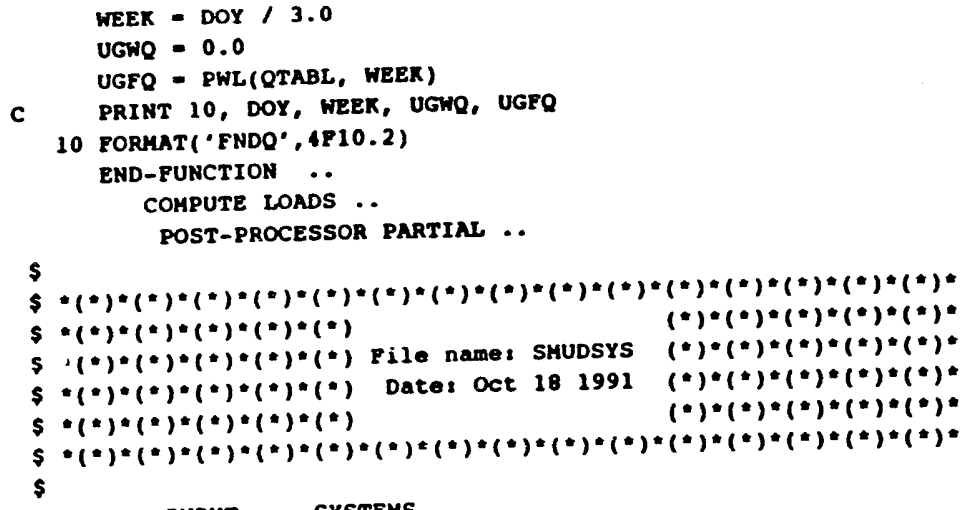

cSCAP is 80 of CTCAP where no literature available

csap is 15000 Btu/hr is valid for all HP Mefault DOE2 curve for cooling equipment used.

Default Drom product literature for Res2, 5,6,7

$\$$ Cooling COPs from product literature

\$ Sitel and Site 6 assumed same as Ress

$\$$ All other data from product literature.

s cooling thermostat setpoints from investigating measured data

$\begin{array}{llllll}\$ & & & & \\ \text { SReB6 } & \$ & \text { HEATSET }=68 & \text { SETBACK }=68 & \text { COOLSET }=82 & \text { SETUP=82 } \\ \text { SReB6 } & \text { H } & \text { HCAPF }=-60000 & \text { CTCAP }=38000 & \text { CSCAP }=30400 & \end{array}$

SRes6 \$ ACCFM $=1200$

$\$$

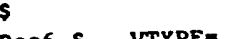

Res6 \$ $\$$ no venting

SFurn \$ FHIR-1.4286 \$778 efficiency + 108 duct losses

MAXTEMP=120
SRes6 \$ CBF $=.098 \quad$ CEIR $=.1255$ 


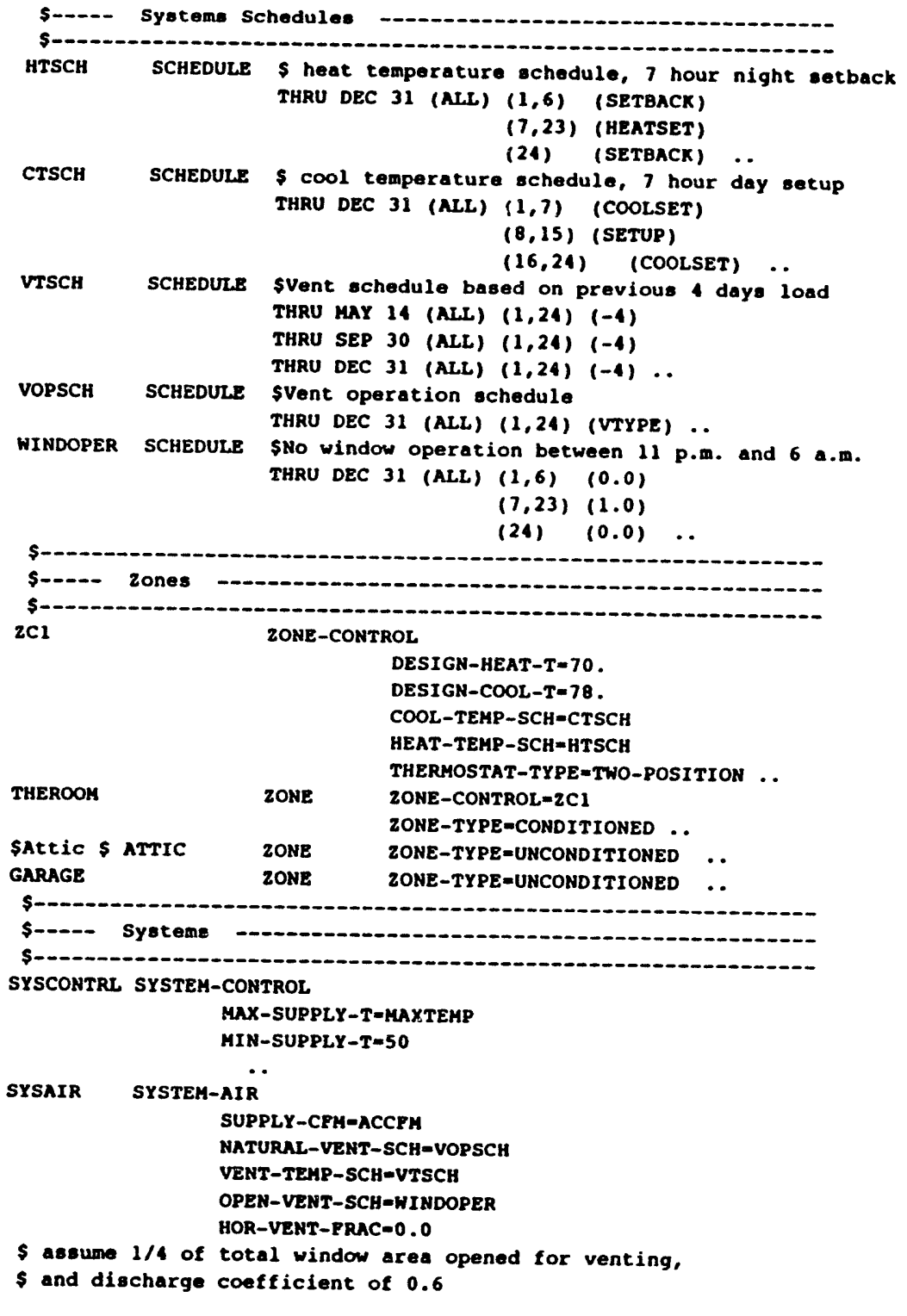

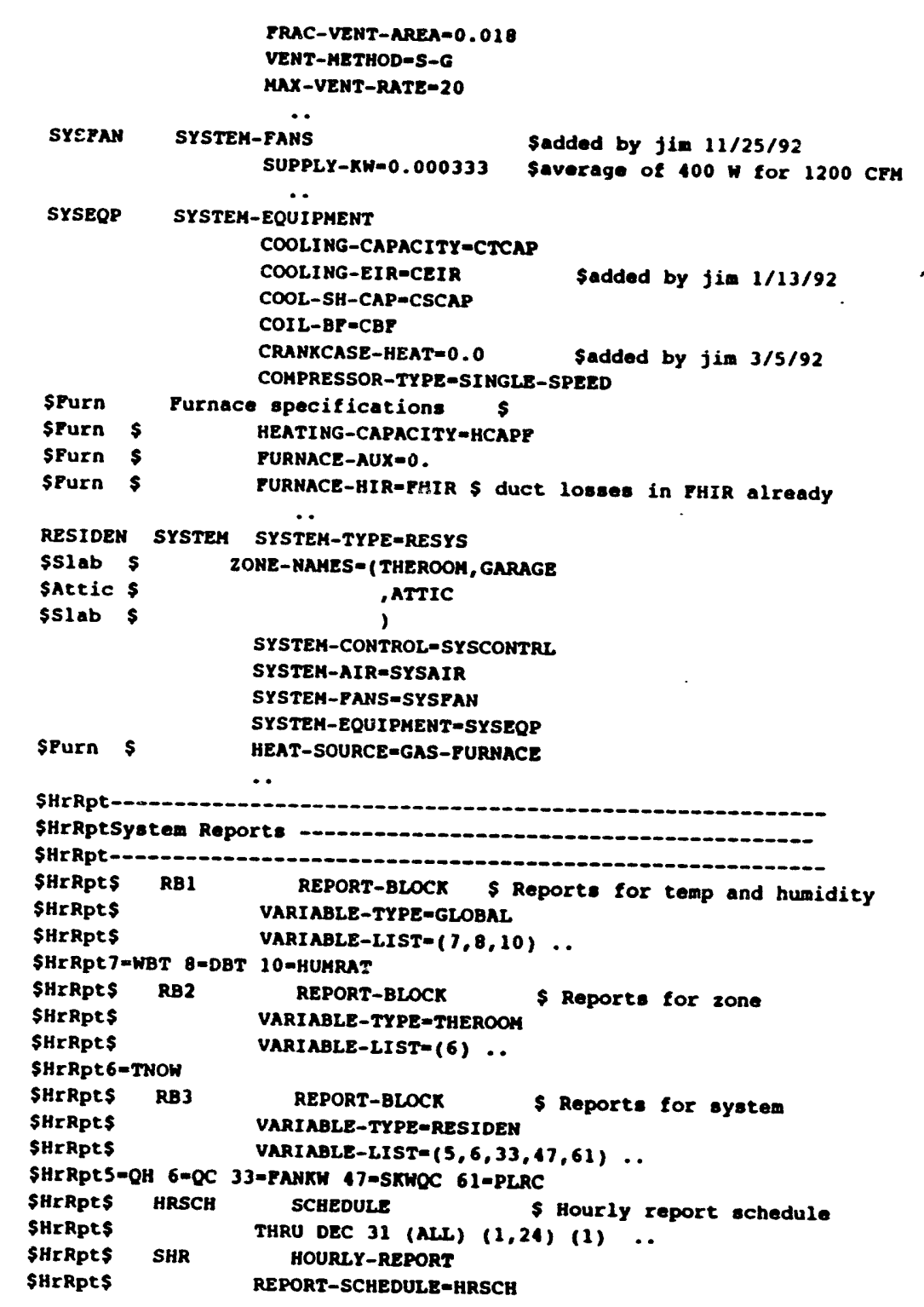




\section{END ..}

FUNCTION NAME - DUCT ..

s

S This function multiplies the AC EIR

\$ by the duct officiency which varies

$\$$ with attic temperature

$\$$ old ducts in attic

s

ASSIGN MON-IMO DAY=IDAY HR-IHR TOUT=DB

COOLEIR-COOLING-EIR COOLCAP-COOLING-CAPACITY

COOLSEN-COOL-SH-CAP

DEFFC $=X X X 22$

CALCULATE .

CALCULATE

DEFPC $-0.0077-$ TATT +1.379

COOLEIR - COOLEIR/DEFTC

COOLCAP = COOLCAP-DEFFC

C PRINT 20, HON, DAY, HR, TATT, DEFFC, COLLEIR

C 20 format('DUCT, ,3F4.0,' TATT-', F4.0, DEFFC-'

C + FS.3, EIR-', F5.3)

END

END-FUNCTION .

FUNCTION NAME = DUCT2 ..

\$ This function resets AC EIR to the input value

s old ducts in attic

s

ASSIGN MON-IMO DAY=IDAY HR-IHR TOUT-DBT

COOLEIR-COOLING-EIR COOLCAP-COOLING-CAPACITY

COOLSEN-COOL-SH-CAP

DEFFC-XXX22 TATT $=X \times X 23 \ldots$

CALCULATE .

COOLEIR $=$ COOLEIR $\cdot$ DEFFC

COOLCAP - COOLCAP/DEFFC

COOLSEM - COOLSEN/DEFFC

C PRINT 20, MON, DAY, HR, TATT, DEFFC, COOLEIR

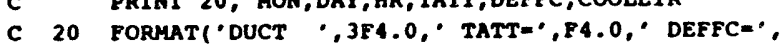

$+$ F5.3.' EIR=', 55.3$)$

END-FUNCTION .

FUNCTION NAME-SAVETEMP ..

\$ saves last hours zone temps for next hour's heat load $\$$ calculations

$\$$

ASSIGN TATT $=X X X 23 \ldots$
ASSIGH TNOH = TNOW 2NAME - 2ONE-NAME DBT-DBT N2-N2 .. ASSIGN GUMRAT-GUARAT ..

CALCULATE ..

IF (2NAME.EQ. THER") GO TO 100

IF (2NAME.EQ. GARA') GO TO 100

IF (ZNAME.EQ.-ATTI-) GO TO 70

IF (NZ.EQ.1) GO TO 100

IF ( $(\mathrm{NZ} . \mathrm{EQ} .2)$ GO TO 100

IF (N2.EQ.3) GO TO 70

IF (N2.EQ.

c attic

70 TATT=TNOW

GO TO 100

100 CONTINUE

END

END-FUNCTION ..

COMPUTE SYSTEMS ..

STOP .. 


\section{DOE-2 INPUT FILE FOR SITE 7 BASE CASE}

POST-PROCESSOR PARTIAL ...

$\$$

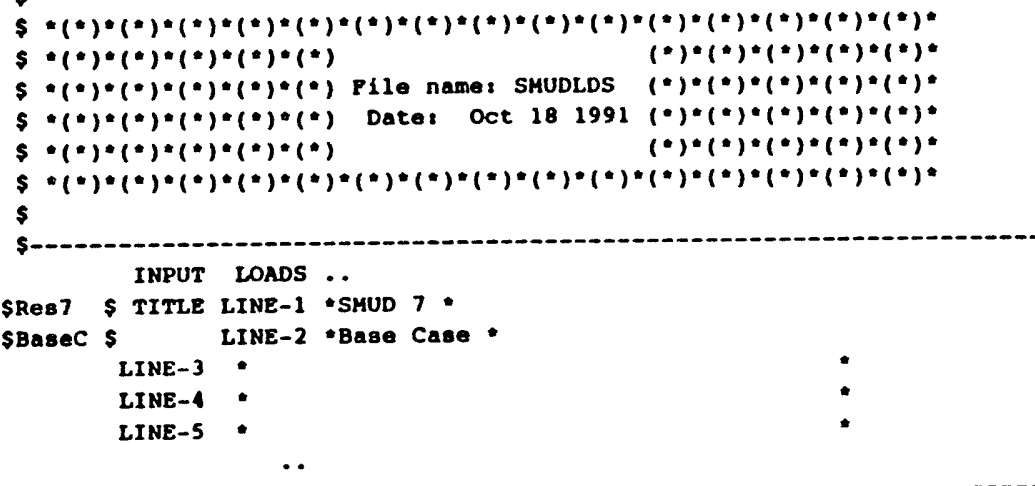

PARAMETER

S-1-0

IWALLAREA - area of interior walls

\section{s}

IWALIAREA is estimated from Haider's drawings (see notes) For HOUSVOL, assume average ceiling $\mathrm{Ht}$ of $9 \mathrm{ft}$.

Por HOUSVOL, ascime average cailing He of 9 et.

- .75 $x$ minimum month daily electric usage SENS,

$+10 \times$ minimur month daily electric usage LATN,

$+(290 \mathrm{Btu} / \mathrm{day}$ SENS + 580 Btu/day LATN $) /$ person for DHW use
+ ( 2770 Btu/day SENS + 2290 Btu/day LATN $) /$ person for occupancy

(children counted as $.75 \times$ Adults)

$10 / 5$ internal loads changed to include only appliances and dhw $\$$ occupants calculated differently

SRE97 S FLRAREA-1165 HOUSVOL-10485 PERTM=188.6 IWALLAREA-999

$\begin{array}{ll}\text { \$Res7 } & \text { \$ GARAREA }=468 \text { NEX }=40.88 \text { NEY }=48 \\ \text { SRes } 7 & \text { S ROOFZ }=8.5 \text { ROOFHT=15.16 ROOFWD }-28.58\end{array}$

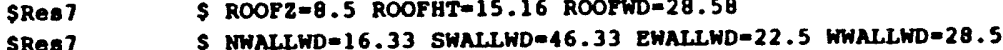

\$Res7 \$ NWALLWD=16.33 SWALLWD=46.33

\$RES7 S WALLHT $=8.5$ SHADEHT -8.136

SRes7 INTLOAD=66293 LATLOAD=.180

SSacramento CS FSLABL-FSLABLDP BSLABL-BSLABLDP CGNDL=CGNDLDP
SSaCramento CS RSBWALL-RSBWLLDP RL OBWALL-R10BWLDP ROBWALL-ROBHLLDP SRl9 Ceiling \$ VAULL = rl9vaul CEILL - rl9ceil \$R11 Stucco wall \$ HALLL - Kllswall

SBase7 \$ HALLABS= 0.55 \$ of fwhite stucco

SBase7 \& ROOPABS- 0.84 s med brown shingle

SRes7 S T1AX-21.7 T1DX-7.78 T2AX-31.7 T2DX-17.7 T3AY-14.8 T3CY=0.8

SRe日7 S TAAX-63.33 TAAY-13.74 TACY=-0.26 TADX-49.33

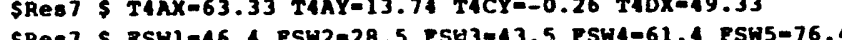

SRes7 S FSH1=46.4 FSW2-28.5 PSH3-43.5 PSW4-61.4 FSW5-76.4

SSacram One slab mino

5 --- end of paran

$\begin{aligned} \text { \$Year } \$ & \text { RUN-PERIOD } \\ & \text { DIAGNOSTIC } \\ & \text { BUILDING-LOCATION }\end{aligned}$

JAN 11991 THRU DEC $311991 \ldots$

CAUTIONS, HIDE, ECHO, SINGLE-SPACED
LAT-38.52 LON=121.50 T-2=8 ALT $=17$

WS-HEIGHT-LIST-

\$Res7 \$

$(50,50,50,50,0$
AZIMUTH -40

$\begin{array}{ll} & \text { SHIELDING-COEF }=0.19 \\ \text { SNownds } & \text { TERRAIN-PARI }=.85 \text { TERRAIN-PAR2-.20 } \\ \text { SNOwndS } & \text { WS-TERRAIN-PAR1 }-.85 \text { WS-TERRAIN-PAR }\end{array}$
WS-TERPAIV-PARI= 85 WS-TEPRAIN-PAR2- 20

\section{ABORT ERRORS .. \\ ABORT LADS-REPORT \\ SHTRPTS HOURLY-DATA-SAVE - YES \\ SUMAMARY $=($ LS-E)}

S----- Loads Schedules

DAYINTSCH DAY-SCHEDULE SCEC internal loads profile- fraction of total

$\begin{array}{llll}\text { (1) }(.024) & \text { (2) }(.022) & (3,5)(.021)\end{array}$

(6) 1.026$)$ (7) $(.038)$ (8) $(.059)$

(9) 1.056$)(10)(.060)$ (11) $(.059)$

(12) $(.046)(13)(.045)$ (14) $(.030)$

(15) $(.028)(16)(.031)(17)(.057)$

$(18.19)(.064)(20)(.052)(21)(.050)$

(22) $(.055)(23)(.041)$ (24) $(.027) \ldots$

UOCCAPPS DAY-SCHEDULE SCEC modified $z$ appl on unoccupied day

(1) $(.024)$ (2) $(.022) \quad(3.5)(.021)$

(6) $(.026)(7,8)(.075)(9,17)(.059)$

(18) $(.072)(19,22)(.080)$

(23) $(.072)$ (24) $(.027) \ldots$

OCCYES DAY-SCHEDULE Sold CEC/GRI OCC schedule - fraction of peak

$\begin{array}{llll}(1.6)(0.44) & \text { (7) }(0.53) & \text { (8) }(0.87) & (9)(0.43)\end{array}$ 


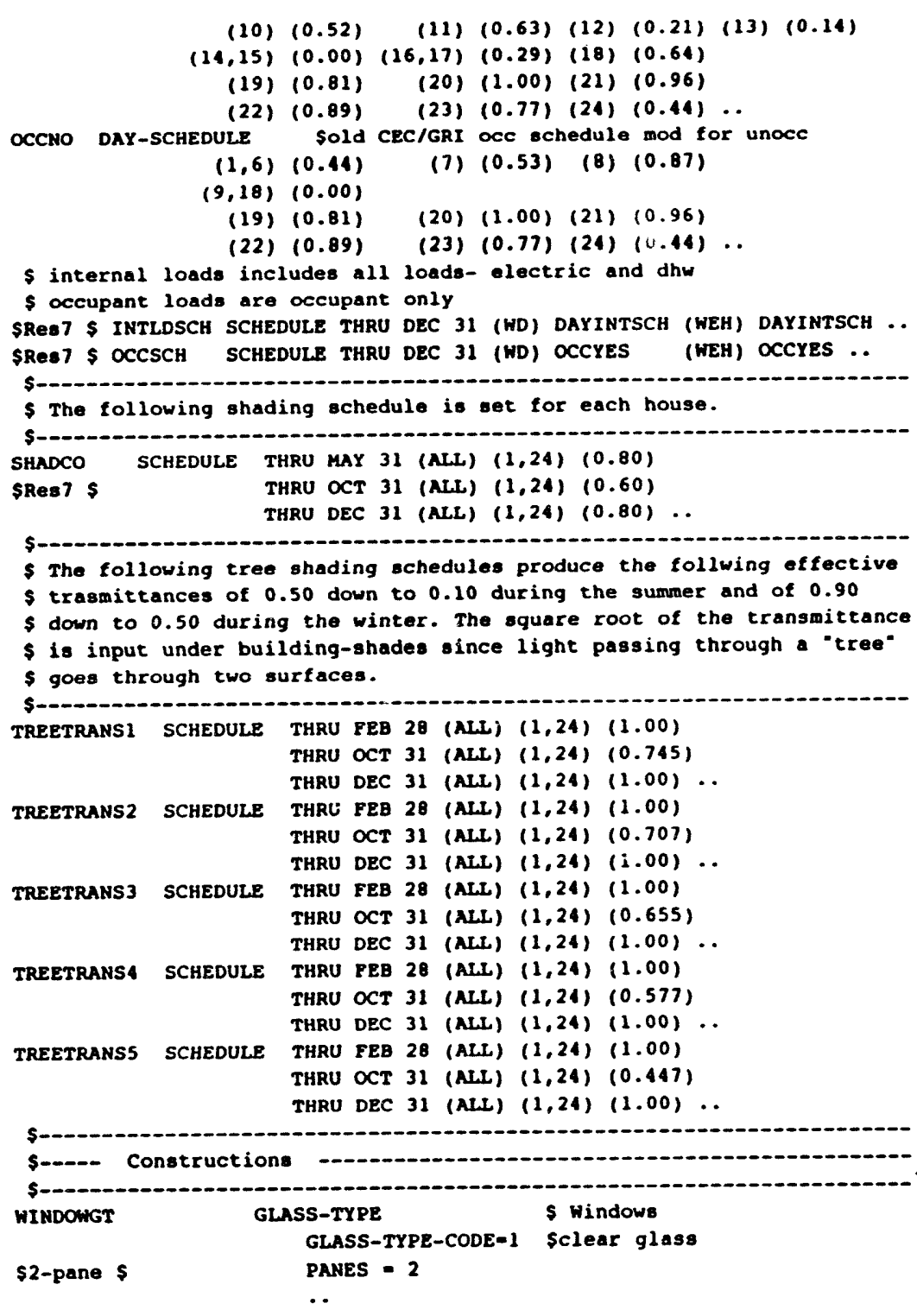

\section{CONSTRUCTION \$ Wall section}

ABSORPTANCE- MALLABS

ROUGHNESS-1 \$ StUCCO

SReg7 7

VAULCON

\$Res7 \$

CEILCON

ROOFCON

\$Res7 \$

IWALICON

GWALLCON

SRes7 \$

\$stucco

CONSTRUCTION S Vault ceiling section, with joist ABSORPTANCE- ROORABS ROUGHNESS- 3 S shingle LAYERS-VAULL .

CONSTRUCTION \& Cailing below attic section, with joist LAYERS-CEILL .

CONSTRUCTION \$ ROof above attic section, with joist ABSORPTANCE= ROOPABS

ROUGHNESS-3 S shingle

LAYERS-rOgroof

CONSTRUCTION \$ Interior walls LAYERS-iwa111 ..

CONSTRUCTION \$ garage wall

ABSORPTANCE= WMLLABS

ROUGHNESS-1 S stucCO

S LAYERS - roscwall

IGWALLCON CONSTRUCTION $S$ interior insulated garage wall

SRES7 \$ LAYERS = r11gwal1

GRCOFCON CONSTRUCTION \$ garage rOOF

ABSORPTANCE= ROORABS

ROUGHNESS-3 S shingle

LAYERS-rOgroof .

DOORCON CONSTRUCTION \$ SOLId door U-VALUE-.7181..

GSLABCON CONSTRUCTION \$ garage slab in contact with soi?

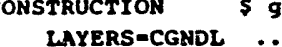

PSLABCON CONSTRUCTION S Floor slab in contact with soil

\$Slab concrete floor\$ LAYERS-PSLABL ..

SStucrawl \$ CWALLCON CONSTRUCTION \$ Uninsul. stucco crawlspace walls \$stucrawl \$ 
EAVEN BUILDING-SHADE $\$$ north eave

\$Res7 s

HEIGHT-9.75 WIDTH=1 $X=23.5 \quad$ Y=49 A2=-90 TILT=20 2-SHADEAT ..

SRear S EAVEN2 BUILDING-SHADE S nOrth eave

SRes7 S LIKE EAVEN $X=41.9$ Y=48 AZ=90 .

SRee7 S EAVEN3 BUILDING-SHADE $\$$ northwest eave

\$Res7 \$ HEIGHT=1.06 WIDTH=18.5 X-23.5 Y=48 2-SHADEHT

\$Res7 \$ A2 $=-90$ TILT=20 .

\$Res7 \$ EAVENA BUILDING-SHADE $\$$ north eave 2

SRes7 \$ HEIGHT=1.06 WIDTH=24.5 X-24.5 Y=29.5 2=SHADEHT

\$Res7 \$ TILT $=20$..

EAVES BUILDING-SHADE LIKE EAVEN \$ Bouth eave

\$Res 7 HEIGHT-1.06 HIDTH $-28.58 \quad X=0 \quad Y=-1 \quad A 2=180$

EAVEE BUILDING-SHADE LIKE EAVEN S east eave

\$Res7 \$ HEIGHT=7.8 WIDTH=12 X-48.21 $\quad$ Y-13.5 $\quad 2=7.14$

SRes7 S $A Z=90$ TILT $=10$

SRes7 S EAVEE2 BUILDING-SHADE LIKE EAVEE HEIGHT-2 WIDTH=13.6 Y=0 SRes7 $S$ TILT=20 $z=5.96 \ldots$

EAVEW BUILDING-SHADE LIKE EAVEE \$ west eave

SRes7 \$ HEIGHT=16.23 WIDTH=1.5 $X=0 \quad y=29.5$ Z-SHADEHT SRes 7 s

SRes7 S EAVEWZ BUILDING-SHADE LIKE EAVEW $X=-1.5 \quad Y=-1$ AZ-180 $\ldots$

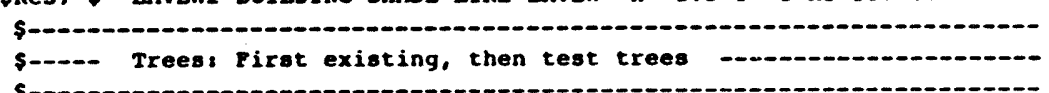

\$ Treess First existing, then test trees

SEXTr7S TREET1A B-S HEIGHT-21 WIDTH=21 $\quad x=82.8 \quad$ Y-10.5 $\quad 2=7$ TILT=90

SEXTr7\$ TRANSMITTANCE=0.775 SHADE-SCHEDULE-TPEETRANS4

SEXTr7\$ TREET1B B-S LIKE TREETIA AZ-270 ..

SEXTr7S TREETIC B-S LIKE TREET1A $Y=-10.5$.

SEXTY7S TREETIC B-S LIKE TREETIA Y=-10.5 .

SEXTY7S TREET1E B-S LIKE TREET1A $2=28$ TILT=0 $X=82.8 \quad Y=10.5$ AZ=0.

SEXTr7\$ TREET2A B-S HEIGHT=14 WIDTH=14 $x=-13 \quad y=7 \quad 2=7$ TILT=90

TRANSMITTANCE $=0.775$ SHADE-SCHEDULE-TREETRANS4 .

\$EXTr7\$ TREET2B B-S LIKE TREET2A A2-270 ..

SEXTr7\$ TREET2C B-S LIKE TREET2A $Y=-7 \ldots$

SEXTr7S TREET2D B-S LIKE TREET2B $X=-27$.

SEXTY7S TREET2E B-S LIKE TREET2A 2-21 TILT=0 $x=-13$ Y=7 Az=0 ..

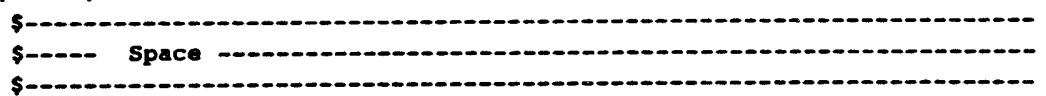

$$
\$
$$

ROOHCOND SPACE-CONDITIONS

$$
\text { TEMPERATURE - (74) }
$$

SOURCE-TYPE-PROCESS

SOURCE-SCAEDULE-INTLOSCA

SOURCE-BTUTHR-INTLOAD

SOURCE-SENSTBLE-1.

SOURCE-LATENT=LATLOAD

PEOPLE-SCHEDULE-OCCSCH

NUMBER-OF-PEOPLE-NUMOCC

PEOPLE-HG-LAT $=190$

PEOPLE-HG-SENS=230

INF-METHOD=S-G

SHedium Infiltration \$ FRAC-LEAK-AREA - .0005

FLCOR-WEIGHT $=0$

FURNI TURE-TYPE-LIGHT

FURN-FRACTION=0.29

EURN-WEIGHT-3.30

SET-DEPAULT POR DOOR HEIGHT=6.5 WIDTH=3.0 CONSTRUCTION=DOORCON .

SET-DEPAULT FOR EXTERIOR-WALL SHADING-SURFACE-YES .

SET-DEFAULT FOR WINDOW

GLASS-TYPE-WINDOWGT SHADING-SCHEDULE-SHADCO ..

THEROOM SPACE

SPACE-CONDITIONS=ROOMCOND

AREA-FLRAREA VOLUME-HOUSVOL.

INTWALL INTERIOR-WALI

INT-WALL-TYPE-INTERNAI

AREA-IWALLAREA CONSTRUCTION-IWALLCON ..

\$REs7 \$ MWALLI EXTERIOR-WALL CONSTRUCTION-WALLCON X-NEX Y-NEY HEIGHT-HALLHT WIDTH-MHALLND

\$Res7 \$ WWALL2 EXTERIOR-HALL LIKE NWALL1 X-24.5 WIDTH=19.5 AZ=-90 . $\$ R E 87$ W WWIND2A WINDOW $X=7.5$ BEIGHT=6.5 WIDTH=7.2.

SRes7 \$ NWALL3 EXTERIOR-WALL LIXE MWALLI X-24.5 $y=28.5$ WIDTH=24.5

\$Re87 \$ NWIND3A WINDOW $X=0.5$ Y=6 BEIGHT=1.5 WIDTH-3.6 $\ldots$

SREs7 S NWIND3B WINDOW $x=6 \quad y=6$ HEIGHT=1.5 WIDTH=3.6 $\ldots$

\$REs7 \& NWIND3C WINDOW $x=14 x=3.5$ HEIGHT=3.3 WIDTH=5.4 ... SWALL1 EXTERIOR-WALL

SRes7 $\$$ LIKE NWALLI $X=0.0$

HEIGHT-WALLHT WIDTH-SWALLWD $Y=0.0$ AZ-180

SREST S SWINDIA WINDOW $X-12$ Y=3.5 HEIGHT=3.3 WIDTH=5.4 .

\$Rea 7 \& SHIND1B HINDOW LIKE SHIND1A $X-22$..

\$RES7 \$ EWALLI INTERIOR-WALL CONSTRUCTION-IGWALLCON

\$Res7 \$

$$
\text { KEIGHT-WALLHT NEXT-TO-GARAGE }
$$

SREs7 S EWALL2 EXTERIOR-WHLL CONSTRUCTION=WALLCON 


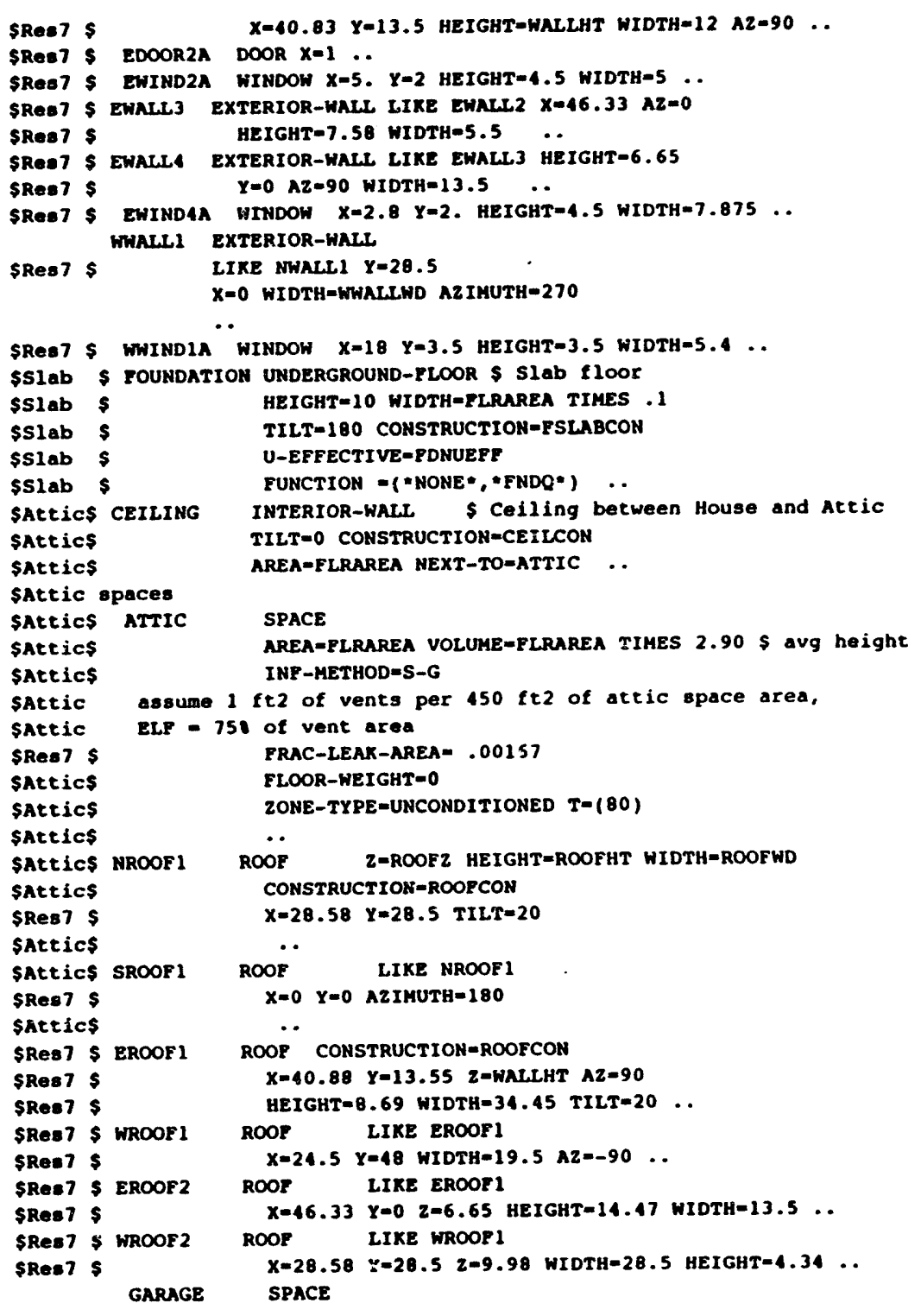

AREA-GARAREA VOLUAE-GARAREA TIMES $9.80 \$$ avg hoight INE-METHOD-S-G

FRAC-LEAK-AREA- .0015 $\$$ assume 3 times normal infilt FLOOR-WEIGHT=O

2ONE-TYPE-UNCONDITIONED $T=(60)$

GARI EXTERIÖ-HALL

HEIGHT-WAILHT TILT $=90$

WIDTH=19.67 $X=60.55 \quad Y=48$ AZ=0 $\$$ garage Mull

constructon

..

GAR2 EXTERIOR-HALL

$$
\begin{aligned}
& \text { LIKE GARI } \\
& X=40.83 \quad Y=25.5 \text { AZ }-180 \quad \text { \$ garage Swall }
\end{aligned}
$$

\$Rea7 \$

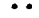

GAR3 EXTERIOR-WALL

LIKE GAR1 \$ garage door wall

\$Re.7 \$ HEIGHT=9.8 WIDTH=22.5 $x=60.55 \quad$ X-25.5 AZ-90

SRes? $s \quad$ GDOOR DOOR $X=1$ MIDTH-20.5 .. \$ garage door

GAR4 INTERIOR-WALL $\$$ insulated wall against house

SREe7 \$ NEXT-TO-THEROOH

GROOF 1 EXTERIOR-WALI

SRES7 S LIKE GARI HEIGHT=11.97 TILT=20.0

2-ROOFZ CONSTRUCTION=GROOFCON

2 EXTERIOR-WALT

SREA7 S GROOP2 EXTERIOR-WALL 11.97 TILT-20.0

SRES7 \$ LIKE GAR2 HEIGHT=11.97 TILT-20.0
SREA7 \$

GSLAB UNDERGROUND-FLOOR \$ GATAgE FlOOK HEIGHT=10 HIDTH-GARAREA TIHES TILT-180 CONSTRUCTION-GSLABCON U-EFFECTIVE= .143 .. S Ref j.huang - ashrae paper

SHrRpt--

SHrRptLoads Reports

SHrRpt-
SHIRPtS RBI

SHrRptS RBI

SHRRPS VARTABLE

SHrRptS VARIABLE-LIST=(6) ..

SHrRPt6-8urface T
SHrRptS RB2 REPORT-BLOCK

SHRRPT\$ VARIABLE-TYPE-SROOF1

SHTRPES VARIABLE-LIST=(6).

SHrRpt6-eurface I

SHrRptS HRSCH SCHEDULE \$ Hourly report schedule 


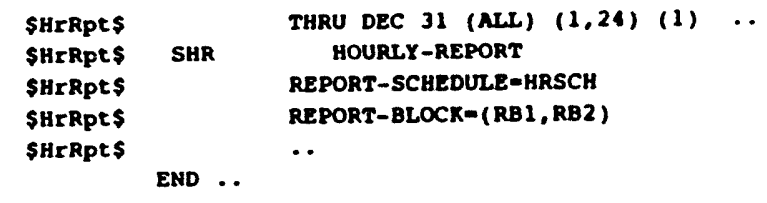

FUNCTION NAME - FNDQ

LEVEL - UNDERGROUND-HALL ...

ASSIGN DOY-IDOY UGFQ-QUGF UGWQ-QUGW .

ASSIGN OTABL - TABLE

$(0,-3336.3)(1,-3389.2)(2,-3462.1)(3,-3450.6)(4,-3494.9)$ $(5,-3548.8)(6,-3512.7)(7,-3387.8)(8,-3400.9)(9,-3432.8)$

$(10,-3467.4)(11,-3408.3)(12,-3335.8)(13,-3164.1)(14,-3056.2)$

$(15,-3061.6)(16,-3176.4)(17,-3309.6)(18,-3360.7)(19,-3255.2)$

$(20,-3035.1)(21,-2849.8)(22,-2809.7)(23,-2858.6)(24,-2872.7)$

$(25,-2901.3)(26,-2954.2)(27,-2910.6)(28,-2832.9)(29,-2737.7)$

$(30,-2508.2)(31,-2379.1)(32,-2303.7)(33,-2479.3)(34,-2686.4)$

$(35,-2608.0)(36,-2500.5)(37,-2413.6)(38,-2188.9)(39,-2045.6)$

$(40,-2134.6)(41,-2002.3)(12,-1946.5)(13,-1931.6)(44,-1942.3)$

$(45,-2040.4)(46,-1852.8)(47,-1659.4)(48,-1673.6)(49,-1538.1)$

$(50,-1285.3)(51,-1176.9)(52,-1189.2)(53,-1122.8)(54,-1020.4)$

$(55,-1070.9)(56,-1147.7)(57,-839.9)(58,-621.7)(59,-592.9)$

$(55,-1070.9)(56,-1167.7)(57,-539.9)(60,-621.7)(59,-493.0)(64,-494.7)$

$(60,-577.7)(61,-569.9)(62,-507.0)(63,-493.0)(64,-494.7)$

$\left(\begin{array}{rrrrrr}65, & -338.1)(66, & -236.5)(67, & -199.1)(68, & -206.2)(69, & -148.7) \\ (70,-30.5)(71, & 25.0)(72, & 81.5)(73, & 68.1)(74, & -28.9)\end{array}\right.$

$\begin{array}{llllll}(70, & -30.5)(71, & 25.0)(72, & 81.5)(73, & 68.1)(74, & -28.9) \\ (75, & -49.4)(76, & 50.9)(77, & 73.1)(78, & 34.9)(79, & -123.6)\end{array}$

$\begin{array}{lrrrrrr}(75,-49.4)(76, & 50.9)(77, & 73.1)(78, & 34.9)(79, & -123.6) \\ (80,-331.5)(81, & -320.9)(82, & -271.8)(83, & -264.4)(84, & -250.2)\end{array}$

$\begin{array}{lllllll}(80,-331.5)(81, & -320.9)(82, & -271.8)(83, & -264.4)(84, & -250.2) \\ (85,-281.9)(86, & -345.3)(87, & -377.1)(88, & -471.5)(89, & -680.4)\end{array}$

$(85,-281.9)(86,-665.3)(92,-717.0)(93,-771.9)(94,-825.7)$

$(95,-845.2)(96,-1001.8)(97,-1214.9)(98,-1290.1)(99,-1357.0)$

$(100,-1332.1)(101,-1377.6)(102,-1458.1)(103,-1635.8)(104,-1807.5)$

$(105,-1935.5)(106,-1957.5)(107,-2015.7)(108,-2097.4)(109,-2161.6)$

(110, -2276,3)(111, 2428.2$)(112,-2591.7)(113,-281448)(114,-2984.9)$

$(115,-2965.2)(116,-2985.4)(117,-2984.5)(118,-3194.8)(119,-3339.1)$

$(120,-3281.2)(121,-3316.4)(122,-3332.9) \ldots$

CALCULATE

WEEK $=$ DOY $/ 3.0$

UGWQ $=0.0$

UGFQ - PWL (QTABL, WEEK)

C PRINT 10, DOY, WEER, UGWQ, UGFO

10 FORMAT ('FNDQ', 4P10.2)

END-FUNCTION

COMPUTE LOADS.

DOST-PROCESSOR PARTIAT.

\$

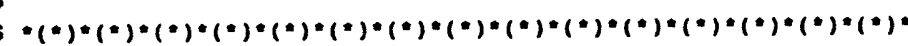
$s \cdot(*) *(*) *(*) *(*) *(*)$ $(\cdot) \cdot(\cdot) \cdot(\cdot) \cdot(\cdot) \cdot(\cdot) \cdot$

$2 \cdot(\cdot) \cdot(\cdot) \cdot(\cdot) \cdot(\cdot) \cdot(*)$ file namer SMUDSYS $(*) \cdot(\cdot) \cdot(\cdot) *(*) *(*) *$ $s \cdot(*) \cdot(\cdot) \cdot(\cdot) *(*) \cdot(*)$ Datez Oct $181991(*) *(*) *(*) \cdot(*) *(*) *$ $\{\cdot(\cdot) \cdot(\cdot) \cdot(\cdot) *(\cdot) *(*) \quad(*) \cdot(\cdot) *(\cdot) *(\cdot) \cdot(\cdot))$

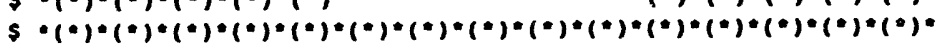

INPUT SYSTEMS ..

diagnostic " Cautions echo ..

SDuCE $\$$ SUBR-PUNCTIONS
RESYS-0--DUCT*

$\begin{array}{ll}\text { SDuct } \$ & \text { RESYS-0-・DUCT* } \\ \text { SDuct } \$ & \text { RESYS-32-OSAVETEMP* }\end{array}$

SDuct \$ DAYCLS-1-•DUCT2*.

SYSTEMS-REPORT

SHRRES HOURLY-DATA-SAVE - YES

SUMMARY $=($ SS-A, SS-B, SS-C, SS-F, SS-H, SS-I)

PARAMETER

5 CSCAP is 808 of CTCAP where no literature available

\$ CSCAP is 801 of CTCAP where no literature available
$\$$ Assume heat pump backup of 15000 Btu/hr is valid for all HP

\$ Default DOE2 curve for cooling equipment used.

\$ Cooling COPs from product literature

S All other data from product literature.

s cooling thermostat setpoints from investigating measured dato

SRES7 \$ HEATSET=68 SETBACK=68 COOLSET=78 SETUP-78

SRES7 S HCAPF $=-47000$ CTCAP $=36000 \quad$ CSCAP $=28800$

SRes7 \$ ACCFM-1200

$S$

\$Res7 S VTYPE= 0 S no venting

$\$$

SFurn $\$$ FHIR-1.4286 \$ $\$ 77$ efficiency + 108 duct losses

SFurn $\$$ MAXTEMP=120

\$Res7 \$ CBF=.098 CEIR=.3610 \$2.7 COP air conditioner

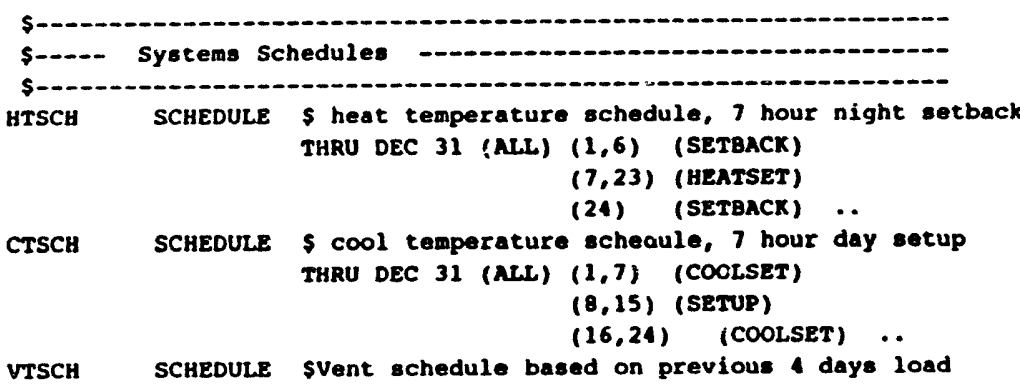


THRU MAY 14 (ALL) $(1,24)(-4)$

THRU SEP 30 (ALL) $(1,24)(-4)$

THRU DEC 31 (ALL) $(1,24)(-1) \ldots$
SVESTE Operation achedule
THRU DEC 31 (ALL) $(1,24)$ (VTYPE) ..

WINDOPER SCHEDULE SNO WINdON OPERaCIOS betUOCH

THRU DEC 31 (ALL) $(1,6)(0.0)$

$(7.23)(1.0)$

(24) $(0.0) \quad \ldots$

\$-1 5 sones

zONE-CONTROL

DESIGN-HEAT-T $=70$

DESIGN-COOL-T $=78$

COOL-TEHP-SCH-CTSC

HEAT-TEMP-SCH-HTSCH

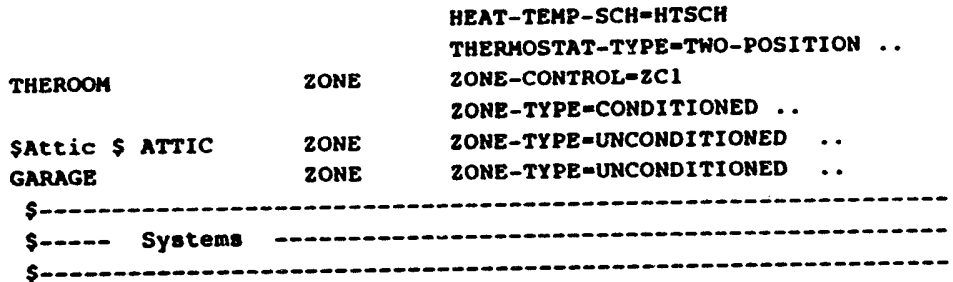

SYSCONTRL SYSTEM-CONTROL

MAX-SUPPL $Y-T=M A X T E M P$

MIN-SUPPLY -T $=50$

SYSAIR SYSTEH-AIR

SUPPLY-CEH=ACCFH

NATURAL-VENT-SCH-VOPSCH

VENT-TEMP-SCH=VTSCH

OPEN-VENT-SCH=HINDOPER

HOR-VENT-FRAC $=0.0$

S assume $1 / 4$ of total window area opened for venting,

$\$$ and discharge coefficient of 0.6

FRAC-VENT-AREA $=0.01$

VENT-METHOD $=S-G$

MAX-VENT-RATE-20

SYSEAN SYSTEM-EANS Sadded by jim $11 / 25 / 92$ SUPPLY-KW=0.000333 Saverage of $100 \mathrm{~W}$ for $1200 \mathrm{CFM}$

SYSEOP SYSTEH-EQUIPMENT COOLING-CAPACITY-CTCAP COOLING-EIR-CEIR Sadded by jim 1/13/92
COIL-BF-CBE

CRANKCASE-BEAT=0.0 \$added by jim 3/5/92 COMPRESSOR-TYPE-SINGLE-SPEED

SFurn Furnace opecifications \$

SFurn \$ HEATING-CAPACITY
SPurn $\$$ PURNACE-AUX=0.

SFurn \$ FURACE-HIR-PHIR \$ duct losses in FHIR already

STUT $s$..

RESIDEN SYSTEM SYSTEM-TYPE-RESYS
SSIAb S ZONE-NAMES-( THEROOH, GARAGE

$\begin{array}{lr}\text { SSlab } \$ & \text { ZONE-HAMES-( THEROOM, } \\ \text { SAttic } \$ & \text {,ATTIC }\end{array}$

ssiab $\$$

SYSTEM-CONTROL-SYSCONTRL

SYSTEM-AIR-SYSAIR

SYSTEM-FANS-SYSFAN

SYSTEH-EQUTPHENT-SYSEQP

SPUTn \$ HEAT-SOURCE-GAS-FURNACE

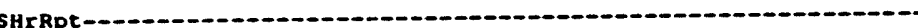

SHrRptSystem Reports - -

SHrRptS RBI REPORT-BLOCK \$ Reports for temp and humidity

SHIRPTS VARIABLE-TYPE-GLOBAL

SHIRPTS VARTABLE-LIST= $(7,8,10) \ldots$

SHrRPt7-HBT 8-DBT 10-HUMRAT

SHrRPS RB2 REPORT-BLOCK S Reports for zOne

SHIRPTS VARIABLE-TYPE-THEROOH

SHrRptS VARIABLE-LIST=(6) .

SHrRpt\$

SHrRptS RB3 REPORT-BLOCK S Reports for system

\section{SHIRPTS VARIABLE-TYPE-RESIDEM}

SHIRPtS VARIABLE-LIST= $(5,6,33,47,61)$.

SHRRPt5-OH 6-OC 33-FANKW 17-SKMQC 61-PLRC

SHrRptS HRSCH SCHEDULE S Hourly report schedula

SHIRPES THRU DEC 31 (ALL) $(1,24)$ (1)

SHrRPtS SHR HOURLY-REPORT
SHIRPES

SHrRptS REPORT-BLOCK= $(R B 1, R B 2, R B 3)$

Surgets ..

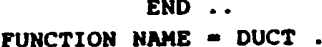

$s$

S This function multiplies the AC EIR

$S$ by the duct efficiency which varies

$\$$ with attic temperature

$\$$ old ducts in attic

ASSIGN MON=IMO DAY=IDAY HR=IHR TOUT=DBY 
CCULEIR-COOLING-EIR COOLCAP-COOLING-CAPACITY COOLSEN-COOL-SH-CAP

DEFFC-XXX22 TATT $=X \times \times 23 \ldots$

CALCULATE

DEFFC=-0.0077-TATT + 1.379

cortr = cooters

COOLETR - COOLEIR/DEFTC

COOLCAF - COOLCAP.DEFTC

PRINT 20, MON, DAY, HR, TATT, DEFTC, COOLEIR

C 20 PORMATI'DUCT $\cdot, 3$ F4.0, $\cdot$ TATT-O, F4.0, DEFFC='

$C+$ E5.3, EIR-, .75.3)

END-PUNCTION .

FUNCTIOH MAME - DUCT2

$\$$

\$ This function resets AC EIR to the input value

$s$ old ducts in attie

s

ASSIGN MON-IMO DAY=IDAY HR=IHR TOUT=DBT

COOLEIR-COOLING-EIR COOLCAP-COOLING-CAPACITY

COOLSEN-COOL-SH-CAP

DEFFC=XXX22 TATT-XXX23 -

CALCULATE ..

COOLEIR - COOLEIR.DEFFC

COOLCAP = COOLCAP/DETTC

COOLSEM - COOLSEM/DEFFC

PRINT 20, MON, DAY, HR, TATT, DEFFC, COOLEIR

C 20 PRINT 20, MON, DAY, HR, TATT, DEFFC, DUCT $\cdot, 3 F 4.00^{\circ}$ TATT=', F4.0, DEFFC-'

C 20 FORMAT('DUCT, BFA.0,

END-FUNCTION .

FUNCTION NAME-SAVETEMP ..

saves last hours zone temps for next hour's heat load

\$ calculations

ASSIGN TATT-XXX23

- ZONE-NAME DBT-DBT NZ-N2 .

ASSIGN HUMRAT=HUMRAT ..

CALCULATE ..

IF (ZNAME.EQ. "THER") , CO TO 100

IF (ZNAME.EQ. "GARA") GO TO 100

IF (2NAME.EQ. -ATTI") GO TO 70

IF (NZ.EQ.1) GO TO 100

IF (NZ.EQ.2) GO TO 100

IF (N2.EQ.3) 60 TO 70

IF (N2.EQ.3)

c attic
10 TATT-THOH

co 20100

100 CONTINUO

END

END-PUNCTION ..

COMPUTE SYSTEHS ..

STOP 


\section{DOE-2 INPUT FILE FOR SITE 8 BASE CASE}

s

POST-PROCESSOR PARTIAL

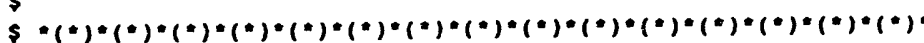
s $\quad(*) *(*) *(*) *(*) *(*) \quad(*) *(*) *(*) *(*) *(*)$ $\$ \cdot(*) *(*) *(*) *(*) *(*)$ pile names smudLd $(*) *(*) *(*) *(*) *(*)$ $s *(*) *(*) \cdot(*) *(*) *(*)$ Dates Oct $181991(*) *(*) *(*) *(*) *(*)$ $(* 1 *) *(\cdot) \cdot(\cdot) \cdot(\cdot) \cdot(\cdot)$ $(\cdot) \cdot(\cdot) \cdot(\cdot) \cdot(\cdot) \cdot(\cdot)$ 2
$2 *(*) *(\cdot) *(\cdot) \cdot(\cdot) \cdot(\cdot)$ $s$

INPUT LOADS ..

SReB8 \$ TITLE

\$BAseC \$ LINE-2 PBase Case *

LINE-3 -

LINE-4:

LINE-5

S-1-0-10-0

IWALLAREA - aroe of interior walle

$\$$ IWALLAREA is estimated from Haider's drawings (see notes)

$\$$ For HOUSVOL, assume average coiling Ht of $9 \mathrm{ft}$.

INTLOAD - .75 $\times$ minimum month daily electric usage SENS

$+.10 \times$ minimuw month daily electric usage LATN,

$+(290$ Btu/day SENS + 580 Btu/day LATN)/person for DHW use

$+(2770$ Btu/day SENS + 2290 Btu/day LATN $) / p e r s o n$ for occupancy

(children counted as $.75 \times$ Adults)

$10 / 5$ internal loads changed to include only appliances and dhw soccupants calculated differently

S PLRAREA-1122 HOUSVOL-10098 PERIH=143 IWALLLREA-799.99

SRESB S GARAREA 468 NEX-40.5 NEY $=25.5$

SRes8 \$ ROOPZ $=7.999$ ROORHT $=16.15$ ROOFWD $=40.5$

SRes 8 S NWALLWD-19.5 SWALLAD=40.5 EWALLWD=25.5 WWALLWD=30.0

SRes 0

$\$$ WALLAT $=7.999$ SHADEHT $=7.07$

INTLOAD -46888 LATLOAD-.185

INTOAD-46114 LATLOAD=.145 NUMOCC-1

SSecramento CS FSLABL-PSLABLDP BSLABL-BSLABLDP CGNDL-CGNDLDP

\author{
SSaCramento CS RSBWALL-RSBHLLDP RL OBWALL-R10BWLDP ROBWALL-ROBWLLDP \\ SR19 Colling S VAULL - rl9vaul CEILL - r19Ceil \\ SR11 Stucco wall S WhLLL - rl1swall \\ SBases S WhLABS- 0.70 s tan stucco \\ ROOFABS= $0.84 \$$ med brown shingle

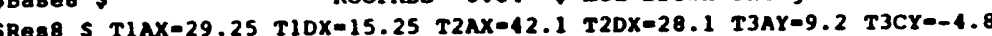 \\ SRes \\ SRes8 S T4AX-57.5 TAAY-28.75 TACY=14.75 T4DX-43.S \\ SRes8 \$ FSW1-40.5 FSW2=30.0 FSW3=45.0 RSWA-5S.S FSWS=70.5 \\ S -.- end of parameters
JAN 11991 THRU DEC 311991 .
BUILDING-LOCATION LAT=38.52 LON-121.50 T-2=8 ALT=17
WS-HEIGHT-LIST-
$(50,50,50,50,50,50,50,50,50,50,50,50)$
\$ReB8 \$
SEIELDING-COEP-0.19
THELOTNG-COER 0.19 TERRAIN-PAR2-. 20
SNownd\$ WS-TERRAIN-PAR1=.85 WS-TERRAIN-PAR2=.20 $\cdot$

\section{ABORT ERRORS ..}
LOADS-REPORT
SHERPTS HOURLY-DATA-SAVE - YES

S--- Loads Schedules

s-cot

DAYINTSCH DAY SCHEC

(1) $(.024)$ (2) $(.022)(3,5)(.021)$

(6) 1.026$)$ (7) $(.038)$ (8) $(.059)$

(9) 1.056$)(10)(.060)$ (11) $(.059)$

(12) $(.046)(13)(.045)(14)(.030)$

(15) $(.028)(16)(.031)(17)(.057)$

$(18,19)(.064)(20)(.052)(21)(.050)$

(22) $(.055)(23)(.044)(24)(.027) \ldots$

UOCCAPPS DAY-SCHEDULE SCEC modified, appl on unoccupled day

(1) $(.024)$ (2) $(.022) \quad(3.5)(.021)$

(6) $(.026)(7.8)(.075)(9.17)(.059)$

(18) $(.072)(19,22)(.080)$

(23) $(.072)(24)(.027)$.

OCCYES DAY-SCHEDULE Sold CEC/GRI oce schedule - fraction of peak

$\begin{array}{llll}(1.6)(0.44) & (7)(0.53) & (8)(0.87) & (9)(0.43)\end{array}$ 


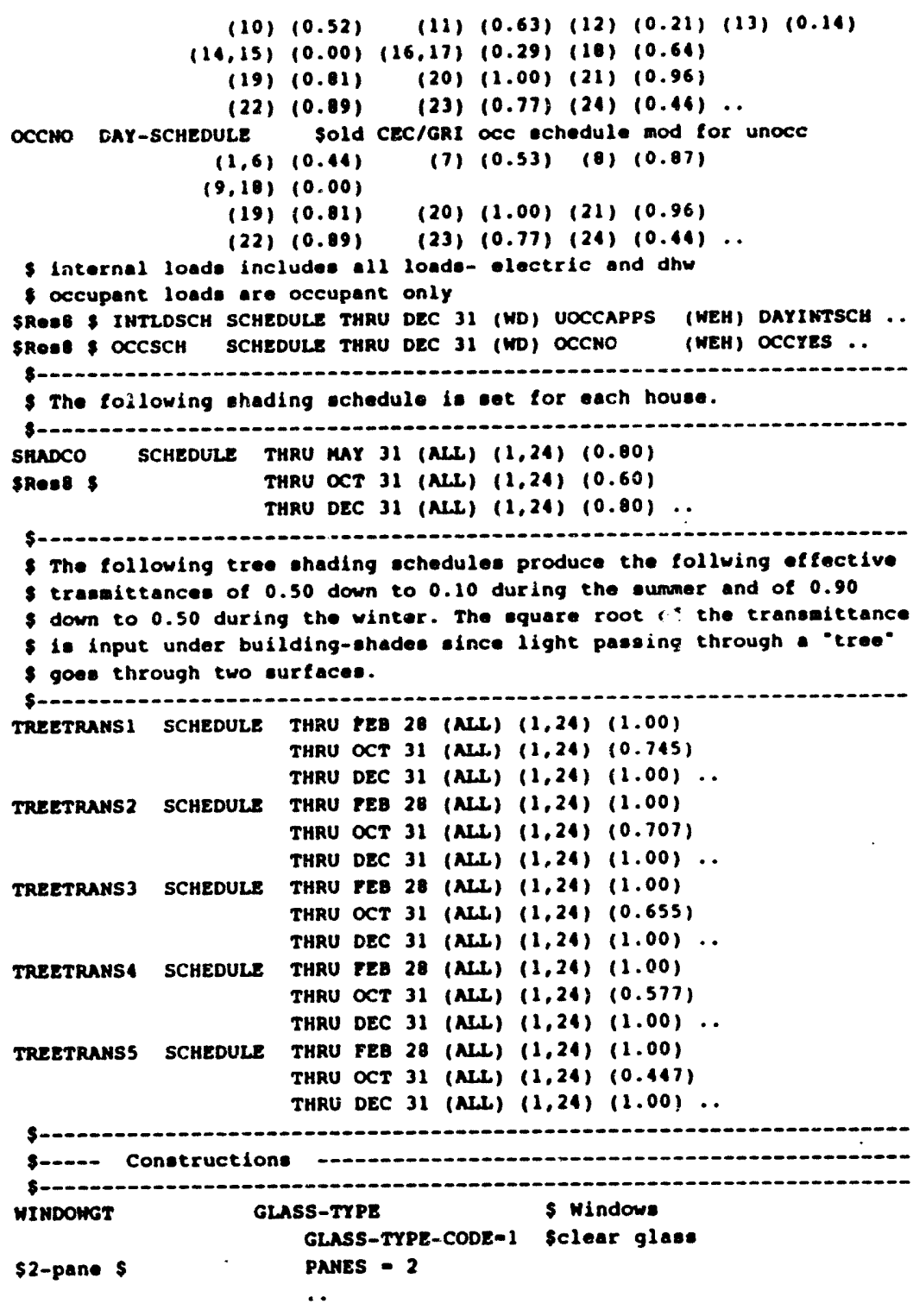


EAVEN BUILDING-SHADE $\$$ north Gave

SRest S

HEIGHT-2.69 WIDTH=21 $\quad X=21 \quad Y=32.5$ TILT-21.8

Z-SHADEHT ..

EAVES BUILDING-SHADE LIKE EAVEN \$ wouth Eave

SRese \$ (1) $\cdots$

RAVEE BUILDING-SHADE LIKE EAVEN \$ east eave RRes 8 HEIGHT-18.8 WIDTH-1 $x-41.5$ Y-32.5 2-SHADEHT

SRESB \$ EAVEE2 BUILDING-SHADE LIKE EAVEE HEIGHT-17.2

\$Reses $\$$

$x=40.5 \quad x=-1 \quad 2-7.62 \quad A 2-180 \ldots$

EAVEH BUILDING-SHADE LIKE EAVEE \$ wast eave

SRese $\$$ $x=0$

SREB8 \$ EAVEH2 BUILDING-SHADE LIKE EAVEE2 $X=-1 \ldots$

SREsB \$ DECKOH BUILDING-SHADE \$ backyard deck overhang

SRES $\$$ HEIGHT-11 WIDTH=16 TRANSHITTANCE=0.70

SRes8 S $X-16 . \quad Y=0$ Z-WALLHT ..

S- Trees, Pirst exieting, then test trees

S-c- Treesi Pirst exinting, then tast crees

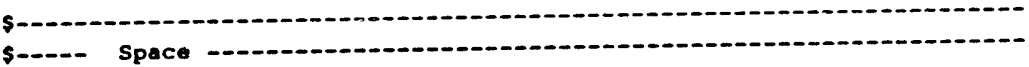

ROOMCOND SPACE-CONDITIONS

TEMPERATURE - (74)

SOURCE-TYPE-PROCES

SOURCE-SCHEDULE=INTLDSCH

SOURCE-BTU/HR-INTLOAD

SOURCE-LATENT-LATLOAD

PEOPLE-SCHEDULE-OCCSCH

NUMBER-OF-PEOPLE-NUMOCC

PEOPLE-HG-LAT- 190

PEOPLE-HG-SENS -230

INF-METHOD-S-G

SHedium Infiltration

$$
\$ \text { PRAC-LEAK-AREA - .0005 }
$$

FLOOR-WEIGHT 0

FURNI TURE-TYPE-LIGHT

FURN-WE ICHT $=3.30$

SET-DEFAULT FOR DOOR HEIGHT-6.5 WIDTH-3.0 CONSTRUCTION-DOORCON ..
SET-DEFAULT EOR EXTERIOR-HALL SHADING-SURYACE-YES.

SET-DEFAULT FOR HINDOW

GLASS-TYPE-WINDOWGT SHADING-SCHEDULE-SHADCO ..

THEROOM SPACE

SPACE-CONDITIONS=ROOHCOND AREA-PLRAREA VOLURE-HOUSUOL ..

INTWALL INTERIOR-WALL

INT-WALLLTYPE-INTERNAL

AREA-IWALLAREA COHSTRUCTION-IWALLCON ..

SREOS S NWALI INTERIOR-HALL CONSTRUCTION-IGWALLCON NEXT-TO-GARAGE HEICHT-WALLHT HIDTH-NWALLWD

SREBQ \$ WWALL2 INTERIOR-WALL LIKE NWALLL WIDTH=3 ..

SRESB S MHALL3 EXTERIOR-WALL CONSTRUCTION-WALLCON

SRes8 \$ $X=21 \quad Y=28.5$ HEIGHT-WALLHT WIDTH=7.0 $A Z=0 \quad$.

SRESB \$ NDOOR4A DOOR $X=4 \ldots$

SRES S MWALA EXTERIOR-WALL LIKE NWALL3 X-14 WIDTH=1.5 A2-90 .

RRES $\$$ MWALLS EXTERTOR-HALL LIRE NHALL 3 X-14 $Y=30$ WIDTH=2 .

SREO

WRE

SRESB S NWALL7 EXTERIOR-WALL LIKE MHALL3 X=10 Y=32

SRESB S NWIND7A WINDOW LIKE NWIND6A WIDTH-4.5 0 .

\$Res8 S NWALL8 EXTERIOR-WALL LIKE MWALT

SRESB S NWINDBA WINDOW LIKE NWIND6A ..

SHALL1 EXTERIOR-WALI

SRes8 \$ LIKE NWALL3 $X=0.0$

HEIGHT-HALLHT WIDTH-SWNLLWD $Y=0.0 \quad$ AZ=180

SRESB S SWINDIA WINDOW $X=2.1 \quad Y=0.0$ HEIGHT=6.0 WIDTH=S.4

SRess S SHIND1B HINDOH $X=11.2$ Y-2.7 HEIGHT=3.0 WIDTH=3.3.

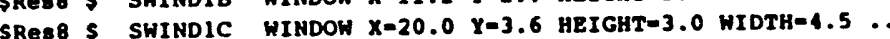

SRes8 $\$$ SWINDID WINDOW $x-32.7$ y-3.6 HEIGHT-2.7 WIDTH-1.8

SRESB \$ EWALL1 EXTERIOR-WALL LIXB NWALL3 $x=40.5 \quad y=0$ AZ=90

WIDTH-EWALLWD ...

SREB $\$$ EWINDIA WINDOW $x=21 \quad y-4.20$ HEIGHT-2.40 WIDTH-1.50 $\ldots$

WHALLI EXTERIOR-WAL

SReso S LIKE NHALL3 $X=30.0$

$X=0$ WIDTH-WWALLMD A2IRUTH $=270$

SReE 5 WWIND1A HINDOW $x=26.6 \quad x=0.6$ HEIGHT=5.7 WIDTH-2.4 $\ldots$

SSIab S FOUNDATION UNDERGROUND-FLOOR \$ Slab tloor

SSIAb S POUNDATION UNDERGROUND-PLOOR S SIAB TIMES

\$Slab \$ TIT

$\begin{array}{ll}\text { SSIAb } \$ & \text { TILT=180 CONSTRUCTI } \\ \text { SSIAb } \$ & \text { U-EFPECTIVE-FDNUEFP }\end{array}$

\$Slab \$ PUNCTION - (*NONE*, "FNDQ*) .

SAttics CEILING INTERIOR-WALL \$ Ceiling between House and attic 
SAttic\$

SAttic\$ NROOF

SAttics

SRES S

SAttics

SAttic\$ SROOF

SRes8 $\$$

SAttics

GARAGE

\section{SPACE}

AREA-PLRAREA VOLUME-PLRAREA TIMES 2.90 S Avg height INF-METHOD-S-G

assume 1 ft2 of vents per 450 ft2 of attic space area,

ELF - 751 of vent area

FRAC-LEAK-AREA- .00167

FLOOR-WEIGHT-O

ZONE-TYPE-UNCONDITIONED $T=(80)$

ROOF 2-ROOPZ HEIGHT-ROOFHT WIDTH-ROOFWD

CONSTRUCTION-ROORCON

$X=N E X \quad Y=30$ TILT=21.8 ROOF

$x=\frac{1}{x=0}$ LIKE NROOF 1

$X=0 \quad Y=0$ A2IMUTH=180

SPACE

AREA-GARAREA VOLUME-GARAREA TIMES $9.80 \$$ avg hoight

INF-METHOD=S-G

FRAC-LEAR-AREA- .0015 $\$$ assume 3 times normal infilt

FLOOR-HEIGHT-O

ZONE-TYPE=UNCONDITIONED $T=(60)$

GARI EXTERIOR-HALL

HEIGHT-WALLHT TILT-90 \$ResB \$ $\quad$ WIDTH-21 X-21 Y=49.5 A2IMUTH=-90 $\$$ garage WWall
CONSTRUCTION=GWALLCON

GAR2 EXTERIOR-WALL

LIKE GARI

SRes8 \$ WIDTH=24 $x=40.5$ Y-25.5 A2-90 \$ garage EWALll ..

GAR3 EXTERIOR-WALL

LIKE GAR1 \$ garage door wall

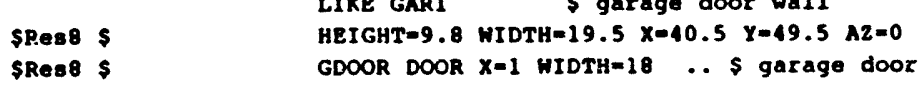

GARA INTERTOR-WALL S insulated wall against house AREA-180 CONSTRUCTION-IGWALLCON INT-WALL-TYPE-STANDARD NEXT-TO-THEROOM

‥

\$Reas \$
EXTERIOR-HALI

LIKE GARI HEIGHT=11.4 TILT-31.6

2-ROOR2 CONSTRUCTION-GROORCON
\$RESA \$ GROOR2 EXTERIOR-WALL

\$REA S LIKE GAR2 HEIGHT=11.4 HIDTH-21 TILT-31.6

\$REB S Y-28.5 Z-ROOZZ CONSTRUCTION-GROOFCOH ..

GSLAB UNDERGROUND-FLOOR \$ GaTage tloOT HEIGHT=10 WIDTH-GARAREA TIHES . TILT-180 CONSTRUCTION-GSLABCOH U-EFFECTIVE= - .143 ‥ \$ Ret j.huang - ashree paper

\$HrRpt (1)

SHrRpeloads Report.

SHrRPt-
SHERPES RBI
SEPORT-BLOCK

SHrRpt

SHrRptS VARIABLE-TYPE-SWALL VARIABLE-LIST= (6)

SHrRpt

SHIRPE6=-surf ACE T

RB2 REPORT-BLOCK S Reports for roof temp

SHIRPES VARIABLE-TYPE-SROOE

SHrRpt\$
SHrRpt6-surface T

SHrRptS HRSCH SCHEDULE \$ Hourly report schedule

SHrRPtS THRU DEC 31 (ALC) (1,24) (1) ..

SHTRPES SHR HOURLY-REPORT

SHrRPES REPORT-SCHEDULE-HRSCH

SHRRPTS REPORT-BLOCK-(RB1,RB2)

SHrRptS ..

PUNCTION NAME - FNDO

LEVEL - UNDERGROUND-WALL ..

ASSIGN DOY-IDOY UGFQ-QUGT UGWQ-QUGW ..

ASSIGN QTABL - TABLE

$(0,-3336.3)(1,-3389.2)(2,-3462.1)(3,-3450.6)(4,-3494.9)$

$(5,-3548.8)(6,-3512.7)(7,-3387.8)(8,-3400.9)(9,-3432.8)$

$(10,-3467.4)(11,-3408.3)(12,-3335.8)(13,-3164.1)(14,-3056.2)$

$(15,-3061.6)(16,-3176.4)(17,-3309.6)(18,-3360.7)(19,-3255.2)$

$(20,-3035,2)(21,-2849.8)(22,-2809.7)(23,-2858.6)(24,-2872.7)$

$(25,-2901.3)(26,-2954.2)(27,-2910.6)(28,-2832.9)(29,-2737.7)$

( $25,-2900.3)(26,-2954.2)(27,-2910.6)(28,-2832.9)(29,-2737.7)$

( $35,-2500.2)(31,-2379.1)(32,-2303.7)(33,-2479.3)(34,-2686.4)$

(35, -2608.0)( 36, -2500.5)( $31,-2013.6)(38,-2188.9)(39,-2045.6)$

$(40,-2134.6)(41,-2002.3)(42,-1946.5)(43,-1931.6)(44,-1942.3)$

$(45,-2040.4)(46,-1852.8)(47,-1659.4)(48,-1673.6)(49,-1538.1)$

$(50,-1285.3)(51,-1176.9)(52,-1189.2)(53,-1122.8)(54,-1020.4)$

$(55,-1070.9)(56,-1147.7)(57,-839.9)(58,-621.7)(59,-592.9)$

$(60,-577.7)(61,-569.9)(62,-507.0)(63,-493.0)(64,-494.7)$

$(65,-338.1)(66,-236.5)(67,-199.1)(68,-206.2)(69,-148.7)$

$(70,-30.5)(71,25.0)(72,01.5)(73,68.1)(74,-28.9)$

$(75,-49.4)(76,50.9)(77,73.1)(78, \quad 34.9)(79,-123.6)$

$(75,-19.4)(76,-50.9)(77,-73.1)(78,-34.9)(79,-123.6)$
$(80,-331.5)(81,-320.9)(82,-271.8)(83,-264.4)(84,-250.2)$ 
$(85,-281.9)(86,-345.3)(87,-377.1)(88,-471.5)(89,-680.4)$ $(90,-661.4)(91,-665.3)(92,-717.0)(93,-771.9)(94,-825.7)$ $(95,-845.2)(96,-1001.8)(97,-1214.9)(98,-1290.1)(99,-1357.0)$ $(100,-1332.1)(101,-1377.6)(102,-1450.1)(103,-1635.0)(109,-1007.5)$ $(105,-1935.5)(106,-1957.5)(107,-2015.7)(100,-2097.4)(109,-2161.6)$ $(110,-2276.3)(111,-2428.2)(112,-2591.7)(113,-2814.8)(114,-2984.9)$ $(115,-2965.2)(116,-2985.4)(117,-2984.5)(118$,

$(120,-3281.2)(121$

CALCULATE $\because 3$

WEER $=$ DOY

UGPO - PWL(OTABL, WEEK)

PRINT 10, DOY, HEEK, UGWQ, UGFO

10 PORMAT('FNDQ', 4F10.2)

END-FUNCTION ..

COMPUTE LOADS.

POST-PROCESSOR PARTIAL.

$\$$

$(\cdot *) *(*) *(*) *(*) *(*) \cdot(*) \cdot(\cdot) *(*) *(*) \cdot(*) *(*) *(*) *(*) *(*) *(*) *$ $s *(*) *(*) *(*) *(*) *(*) \quad(*) *(*) *(*) *(*) *(*)$ $\$(*) *(*) *(*) *(*) *(*)$ File namez SMUDSYS $(*) *(*) *(*) *(*) *(*) *$ $s^{2}(*) *(*) *(*) *(*) *(*)$ Dater Oct $181991(*) *(*) *(*) *(*) *(*)$

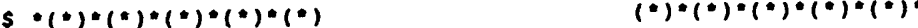

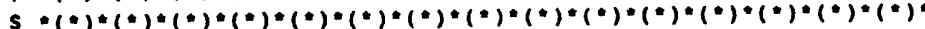
$\$$

INPUT SYSTEMS ..

diagnostic " Cautions echo ..

SDuct $S$ SUBR Tuncrions

SDUCE $\$$ SUBR-FUNCTIONS

$\begin{array}{ll}\text { SDuCt } \$ & \text { RESYS-0-*DUCT: } \\ \text { SDuCt } \$ & \text { RESYS-32--SAVETEMP* }\end{array}$

DAYCLS-4=-DUCT2* ..

SYSTEMS-REPORT

SHrRpt\$

HOURLY-DATA-SAVE = YES C, SS-P,SS-H,SS-I) ..

PARAMETER

$\$$ CSCAP is 808 of CTCAP where no literature available

\$ Assume heat pump backup of 15000 Btu/hr is val
5 Default DOE2 curve for cooling equipment used.

s Cooling COPs from product literature for Res2,5,6, ?

$\$$ Sitel and Siter assumed same as Ress

S All other data from product literature.

s cooling thermostat setpoints from inveotigating measured data

$\$$

SREB 5 HEATSET-70 SETBACK-70 COOLSET-76 SETUP-76

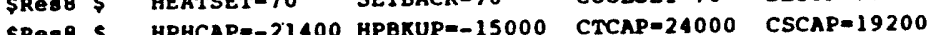

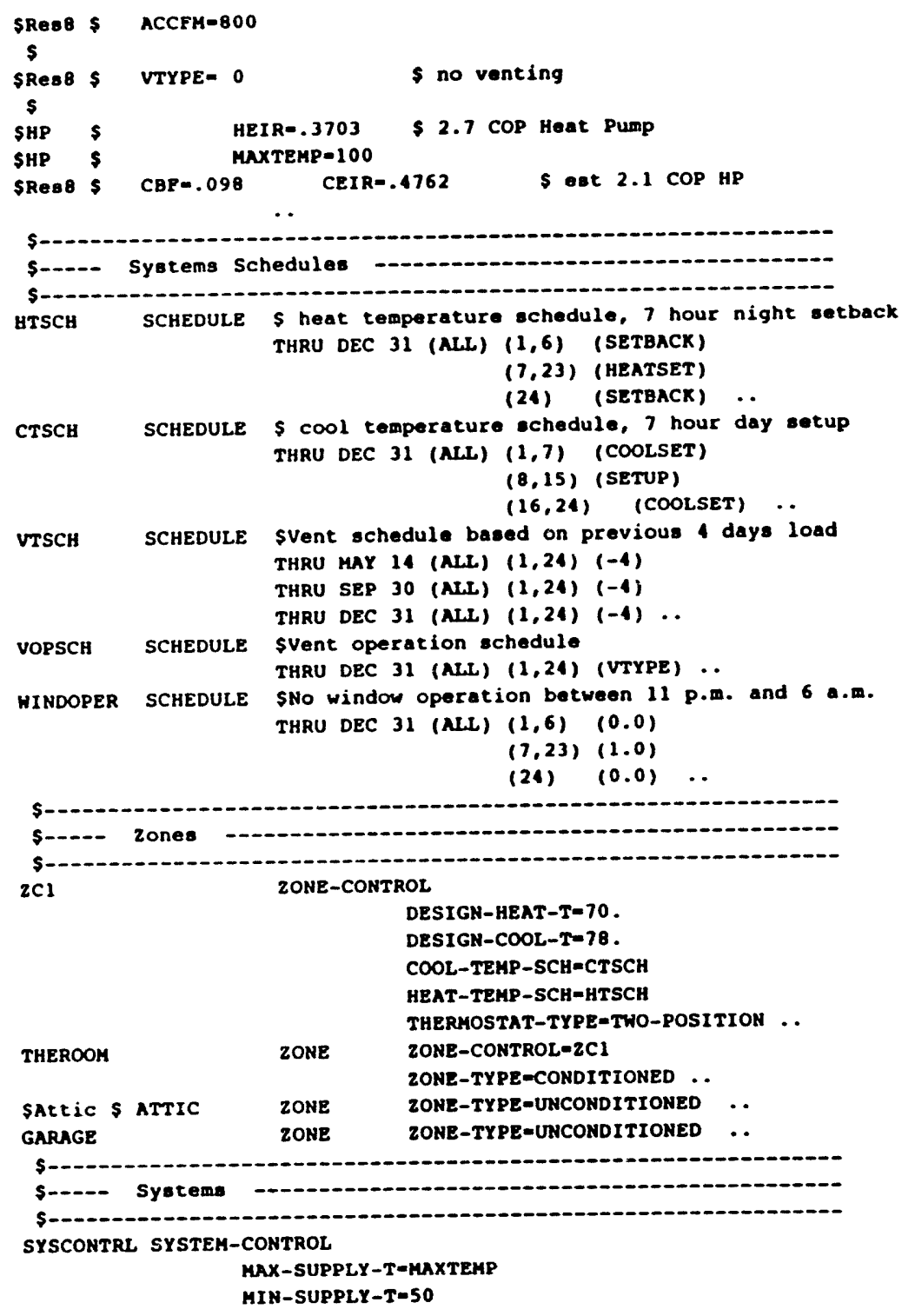


SYSAIR SYSTEM-AIR

SUPPLY-CFH-ACCPM

NATURAL-VENT-SCH-VOPSCB

VENT-TEMP-SCH-VTSCH

OPEN-VENT-SCH-HINDOPER

HOR-VENT-PRAC 0.0

$\$$ assume $1 / 4$ of total window arsa opened for venting,

$\$$ and discharge coef ficient of 0.6

PRAC-VENT-AREA-0.018

VENT-METHOD-S-G

MAX-VENT-RATE-20

SYSFAN SYSTEM-FAYS

Sadded by jim $11 / 25 / 92$

SUPPLY-KW=0.000333 Saverage of $400 \mathrm{~W}$ for $1200 \mathrm{CPM}$

SYSEQP SYSTEM-EQUIPMENT

COOLING-CAPACITY-CTCAP

COOLING-EIR-CEIR

COOL-SH-CAP-CSCA

COIL-BF-CBP

CRANKCASE-HEAT=0.0 Sadded by jim 3/5/92

COMPRESSOR-TYPE-SINGLE-SPEED

SHP Heatpump specifications \$
SHP $\$$ HEATING-CAPACITY-HPHCAP

SHP \$ HEATING-EIR-HEIR

SHP S HP-SUPP-HT-CAPAHPBXUP

SHP $\$$ MAX-HP-SUPP-T=40.

RESIDEN SYSTEH SYSTEH-TYPE-RESYS

SSIAb $\$$ ZONE-NAMES- (THEROOM, GARAGE

SAtic $\$$,ATTIC

\$slab $\$$

SYSTEH-CONTROL=SYSCONTRL

SYSTEH-AIR-SYSAIR

SYSTEH-FANS-SYSFAN

SYSTEM-EQUTPMENT-SYSEOP

GEAT-SOURCE=HEAT-PUMP

SHrRpt-$\cdots$

SHrRpt-- Reports - -

SHrRpt\$ RBI REPORT-BLOCR \$ Reports for temp and humidity SHIRPt\$ VARIABLE-TYPE-GLOBAL

SHrRpt\$ VARIABLE-LIST= $(7,8,10)$.

SHrRPt 7-WBT 8-DBT 10-HUMRAT

SHRRPS RB2 REPORT-BLOCR \$ Reports for zone

SHIRPES VARIABLE-TYPE-THEROOM

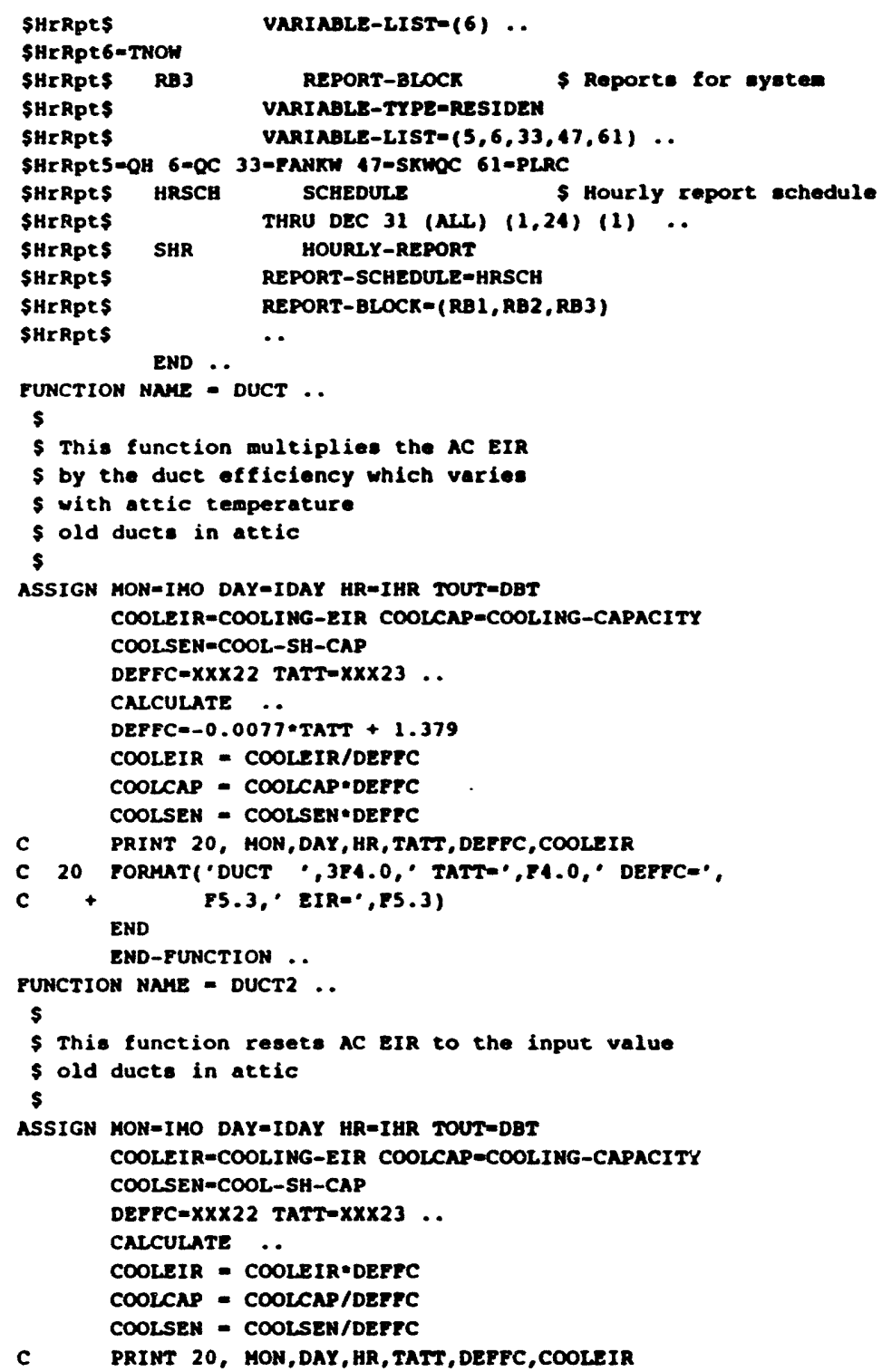

C PRINT 20, MON, DAY, HR, TATT, DEFFC, COOLEIR 
C 20 FoRmat('DUCT $\cdot, 374.0, \cdot$ tatT-', P4.0, DEFFC=',

C +

F5.3, EIR=-, (55.3)

END

END-PUNCTION .

FUNCTION NAME-SAVETEMP ..

$\$$

S saves last hours zone temps for next hour's heat load

S calculatione

s

ASSIGN TATT-XXX23 .

ASSIGN TNOW - THOW ZMNME = ZONE-NAME DBT-DBT NZ-NZ ..

ASSIGN HUMRAT-HUMRAT ..

Calculate ..

c IP (ZNMME.EQ. "THER") GO TO 100

IP (ZNAME.EQ. "GARA") GO TO 100

IF (ZNNME.EQ. ${ }^{-A T T I}{ }^{-}$) GO TO 70

IF (NZ.EQ.1) GO TO 100

IF (N2.EQ.2) GO TO 100

IF (N2.EQ.3) GO TO 70

GO TO 100

c attic

70 TATT-TNOW

100 CONTINUE

END

END
END-FUNCTION .

COMPUTE SYSTEMS ..

STOP .. 
DOE-2 INPUT FILE FOR SITE B BASE CASE

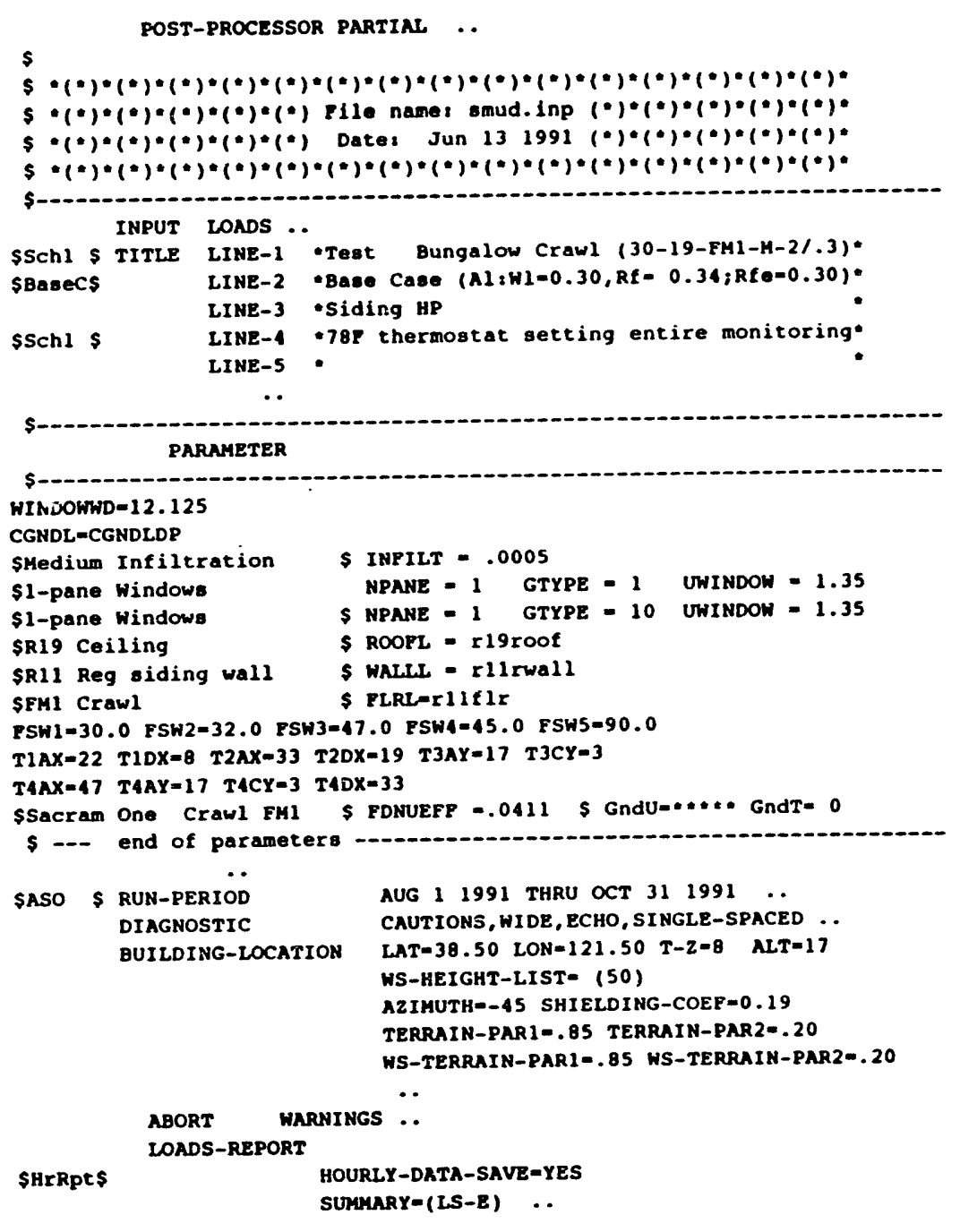

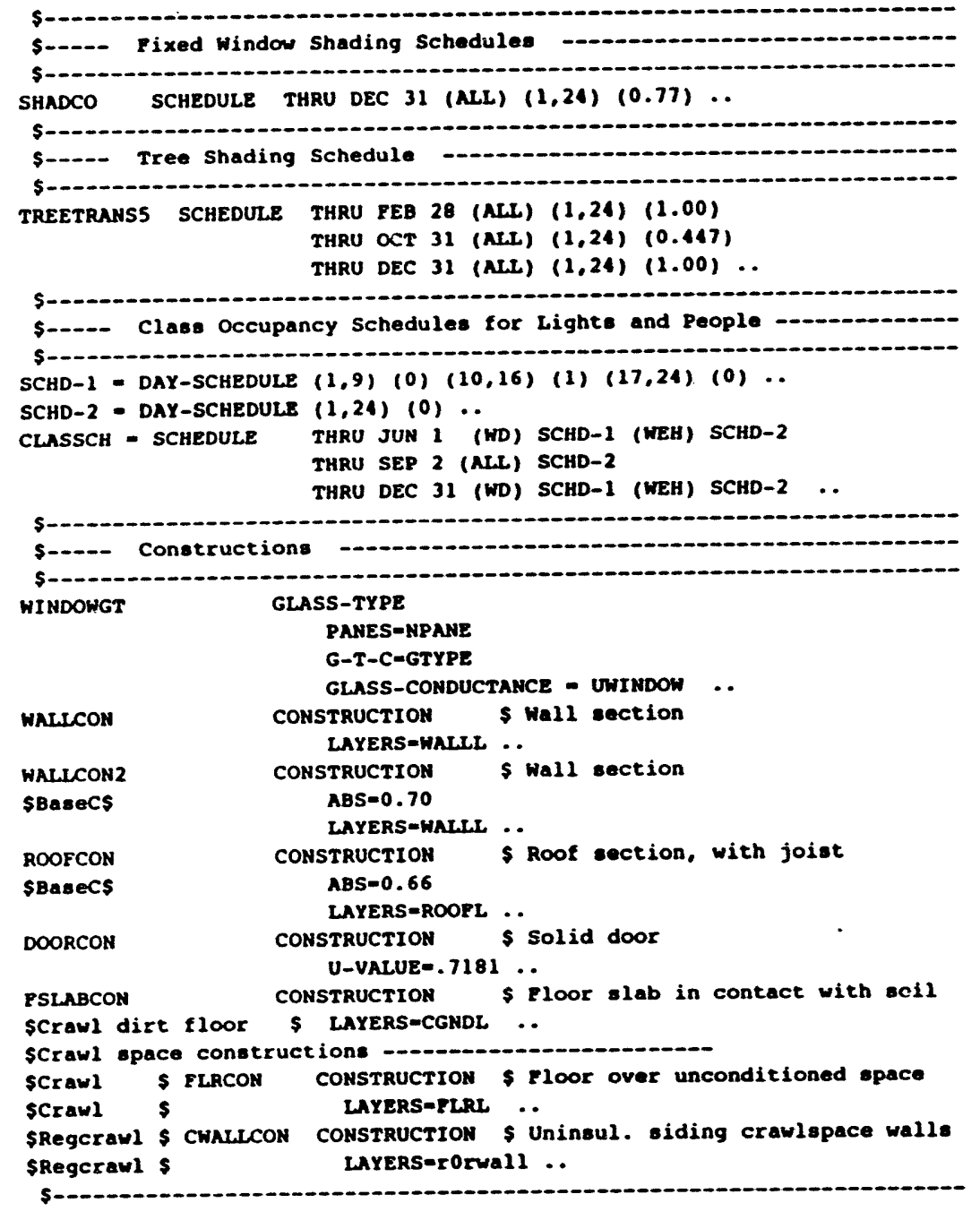




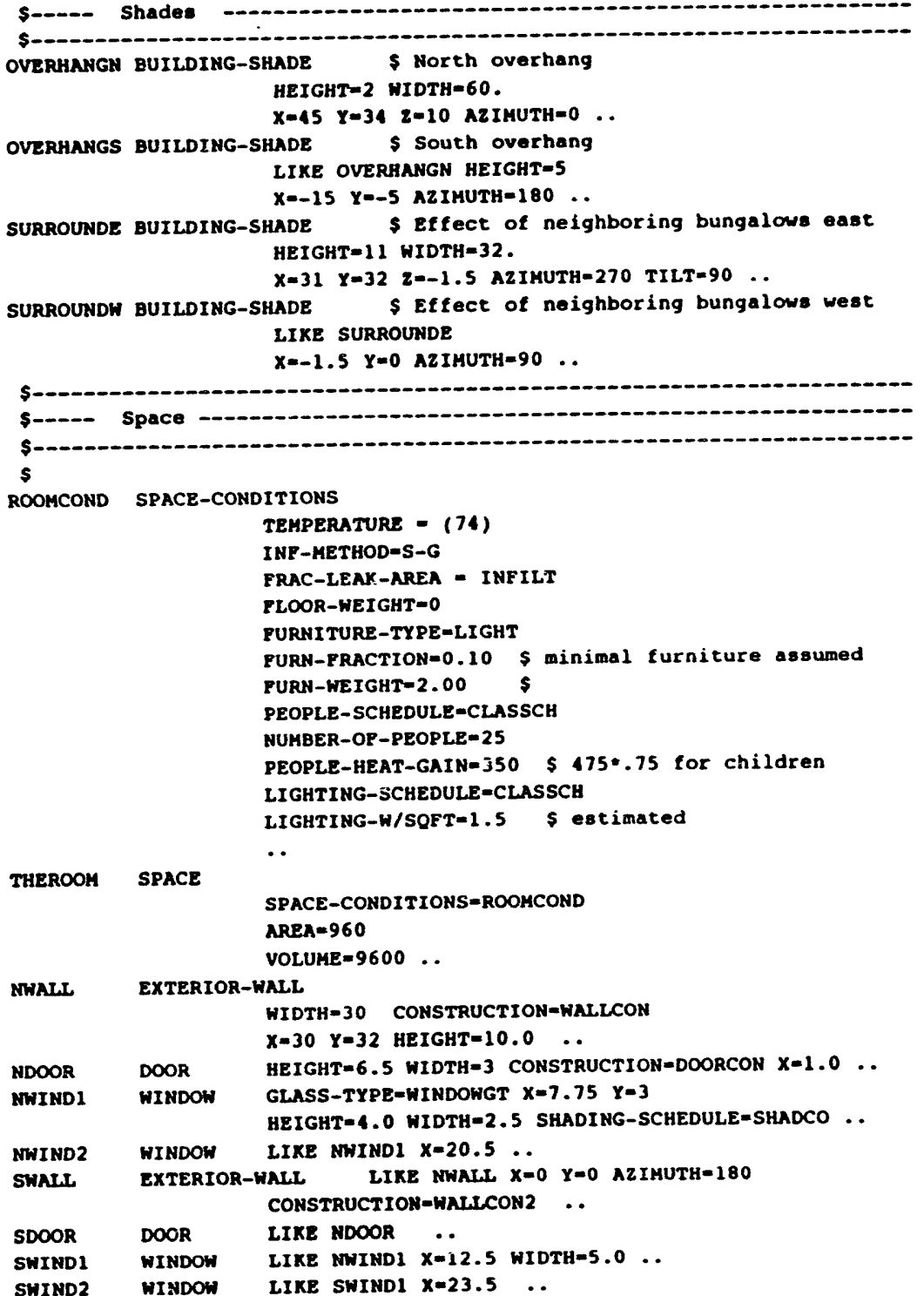

SWIND2 WINDON LIKE SWIND1 $x=23.5$.

EWALL EXTERIOR-WALL LIKE MMALL WIDTH-32 X-30 Y=0 AZIMUTH-90 ..

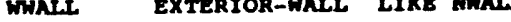

SCrawl \$ INTERPLR INTERIOR-WNLL \$ Floor bet Theroom and Crawlepace SCrawl s TILT=180 CONSTRUCTION=PLRCON

SCrawl S AREA-960. NEXT-TO-CRAMLSPACE .

TROOF ROOF $X-30 \quad x=32$ 2-10.0 HEIGHT-32 WIDTH-30 TILT=0

CONSTRUCTION-ROOFCON

SLOWE 5 PONCTION=(-EHISIO.

\$Crawl S CRAWLSPACE SPACE AREA-960 VOLUAR-1440

SCraul S INF-METHOD=S- $C$

scrawl assume 1 ft2 of vents per $150 \mathrm{ft} 2$ of crawl space area,

\$Crawl effective-leakage-area -758 of vent area

scrawl increase to a higher value - jh

FRAC-LEAK-AREA- .007

SCrawl \$ FLOOR-HEIGHT=0

SCrawl \$ 2ONE-TYPE-UNCONDITIONED T=(60)

SCrawl s

SCTAWI S NCHALL EXTERIOR-HALL LIKE NWALC.

SCrawl $\$$ CONSTRUCTION-CWALLCON HEIGHT-1.00 2=-1.00 ..

SCTAWI S SCWALL EXTERIOR-HALL LIKE SWNLI

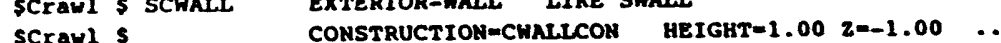

SCrawl \$ ECWALL EXTERIOR-WHLL LIKE EWALL

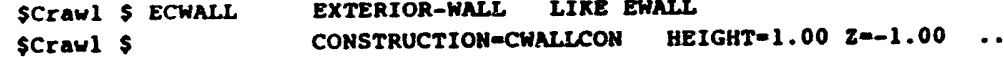

SCrawl \$ WCWALL EXTERIOR-WALL LIKE WWALI

CONSTRUCTION-CWALLCON HEIGHT-1.50 Z=-1.00 .

SCraWI FOUNDATION UNDERGROUND-FLOOR \$ CrawlspaCe dirt floOr

SCraul \$ TILT=180 CONSTRUCTION=PSLABCON

SCraul $\$$ U-EFFECTIVE-FDNUEFT

$\begin{array}{ll}\text { SCraul \$ } & \text { U-EFFECTIVE-FOHUEFT } \\ \text { SCrawl \$ } & \text { PUNCTION-("NONE*, * FNDQ*) .. }\end{array}$

SCrawl $\$$

SHrRptLoads Reports

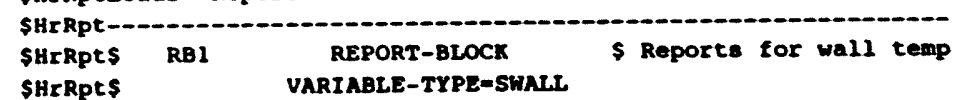

SHrRpt\$ VARTABLE-TYPE-SWALC

SHIRPES VARTABLE-LIST=(6) ..

SHrRpt 6-surface T

SHrRptS RB2 REPORT-BLOCK S Reports for roof temp

SHIRPT\$ VARIABLE-TYPE-TROOE

SHIRPtS VARIABLE-LIST $=(6) \ldots$

SHrRpt6-8urface

S Hourly report schedule

SHrRptS THRU DEC 31 (AIS) $(1,24)$ (1) ..

SArRPtS SHR HOURLY-REPORT

SHTRPS\$ REPORT-SCHEDULE-HRSCH

SHrRpt\$ REPORT-BLOCK $=($ RB1, RB2)

SHrRpt\$ 
END ..

PUNCTION NAME - PNDO

LEVEL - UNDERGROUND-WALL ..

ASSIGN DOY-IDOY UGFO-QUGF UGWO-OUGH ..

ASSIGN QTABL - TABLE

-

$(5,-1128.2)(6,-1121.9)(7,-10)$

$(10,-1073.1)(11,-1044.6)(22,-983.8)(13,-858.8)(14,-749.8)$

$\left(\begin{array}{lllllll}(15, & -730.2)(16, & -791.0)(17, & -905.5)(18, & -965.5)(19, & -915.7) \\ (20, & -754.4)(21, & -587.8)(22, & -520.4)(23, & -533.8)(24, & -547.7)\end{array}\right.$

$\begin{array}{lllllll}(20,-754.4)(21, & -587.8)(22, & -520.4)(23, & -533.8)(24, & -547.7) \\ (25, & -566.3)(26, & -604.3)(27, & -591.0)(28, & -532.2)(29, & -458.6)\end{array}$

$(30,-282.3)(31,-146.2)(32,-64.8)(33,-144.9)(34,-320.5)$

$(35,-307.0)(36,-229.1)(37,-157.9)(38,10.0)(39,154.5)$

(40, 132.1)( 41, 214.0)( 12, 278.9)( 13, 30).2)( 44, 307.5)

$(45,238.6)(46,347.9)(47,519.3)(48,543.7)(49,638.7)$

(50, 851.0$)(51,970.8)(52,995.7)(53,1045.6)(54,1136.0)$

$(55,1129.6)(56,1052.6)(5 \%, 1272.9)(58,1482.2)(59,1541.2)$

(55, 1129.6)( 56, 1062.6)( 5;, 1272.9)( 58, 1482.2)( 59, 1541.2)

$(60,1570.1)(61,1587.3)(62,1635.8)(63,1662.3)(64,1667.0)$

(65, 1778.5)( 66, 1874.8)( 67, 1926.5)( 68, 1936.4)( 69, 1981.3)

$(70,2075.1)(71,2137.9)(72,2194.4)(73,2204.5)(74,2145.8)$

(75, 2110.9)( 76, 2176.1)( 77, 2208.5)( 78, 2196.5)( 79, 2060.9)

(80, 1889.1)( 81, 1862.0)( 82, 1892.5)( 83, 1905.9)( 81, 1919.5)

( 85, 1898.0)( 86, 1854.9)( 87, 1818.2)(88, 1758.9)(89, 1582.3)

(90, 1558.8)( 91, 1553.4)( 92, 1515.6)(93, 1466.1)( 94, 1415.4)

(95, 1393.7)( 96, 1290.6)(97, 1105.7)( 98, 1014.4)( 99, 937.3)

(100, 934.5)(101,900.5)(102, 841.2)(103, 710.6)(104, 555.1)

(105, 427.5)(106, 371.6)(107, 320.3)(108, 245.0)(109, 183.5)

(110, 84.3)(111, -40.1$)(112,-181.7)(113,-357.3)(114,-536.0)$

(115, -566.9)(116, -601.4)(117, -604.4)(118, -745.9)(119, -895.5)

$(120,-893.2)(121,-918.5)(122,-933.9) \ldots$

Calculate

MEEK $=$ DOY $\ddot{3}$.

UGWQ $=0.0$

UGFO - PWL (QTABL, WEEK)

C PRINT 10, DOY, WEEK, UGWO, UGFO

10 PORMAT ('FNDQ', 4F10.2)

END-FUNCTION ..

FUNCTION NAME-EHIS1.

ASSIGN TI $T$

TIREWI $=$ QIREW
FILAUI-FILAU

EMISRF $=0.3$

DBTR -DBTR

IR CORRECTION

S OSA FILA CONDUCTANCE

OUTSIDE SURPACE EHISSIVITY

\$ OUTSIDE AIR TEMPERATURE

sigm

C PRINT 100, OIREW, OIREW1, OIREW2, FILHU, FILHU1, PILHU

QIREW2-(EHISRP/0.9) -QIREWI
C PILAU2-PILMU1-0.9+4.-EMISRF 5 STGM

C $+((T 1+460.0+D B T R) / 2.0) * 3$

FILMU2-FILMU1-0.9+4. -EMISRT *SIGMA * (DBTR**3)

QIREW1-OIREW2

ILAUI-PILMU2

PRINT 100, OIREW, OIREH , OIREW2, FILMU, FILHU1, FIIMU2

C 100 TORMAT (1X,6F10.3)

END

END-FUNCTION .

POST-PROCESSOR PARTIAL ..

INPUT SYSTEMS .

Diagostic Cautions echo ..

SYSTEMS-REPORT

SHrRpt\$

SUMAMRY-(SS-A, SS-B, SS-C,SS-R, SS-H, SS-I) ...

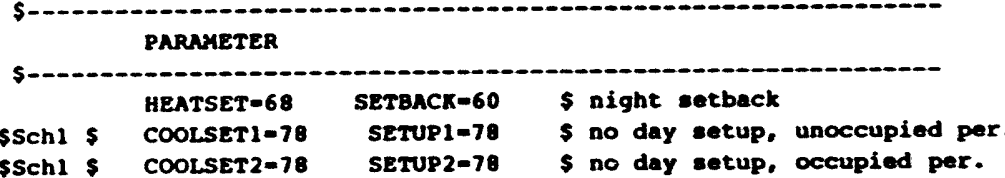

SSch1 s cOOLSET1-78 SETUP1-70 S no day cotup, unoccupied per.

SHP $\$$ C 2.7 cOP heat Pump

SHP $\$$

CBF-.098 CEIR=.3703 \$2.7 COP air conditioner

HCAPF $=-50000$. HPHCAP $=-33000$ HPBKUP $=-17000$

CTCAP $=34600$ CSCAP $=27680$.

$\$$

ACCFM-1760 \& Erom plans

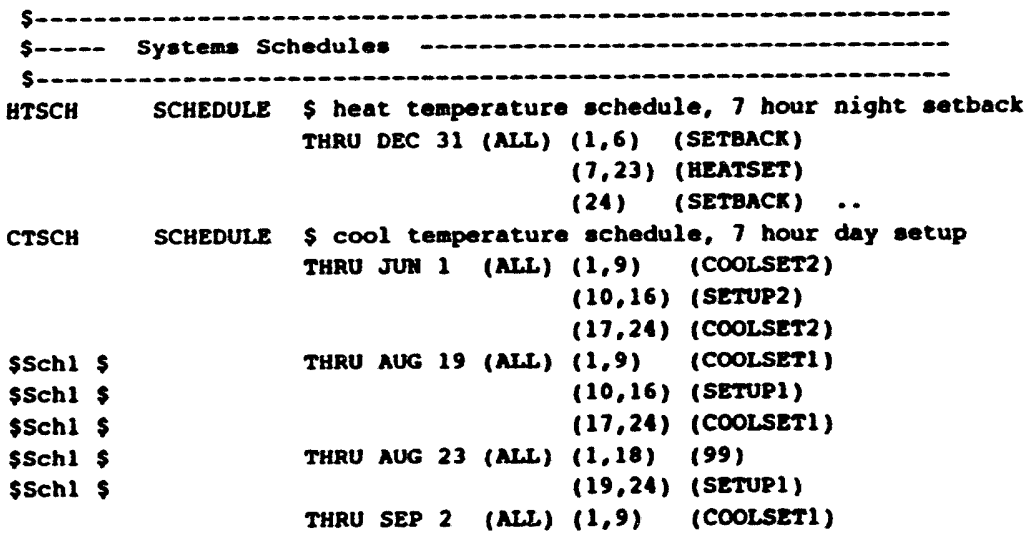




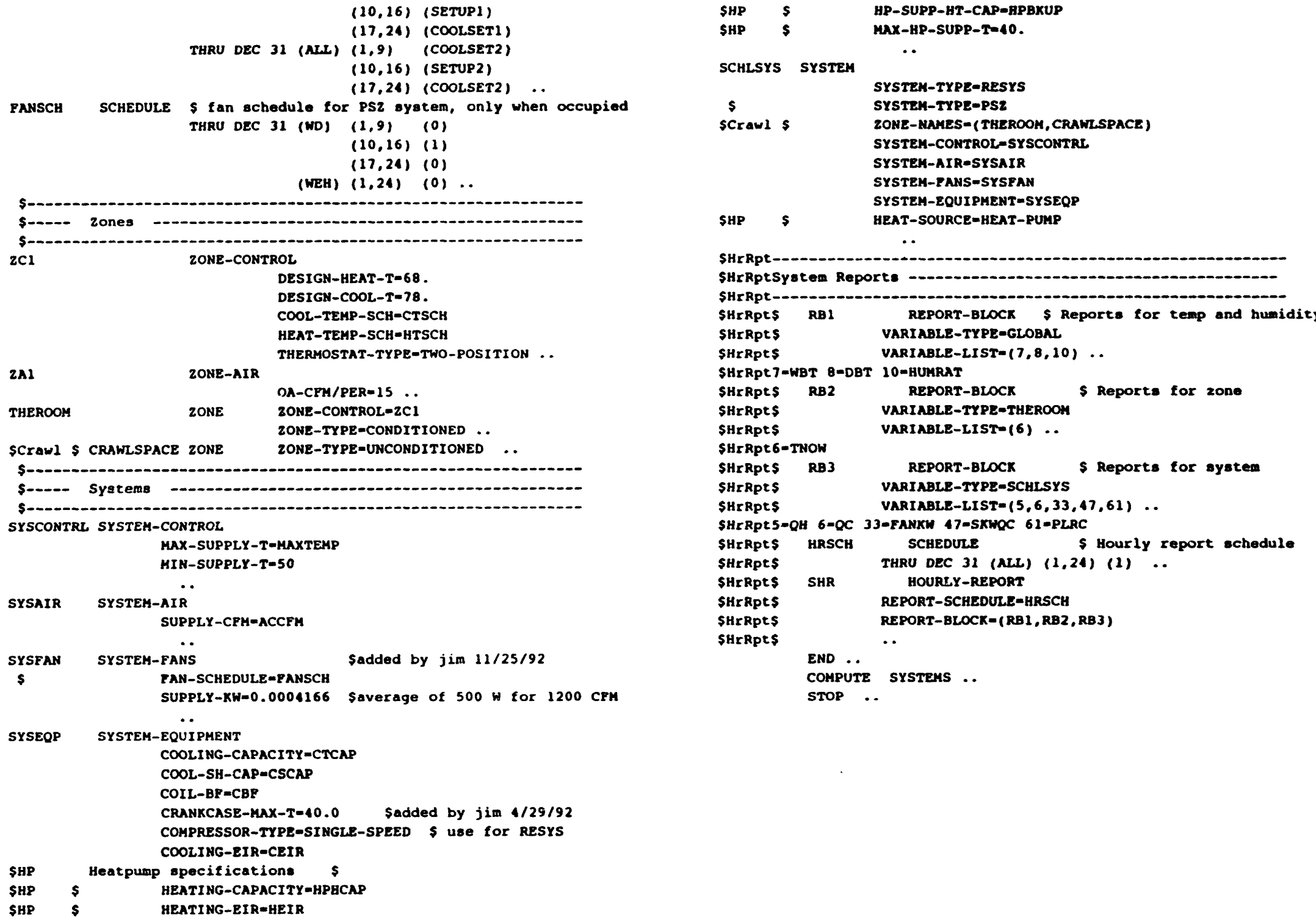


EXPERIMENT DESIGN/PROTOCOL 


\section{Monitoring Energy Savings from \\ Vegetation and High-Albedo Surfaces \\ SMUD/CIEE/LBL}

\section{Experiment design/protocol}

\section{Site ID: Site 1}

Case: This is the control station for other sites.

\section{A. Measurements goals:}

The objective in this case is to provide a control site with which the performance of the other sites may be compared. This site will undergo no changes in albedo or vegetative cover.

We plan to measure the outdoor microclimate variables in the vicinity of the building. Variables to be measured include solar radiation, dry-bulb temperature, relative humidity, wind speed, and wind direction.

We will measure the surface temperature and solar radiation at the outside walls and roof. We will also measure the inside surface temperature of the roof and walls. Additional measurements of the indoor microclimate variables including air temperature and relative humidity will be made. The energy used by the air-conditioner will be monitored. All of these variables will be measured under a variety of weather conditions. One-time, characteristic descriptors, such as albedo of the building and surroundings, and the vegetation type and cover within the site and surroundings, will be measured.

B. Data product and output:

There will be two types of products. The first includes environmental characteristic data such as the albedo of the building and surroundings, the vegetation type/tree cover on site and in the building's vicinity, building materials, landscape elements, and view factor estimations. The second type of data includes the microclimate, envelope, and energy use data mentioned in Measurement goals above. These data will be averaged at 10 or 20 minute intervals (see Data analysis below). Data from other sites will be normalized to this 
control station based on results from dynamic calibration prior to equipment installation in the field.

The data analysis stage will involve: 1) examination of data and handling of missing entries, errors, and irrelevant/outlier data, 2) intercomparison among all sites within the basecase (no modification) period, 3) intercomparison with concurrent data from other sites (parallel) and with prior data from same site (series) after albedo and/or vegetation modifications have been performed, 4) comparisons after the sites have been returned to the basecase configurations.

Output will be presented in several interim reports and a final draft report. Data analysis will be performed while collection is in progress. Refer to Table 1 (attached) for a summary of items to be reported.

\section{Experimental design approach}

A combination of before-after and test-reference experimental approaches will be used. Analysis and comparisons for microclimate and envelope conditions and building energy use figures will be performed. During the basecase monitoring, a test-reference comparison with other sites will be performed.

Since this site will be the control site, the experiment schedule is simple: The site will remain in its basecase configuration throughout the duration of this project.

The building will be simulated with the DOE-2 program for confirmation and validation purposes.

Note that this house and house \#8 have identical plans (mirror images of each other) except for orientation and tree cover. Site 8 has much less vegetation and higher cooling energy bills, according to the owner. A comparison of these two houses during the basecase monitoring period will give an estimate of tree effects, despite the fact that Site 1 is the control case. After trees have been added to Site 8, comparison with Site 1 will also be useful.

In order to be able to compare buildings in terms of their response to certain modifications 
in albedo and/or vegetation, it is necessary to make sure that their operating conditions are as similar to each other as possible. Since the houses have mostly similar configurations (2-3 bedrooms) and have the same kind of occupant schedules**, the main variables to factor out are:

Window operation: Windows should be closed at all times.

Air conditioner operation: Thermostat setting should be the same in all cases.

Lights: Lights should be tumed on/off in a consistent, similar, and predictable fashion.

Appliances: Energy use of appliances will be estimated based on qualitative estimates to be provided by the occupants.

The attached floor plan shows the locations of sensors and the inventory for this particular site. Also refer to Table 1 . In this site, sensors $1-5$ will be placed on a station post at or above roof level (-3-4 m above ground) possibly on the deck's overhang (first choice), or in the large backyard, at an unobstructed location that is not affected by local turbulence (second choice). Sensors 6-8 will be placed at a representative location that is unobstructed and non-shaded during all daylight hours. Representative areas are those of large extent: abnormal or atypical spots should be avoided. Sensors 9-11 will be located on the exterior of the building adjacent to the walls/roof of the south-east and south bedrooms (sensors 9-10 will be on walls at an elevation of $1.5 \mathrm{~m}$ above ground, whereas sensor 11 will be on the roof at an unshaded/unobstructed location above the south bedroom). Sensors 12-13 will not be used at this location. Sensors 14-16 will be located inside at spots corresponding to those of outside sensors 9-11. Sensors 17-18 will be in both bedrooms, whereas sensor 19 will be located in the south bedroom (sensors $17-19$ will be at a height of 1.5 above floor to avoid stratification effects). Finally, sensors 20-22 will be located as appropriate.

A high precision pyranometer will be used to measure the albedo of the roof, walls, and surroundings of the building. Limited albedo measurements in the neighborhood will also be performed. Measurements will be performed under clear sky conditions. Vegetation type will be identified and density will be described via cover (\%) and Leaf-Area-Index

\footnotetext{
- The basecase field-monitoring ("first two weeks) and supporting computer simulations should minimize the noise from occupancy and related factors. This will also help identify differences in baseloads if they are large.
} 
(LAI) at the building site and in the neighborhood. Limited surface temperatures of the surroundings will also be taken with a hand-held infrared thermometer.

\section{Data analysis}

The data will be grouped into several sub-categories, i.e., daytime, nighttime, clear, overcast, windy, and calm. Additionally, analyses will be performed separately for albedo cases and vegetation cases, and also based on their surrounding environmental conditions (neighborhoods).

syntax error file , between lines 278 and 279 The following table gives the sampling/averaging and logging intervals :

\begin{tabular}{|l||l|l|l|l|l|l|l|}
\hline Sensor \# & 1,2 & $3-5$ & $6-8$ & $9-11$ & $14-19$ & 20 & 21,22 \\
Sampling (min) & 5 & 2 & 5 & 5 & 5 & 1 & 2 \\
Avrglogging (min) & 20 & 10 & 20 & 20 & 20 & 10 & 10 \\
\hline
\end{tabular}

At each recording period, the stored value for each of these variable is as follows:

Outdoor air temp $\left({ }^{\circ} \mathrm{C}\right)$

Outdoor relative humidity (\%)

Solar radiation $(\mathrm{W} / \mathrm{m} 2)$

Wind speed $(\mathrm{m} / \mathrm{s})$

Wind direction $\left({ }^{\circ}\right)$

Ground surface temperature $\left({ }^{\circ} \mathrm{C}\right)$

Subsoil surface temperature $\left({ }^{\circ} \mathrm{C}\right)$

Subsoil moisture content (\%)

Outside waill surface temperature $\left({ }^{\circ} \mathrm{C}\right)$

Outside wall2 surface temperature $\left({ }^{\circ} \mathrm{C}\right)$

Outside roof surface temperature $\left({ }^{\circ} \mathrm{C}\right)$

Roof solar radiation estimate (W/m2)

Wall solar radiation estimate $(\mathrm{W} / \mathrm{m} 2)$
Average temperature

Average humidity

Total horizontal radiation

Average speed

Average direction

Average temperature

Average temperature

Average concentration

Average temperature

Average temperature

Average temperature

Total horizontal radiation

Total vertical radiation

† These intervals are fiexible and may be changed as appropriate. 
Inside roof surface temperature $\left({ }^{\circ} \mathrm{C}\right)$

Inside wall1 surface temperature $\left({ }^{\circ} \mathrm{C}\right)$

Inside wall2 surface temperature $\left({ }^{\circ} \mathrm{C}\right)$

Inside room 1 air temperature $\left({ }^{\circ} \mathrm{C}\right)$

Inside room 2 air temperature $\left({ }^{\circ} \mathrm{C}\right)$

Inside room 2 relative humidity (\%)

Air-conditioner energy use ( $\mathrm{kWh}$ )

Supply air temperature $\left({ }^{\circ} \mathrm{C}\right)$

Return air temperature $\left({ }^{\circ} \mathrm{C}\right)$
Average temperature

Average temperature

Average temperature

Average temperature

Average temperature

Average humidity

Total consumption

Average temperature

Average temperature

In order to be able to compare the performance of buildings, a simple index would consist of normalizing the air-conditioner energy use over the conditioned floor area. A modified energy use index (EUI) will thus be obtained for comparison with other sites. If only portions of roofs will be modified, the ratio of the modified area to the total roof area (over conditioned zones) must be equal. Also, roof orientations treated with albedo modifications should be similar. Consideration to insulation level and material type should also be given.

E. Data accuracy, quality control/verification, and format.

The precision of data products will be determined based on the precision of the data acquisition system and the relationship between the variables being measured due to variations induced by weather, occupant behavior, operational variations, and measurement periods. The potential bias in the final products will be estimated assuming that the uncertainties in the measured parameters are small compared to the mean parameter values. Once a specific data reduction procedure has been established, there will be many techniques available to incorporate uncertainties into the final data product.

After initial static calibration, all sensors/equipment will be dynamically calibrated in one location for about one week to establish calibration curves and assign a control station for later normalization of data. After dynamic calibration, matched sets of sensors/equipment will be kept together and transported to the field. The data flow path (from sensor to logger to modem) will be continuously checked for equipment failure and unexpected modifications. Downloaded data, at the other end of the phone line, will be analyzed in progress to identify potential errors in transmission or sensors operation. Daily diagnosis 
of data at all stages (start-up, ongoing, periodic, and final) will be performed to screen for these potential errors so that immediate action can be taken to corrert thcm.

Data will also be compared to simulation results to get an order of magnitude for expected output and identify severe deviations therefrom. Finally, post calibration at the end of the data collection period will be performed to ensure that no major drift has occurred.

Data will be downloaded via modems to SMUD. This raw data will then be transferred to LBL on floppy disks in comma-separated ASCII or spreadsheet formats (other separators are also acceptable). Macintosh- readable disks can also be used. At project start-up, SMUD will provide LBL with daily data (96 15 -min intervals times 8 stations times 22 variables), but later into the project, data will be supplied to LBL on a weekly basis ( 672 15 -min intervals times 8 stations times 22 variables). 
Site No. 1

(Drawing not to scale or proportions)

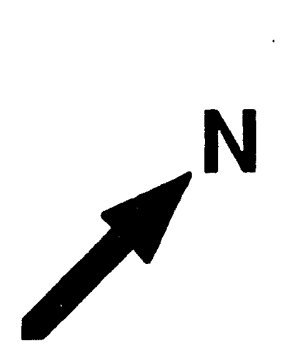

Air return is near floor, on wall

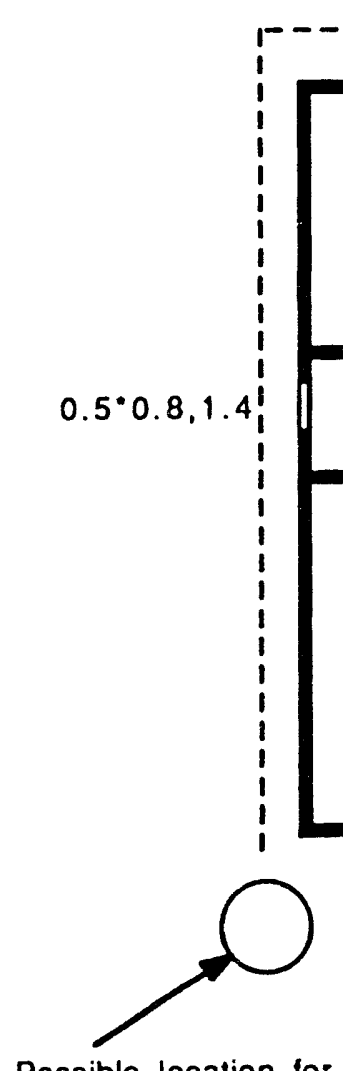

Possible location for a tall tree $(5 \mathrm{~m}+)$ to shade the roof

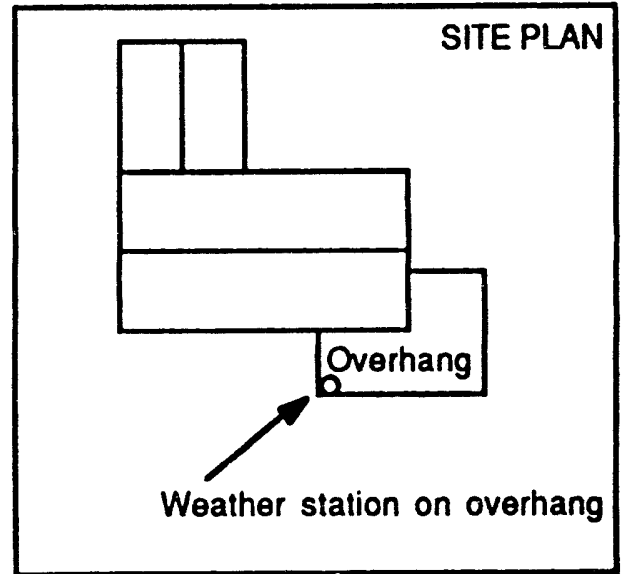

\begin{tabular}{|l|}
\hline Air temperature point \\
Surface temperature point \\
$\square \quad$ Relative humidity point \\
$\mathrm{h} \quad$ Inside ceiling height $(\mathrm{m})$ \\
$x^{*} y, z \quad$ window width*height, sill $(\mathrm{m})$
\end{tabular}




\section{Monitoring Energy Savings from \\ Vegetation and High-AJbedo Surfaces \\ SMUD/CIEE/LBL}

\section{Experiment design/protocol}

\section{Site ID: Site 2}

Case: This is an albedo site.

A. Measurements goals:

The objective in this case is to determine the impact of albedo on the air conditioner's energy use.

We plan to measure the outdoor microclimate variables in the vicinity of the building. Variables to be measured include dry-bulb temperature, relative humidity, wind speed, and wind direction.

We will measure the surface temperature and solar radiation at the outside walls and roof. We will also measure the inside surface temperature of the roof and walls. Additional measurements of the indoor microclimate variables including air temperature and relative humidity will be made. The energy used by the air-conditioner will be monitored. All of these variables will be measured under a variety of weather conditions and before and after albedo modification. One-time, characteristic descriptors, such as albedo of the building and surroundings, and the vegetation type and cover within the site and surroundings, will be measured before and after modifications.

B. Data product and outpuf:

There will be two types of products. The first includes environmental characteristic data such as the albedo of the building and surroundings, the vegetation type/tree cover on site and in the building's vicinity, building materials, landscape elements, and view factor estimations. The second type of data includes the microclimate, envelope, and energy use data mentioned in Measurement goals above. These data will be averaged at 10 or 20 minute intervals (see Data analysis below). Data will be normalized to a control station (site) 
based on results from dynamic calibration prior to equipment installation in the field.

The data analysis stage will involve: 1) examination of data and handling of missing entries, errors, and irrelevant/outlier data, 2) comparison among all sites within the basecase (no modification) period, 3) intercomparison with concurrent data from other sites (parallel) and with prior data from same site (series) after albedo and/or vegetation modifications have been performed, 4) comparisons after sites have been returned to basecase configurations.

Data analysis will be performed while collection is in progress. Refer to Table 1 (attached) for a summary of items to be reported.

\section{Experimental design approach}

A combination of before-after and test-reference experimental approaches will be used. Analysis and comparisons for microclimate and envelope conditions and building energy use figures will be performed. During the basecase monitoring, a test-reference comparison with other sites will be made.

The experiment schedule for this house is as follows:

\begin{tabular}{|l|l|}
\hline weeks 1-2 & weeks 3-8 \\
\hline basecase & albedo modification \\
\hline
\end{tabular}

Note: The albedo modification to this building will be in the form of a permanent elastomeric coating of the roof.

The building will be simulated with the DOE-2 program for confirmation and validation purposes. It will be simulated as a basecase and in a case with albedo modification.

In order to be able to compare buildings in terms of their response to certain modifications in albedo and/or vegetation, it is necessary to make sure that their operating conditions are as similar to each other as possible. Since the houses have mostly similar configurations ( $2-3$ bedrooms) and have the same kind of occupant schedules**, the main variables to 
factor out are:

Window operation: Windows should be closed at all times.

Air conditioner operation: Thermostat selting should be the same in all cases.

Lights: Lights should be turned on/off in a consistent, similar, and predictable fashion.

Appliances: Energy use of appliances will be estimated based on qualitative estimates to be provided by the occupants.

The attached floor plan shows the locations of sensors and the inventory for this particular site. Also refer to Table 1 . In this site, sensors 1,2 , and 4 will be placed on a station post on the roof (-3-4 $\mathrm{m}$ above ground). Sensors 3 , and 6-8 will not be used at this location.

Sensors 9-10 will be located on the exterior of the building adjacent to the walls/roof of the south-east and east bedrooms at an elevation of $1.5 \mathrm{~m}$ above ground. Sensor 11 will be on the roof at an unshaded/unobstructed location above the hallway near the main entrance. Sensors 12-13 will not be used at this location. Sensors 14-16 will be located inside at spots corresponding to those of outside sensors 9-11. Sensors 17-18 will be in the south-east and the east bedrooms. Sensor 19 will be located in the south-east bedroom (sensors $17-19$ will be at a height of 1.5 above floor to avoid stratification effects). Finally, sensors 20-22 will be located as appropriate.

Roof albedo modification will be performed using a permanent white elastomeric coating applied to the entire roof. The outside unit (condenser) should not be shaded nor should its a!bedo be modified. It should be left in its original condition.

A high precision pyranometer will be used to measure the current and modified albedos of the roof, walls, and surroundings of the building. Limited albedo measurements in the neighborhood will also be performed. Measurements will be performed under clear sky conditions. Vegetation type will be identified and density will be described via cover (\%) and Leaf-Area-Index (LAI) at the building site and in the neighborhood. Limited surface temperatures of the surroundings will also be taken with a hand-held infrared thermometer.

- The basecase field-monitoring ("first two weeks) and supporting computer simulations should minimize the noise from occupancy and related factors. This will also help identify differences in baseloads if they are large. 


\section{Data analysis}

Data analysis will proceed assuming that the changes in air conditioner energy use are results of modifications in albedo. That implies all other factors to be as close to constant as possible. Factors that cannot be held constant must be varied in a predictable manner (see Experimental design approach above). In addition, we will use the DOE-2.1D program to investigate the effects of variations in such parameters on air conditioner energy use.

The data will be grouped into several sub-categories, i.e., daytime, nighttime, clear, overcast, windy, and calm. Additionally, analyses will be performed separately for albedo cases (this site) and vegetation cases, and also based on their surrounding environmental conditions (neighborhoods).

The following table gives the sampling/averaging and logging intervals: $\mathrm{XX}$ there is an error in this table, butI can't find it.

\begin{tabular}{|l||c|l|l|l|l|l|}
\hline Sensor \# & 1,2 & 4 & $9-11$ & $14-19$ & 20 & 21,22 \\
Sampling (min) & 5 & 5 & 5 & 5 & 1 & 2 \\
Avrg/logging (min) & 20 & 20 & 20 & 20 & 10 & 10 \\
\hline
\end{tabular}

At each recording period, the stored value for each of these variable is as follows:

Outdoor air temp $\left({ }^{\circ} \mathrm{C}\right)$

Outdoor relative humidity (\%)

Solar radiation $(\mathrm{W} / \mathrm{m} 2)$

Wind speed $(\mathrm{m} / \mathrm{s})$

Wind direction $\left({ }^{\circ}\right)$

Outside wall1 surface temperature $\left({ }^{\circ} \mathrm{C}\right)$

Outside wall2 surface temperature $\left({ }^{\circ} \mathrm{C}\right)$

Outside roof surface temperature $\left({ }^{\circ} \mathrm{C}\right)$

Roof solar radiation estimate $(\mathrm{W} / \mathrm{m} 2)$

Wall solar radiation estimate $(\mathrm{W} / \mathrm{m} 2)$
Average temperature

Average humidity

Total horizontal radiation

Average speed

Average direction

Average temperature

Average temperature

Average temperature

Total horizontal radiation

Total vertical radiation 
Inside roof surface temperature $\left({ }^{\circ} \mathrm{C}\right)$

Inside wall1 surface temperature $\left({ }^{\circ} \mathrm{C}\right)$

Inside wall2 surface temperature $\left({ }^{\circ} \mathrm{C}\right)$

Inside room 1 air temperature $\left({ }^{\circ} \mathrm{C}\right)$

Inside room2 air temperature $\left({ }^{\circ} \mathrm{C}\right)$

Inside room 2 relative humidity (\%)

Airconditioner energy use ( $k W h$ )

Supply air temperature $\left({ }^{\circ} \mathrm{C}\right)$

Return air temperature $\left({ }^{\circ} \mathrm{C}\right)$
Average temperature

Average temperature

Average temperature

Average temperature

Average temperature

Average humidity

Total consumption

Average temperature

Average temperature

In order to be able to compare the performance of buildings, a simple index would consist of normalizing the air conditioner energy use over the conditioned floor area. A modified energy use index (EUI) will thus be obtained for comparison with other albedo cases. If only portions of roofs will be modified, the ratio of the modified area to the total roof area (over conditioned zones) must be equal. Also, roof orientations treated with albedo modifications should be similar. Consideration to insulation level and material type should also be given.

E. Data accuracy, quality control/verification, and format.

The precision of data products will be determined based on the precision of the data acquisition system and the relationship between the variables being measured due to variations induced by weather, occupant behavior, operational variations, and measurement periods. The potential bias in the final products will be estimated assuming that the uncertainties in the measured parameters are small compared to the mean parameter values. Once a specific data reduction procedure has been established, there will be many techniques available to incorporate uncertainties into the final data product.

After initial static calibration, all sensors/equipment will be dynamically calibrated in one location for about one week to establish calibration curves and assign a control station for later normalization of data. After dynamic calibration, matched sets of sensors/equipment will be kept together and transported to the field. The data flow path (from sensor to logger to modem) will be continuously checked for equipment failure and unexpected modifications. Downloaded data, at the other end of the phone line, will be analyzed in progress to identify potential errors in transmission or sensors operation. Daily diagnosis 
of data at all stages (start-up, ongoing, periodic, and final) will be performed to screen for these potential errors so that immediate action can be taken to correct them.

Data will also be compared to simulation results to get an order of magnitude for expected output and identify severe deviations therefrom. Finally, post calibration at the end of the data collection period will be performed to ensure that no major drift has occurred.

Data will be downloaded via modems to SMUD. This raw data will then be transferred to LBL on floppy disks in comma-separated ASCII or spreadsheet formats (other separators are also acceptable). Macintosh- readable disks can also be used. At project start-up, SMUD will provide LBL with daily data (96 15-min intervals times 8 stations times 22 variables), but later into the project, data will be supplied to LBL on a weekly basis (672 15-min intervals times 8 stations times 22 variables). 
Site No. 2

(Drawing not to scale or proportions)

\section{Built 1962}

No. of stories: 1

Square footage (garage excluded): 1825

Ceiling: R-11

Walls: R-6 to R-8

A/C capacity: 42,000 Btu

Vegetation: heavy

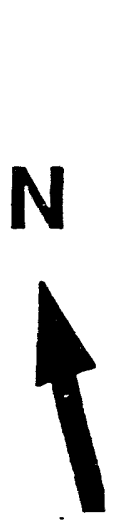

Relurn air near ceiling. on wall.
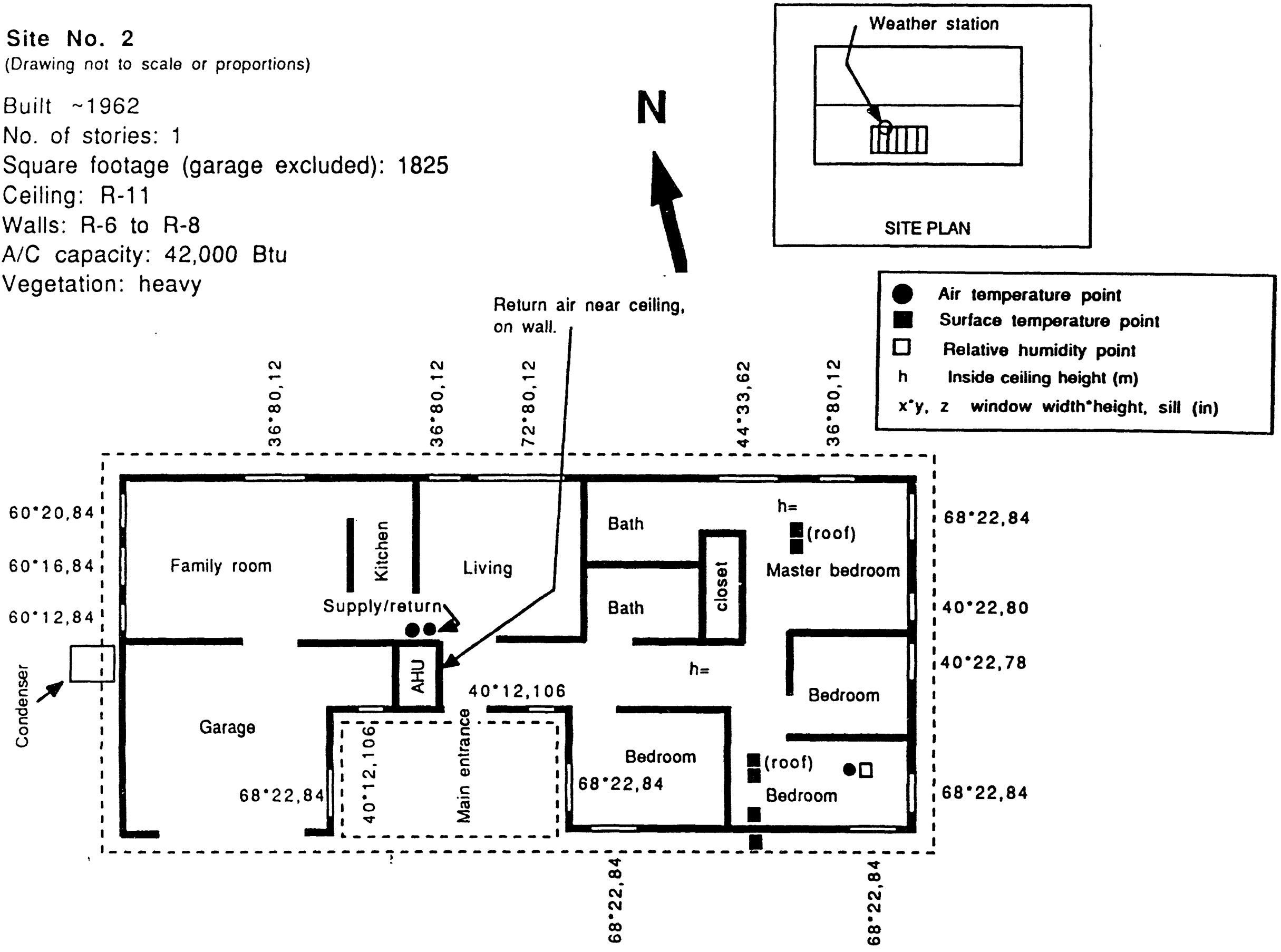

Heavily shaded windows (with irees) on east, south, and west sides 


\section{Monitoring Energy Savings from \\ Vegetation and High-Albedo Surfaces \\ SMUD/CIEE/LBL}

\section{Experiment design/protocol}

\section{Site ID: Site 5}

Case: This is primarily an albedo site, although some vegetative modifications will be made during the test program.

\section{A. Measurements goals:}

The primary objective in this case is to determine the impact of albedo on the air conditioner's energy use. A secondary objective is to determine the combined impact of vegetative and albedo modifications on air conditioner energy use.

We plan to measure the outdoor microclimate variables in the vicinity of the building. Variables to be measured include dry-bulb temperature, relative humidity, wind speed, and wind direction.

We will measure the surface temperature of the outside walls and roof. We will also measure the inside surface temperature of the roof and walls. Additional measurements of the indoor microclimate variables including air temperature and relative humidity will be made. The energy used by the air-conditioner will be monitored. All of these variables will be measured under a variety of weather conditions and of albedo modifications, including a period of time during which albedo and vegetative modifications coexist. One-time, characteristic descriptors, such as albedo of the building and surroundings, and the vegetation type and cover within the site and surroundings, will be measured before and after modifications.

B. Data product and output:

There will be two types of products. The first includes environmental characteristic data such as the albedo of the building and surroundings, the vegetation type/tree cover on site and in the building's vicinity, building materials, landscape elements, and view factor 
estimations. The second type of data includes the microclimate, envelope, and energy use data mentioned in Measurement goals above. These data will be averaged at 10 or 20 minute intervals (see Data analysis below). Data will be normalized to a control station (site) based on results from dynamic calibration prior to equipment installation in the field.

The data analysis stage will involve: 1) examination of data and handling of missing entries, errors, and irrelevant/outlier data, 2) comparison among all sites within the basecase (no modification) period, 3) comparison with concurrent data from other sites (parallel) and with prior data from same site (series) after albedo and/or vegetation modifications have been performed, 4) comparisons after site has been returned to basecase configuration.

Data analysis will be performed while collection is in progress. Refer to Table 1 (attached) for a summary of items to be reported.

\section{Experimental design approach}

A combination of before-after and test-reference experimental approaches will be used. Analysis and comparisons for microclimate and envelope conditions and building energy use figures will be performed. During the basecase monitoring, a test-reference comparison with other sites will be performed.

The experiment schedule for this house is as follows:

\begin{tabular}{|l|l|l|l|}
\hline weeks 1-2 & weeks 3-4 & weeks 5-6 & weeks 7-8 \\
\hline basecase & albedo modification & albedo and vegetation & base configuration \\
\hline
\end{tabular}

The building will be simulated with the DOE-2 program for confirmation and validation purposes. It will be simulated as a basecase and in a case with albedo and modification alone, followed by a simulation of concurrent albedo and vegetation modification.

In order to be able to compare buildings in terms of their response to certain modifications in albedo and/or vegetation, it is necessary to make sure that their operating conditions are 
as similar to each other as possible. Since the houses have mostly similar configurations (2-3 bedrooms) and have the same kind of occupant schedules**, the main variables to factor out are:

Window operation: Windows should be closed at all times.

Air conditioner operation: Thermostat setting should be the same in all cases.

Lights: Lights should be tumed on/off in a consistent, similar, and predictable fashion.

Appliances: Energy use of appliances will be estimated based on qualitative estimates to be provided by the occupants.

The attached floor plan shows the locations of sensors and the inventory for this particular site. Also refer to Table 1 . In this site, sensors

1,2 , and 4 will be placed on a station post attached to the deck's overhang in the backyard ( $-3-4 \mathrm{~m}$ above ground). Sensors $6-8$ will not be used at this site. Sensors 9 and 10 will be located on the exterior of the building adjacent to the south wall of the living room and the east wall of the master bedroom (at an elevation of $1.5 \mathrm{~m}$ above ground). Sensor 11 will be located on the roof above the living room. Sensors 12-13 will not be used at this location. Sensors 14-16 will be located inside at spots corresponding to those of outside sensors 9-11. Sensors 17-18 will be in the living room and master bedroom. Sensor 19 will be located in the living room (sensors 17-19 will be at a height of 1.5 above floor to avoid stratification effects). Finally, sensors 20-22 will be located as appropriate.

Roof albedo modification will be performed using a white cloth fixed in place with counter-weights. The outside unit (condenser) should not be shaded nor should its albedo be modified. It should be run as it currently is.

A high precision pyranometer will be used to measure the current and modified albedos of the roof, walls, and surroundings of the building. Limited albedo measurements in the neighborhood will also be performed. Measurements will be performed under clear sky conditions. Vegetation type will be identified and density will be described via cover (\%)

*. The basecase field-monitoring ("first two weeks) and supporting computer simulations should minimize the noise from occupancy and related factors. This will also help identify differences in baseloads if they are large. 
and Leaf-Area-Index (LAI) at the building site and in the neighborhood. Limited surface temperatures of the surroundings will also be taken with a hand-held infrared thermometer.

D. Data analysis

Data analysis will proceed assuming that the changes in airconditioner energy use are results of modifications in albedo. That implies all other factors to be as close to constant as possible. Factors that cannot be held constant must be varied in a predictable manner (see Experimental design approach above). In addition, we will use the DOE-2.1D program to investigate the effects of variations in such parameters on air conditioner energy use.

The data will be grouped into several sub-categories, i.e., daytime, nighttime, clear, overcast, windy, and calm. Additionally, analyses will be performed separately for albedo cases (this site) and vegetation cases, and also based on their surrounding environmental conditions (neighborhoods).

The following table gives the sampling/averaging and logging intervals:

\begin{tabular}{|l||l|l|l|l|l|l|}
\hline Sensor \# & 1,2 & 4 & $9-11$ & $14-19$ & 20 & 21,22 \\
Sampling (min) & 5 & 5 & 5 & 5 & 1 & 2 \\
Avrg/logging (min) & 20 & 20 & 20 & 20 & 10 & 10 \\
\hline
\end{tabular}

At each recording period, the stored value for each of these variable is as follows:

Outdoor air temp $\left({ }^{\circ} \mathrm{C}\right)$

Outdoor relative humidity (\%)

Solar radiation $(\mathrm{W} / \mathrm{m} 2)$

Wind speed $(\mathrm{m} / \mathrm{s})$

Wind direction $\left({ }^{\circ}\right)$

Ground surface temperature $\left({ }^{\circ} \mathrm{C}\right)$

Subsoil surface temperature $\left({ }^{\circ} \mathrm{C}\right)$

Subsoil moisture content (\%)

Outside wall1 surface temperature $\left({ }^{\circ} \mathrm{C}\right)$
Average temperature

Average humidity

Total horizontal radiation

Average speed

Average direction

Average temperature

Average temperature

Average concentration

Average temperature 


$\begin{array}{ll}\text { Outside wall2 surface temperature }\left({ }^{\circ} \mathrm{C}\right) & \text { Average temperature } \\ \text { Outside roof surface temperature }\left({ }^{\circ} \mathrm{C}\right) & \text { Average temperature } \\ \text { Roof solar radiation estimate }(\mathrm{W} / \mathrm{m} 2) & \text { Total horizontal radiation } \\ \text { Wall solar radiation estimate }(\mathrm{W} / \mathrm{m} 2) & \text { Total vertical radiation } \\ \text { Inside roof surface temperature }\left({ }^{\circ} \mathrm{C}\right) & \text { Average temperature } \\ \text { Inside wall1 surface temperature }\left({ }^{\circ} \mathrm{C}\right) & \text { Average temperature } \\ \text { Inside wall2 surface temperature }\left({ }^{\circ} \mathrm{C}\right) & \text { Average temperature } \\ \text { Inside room1 air temperature }\left({ }^{\circ} \mathrm{C}\right) & \text { Average temperature } \\ \text { Inside room2 air temperature }\left({ }^{\circ} \mathrm{C}\right) & \text { Average temperature } \\ \text { Inside room2 relative humidity }(\%) & \text { Average humidity } \\ \text { Airconditioner energy use }(\mathrm{kWh}) & \text { Total consumption } \\ \text { Supply air temperature }\left({ }^{\circ} \mathrm{C}\right) & \text { Average temperature } \\ \text { Return air temperature }\left({ }^{\circ} \mathrm{C}\right) & \text { Average temperature }\end{array}$

In order to be able to compare the performanc: of buildings, a simple index would consist of normalizing the air conditioner energy use over the conditioned floor area. A modified energy use index (EUI) will thus be obtained for comparison with other albedo cases. If only portions of roofs will be modified, the ratio of the modified area to the total roof area (over conditioned zones) must be equal. Also, roof orientations treated with albedo modifications should be similar. Consideration to insulation level and material type should also be given.

F. Data accuracy, quality control/verification, and format.

The precision of data products will be determined based on the precision of the data acquisition system and the relationship between the variables being measured due to variations induced by weather, occupant behavior, operational variations, and measurement periods. The potential bias in the final products will be estimated assuming that the uncertainties in the measured parameters are small compared to the mean parameter values. Once a specific data reduction procedure has been established, there will be many techniques available to incorporate uncertainties into the final data product.

After initial static calibration, all sensors/equipment will be dynamically calibrated in one location for about one week to establish calibration curves and assign a control station for later normalization of data. After dynamic calibration, matched sets of sensors/equipment 
will be kept together and transported to the field. The data flow path (from sensor to logger to modem) will be continuously checked for equipment failure and unexpected modifications. Downloaded data, at the other end of the phone line, will be analyzed in progress to identify potential errors in transmission or sensors operation. Daily diagnosis of data at all stages (start-up, ongoing, periodic, and final) will be performed to screen for these potential errors so that immediate action can be taken to correct them.

Data will also be compared to simulation results to get an order of magnitude for expected output and identify severe deviations therefrom. Finally, post calibration at the end of the data collection period will be performed to ensure that no major drift has occurred.

Data will be downloaded via modems to SMUD. This raw data will then be transferred to LBL on floppy disks in comma-separated ASCII or spreadsheet formats (other separators are also acceptable). Macintosh- readable disks can also be used. At project start-up, SMUD will provide LBL with daily data (96 15 -min intervals times 8 stations times 22 variables), but later into the project, data will be supplied to LBL on a weekly basis (672 15 -min intervals times 8 stations times 22 variables). 
Site No. 5

(Drawing not to scale or proportions)

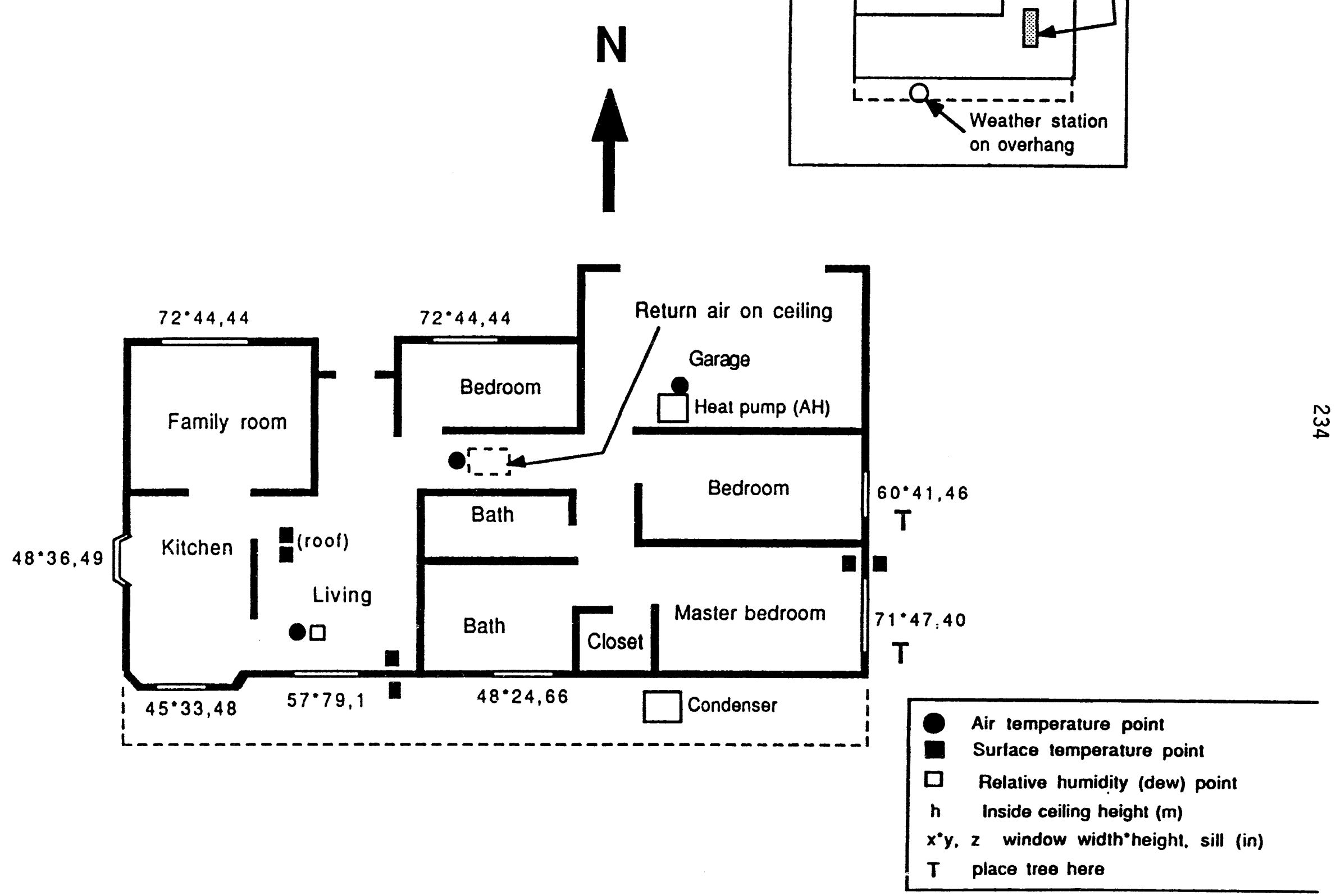




\section{Monitoring Energy Savings from \\ Vegetation and High-Albedo Surfaces \\ SMUD/CIEE/LBL}

\section{Experiment design/protocol}

Site ID: Site 6

Case: This site is a vegetation study site.

A. Measurements goals:

The objective in this case is to determine the impact of increased vegetation on the air conditioner's energy use.

We plan to measure the outdoor microclimate variables in the vicinity of the building. Variables to be measured include solar radiation, dry-bulb temperature, relative humidity, wind speed, and wind direction.

We will measure the surface temperature and solar radiation at the outside walls and roof. We will also measure the inside surface temperature of the roof and walls. Additional measurements of the indoor microclimate variables including air temperature and relative humidity will be made. The energy used by the air-conditioner will be monitored. All of these variables will be measured under a variety of weather conditions and before and after modifications are made. One-time, characteristic descriptors, such as albedo of the building and surroundings, and the vegetation type and cover within the site and surroundings, will be measured before and after modifications.

B. Data product and output:

There will be two types of products. The first includes environmental characteristic data such as the albedo of the building and surroundings, the vegetation type/tree cover on site and in the building's vicinity, building materials, landscape elements, and view factor estimations. The second type of data includes the microclimate, envelope, and energy use data mentioned in Measurement goals above. These data will be averaged at 10 or 20 minute intervals (see Data analysis below). Data will be normalized to a control station (site) 
based on results from dynamic calibration prior to equipment installation in the field.

The data analysis stage will involve: 1) examination of data and handling of missing entries, errors, and irrelevant/outlier data, 2) comparison among all sites within the basecase (no modification) period, 3) comparison with concurrent data from other sites (parallel) and with prior data from same site (series) after albedo and/or vegetation modifications have been performed, 4) comparisons after site has been returned to basecase configuration.

Data analysis will be performed while collection is in progress. Refer to Table 1 (attached) for a summary of items to be reported.

\section{Experimental design approach}

A combination of before-after and test-reference experimental approaches will be used. Analysis and comparisons for microclimate and envelope conditions and building energy use figures will be performed. During the basecase monitoring, a test-reference comparison with other sites will be performed.

The experiment schedule for this house is as follows:

\begin{tabular}{|l|l|l|}
\hline weeks 1-2 & weeks 3-6 & weeks 7.8 \\
\hline basecase & vegetation mod. & base configuration \\
\hline
\end{tabular}

The building will be simulated with the DOE-2 program for confirmation and validation purposes. It will be simulated as a basecase and in a case with vegetative modifications.

In order to be able to compare buildings in terms of their response to certain modifications in albedo and/or vegetation, it is necessary to make sure that their operating conditions are as similar to each other as possible. Since the houses have mostly similar configurations (2-3 bedrooms) and have the same kind of occupant schedules**, the main variables to factor out are:

- The basecase field-monitoring ("first two weeks) and supporting computer simulations should minimize the noise from occupancy and related factors. This will also help identify differences in baseloads if they are large. 
Window operation: Windows should be closed at all times.

Air conditioner operation: Thermostat setting should be the same in all cases.

Lights: Lights should be turned on/off in a consistent, similar, and predictable fashion.

Appliances: Energy use of appliances will be estimated based on qualitative estimates to be provided by the occupants.

The attached floor plan shows the locations of sensors and the inventory for this particular site. Also refer to Table 1 . In this site, sensors $1,2,4$, and 5 will be placed on a station post on the deck's overhang in the backyard (" $3-4 \mathrm{~m}$ above ground)

Sensors 6-8 will be placed at a representative location that is unobstructed and non-shaded during all daylight hours. Representative areas are those of large extent: abnormal or atypical spots should be avoided. Sensors 9-10 will be located on the exterior of the building adjacent to the walls of the south and master bedrooms at an elevation of $1.5 \mathrm{~m}$ above ground. Sensor 11 will be on the roof above the master bedroom. Sensor 12 will be located with the sensors on the deck's overhang. Sensor 13 will be located on an exterior wall which is to be shaded by the addition of a tree. This sensor may be moved during the study so that the impacts of the shading of each tree may be evaluated. Sensors 14-16 will be located inside at spots corresponding to those of outside sensors 9-11. Sensors 17-18 will be in the living room and master bedroom. Sensor 19 will be located in the master bedroom. Sensors 17-19 will all be at a height of 1.5 above floor to avoid stratification effects. Finally, sensors 20-22 will be located as appropriate.

Vegetation modification will be accomplished by addition of shade trees. Trees will either be planted (if appropriate), or simply placed (with their containers) at several beneficial locations. For this site, one tree will be required to shade a south-facing window, one tree will be required to shade a west-facing window, and one or two trees will be needed to shade the condenser unit.

A high precision pyranometer will be used to measure the current and modified albedos of the roof, walls, and surroundings of the building. Limited albedo measurements in the neighborhood will also be performed. Measurements will be performed under clear sky conditions. Vegetation type will be identified and density will be described via cover (\%) 
and Leaf-Area-Index (LAI) at the building site and in the neighborhood. Limited surface temperatures of the surroundings will also be taken with a hand-held infrared thermometer.

D. Data analysis

Data analysis will proceed assuming that the changes in airconditioner energy use are results of modifications in albedo. That implies all other factors to be as close to constant as possible. Factors that cannot be held constant must be varied in a predictable manner (see Experimental design approach above). In addition, we will use the DOE-2.1D program to investigate the effects of variations in such parameters on air conditioner energy use.

The data will be grouped into several sub-categories, i.e., daytime, nighttime, clear, overcast, windy, and calm. Additionally, analyses will be performed separately for albedo cases and vegetation cases (this site), and also based on their surrounding environmental conditions (neighborhoods).

The following table gives the sampling/averaging and logging intervals:

\begin{tabular}{|l||l|l|l|l|l|l|l|}
\hline Sensor \# & 1,2 & $4-5$ & $6-8$ & $9-13$ & $14-19$ & 20 & 21,22 \\
Sampling (min) & 5 & 2 & 5 & 5 & 5 & 1 & 2 \\
Avrg/logging (min) & 20 & 10 & 20 & 20 & 20 & 10 & 10 \\
\hline
\end{tabular}

At each recording period, the stored value for each of these variable is as follows:

Outdoor air temp $\left({ }^{\circ} \mathrm{C}\right)$

Outdoor relative humidity (\%)

Solar radiation $(\mathrm{W} / \mathrm{m} 2)$

Wind speed $(\mathrm{m} / \mathrm{s})$

Wind direction $\left(^{\circ}\right)$

Ground surface temperature $\left({ }^{\circ} \mathrm{C}\right)$

Subsoil surface temperature $\left({ }^{\circ} \mathrm{C}\right)$

Subsoil moisture content (\%)

Outside wall1 surface temperature $\left({ }^{\circ} \mathrm{C}\right)$
Average temperature

Average humidity

Total horizontal radiation

Average speed

Average direction

Average temperature

Average temperature

Average concentration

Average temperature 


$\begin{array}{ll}\text { Outside wall2 surface temperature }\left({ }^{\circ} \mathrm{C}\right) & \text { Average temperature } \\ \text { Outside roof surface temperature }\left({ }^{\circ} \mathrm{C}\right) & \text { Average temperature } \\ \text { Roof solar radiation estimate }(\mathrm{W} / \mathrm{m} 2) & \text { Total horizontal radiation } \\ \text { Wall solar radiation estimate }(\mathrm{W} / \mathrm{m} 2) & \text { Total vertical radiation } \\ \text { Inside roof surface temperature }\left({ }^{\circ} \mathrm{C}\right) & \text { Average temperature } \\ \text { Inside wall1 surface temperature }\left({ }^{\circ} \mathrm{C}\right) & \text { Average temperature } \\ \text { Inside wall2 surface temperature }\left({ }^{\circ} \mathrm{C}\right) & \text { Average temperature } \\ \text { Inside room1 air temperature }\left({ }^{\circ} \mathrm{C}\right) & \text { Average temperature } \\ \text { Inside room2 air temperature }\left({ }^{\circ} \mathrm{C}\right) & \text { Average temperature } \\ \text { Inside room2 relative humidity }(\%) & \text { Average humidity } \\ \text { Airconditioner energy use }(\mathrm{kWh}) & \text { Total consumption } \\ \text { Supply air temperature }\left({ }^{\circ} \mathrm{C}\right) & \text { Average temperature } \\ \text { Return air temperature }\left({ }^{\circ} \mathrm{C}\right) & \text { Average temperature }\end{array}$

In order to be able to compare the performance of buildings, a simple index would consist of normalizing the air conditioner energy use over the conditioned floor area. Consideration to insulation level and material type should also be given.

E. Data accuracy, quality control/verification, and format.

The precision of data products will be determined based on the precision of the data acquisition system and the relationship between the variables being measured due to variations induced by weather, occupant behavior, operational variations, and measurement periods. The potential bias in the final products will be estimated assuming that the uncertainties in the measured parameters are small compared to the mean parameter values. Once a specific data reduction procedure has been established, there will be many techniques available to incorporate uncertainties into the final data product.

After initial static calibration, all sensors/equipment will be dynamically calibrated in one location for about one week to establish calibration curves and assign a control station for later normalization of data. After dynamic calibration, matched sets of sensors/equipment will be kept together and transported to the field. The data flow path (from sensor to logger to modem) will be continuously checked for equipment failure and unexpected modifications. Downloaded data, at the other end of the phone line, will be analyzed in progress to identify potential errors in transmission or sensors operation. Daily diagnosis 
of data at all stages (start-up, ongoing, periodic, and final) will be performed to screen for these potential errors so that immediate action can be taken to correct them.

Data will also be compared to simulation results to get an order of magnitude for expected output and identify severe deviations therefrom. Finally, post calibration at the end of the data collection period will be performed to ensure that no major drift has occurred.

Data will be downloaded via modems to SMUD. This raw data will then be transferred to LBL on floppy disks in comma-separated ASCII or spreadsheet formats (other separators are also acceptable). Macintosh- readable disks can also be used. At project start-up, SMUD will provide LBL with daily data (96 15-min intervals times 8 stations times 22 variables), but later into the project, data will be supplied to LBL on a weekly basis (672 $15-\min$ intervals times 8 stations times 22 variables). 
Site No. 6

(Drawing not to scale or proportions)

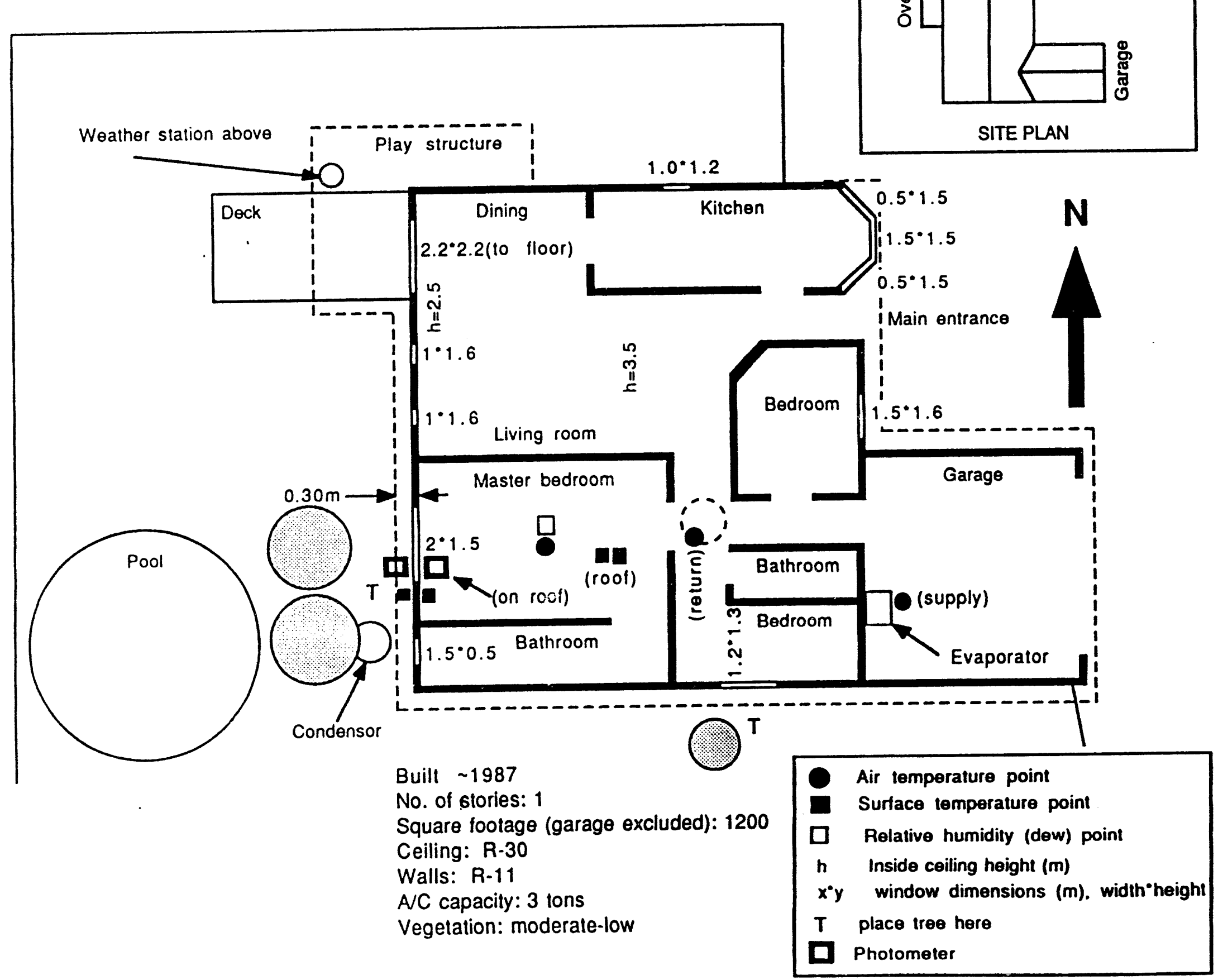




\section{Monitoring Energy Savings from \\ Vegetation and High-Albedo Surfaces \\ SMUD/CIEE/LBL}

\section{Experiment design/protocol}

\section{Site ID: $\quad$ Site 7}

Case: This site is a vegetation study site. Albedo will be modified if time permits.

\section{A. Measurements goals:}

The objective in this case is to determine the impact of increased vegetation on the air conditioner's energy use.

We plan to measure the outdoor microclimate variables in the vicinity of the building. Variables to be measured include solar radiation, dry-bulb temperature, relative humidity, wind speed, and wind direction.

We will measure the surface temperature at the outside walls and roof. We will also measure the inside surface temperature of the roof and walls. Additional measurements of the indoor microclimate variables including air temperature and relative humidity will be made. The energy used by the air-conditioner will be monitored. All of these variables will be measured under a variety of weather conditions and before and after vegetation modifications are made. One-time, characteristic descriptors, such as albedo of the building and surroundings, and the vegetation type and cover within the site and surroundings, will be measured before and after modifications.

B. Data product and output:

There will be two types of products. The first includes environmental characteristic data such as the albedo of the building and surroundings, the vegetation type/tree cover on site and in the building's vicinity, building materials, landscape ciements, and view factor estimations. The second type of data includes the microclimate, envelope, and energy use data mentioned in Measurement goals above. These data will be averaged at 10 or 20 minute intervals (see Data analysis below). Data will be normalized to a control station (site) 
based on results from dynamic calibration prior to equipment installation in the field.

The data analysis stage will involve: 1) examination of data and handling of missing entries, errors, and irrelevant/outlier data, 2) comparison among all sites within the basecase (no modification) period, 3) comparison with concurrent data from other sites (parallel) and with prior data from same site (series) after albedo and/or vegetation modifications have been performed, 4) comparisons after site has been returned to basecase configuration.

Data analysis will be performed while collection is in progress. Refer to Table 1 (attached) for a summary of items to be reported.

\section{Experimental design approach}

A combination of before-after and test-reference experimental approaches will be used. Analysis and comparisons for microclimate and envelope conditions and building energy use figures will be performed. During the basecase monitoring, a test-reference comparison with other sites will be performed.

The experiment schedule for this house is as follows:

\begin{tabular}{|l|l|l|}
\hline weeks 1-2 & weeks 3-6 & weeks $7-8$ \\
\hline basecase & vegetation mod. albedo mod. & \\
\hline
\end{tabular}

The building will be simulated with the DOE-2 program for confirmation and validation purposes. It will be simulated as a basecase and in a case with shading modifications.

In order to be able to compare buildings in terms of their response to certain modifications in albedo and/or vegetation, it is necessary to make sure that their operating conditions are as similar to each other as possible. Since the houses have mostly similar configurations (2-3 bedrooms) and have the same kind of occupant schedules** , the main variables to factor out are:

\footnotetext{
** The basecase field-monitoring ("first two weeks) and supporting computer simulations should minimize the noise from occupancy and related factors. This will also help identify differences in baseloads if they are large.
} 
Window operation: Windows should be closed at all times.

Air conditioner operation: Thermostat setting should be the same in all cases.

Lights: Lights should be turned on/off in a consistent, similar, and predictable fashion.

Appliances: Energy use of appliances will be estimated based on qualitative estimates to be provided by the occupants.

The attached floor plan shows the locations of sensors and the inventory for this particular site. Also refer to Table 1 . In this site, sensors 1 and 2 will be placed below an overhang adjacent to the garage. Sensors 4 and 5 will be on the roof above the main entrance.

Sensor 9 will be located on the exterior of the building corresponding to the wall of the bedroom adjacent to the living room at an elevation of $1.5 \mathrm{~m}$ above ground. Sensor 11 will be on the roof above the same bedroom. Sensors 14 and 16 will be located inside at spots corresponding to those of outside sensors 9 and 11. Sensors 17 and 19 will also be in the bedroom adjacent to the living room. Sensors 17 and 19 will be at a height of 1.5 above floor to avoid stratification effects. Finally, sensors 20-22 will be located as appropriate.

Vegetation modification will be accomplished by addition of shade trees. Trees will either be planted (if appropriate), or simply placed (with thcir containers) at several beneficial locations. For this site, trees will be required to shade a south-facing windows.

A high precision pyranometer will be used to measure the current and modified albedos of the roof, walls, and surroundings of the building. Limited albedo measurements in the neighborhood will also be performed. Measurements will be performed under clear sky conditions. Vegetation type will be identified and density will be described via cover (\%) and Leaf-Area-Index (LAl) at the building site and in the neighborhood. Limited surface temperatures of the surroundings will also be taken with a hand-held infrared thermometer.

D. Data analysis

Data analysis will proceed assuming that the changes in air conditioner energy use are results of modifications in albedo. All other factors will be assumed to be as close to constant as possible. Factors that cannot be held constant must be varied in a predictable manner (see Experimental design approach above). In addition, we will use the DOE- 
2.1D program to investigate the effects of variations in such parameters on air conditioner energy use.

The data will be grouped into several sub-categories, i.e., daytime, nighttime, clear, overcast, windy, and calm. Additionally, analyses will be performed separately for albedo cases and vegetation cases (this site), and also based on their surrounding environmental conditions (neighborhoods).

The following table gives the sampling/averaging and logging intervals:

\begin{tabular}{|l||l|l|l|l|l|l|l|}
\hline Sensor \# & 1,2 & $4-5$ & $6-8$ & $9-13$ & $14-19$ & 20 & 21,22 \\
Sampling (min) & 5 & 2 & 5 & 5 & 5 & 1 & 2 \\
Avrg/logging (min) & 20 & 10 & 20 & 20 & 20 & 10 & 10 \\
\hline
\end{tabular}

At each recording period, the stored value for each of these variable is as follows:

Outdoor air temp $\left({ }^{\circ} \mathrm{C}\right)$

Outdoor relative humidity (\%)

Solar radiation $(\mathrm{W} / \mathrm{m} 2)$

Wind speed $(\mathrm{m} / \mathrm{s})$

Wind direction $\left(^{\circ}\right)$

Ground surface temperature $\left({ }^{\circ} \mathrm{C}\right)$

Subsoil surface temperature $\left({ }^{\circ} \mathrm{C}\right)$

Subsoil moisture content (\%)

Outside wall1 surface temperature $\left({ }^{\circ} \mathrm{C}\right)$

Outside wall 2 surface temperature $\left({ }^{\circ} \mathrm{C}\right)$

Outside roof surface temperature $\left({ }^{\circ} \mathrm{C}\right)$

Roof solar radiation estimate $(\mathrm{W} / \mathrm{m} 2)$

Wall solar radiation estimate $(\mathrm{W} / \mathrm{m} 2)$

Inside roof surface temperature $\left({ }^{\circ} \mathrm{C}\right)$

Inside wall1 surface temperature $\left({ }^{\circ} \mathrm{C}\right)$

Inside wall2 surface temperature $\left({ }^{\circ} \mathrm{C}\right)$
Average temperature

Average humidity

Total horizontal radiation

Average speed

Average direction

Average temperature

Average temperature

Average concentration

Average temperature

Average temperature

Average temperature

Total horizontal radiation

Total vertical radiation

Average temperature

Average temperature

Average temperature 
Inside room 1 air temperature $\left({ }^{\circ} \mathrm{C}\right)$

Inside room2 air temperature $\left({ }^{\circ} \mathrm{C}\right)$

Inside room2 relative humidity (\%)

Airconditioner energy use ( $\mathrm{kWh}$ )

Supply air temperature $\left({ }^{\circ} \mathrm{C}\right)$

Return air temperature $\left({ }^{\circ} \mathrm{C}\right)$
Average temperature

Average temperature

Average humidity

Total consumption

Average temperature

Average temperature

In order to be able to compare the performance of buildings, a simple index would consist of normalizing the air conditioner energy use over the conditioned floor area. Consideration to insulation level and material type should also be given.

E. Data accuracy, quality control/verification, and format.

The precision of data products will be determined based on the precision of the data acquisition system and the relationship between the variables being measured due to variations induced by weather, occupant behavior, operational variations, and measurement periods. The potential bias in the final products will be estimated assuming that the uncertainties in the measured parameters are small compared to the mean parameter values. Once a specific data reduction procedure has been established, there will be many techniques available to incorporate uncertainties into the final data product.

After initial static calibration, all sensors/equipment will be dynamically calibrated in one location for about one week to establish calibration curves and assign a control station for later normalization of data. After dynamic calibration, matched sets of sensors/equipment will be kept together and transported to the field. The data flow path (from sensor to logger to modem) will be continuously checked for equipment failure and unexpected modifications. Downloaded data, at the other end of the phone line, will be analyzed in progress to identify potential errors in transmission or sensors operation. Daily diagnosis of data at all stages (start-up, ongoing, periodic, and final) will be performed to screen for these potential errors so that immediate action can be taken to correct them.

Data will also be compared to simulation results to get an order of magnitude for expected output and identify severe deviations therefrom. Finally, post calibration at the end of the data collection period will be performed to ensure that no major drift has occurred. 
Data will be downloaded via modems to SMUD. This raw data will then be transferred to LBL on floppy disks in comma-separated ASCII or spreadsheet formats (other separators are also acceptable). Macintosh- readable disks can also be used. At project start-up, SMUD will provide LBL with daily data (96 15-min intervals times 8 stations times 22 variables), but later into the project, data will be supplied to LBL on a weekly basis (672 15-min intervals times 8 stations times 22 variables). 
Site No. 7

(1) rawing not to scale or proportions)

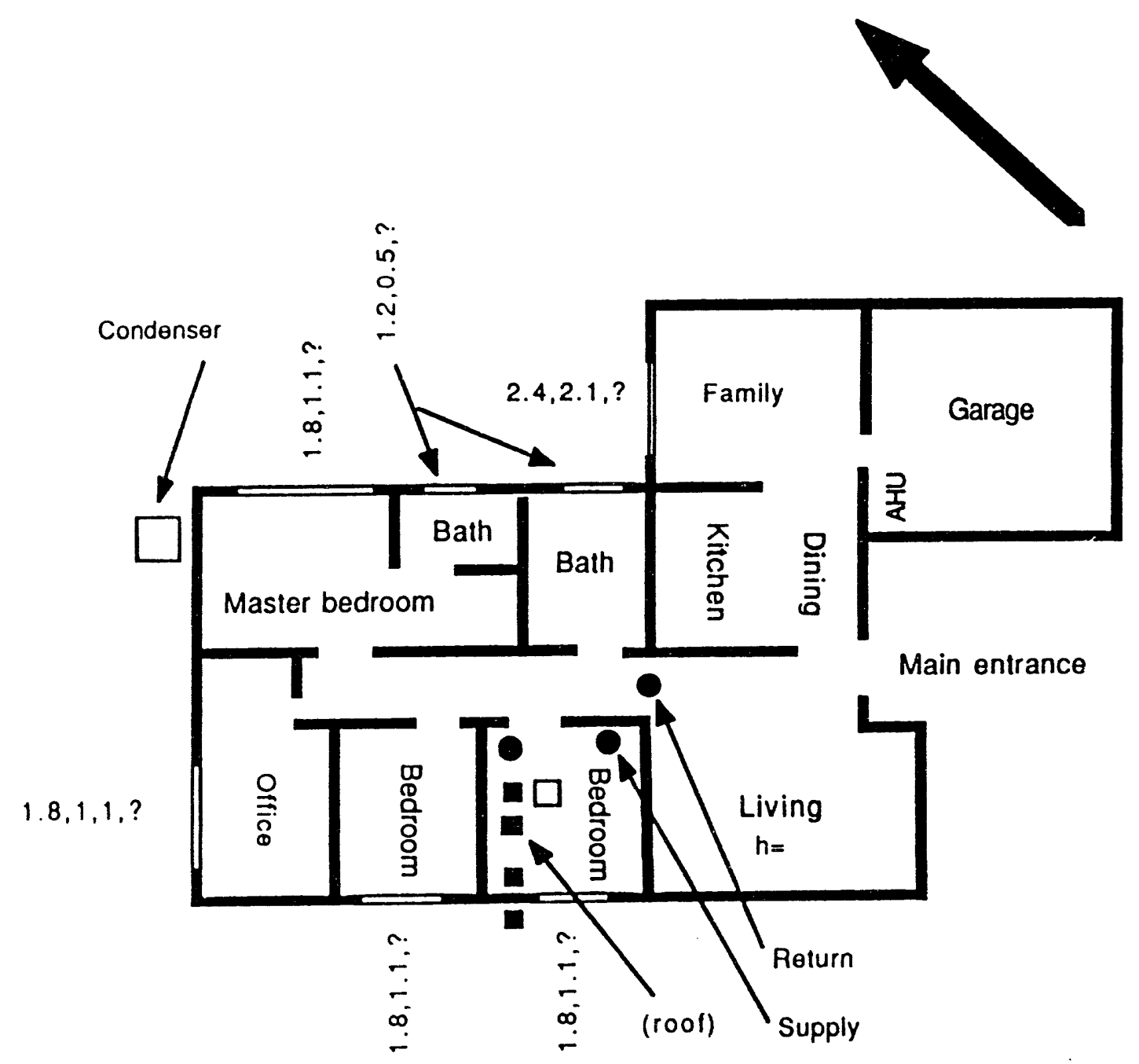

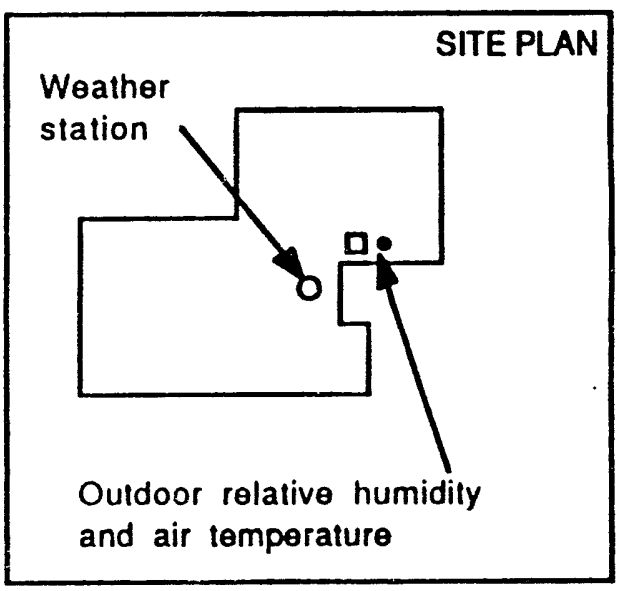

$\stackrel{N}{\mathbb{D}}$ 


\section{Monitoring Energy Savings from \\ Vegetation and High-Albedo Surfaces \\ SMUD/CIEE/LBL}

\section{Experiment design/protocol}

Site ID: Site 8

Case: This site is a vegetation study site.

\section{A. Measurements goals:}

The objective in this case is to determine the impact of increased vegetation on the air conditioner's energy use.

We plan to measure the outdoor microclimate variables in the vicinity of the building. Variables to be measured include solar radiation, dry-bulb temperature, relative humidity, wind speed, and wind direction.

We will measure the surface temperature and solar radiation at the outside walls and roof. We will also measure the inside surface temperature of the roof and walls. Additional measurements of the indoor microclimate variables including air temperature and relative humidity will be made. The energy used by the air conditioner will be monitored. All of these variables will be measured under a variety of weather conditions and before and after vegetation modifications are made. One-time, characteristic descriptors, such as albedo of the building and surroundings, and the vegetation type and cover within the site and surroundings, will be measured before and after modifications.

B. Data product and output:

There will be two types of products. The first includes environmental characteristic data such as the albedo of the building and surroundings, the vegetation type/tree cover on site and in the building's vicinity, building materials, landscape elements, and view factor estimations. The second type of $r$ ata includes the microclimate, envelope, and energy use data mentioned in Measurement goals above. These data will be averaged at 10 or 20 minute intervals (see Data analysis below). Data will be normalized to a control station (site) 
based on results from dynamic calibration prior to equipment installation in the field.

The data analysis stage will involve: 1) examination of data and handling of missing entries, errors, and irrelevant/outlier data, 2) comparison among all sites within the basecase (no modification) period, 3) comparison with concurrent data from other sites (parallel) and with prior data from same site (series) after vegetation modifications have been performed, 4) comparisons after site has been returned to basecase configuration.

Data analysis will be performed while collection is in progress. Refer to Table 1 (attached) for a summary of items to be reported.

C. Experimental design approach

A combination of before-after and test-reference experimental approaches will be used. Analysis and comparisc"s for microclimate and envelope conditions and building energy use figures will be performed. During the basecase monitoring, a test-reference comparison with other sites will be performed.

The experiment schedule for this house is as follows:

\begin{tabular}{|l|l|}
\hline weeks 1-2 & weeks 3-8 \\
\hline basecase & vegetation modification \\
\hline
\end{tabular}

The building will be simulated with the DOE-2 program for confirmation and validation purposes. It will be simulated as a basecase and in a case with shading modifications.

In order to be able to compare buildings in terms of their response to certain modifications in albedo and/or vegetation, it is necessary to make sure that their operating conditions are as similar to each other as possible. Since the houses have mostly similar configurations (2-3 bedrooms) and have the same kind of occupant schedules**, the main variables to factor out are:

*- The basecase field-monitoring ("first two weeks) and supporting computer simulations should minimize the noise from occupancy and related factors. This will also help identify differences in baseloads if they are large. 
Window operation: Windows should be closed at all times.

Air conditioner operation: Thermostat setting should be the same in all cases.

Lights: Lights should be tumed on/off in a consistent, similar, and predictable fashion.

Appliances: Energy use of appliances will be estimated based on qualitative estimates to be provided by the occupants.

The attached floor plan shows the locations of sensors and the inventory for this particular site. Also refer to Table 1 . In this site, sensors 4 and 5 will be placed at Site 1, the neighboring house to the east ( $-3-4 \mathrm{~m}$ above ground).

Sensor 9 will be located on the exterior of the building adjacent to the wall of the dining room at an elevation of $1.5 \mathrm{~m}$ above ground. Sensor 11 will be on the roof above the dining room. Sensors 14 and 15 will be located inside at spots corresponding to those of outside sensors 9 and 11 . Sensors 18 and 19 will be in the living room. Sensors 18 and 19 will be at a height of 1.5 above floor to avoid stratification effects. Finally, sensors 20-22 will be located as appropriate.

Vegetation modification will be accomplished by addition of shade trees. Trees will be planted at several beneficial locations. For this site, trees will be required to shade southfacing windows.

A high precision pyranometer will be used to measure the current and modified albedos of the roof, walls, and surroundings of the building. Limited albedo measurements in the neighborhood will also be performed. Measurements will be performed under clear sky conditions. Vegetation type will be identified and density will be described via cover (\%) and Leaf-Area-Index (LAI) at the building site and in the neighborhood. Limited surface temperatures of the surroundings will also be taken with a hand-held infrared thermometer.

D. Data analysis

Data analysis will proceed assuming that the changes in air-conditioner energy use are results of modifications in albedo. All other factors will be assumed to be as close to constant as possible. Factors that cannot be held constant must be varied in a predictable manner (see Experimental design approach above). In addition, we will use the DOE- 
2.1D program to investigate the effects of variations in such parameters on air conditioner energy use.

The data will be grouped into several sub-categories, i.e., daytime, nighttime, clear, overcast, windy, and calm. Additionally, analyses will be performed separately for albedo cases and vegetation cases (this site), and also based on their surrounding environmental conditions (neighborhoods).

The following table gives the sampling/averaging and logging intervals:

\begin{tabular}{|l||l|l|l|l|l|l|l|}
\hline Sensor \# & 1,2 & $4-5$ & $6-8$ & $9-13$ & $14-19$ & 20 & 21,22 \\
Sampling (min) & 5 & 2 & 5 & 5 & 5 & 1 & 2 \\
Avrg/logging (min) & 20 & 10 & 20 & 20 & 20 & 10 & 10 \\
\hline
\end{tabular}

At each recording period, the stored value for each of these variable is as follows:

Outdoor air temp $\left({ }^{\circ} \mathrm{C}\right)$

Outdoor relative humidity (\%)

Solar radiation $(\mathrm{W} / \mathrm{m} 2)$

Wind speed $(\mathrm{m} / \mathrm{s})$

Wind direction $\left({ }^{\circ}\right)$

Ground surface temperature $\left({ }^{\circ} \mathrm{C}\right)$

Subsoil surface temperature $\left({ }^{\circ} \mathrm{C}\right)$

Subsoil moisture content (\%)

Outside wall1 surface temperature $\left({ }^{\circ} \mathrm{C}\right)$

Outside wall2 surface temperature $\left({ }^{\circ} \mathrm{C}\right)$

Outside roof surface temperature $\left({ }^{\circ} \mathrm{C}\right)$

Roof solar radiation estimate $(\mathrm{W} / \mathrm{m} 2)$

Wall solar radiation estimate $(\mathrm{W} / \mathrm{m} 2)$

Inside roof surface temperature $\left({ }^{\circ} \mathrm{C}\right)$

Inside wall1 surface temperature $\left({ }^{\circ} \mathrm{C}\right)$

Inside wall2 surface temperature $\left({ }^{\circ} \mathrm{C}\right)$
Average temperature

Average humidity

Total horizontal radiation

Average speed

Average direction

Average temperature

Average temperature

Average concentration

Average temperature

Average temperature

Average temperature

Total horizontal radiation

Total vertical radiation

Average temperature

Average temperature

Average temperature 
Inside room 1 air temperature $\left({ }^{\circ} \mathrm{C}\right)$

Inside room2 air temperature $\left({ }^{\circ} \mathrm{C}\right)$

Inside room 2 relative humidity (\%)

Airconditioner energy use ( $\mathrm{kWh}$ )

Supply air temperature $\left({ }^{\circ} \mathrm{C}\right)$

Return air temperature $\left({ }^{\circ} \mathrm{C}\right)$
Average temperature

Average temperature

Average humidity

Total consumption

Average temperature

Average temperature

In order to be able to compare the performance of buildings, a simple index would consist of normalizing the air conditioner energy use over the conditioned floor area. Consideration to insulation level and material type should also be given.

E. Data accuracy, quality control/verification, and format.

The precision of data products will be determined based on the precision of the data acquisition system and the relationship between the variables being measured due to variations induced by weather, occupant behavior, operational variations, and measurement periods. The potential bias in the final products will be estimated assuming that the uncertainties in the measured parameters are small compared to the mean parameter values. Once a specific data reduction procedure has been established, there will be many techniques available to incorporate uncertainties into the final data product.

After initial static calibration, all sensors/equipment will be dynamically calibrated in one location for about one week to establish calibration curves and assign a control station for later normalization of data. After dynamic calibration, matched sets of sensors/equipment will be kept together and transported to the field. The data flow path (from sensor to logger to modem) will be continuously checked for equipment failure and unexpected modifications. Downloaded data, at the other end of the phone line, will be analyzed in progress to identify potential errors in transmission or sensors operation. Daily diagnosis of data at all stages (start-up, ongoing, periodic, and final) will be performed to screen for these potential errors so that immediate action can be taken to correct them.

Data will also be compared to simulation results to get an order of magnitude for expected output and identify severe deviations therefrom. Finally, post calibration at the end of the data collection period will be performed to ensure that no major drift has occurred. 
Data will be downloaded via modems to SMUD. This raw data will then be transferred to LBL on floppy disks in comma-separated ASCII or spreadsheet formats (other separators are also acceptable). Macintosh- readable disks can also be used. At project start-up, SMUD will provide LBL with daily data (96 15-min intervals times 8 stations times 22 variables), but later into the project, data will be supplied to LBL on a weekly basis (672 15 -min intervals times 8 stations times 22 variables). 
Site No. 8

(Drawing not to scale or proportions)

\section{Built 1983}

No. of stories: 1

Square footage (garage excluded): 1000

Ceiling: R-19

Walls: R-11

Vegetation: Little

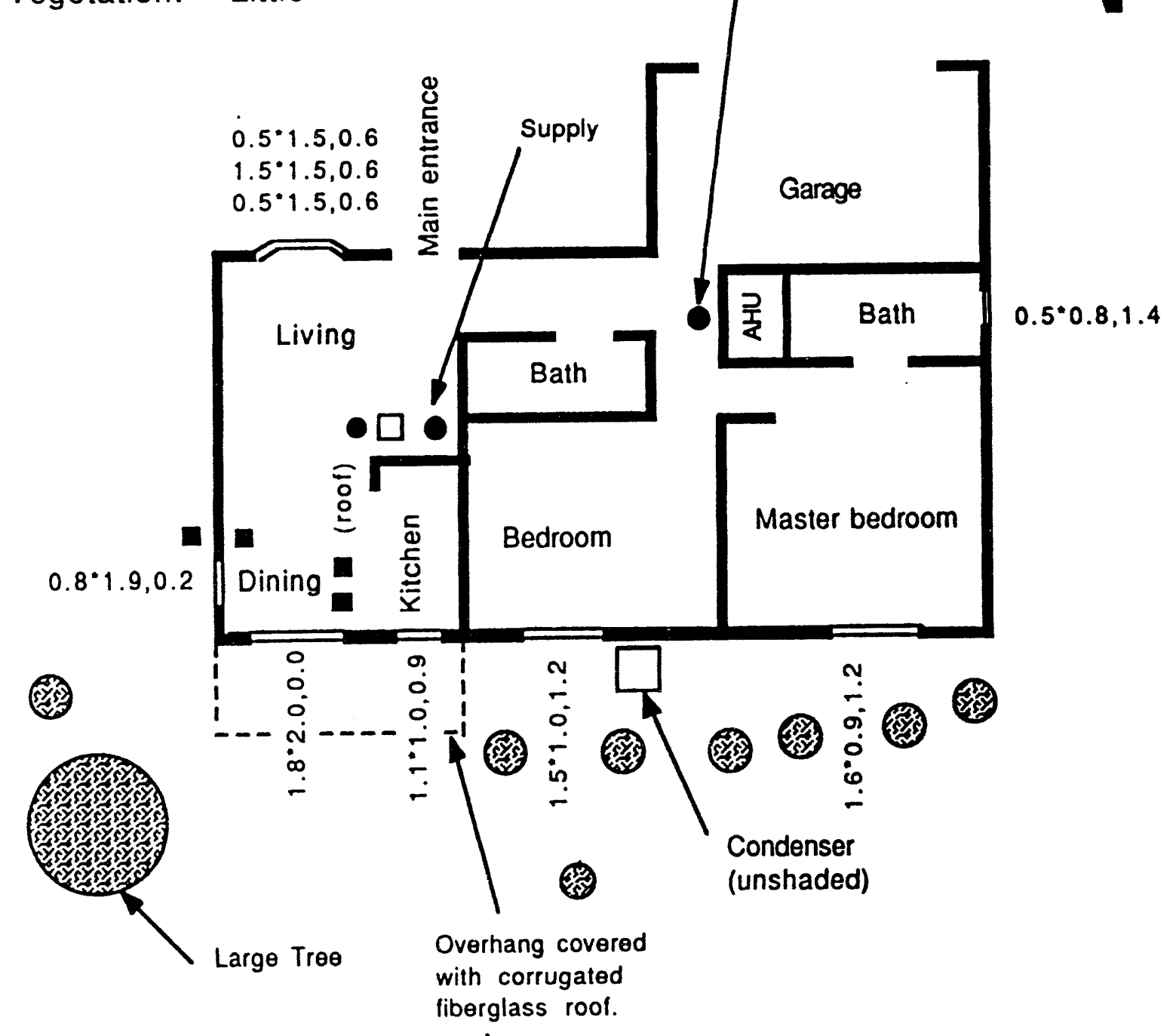

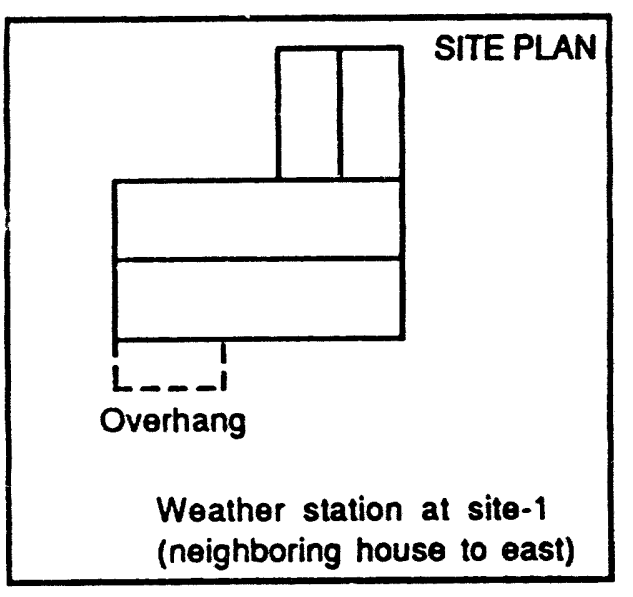

Air temperature point

- Surface temperature point

D Relative humidity point

h Inside ceiling height (m)

$x^{*} y, z$ window width height, sill $(m)$ 


\section{Monitoring Energy Savings from \\ Vegetation and High-Albedo Surfaces \\ SMUD/CIEE/LBL}

\section{Experiment design/protocol}

\section{Site ID: School Bungalow}

Case: Albedo. Two adjacent bungalows will be used. One will remain unchanged and act as the control case. The other will undergo two albedo modifications: from existing (moderate) to low, then from low to high.

\section{A. Measurements goals:}

The objective in this case is to determine the impact of albedo on the air conditioner's energy use.

Outdoor microclimate variables in the vicinity of the bungalows will be measured. These variables include solar radiation, dry-bulb temperature, relative humidity, wind speed, and wind direction.

Additional measurements will consist of exterior and interior surface temperatures, solar radiation, and indoor microclimate variables including air temperature and relative humidity. The energy used by the air-conditioner will also be monitored. All of these variables will be measured under a variety of weather conditions and of albedo modifications. Onetime, characteristic descriptors, such as albedo of the building and surroundings, and the vegetation type and cover within the site and surroundings, will be measured before and after modifications.

B. Data product and output:

There will be two types of products. The first includes environmental characteristic data such as the albedo of the building and surroundings, the vegetation type/tree cover on site and in the building's vicinity, building materials, landscape elements, and view factor estimations. The second type of data includes the microclimate, envelope, and energy use data mentioned in Measurement goals above. These data will be averaged at 10 or 20 minute 
intervals (see Data analysis below). Data will be normalized to a control station (site) based on results from dynamic calibration prior to equipment installation in the field.

The data analysis stage will involve: 1) examination of data and handling of missing entries, errors, and irrelevant/outlier data, 2) comparison among all sites within the basecase (no modification) period, 3) comparison with concurrent data from other sites (parallel) and with prior data from same site (series) after albedo and/or vegetation modifications have been performed, 4) intercomparisons after site has been returned to basecase configuration.

Data analysis will be performed while collection is in progress. Refer to Table 1 (attached) for a summary of items to be reported.

\section{Experimental design approach}

A combination of before-after and test-reference experimental approaches will be used. Analysis and comparisons for microclimate and envelope conditions and building energy use figures will be performed. During th: b basecase monitoring, a test-reference comparison with other sites will be performed.

The experiment schedule for this building is as follows:

\begin{tabular}{|l|l|l|l|l|l|}
\hline Aug. 9 & Aug. 10-14 & Aug. 15-16 & Aug. 17-21 & Aug. 22-23 & Aug. 24-31 \\
\hline Install Equip. & monitor basecase & paint dark & monitor & paint light & monitor \\
\hline
\end{tabular}

Note: Due to the start of the school year, the building will be occupied starting approximately September 3. Monitoring will continue into the first several weeks of the school year to determine the impact of the albedo change. The building should remain relatively unoccupied during the weekends, allowing us to augment the data set for the unoccupied building.

The building will be simulated with the DOE-2 program for confirmation and validation purposes. It will be simulated as a basecase and as a case for each albedo modification.

In order to be able to compare buildings in terms of their response to certain modifications in albedo and/or vegetation, it is necessary to make sure that their operating conditions are 
as similar to each other as possible. Since the two adjacent bungalows have similar configurations** the main variables to faciur out are:

Window operation: Windows should be closed at all times.

Air conditioner operation: Thermostat setting should be the same in all cases.

Lights: Lights should be turned on/off in a consistent, similar, and predictable fashion.

Appliances: There will be no additional appliances in operation.

The attached floor plan shows the locations of sensors and the inventory for this particular site. Also refer to Table 1. At this site, sensors 1-5 will be placed either on the roof or on the roof of an adjacent bungalow. Sensors 6-8 will be placed at a representative location that is unobstructed and non-shaded during all daylight hours. Representative areas are those of large extent: abnormal or atypical spots should be avoided. Sensors 9-11 will be located on the exterior of the building adjacent to the walls/roof (sensors 9-10 will be on walls at an elevation of $1.5 \mathrm{~m}$ above ground, whereas sensor 11 will be on the roof at an unshaded/unobstructed location). Sensors 12-13 will not be used at this location. Sensors 14-16 will be located inside at spots corresponding to those of outside sensors 9-11. Sensors 17-19 will be located inside the building at appropriate locations $1.5 \mathrm{~m}$ above the floor. Finally, sensors 20-22 will be located as appropriate.

Roof albedo modification will be performed in two phases. First, the original metallic roof will be painted dark brown or grey. After a sufficient monitoring period (see table) the roof will be painted with a light color paint. If possible, we will extend our albedo modification to include painting the south-east wall and possibly the north-west wall. The outside unit (condenser) should not be shaded nor should its albedo be modified. It should remain in its original condition.

A high precision pyranometer will be used to peiform measurements of the current and modified albedos of the roof, walls, and surroundings of the building. Limited albedo measurements in the neighborhood will also be performed. Measurements will be performed under clear sky conditions. Vegetation type will be identified and density will be

** The basecase field-monitoring ("first five days) and supporting computer simulations should minimize the noise from miscellaneous factors. This will also help identify differences in baseloads if they are large. 
described via cover (\%) and Leaf-Area-Index (LAI) at the building site and in the neighborhood. Limited surface temperatures of the surroundings will also be taken with a handheld infrared thermometer.

D. Data analysis

Data analysis will proceed assuming that the changes in air conditioner energy use are results of modifications in albedo. We will assume that ail other factors are as close to constant as possible. Factors that cannot be held constant must be varied in a predictable manner (see Experimental design approach above). In addition, we will use the DOE$21 \mathrm{D}$ program to investigate the effects of variations in such parameters on air conditioner energy use.

The data will be grouped into several sub-categories, i.e., daytime, nighttime, clear, overcast, windy, and calm.

The following table gives the sampling/averaging and logging intervals:

\begin{tabular}{|l||l|l|l|l|l|l|l|}
\hline Sensor \# & 1,2 & $3-5$ & $6-8$ & $9-11$ & $14-19$ & 20 & 21,22 \\
Sampling (min) & 5 & 2 & $e$ & 5 & 5 & 1 & 2 \\
Avrg/logging (min) & 20 & 10 & & 20 & 20 & 10 & 10 \\
\hline
\end{tabular}

At each recording period, the stored value for each of these variable is as follows:

Outdoor air temp $\left({ }^{\circ} \mathrm{C}\right)$

Outdoor relative humidity (\%)

Solar radiation $(\mathrm{W} / \mathrm{m} 2)$

Wind speed $(\mathrm{m} / \mathrm{s})$

Wind direction $\left({ }^{\circ}\right)$

Ground surface temperature $\left({ }^{\circ} \mathrm{C}\right)$

Subsoil surface temperature $\left({ }^{\circ} \mathrm{C}\right)$

Subsoil moisture content (\%)

Outside wall1 surface temperature $\left({ }^{\circ} \mathrm{C}\right)$

Outside wall2 surface temperature $\left({ }^{\circ} \mathrm{C}\right)$
Average temperature

Average humidity

Average horizontal flux

Average speed

Average direction

Average temperature

Average temperature

Average concentration

Average temperature

Average temperature 
Outside roof surface temperature $\left({ }^{\circ} \mathrm{C}\right)$

Roof solar radiation estimate $(\mathrm{W} / \mathrm{m} 2)$

Wall solar radiation estimate $(\mathrm{W} / \mathrm{m} 2)$

Inside roof surface temperature $\left({ }^{\circ} \mathrm{C}\right)$

Inside wall1 surface temperature $\left({ }^{\circ} \mathrm{C}\right)$

Inside wall 2 surface temperature $\left({ }^{\circ} \mathrm{C}\right)$

Inside room 1 air temperature $\left({ }^{\circ} \mathrm{C}\right)$

Inside room 2 air temperature $\left({ }^{\circ} \mathrm{C}\right)$

Inside room 2 relative humidity (\%)

Airconditioner energy use ( $\mathrm{kWh}$ )

Supply air temperature $\left({ }^{\circ} \mathrm{C}\right)$

Return air temperature $\left({ }^{\circ} \mathrm{C}\right)$
Average temperature

Average horizontal flux

Average vertical flux

Average temperature

Average temperature

Average temperature

Average temperature

Average temperature

Average humidity

Total consumption

Average temperature

Average temperature

In order to be able to compare the performance of buildings, a simple index will be developed for normalizing the air-conditioner energy use over the conditioned floor area. A modified energy use index (EUI) will thus be obtained for comparison with other albedo cases. If only portions of roofs will be modified, the ratio of the modified area to the total roof area (over conditioned zones) must be equal. Also, roof orientations treated with albedo modifications should be similar. Consideration will be given to insulation level and material type.

E. Building and site characteristics:

Description:

Square footage:

No. of stories:

Roof:

Walls:

Roof insulation:

Wall insulation:

Windows:

Foundation:

Occupants:

Weekday schedule:
Attached Bungalow 1 room.

$960 \mathrm{ft}^{2}$.

1.

Corrugated metal roof.

Plywood siding.

R-19

R-11

Double pane.

Crawl space.

0 in summer.

Not occupied over summer. 
Weekend schedule:

Airconditioner:

Heater:

Typical thermostat setting:
Not occupied.

Heat Pump, Capacity: 34600 BTUH

33000 BTUH.

Cooling $78^{\circ} \mathrm{F}$.

F. Data accuracy, quality control/verification, and format.

The precision of data products will be determined based on the precision of the data acquisition system and the relationship between the variables being measured due to variations induced by weather, occupant behavior, operational variations, and measurement periods. The potential bias in the final products will be estimated assuming that the uncertainties in the measured parameters are small compared to the mean parameter values. Once a specific data reduction procedure has been established, there will be many techniques available to incorporate uncertainties into the final data product.

After initial static calibration, all sensors/equipment will be dynamically calibrated in one location for about one week to establish calibration curves and assign a control station for later normalization of data. After dynamic calibration, matched sets of sensors/equipment will be kept together and transported to the field. The data flow path (from sensor to logger to modem) will be continuously checked for equipment failure and unexpected modifications. Downloaded data, at the other end of the phone line, will be analyzed in progress to identify potential errors in transmission or sensors operation. Frequent diagnosis of data at all stages (start-up, ongoing, periodic, and final) will be performed to screen for these potential errors so that immediate action can be taken to correct them.

Data will also be compared to simulation results to get an order of magnitude for expected output and identify severe deviations therefrom. Finally, post calibration at the end of the data collection period will be performed to ensure that no major drift has occurred.

Data will be downloaded via modems to SMUD. This raw data will then be transferred to LBL on floppy disks in comma-separated ASCII or spreadsheet formats (other separators are also acceptable). Macintosh- readable disks can also be used. SMUD will provide LBL with a copy of the downloaded data on a weekly basis. 


\section{School Site}

(Drawing not to scale or proportions)

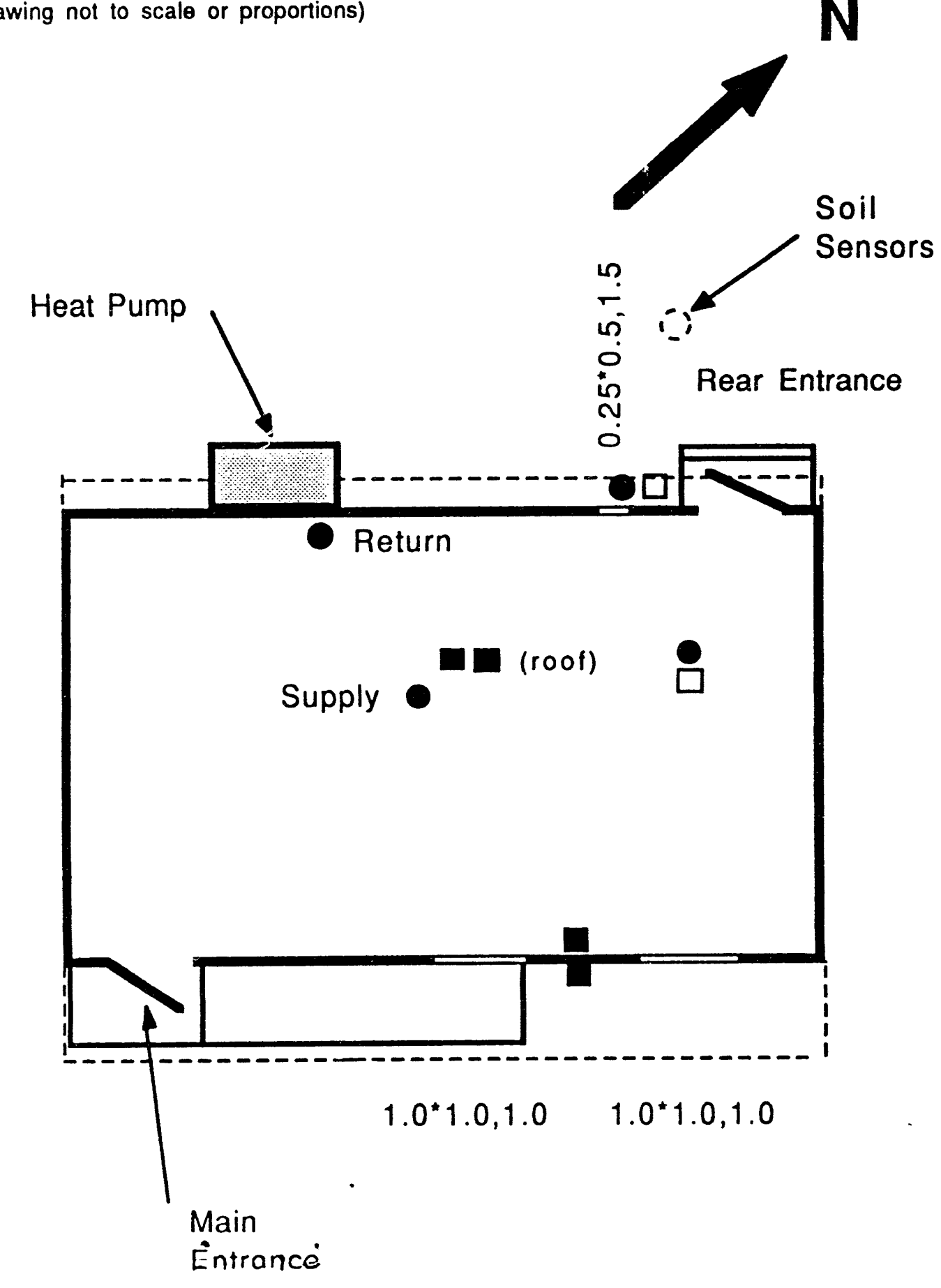

Air temperature point
Surface temperature point
Relative humidity point
h Inside ceiling height $(\mathrm{m})$
$x^{*} y, z \quad$ window width*height, sill $(\mathrm{m})$

- Air temperature point

- Surface temperature poin

$h$ Inside ceiling height (m) 

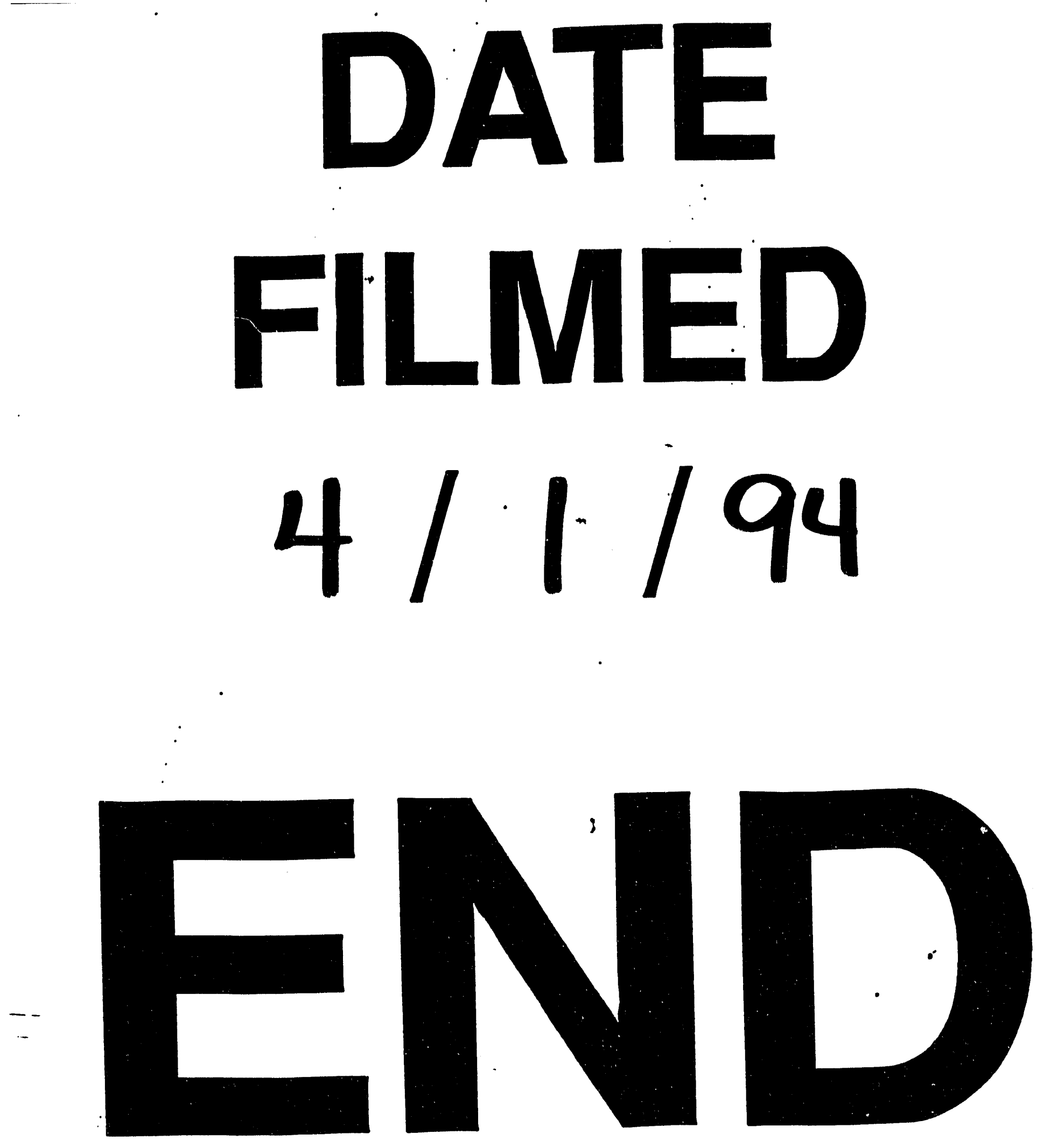


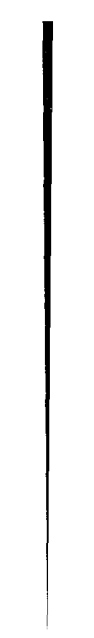

